Steuerberater-Jahrbuch 2010/2011 



\title{
Steuerberater-Jahrbuch 2010/2011
}

\author{
zugleich Bericht \\ über den 62. Fachkongress der Steuerberater \\ Köln, 28. und 29. September 2010
}

Herausgegeben

im Auftrag des Fachinstituts der Steuerberater von

\begin{abstract}
Prof. Dr. Detlev J. Piltz Rechtsanwalt, Fachanwalt für Steuerrecht

Dipl.-Kfm. Manfred Günkel Steuerberater u. Wirtschaftsprüfer
\end{abstract}

Dr. Dr. Ursula Niemann

Steuerberater

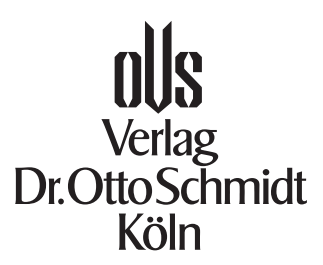




\section{Zitierempfehlung:}

Verfasser, StbJb. 2010/2011, Seite ...

\section{Bibliografische Information}

der Deutschen Nationalbibliothek

Die Deutsche Nationalbibliothek verzeichnet diese Publikation in der Deutschen Nationalbibliografie; detaillierte bibliografische Daten sind im Internet über http://dnb.d-nb.de abrufbar.

Verlag Dr. Otto Schmidt KG

Gustav-Heinemann-Ufer 58, 50968 Köln

Tel. 02 21/9 37 38-01, Fax 02 21/9 3738-943

info@otto-schmidt.de

www.otto-schmidt.de

ISSN 0081-5519

ISBN 978-3-504-62656-3

C2011 by Verlag Dr. Otto Schmidt KG, Köln

Das Werk einschließlich aller seiner Teile ist urheberrechtlich geschützt. Jede Verwertung, die nicht ausdrücklich vom Urheberrechtsgesetz zugelassen ist, bedarf der vorherigen Zustimmung des Verlages. Das gilt insbesondere für Vervielfältigungen, Bearbeitungen, Übersetzungen, Mikroverfilmungen und die Einspeicherung und Verarbeitung in elektronischen Systemen.

Das verwendete Papier ist aus chlorfrei gebleichten Rohstoffen hergestellt, holz- und säurefrei, alterungsbeständig und umweltfreundlich.

Satz: C. Wild, Konstanz

Druck und Verarbeitung: Bercker, Kevelaer

Printed in Germany 


\section{Vorwort}

Der 62. Fachkongress der Steuerberater, der am 28. und 29. September 2010 traditionell in der Industrie- und Handelskammer zu Köln stattfand, eröffnete - ebenfalls traditionell - mit einem Vortrag des Staatssekretärs im Bundesfinanzministerium Dr. Hans Bernhard Beus zur Steuerpolitik der Bundesregierung mit anschließender Diskussion mit Dr. Neumann, Finanzministerium NRW sowie Vertretern aus Wirtschaft, Wissenschaft und Beratung. Die „große Reform“ bleibt aus, aber wichtige Einzeländerungen sind geschehen oder im Werden, z. B. zur E-Bilanz.

Die Entscheidung des Großen Senats des Bundesfinanzhofs zur Abzugsfähigkeit gemischter Aufwendungen ist ein bemerkenswertes Beispiel dafür, dass ein Gericht aus einem unveränderten Gesetzestext das Gegenteil von dem herauslesen kann, was es viele Jahrzehnte zuvor entnommen hat.

Unter dem Leitthema Mittelstand wurden "alte Bekannte" behandelt, großenteils aber mit neuen Erkenntnissen: Gesellschafterdarlehen bei Personen- und Kapitalgesellschaften und Abfindungsklauseln in Gesellschaftsverträgen. Zur neuen Erbschaftsteuer liegen nunmehr die ersten Praxiserkenntnisse vor.

Im Internationalen Steuerrecht werfen die Betriebsstätten immer wieder bezüglich ihres Begriffs und ihrer Gewinnermittlung Probleme auf. Funktionsverlagerungen sind das neue Lieblingsthema des Gesetzgebers und der Finanzverwaltung, aber leider hoch rechtsunsicher. Das gilt auch für die neuen Entstrickungsregeln, die der Bundesfinanzhof teilweise anders auslegt als die Finanzverwaltung.

Das Leitthema „Bilanzen und Steuern“ widmete sich der Steuerbilanzpolitik unter dem BilMoG einschließlich der wichtigen Ausschüttungssperren sowie dem neuen $\S 5 \mathrm{~b}$ EStG mit der elektronischen Bilanz, die für viele Unternehmen eine ganz neue detaillierte Zeitrechnung anbrechen lässt. Aktuelle Probleme aus dem Bilanzsteuerrecht sind jedes Jahr aufs Neue interessant.

Für Kapitalgesellschaften ist der Ausschluss des Verlustabzugs nach $\S 8 \mathrm{c}$ KStG ein brisantes Thema, auch durch neue europäische Rechtsprechung. Dass die Organschaft nicht nur steuerrechtliche Seiten hat, sondern auch zivilrechtliche und dort insbesondere die Haftung, hob der diesbezügliche Beitrag hervor.

In Zeiten immer intensiverer Durchdringung des Privatlebens durch staatliche Maßnahmen wird das Steuerstrafrecht einschließlich internationale Finanzanlagen zum drängenden Thema. Die Abgeltungsteuer 
sollte (auch) der Vereinfachung dienen, hat sich aber vornehmlich für die Banken, in vermindertem Maße auch für die Steuerpflichtigen, zu einer extrem komplizierten Angelegenheit entwickelt, was sich unter anderem in einem 70-seitigen Erlass der Finanzverwaltung niederschlägt.

Der Gerhard-Thoma-Ehrenpreis 2010 wurde zuerkannt Herrn Dipl.-Kfm. Dr. Alexander Manuel Bohn für seine Arbeit „Zinsschranke und Alternativmodelle zur Beschränkung des steuerlichen Zinsabzugs". Die Laudatio hat Prof. Dr. Wolfgang Kessler gehalten.

Köln, im April 2011

Detlev J. Piltz

Manfred Günkel

Ursula Niemann 


\section{Inhalt ${ }^{*}$}

Seite

Prof. Dr. Wolfgang Kessler

Steuerberater, Albert-Ludwigs-Universität, Freiburg i. Br.

Verleihung des "Gerhard-Thoma-Ehrenpreises 2010“

des Fachinstituts der Steuerberater . . . . . . . . . . . . 1

\section{Leitthema: \\ Steuerpolitik der Bundesregierung}

Dr. Hans Bernhard Beus

Staatssekretär im Bundesfinanzministerium, Berlin

Steuerpolitik der Bundesregierung ................ 9

Leitung: Prof. Dr. Detlev J. Piltz

Diskussion zum Leitthema:

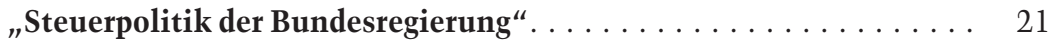

\section{Leitthema:}

Großer Senat des Bundesfinanzhofes zur Abzugsfähigkeit gemischter Aufwendungen

Prof. Dr. Hans-Joachim Kanzler

Vorsitzender Richter am BFH, München

Großer Senat des BFH zur Abzugsfähigkeit

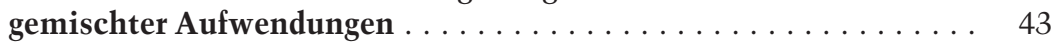

I. Der Beschluss des Großen Senats vom 21.9.2009 . . . . . . . . . 43

II. Die Umsetzung der Vorgaben des Beschlusses v. 21.9.2009. . . . 53

III. Künftige Behandlung gemischter Aufwendungen . . . . . . . 59

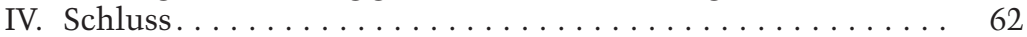

* Ausführliche Inhaltsübersichten zu Beginn der jeweiligen Beiträge. 
Seite

Prof. Dr. Klaus-Dieter Drüen

Düsseldorf

Der Rechtsprechungswechsel des Großen Senats vom

allgemeinen Aufteilungsverbot zum Aufteilungsgebot. . . . . . . . 65

I. Rückblick: Ständige Kritik am allgemeinen Aufteilungsund Abzugsverbot . . . . . . . . . . . . . . . . . . . . . 65

II. Seitenblick: Spezielle Aufteilungsgebote und -verbote im Steuerrecht. . . . . . . . . . . . . . . . . . . . . 68

III. Ausblick: Denkbare Konsequenzen für Steuerrecht und -vollzug. . . . . . . . . . . . . . . . . . . . . 73

\section{Leitthema: Mittelstand}

Dr. Martin Strahl

Steuerberater, Köln

Aktuelle Steuerrechts- und Gestaltungsfragen zu Gesellschafterdarlehen bei Personen- und Kapitalgesellschaften. . . . . . . . . . 81

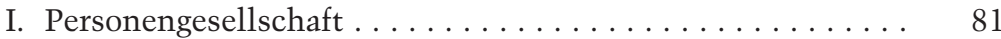

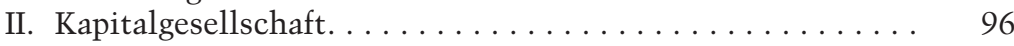

Dr. Eckhard Wälzholz

Notar, Füssen

Abfindungsklauseln in Gesellschaftsverträgen

-Zivil- und Steuerrecht . . . . . . . . . . . . . . . . . . . . . . . . . . 109

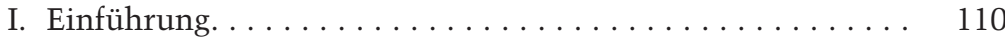

II. Aktuelle gesellschaftsrechtliche Probleme von Abfindungsklauseln. . . . . . . . . . . . . . . . . . 113

III. Steuerliche Folgen von Abfindungsklauseln . . . . . . . . . . 127

IV. Exkurs: Die neue steuerliche Behandlung der qualifizierten Nachfolgeklausel. . . . . . . . . . . . . . . . . . . . 145

V. Zusammenfassung. ..................... 146

Dr. Reinhard Geck

Rechtsanwalt, Notar und Steuerberater, Hannover

Praxiserkenntnisse zur neuen Erbschaftsteuer . . . . . . . . . . . . . . 149

1. Einleitung . . . . . . . . . . . . . . . . . . . . . . 149

2. Renaissance der Übertragung von Unternehmen . . . . . . . . 150

3. Die Personengesellschaft im Aufwind . . . . . . . . . . . . . 154 
4. Übertragung unter Nießbrauchsvorbehalt . . . . . . . . . . . 158

5. Erwerb des Familienheims, insbesondere durch den Ehegatten........................... 162

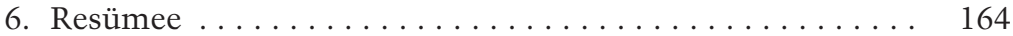

\section{Leitthema: \\ Internationales Steuerrecht}

Dr. Andreas Roth

Mannheim

Neues zu Betriebsstättenbegriff und Gewinnermittlung . . . . . . 167

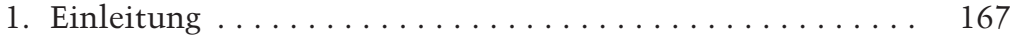

2. Auflösungstendenzen beim Betriebsstättenbegriff . . . . . . 168

3. Potenzielle Betriebsstätten bei Konzernstrukturen . . . . . . 173

4. Gewinnabgrenzung zwischen $\S 4$ Abs. 1 Satz 3 EStG, BFH und dem Authorized OECD Approach . . . . . . . . . . . . . 177

5. Ausblick. . . . . . . . . . . . . . . . . . . . . 182

Prof. Dr. Hubertus Baumhoff

Steuerberater, Wirtschaftsprüfer, Bonn

Die Besteuerung von Funktionsverlagerungen

- neue Rechtslage . . . . . . . . . . . . . . . . . . . . . 183

I. Änderung der Funktionsverlagerungsbesteuerung durch das EU-Umsetzungsgesetz . . . . . . . . . . . . . . . 183

II. Redaktionelle Änderungen. . . . . . . . . . . . . . . . . . . 186

III. Die neue „Escape-Klausel“ des § 1 Abs. 3 Satz 10,

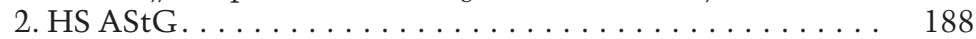

IV. Praktische Relevanz der Neuregelung und zeitliche Anwendung . . . . . . . . . . . . . . . . . . . . 197

Dr. Rolf Möhlenbrock

Berlin

Entstrickung - quo vadis?

- Rechtsprechung, Gesetzgebung und Verwaltung . . . . . . . . . 199

A. Einleitung . . . . . . . . . . . . . . . . . . . . 199

B. Befund ......................... 200

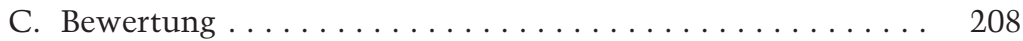

D. Zukunft der Entstrickung $\ldots \ldots \ldots \ldots \ldots \ldots \ldots$ 


\section{Leitthema: Bilanzen und Steuern}

Dr. Ingo Ernsting

Düsseldorf

\section{Steuerbilanzpolitik unter dem BilMoG einschließlich}

Ausschüttungssperren ... . . . . . . . . . . . . . . . . . . . 219

1. Einführung. . . . . . . . . . . . . . . . . . . . 219

2. Eigenständigkeit der Steuerbilanzpolitik unter dem BilMoG. 220

3. Praxisfragen bei der Ausübung steuerbilanzieller

Wahlrechte ........................... 224

4. Zur Relevanz von Ausschüttungssperren . . . . . . . . . . 236

5. Thesenförmige Zusammenfassung . . . . . . . . . . . . . 243

Dipl.-Finw. Markus Hülshoff

Münster

§ 5b EStG: Elektronische Bilanz - Sachstandsbericht . . . . . . . 245

A. Ausgangslage............................ 245

B. Gesetzliche Grundlagen . . . . . . . . . . . . . . . . . 246

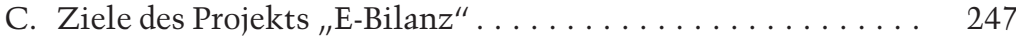

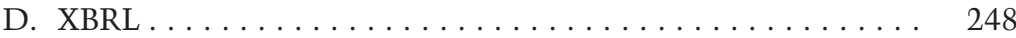

E. Sonderfälle.............................. 259

F. Stellungnahme der im Projekt beteiligten

Wirtschaftsvertreter. . . . . . . . . . . . . . . . 260

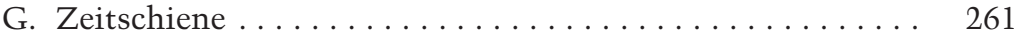

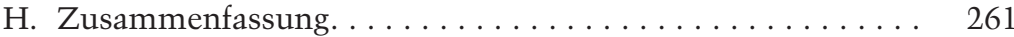

Dipl.-Kfm. Manfred Günkel,

Steuerberater, Wirtschaftsprüfer, Düsseldorf

Aktuelle Probleme aus dem Bilanzsteuerrecht . . . . . . . . . . 263

I. Teilwertzuschreibung auf

Fremdwährungsverbindlichkeiten................ 264

II. Bilanzierung von angeschafften Drohverlustrückstellungen . 270

III. „Lifo-Methode" bei Teilwertzuschreibungen von Beteiligungen (last down, first up) . . . . . . . . . . . . 275

IV. Subjektiver Fehlerbegriff zu (Un)Gunsten der Finanzverwaltung. . . . . . . . . . . . . . . . . . . . 279

V. Laufzeitfiktion von unverzinslichen (Gesellschafter-|Darlehen . . . . . . . . . . . . . . . . . . 284 
Seite

VI. Steuerliche Herstellungskosten nach BilMoG . . . . . . . 288

VII. Konsequenzen nicht vorgenommener

Teilwertabschreibungen bei Umwandlungsvorgängen . . . . . 295

\section{Leitthema: \\ Kapitalgesellschaften}

Dr. Gottfried E. Breuninger

Rechtsanwalt, München

Anwendungsfragen des neuen $\$ \mathbf{8} \mathbf{c ~ K S t G} \ldots \ldots \ldots \ldots \ldots \ldots 303$

I. Beschränkung der Verlustnutzung ohne Ende? . . . . . . . . 304

II. Kernproblemfelder der Neuregelung . . . . . . . . . . . . . . 312

III. Der neue $\S 8 \mathrm{c}$ und Debt-Equity-Swap-Strukturen:

Notleidende Gesellschafterdarlehensstrukturen und die

Defizite des deutschen Sanierungssteuerrechts . . . . . . . . 322

IV. Resümee ........................... 326

Dr. Norbert Schneider

Rechtsanwalt, Steuerberater, Köln

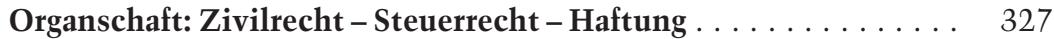

I. Einleitung: Bedeutung des Zivilrechts für das Recht der Organschaft . . . . . . . . . . . . . . . . . . . . 328

II. Auslegung von Gewinnabführungsverträgen . . . . . . . . . . 329

III. Tatsächliche Durchführung des GAV . . . . . . . . . . . . . . 348

IV. Heilung eines steuerlich unwirksamen GAV . . . . . . . 352

V. Ausgleichszahlungen an außenstehende Aktionäre. . . . . . . 354

VI. Haftung bei Organschaft . . . . . . . . . . . . . . 360

\section{Leitthema: \\ Steuerstrafrecht und Kapitaleinkünfte}

Alexandra Mack

Rechtsanwältin, Fachanwältin für StR, Köln

Aktuelles Steuerstrafrecht einschließlich internationaler

Finanzanlagen . . . . . . . . . . . . . . . . . . . . . . . 369

A. Selbstanzeigeberatung in Zeiten des Datendiebstahls . . . . 369 
Seite

B. Selbstanzeige - und was dann?

Beratererfahrungen und Handlungsalternativen für laufende Selbstanzeigeverfahren ................... 376

C. Anlageberatung als Beihilfe zur Steuerhinterziehung? . . . . . 377

D. Wenn die Steuerfahndung kommt. Grundsätzliche Verhaltensmaximen für Mandant und Berater . . . . . . . . . . 379

Dr. Thomas Arntz

Rechtsanwalt, Frankfurt am Main

Abgeltungsteuer auf Einkünfte aus Kapitalvermögen . . . . . . . . 381

I. Grundzüge der Kapitalertragsteuerregelungen . . . . . . . . . 382

II. Wirtschaftliche Auswirkungen beim Privatanleger . . . . . . . 384

III. Persönliche Kapitalertragsteuerpflicht. . . . . . . . . . . . . . 387

IV. Sachliche Kapitalertragsteuerpflicht/Abgeltungswirkung . . . 388

V. Abzugspflichtige Kapitalerträge/Bemessungsgrundlage. . . . 393

VI. Verlustverrechnung durch die Kreditinstitute . . . . . . . . . . 407

VII. Abstandnahme vom Steuerabzug/Steuererstattung. . . . . . . 413

VIII. Steuersatz und Steuerberechnung . . . . . . . . . . . . . . 415

IX. Veranlagungsfälle ...................... 416

Sachregister. . . . . . . . . . . . . . . . . . . . . . . . . . . . 419 


\title{
Verleihung des „Gerhard-Thoma-Ehrenpreises 2010“ des Fachinstituts der Steuerberater
}

\author{
Professor Dr. Wolfgang Kessler \\ Steuerberater, Albert-Ludwigs-Universität, Freiburg i. Br.
}

Seit 1953 verleiht das Fachinstitut der Steuerberater den Gerhard-ThomaEhrenpreis an verdiente Steuerwissenschaftler zur Würdigung ihres Gesamtwerks oder als Auszeichnung herausragender wissenschaftlicher Arbeiten junger Nachwuchswissenschaftler. Die Jury hat sich dieses Jahr dazu entschlossen, den Ehrenpreis an einen jungen Wissenschaftler zu vergeben. Erfreulicherweise konnten wir dabei auch in diesem Jahr zwischen mehreren verdienstvollen Schriften wählen. Das Ergebnis stand dennoch ganz schnell und einmütig fest. Es gab zwar eine ganze Reihe interessanter Arbeiten; die beiden zentralen Kriterien für den GerhardThoma-Ehrenpreis - einer wissenschaftlich anspruchsvollen und zugleich praktisch relevanten Monographie - erfüllt jedoch vor allem eine Dissertation in geradezu idealer Weise.

Der Träger des Gerhard-Thoma Ehrenpreises 2010 ist:

Herr Dipl.-Kfm. Dr. Alexander Manuel Bohn mit seiner Arbeit

"Zinsschranke und Alternativmodelle zur Beschränkung des steuerlichen Zinsabzugs"

Als Vorsitzender der Jury habe ich die ehrenvolle Aufgabe, dem Kongress das Werk und den Preisträger vorzustellen und im Anschluss daran die Urkunde zu überreichen.

Die Monographie des diesjährigen Preisträgers analysiert - entsprechend den drei Hauptaufgaben der Betriebswirtschaftlichen Steuerlehre - die Steuerwirkungen von Zinsabzugsbeschränkungen und leitet daraus einerseits Handlungsempfehlungen an den Gesetzgeber im Sinne einer normativen Betriebswirtschaftlichen Steuerlehre sowie andererseits Handlungsempfehlungen an die betrieblichen Entscheidungsträger im Sinne der betriebswirtschaftlichen Steuerplanungslehre ab. Der Fokus liegt dabei allerdings nicht allein auf der im Rahmen der Unternehmenssteuerreform 2008 eingeführten „deutschen" Variante einer Zinsabzugsbegrenzung. Der Blickwinkel der Arbeit geht vielmehr weit darüber hinaus und verfolgt eine doppelte Zielsetzung: Einmal wird de lege lata die Neuregelung des $\S 4$ h EStG i. V.m. $\S 8$ a KStG in ihren Anwendungsvoraussetzungen und Steuerwirkungen analysiert. Zum anderen wird die deutsche Zinsschranke in einen größeren Zusammenhang eingeordnet und mit Alternativmodellen einer Zinsabzugsbeschränkung verglichen, 
die in anderen Staaten der EU und ausgewählten Drittstaaten Anwendung finden. Die Dissertation kann daher dem Rechtsanwender wie dem Wissenschaftler gleichermaßen empfohlen werden.

Nach einer Darstellung der Problemstellung, des Untersuchungsgegenstands sowie des Ziels und Aufbaus der Untersuchung, stellt der Verfasser die Finanzierungsfreiheit, die fehlende Finanzierungsneutralität und das internationale Steuergefälle als die drei zentralen Impulsgeber für die Unterkapitalisierung vor und arbeitet wiederum drei aus fiskalischer Sicht idealtypische Erscheinungsformen heraus, die da sind: Gesellschafter-Fremdfinanzierung, Fremdfinanzierung ausländischen Anteilserwerbs und der Einsatz ausländischer Finanzierungsgesellschaften, wobei er allerdings die Sanktionsbedürftigkeit der Outboundfinanzierung ausländischer Tochtergesellschaften - im Kern also die alte Diskussion über die Anwendung von § $3 \mathrm{c}$ EStG im Zusammenhang mit DBA-Schachtelbeteiligungen - mit guten Gründen als höchst fragwürdig einstuft. Im Anschluss prognostiziert der Verfasser der Thematik der Unterkapitalisierung eine längere Lebenserwartung, was angesichts des aufgezeigten fiskalischen Drucks zur Sicherung des Steuersubstrats, der Erkenntnis, dass rein unilaterale Lösungen zwangsläufig zu Doppelbesteuerungen führen und der rechtspolitischen Festlegung in der EU, auf Zinsen keine Quellensteuern zu erheben, niemand ernsthaft bestreiten wird. Ganz subtil gibt uns Herr Bohn damit natürlich auch ein weiteres Argument dafür, wie sinnvoll es doch ist, seine Arbeit in unsere Bibliothek aufzunehmen.

Wenn Sie dies tun und dem Gang der Untersuchung weiter folgen, können Sie eine präzise, konzise und naturgemäß leider auch etwas ernüchternde Analyse der rechtlichen und wirtschaftlichen Vorgaben lesen. Auch wenn das Nettoprinzip in jüngster Zeit auf dem Vormarsch scheint, lässt das BVerfG die verfassungsrechtliche Fundierung dieses Prinzips ausdrücklich offen. Und Art. 24 Abs. 5 OECD-MA hilft i. d. R. auch nicht richtig weiter. Etwas mehr Hoffnung macht da schon Art. 9 Abs. 1 OECD-MA, wonach dem Steuerpflichtigen u. U. die Möglichkeit eines Gegenbeweises eingeräumt werden sollte, was allerdings dann wieder wenig Hilfestellung bietet, wenn Zinsen auf Fremdkapital, das bei fremden Dritten aufgenommen wird, in den Anwendungsbereich der Ergebnisgrenze fallen.

Unionsrechtlich ist der Handlungsspielraum des Gesetzgebers durch die Rechtsprechung des EuGH und das Sekundärrecht nur wenig eingegrenzt. Er kann entweder ganz auf eine Zinsabzugsbeschränkung verzichten, den Zinsabzug - wie in vielen EU-Nachbarstaaten üblich - im Verhältnis Gesellschaft-Gesellschafter begrenzen oder umfassend für alle Zinsen einschränken. Entscheidet sich der Mitgliedstaat für die Begrenzung des Zinsabzugs auf Darlehen von wesentlich beteiligten Gesellschaftern, so kann er zwischen EU- und Drittstaaten differenzieren, 
unterliegen dagegen - wie in Deutschland - auch Darlehen von fremden Dritten einer Abzugsbeschränkung, so spricht viel dafür, dass die Kapitalverkehrsfreiheit einer Differenzierung zwischen EU- und Drittstaaten entgegensteht.

Wissenschaftliches Neuland betritt die Arbeit durch die Systematisierung der Zinsabzugsbeschränkungen in die drei grundlegenden Modelle des Verschuldungsgrads, der Ergebnisgrenzen und der Aktivagrenzen. Diese sehr leistungsfähige und innovative Typologisierung bildet die Grundlage für eine umfassende und sehr instruktive Analyse der Leitgedanken und ökonomischen Wirkungen der verschiedenen Modelle, wobei der Schwerpunkt naturgemäß auf der auch in Deutschland praktizierten Variante der Ergebnisgrenze liegt. Der internationale Vergleich zeigt, dass Deutschland mit der Umstellung des Rechtsfolgenkonzepts weg von der Umqualifizierung der Zinsen in (verdeckte) Gewinnausschüttungen hin zu einem Betriebsausgabenabzugsverbot zwar einem internationalen Trend folgt, hinsichtlich des Tatbestandskonzepts allerdings nur wenige Vorbilder kennt. Hinzu kommt der sehr weite Anwendungsbereich, welcher nicht nur alle Rechtsformen, sondern neben der Gesellschafter-Fremdfinanzierung auch Darlehen von fremden Dritten erfasst. Auch die Konzernklausel und der Eigenkapitalquotenvergleich als Gegenausnahmen zur (vermeintlichen) Erhöhung der Zielgenauigkeit sind insbesondere wegen der Bezugnahme auf internationale Rechnungslegungsvorschriften einzigartig. Ähnlich beispiellos ist auch der sehr niedrige Schwellenwert von 30 \% des steuerlichen EBITDA für das Auslösen der Zinsschranke; eine derart niedrige Grenze zieht sonst nur das italienische Recht.

Aufbauend auf diesem ausgesprochen detaillierten und kenntnisreichen Ländervergleich setzt sich das Werk im zweiten Hauptteil sehr sorgfältig und umfassend mit der deutschen Zinsschrankenregelung auseinander. Es werden zahlreiche Auslegungsfragen und Umsetzungsschwierigkeiten dargestellt und bewertet sowie für die relevanten Problemfelder praktikable und systematisch überzeugende Lösungsansätze abgeleitet. Beginnend mit dem Betriebsbegriff, über Abgrenzung des Begriffs „Vergütungen für Fremdkapital", wo z.B. die Frage diskutiert wird: sind fiktive Zinsen aus einem Vorteilsverbrauch Vergütungen i.S.d. $\S 4 \mathrm{~h}$ Abs. 3 EStG, geht es weiter über die Problematik der (Nicht-)Einbeziehung von Sondervergütungen, die Aufteilung bei Mitunternehmerschaften, den auch aus Sicht der Gestaltungsberatung interessanten Dependenzen und Interdependenzen zwischen Zinsvortrag und Verlustvortrag, den Unschärfen des Konzernbegriffs, den Rückausnahmen bis hin zu den Möglichkeiten einer Vermeidung von Doppelbelastungen. Aus Sicht des Praktikers ist dieser Teil der Arbeit eine wahre Fundgrube. 
Und auch alle Steuerpolitiker, die grundsätzlich an dem Konzept einer Ergebnisgrenze festhalten wollen, finden in der Arbeit zahlreiche Anregungen für eine zielgenauere Ausgestaltung der Regelungen. Zu denken ist hier vor allem an eine Anhebung der Zinsschranke. Dies würde nicht nur verfassungsrechtliche Bedenken abschwächen, weil das Gesetz dann besser dem wirtschaftlichen Regelfall Rechnung tragen würde, es würde - wie der Verfasser eindrucksvoll nachweist - auch den Anreiz zur Ergebnisverlagerung ins Inland erhöhen. Noch radikaler und noch wichtiger erscheint mir der Vorschlag einer baldigen Rückbesinnung auf das eigentliche Ziel der Zinsschranke im Sinne einer Beschränkung auf die Gesellschafter-Fremdfinanzierung. Idealerweise sogar in einer mikroinvasiven Variante, wie die Österreicher uns gerade wieder einmal vorexerzieren. Nach einem Vorschlag des österreichischen BMF sollen u. a. Zinsen aus einem fremdfinanzierten Beteiligungserwerb im Konzern (deb-push-down) zukünftig nicht mehr abzugsfähig sein. Wenn es „nur“ um die Missbrauchsabwehr ginge, dann würde eine solche Reaktivierung des alten $\S 8$ a Abs. $6 \mathrm{KStG}$ m. E. vollauf genügen. Die Tatsache, dass ausgerechnet diese Norm im Rahmen der Unternehmenssteuerreform 2008 vollkommen durch den Rost gefallen ist, hat sicher nicht nur mich persönlich sehr überrascht.

Da aber alle diese Modelle zur Zinsabzugsbeschränkung aus steuersystematischer Sicht als unvollkommene kurzfristige Lösungen anzusehen sind, lassen sich überzeugende Lösungen nur durch ein koordiniertes Vorgehen zunächst wohl in der EU erreichen. Interessante Anregungen hierfür gibt das letzte Kapitel der Arbeit. Neben einer Koordinierung der Unterkapitalisierungsregelungen in der EU mit Freistellung der korrespondierenden Zinserträge im Empfängerstaat, bietet sich hier insbesondere eine (Wieder-)Einführung des Quellensteuerabzugs für Zinsen an, was naturgemäß eine Revision der Zins- und Lizenzgebührenrichtlinie und nahezu sämtlicher DBA bedingt. Alternativ ist auch die Einführung einer switch over-Klausel denkbar, wonach ein Zinsabzug nur vorgenommen werden kann, wenn erfolgreich der Nachweis geführt wird, dass der Empfänger mit den Zinserträgen einer regulären Besteuerung unterliegt.

Herr Dr. Bohn wurde am 28. März 1980 in Troisdorf geboren. Mit Beginn des Wintersemesters 2000/2001 nahm er das Studium der Betriebswirtschaftslehre an der Universität zu Köln auf und schloss dieses im Juni 2005 mit einem hervorragenden 5. Listenplatz als Diplom-Kaufmann ab. Direkt im Anschluss begann er eine Tätigkeit als wissenschaftlicher Mitarbeiter am Seminar für Allgemeine Betriebswirtschaftslehre und Betriebswirtschaftliche Steuerlehre von Prof. Dr. Herzig. Seit Januar arbeitet er bei einer renommierten Wirtschaftsprüfungsgesellschaft in Düsseldorf und hat im März dieses Jahres die Steuerberaterprüfung erfolgreich abgelegt. Im Schrifttum ist er bereits durch mehrere gehaltvolle 
Veröffentlichungen hervorgetreten. Lieber Herr Dr. Bohn, genau dazu möchte Sie das Fachinstitut mit der Preisverleihung zusätzlich anspornen, setzen Sie den eingeschlagenen Weg fort und bereichern Sie das steuerliche Schrifttum mit weiteren wissenschaftlichen Arbeiten. 

1. Leitthema:

Steuerpolitik der Bundesregierung 



\title{
Steuerpolitik der Bundesregierung
}

\author{
Dr. Hans Bernhard Beus \\ Staatssekretär im Bundesfinanzministerium, Berlin
}

Das Thema meines Beitrags lautet „Die Steuerpolitik der Bundesregierung". Wir wissen, dass die Steuerpolitik sich zu jeder Zeit in die finanzund wirtschaftspolitischen Notwendigkeiten einfügen muss. Sie war zugleich aber auch immer Teil dieser Agenda. Das gilt naturgemäß auch heute. Worin bestehen die aktuellen Aufgaben? Herr Piltz hat es eben schon im Rückblick auf Ihre vorigen Jahrestagungen angesprochen. Sie ergeben sich aus der Herausforderung, aus den Aufgaben der Finanz- und Wirtschaftspolitik den Übergang von einer expansiven konjunkturstützenden Politik, wie sie in den vergangenen Jahren notwendig war, hin zu einer mittelfristigen und langfristigen Konsolidierung ab dem Jahr 2011 und mit Blickwinkel auf das Jahr $2016 \mathrm{zu}$ gestalten. Eine expansive Finanzpolitik war angesichts der Größe der Krise, die uns da bevorstand, und die wir jetzt hoffentlich überwunden haben, zwingend. Aber nachdem wir viele Maßnahmen zur Stützung der Wirtschaft und der Finanzmärkte ergriffen haben, ist es jetzt ebenso zwingend, eine Equity-Strategie umzusetzen, u. a. auch, um dem Ziel der grundgesetzlich verankerten Schuldenbremse nachzukommen und um die Ziele des Europäischen Wachstums- und Stabilitätspakts wieder zu erreichen. Wir liegen im Augenblick, was das Defizitkriterium betrifft, in diesem Jahr deutlich darüber. Der Entwurf des Haushalts 2011, der von der Bundesregierung ja beschlossen ist und jetzt im Kabinett beraten wird, markiert diesen Wendepunkt in der Haushalts- und Finanzpolitik des Bundes. Denn nicht nur die verbesserten wirtschaftlichen Ausgangsbedingungen spiegeln sich in ihm wieder, sondern auch die Abkehr von der krisenbedingten expansiven Haushaltspolitik, in der die Ausgaben des Bundes anstiegen, die Steuern dann wegbrachen und dementsprechend die Neuverschuldung bisher für uns auf jeden Fall unbekannte Dimensionen erreicht hat. Mit dem Entwurf, der jetzt im Parlament beraten wird, verringert die Bundesregierung gegenüber dem Haushalt 2010 ihre Ausgaben um 3,8\%. Das trägt wesentlich zur Konsolidierung bei. Die Bundesregierung hat sich in ihrer Kabinettklausur Anfang Juni über diesen Haushalt bewusst für Ausgabenreduzierungen entschieden zugleich verbunden mit sektoralen Steuererhöhungen auf der Einnahmeseite, um so das Wirtschaftswachstum in Deutschland insgesamt nicht zu gefährden. Wie schon gesagt, trägt neben der Ausgabenreduzierung auch die Einnahmeseite zur Sanierung der Bundesfinanzen bei. Hier hat die Bundesregierung gerade mit Blick auf ökologische Gesichtspunkte Akzente gesetzt, und zwar im 
Bereich Energie. Sie kennen die beiden Projekte Kernbrennstoffsteuer und Luftverkehrsteuer, die wir im Augenblick im Parlament beraten.

Unter diesen Rahmenbedingungen ist es weiterhin möglich, kräftig Investitionen in Bildung und Forschung vorzunehmen. Allein in den Jahren 2010 bis 2013 sind, wie es im Koalitionsvertrag vereinbart ist, 12 Mrd. Euro zusätzlich für diesen Bereich vorgesehen. Ich denke, das verdeutlicht, wie die Spielräume, die durch Konsolidierung entstehen, genutzt werden können, um auch in Zukunft in diesen Bereichen zu investieren. Ich will dazu gleich sagen, weil das ja auch ein steuerliches Thema ist, das sie beschäftigt, dass Spielräume für eine weitere darüber hinausgehende steuerliche Förderung von Forschung und Entwicklung gegenwärtig nicht zur Verfügung stehen.

Auch in der Steuerpolitik muss nun diese Wende gestaltet werden, d.h. zunächst, dass krisenbedingte Maßnahmen wie vorgesehen auslaufen müssen. Das gilt für alle Bereiche. Das gilt aber auch für das Steuerrecht. Auch da hat es Maßnahmen gegeben, die krisenbedingt waren. Die müssen jetzt planmäßig ihr Ende finden. Denn wir wissen, dass wir nach dem realen Einbruch, den wir in 2009 mit knapp 5 \% hatten, jetzt wieder konjunkturelle Aussichten haben, die sich aufgehellt haben. Das ist auch maßgeblich den staatlichen Stützungsmaßnahmen zu verdanken, den Konjunkturpaketen I und II und vielen anderen Dingen. Aber jetzt, wo sich die konjunkturelle Situation aufhellt, müssen diese auch wieder ihr Ende finden. Ich will nochmal erinnern, dass wir diesen Weg auch zu Beginn dieses Jahres noch einmal steuerlich fortgesetzt haben und so insgesamt durch Bürgerentlastungsgesetz und Wachstumsbeschleunigungsgesetz Bürgerinnen, Bürger und Unternehmen um ca. 20 Mrd. Euro entlastet haben. Und das zeigt sich jetzt auch und hat zu dem Aufschwung, den wir im Augenblick erleben, beigetragen. Sie kennen die Zahlen des 2. Quartals dieses Jahres mit einem Wachstum von 2,2\% gegenüber dem Vorquartal. Ich denke, das ist eine erfreuliche Entwicklung. Es ist der stärkste Aufschwung, den wir in dieser Form seit der Deutschen Einheit gehabt haben. Und er macht deutlich, dass die Wachstumsimpulse, die die Bundesregierung auf verschiedene Art gegeben hat, auch dazu beigetragen haben, diese positive Entwicklung zu fördern.

Im Rahmen dieser wachstumsfördernden Finanzpolitik kommt auch der Steuerpolitik eine entscheidende Bedeutung zu. Es geht darum, durch steuerliche Entlastung produktive Kräfte der Gesellschaft weiterhin zu fördern und die notwendigen finanziellen Spielräume dafür zu eröffnen. Zugleich muss im Rahmen einer konsistenten Finanzpolitik aber auch beachtet werden, dass wir den Konsolidierungskurs der Bundesregierung zu unterstützen haben. Der Weg des Abbaus der hohen Staatsverschuldung ist in der mittelfristigen Finanzplanung bis 2016 angelegt. Ich habe schon die Schuldenbremse erwähnt. Diese Schuldenbremse muss ja dazu führen 
und führt dazu, dass wir im Jahr 2016 noch eine Neuverschuldung von $0,35 \%$ des BIP haben werden, d. h. ungefähr 10 Mrd. Euro. Sie kennen die Verschuldungszahlen dieses Jahres. Im Haushalt waren mal 18 Jahre vorgesehen. Wir werden erheblich darunter liegen. In der Zeit, als das Kabinett den Haushaltsentwurf beschlossen hat, waren wir von $65 \mathrm{Mrd}$. Euro ausgegangen. Das hat sich inzwischen weiter verbessert. Aber auch das ist immer noch eine Neuverschuldung in einer Höhe, die wir bisher nicht gekannt haben. Und wir müssen von dieser Höhe herunter bis zum Jahr 2016 auf 10 Mrd. Euro. Ich denke, das macht die Größe der Schritte deutlich, die noch vor uns liegen und für die alle Bereiche ihren Beitrag leisten müssen und auch leisten können, u. a. eben auch die Steuerpolitik. Das macht zugleich den Spielraum deutlich, den wir in den nächsten Jahren haben oder, um es anders zu sagen, die geringe Größe dieses Spielraums.

Bei diesen Rahmenbedingungen hat für uns im Augenblick eine Verbesserung der Lage der Kommunalfinanzen Vorrang. Das ist die dringendste Aufgabe, die der Bund, die Länder und die Gemeinden gemeinsam leisten müssen. Wir brauchen eine Verbesserung der Kommunalfinanzen, um die kommunale Selbstverwaltung zu stärken und nicht weiter erodieren zu lassen. Mit diesen Reformoptionen befasst sich seit März dieses Jahres die Gemeindefinanzkommission, die die Regierung eingesetzt hat, an der außer der Bundesseite die Länder und Vertreter der Kommunen selbstverständlich mitarbeiten. Eine angemessene Finanzausstattung der Kommunen ist erforderlich und notwendig, um die Aufgaben, die Ausgaben und die Einnahmen der Kommunen wieder in ein Gleichgewicht zu bringen. Und dabei müssen wir unterscheiden zwischen den konjunkturellen Fragen, die es bei den Kommunen natürlich ebenso gegeben hat und gibt wie bei Bund und Ländern. Aber es gibt auch dauerhafte strukturelle Probleme bei den kommunalen Finanzen und die müssen wir in besonderer Weise in den Blick nehmen und bei der Arbeit dieser Kommission anfassen. Auch hier geht es nicht mehr um die Einnahmeseite, also um die Frage der Steuern, sondern für kommunale Haushalte ist genauso wichtig die Ausgabenseite, insbesondere die Ausgaben im sozialen Bereich. Und deshalb wird sich diese Kommission mit beiden Seiten der Medaille befassen. Die Kommission prüft, wie Sie wissen, die Möglichkeit, die Gewerbesteuer durch eine andere Art der kommunalen Einnahmen zu ersetzen, nämlich durch Zuschläge auf die Einkommen- und Körperschaftsteuer jeweils mit Hebesatzrecht und durch einen größeren Anteil der Kommunen an der Umsatzsteuer. Ich denke, das ist nach wie vor ein richtiger Ansatz, um die Volatilität der kommunalen Einnahmen zu verringern, wie es sich ja gerade in der Krise in besonderer Weise gezeigt hat. Die Gewerbesteuer ist den Kommunen im großen Umfang weggebrochen. Das hat sicher mit zu dieser schwierigen Finanzsituation beigetragen. Und das ist und wird für eine künftige Gewerbesteuer typisch blei- 
ben, dass sie in dieser Weise auf konjunkturelle Entwicklungen reagiert. Und wenn man sieht, dass die Kommunen dauerhafte Aufgaben haben, die sie unabhängig von der Konjunktursituation lösen und verarbeiten müssen, dann ist es richtig, diese Frage zu stellen, ob es nicht eine Einnahmesituation für die Kommunen geben soll, die weniger auf konjunkturelle Schwankungen reagiert. Das ist unsere Auffassung. Deshalb befasst sich die Kommission mit dieser Frage des Ersatzes der Gewerbesteuer durch eine andere Art kommunaler steuerlicher Einnahmen. Ebenso wichtig ist es, das, was von Bundesseite den Kommunen an Standards und Leistungen vorgegeben ist, zu überprüfen. Das tun wir ebenfalls in dieser Kommission, um so u. a. auch mehr Spielraum für die Kommunen, mehr Flexibilität für eigenverantwortliche Wahrnehmung, eigenen Entscheidungsspielraum zu schaffen und diese auf diese Weise in die Lage zu versetzen, ihre Aufgaben produktiver und kostengünstiger wahrzunehmen.

Lassen Sie mich zwei Dinge bei der Gelegenheit ganz deutlich sagen, auch um Missverständnissen in der öffentlichen Diskussion entgegenzutreten. Einmal geht es bei der Frage Gemeindefinanzkommission nicht um Entlastung der Unternehmen. Wie immer das Modell aussehen wird, das hinterher die Kommission vorschlagen oder auf jeden Fall zur Diskussion stellen wird, Entlastung der Unternehmen ist nicht das Thema. Genauso wenig geht es darum, die Bürger zusätzlich zu belasten. Das sind zwei ganz wichtige Dinge, die man bei dem Anlass immer wieder sagen muss, um auch Diskussionen, die das etwas in Zweifel ziehen, zu beenden und ihnen entgegenzutreten. Ich denke, wir werden im Herbst dieses Jahres einen Bericht dieser Kommission mit einem guten Vorschlag haben. Und es wird dann Aufgabe des Gesetzgebers sein, das aufzugreifen, wenn er es für richtig hält, und in Steuergesetze umzusetzen.

Lassen Sie mich in dem Zusammenhang ein Wort zur Grundsteuer sagen. Die Grundsteuer ist bewusst nicht Thema dieser Gemeindefinanzkommission, weil es dort eine andere Diskussionsebene gibt. Wie Sie wissen, gibt es eine Arbeitsgruppe der Länder, die sich im Auftrag der Finanzministerkonferenz schon seit einiger Zeit mit dem Thema befasst. Das Thema ist jetzt durch die letzte Entscheidung des BFH noch ein Stück aktueller geworden. Die Kommission hat die Aufgabe, bis zur ersten Sitzung des Finanzministers in 2011 ein Konzept vorzulegen. Der Bund arbeitet in dieser Gruppe mit. Aber in erster Linie sind die Länder dort am Zuge, ein Konzept für die neue veränderte Grundsteuer vorzulegen. Wir wünschen uns das und hoffen, dass es dort eine einheitliche Meinung der Länder geben wird, denn das Problem drängt jetzt in der Tat und es muss gelöst werden, und zwar in absehbarer Zeit. Die Gerichte haben heute nochmal deutlich darauf hingewiesen, dass die gegenwärtige Situation dauerhaft auch mittelfristig so nicht bleiben kann. 
Ein weiteres Ziel der Steuerpolitik, das auch öffentlich intensiv diskutiert wird, ist die Steuervereinfachung. Kein neues Thema. Ein Dauerthema, das Sie wahrscheinlich auf ihren Tagungen schon öfter behandelt und gehört haben. Wir denken dennoch, es gibt weiterhin genug Möglichkeiten, im Verfahren bei vielen Einzelfragen zur Vereinfachung zu kommen, auch ohne das Steueraufkommen massiv zu beeinträchtigen. Wir arbeiten intensiv mit den Bundesländern daran, hier Vorschläge umzusetzen. Sie kennen die Vorschläge der Bundesländer, die gemeinsam 13 Vorschläge in einem Papier unterbreitet haben. Das ist für uns auch die Grundlage dessen, was wir im Augenblick selbst prüfen. Mit den Bundesländern besteht ein Einvernehmen, dass wir hier zu Lösungen kommen müssen, die nur geringe Steuermindereinnahmen nach sich ziehen. Das ist in der gegenwärtigen Haushalts- und Finanzlage nicht anders möglich.

Natürlich ist das deutsche Steuerrecht auch eine komplexe Materie, aber schwerpunktmäßig da, wo es um komplexe wirtschaftliche Vorgänge geht. Ich glaube, dass man das auch immer wieder sagen soll. Und das wird sich bei der internationalen Verflechtung unserer Wirtschaft und auch bei den komplexen nationalen Vorgängen nicht wesentlich verändern lassen. Für den Lohnsteuerzahler, der seine Steuererklärung abgibt, sieht das auch heute schon ein Stück anders aus. Daran können wir aber weiter arbeiten, gerade in diesem Verfahren weitere Vereinfachungen umzusetzen. Wir wollen die papierlose Kommunikation mit den Finanzämtern auch für die Bürger deutlich stärken. Da wird es das Projekt vorausgefüllte Steuererklärungen geben, was gerade in diesen einfachen Fällen, auch in den Rentenfällen, eine große Hilfe sein kann. Und wir denken, dass so bis zum Jahr 2013 das Gros der Bürger die Möglichkeit haben wird, ohne Papier, also elektronisch, mit dem Finanzamt zu kommunizieren. Das ist auf jeden Fall unser Ziel, das wir gemeinsam mit den Ländern unterstützen und verfolgen. Bei alledem müssen wir immer wieder im Auge behalten, dass wir eine Balance zwischen Einfachheit und Einzelfallgerechtigkeit finden. Wir wissen, dass wir sehr auf Einzelfallgerechtigkeit ausgelegt sind, sowohl in unserer Gesetzgebung als auch in der Rechtsprechung. Deshalb glaube ich, ist Steuervereinfachung nicht nur eine technische Umsetzung, eine Änderung von Steuergesetzen, sondern letztlich ist es eine mentale Frage. Eine Frage, ob wir bereit sind, diese Balance ein Stück anders zu beurteilen, als wir es bis jetzt getan haben. Wenn wir weiterhin darauf abzielen, den letzten, sei es auch nur ausnahmsweise auftretenden Fall, entweder gesetzlich zu regeln oder wenn wir dies nicht tun, und es dann von der Rechtsprechung vorgehalten bekommen, dann glaube ich, werden bei dieser Haltung innerhalb der Steuervereinfachung Grenzen gesetzt, die wir nicht überschreiten können. Deshalb werbe ich dafür, dass wir sozusagen auch diese grundsätzliche Diskussion führen, was Steuergesetze im Einzelnen leisten können, 
wo diese Grenze zur Einzelfallgerechtigkeit liegt, wenn wir gleichzeitig eine wesentliche Vereinfachung erreichen können.

Ich will noch einen Punkt deutlich sagen. Uns erreichen viele Vorschläge zur Steuervereinfachung. Und manches, was jetzt unter dem Etikett Steuervereinfachung bei uns ankommt, hat natürlich mit Steuervereinfachung nichts zu tun, sondern es geht schlicht um materielle Veränderungen des geltenden Steuerrechts in die eine oder andere Richtung. Ich will gar nicht bestreiten, dass es da legitime Anliegen gibt, aber man sollte nicht versuchen, alles unter die Überschrift Steuervereinfachung zu stellen, weil man den Eindruck hat, dass sich da jetzt etwas bewegen wird. Wenn man unter dieser Flagge mit segeln kann, hat man vielleicht auch für Anliegen, die man schon lange verfolgt, eine Erfolgsaussicht. Steuervereinfachung ist wirklich das, was es ist, besagt aber nicht die Verfolgung anderer materieller Ziele im Steuerrecht, so berechtigt sie auch immer sein mögen.

Wir werden im Herbst dieses Jahres dazu einen Referentenentwurf vorlegen, der dann in der Fachöffentlichkeit sicher diskutiert werden wird, der sicher unter der Überschrift steht: Begrenzung von Steuermindereinnahmen. Aber ich denke, es wird ein erster wichtiger Schritt sein, um dort voranzukommen. Und nach meiner Auffassung werden wir das Steuerrecht nur so vereinfachen, wie wir es auch kompliziert gemacht haben, nämlich Schritt für Schritt. Die Vorstellung, dass es einmal einen Big Bang gibt, und dann haben wir sozusagen ein Steuerrecht, das auf ein Papier welcher Größenordnung auch passt, ist nicht realistisch. Wir müssen den mühsamen Weg gehen, den wir sozusagen bei der Komplizierung gegangen sind, jetzt in umgekehrter Weise, nämlich Schritt für Schritt bei jedem Vorhaben und jeder Maßnahme zu sehen, ob wir nicht entweder ganz darauf verzichten können oder es insgesamt ein Stück einfacher machen.

In den Bereich gehören auch die Diskussionen über die Umsatzsteuer, sprich über die ermäßigten Steuersätze in der Umsatzsteuer. Wir kennen alle die Beispiele, die uns immer vorgehalten werden und in der Tat immer einen humoristischen Einschlag haben, was wir nicht bestreiten können. Aber es ist auch nicht tragisch, wenn das Steuerrecht mal etwas zur Erheiterung der Bevölkerung beiträgt. Insofern nehme ich das immer relativ gelassen hin. Wir wissen, dass das jetzige System der Ausnahme und der Ausnahmen von den Ausnahmen weder systematisch noch einfach ist. Das bestreitet auch niemand. Deshalb sieht die Koalitionsvereinbarung vor, dass sich eine Kommission mit dieser Frage, mit der Struktur und dem Katalog der ermäßigten Steuersätze beschäftigen soll und dort Vorschläge machen soll, ob es zur Vereinfachung kommen kann. Unser Haus, das Finanzministerium, hatte schon in der letzten Legislaturperiode auf Veranlassung des Finanzausschusses ein Gutachten in Auftrag 
gegeben, das sich intensiv mit dieser Frage befassen soll. Das Gutachten liegt seit einigen Tagen vor. Es ist bei uns auch auf der Internetseite veröffentlicht und kann dort abgerufen werden. Das Ergebnis ist nicht besonders überraschend. Es ist nicht das erste Gutachten in dieser Frage, sondern es gibt schon eine Reihe von verschiedenen Seiten. Dieses Gutachten, das ich eben erwähnt habe, kommt zum Ergebnis, dass der ermäßigte Steuersatz nur für Lebensmittel beibehalten werden soll und sonst im Übrigen abgeschafft werden soll. Das wird sicher in die Arbeit der Kommission eingehen, ebenso wie die anderen Äußerungen. Dabei sollte man aber über die Bereitschaft der Bereiche, die an solchen Änderungen mitwirken, nicht allzu große Illusionen haben. Wenn ich so unseren Posteingang sehe, wo schon sozusagen vorbeugend protestiert wird, bevor überhaupt ein Vorschlag auf dem Tisch liegt, kann man sich vorstellen, wie sich das entwickeln wird. Also hier ist Realismus angezeigt, wenn man dort an Veränderungen herangeht. Aber die Aussage der Koalitionsvereinbarung steht. Da brauchen wir dann auch jede Unterstützung sozusagen von fachkundiger Seite. D.h. auch von Ihrer Seite, die dann deutlich macht, wie groß der Vereinfachungsgrad ist und was dann an Bürokratie bei den Unternehmen bei der Finanzverwaltung und auch bei den beratenden Berufen wegfällt, wenn wir sozusagen da zu einer einfacheren besseren Abgrenzung kommen.

Lassen Sich mich einige Worte zur Unternehmensbesteuerung sagen. Einiges ist im Wachstumsbeschleunigungsgesetz passiert. Auch mit einem Entlastungsvolumen, das über 3 Mrd. Euro liegt, das sich sehen lassen kann. Wir wissen, dass es aus dem Koalitionsvertrag weitere Aufträge an uns zur Neustrukturierung der Verlustnutzung, zur Einführung einer Gruppenbesteuerung, zur Auseinandersetzung mit der Frage steuerliche Behandlung von Eigenkapital und Fremdkapital gibt. Alles sind sehr anspruchsvolle Themen, denen wir uns stellen werden und stellen müssen. Wir haben uns das schwerpunktmäßig für das nächste Jahr vorgenommen und arbeiten an Konzepten daran, die wir dann vorstellen werden. Ich denke insbesondere das Thema Verlustnutzung ist ein Thema, was wir lösen müssen. Wir schieben da einen großen Betrag von Verlusten vor uns her, von dem, so glaube ich, alle wissen, dass wir ihn so, wie wir ihn jetzt haben, nicht umsetzen können. Die Aufgabe wird darin bestehen, eine vernünftige und verfassungsrechtlich gängige Lösung dort $\mathrm{zu}$ erarbeiten und vorzuschlagen. Wie gesagt, das ist für uns das Thema des nächsten Jahres.

Gestatten Sie mir einige Worte zu dem Gesetzgebungsverfahren, das im Augenblick beraten wird und zu dem auch in Kürze die Anhörung stattfinden wird, das Jahressteuergesetz 2010. Das ist, wie Sie es aus der Vergangenheit kennen, ein Gesetz, was sich mit einer Vielzahl von Themen, auch Einzelthemen beschäftigt, und auch eine Vielzahl von technischen 
Dingen regelt, die im Laufe der Zeit aufgelaufen sind. Es ist diesmal deshalb besonders umfangreich, weil es im Jahr 2009 nicht so ein Jahressteuergesetz gegeben hat im Hinblick auf die Bundestagswahl. Ich will aber zugleich sagen, dass wir nicht anstreben, jedes Jahr ein Jahressteuergesetz vorzulegen. Wir werden das nur tun, wenn es sozusagen unabweisbar ist, weil natürlich solche Gesetze letztlich auch nicht dazu führen, dass das Steuerrecht einfacher wird, sondern erfahrungsgemäß führen Gesetzgebungsfragen eher dazu, dass sie ein Stück Komplexität weiter anbauen. Also wir haben auf jeden Fall politisch den deutlichen Auftrag von unserem Minister Schäuble, dass Ding nur dann zu machen, wenn wir beweisen können, dass ohne dieses Gesetz diese steuerliche Welt doch einigermaßen aus den Fugen gerät, und nicht deshalb ein Gesetz zu machen, weil es nun eben mal Tradition jedes Jahr ist. Auch dieses Jahr, Sie wissen es im Einzelnen, ist es wieder ein bunter Strauß von vielen Dingen, die sich angesammelt haben: Sei es durch Rechtsprechung, sei es auf europäischer Ebene. Ich will eigentlich nur zwei Dinge herausheben: Im Bereich der Steuerermäßigung für haushaltsnahe Dienstleistungen finden wir eine Regelung, die Doppelförderung vermeidet. Dann ziehen wir erste Konsequenzen bei der Kapitalertragsteuer aus dem, was wir bei der Abgeltungssteuer bisher gelernt haben. Das ist wichtig, dass wir das tun. Im Bereich der Abgabenordnung gibt es eine Reihe von Änderungen und ansonsten wie gesagt viele Änderungen, viele Reaktionen auch auf Rechtsprechung, um dort Konsequenzen zu ziehen. Auch deshalb, weil ja die Koalitionsvereinbarung, wie Sie wissen, den Auftrag enthält, Nichtanwendungsschreiben $z u$ begrenzen. Wir nehmen das ernst und prüfen intensiver als es in der Vergangenheit der Fall war, ob wir solche Anwendungsentscheidungen treffen müssen. Das führt aber auch dazu, dass das eine oder andere dann sozusagen gesetzgeberisch korrigiert wird, wenn wir glauben, dass wir mit einer Entscheidung auf Dauer so nicht leben können.

Ich will die Gelegenheit dieses Forums gerne nutzen, um ein paar Worte zur E-Bilanz und zu den Datenfeldern, die damit zusammenhängen, also mit der Taxonomie, zu sagen. Wir nehmen ja auch zur Kenntnis, dass es dort öffentliche Kritik gibt. Wie Sie wissen, gibt es in der übernächsten Woche eine Anhörung des Bundesministeriums der Finanzen zu dem Thema. Ich würde Sie herzlich bitten, dort dann auch konkrete Kritikpunkte und Vorschläge anzubringen. Pauschale Kritik ist auch Ihr gutes Recht und wichtig, hilft uns aber relativ wenig weiter. Ich denke, wir stimmen darin überein, dass wir den Weg ins elektronische Zeitalter machen müssen. Da führt kein Weg daran vorbei. Das bedeutet auch, dass es Umstellungsaufwand gibt, wenn man diesen Weg geht. Der ist, glaube ich, auch unvermeidbar, aber für den Dauerbetrieb muss es natürlich für alle eine Erleichterung und Verbesserung sein. Das ist auf jeden 
Fall auch unser gemeinsames Anliegen. Deshalb ist es wichtig, dass man da konkret über die Details redet, was Sie für überflüssig halten, auf was man verzichten kann, um dann, wenn diese Umstellungsperiode vorbei ist, ein System zu haben, von dem wir und Sie sagen, es ist eine Verbesserung gegenüber dem Status Quo. Meine Bitte ist, die Anhörung auch für diese Diskussion zu nutzen.

Ich will Ihnen einige Worte sagen $z u$ dem, was wir im internationalen Steuerrecht, insbesondere im Bereich der Doppelbesteuerungsabkommen machen. Das ist für uns im Augenblick ein sehr intensives Thema unserer Tätigkeit. Im Fokus steht die Modernisierung der Abkommen im Lichte des Musterabkommens der OECD. D.h. also Veränderung der bestehenden Abkommen unter dem Gesichtspunkt dessen, was dort in dem Musterabkommen geregelt ist. D. h. wir werden sie anpassen. Gutes Beispiel dafür ist das neue Abkommen mit Großbritannien, das sich im Ratifizierungsverfahren befindet und wo wir davon ausgehen, dass die Ratifizierung noch in diesem Jahr erfolgen kann. Wir haben eine Reihe von Abkommen mit Entwicklungsländern verhandelt mit der Überschrift und der Maßgabe, dass wir nur noch dort Abweichungen von dem OECD-Standard machen, wo sie wirklich aus dem Entwicklungsstand dieses Landes begründet sind und zwingend erforderlich sind. Sie kennen die Methodenfrage der Anrechnungs- oder Freistellungsmethode. Die Anrechnungsmethode wird nur in Einzelfällen angewandt. Es hat in der Vergangenheit ein oder zwei Fälle gegeben, dass es nicht ein Wechsel in unserer Politik im Bereich DBA ist, sondern dass es jeweils spezifische Gründe im bilateralen Verhältnis zu dem Staat gibt, dass wir dort wieder zur Anrechnungsmethode übergangen sind. Das gilt insbesondere gegenüber solchen Staaten, die nur niedrig oder gar nicht besteuern, die aber trotzdem in der Regel aus politischen Gründen wünschen, mit uns ein DBA abzuschließen. Wenn man es rein fachlich sieht, sind das oftmals Fälle, wo aus unserer Sicht keine Doppelbesteuerung erfolgt wegen der geringen oder keinen Besteuerung in dem Staat. Aber wenn ein Abkommen geschlossen werden soll, müssen wir jedenfalls sicher stellen, dass es keine weißen, also unversteuerten Einkünfte gibt und das kann dann dazu führen, dass wir die Anrechnungsmethode anwenden. Und es gibt Fälle, wo sich Staaten weigern, mit denen wir üblicherweise die Freistellungsmethode vereinbaren, die Klauseln zu akzeptieren, die wir brauchen, um unter Zugrundelegung der Freistellungsmethode trotzdem nicht zu Ergebnissen kommen, die diese Methode ausnützen. Also wie gesagt kein grundsätzlicher Methodenwechsel, sondern beschränkt auf die genannten Einzelfälle. Auch das entspricht der Koalitionsvereinbarung, die davon spricht, dass wir grundsätzlich die Freistellungsmethode anwenden und die Anrechnungsmethode eben nur in den genannten Einzelfällen. 
Ich will einige Worte sagen über die Vereinbarung zum Informationsaustausch. Das ist ja etwas, was wir sozusagen parallel zu den DBAs betreiben oder in die DBAs integrieren. Ich denke, da sind wir ein erhebliches Stück weitergekommen als in der letzten Zeit. Die Bereitschaft, solche Abkommen mit uns abzuschließen, ist erheblich gewachsen. Es gibt eigentlich kein Finanzzentrum, das sich weigert, in Verhandlungen über solch ein Abkommen einzutreten. Es ist sicher auch ein Ergebnis des Steuerhinterziehungsbekämpfungsgesetzes, dass diese Bereitschaft auf jeden Fall im Verhältnis zu Deutschland erheblich gewachsen ist. Und ich denke, damit hat dieses Gesetz ebenso wie der OECD-Standard eines seiner Ziele auch erreicht. Wir haben Abkommen geschlossen mit Jersey, Gibraltar, Guernsey, Isle of Man. Wir werden weitere Abkommen schließen mit den Bahamas, den Cayman Inseln, San Marino und Monaco. Das zeigt, dass wir doch allmählich flächendeckend werden. Und wir werden alle diese Abkommen zügig dem Parlament vorlegen, um sie dann in Kraft treten zu lassen. Wir haben mit der Schweiz ein Revisionsprotokoll zum bestehenden Doppelbesteuerungsabkommen vereinbart und streben an, dass dieses Revisionsprotokoll noch im Oktober unterzeichnet wird, um auch damit in das Ratifizierungsverfahren einzutreten. Und ich will auch an dieser Stelle sagen, dass es in dieser und in der letzten Woche nochmal Thema der Presse war, dass dieses Revisionsprotokoll von der Amtshilfeverordnung, die die Schweiz zur Umsetzung betreibt und vorlegt, nicht gehindert wird, sondern dass ganz klar ist, dass das Revisionsprotokoll, d. h. das DBA Vorrang hat, und danach ist zu verfahren. Ich bin mir sicher, dass die Schweiz dort einen effektiven Austausch von Informationen sicherstellen wird.

Ich glaube, das sind alles wichtige Schritte, um Steuerflucht und Steuerhinterziehung zu bekämpfen und diesen Methoden den Boden zu unterziehen. Ich denke, ich erlebe das auf jeden Fall in den Gesprächen mit den Kollegen aus diesen Staaten, dass sich da schon ein Bewusstseinswandel einstellt, dass allen deutlich wird, das die Zeiten, wo diese Methoden der Steuerhinterziehung relativ einfach waren, zu Ende gehen und dass die Staaten jetzt kooperieren und die Informationen austauschen, die erforderlich sind, um zu einer gerechten und richtigen Besteuerung zu kommen.

Das ist in kurzen Worten das, was uns im Augenblick besonders beschäftigt. Daneben gibt es natürlich viele andere Themen, die wir weiter betreiben, die ich jetzt im Einzelnen hier nicht erwähnen kann. Ich denke, dass die Legislaturperiode davon geprägt sein wird, dass die Steuerpolitik sich in dem Spannungsfeld zwischen dem bewegen wird, was finanziell machbar ist, was durch die erwähnte Schuldenbremse und die Entwicklung, die wir vor uns haben begrenzt ist, aber auch in Spannung stehen wird zu dem, was wir wachstumspolitisch wollen und was wir 
steuerpolitisch für richtig halten. Da müssen wir immer wieder die Balance finden und darüber diskutieren und wahrscheinlich auch streiten, was aus der einen oder anderen Sicht geht und was nicht geht. Ich freue mich da über Ihre Beiträge, die ja dadurch gekennzeichnet sind, dass sie sachkundige Beiträge sind. Und die sind uns immer willkommen. Auch wenn sie Kritik sind, helfen sie uns weiter und geben uns Hinweise und Gelegenheit zum Nachdenken. Deshalb vielen Dank für die Möglichkeit, das hier vorzustellen und für die Kontakte, die wir ja in vieler Weise mit Ihnen haben und die wir gerne haben und die wir auch gerne beibehalten. 



\title{
Diskussion zum Leitthema: "Steuerpolitik der Bundesregierung “
}

\author{
Leitung: Professor Dr. Detlev J. Piltz
}

\section{Teilnehmer:}

Dr. Hans Bernhard Beus, Staatssekretär im Bundesfinanzministerium, Berlin

Dr. Steffen Neumann, Leiter der Steuerabteilung, Finanzministerium NRW, Düsseldorf

Prof. Dr. Norbert Herzig, Steuerberater, Wirtschaftsprüfer, Universität Köln

Bernd Jonas, Rechtsanwalt, ThyssenKrupp AG, Düsseldorf

Prof. Dr. Thomas Rödder, Wirtschaftsprüfer, Steuerberater, Flick Gocke Schaumburg, Bonn

Prof. Dr. Detlev J. Piltz, Vorsitzender des Fachinstituts der Steuerberater e. V., Köln

Piltz: Vielen herzlichen Dank, Herr Beus, für diesen informativen Durchgang zur Steuerpolitik der Bundesregierung. Wir wollen das jetzt diskutieren, und ich darf unsere Diskutanten bitten auf das Podium zu kommen.

Wir haben hier auf der einen Seite die Bundespolitik. Aber es gibt natürlich auch Landesgesichtspunkte. Neben mir sitzt Herr Dr. Neumann, den Sie schon kennen. Er wird uns jetzt in kurzer Form darstellen, wie aus der Sicht des Landes Nordrhein-Westfalen Steuerpolitik sein könnte. Das ist natürlich auch deswegen ganz spannend, weil er dazu im letzten Jahr schon gesprochen hat. Nur die politische Farbe zwischen dem letzten Jahr und heute hat sich eben sehr geändert. Und wir werden sehen, es sind am Ende doch Politiker, die Steuerpolitik machen und nicht nur Beamte, wie auch Herr Neumann. Bitte schön.

Neumann: Guten Morgen, meine Damen und Herren. Schönen Dank für die einleitenden Worte, Herr Prof. Piltz. Wenn ich hier aus der Sicht des Landes Nordrhein-Westfalen etwas sagen soll, bitte ich Sie, mir nachzusehen, dass ich ein wenig zurückhaltend bin, was die nordrhein-westfälische Position angeht. Viele Aspekte werden daher subjektiv geprägt sein, die ich hier heute kurz vortragen möchte. Nur ganz kurz zu den steuerlichen Themen, die im Moment aktuell sind und auch aus der Sicht der Länder von Interesse sind. 
Zunächst zum Jahressteuergesetz 2010, meine Damen und Herren. Sie wissen, dass die finale Entnahmelehre, die die Überführung von Wirtschaftsgütern in ausländische Betriebsstätten betrifft, von dem BFH in seiner Entscheidung aus 2008 aufgegeben worden ist. Hier ist der Bundesrat sehr stark daran interessiert, den alten Rechtszustand im Wege eines Nichtanwendungsgesetzes wiederherzustellen.

Der Gewinnabführungsvertrag bereitet große Probleme und zwar deswegen, weil $\S 17 \mathrm{KStG}$ für Gewinnabführungsverträge von $\mathrm{GmbHs}$ eine exakte Anwendung des $\S 302 \mathrm{AktG}$ mit allen Verästelungen verlangt, was in der letzten Zeit wohl nicht immer gelungen ist. Der Bundesrat hat deswegen vorgeschlagen, den $\S 17 \mathrm{KStG}$ zu ändern mit der Folge, dass auch Gewinnabführungsverträge akzeptiert werden, die die sehr starken rechtsförmlichen Anforderungen des BFH nicht erfüllen, aber gleichwohl "gelebt" werden. Ein wenig im Hintergrund ist wohl auch der Gedanke, dass man auf diese Weise etwas für die Rettung der Organschaft machen könnte. Es heißt nämlich im Koalitionsvertrag der Bundesregierung, man bemühe sich um eine moderne Gruppenbesteuerung, was auch immer das heißen mag. Die Vorteile einer Gruppenbesteuerung liegen sicherlich im Wegfall des Gewinnabführungsvertrages und in dem Verzicht auf die Gewinnabführung bzw. Verlustübernahme. Auch die Bilanzierungsunterschiede in Steuerbilanz und Handelsbilanz aufgrund des BilMoG sind sicherlich ein wichtiger Gesichtspunkt, wie z.B. der Ausweis latenter Steuern zu der Frage führt, ob das Mehrergebnis abzuführen ist oder nicht. Alles richtig auf der einen Seite. Aber auf der anderen Seite macht mir Sorge, wie denn die Gruppenbesteuerung aussehen soll. Wie sollen denn die Teilnahmebedingungen dazu gestaltet sein? Die Österreicher geben es vielleicht als Muster vor. Die österreichischen Fachleute raten z. B. dringend davon ab, natürliche Personen und Personengesellschaften als Teilnahmeberechtigte erscheinen zu lassen, also nur Kapitalgesellschaften zuzulassen. Wie soll die Höhe der Beteiligung für eine Gruppenmitgliedschaft aussehen? Soll sie mindestens $75 \%$ oder $95 \%$ betragen? Mit anderen Worten: unter diesen Voraussetzungen wäre der unternehmerische Mittelstand für eine Ergebniskonsolidierung auszugrenzen. Das ist ein Problem. Wenn die Gruppenmitgliedschaft $z u$ einer Vollkonsolidierung führen soll, würden die Probleme der Mehr - und Minderabführungen unverändert bestehen bleiben. Wollte man dies verhindern, müsste über Steuerumlagen nachgedacht werden. Aber Steuerumlagen im Konzern ist ebenfalls ein Komplex, der sich nicht aus sich selbst heraus erklärt. Er muss gesellschaftsrechtlich dargestellt und geregelt werden wie auch die Verlustkonsolidierung. Ebenso muss die Ergebniskonsolidierung bei Verlusten ausländischer Gruppenmitglieder geklärt werden. Bei Einführung einer Gruppenbesteuerung werden also eine Reihe alter Fragen gegen eine Reihe neuer Fragen ausgetauscht wer- 
den, die bisher noch unbeantwortet geblieben sind. Deswegen das Bemühen der Bundesländer, den § $17 \mathrm{KStG}$ nachbessern zu wollen.

Einige Neuregelungen aus dem Haushaltsbegleitgesetz 2011 berühren die Interessen der Länder durchaus. So dient die Stärkung des Fiskus im Insolvenzverfahren durch Änderung der Insolvenzordnung der Verhinderung von Umsatzsteuereinbußen, insbesondere der Umsatzausfälle aus der Zeit der vorläufigen Insolvenz. Dies ist ein sehr starkes Anliegen der Länder schon seit fast 20 Jahren gewesen. Dagegen, dass die angedachte Wiedereinführung des Fiskusvorrechts nach dem Muster des §61 der Konkursordnung von der Bundesregierung fallengelassen worden ist, ist wohl nichts einzuwenden. Andere Maßnahmen wie das Luftverkehrssteuergesetz, mit dem neuartige Abgaben bei Abflug von einem inländischen Flughafen eingeführt worden sind, der Wegfall von Begünstigungen durch die Energiesteuergesetze, die zur Verteuerung von Stromkosten führen, sowie das Kernbrennstoffsteuergesetz betreffen teils nur wenige Steuerpflichtige. Hieraus resultieren künftige Einnahmen, die allein dem Bund zufließen, und das interessiert die Länder. Die Länder wissen, dass diese drei Positionen bei den betreffenden Unternehmen zu Betriebsausgaben in Milliardenhöhe führen werden. Die damit verbundene Umfinanzierung, weil das Aufkommen dem Bund zufließt, während das geminderte Aufkommen insbesondere bei der Körperschaftsteuer hingegen die Länder betrifft, wird von den Länder aus fiskalpolitischer Sicht kritisch begleitet werden.

Sie, Herr Prof. Piltz, haben gesagt, die politische Farbenlehre habe sich in Nordrhein-Westfalen geändert. Die SPD hat natürlich auch neue Vorschläge und auch die neue Landesregierung. Erwähnen möchte ich die Erhöhung des Spitzensteuersatzes, die vom SPD-Parteitag am 26.9.2010 angedacht ist. Ziel der Aktion ist die Anhebung des Einkommensteuerspitzensatzes von derzeit $42 \%$ auf $49 \%$. Die Berechtigung der Steuersatzerhöhung ist Teil der Diskussion um die soziale Ausgewogenheit von Sparpaketen, die nicht ganz von der Hand zu weisen ist. Nur muss man sehen, dass die Anhebung des Spitzensteuersatzes auf drei Wegen erreichbar ist. Welcher Weg gegangen wird, ist derzeit unklar. Der erste Weg wäre, dass man bei dem ersten Tarifknick, d.h. nach der ersten Progressionsstufe bei 13.750 Euro eine lineare Progressionsstufe z. B. bis 100.000 Euro einbaut. Das ist eine Variante, bei der der sog. Mittelstandsbauch ordentlich abgeflacht würde. Die gewünschten Mehreinnahmen von 4 bis 5 Mrd. Euro würden sich dabei allerdings genau ins Gegenteil verkehren in Mindereinnahmen von 4 bis 5 Mrd. Euro, weil eben der Mittelstand entlastet würde. Eine andere Möglichkeit bestünde darin, bei 52.882 Euro, also da, wo die Stufe von $42 \%$ beginnt, anzusetzen und in einer dritten Progressionszone auf 49 \% hochzugehen. Das würde bedeuten, es käme zu überhaupt keiner Entlastung. Die Variante führt zu Mehreinnahmen, 
bedeutet aber, dass diejenigen, die mehr als 53.000 Euro verdienen, in der Spitze höher belastet werden. Eine dritte Möglichkeit besteht darin, die Reichensteuer von $45 \%$ auf $49 \%$ aufzusatteln, sie aber schon ab 100.000 Euro oder 125.000 Euro beginnen zu lassen. Diese Variante würde den Mittelstand letztendlich finanziell nicht sonderlich berühren.

Die Landesregierung denkt im Koalitionsvertrag auch über die Wiedereinführung der Vermögensteuer nach. Auch der SPD-Parteivorstand auf Bundesebene denkt darüber nach. Je nach Ausgestaltung der Vermögensteuer - dies hängt ab von der Höhe des Steuersatzes, des Verschonungsumfangs, aber auch davon, wer Adressat der Vermögensteuer werden soll, etwa nur natürliche Personen oder auch Kapitalgesellschaften - würden Steuermehreinnahmen zwischen 4 und 10 Mrd. Euro bundesweit jährlich erbracht werden. Problematisch aus meiner sehr subjektiven Sicht ist die Kombination der Dinge: Anhebung des Steuersatzes bei der Einkommensteuer, die Einführung der Vermögensteuer und kumulativ dazu noch die Erbschaftsteuer. Wenn allerdings die Erbschaftsteuer, was viele prophezeien, ein nicht mehr sehr langes Leben haben sollte nach der nächsten Befassung durch das Bundesverfassungsgericht, stellt sich die Frage, ob die Politik noch einmal die Kraft hat, einen neuen Anlauf bei der Erbschaftsteuer zu versuchen. In diesem Falle wäre die Vermögensteuer sicherlich eine Alternative zu der Erbschaftsteuer.

Die Gemeindefinanzkommission - wir haben die Ausführungen von Herrn Staatssekretär Dr. Beus hierzu schon gehört - wird ein Modell prüfen, nach dem die Gewerbesteuer durch eine sog. Zuschlagssteuer mit Ausweis des Einkommensteueranteils bei natürlichen Personen und parallel auch durch einen Zuschlag auf die Körperschaftsteuer zu ersetzen. Der finanzielle Ausgleich für den ersatzlosen Wegfall der Gewerbesteuer soll im Wesentlichen durch eine entsprechende Umsatzsteuerbeteiligung der Kommunen erfolgen. Wir in Nordrhein-Westfalen haben dieses Verfahren ein wenig begleitet. Das geprüfte Modell ist sicherlich keines, das einfach wird, aber das war auch nicht der Anspruch. Allerdings sind wir auch der Meinung, dass die Ausschläge beim Aufkommen der Kommunen künftig in der Tat geringer ausfallen dürften, weil die Schwankungen bei der Umsatzsteuer wie auch bei den Lohnsteuereinnahmen wesentlich geringer als bei den ertragsabhängigen Steuern sind. Gleichwohl sind sich die Gemeindeverbände in Nordrhein-Westfalen einig und wollen keine Änderung des Systems. Es soll so bleiben wie bisher. Vielmehr soll die Bemessungsgrundlage möglichst noch verbreitert werden. Da wird man wahrscheinlich über eine Erweiterung der Hinzurechnungen der gewinnunabhängigen Bestandteile nachdenken. Wahrscheinlich nicht über die Zinsanteile selbst, denn die werden nach sachlichen Kriterien festgelegt, aber wohl in Bezug auf die Quote von $25 \%$. Man denkt auch über eine Erweiterung des Kreises der Steuerpflichtigen, 
also über die Einbeziehung der Freiberufler nach. Die kommunale Seite will insgesamt kein Mehraufkommen generieren, sondern ein stabileres Aufkommen. Daher wird eine Entlastung auf der anderen Seite durch Absenkung der Messzahl erwogen. Warum die Kommunen so vehement an der bisherigen Gewerbesteuer festhalten, weiß ich nicht so recht. Denn der Gemeindefinanzbericht des Städtetages Nordrhein-Westfalen hat deutlich gemacht, dass die Gewerbesteuer in 2009 im Vergleich zum Vorjahr bis zu $75 \%$ eingebrochen war.

Der Grundsteuer ist von Herrn Dr. Beus auch schon angesprochen worden. Insofern will ich noch ergänzen, als dass Nordrhein-Westfalen eine koordinierende Funktion zur Ermittlung, welche Grundsteuermodelle in Betracht kommen, wahrnimmt. Da der BFH ausgeführt hat, die Grundsteuer sei bis zum Feststellungszeitpunkt 1.1.2007 noch verfassungsgemäß, könnte es für nachfolgende Feststellungszeitpunkte problematisch werden. Also ist Gefahr im Verzuge. Das größte Problem bei der Reform der Grundsteuer besteht in der Bewertung des Vermögens auf eine Art und Weise, die wirtschaftlich für alle Beteiligten, also insb. auch für die Finanzverwaltung, vertretbar ist, die eine Einheitsbewertung vermeiden möchte. Wir sind guten Mutes. Es gibt wie gesagt mehrere Vorschläge. Vom Zeitplan her ist es so gedacht, dass die Finanzministerkonferenz Anfang kommenden Jahres entscheiden muss, welche der Vorschläge näher geprüft werden soll.

$\mathrm{Zu}$ guter Letzt, meine Damen und Herren das Thema Steuervereinfachung. Die Finanzministerkonferenz vom Mai dieses Jahres hat 13 Vorschläge hierzu gemacht. Das mag banal klingen. Das gebe ich zu. Jedoch haben wir uns in letzter Zeit wiederholt bemüht herauszubekommen, wie man einen großen Wurf zur Vereinfachung des Steuerrechts hinbekommt, und dabei festgestellt, es geht nicht, es funktioniert nicht. Ich bin überzeugt, es wird auch in Zukunft nicht funktionieren. Deswegen haben wir Länder vorgeschlagen, den kleinen Weg zu gehen, also einfach im Detail Vereinfachungen vorzuschlagen, um so eine Entwicklung anzustoßen. Es ist ein erster Schritt in eine richtige Richtung. Die Länder haben sich ohne irgendwelche Unterschiede parteipolitischer Art in dem Punkt geeinigt. Parallel werden auch die Bemühungen der Bundesregierung zur Steuervereinfachung sehr begrüßt. Von dort aus werden insbesondere viele Dinge im technischen Bereich angestoßen werden. Die vorausgefüllte Steuererklärung war schon genannt worden.

Die E-Bilanz ist in letzter Zeit ein wenig in die Kritik geraten. Ich muss dazu zur Verteidigung anführen, dass Bayern zusammen mit NordrheinWestfalen dieses Projekt in einer ausgesprochen behutsamen Weise angegangen ist. Wir waren gewarnt durch das Beispiel EÜR-Vordruck und haben die berechtigten Belange auch der Beraterschaft beherzigt. Wir haben alle einbezogen. Wir haben alle Verbände einbezogen, die Berater 
einbezogen und vieles gemeinsam entwickelt. Und ich meine, wir hätten auch in einer angemessenen Weise agiert, indem die Einzelpositionen, die ausgefüllt werden müssen, die sog. Muss-Positionen, moderat ausgefallen sind. Herr Dr. Beus hat völlig zu Recht gesagt, man kann über alles diskutieren. Aber wenn in dem Zusammenhang schon jetzt davon gesprochen wird, es käme ein Verwaltungsmonster auf uns, kann ich das letztendlich nicht mehr nachvollziehen. Vielleicht haben sich solche Kritiker in den Prozess ein wenig spät eingeschaltet. Aber sie waren und sind immer herzlich zu der weiteren Mitwirkung eingeladen. Meine Damen und Herren, ich bedanke mich sehr für Ihre Aufmerksamkeit und freue mich auf die Diskussion, die jetzt beginnt.

Piltz: Vielen Dank, Herr Neumann. Wir wollen diskutieren. Ich stelle nochmals kurz vor. Auf der Seite außen Herr Herzig, der für die Wissenschaft spricht. Links aus meiner Sicht neben Herrn Beus, Herr Rödder für die Beratung und links davon Herr Jonas, der hier für die Industrie spricht. Ich schlage vor, dass wir in der Reihenfolge, in der Herr Beus uns vorgetragen hat, nachdem er die Rahmenbedingungen dargestellt hat, vorgehen und uns den Punkt 1 vornehmen, nämlich die Kommunalfinanzen. Ich frage einfach direkt, Herr Beus, so gerüchteweise hört man immer: Ach die Bürgermeister sind dagegen, daraus wird doch nichts. Ist da etwas dran oder ist das zu pessimistisch?

Beus: Also, es ist sicher richtig, dass sich die Begeisterung für Veränderungen im kommunalen Bereich in Grenzen hält, um es vorsichtig zu sagen, was ich nicht so richtig verstehe. Wenn man sich die Verteilung der Gewerbesteuer ansieht - ich habe mir das jetzt aus aktuellem Anlass mal für Bayern angesehen - da gibt es z. B. eine Kommune, die hat pro Kopf 1.400 Euro im Jahr und dann gibt es eine Kommune, die hat 100 Euro pro Jahr. Und das wird als idealer Zustand angesehen. Ich kann das nicht so richtig nachvollziehen. Ich denke, es ist ein Angebot auch des Bundes an die Kommunen, und ich glaube, als solches sollte man es auch wirklich kommunizieren. Es geht nicht darum, die Einnahmebasis der Kommunen zu schmälern. Das ist überhaupt nicht das Thema. Sondern es soll Plus minus Null ausgehen bei den steuerlichen Einnahmen. Wir arbeiten intensiv daran, die Verteilungswirkung, die wir jetzt haben, einigermaßen abzubilden. Das ist eigentlich das Anspruchsvollste bei dem ganzen Bereich.

Und lassen Sie mich ein Wort zu dem Kommunalvorschlag sagen, die Freiberufler einzubeziehen. Das klingt ja zunächst nach Steuererhöhung, aber Sie wissen alle, das ist keine Steuererhöhung, sondern eine Umverteilung zwischen Bund und Ländern auf der einen Seite und Kommunen auf der anderen Seite. Da geht es dann so um 5 Mrd. Euro hin und her. Solche Vorschläge können wir auch machen und sagen, dass wir auf die Weise das Problem lösen. Ich glaube, da werden wir nicht weiterkom- 
men. Was den Ausbau der Hinzurechnungen betrifft, können Sie sich vorstellen, was der kleine Koalitionspartner im Bund davon hält. Wenn man die beiden Vorschläge nimmt, die von kommunaler Seite auf dem Tisch liegen, werden Sie das Problem nicht lösen. Das muss man auch sagen. Wenn die Kommunen glauben, sie brauchten das Problem nicht gelöst haben, weiß ich nicht, ob das weiterhilft. Ich glaube das schon. Und ich glaube, dazu sind Bund und Länder bereit, und Nordrhein-Westfalen hat ja auch schon etwas getan. Wir sehen schon, dass die Finanzbasis der Kommunen gestärkt und verstetigt werden muss. Es ist für uns auch ein Thema, weil wir bei jeder Rezession merken, dass der Großteil der staatlichen Investitionen durch die Kommunen erfolgt. Und eigentlich müssen die in der Rezession weitergehen, und dürfen nicht abrutschen. Im Augenblick passiert das Gegenteil. Die Steuereinnahmen der Kommunen brechen weg. Sie müssen da reagieren, und das ist nicht im gesamtwirtschaftlichen Interesse. Und deshalb haben wir ein Interesse an einer stetigen Einnahmebasis der Kommunen, und wir werden weiter dafür werben und eintreten.

Piltz: Plus minus Null ist ja ein anderes Wort für aufkommensneutrale Steuerreform. Das heißt natürlich, dass sich die Belastung innerhalb der Steuerpflichtigen verschiebt. Manche, die vorher mehr hatten, haben hinterher weniger. Es ist klar, die Hälfte, für die es besser wird, die hat man auf seiner Seite, und die Hälfte, für die es schlechter wird, die hat man nicht auf seiner Seite. Das war jetzt die Sicht der Kommunen als Steuergläubiger. Herr Jonas, wie ist die Sicht der Unternehmen, die ja ganz überwiegend die Gewerbesteuer tragen.

Jonas: Zunächst einmal haben die Unternehmen ein Interesse daran, dass es auch den Kommunen gut geht und dass die Arbeitnehmer nicht in Kommunen leben müssen, wo die Schwimmbäder geschlossen werden und wo die Kindereinrichtungen nicht mehr gebaut werden können. Das ist das Erste. Der zweite Punkt ist, dass die Kommunen in der Tat ein Ausgabenproblem haben. Das liegt daran, dass immer wieder auch Aufgaben des Bundes und der Länder auf sie abgewälzt werden, ohne dass eine Deckung dafür da ist. Das ist ja auch Aufgabe der Gemeindefinanzkommission, von der Herr Dr. Beus sprach. Ich glaube, dass da eine Lösung angedacht ist oder dass da eine Lösung möglich ist. Darüber hinaus besteht das Problem des Schicksals der Gewerbesteuer. Ich habe gestern auf einer Veranstaltung in Berlin mitbekommen, dass auch der Vertreter des Landes Bayern, der Finanzminister von Bayern, Herr Fahrenschon, relativ skeptisch ist, was die Abschaffung oder den Ersatz der Gewerbesteuer angeht. Dennoch glaube ich, dass nach wie vor hier Handlungsbedarf besteht. Herr Beus hat das Gefälle innerhalb der Kommunen angesprochen. Ich könnte andere Beispiele bringen, nämlich, dass Frankfurt zehnmal so viel Gewerbesteuer je Einwohner erzielt wie sämtliche 
Ruhrgebietskommunen. Und in München ist das auch nicht viel schlechter. Gleichzeitig ist aber die Sozialleistungsdichte in diesen Kommunen dreimal so hoch wie z. B. in München. Hartz IV-Empfänger in Gelsenkirchen gibt es $18 \%$ und in München vielleicht $5 \%$. Gleichzeitig, und das ist eigentlich das, was jetzt die Unternehmen interessiert, ist aber in diesen Kommunen ein Trend zu erkennen, dass die Hebesätze ansteigen. Duisburg hat jetzt z. B. beschlossen, in diesem Jahr auf $490 \%$ zu gehen. Wenn Sie das ausrechnen, haben Sie eine Nominalbelastung ohne die hinzurechnungspflichtigen Tatbestände von $32,397 \%$. Das ist schon mal $10 \%$ mehr, als das, was im Unternehmenssteuerreformgesetz 2008 versprochen worden ist. Wenn dieser Trend anhält, dann sind natürlich massiv auch die Unternehmen betroffen, denen ja vor zwei Jahren gesagt worden ist, wir wollen eine internationale oder europaweit vergleichbare Steuerbelastung haben. Deshalb ist hier nach wie vor Handlungsbedarf gegeben. Interessanter Weise klang gestern in den Anmerkungen von Herrn Fahrenschon durch, dass er sich eine Lösung vorstellen könnte, bei der zumindest die hinzurechnungspflichtigen Tatbestände abgeschafft werden und ersetzt werden durch eine höhere Beteiligung der Kommunen an der Umsatzsteuer. Das würde ein bisschen bei der Volatilität helfen. Es würde aber zumindest auch für die Unternehmen dafür sorgen, dass alle krisenverschärfenden Elemente, die durch die Hinzurechnung kommen, die ja auch in Verlustfällen anfallen, bis hin zur $70 \%$-Versteuerung von Geschäften von Handelsbetrieben in guten Innenstadtlagen für die Zukunft vermieden werden. Vielleicht ist das zumindest ein halber Schritt auf dem richtigen Weg zur Beseitigung der Problematik der Gewerbesteuer.

Piltz: Vielen Dank, Herr Jonas. Auf dem Podium noch etwas zur Gewerbesteuer, Gemeindefinanzreform?

Herzig: Was man feststellen kann, ist ja die Tatsache, dass in den Zielen offensichtlich breite Übereinstimmung besteht. Alle wollen die Stärkung und die Verstetigung der kommunalen Finanzen. Aber wir können uns seit vielen Jahren nicht über die Instrumente einigen. Da ist offensichtlich eine große Disparität zu beobachten und die Gefahr, dass es eben wirklich in die Richtung geht, dass die Bemessungsgrundlage verbreitert wird durch die Hinzurechnung von gewinnunabhängigen Bestandteilen. Das ist sicherlich ein Weg, der nicht sinnvoll und zweckmäßig wäre. Deswegen sollten wir wirklich ernsthaft diese anderen Wege überprüfen, nämlich den Anteil der Kommunen an langfristig stabilen Steuern zu stärken.

Rödder: An Herrn Beus gerichtet: Was ich nicht nachvollziehen kann, ist, dass nicht das elementare Fiskalinteresse an der Ersetzung der Gewerbesteuer stärker deutlich wird. Wir müssen uns doch einfach immer wieder klarmachen, dass seit 2008 mehr als die Hälfte der Ertragsteuerbelas- 
tung von körperschaftsteuerpflichtigen Unternehmen die Gewerbesteuer ausmacht, die eine territoriale Steuer ist. Wir haben sozusagen als Welteinkommensteuerbelastung einen Anteil der Gesamtunternehmenssteuerbelastung von unter $50 \%$ mit der Körperschaftsteuer und im übrigen eine territoriale Steuerbelastung, was ja zu allen möglichen Verwerfungen führt in einer globalisierten Welt, auch aus Sicht des Fiskus. Und das muss man doch auch aus Fiskalsicht registrieren und sagen, das geht so nicht. Und was wir gerade besprochen haben, Herr Beus, dass der BFH auch noch gesagt hat, die finalen Auslandsbetriebsstättenverluste seien auch noch gewerbesteuerlich abzugsfähig, toppt das ja nur noch mal. Also sozusagen ist die Ertragsseite in der globalen Sicht der Dinge nur noch hälftig in der Unternehmenssteuerbelastung. Deswegen meine ich - mir geht das immer zu sehr aus Sicht der Wirtschaft - besteht auch aus Sicht des Bundesfinanzministeriums ein elementares Interesse an einer Ersetzung der Gewerbesteuer, weil wir sonst ein riesiges Strukturproblem der internationalen Unternehmensbesteuerung haben.

Piltz: Vielen Dank, Herr Rödder. Nächster Punkt ist die Vereinfachung. Meine Damen und Herren, wenn wir von Vereinfachung reden, dann reden wir normaler Weise von der Vereinfachung materieller Steuernormen, weil die teilweise schwer verständlich sind. Ich habe den Staatssekretär eben so verstanden, dass das Gewicht nicht im Materiellen liegt, sondern eher im Formellen. Meine erste Frage: Habe ich das richtig verstanden?

Beus: Da wird sicher der Schwerpunkt liegen. Wir sind halt, ich habe das versucht deutlich zu machen, durch die finanziellen Rahmenbedingungen eingeengt. Wir können uns natürlich idealer Weise auch vorstellen, dass wir Pauschbeträge deutlich erhöhen und auf diese Weise Einzelnachweise in vielen Bereichen weitgehend entbehrlich machen. Wir haben das mal gerechnet. Sie müssen dann jeweils dreistellige Millionenbeträge in die Hand nehmen, um da wirklich etwas zu bewirken. Sie kennen auch die Rechtsprechung, die da sagt, dass nicht irgendwie ein durchschnittlicher Betrag reicht, sondern Sie müssen schon im oberen Drittel liegen, was sozusagen erschwerend hinzukommt. Und diese Finanzmasse steht im Augenblick nicht zur Verfügung. Das muss man deutlich sehen. Selbst bei relativ kleinen Maßnahmen kommen Sie rechnerisch oft zu Mindereinnahmen, und wenn Sie die mal in so einem Rechtspaket addieren, sind Sie eben doch relativ schnell bei 300 bis 400 Millionen Euro. Den Werbekostenpauschbetrag so auszugestalten, dass der Großteil der Arbeitnehmer keinen Einzelnachweis mehr führen muss, ist im Augenblick finanziell nicht darstellbar. Das muss man einfach mal sagen, so schön es wäre. Und deshalb muss man sehen, was man unterhalb dieser Schwelle tun kann. Da kann man auch eine Menge tun in vielen Einzelmaßnahmen. Aber es ist natürlich nicht so etwas Plakatives, wie viel- 
leicht manche sich das wünschen und wir uns auch wünschen würden. Wir haben halt den Konflikt mit den Haushaltsnotwendigkeiten und die sind für unser Haus eben auch wichtig und müssen ein bisschen realisiert werden.

Jonas: Ich fühle mich ein bisschen persönlich angesprochen durch die Ausführungen zum Thema E-Bilanz. Das ist unter der Flagge Steuervereinfachung hier sowohl von Herrn Beus als auch von Herrn Neumann angesprochen worden. Worum geht es hierbei? Es gab vor zwei Jahren im Dezember 2008 ein Gesetz, das hieß Steuerbürokratieabbaugesetz. Da ist ein $\S 5$ b EStG eingeführt worden, wonach die Finanzverwaltung von den Unternehmen auf elektronischem Wege die Übersendung der Bilanz inklusive der dazu erforderlichen steuerlichen Überleitungsrechnungen verlangen kann. Interessanter Weise ist damals im Gesetzgebungsverfahren von einem Umstellungsaufwand von 500.000 Euro die Rede gewesen. Nicht pro Unternehmen, sondern für alle Unternehmen. Es war auch die Rede von 1.350 .000 betroffenen Unternehmen, also 37 Cent je Unternehmen. Das hat den Kontrollrat zu der Stellungnahme veranlasst, dass dies ja wohl nur heißen kann, dass es nur darum geht, die bereits bestehende Bilanz auf elektronischem Wege der Finanzverwaltung zu schicken. Deswegen waren alle über das überrascht, was jetzt Ende August mit einem 300-Seiten-Entwurf eines BMF-Schreibens herauskam, nämlich eine total vertiefende Gliederung bzw. Aufgliederung der Bilanz und der Gewinnund Verlustrechnung im Vergleich zu den HGB-Vorgaben. Wenn Sie sich das näher anschauen, werden Sie feststellen, dass das nichts mit einer Vereinfachung für die Unternehmen zu tun hat, sondern einfach nur mit einer Vereinfachung des Betriebsprüfungsgeschäfts für die Finanzverwaltung. Also ganz klar ein Bürokratieaufbau zu Lasten der Unternehmen und zu Gunsten der Finanzverwaltung. Ob die viel davon hat, weiß ich noch nicht. Das wird sich zeigen. Jedenfalls nach meiner Schätzung sind es nicht 500.000 Euro Umstellungsaufwand, sondern, wenn man mal eine Durchschnittsrechnung pro Unternehmen anstellt von 5.000 Euro, kommen Sie auf fast 7 Milliarden Euro. Was die Beteiligung betrifft, Herr Neumann, Sie haben gesagt, die Verbände hätten es nicht gemerkt. Das ist nicht ganz richtig. Die Verbände sind zunächst nicht eingeladen gewesen zu den Beratungen, und haben dann durch einen Kraftakt erreicht, dass Sie noch teilnehmen konnten. Da war aber die Hälfte der Arbeiten schon herum. Die Verbände haben dann auch Stellung genommen zu dem Vorhaben. Alle die Kritikpunkte, die darin stehen, die kommen jetzt natürlich wieder hoch. Die sind alle in den Beratungen nicht aufgegriffen worden und irgendwann muss man dann auch sagen können, dass man dieses Verfahren für nicht in Ordnung hält. Ich muss ehrlich sagen, es ist ein unsauberes Verfahren im Gesetzgebungsbereich, weil ich davon ausgehe, dass die Finanzausschussmitglieder des Bundestags auch nicht 
damit gerechnet haben, was aus dem herauskommt, was sie damals beschlossen haben. Insoweit kann man sagen, ist den Steuerbürgern, den Unternehmen insoweit eine Instanz genommen worden. Wenn wir das gewusst hätten, hätten wir das natürlich alles im Steuerbürokratieabbaugesetz vor zwei Jahren schon als Kritik geltend gemacht.

Neumann: Also, nach meinem Dafürhalten, Herr Jonas, war der BDI immer eingeladen gewesen. Sie haben die Einladung nur nicht angenommen zu Beginn, während die anderen es getan haben. Die Steuerberaterkammern waren da, die Bundessteuerberaterkammer war da, die DATEV war da gewesen und ist auch bereit, alle technischen Hilfeleistungen zu leisten. Das ist ein Problem. Sie haben es so nicht richtig dargestellt.

Jonas: Nehmen Sie mir das bitte so ab, das es so gelaufen ist, wie ich es dargestellt habe.

Neumann: Bei den im Anschluss geprüften Konzernen mag die Einführung der E-Bilanz ein Problem sein, aber weniger bei den anderen.

Piltz: Die E-Bilanz wird eine neue Zeitrechnung hervorrufen. Viel früher als sonst sind fast alle Daten da. Das ist sicherlich ein Vorteil aus der Sicht der Finanzverwaltung, weil sie viel früher irgendwelche Dinge erkennen kann. Herr Herzig, wollten Sie dazu etwas sagen?

Herzig: Das ist in der Tat ein brisantes Thema. Ich glaube, es ist vollkommen einleuchtend, dass wir in das digitale Zeitalter einsteigen, auch im Rahmen des Steuervollzugs. Das ist vollkommen klar. Wir können im Steuerbereich nicht in der Steinzeit verbleiben, sondern müssen uns diesen Techniken öffnen. Die Frage, die sich da letztlich stellt, ist die, in welchem Tempo, in welcher Tiefe steigen wir da ein. Und wenn wir dann mal davon ausgehen, dass in dem Gesetz vorgesehen ist, dass wir schon ab 2011 die E-Bilanz erstellen sollen, also für den Veranlagungszeitraum 2011, dann glaube ich, ist klar und das muss man deutlich sehen, dafür sind offensichtlich die Voraussetzungen in vielen Fällen nicht gegeben. Ich denke mal, der Gesetzgeber wäre gut beraten, von der dort schon angelegten Ermächtigung Gebrauch zu machen, nämlich den Anwendungszeitraum herauszuschieben, und dann zumindest ein Jahr mehr Zeit zu geben.

Die spannende Frage, die auch angesprochen ist, ist auch die nach der Gliederungstiefe. Und in der Tat, man muss sich das wirklich klar anschauen. Das Ganze ist zunächst immer gesegelt unter dem Gedanken Elektronik statt Papier. Da ist ja was dran, meine Damen und Herren. Wichtig ist nur, dass sich darin die Wirkung der E-Bilanz natürlich nicht erschöpft. Das ist die eine Funktion. Die andere ist natürlich, dass in der Tat eine sehr viel tiefer greifende Gliederung gefordert wird. Die Frage ist aber, wie tief muss sie gehen, und inwieweit muss sie über das Gliederungsschema im HGB $\S \S 266$ bzw. 275 hinaus gehen. Wenn man sich 
dann diese drei Taxonomien ansieht, die im Erlass im Detail stehen, für Einzelunternehmen, für Personengesellschaften, für Kapitalgesellschaften, dann sieht man interessanter Weise, dass die für Kapitalgesellschaften am intensivsten ist. Da gibt es die meisten Muss-Felder. Die müssen das meiste berichten. Und das ist schon vergleichsweise tief, was da gemacht wird. Da ist schon ein Umstellungsaufwand gegeben für alle die, die nicht in Ihrer Kontenführung bereits jetzt einen Kontoplan haben, der all diese Informationen liefert. Natürlich gibt es auch gegenwärtig Kontenpläne, die diese Informationen liefern. Nur wer einen solchen Kontenplan nicht hat und nicht nach einem solchen verfährt, der muss in der Tat eine Menge von Zusatzaufwand leisten, und da reichen sicherlich die im Gesetz genannten Werte nicht aus. Und von daher scheint mir fraglich, ob man gleich beim ersten Zugriff in allen Fällen in diese Tiefe gehen muss. Oder ob es nicht einen Weg gibt, schrittweise in diese Elektronik hineinzufinden mit der Maßgabe, dass man auf diese Weise den Umstellungsaufwand doch deutlich reduzieren und ein Eingewöhnen in diese neue Welt feststellen kann. Wenn man das mal vergleicht mit anderen Staaten, wo es auch E-Bilanzen gibt, z. B. Österreich, sieht man deutlich, dass die Gliederungstiefe bei Weitem nicht so intensiv ist, wie das bei uns der Fall ist. Und von daher sollten wir wirklich überlegen, sowohl in der zeitlichen Dimension als auch in der Dimension Gliederungstiefe, ob wir das wirklich im ersten Schritt schon in dieser Intensität tun. Das ändert nichts daran, dass wir den Weg in die Elektronik gehen müssen. Ich glaube, das ist auch die Zukunft. Das wird sich auch als Verfahren durchsetzen.

Piltz: Vielen Dank, Herr Herzig. Zu der Vereinfachungsdebatte im materiellen Steuerrecht hat Herr Beus angedeutet, dass materielle Vereinfachung zu viel Geld kosten könnte. Ich meine, es ist gar nicht selbstverständlich, dass eine Vereinfachung immer zu Steuersenkungen führt. Das können Sie auch umgekehrt machen. Aber es zeigt eben, dass Sie normaler Weise materielle Vereinfachungen nur durchsetzen können, wenn damit gleichzeitig gewisse Steuersenkungen mitgehen. Gut beratene oder selbst kompetente Steuerpflichtige können natürlich jede Komplizierung mitgehen, wenn es zu einer Steuersenkung führt. Der Ruf nach Vereinfachung verdeckt gewöhnlich mindestens ein mitlaufendes Interesse an einer Steuersenkung. Das ist genau der Gedanke, den Sie angesprochen haben, weshalb ich verstehe, dass Vereinfachungen, die gleichzeitig Steuersenkungen im materiellen Steuerrecht sind, noch eine Zeitlang warten müssen.

Wir haben als nächsten Punkt die Umsatzsteuersätze. Da gibt es in der Tat Erheiterung. Man sieht ja immer die Karikaturen mit verschiedenen Formen von Eseln. Der eine Esel hat 7\%, der andere Esel 19\%. Aber Esel haben wir hier nicht im Steuerrecht. Meine Damen und Herren, möchte 
jemand von Ihnen auf dem Podium etwas zu den Umsatzsteuersätzen sagen? Sieht nicht so aus.

Dann kommen wir zur Unternehmensbesteuerung. Der Staatssekretär hat auch gesagt, was im Moment nicht angefasst wird: die Bereiche Gruppenbesteuerung, Verlustverrechnung und Forschung und Entwicklung. Was wird denn aus der Sicht der Unternehmen als dringender oder wichtiger Punkt bei der Unternehmensbesteuerung gesehen, Herr Rödder?

Rödder: Ich hatte ein anderes Verständnis der Aussagen von Herrn Beus. Ich hatte das so verstanden, dass die F\&E-Förderung ist vom Tisch. In der Tat. Aber Gruppenbesteuerung und Neuregelung der Verlustverrechnung nächstes Jahr. Das ist ja nicht mehr so lang. Vielleicht darf ich zwei drei Punkte herausgreifen im Zusammenhang mit Gruppenbesteuerung. Herr Neumann hatte über die Bundesratsinitiative Änderung des $\S 17$ KStG berichtet, die vielen praktisch auf den Nägeln brennt mit der Frage, wie detailliert muss denn die Verlustübernahmeverpflichtung geregelt sein in einem Gewinnabführungsvertrag mit einer $\mathrm{GmbH}$. Da gibt es einen sehr entlastenden Vorschlag für die Praxis aus dem Bundesrat heraus. Herr Beus, es würde mich interessieren, wie Sie die Realisationschancen, das ist ja ein Teil des Jahressteuergesetztes 2010, ansehen. Begleitet worden ist dieser Gesetzgebungsvorschlag jetzt auch durch einen Aussetzungsbeschluss des Bundesfinanzhofs zu der bekannten OFD-Rheinland-Verfügung, wobei das nicht ganz der Fall der OFD-Rheinland-Verfügung ist. Aber jedenfalls ansatzweise bringt der BFH zum Ausdruck, dass er sozusagen die Erweiterung, die die Finanzverwaltung jetzt versucht, aus der relativen restriktiven $\mathrm{BFH}$-Rechtsprechung zu ziehen, schon de lege lata nicht teilt. De lege ferenda interessiert uns der etwas größere Entlastungsschritt für die Unternehmen, ob der eine Realisationschance hat, Herr Beus.

Beus: Sie wissen ja, das Gesetz ist jetzt im Parlament. Insofern ist es ein bisschen schwierig, den Parlamentariern zuvorzukommen. Wenn ich das richtig einschätze, gibt es die Bereitschaft, dieses Problem zu lösen. Es ist ja vielleicht auch eins, dass wir uns gewissermaßen selbst gemacht haben. Die Parlamentarier werden auch sozusagen von vielen Seiten darauf hingewiesen, dass es etwas ist, das gelöst werden muss. Also ich denke, da sind die Chancen nicht so schlecht.

Rödder: Das ist eine sehr gute Botschaft, Herr Beus. Zur Gruppenbesteuerung kann man über viele Dinge streiten und diskutieren, die Herr Neumann andiskutiert und angesprochen hat. Aus Beratersicht kann man eigentlich nur vor dem Hintergrund dieser Erfahrung über die Frage der Erfüllung der Voraussetzung des Gewinnabführungsvertrags wie Formulierung und Durchführung sagen, dass es erste praktische Probleme gibt, die durch die Finanzverwaltung in sehr schwierigen Fällen bereitet wer- 
den. Da muss einfach im Vordergrund die Frage stehen, ob wir nicht den Gewinnabführungsvertrag ersetzen können durch ein anderes Merkmal der Voraussetzung für die Gruppenbesteuerung und das ist eigentlich das zentrale Thema. Im Bereich der Verlustverrechnung ist sicherlich das Zentrale wie wir einerseits mit dem Riesenbatzen von Verlustvorträgen umgehen, den Sie angesprochen haben, aber andererseits auch das Thema der Mindestbesteuerung besetzt bekommen. Das ist das, was in der Praxis das allergrößte Unbehagen bereitet, dass man Steuern zahlen muss, obwohl im Zeitablauf gar kein Gewinn entstanden ist. Da die richtige Lösung zu finden in dem Bereich Verlustvortragsvolumen einerseits, dass man aus Fiskalsicht sicher nicht unbegrenzt in die Verrechenbarkeit bringen kann, aber Erledigung des Problems der Mindestbesteuerung, das scheint mir aus Beratersicht das Wichtigste zu sein.

Neumann: Meine Damen und Herren. Meine Sicht zur Verlustverrechnung. Wir haben in der Tat immer die mahnenden Finger hochgehoben in Nordrhein-Westfalen, weil wir von einem Verlustvortragsvolumen von 500 bis 600 Mrd. Euro ausgehen bundesweit. Das haben wir einfach errechnet durch die Verlustfeststellung. Ich gebe immer zu, wenn ich gefragt werde, wo die herkommen, habe ich ein Problem, weil wir die Verluststruktur nicht kennen. Wir wissen nicht genau, wo sie herkommen. Von lebenden Unternehmen, von nicht lebenden Unternehmen, von der öffentlichen Hand? Sie können überall sein. Wir wissen es einfach nicht. Deswegen kann man nur begrenzt dieses Schreckgespenst aufbauen. Ich gebe auch zu, dass der $\S 10 \mathrm{~d}$ Abs. 2 EStG so beschaffen ist, dass er seinerzeit eine Notmaßnahme war. Notmaßnahmen müssen ja nicht ewig bleiben. Aber andererseits habe ich den Vorschlag gehört, den ich sehr interessant fand. Herr Prof. Herzig hat sich in die Richtung mal geäußert, man könnte die Verluste ja anstreichen. Alte Verluste werden durch den $\S 10 \mathrm{~d}$ Abs. 2 eingefangen und für neue Verluste könnte man eine neue $\S 10 \mathrm{~d}$ Abs. 2-Regelung schaffen. Das muss man voneinander trennen. Vielleicht könnte man in dieser Richtung weiter nachdenken.

Piltz: Die Zahl von 500 Mrd. Euro Verlusten ist natürlich beeindruckend. Der Staatssekretär hat eben gesagt, da gibt es auch ein verfassungsrechtliches Problem. Ist damit gemeint, dass Sie der Auffassung sind, die Verluste müssten irgendwie verwertet werden können, dürfen also nicht gestrichen werden? Ist das ein richtiges Verständnis?

Beus: Bei beiden Behandlungen oder Streichungen, wie Sie es nennen wollen, muss man in der Tat verfassungsrechtliche Prinzipien beachten. Das ist schon ein Punkt, den man da sehr im Auge haben muss. Auf der anderen Seite haben wir ähnliche Zahlen wie Herr Neumann. In der Tat liegt es so um die 500 Mrd. Euro. Wir können das nicht sehenden Auges sich weiter so entwickeln lassen. Wir müssen zu einer Lösung kommen, die wir auch mit den Ländern schrittweise entwickeln müssen. 
Herzig: Ich glaube auch, das Streichen dürfte problematisch sein. Aber ich denke doch, dieser Gedanke, dass man differenziert zeitlich zwischen alten und neuen Verlusten, scheint mir ein Weg zu sein, der dieses gravierende Haushaltsproblem entschärft und damit auch den Interessen des Fiskus Rechnung trägt. Ich glaube, dass wir in der Konzernbesteuerung etwas tun müssen hin zu einer Gruppenbesteuerung. Da sollte man in der Tat auch die Ziele sehr klar formulieren. Wenn man mit dem Übergang zur Gruppenbesteuerung meint, damit würde es jetzt auch eine Chance geben, alle möglichen Auslandsverluste im Inland geltend zu machen, dann kann dieses Projekt nicht laufen. Ich glaube, das ist haushaltsmäßig nicht zu verkraften. Dafür muss man sehr viel Verständnis haben, wenn der Konsolidierungskurs gefahren wird. Umso wichtiger ist aber, deutlich zu machen, dass hier eine Strukturmaßnahme möglich ist, die auch unter Standortgesichtspunkten für den Wirtschaftsstandort Deutschland wichtig ist. Und das scheint mir in der Tat der Punkt zu sein, ob wir an diesem Gewinnabführungsvertrag festhalten können. Wir müssen uns klar machen, der kommt ja aus einer Zeit, wo wir eine ganz enge Verbindung zwischen Handels- und Steuerbilanz hatten und diese Größen, um die es geht, ziemlich weit übereinstimmen und nur begrenzt Abweichungen gegeben sind. Und das hat sich ja dramatisch geändert, nicht zuletzt auch durch BilMoG. Von daher meine ich schon, hat die Überzeugungskraft dieses Gewinnabführungsvertrags gelitten. Wir sollten hier über ein neues System nachdenken, wie es auch viele andere Staaten praktizieren. Es gibt nur noch ganz wenige, die an einem Gewinnabführungsvertrag festhalten. Slowenien und Portugal werden da immer genannt. Alle anderen haben sich im Zeitablauf davon getrennt. Und wenn man dann sagt, wir wollen das nicht als Instrument nutzen, um alle möglichen Auslandsverluste in das Inland zu tragen, sondern wirklich um im Inland eine vernünftige Struktur zu schaffen, also bei Konzernstrukturen, nicht zwingend aus steuerlichen Gründen einen Gewinnabführungsvertrag abschließen zu müssen, dann denke ich, wäre das eine Überlegung, mit der man sich wirklich befassen sollte, die zwar zur Strukturverbesserung beitragen könnte und die in der Tat auch fiskalisch nicht zu einem Minderaufkommen führen würde. Und deswegen auch aus Sicht des Fiskus ist dies eine Maßnahme, die auch in der gegenwärtigen Zeit sehr wohl sinnvoll und zweckmäßig wäre und die dazu führen würde, dass hier sogar ein Standortvorteil begründet würde, weil eben, wenn ein ausländischer Investor in die Situation kommt, hier verschiedene Engagements betreibt, er dann eben auch in der Lage ist, die Verluste, die in einer Gesellschaft entstehen, mit den Gewinnen einer anderen verrechnen zu können. Von daher scheint mir in der Tat das wichtiger zentraler Punkt zu sein und darüber sollten wir weiter nachdenken. 
Neumann: Ich bin auch der Meinung, Herr Prof. Herzig, dass wir darüber nachdenken müssen. Aber wir dürfen nicht ausklammern, welche anderen Schwierigkeiten dabei eine Rolle spielen könnten. Wir müssen nur einmal die kritischen Stimmen anhören, die nachdenklich stimmen, selbst die der Befürworter einer Gruppenbesteuerung aus Österreich. Sie sehen sehr wohl, dass in Deutschland ein Großteil aller Unternehmen in Personengesellschaften engagiert ist. Sie sehen auch, dass die Besteuerungssysteme für Personengesellschaften zum Teil etwas anderes sind als die normale Körperschaftsbesteuerung. Und Sie sehen auch, dass durch diesen Bruch der Systeme Missbrauchspotenzial bestehen könnte. Und deswegen würde ich dringend davon abraten, eine derartige Ausweitung der Gruppenmitgliedschaft zuzulassen. Das sind nicht nur kritische Töne aus Österreich. Problematisch ist auch die Höhe der Beteiligung des Gruppenträgers an den Untergesellschaften. Dann habe ich die Sorge, dass wir einen Großteil unserer Wirtschaft nicht mehr mitnehmen können in die Verlustverrechnungsmöglichkeit. Dieses Problem müssen wir auch lösen.

Piltz: Ja, noch etwas zu diesem Bereich?

Herzig: Nur weil das Beispiel Österreich genannt wird. Herr Neumann, ich glaube wirklich, dass es wichtig wäre, den Austausch mit Österreich zu pflegen und aus den Erfahrungen, die da gewonnen worden sind, zu lernen. Wenn ich das richtig verstehe, wird in Österreich insbesondere kritisch beurteilt, dass sie so ein Element haben wie eine Firmenwertabschreibung und dass sie die Auslandsverluste ohne jede Einschränkung hier berücksichtigen. Ich würde dringend davor warnen, diese Elemente zu übernehmen. Aber ansonsten habe ich den Eindruck, dass die Österreicher ihre Gruppenbesteuerung als Erfolgsmodell immer wieder propagieren und auch verkaufen. In der Tat haben wir in Deutschland die Besonderheit, dass bei uns Personengesellschaften eine besondere Rolle spielen. Das ist in Österreich grundlegend anders. Die haben nur Organschafts- oder Gruppenbesteuerung zwischen Kapitalgesellschaften. Wir lassen aber auch Personenunternehmen als Gruppenträger, als Organträger zu. Daraus resultieren Probleme. Und da müssen wir gucken, wie wir mit denen umgehen können. Möglicher Weise müssen wir dafür dann spezifische Regelungen finden. Das ist eine Schwierigkeit, die sich aus der deutschen Rechtstradition ergibt. Denn ich glaube, ernsthaft können wir nicht erwarten, dass wir die Personengesellschaften aus der Organschaft herausnehmen können, dass wir sie nicht mehr als Organträger, als Gruppenträger zulassen können. Das scheint mir irreal. Wenn wir sie aber zulassen, dann ist die Gruppenbesteuerung ein Instrument, mit dem Verluste aus der körperschaftsteuerlichen in die einkommensteuerliche Sphäre überschwappen können und das muss man sorgfältig überlegen, wie weit man da geht. Da stimme ich mit Ihnen überein. 
Piltz: Ich möchte nochmal auf die Forschung und Entwicklung kommen. Forschungs- und Entwicklungsförderung wird ja gewöhnlicher Weise damit motiviert, dass wir keine Rohstoffe haben, sondern wir haben unsere Köpfe, und dass es besser ist, wenn in Deutschland geforscht wird, als wenn die Ableger von deutschen Unternehmern im Ausland forschen. Hat die derzeitige Nichtdiskutierung einer steuerlichen Forschung- und Entwicklungsförderung in Deutschland ausschließlich Haushaltsgründe, Herr Beus?

Beus: Das sind sicher überwiegend Haushaltsgründe. Selbst wenn man dem Thema näher treten könnte, wenn sich die Haushaltsgründe verbessern würden, muss man sehen, dass wir im Augenblick ein ganz anderes System der Forschungsförderung haben. Wir haben ein System, das auf Zuweisungen von Geldmitteln basiert. Und das auch gut funktioniert. Nach unseren Erkenntnissen ist der Mehrwert dadurch der steuerlichen Förderung überlegen. Eins müsste man sicher mindestens leisten. Man muss Konkurrenzregelungen schaffen. Zwischen Zuweisungen aus dem bisherigen System und steuerlicher Geltendmachung. D.h. also, selbst wenn man die Auslandsrestriktionen mal weg lässt, ist das nicht so ganz simpel, wie das auf den ersten Blick klingt. Sondern wir haben eine im Augenblick ganz andere Struktur der Forschungsförderung, die eben nicht auf steuerliche Förderung angelegt ist. Wenn man das zusätzlich machen würde, muss man sehen, wie das überhaupt kompatibel zu machen ist mit dem, was wir im Augenblick haben. Im Augenblick gehen alle Modelle, die ich kenne, von Mindereinahmen von mindestens 1,5 Mrd. Euro aus. Das ist wahrscheinlich auch eine Größenordnung, die man braucht, um überhaupt irgendwie etwas ans Laufen zu bringen. Und das ist im Augenblick in der Finanzplanung nicht drin. Deshalb kann gegenwärtig eine konkrete Umsetzung nicht Thema sein.

Jonas: Ich habe die Hoffnung noch nicht aufgegeben, dass es vielleicht doch noch im Laufe der Legislaturperiode zu einer solchen Regelung kommt, die ja auch im Koalitionsvertrag verankert ist. Hoffnung deshalb, weil die CDU/CSU-Fraktion sich entsprechend geäußert hat, dass das nicht ausgeschlossen ist, insbesondere weil ja die Entwicklung im Moment doch ganz positiv ist, was die Einnahmeseite angeht. Der Handlungsbedarf ergibt sich aus meiner Sicht daraus, dass wir, wenn wir uns in Europa umschauen, auch in anderen Ländern, dass es ringsherum überall eine solche Forschungsförderung auf steuerlichem Wege gibt, und dass natürlich bei Unternehmen, die ja an verschiedenen Forschungsstandorten tätig sind, immer wieder bei der Auswahl eines Forschungsprojekts abzuwägen ist, nimmt man ein Land, wo eine Forschungsförderung besteht oder nicht, und wenn das in Deutschland nicht der Fall ist, geht oft genug die Waagschale in die falsche Richtung, nämlich nicht zu Gunsten von Deutschland. 
Piltz: Ich habe den Staatssekretär so verstanden, dass er sagt, wir beurteilen das außer nach dem Haushalt nach der Frage der Effektivität. Wenn dieses System, das wir jetzt haben, mit direkten Zuweisungen effektiver ist als die steuerliche Forschungsförderung, dann können wir das jedenfalls eine Zeitlang so lassen.

Wir haben noch einen Punkt, das sind die Doppelbesteuerungsabkommen, zu denen Sie viele Ausführungen gemacht haben. Ich habe das so verstanden, dass die Kernabkommenspolitik, die wir haben, also Befreiungsmethode für bestimmte wichtige Einkünfte (Betriebsstättengewinne beispielsweise, Schachteldividenden, was wir auch schon national haben und verschiedene andere), so bleibt, aber eingeschränkt wird für den Fall, dass ungerechtfertigte Steuervorteile damit verbunden sind und dass die Abkommen angepasst werden sollen in Hinblick auf den neuen Standard, den wir haben. Die Abkommen sind ja relativ alt. Die Abkommen sind nach dem Krieg abgeschlossen. So sechziger, siebziger Jahre, d. h. sie sind jetzt 30 bis 40 Jahre alt. Was sind denn die Hauptanpassungen?

Beus: Also, Sie haben unsere Haltung richtig wiedergegeben. Das ist ja auch das, was in der Koalitionsvereinbarung steht, dass die Anrechnungsmethode sozusagen die Ausnahme bleiben soll und bleiben muss. Das ist auch unsere Auffassung. Es gibt aber Fälle, wo wir eigentlich relativ wenig Bedarf für einen DBA sehen, wo das aber aus politischen Gründen gewünscht wird, um deutlich zu machen, dass wir längeren Kontakt mit den Ländern wollen und gut kooperieren wollen. Dann gibt es eben doch in der Regel Anpassungsbedarf in Richtung Informationsaustausch. Da gibt es jetzt eben den Artikel 26 des OECD-Musterabkommens, den wir flächendeckend umsetzen wollen, wo wir i.d.R. auch keine Schwierigkeiten haben, weil wir sozusagen als OECD-Mitgliedstaaten das ohnehin beschlossen haben, aber das ist inzwischen auch der weltweite Standard. Und gerade die Länder, die auf einer grauen oder welchen Liste auch immer stehen, bemühen sich in der Tat, dass sie möglichst schnell solche Abkommen mit uns bekommen, um Klarheit zu schaffen. Da sind wir sozusagen gut unterwegs und werden das relativ schnell abgearbeitet haben. Ansonsten gibt es mit europäischen Ländern, mit denen wir schon sehr alte Abkommen haben, immer wieder Anpassungsbedarf im Hinblick auf die steuerlichen Entwicklungen in beiden Staaten. Großbritannien ist sicher so ein Beispiel. Und auch innerhalb Europas ist das Steuerrecht nicht harmonisiert, sondern bis auf die Umsatzsteuer müssen wir da immer wieder Anpassungen, Revisionsabkommen machen oder grundsätzliche Überarbeitungen. Wobei unsere Kapazitäten auch wiederum irgendwo begrenzt sind in dem Bereich. Es ist immer ein relativ arbeitsaufwendiger Prozess, so ein Abkommen neu zu verhandeln und dann durch das Parlament zu bringen. 
Rödder: Vielleicht eine Ergänzung, nicht direkt zu DBA. Was mich etwas gewundert hat, sind europäische Themen, Herr Beus. Gibt es irgendwelche Richtlinien, Projekte, wo die Bundesregierung sagt, da haben wir ein Interesse dran? Das hatten Sie in Ihrer Rede nicht angesprochen. Sind für diese Legislaturperiode Europäische Themen im Visier?

Beus: Nein, das wollte ich damit nicht ausdrücken. Die sind natürlich im Fokus. Im Bereich der Umsatzsteuer sozusagen. Da gibt es ja ständig Anpassungen. Im Bereich der nicht harmonisierten Steuern gibt es möglicher Weise eine Initiative der Kommission, dort wieder ein Gremium zu aktivieren, wo zumindest ein Austausch über diese Fragen stattfindet. Das hat es ja früher schon gegeben. Es ist dann irgendwie eingeschlafen. Das fänden wir ganz gut, wenn das auf jeden Fall wieder ein Thema der Kommission würde. Also insofern ist Europa überhaupt nicht ausgeblendet und ist immer in unserem Blickpunkt und wird immer bearbeitet.

Piltz: Die gemeinsame Bemessungsgrundlage, ist die noch auf der Agenda, also die vereinheitlichte Bilanz europäischer Unternehmen?

Beus: Die ist in der Tat auf der Agenda und auch ein Thema, das bei uns im Haus im Augenblick diskutiert und abgestimmt wird, und das nicht so ganz einfach ist. Aber das ist in der Tat ein Thema, das Europa auch wieder aufgreifen wird.

Herzig: Dazu soll es ja wohl eine Anhörung geben im Oktober in Brüssel. Das ganze wird jetzt nicht in einem Schritt umsetzbar sein. Aber die Frage wäre ja, ob es im Bereich der steuerlichen Gewinnermittlung möglicherweise Anregungen und Ideen gäbe, die für den deutschen Gesetzgeber interessant sind zu europäisieren. Wäre das eine Idee oder ist das ein Gedanke, dem Sie näher treten könnten in Ihrem Hause?

Beus: Für uns stellt sich in erster Linie die Frage, d. h. was heißt das auch auf die lange Frist, wenn wir dem näher treten. Ich glaube, das muss man sich sehr genau überlegen. Wenn man den ersten Schritt tut, wird man irgendwann den zweiten oder dritten Schritt auch nicht mehr verweigern können. Und das ist im Augenblick die Diskussion bei uns, ob wir uns da nicht einer Menge von Handlungsfreiheit mittel- oder langfristig begeben. Das mag in Europa irgendwann kommen. Wir haben ein bilaterales Projekt mit Frankreich, was entstanden ist aus dem intensiven Austausch, den wir mit Frankreich haben, wo wir jetzt mal die deutsche und französische Besteuerung von Unternehmen erstmals nebeneinander legen. Aber wenn man so etwas mal aufschreibt, kann das auch eine gewisse Eigendynamik entwickeln. Und deshalb ist dieser Schritt mit Frankreich für uns ganz hilfreich, weil wir das mal in einem beschränkten Bereich machen. Auch da taucht gleich die Frage auf, die Sie eben in einem anderen Zusammenhang erwähnt haben. Die Franzosen hatten zunächst nur an Körperschaften gedacht. Das bildet aber unsere Unter- 
nehmenslandschaft nicht ab. D.h. wir kommen zwangsläufig in unser Einkommensteuergesetz hinein. Das macht schon deutlich, wie sich die spezifischen nationalen Strukturen bemerkbar machen und uns da vorsichtig vorgehen lassen. Da stimme ich mit Ihnen völlig überein. Wir haben diese spezifische Struktur bei den Unternehmen, sehr viel Personengesellschaften, was eigentlich im Ausland nicht bekannt ist. Aber daran wollen wir auch nichts ändern. Ich glaube, das ist auch ein Teil des wirtschaftlichen Erfolges, den wir haben, dass in diesem Bereich die Verbindung zwischen Unternehmer und Unternehmen eben besonders intensiv ist und daran sollten wir auch aus steuerlichen Gründen keinen Zweifel lassen, dass das so bleiben kann und bleiben soll.

Piltz: Meine Damen und Herren, Sie wissen, was Sie steuerpolitisch erwartet, auch natürlich was Sie nicht erwartet. Ich danke dem Staatssekretär, Herrn Dr. Beus, und auch den anderen Podiumsteilnehmern ganz herzlich. 


\section{Leitthema:}

Großer Senat des Bundesfinanzhofes zur Abzugsfähigkeit gemischter Aufwendungen 



\title{
Großer Senat des BFH zur Abzugsfähigkeit gemischter Aufwendungen
}

\author{
Professor Dr. Hans-Joachim Kanzler \\ Vorsitzender Richter am BFH, München
}

Inhaltsübersicht

I. Der Beschluss des Großen Senats vom 21.9.2009

1. Das Aufteilungsverbot ist tot, es lebe das Aufteilungsgebot!

2. Die Entscheidung im Las VegasFall

a) Sachverhalt und Entscheidungsformel

b) Dogmatische Grundlagen der Entscheidung und Folgerungen daraus

c) Das eigentliche Abzugsgebot für gemischte Aufwendungen

3. Zur Kritik an dem Beschluss des Großen Senats

II. Die Umsetzung der Vorgaben des Beschlusses v. 21.9.2009
1. Erste Entscheidungen der Gerichte

a) Irlandreise einer Englischlehrerin

b) Ärztliche Fortbildung am Gardasee

c) Keine betriebliche Veranlassung einer "Fachstudienreise" nach Südostasien

d) Auslandsreisen vor dem VIII. Senat des BFH

2. Verwaltungsanweisungen zur Umsetzung der Entscheidung des Großen Senats

III. Künftige Behandlung gemischter Aufwendungen

IV. Schluss

\section{Der Beschluss des Großen Senats vom 21.9.2009}

\section{Das Aufteilungsverbot ist tot, es lebe das Aufteilungsgebot!}

„Tu felix austria“. Österreich, in steuerlichen Dingen progressiv und oft Vorbild für uns, ${ }^{1}$ kennt noch das Aufteilungs- und Abzugsverbot für gemischte Aufwendungen. ${ }^{2}$ Ist der Beschluss des Großen Senats des BFH vom 21.9.2009³ daher falsch? Nein, gewiss nicht. Die Entscheidung hat

1 So wurden etwa bereits 1993 die Abgeltungsteuer und 2005 eine Gruppenbesteuerung eingeführt, sowie ab 1.8.2008 die Erbschaft- und Schenkungsteuer abgeschafft.

2 Es wird dort aus $§ 20$ Abs. 1 Ziff. 1 lit. a öEStG 1988 hergeleitet, dessen Wortlaut weitgehend mit $\S 12$ Nr. 1 Satz 2 EStG übereinstimmt. Danach unterliegen einem Abzugsverbot "Aufwendungen oder Ausgaben für die Lebensführung, selbst wenn sie die wirtschaftliche oder gesellschaftliche Stellung des Steuerpflichtigen mit sich bringt und sie zur Förderung des Berufes oder der Tätigkeit des Steuerpflichtigen erfolgen".

3 BFH v. 21.9.2009 - GrS 1/06, BFHE 227, 1, BStB1. II 2010, 672. 
einhellige Zustimmung erfahren, wurde in der Fachöffentlichkeit zum Teil überschwenglich gefeiert und von den Medien mit den üblichen knalligen Schlagzeilen bedacht, die allerdings eher geeignet sind, falsche Erwartungen zu wecken. Der Große Senat hat gewiss keine Anleitungen im Sinne gehabt, " wie man den Fiskus an privaten Reisen beteiligt ${ }^{\prime 4}{ }^{4}$ oder wie sich "Job und Urlaub kombinieren" lassen. ${ }^{5}$ Übertrieben scheint mir auch, in dem Beschluss einen "Paradigmenwechsel ${ }^{\prime 6} \mathrm{zu}$ sehen. Der Rückgriff des Großen Senats auf das objektive Nettoprinzip und den Veranlassungsgrundsatz begründet gewiss kein neues Denkmodell, hat sich doch der Große Senat des BFH bereits 1977 wegen der Kosten eines Verkehrsunfalls ${ }^{7}$ auf das Veranlassungsprinzip berufen und 1980 zu den Reisekosten eines Gewerkschaftsmitglieds ${ }^{8}$ auf das objektive Nettoprinzip gestützt. ${ }^{9}$ Nicht ganz zu Unrecht wird auch der Entscheidung des VI. Senats des $\mathrm{BFH}^{10}$ zur Aufteilung von Einnahmen (sog. Portugalfall) eine Miturheberschaft am Beschluss des Großen Senats zugeschrieben. ${ }^{11}$ Der Beschluss vom 21.9.2009 ist indessen nur der vorläufige Schlussakkord einer Rechtsprechung des $\mathrm{BFH},{ }^{12}$ die schon seit Jahren den Topos des Aufteilungs- und Abzugsverbots vermieden oder distanziert verwendet ${ }^{13}$ und für einzelne Mischaufwendungen nach und nach eine Aufteilung zugelassen hat. ${ }^{14}$ Diese Ausnahmen waren aber schon immer Ausdruck eines Aufteilungsgebots, das stets dann angewendet wurde, wenn sich ein praktikabler Aufteilungsmaßstab finden ließ. ${ }^{15}$

4 Sigmund, Handelsblatt s. „http://www.handelsblatt.com/steuerlicheabsetzbarkeit-wie-man-den-fiskus-an-privaten-reisen-beteiligt; $2645810^{\prime \prime}$ und wesentlich sachlicher: Sigmund, Arbeiten und Feiern, Handelsblatt v. 1.9.2010, 18 .

5 So bereits Focus Money v. 7.3.2007 „http://www.focus.de/finanzen/steuern/ reisekosten-richtig-reisen_aid_258722.html“.

6 So aber Pezzer, DStR 2010, 93, 96 und Heuermann, StBp 2010, 86; ähnlich auch Leisner-Egenspeger, die eine „überzeugende Wende" registriert (DStZ 2010, 185, 187).

7 BFH v. 28.11.1977 - GrS 3/77, BFHE 124, 43, BStBl. II 1978, 105.

8 BFH v. 28.11.1980 - VI R 193/77, BFHE 132, 431, BStBl. II 1981, 368.

9 Die engagierte Kritik von Leisner-Egenspeger (DStZ 2010, 185, $187 \mathrm{ff}$.) ist daher nicht nur überzogen, sondern in diesem Punkt auch unzutreffend.

10 BFH v. 18.8.2005 - VI R 32/03, BFHE 210, 420, BStBl. II 2006, 30.

11 Albert, FR 2010, 220, 223.

12 Ähnlich auch Jochum, DStZ 2010, 665, 666, die von einem „vorläufigen Schlusspunkt der Diskussion" ausgeht.

13 S. etwa der Vorlagebeschluss zur Entfernungspauschale, BFH v. 10.1.2008 VI R 17/07 (BFHE 219, 358, BStBl. II 2008, 234 Rz. 138): „das sog. Aufteilungsund Abzugsverbot des $\S 12$ Nr. 1 Satz 2 EStG" (Hervorhebung vom Verf.).

14 Streck, NJW 2010, 896.

15 Ähnlich die Einschätzung von Heuermann, StBp 2010, 86, 89. 
Freilich gab es die beiden Grundsatzentscheidungen des Großen Senats des BFH aus den Jahren $1970^{16}$ und $1978,{ }^{17}$ die es zu überwinden galt und eine bemerkenswerte Resistenz gegen die Aufteilung der Kosten einer Reise für einen einkünftebezogenen Aufenthalt mit anschließendem Urlaub. ${ }^{18}$ Dies hat der Große Senat des BFH nun korrigiert und den Las Vegas-Fall zugleich zum Anlass genommen, das Aufteilungsverbot durch ein grundsätzliches Aufteilungsgebot für alle gemischten Aufwendungen zu ersetzen, gleichwohl aber auch weiterhin auf einem Aufteilungsverbot für untrennbar gemischt veranlasste Aufwendungen zu bestehen. Diese Entscheidung hat wohl auch unsere Nachbarn in Österreich beeindruckt und zu der Frage veranlasst, ob sich die Rechtsprechung des Verwaltungsgerichtshofs der Rechtsansicht des BFH anschließt. ${ }^{19}$

\section{Die Entscheidung im Las Vegas-Fall}

\section{a) Sachverhalt und Entscheidungsformel}

In der Sache ist der Große Senat des BFH „im Wesentlichen“ dem Vorlagebeschluss des VI. Senats und dem Urteil des FG gefolgt. Er hat entschieden, dass Aufwendungen für die Hin- und Rückreise bei gemischt beruflich (betrieblich) und privat veranlassten Reisen grundsätzlich in abziehbare Werbungskosten oder Betriebsausgaben und nicht abziehbare Aufwendungen für die private Lebensführung nach Maßgabe der beruflich und privat veranlassten Zeitanteile der Reise aufgeteilt werden können, wenn die beruflich veranlassten Zeitanteile feststehen und nicht von untergeordneter Bedeutung sind. Allerdings kann es das unterschiedliche Gewicht der verschiedenen Veranlassungsbeiträge im Einzelfall erfordern, einen anderen Aufteilungsmaßstab heranzuziehen oder ganz von einer Aufteilung abzusehen.

Der dem Beschluss zugrundeliegende Sachverhalt ist relativ einfach wiedergegeben. ${ }^{20}$ Der Kläger, ein bei einer Versicherungsgesellschaft angestellter „EDV-Controller", hatte eine viertägige Computerkonferenz und -messe in Las Vegas besucht, auf der er ein Jahr zuvor selbst einen Vortrag

16 BFH v. 19.10.1970 - GrS 2/70, BFHE 100, 309, BStBl. II 1971, 17 (Schreibmaschine und Tonbandgerät eines Gerichtsassessors) und v. 19.10.1970 GrS 3/70, BFHE 100, 317, BStB1. II 1971, 21 (Fernseher eines Filmschaffenden).

17 BFH v. 27.11.1978 - GrS 8/77, BFHE 126, 533, BStB1. II 1979, 213 (USA-Gruppenreise eines Müllunternehmers).

18 Zuletzt noch BFH v. 18.5.2005 - VIII R 43/03, BFH/NV 2005, 2174 zu Rz. 17 m. w. N. zu älterer Rechtsprechung

19 Lenneis, Abgrenzung der Betriebsausgaben/Werbungskosten von den abzugsfähigen Aufwendungen gemäß $§ 20$ EStG - Aufteilungsverbot, in Gedenkschr. für Quantschnigg, Wien 2010, 231, 241.

20 Etwas übertrieben sind daher die schematischen Darstellungen, wie sie in der ÖStZ zu finden sind (Renner, ÖStZ 2010, 123 und 125). 
gehalten hatte. Während er die Aufwendungen für seine 7-tägige Reise in vollem Umfang als Werbungskosten geltend machte, ließ das FA nur die Tagungsgebühren zum Abzug zu. Die dagegen gerichtete Klage hatte insoweit Erfolg, als weitere Kosten für vier Übernachtungen und Verpflegungsmehraufwendungen für fünf Tage berücksichtigt wurden; im Übrigen erkannte das FG die Flugkosten $\mathrm{zu}^{4} / 7$ als Werbungskosten an. Diese Aufteilung der Hin- und Rückreisekosten, die auch der Lohnsteuersenat des BFH favorisiert hatte, waren dann der Anlass für die Vorlage des Streitfalls zum Großen Senat. Es gab zwar eine Bereitschaft des divergierenden IV. Senats, einer Änderung der Rechtsprechung zuzustimmen, dieser sah sich daran aber durch die Rechtsprechung des Großen Senats gehindert. Da der VI. Senat des BFH indes keine Abweichung von der früheren Rechtsprechung des Großen Senats sah, stützte er seine Vorlage in erster Linie auf die grundsätzliche Bedeutung der Sache.

Grundsätzlicher noch als der VI. Senat des BFH in seinem Vorlagebeschluss hat der Große Senat mit seiner Entscheidung GrS 1/06 die vollständige Abkehr vom Aufteilungs- und Abzugsverbot vollzogen. Zur strikten Beantwortung der Vorlagefrage hätte wohl auch eine weitere Ausnahme vom Aufteilungs- und Abzugsverbot für Flug- oder Reisekosten genügt, wie sie bereits für die Telefongrundgebühr oder die fixen PKW-Kosten anerkannt war. Damit aber wäre das Aufteilungs- und Abzugsverbot stillschweigend fortgeschrieben worden. Eine solche Lösung, wie sie dem Vorlagebeschluss zugrunde lag, hat der Große Senat nicht gewählt, sondern eindeutig entschieden, dass § 12 Nr. 1 Satz 2 EStG kein allgemeines Aufteilungs- und Abzugsverbot normiert. ${ }^{21}$ Diese Aussage ergibt sich zwar nicht aus der Beantwortung der Vorlagefrage am Ende der Beschlussgründe oder den gleichlautenden Leitsätzen, sie ist aber Grundlage der Entscheidung der Vorlagefrage und eröffnet damit zugleich die Möglichkeit zu einer grundsätzlichen Neuorientierung der Rechtsprechung zu den gemischten Aufwendungen. ${ }^{22} \mathrm{Ob}$ der Große Senat damit die Vorlagefrage erweitert hat, kann dahinstehen; jedenfalls wäre er dazu befugt. ${ }^{23}$ Diese grundlegende Entscheidung war angesichts der beiden Beschlüsse des Großen Senats aus den Jahren 1970 und $1978^{24}$ erforderlich. Der Große Senat hat damit schließlich den ihm durch § 11 FGO zugewiesenen Auftrag zur Rechtsfortbildung wahrgenommen.

21 BFH v. 21.9.2009 - GrS 1/06, BFHE 227, 1, BStBl. II 2010, 672, Rz. 100.

22 S. etwa Spindler, DB 2010, Nr.3 M1; Streck, NJW 2010, 896; Kanzler, NWB 2010, 169.

23 Sunder-Plassmann in HHSp, § 11 FGO Rz. 124.

24 A. a. O. Fn. 7 und 8. 


\section{b) Dogmatische Grundlagen der Entscheidung und Folgerungen daraus}

Reisekosten - um die es ja primär ging - sieht der Große Senat abweichend von der bisherigen Rechtsprechung nicht mehr in jedem Fall als Einheit an, sondern berücksichtigt, dass einzelne Reiseabschnitte unterschiedlich betrieblich bzw. beruflich oder privat veranlasst und entsprechend aufzuteilen sind. ${ }^{25}$

Rechtsdogmatische Grundlage für diese neue veranlassungsbezogene Sicht ist das objektive Nettoprinzip, das in dem Beschluss des Großen Senats zur Gruppenreise eines Abfallbeseitigungsunternehmers im Jahre 1978 noch keine Rolle spielte. ${ }^{26}$ Immerhin war auch schon damals der Veranlassungsgrundsatz Richtschnur der Entscheidung, denn es heißt dort: „Der Große Senat hält es für zutreffend, auch im Falle einer insgesamt als privat gewürdigten Reise einzelne Aufwendungen, die ausschließlich betrieblich (beruflich) veranlaßt sind, zum Abzug als Betriebsausgaben zuzulassen. " ${ }^{27}$ Inzwischen ist zum objektiven (wie auch zum subjektiven) Nettoprinzip „schon alles gesagt, nur noch nicht von allen“. Diese Sentenz Karl Valentins mag andeuten, dass die wissenschaftliche Auseinandersetzung um das objektive Nettoprinzip vorerst abgeschlossen scheint. Während die wohl h. M. in der Steuerrechtswissenschaft dem objektiven Nettoprinzip Verfassungsrang einräumt und damit eine Gleichstellung mit dem subjektiven Nettoprinzip anstrebt, ${ }^{28}$ hat das BVerfG bisher offen gelassen, ob diesem Prinzip Verfassungsrang zukommt. Diese Zurückhaltung hat das BVerfG erst jüngst in seiner Arbeitszimmerentscheidung bekräftigt. ${ }^{29}$

25 BFH v. 21.9.2009 - GrS 1/06, BFHE 227, 1, BStB1. II 2010, 672, Rz. 127.

26 Dieser Elementargrundsatz des Einkommensteuerrechts rückte erst durch die Tagung der DStJG 1980 und die Beiträge von Söhn (DStJG 1980 [3] 13, 18), Ruppe (DStJG 1980 [3] 103, 105, 115 ff.) und Tanzer (DStJG 1980 [3] 227, 230 ff.) in den Blickpunkt einer breiteren Fachöffentlichkeit. Dass der BFH dieses Prinzip daher erst relativ spät - aber doch auch schon 1980 (s. Fn. 8) - zur Kenntnis genommen hat, ist ihm kaum vorzuwerfen; immerhin hatte das BVerfG noch 1972 entschieden, "dem Einkommensteuer- und Körperschaftsteuerrecht" sei „bei einer Gesamtbetrachtung des Einkommensbegriffs ein Nettoprinzip im strengen Sinn, dass der Gesetzgeber jede Durchbrechung, für die kein besonderer Grund besteht, unterlassen müsste (vom Gesetz statuierte Sachgesetzlichkeit), nicht zu entnehmen" (BVerfG v. 7.11.1972 - 1 BvR 338/68, BVerfGE 34, $103 \mathrm{Rz}$. 36. Es ist daher nicht ganz fair, wenn dem BFH insoweit a posteriori ein Versäumnis vorgeworfen wird (so aber wohl Bergkemper, StuW 1996, 311, 312).

27 BFH v. 27.11.1978 - GrS 8/77, BFHE 126, 533, BStBl. II 1979, 213.

28 Statt vieler Englisch, DStR 2009 Beihefter zu Nr.34 S.92 und Lehner, DStR 2009, 185 jeweils m. w. N.

29 BVerfG v. 6.7.2010 - 2 BvL 13/09, BGBl. 2010, 1157; dazu Schneider, DStR 2009 Beihefter zu Nr. 34, S. 87 m. w. N. 
Auch der Große Senat des BFH geht nicht weiter. Er beruft sich vor allem auf die Entscheidung des BVerfG zur Pendlerpauschale ${ }^{30}$ und verweist auf seine eigene Rechtsprechung. Für die Entscheidung zum Abzug gemischter Aufwendungen reicht dies auch. Danach erlangt das objektive Nettoprinzip zum einen verfassungsrechtliche Bedeutung vor allem im Zusammenhang mit den Anforderungen an hinreichende Folgerichtigkeit bei der näheren Ausgestaltung der gesetzgeberischen Grundentscheidungen und ist darüber hinaus bei der Rechtsanwendung als Auslegungsrichtschnur heranzuziehen. ${ }^{31}$ Seine Konkretisierung findet das objektive Nettoprinzip durch den Veranlassungsgrundsatz, wie er in § 4 Abs. 4 EStG seinen Ausdruck gefunden hat und auch für den Bereich der Werbungskosten gilt. Die einkunftsbezogene Veranlassung von Reisekosten umschreibt der Große Senat dann wie folgt: „Ob und inwieweit Aufwendungen für eine Reise in wirtschaftlichem Zusammenhang mit einer Einkunftsart stehen, hängt von den Gründen ab, aus denen der Steuerpflichtige die Reise oder verschiedene Teile einer Reise unternimmt. Die Gründe bilden das , auslösende Moment ${ }^{\prime}$, das den Steuerpflichtigen bewogen hat, die Reisekosten zu tragen" ${ }^{32}$ Hieraus folgt für die sog. gemischten Aufwendungen eine Unterscheidung in drei Fallgruppen, die der Große Senat auch darstellt:

- Stets aufzuteilen sind Aufwendungen, die auf abgrenzbaren erwerbsbedingten und privaten Veranlassungsbeiträgen nicht untergeordneter Bedeutung beruhen. ${ }^{33}$

- Untrennbar gemischt betrieblich oder beruflich und privat veranlasste Aufwendungen sind nicht aufteilbar. ${ }^{34}$

- Reine Lebensführungskosten sind auch bei erwerbsbedingter Mitveranlassung nicht aufteilbar. ${ }^{35}$

Mit der ersten Variante war der Las Vegas-Fall entschieden. Alle weiteren Ausführungen des Großen Senats sind streng genommen obiter dicta. Diese nicht entscheidungserheblichen Varianten dienen aber dem systematischen Verständnis der Regelungen zur Abgrenzung der Einkommenserzielung und Einkommensverwendung; sie sind daher vorab zu erläutern.

Greifen die beruflichen und privaten Veranlassungsbeiträge - so der Große Senat - derart ineinander, dass eine Trennung nicht möglich ist, fehlt es also an objektivierbaren Kriterien für eine Aufteilung, so kommt

30 BVerfG v. 9.12.2008 - 2 BvL 2/08 u. a., BVerfGE 122, 210.

31 BFH v. 21.9.2009 - GrS 1/06, BFHE 227, 1, BStBl. II 2010, 672, Rz. 94.

32 BFH v. 21.9.2009 - GrS 1/06, BFHE 227, 1, BStBl. II 2010, 672, Rz. 95.

33 BFH v. 21.9.2009 - GrS 1/06, BFHE 227, 1, BStBl. II 2010, 672, Rz. 98 ff.

34 BFH v. 21.9.2009 - GrS 1/06, BFHE 227, 1, BStBl. II 2010, 672, Rz. 125.

35 BFH v. 21.9.2009 - GrS 1/06, BFHE 227, 1, BStBl. II 2010, 672, Rz. 122 ff. 
ein Abzug der Aufwendungen insgesamt nicht in Betracht, weil es dann an ihrer Veranlassung durch die Einkünfteerzielung fehlt. Der Große Senat nennt selbst das Beispiel einer beruflich/privaten Doppelmotivation für eine Reise. ${ }^{36}$ Hierher gehören aber auch die in $\S 12$ Nr. 1 Satz 2 EStG bezeichneten betrieblich oder beruflich nützlichen Aufwendungen für die Lebensführung, die die wirtschaftliche oder gesellschaftliche Stellung mit sich bringt. Im Schrifttum wird behauptet, das Abzugsverbot für derartige Repräsentationsaufwendungen sei "normativer Ausdruck einer bourgeoisen Zeit" ${ }^{\prime \prime 37}$ und daher überholt. Tatsächlich haben das typische Herrenzimmer oder der Titel des Kommerzienrats heutzutage nicht mehr die Bedeutung wie vor 80 Jahren. Dafür gibt es aber nun vielleicht die Mitgliedschaft im Golfclub und die Würde des Karnevalsprinzen oder Schützenkönigs.

Auch die erwerbsbedingte Mitveranlassung reiner Lebensführungskosten unterliegt weiterhin einem Aufteilungs- und einkünftebezogenen Abzugsverbot. Dadurch wird eine Doppelberücksichtigung vermieden, weil diese Aufwendungen (also etwa Kleidung, Nahrung und Hilfsmittel, wie Brillen oder Hörgeräte) bereits typisierend durch den Grundfreibetrag berücksichtigt werden. ${ }^{38}$ Insoweit kommt dem subjektiven Nettoprinzip eine Ausschlussfunktion zu. „Inwieweit gleichwohl“ - so der Große Senat unter Hinweis auf die Regelungen zum Abzug von Aufwendungen für typische Berufskleidung - „insoweit ein etwa gegebener beruflicher Mehraufwand zu berücksichtigen ist, bleibt danach in erster Linie der Entscheidung des Gesetzgebers überlassen". 39

\section{c) Das eigentliche Abzugsgebot für gemischte Aufwendungen}

Nach den entscheidungserheblichen Ausführungen des Großen Senats sind Aufwendungen für Reisen, die abgrenzbare berufliche und private Anteile enthalten, grundsätzlich aufzuteilen, sofern die berufliche oder private Veranlassung nicht von völlig untergeordneter Bedeutung ist. Nachdem die Vorstellung von der Einheit einer Reise aufgegeben wur$\mathrm{de}^{40}$ sind gemischte Aufwendungen hier nicht die bereits eindeutig der beruflichen Sphäre zuzuordnenden Tagungsgebühren und sonstigen

36 BFH v. 21.9.2009 - GrS 1/06, BFHE 227, 1, BStBl. II 2010, 672, Rz. 125 m. w. N.

37 So Leisner-Egenspeger, DStZ 2010, 185, 191.

38 Der Große Senat verzichtet hier zu Recht auf das Argument, es handele sich um untrennbar gemischte Aufwendungen. In einem Schedulensystem, wie der englischen Einkommensbesteuerung, muss das Abzugsverbot für solche Aufwendungen aber so begründet werden (s. etwa Mallalieu v. Drummond [1983] STC 665 (HL) zum „principle of duality“ bei Bekleidungskosten einer Anwältin).

39 BFH v. 21.9.2009 - GrS 1/06, BFHE 227, 1, BStBl. II 2010, 672, Rz. 122.

40 BFH v. 21.9.2009 - GrS 1/06, BFHE 227, 1, BStBl. II 2010, 672, Rz. 127. 
durch die Computerkonferenz veranlassten Kosten einerseits und die Kosten eines vorangehenden oder nachfolgenden Urlaubs andererseits. Diese Aufwendungen erfordern nur eine Aufteilung, wenn es sich um eine Pauschalreise gehandelt haben sollte. Die dem neuen Aufteilungsgebot unterliegenden gemischten Aufwendungen sind die durch die kombinierte Dienst- und Urlaubsreise veranlassten Kosten der Hin- und Rückreise und weitere denkbare Aufwendungen, denen eine Doppelmotivation zugrunde liegen könnte. Hier ist indessen eine Aufteilung nur dann geboten, wenn der private oder beruflich-betriebliche Veranlassungsbeitrag nicht von untergeordneter Bedeutung ist. Private Veranlassungsbeiträge von untergeordneter Bedeutung führen zum vollen Abzug auch der gemischten Aufwendungen als Betriebsausgaben oder Werbungskosten und vice versa.

Als sachgerechten Aufteilungsmaßstab für diese doppelmotivierten Aufwendungen sieht der Große Senat das Verhältnis der beruflich oder betrieblichen und der privaten Zeitanteile der Reise an, lässt aber Raum für eine andere Aufteilung. So soll es "das unterschiedliche Gewicht der verschiedenen Veranlassungsbeiträge im Einzelfall erfordern" können, „einen anderen Aufteilungsmaßstab heranzuziehen oder ganz von einer Aufteilung abzusehen." Hierzu führt der Große Senat gleich ein Beispiel an: Nimmt der Steuerpflichtige etwa "aufgrund einer Weisung seines Arbeitgebers einen beruflichen Termin wahr, so können die Kosten der Hin- und Rückreise auch dann in vollem Umfang beruflich veranlasst sein, wenn der Steuerpflichtige den beruflichen Pflichttermin mit einem vorangehenden oder nachfolgenden Privataufenthalt verbindet. Dabei kommt es nicht notwendig darauf an, ob der private Teil der Reise kürzer oder länger ist als der berufliche Teil." Dies ist allerdings kein anderer „Maßstab" für die Aufteilung, wie etwa Zeit-, Mengen-, Finanzierungsoder Flächenanteile, sowie die Aufteilung nach Köpfen, ${ }^{41}$ sondern nur eine vom Maßstab abweichende, anders gewichtete Aufteilung.

\section{Zur Kritik an dem Beschluss des Großen Senats}

Die wohlwollende Aufnahme, die der Beschluss des Großen Senats erfahren hat, ließ bisher kaum Raum für eine grundlegende Kritik an der Entscheidung. Zwar wurde darauf hingewiesen, dass die Arbeit der Finanzverwaltung, der Berater und der Finanzgerichte durch die Notwendigkeit einer schätzweisen Aufteilung nicht leichter werde. ${ }^{42}$ Der Große Senat selbst hat diese Einschätzung mit seinen Ausführungen zur Verifikation der unterschiedlichen Veranlassungsbeiträge gefördert. ${ }^{43}$ Sorgfältige Tat-

41 Dazu BMF v. 6.7.2010, BStBl. I 2010, 614 Tz. 15.

42 So Fischer, NWB 2010, 412, 421; a. A. Pezzer, DStR 2010, 93, 96.

43 BFH v. 21.9.2009 - GrS 1/06, BFHE 227, 1, BStB1. II 2010, 672, Rz. 119 und 126. 
sachenfeststellungen waren aber schon früher geboten, um die Gesamtwürdigung einer Reise als erwerbsbedingt oder privat veranlasst zu stützen; nun dienen sie der Ermittlung der einzelnen Veranlassungsbeiträge einer Veranstaltung oder Maßnahme und zugleich der Feststellung eines geeigneten Aufteilungsmaßstabs.

Dass der Große Senat die Erkenntnisse der dritten Tagung der Deutschen Steuerjuristischen Gesellschaft zur deklaratorischen Rechtsnatur des $\S 12$ Nr. 1 EStG - auch seines Satzes $2^{44}$ - nicht aufgegriffen hat, ist im Ergebnis ohne Bedeutung. Auch seine Auslegung führt dazu, dass $§ 12$ Nr. 1 Satz 2 EStG kein allgemeines Aufteilungs- und Abzugsverbot begründet. Gleichwohl hätte ein Bekenntnis zur deklaratorischen Bedeutung der Regelung hermeneutisch überzeugender und steuersystematisch eindeutiger die Deduktion eines grundsätzlichen Aufteilungsgebots aus dem objektiven Nettoprinzip belegt.

Etwas irritierend wirken die eher beiläufigen Ausführungen des Großen Senats, wonach er "weder unter dem Aspekt des Gewohnheitsrechts noch im Hinblick auf das Gebot zur Wahrung der Rechtsprechungskontinuität gehindert" sei, die Rechtsprechung zum Aufteilungs- und Abzugsverbot des $\S 12$ Nr. 1 Satz 2 EStG zu ändern. ${ }^{45}$ Bemerkenswert sind diese Zeilen deshalb, weil sie sich auf den Beschluss zur Vererblichkeit des Verlustabzugs beziehen, der zum Nachteil der Steuerpflichtigen ergangen ist, die von der Aufgabe des Aufteilungs- und Abzugsverbots wohl eher profitieren dürften. Zwar gibt es kaum eine Entscheidung des Großen Senats des BFH, die nicht zu Rechtsprechungswandel und -kontinuität und dem Problem der Rückwirkung eines Rechtsprechungswandels Stellung genommen hätte, um damit die eine oder andere Lösung zu rechtfertigen oder abzusichern. So hat der Große Senat des BFH die "Stetigkeit der Rechtsprechung des obersten Steuergerichts" als „Rechtsgut von hohem Rang" bezeichnet. ${ }^{46}$ Diese Aussage bezeichnet aber weder eine Norm, noch deutet sie auf einen fundamentalen Grundsatz hin, der gegen rechtsprechungsändernde Bestrebungen ins Feld zu führen wäre. Freilich gehören Rechtssicherheit und Funktionsfähigkeit der Rechtspflege zu den Universalrechtsgütern, denn Recht -auch Gewohnheitsrecht- verbürgt eine bestimmte Erwartungssicherheit. ${ }^{47}$ Hierauf kann sich aber die Finanzverwaltung ebensowenig berufen, wie auf einen Vertrauensschutz. Ob die bisherige, nun als unzutreffend erkannte Recht-

44 So Söhn, DStJG 1980 [3] 13, 41 m.w. N. daselbst Fn. 141; gl. A. Kanzler, NSt. Darst. 1 Privatausgaben [1981], 3, 7; wohl auch Ruppe, DStJG 1980 [3] 103, $124,141$.

45 BFH v. 21.9.2009 - GrS 1/06, BFHE 227, 1, BStBl. II 2010, 672, Rz. 120.

46 BFH v. 13.11.1963 - GrS 1/63 S, BStBl. III 1964, 124 Rz. 16.

47 Luhmann, Ausdifferenzierungen des Rechts. Beiträge zur Rechtssoziologie und Rechtstheorie, Frankfurt a.M. 1981, 73 ff., 92 ff. 
sprechung zum Aufteilungs- und Abzugsverbot des $§ 12$ Nr. 1 Satz 2 EStG daher einen Vertrauenstatbestand begründet hat, konnte für den Beschluss des Großen Senats allenfalls entscheidend sein, wenn man ernsthaft annimmt, der eine oder andere Steuerpflichtige habe im Vertrauen auf die bisherige Rechtsprechung auf den Abzug gemischter Aufwendungen verzichtet. Dafür aber kann nicht entscheidend sein, ob ihm der Nachweis eines „bezifferbaren negativen Vertrauensschadens" möglich wäre. ${ }^{48}$ Er hatte jederzeit die Möglichkeit sein Recht einzuklagen (volenti non fit injuria); nimmt er dieses Recht nicht wahr, so kann er kaum besser gestellt sein, als ein Kläger, der unter Anwendung der nun überwundenen Rechtsprechung zum Aufteilungs- und Abzugsverbot unterlag.

Grundlegender ist ein Zweifel an der Schlüssigkeit der Aufteilung der Kosten einer doppelmotivierten Reise unter Beachtung des objektiven Nettoprinzips. Die gefundene Aufteilung nach Maßgabe der beruflich und privat veranlassten Zeitanteile der Reise hat zwar den Charme einer arithmetischen Korrektheit; kausallogisch kann sie aber nicht überzeugen, weil der Steuerpflichtige ohne die An- und Abreise an dem Kongress nicht hätte teilnehmen können. ${ }^{49}$ Wie wäre wohl entschieden worden, wenn der Computerfachmann zur Messe nach Las Vegas gereist wäre, um danach von dort aus einen Badeurlaub in Hawaii zu verbringen und anschließend wieder von Las Vegas nach Deutschland zurückzufliegen? Ist der Steuerpflichtige, der aus überwiegend beruflicher Veranlassung reist und einen Kongress besucht, allein wegen des privaten Teils der Reise gegenüber dem Steuerpflichtigen zu benachteiligen, der nur zu dem Kongress an- und danach wieder abreist?

Diese Überlegungen müssen wohl dazu führen, dass schon eine überwiegend erwerbsbedingte Veranlassung den vollen Abzug der Reisekosten rechtfertigt. Ebenso müsste eine nur anlässlich einer Urlaubsreise aus beruflicher Veranlassung besuchte Veranstaltung in vollem Umfang zu einem Abzugsverbot führen. Das „,auslösende Moment", das den Steuerpflichtigen bewogen hat, die Reisekosten zu tragen, ist im ersten Fall allein und ausschließlich die beruflich-betriebliche Motivation und im zweiten Fall ein privater Beweggrund. Nur bei gleichgewichtigen Veranlassungsbeiträgen wäre dann eine hälftige Aufteilung in Erwägung zu ziehen. ${ }^{50}$ Dieser Gedanke wird nicht zuletzt vom Großen Senat selbst

48 So aber Leisner-Egenspeger, DStZ 2010, 185, 192.

49 Ebenso Englisch, DStR 2009 Beihefter zu Nr. 34, 92, 95 daselbst Fn. 48.

50 Solche gleichgewichtigen Veranlassungsbeiträge wären etwa anzunehmen, wenn der Stpfl. seinen Partner und andere Familienmitglieder auf eine Dienstreise mitnimmt. Dabei handelt es sich durchaus um einen neuen Trend, Berufsund Familienleben unter Einklang zu bringen (s. Weed, A working vacation with family emphasis, The New York Times, Beil. zur SZ v. 4.10.2010, 5). 
aufgegriffen, aber nicht als Grundsatz, sondern als Ausnahme entwickelt. Danach sind die Reisekosten trotz eines mit der Dienstreise verbundenen Privataufenthalts in vollem Umfang abziehbar, wenn der Steuerpflichtige auf Weisung seines Arbeitgebers einen beruflichen Termin wahrnimmt.

\section{Die Umsetzung der Vorgaben des Beschlusses vom 21.9.2009}

\section{Erste Entscheidungen der Gerichte}

Nach dem Beschluss des Großen Senats konnten alle bis zu dieser Entscheidung ruhenden Verfahren wieder aufgenommen werden. Während das Ausgangsverfahren zur Grundsatzentscheidung des Großen Senats im Las Vegas-Fall durch eine Änderung des angefochtenen Einkommensteuerbescheids und Erledigung der Hauptsache abgeschlossen werden konnte, hatte zunächst der VI. Senat des BFH am 21.4.2010 in zwei weiteren Revisionen über den Werbungskostenabzug von Aufwendungen für eine Auslandsgruppenreise und für eine Fortbildungsveranstaltung zu entscheiden. Auch der IV. und der VIII. Senat des BFH hatten Gelegenheit die Grundsätze der Las Vegas-Entscheidung des Großen Senats anzuwenden.

\section{a) Irlandreise einer Englischlehrerin}

Zur Auslandsgruppenreise einer Englischlehrerin entschied der BFH, dass Reisekosten im Fall der Abgrenzbarkeit in Werbungskosten und Aufwendungen für die private Lebensführung aufzuteilen sind und dass als sachgerechter Aufteilungsmaßstab vor allem das Verhältnis der beruflich und privat veranlassten Zeitanteile in Betracht kommt. ${ }^{51}$

In diesem Fall ging es um den Abzug der Aufwendungen, die einer Gymnasiallehrerin für Englisch und Religion anlässlich einer achttägigen Fortbildungsreise für Englischlehrer nach Dublin, Irland, entstanden waren. Der Reise, die von der Englischlehrervereinigung angeboten und durchgeführt wurde und für die die Klägerin Dienstbefreiung erhalten hatte, lag ein Programm zugrunde, das u. a. eine Stadtrundfahrt in Dublin, Vorträge zu kulturellen und sozialpolitischen Themen, den Besuch einer Theateraufführung, einen Tagesausflug und einen „Dublin Literary Pub Crawl" umfasste. Finanzamt und Finanzgericht lehnten den Abzug der Aufwendungen in vollem Umfang unter Hinweis auf das Aufteilungsund Abzugsverbot des $\S 12$ Nr. 1 Satz 2 EStG ab. ${ }^{52}$

51 BFH v. 21.4.2010 - VI R 5/07, BFHE 229, 219, BStBl. II 2010, 687.

52 Schleswig-Holsteinisches FG v. 28.6.2006 - 2 K 95/04, EFG 2007, 754. 
Der BFH gab der Revision der Lehrerin statt und forderte das Finanzgericht auf, erneut zu prüfen, ob die Kosten der Bildungsreise als beruflich veranlasste Aufwendungen ganz oder zumindest teilweise als Werbungskosten zu berücksichtigen seien. Haben nicht nur berufliche Gründe den Steuerpflichtigen bewogen die Reisekosten zu tragen, so ist zu prüfen, ob die beruflichen und privaten Veranlassungsbeiträge objektiv voneinander abgrenzbar sind. Im Fall der Studienreise nach Irland beruhte das Urteil des FG noch auf dem inzwischen aufgegebenen Aufteilungs- und Abzugsverbot des $\S 12$ Nr. 1 Satz 2 EStG. Hier konnte der Senat nicht durchentscheiden, weil es an Feststellungen fehlte, die eine Aufteilung der gemischt veranlassten Aufwendungen ermöglicht hätten.

In seinen Hinweisen an das Finanzgericht für den 2. Rechtsgang (sog. Segelanweisung) hat der VI. Senat im Übrigen klargestellt, dass zur Klärung der Veranlassungsbeiträge bei Teilnahme an einer Auslandsgruppenreise auch nach der Entscheidung des Großen Senats des BFH v. 21.9.2009,53 die früher von ihm entwickelten Abgrenzungsmerkmale grundsätzlich weitergelten. Das FG wird daher für eine berufliche Veranlassung neben einer fachlichen Organisation vor allem festzustellen haben, dass das Programm auf die besonderen beruflichen Bedürfnisse der Teilnehmer zugeschnitten und der Teilnehmerkreis im Wesentlichen homogen ist.

Unter Hinweis auf zwei vor dem Beschluss des Großen Senats ergangenen Urteile ${ }^{54}$ führt der VI. Senat weiter aus, dass es unschädlich ist, wenn die im beruflichen Interesse gewonnenen Erkenntnisse auch im privaten Bereich angewendet werden können. Schließlich bezieht er sich auf Ausführungen im Beschluss des Großen Senats, wonach die berufliche Veranlassung von Reisekosten nicht mit der Begründung verneint werden könne, der Beruf erfordere Aufwendungen, die für andere Steuerpflichtige Privataufwendungen seien. Danach hat das Finanzgericht einzelne Abschnitte oder Veranstaltungen der Reise nach objektiven Maßstäben der beruflichen oder privaten Sphäre zuzuordnen, wie dies bereits für die Einnahmeseite gemischt veranlasster Reisen im sog. Portugalfall ausgeführt worden war. ${ }^{55}$ Eine Aufteilung gemischter Aufwendungen ist dann nur noch für die Kosten der Beförderung, der Hotelunterbringung und Verpflegung vorzunehmen und als sachgerechter Aufteilungsmaßstab das Verhältnis der beruflichen und privat veranlassten Zeitanteile heranzuziehen. Bei der Bemessung der Zeitanteile sind der An- und Abreisetag nur zu berücksichtigen, wenn diese Tage zumindest teilweise für touristische

53 BFH v. 21.9.2009 - GrS 1/06, BFHE 227, 1, BStB1. II 2010, 672.

54 BFH v. 17.7.1992 - VI R 12/91, BStBl. II 1992, 1036 und v. 28.8.2008 - VI R 35/05, BStBl. II 2009, 108.

55 BFH v. 18.8.2005 - VI R 32/03, BStB1. II 2006, 30. 
bzw. berufliche Unternehmungen zur Verfügung standen. Ansonsten sind diese Tage bei der Aufteilung als neutral zu behandeln.

Ob bei der Irlandreise auch ein anderer Aufteilungsmaßstab als die zeitanteilige Zuordnung zu Privatem und Beruflichem anzunehmen wäre, wird das FG zu entscheiden haben. Insoweit könnte auch ganz von einer Aufteilung abgesehen werden. So hat etwa das Sächsische Finanzgericht auch bei einem homogenen Teilnehmerkreis den Werbungskostenabzug für eine Gruppenreise versagt, weil die Reiseteile mit einem eindeutigen und ausschließlich beruflichen Bezug von ganz untergeordneter Bedeutung waren. ${ }^{56}$ Es handelte sich dabei um die Kosten der teilweise von der Schule finanzierten Studienreise einer Deutsch, Kunst und Kunstgeschichte an einem Gymnasium unterrichtenden Lehrerin nach Israel, an der ausschließlich Lehrer teilnahmen und die vom Schulleiter für notwendig, vom Schulamtsleiter hingegen als möglich angesehen wurde. Ganz ähnlich hatte schon der VI. Senat des BFH vor dem Beschluss des Großen Senats verschiedene Nichtzulassungsbeschwerden von Klägern zurückgewiesen, die Studienreisen nach Israel ${ }^{57}$ oder auf dem Jakobspilgerpfad $^{58}$ unternommen hatten. ${ }^{59}$

Entsprechende Überlegungen wie zur Irlandreise wird der BFH in einem anderen Fall anzustellen haben, bei dem der Lohnsteuersenat die Revision zugelassen hatte. Es geht dort um die Frage, ob ein Pfarrer die Kosten für eine dienstlich angeordnete Pilgerwallfahrt nach Rom sowie für eine Fortbildungsveranstaltung nach Jordanien als Werbungskosten absetzen kann. ${ }^{60}$

\section{b) Ärztliche Fortbildung am Gardasee}

In dem Fortbildungsfall ${ }^{61}$ ging es um den Abzug von Aufwendungen für die Teilnahme des Klägers, eines angestellten Unfallchirurgen, an einem sportmedizinischen Wochenkurs als Werbungskosten bei den Einkünften aus nichtselbständiger Arbeit. Die Fortbildungsveranstaltung fand in der Zeit vom 29.8. bis zum 4.9.1999 am Gardasee statt. Die Maßnahme war von der Ärztekammer für den Erwerb der Zusatzbezeichnung „Sportmedizin" anerkannt worden. Sie war an verschiedene Voraussetzungen geknüpft, worunter auch eine Teilnahme an den von der Ärztekammer anerkannten sportmedizinischen Kursen von insgesamt 120 Stunden

56 FG Sachsen v. 11.8.2009 - 3 K 2439/02, Juris.

57 BFH v. 26.10.2004 - VI B 84/04, BFH/NV 2005, 205 und v. 5.11.2008 - VI B 73/08, BFH/NV 2009, 170 .

58 BFH v. 19.10.2004 - VI B 111/04, Juris.

59 S. auch Kempermann, FR 2010, 234.

60 Az. der Revision VI R 42/09.

61 BFH v. 21.4.2010 - VI R 66/04, BFHE 229, 215, BStBl. II 2010, 685. 
Dauer fiel. Das Programm des Kurses sah in den frühen Morgenstunden und am späten Nachmittag Vorträge vor, während die Zeit von 9:15 bis 15:45 der Theorie und Praxis verschiedener Sportarten wie Surfen, Biken, Segeln, Tennis und Bergsteigen vorbehalten war. Der Kläger wurde von seinem Arbeitgeber für die Fortbildung freigestellt.

Während das Finanzamt die Aufwendungen für die Teilnahme an dem Kurs in Höhe von 3.212 DM nicht zum Werbungskostenabzug zuließ, gab das FG der Klage teilweise mit der Begründung statt, die Aufwendungen seien zur Hälfte beruflich veranlasst, auch wenn der Fortbildungslehrgang in einem klassischen Urlaubsgebiet zur Urlaubszeit stattgefunden habe; jedenfalls hätten Freiräume für private Unternehmungen bestanden und der Aufenthalt am Kursort sei auf die Kurstage beschränkt gewesen. ${ }^{62}$ Der BFH bestätigte diese Entscheidung und berief sich dazu auf das Aufteilungsgebot im Beschluss des Großen Senats. Er folgte damit der Würdigung des FG, das die Aufteilung anhand der Zeitanteile vorgenommen hatte, die auf die beruflich veranlassten Vorträge einerseits und die -nach seiner Auffassung- privat veranlassten sportpraktischen Veranstaltungen andererseits, entfielen.

Diesen Fall konnte der BFH durchentscheiden. Hier hatte das Finanzgericht nämlich bereits vor dem Beschluss des Großen Senats des BFH zum Aufteilungs- und Abzugsverbot eine Aufteilung der Aufwendungen in abziehbare Werbungskosten und private nichtabziehbare Lebenshaltungskosten vorgenommen und dies im Einzelnen auch begründet. Der $\mathrm{BFH}$ folgte diesem Ergebnis mit der Begründung, es handele sich um eine Würdigung, die das Revisionsgericht auch dann binde, wenn ein abweichendes Verständnis gleichermaßen möglich oder sogar naheliegend sei. Dieser distanzierten Formulierung lässt sich durchaus entnehmen, dass der BFH auch einen höheren als den hälftigen Teil der Kosten, oder gar alle Aufwendungen der Fortbildungsveranstaltung zum Abzug zugelassen hätte.

Eine Anerkennung aller Kosten des sportmedizinischen Wochenkurses wäre einmal dann möglich, wenn alle Maßnahmen der Veranstaltung, also auch die Ausübung „verbreiteter Sportarten“, beruflich veranlasst wären. Dies entspräche den Ausführungen des Großen Senats, wonach die berufliche Veranlassung von Maßnahmen nicht mit der Begründung $\mathrm{zu}$ verneinen ist, der Beruf erfordere Aufwendungen, die für andere Steuerpflichtige Privataufwendungen sind. ${ }^{63}$ Aber auch die Würdigung der privat veranlassten Teile einer Fortbildungsveranstaltung als solche von untergeordneter Bedeutung, also mit einem Zeitanteil von weniger als $10 \%$, würde den Abzug aller Kosten rechtfertigen. Schließlich kann es

62 FG Sachsen-Anhalt v. 1.9.2004 - 2 K 124/02, EFG 2005, 352.

63 BFH v. 21.9.2009 - GrS 1/06, BFHE 227, 1, BStB1. II 2010, 672, Rz. 110. 
nach dem Beschluss des Großen Senats das unterschiedliche Gewicht der verschiedenen Veranlassungsbeiträge im Einzelfall erfordern, einen anderen Aufteilungsmaßstab heranzuziehen oder von einer Aufteilung ganz abzusehen. Auf diese Formulierung weist auch der VI. Senat des BFH in seinem sportmedizinischen Fortbildungsfall hin. Ein solches Absehen von einer Aufteilung an sich gemischter Aufwendungen wäre m. E. denkbar und zu rechtfertigen, wenn die beruflich veranlassten Veranstaltungen der Reise so stark das Gepräge geben, dass auch ein privater Zeitanteil von mehr als $10 \%$ zu vernachlässigen sein würde.

\section{c) Keine betriebliche Veranlassung einer „Fachstudienreise“ nach Südostasien}

Der Beschluss des IV. Senats des BFH über eine Nichtzulassungsbeschwerde ${ }^{64}$ belegt, dass sich durch die Entscheidung des Großen Senats vielleicht doch nicht so viel geändert haben könnte. Die Gesellschafter der Klägerin, einer Steuerberater- bzw. Rechtsanwalts-Sozietät, nahmen im Streitjahr (2002) mit Inhabern und Geschäftsführern regionaler Unternehmen an einer von der örtlichen Sparkasse veranstalteten „Fachstudienreise" nach Vietnam und Singapur teil. Der Reiseplan umfasste u. a. Stadtrundfahrten, Ausflüge, eine Bootsfahrt, Theater- und Show-Besuche, den Vortrag eines Vertreters der Arbeitsgemeinschaft deutschsprachiger vietnamesischer Unternehmer und eines Repräsentanten einer vietnamesischen Bank sowie Besuche der Deutschen Botschaft in Hanoi und des German Centre in Singapur. Finanzamt und Finanzgericht versagten den Abzug der Reisekosten als Betriebsausgaben bei der Gewinnermittlung der Klägerin. ${ }^{65}$ Der BFH wies die dagegen eingelegte Nichtzulassungsbeschwerde als unbegründet zurück.

Der BFH sah keinen der Zulassungsgründe als gegeben an, stützte sich auf den Beschluss des Großen Senats v. 21.9.2009 und führte aus: In dem genannten Beschluss habe der Große Senat des BFH zwar - unter Aufgabe des bislang aus $\S 12$ Nr. 1 Satz 2 EStG abgeleiteten Aufteilungs- und Abzugsverbotes - entschieden, dass Aufwendungen für Reisen, die abgrenzbare berufliche und private Anteile enthalten, grundsätzlich aufzuteilen seien, sofern die berufliche oder private Veranlassung nicht von völlig untergeordneter Bedeutung ist. Greifen die - für sich gesehen jeweils nicht unbedeutenden - beruflichen und privaten Veranlassungsbeiträge (z. B. bei einer beruflichen und privaten Doppelmotivation für eine Reise) aber so ineinander, dass eine Trennung nicht möglich ist, fehlt es also an objektivierbaren Kriterien für eine Aufteilung, so kommt ein Abzug der Aufwendungen auch nach der geänderten Rechtsprechung des Großen Senats ins-

64 BFH v. 5.2.2010 - IV B 57/09, BFH/NV 2010, 880.

65 FG Baden-Württemberg v. 12.3.2009 - 3 K 255/07, EFG 2009, 996. 
gesamt nicht in Betracht. ${ }^{66}$ Zudem habe der Große Senat grundsätzlich an den früher in seiner Rechtsprechung für Auslandsgruppenreisen entwickelten Abgrenzungsmerkmalen festgehalten; Reisen seien nur nicht mehr in jedem Fall insgesamt als Einheit zu beurteilen.

Das FG sei danach zu Recht zu dem Ergebnis gelangt, dass die Reise der Gesellschafter der Klägerin überwiegend privat veranlasst war. Das betriebliche Interesse der Klägerin, durch ihre Gesellschafter zu repräsentieren und neue Mandanten zu werben, habe es als hiervon nicht trennbar erachtet und eine zeitliche Aufteilung der Aufwendungen abgelehnt, weil kein Zeitabschnitt der Reise nur diesem Zweck gedient habe. Nach Auffassung des BFH steht diese Würdigung im Ergebnis auch mit dem Beschluss des Großen Senats des BFH v. 21.9.2009 in Einklang, nach dem eine unbedeutende berufliche bzw. hier betriebliche Mitveranlassung von Aufwendungen für die Lebensführung auch weiterhin keinen Betriebsausgabenabzug eröffnet.

\section{d) Auslandsreisen vor dem VIII. Senat des BFH}

In zwei Fällen hatte sich der VIII. Senat des BFH nach dem Beschluss des Großen Senats mit Auslandsreisen zu befassen. Bei der Beurteilung mehrerer Fernreisen des Alleingesellschafters einer GmbH als Mitglied einer Wirtschaftsdelegation und zum Weltwirtschaftsforum in Davos ging es vor allem um die Annahme einer verdeckten Gewinnausschüttung (vGA). ${ }^{67}$ Nur am Rande bezieht sich der BFH hier auf den Beschluss des Großen Senats wenn er ausführt, dass im Streitfall eine Aufteilung der Kosten wegen abtrennbarer privat veranlasster Reiseteile nach Maßgabe des neuen Aufteilungsgebots nicht in Betracht komme.

Bedeutsamer ist das amtlich nicht veröffentlichte Urteil zur Ostasienreise eines Steuerberaters, ${ }^{68}$ weil es verdeutlicht, dass die neuen Grundsätze zur Behandlung gemischter Aufwendungen die Tatsacheninstanz in stärkerem Umfang in die Pflicht nimmt. In diesem Fall hatte der Kläger mit seiner Ehefrau an der Reise eines Mandanten aus der Edelsteinbranche und dessen Ehefrau nach Hongkong und Bangkok teilgenommen und seine Reisekosten als Betriebsausgaben behandelt. Sein Vortrag, er habe den Mandanten bei Vertragsverhandlungen unterstützt, überzeugte das Finanzamt nicht. Das Finanzgericht ließ die Aufwendungen jedoch zur Hälfte zum Abzug zu, ohne sich Gewissheit über den tatsächlichen Ablauf der Reise verschafft zu haben.

66 BFH v. 21.9.2009 - GrS 1/06, BFHE 227, 1, BStBl. II 2010, 672, Rz. 125.

67 BFH v. 9.3.2010 - VIII R 32/07, BFHE 229, 129.

68 BFH v. 1.6.2010 - VIII R 80/05, BFH-NV 2010, 1805. 
Der BFH hob dieses Urteil auf und verwies den Rechtsstreit zurück, um dem Finanzgericht Gelegenheit zu geben, dieses Versäumnis nachzuholen. Nach dem Urteil des BFH kann ein Finanzgericht von einer gemischt veranlassten Auslandsreise verfahrensfehlerfrei nur ausgehen, wenn es sich anhand feststehender objektiver Umstände eine nachprüfbare Überzeugung davon bilden konnte, dass Teile der Reisezeit beruflich genutzt worden sind. Im Zweifel ist das Finanzgericht von Amts wegen gehalten, die anderen Reiseteilnehmer zum tatsächlichen Ablauf der Reise als Zeugen zu vernehmen.

\section{Verwaltungsanweisungen zur Umsetzung der Entscheidung des Großen Senats}

Die Finanzverwaltung hat - soweit ersichtlich - mit zwei Anweisungen auf den Beschluss des Großen Senats reagiert: Das BMF-Schreiben vom 6.7.2010 zieht die Folgerungen aus dem Beschluss für die gemischten Aufwendungen allgemein, ${ }^{69}$ während eine Verfügung der Thüringer Landesfinanzdirektion nur die Auslandsgruppenreisen behandelt. ${ }^{70}$ Dabei ist anzuerkennen, dass das BMF um eine faire Umsetzung der Entscheidung des Großen Senats bemüht ist, die Geringfügigkeitsregel beachtet, ${ }^{71}$ das Abzugsgebot für Reisekosten bei unmittelbarer erwerbsbedingter Veranlassung anerkennt ${ }^{72}$ und auch bereits auf die Urteile des BFH nach dem Beschluss des Großen Senats Bezug nimmt. Auch die Verfügung der Thüringer Landesfinanzdirektion gibt die neuen Grundsätze zur steuerlichen Behandlung von Reisekosten wieder, betont insbesondere, dass Reisen nicht mehr als Einheit aufzufassen seien und dass den Steuerpflichtigen eine Darlegungs- und Nachweispflicht treffe.

\section{Künftige Behandlung gemischter Aufwendungen}

Die bisherigen Folgeentscheidungen auf den Beschluss des Großen Senats zeigen die neuen Möglichkeiten der Behandlung gemischter Aufwendungen - wie bei Einzelfallentscheidungen kaum anders zu erwarten nur unvollständig. Nun könnte man alle die Fälle katalogartig erfassen, die bis zum Beschluss des Großen Senats vom Aufteilungs- und Abzugsverbot des $\S 12$ Nr. 1 Satz 2 EStG erfasst waren und so vom Arztkongress über die Berufskleidung, das Schwimmbad und die Waschmaschine bis $z u$ den Zinsaufwendungen zu einer neuen Beurteilung der entsprechen-

69 BMF v. 6.7.2010, BStBl. I 2010, 614.

70 Thüringer Landesfinanzdirektion v. 11.8.2010 - S 2227 A-07-A 2.16, Juris.

71 BMF v. 6.7.2010, BStBl. I 2010, 614 Tz. $11 \mathrm{f}$.

72 BMF v. 6.7.2010, BStBl. I 2010, 614 Tz. 12. 
den Aufwendungen kommen. Dies sollte besser der weiteren Entwicklung der Rechtsprechung überlassen bleiben. Abstrahiert man jedoch die auf Reisekosten bezogenen Ausführungen des Großen Senats, dann lassen sich wohl folgende fünf Thesen aufstellen und anhand von Beispielen verdeutlichen:

- Die Aufteilung von Aufwendungen unterbleibt, wenn der erwerbsbezogene oder der private Anteil von untergeordneter Bedeutung ist. Sind die Veranlassungsbeiträge quantifizierbar, so ist ein Anteil bis zu $10 \%$ von untergeordneter Bedeutung. ${ }^{73}$ Im Übrigen kann sich die untergeordnete Bedeutung auch auf Grund einer wertenden Betrachtung ergeben, wenn die gesamte Maßnahme so stark durch den Erwerbsbezug einzelner Veranlassungsbeiträge geprägt ist, dass die privaten Motive nicht ins Gewicht fallen. Umgekehrt kann die private Veranlassung eine mitwirkende betriebliche oder berufliche Motivation völlig verdrängen.

- Komplexe Maßnahmen sind nicht mehr als Einheit aufzufassen, die insgesamt als erwerbsbezogen oder privat veranlasst $\mathrm{zu}$ würdigen wären: Danach umfasst die mit einem Urlaub verbundene Kongressoder Fortbildungsreise unterschiedliche Veranlassungsbeiträge für eindeutig zuzuordnende Kosten, die von den doppelt motivierten (gemischten) Aufwendungen zu trennen sind.

- Als Maßstab für die Aufteilung doppelt motivierter Aufwendungen kommen die Zeitanteile nur in Betracht, wenn die maßstabsbildenden, unterschiedlich eindeutig zuzuordnenden Veranlassungsbeiträge nacheinander verwirklicht werden: Während eines Urlaubs wird ein Fachkongress besucht; der Besuch von Verwandten geht einer Fortbildungsveranstaltung voraus oder folgt ihr nach.

- Unterschiedliche Veranlassungsbeiträge, die gleichzeitig verwirklicht werden, erfordern einen anderen als den zeitlichen Aufteilungsmaßstab für doppelmotivierte Aufwendungen: So sind die eindeutig zuzuordnenden Kosten einer Jubiläumsfeier, wie etwa Übernachtungskosten, den einzelnen Gästen zuzurechnen. Für die gemischten Aufwendungen einer solchen Veranstaltung, wie Speisen und Getränke, Saalmiete und Personalkosten, eignet sich weder der zeitanteilige Maßstab noch eine Aufteilung nach den unterschiedlichen Finanzierungskosten der individuell zuzuordnenden Aufwendungen. Hier bietet sich nur eine Aufteilung nach Köpfen an.

73 Zur allgemein anerkannten Geringfügigkeitsgrenze, die auch zur Quantifizierung der untergeordneten Bedeutung mit $10 \%$ heranzuziehen wäre, s. etwa BFH v. 2.10.2003 - IV R 13/03, BFHE 203, 373, BStBl. II 2004, 985 m. w. N. zu Tz. 13. 
- Gleichzeitig und nacheinander verwirklichte Veranlassungsbeiträge sind nach den eben genannten Maßstäben zu würdigen: So wären die Aufwendungen für die mit einem Urlaub kombinierte Fortbildungsreise in Begleitung des Ehegatten zeitanteilig und nach Köpfen aufzuteilen; wird die Reise so stark durch die erwerbsbedingte Veranlassung geprägt, dass von einer Aufteilung der Aufwendungen nach dem zeitlichen Maßstab abzusehen wäre, bliebe es immer noch bei der Aufteilung nach Köpfen.

Auch können sich in einem solchen Fall private Veranlassungsbeiträge von zunächst untergeordneter Bedeutung zu Beiträgen entwickeln, die ein Abzugsverbot für einzelne Aufwendungen begründen: So hatte der IV. Senat des BFH bereits im Jahr 2005 über den Betriebsausgabenabzug von Schadensersatzzahlungen an die Opfer eines Flugzeugabsturzes zu befinden und durchaus im Sinne des Beschlusses des Großen Senats entschieden. ${ }^{74}$

Danach teilen Unfallschäden steuerrechtlich das Schicksal der Fahrt, auf der sie entstanden sind. Unfallbedingte Schadensersatzleistungen sind daher betrieblich veranlasste Aufwendungen, soweit sich der Unfall auf einer betrieblichen Reise ereignet hat. Beruht die Reise als solche auf einer doppelten Veranlassung, so kann die private Veranlassung der Aufwendungen von untergeordneter Bedeutung sein. Werden aber aufgrund der privaten Mitveranlassung einer Reise erhebliche Unfallkosten ausgelöst, die nicht mehr von untergeordneter Bedeutung sind, so führt dies zu einem Abzugsverbot für diese privat veranlassten Aufwendungen, das die betriebliche Veranlassung der übrigen Aufwendungen unberührt lässt.

Im Streitfall hatte ein Arzt für die Reise zu einer Fortbildungsveranstaltung, auf der er einen Vortrag halten sollte, ein Privatflugzeug gechartert. Als das Flugzeug bei schlechten Witterungsverhältnissen abstürzte, kamen auch zwei Passagiere ums Leben, die er aus Gefälligkeit mitgenommen hatte. Die Erben des Arztes leisteten Schadensersatz und machten die Aufwendungen dafür erfolglos als Betriebsausgaben geltend.

Auch nach diesen Thesen bleiben wohl noch einige Fragen offen, die vor allem jene gemischten Aufwendungen betreffen, die der Große Senat als durch den Grundfreibetrag und die anderen privaten Steuerermäßigungen abgegolten, identifiziert hat. Dazu gehören etwa Aufwendungen für Tageszeitungen, Lexika oder Musikinstrumente, die auch bei einer beruflichen oder betrieblichen Mitveranlassung nicht aufteilbar sind, aber

74 BFH v. 1.12.2005 - IV R 26/04, BFHE 211, 346, BStBl. II 2006, 182. 
abgezogen werden können, wenn der Steuerpflichtige den gleichen Gegenstand ein zweites Mal anschafft. ${ }^{75}$

Da der Grundfreibetrag aber nur die üblichen Aufwendungen abgilt, bleibt das Problem der Berücksichtigung eines beruflichen oder betrieblichen Mehraufwands. Dass das objektive Nettoprinzip eine Berücksichtigung dieses erwerbsbedingten Mehraufwands fordert, kann kaum zweifelhaft sein. Davon geht auch der Große Senat aus, überlässt diese Aufgabe aber "in erster Linie der Entscheidung des Gesetzgebers" ${ }^{17}{ }^{76}$ Diese Zurückhaltung hat sich der BFH bisher nicht auferlegt; ihr fehlt auch eine Rechtsgrundlage. Wenn der übliche, durch den Grundfreibetrag abgegoltene Aufwand überschritten ist, erfüllt der Mehraufwand die Tatbestandsvoraussetzungen des $\S 4$ Abs. 4 EStG und $\S 9$ Abs. 1 Satz 1 EStG. Aus diesem Grunde hat der IV. Senat des BFH den beruflich veranlassten Anteil an den Aufwendungen für Kleidung, Friseur und Kosmetika einer selbständigen Sängerin nach dem Werbungskostenpauschbetrag für unselbständig tätige Sängerinnen geschätzt und zum Abzug zugelassen. ${ }^{77}$ Dass hier möglicherweise ein Schätzungsproblem entsteht, kann jedenfalls kein Aufteilungs- und Abzugsverbot begründen. Im Zweifel bietet sich eine hälftige Aufteilung an, wie dies der österreichische VwGH für die Anschaffungskosten eines Steinway-Flügels entschieden hat. ${ }^{78}$ Selbst bei einem Musik- und Klavierlehrer ist davon auszugehen, dass er das Instrument auch privat nutzt, andererseits aber einen solchen Flügel nicht aus Gründen der Repräsentation anschafft.

\section{Schluss}

Das Aufteilungs- und Abzugsverbot für gemischte Aufwendungen war lange überfällig. $\mathrm{Ob}$ die Rechtsprechung, die es entwickelt und beharrlich beibehalten hat, tatsächlich „gut gemeint ${ }^{\prime \prime 79}$ war, möchte ich bezweifeln. Schon früh wurde eingewandt, dass es sich um eine richterrechtliche Typisierung auf fragwürdiger Rechtsgrundlage handelte, die allein der Miss-

75 BFH v. 28.4.1972 - VI R 305/69, BFHE 106, 59, BStBl. II 1972, 723 zu Tz. 12 betr. Fachliteratur einer Lehrerin; v. 29.4.1977 - VI R 208/75, BFHE 122, 467, BStBl. II 1977, 716 zu Tz. 10 betr. Brockhaus-Enzyklopädie. Zu dieser Theorie der Doppelanschaffung auch Streck, DStJG 1980 [3] 273, 287 und Kanzler, NSt. Darst. 1 Privatausgaben [1981], 11.

76 BFH v. 21.9.2009 - GrS 1/06, BFHE 227, 1, BStBl. II 2010, 672, Tz. 122.

77 BFH v. 11.11.1976 - IV R 3/73, BB 1978, 1293; allerdings schränkte der IV. Senat diese Beurteilung später wieder ein (BFH v. 6.7.1989 - IV R 91-92/87, BFHE 158, 221, BStBl. II 1990, 49 und v. 18.4.1991 - IV R 13/90, BFHE 164, 419, BStBl. II 1991, 751).

78 Österreichischer VwGH v. 27.5.1999 - 97/15/0142, RIS „Judikatur“.

79 So Pezzer, DStR 2010, 93, 94. 
brauchsabwehr diente, sich jedenfalls nicht aus $\S 12$ Nr. 1 Satz 2 EStG ableiten ließ. ${ }^{80}$ Freilich hatten sich Finanzverwaltung und Rechtsprechung immer wieder mit kleinlichen und oft dreisten Begehrlichkeiten auseinanderzusetzen. ${ }^{81}$ Der Große Senat selbst führt solche Beispiele kleiner Karos auf. Dass das Aufteilungs- und Abzugsverbot hier eine einfache und schnelle Lösung bot, war beabsichtigt; dass dies aber zu einer unberechenbaren Kasuistik führte, kann kaum verwundern. ${ }^{82}$ Ich kann nur hoffen, dass die Beurteilung solcher Fälle künftig berechenbarer ausfallen wird und nicht allein vom Geschick der Berater abhängt. ${ }^{83}$ Mit der Aufgabe des Aufteilungs- und Abzugsverbots hat sich die Beurteilung gemischter Aufwendungen von der Rechtsfrage zu einem Problem der Tatsachenfeststellung gewandelt. Die Tatsacheninstanz steht damit vor der neuen Aufgabe sorgfältiger Sachverhaltsermittlung. Inwieweit sich Gesetzgebung und Finanzverwaltung hier mit realitätsgerechten und verfassungskonformen Typisierungen behelfen werden, ${ }^{84}$ bleibt abzuwarten.

80 Dazu grundlegend bereits Kanzler, NSt. Darst. 1 Privatausgaben [1981] m. w. N.

81 Fischer, NWB 2010, 412, 422.

82 Kanzler, NSt. Darst. 1 Privatausgaben [1981], 13 f.

83 Die auf der Grundlage der geänderten Rechtsprechung auch neue Chancen für außergerichtliche Einigungen sehen (Hilbertz, NWB 2010, 2694, 2698 und Streck, NJW 2010, 896).

84 Auf die Notwendigkeit, die Aufteilung gemischter Aufwendungen durch verfassungsrechtlich zulässige Typisierungen und Pauschalierungen zu erleichtern, weisen auch Albert (FR 2010, 220, 225) und Fischer (NWB 2010, 412, 421) hin. 



\title{
Der Rechtsprechungswechsel des Großen Senats vom allgemeinen Aufteilungsverbot zum Aufteilungsgebot
}

\author{
Professor Dr. Klaus-Dieter Drüen \\ Düsseldorf ${ }^{1}$
}

Inhaltsübersicht

I. Rückblick: Ständige Kritik am allgemeinen Aufteilungs- und Abzugsverbot
II. Seitenblick: Spezielle Aufteilungsgebote und -verbote im Steuerrecht

III. Ausblick: Denkbare Konsequenzen für Steuerrecht und -vollzug

\section{Rückblick: Ständige Kritik am allgemeinen Aufteilungs- und Abzugsverbot}

1. Unser Thema gilt einem steuerrechtlichen Klassiker. Mehrere Dissertationen sind ihm gewidmet. ${ }^{2}$ Wolfgang Jakob hat die einschlägige Passage seines Einkommensteuerlehrbuchs zum Aufteilungs- und Abzugsverbot perspektivisch mit ",gestern, heute und morgen " überschrieben. ${ }^{3}$ Am Beginn meines Kommentars zur Entscheidung des Großen Senats des Bundesfinanzhofs ${ }^{4}$ steht daher ein Rückblick. Dieser ist auch darum geboten, weil die Entscheidung zum Teil als „Neuausrichtung der Abzugsfähigkeit von gemischt veranlassten Aufwendungen" begrüßt wurde. ${ }^{5}$ Dabei ist das Aufteilungsgebot - wie bereits die eingehende Darstellung der Rechtsentwicklung und Rechtsprechung im Beschluss seit dem Jahre 1891 belegt $^{6}$ - keineswegs neu. Der Große Senat hat das steuerrechtliche Rad keineswegs neu erfunden. Vielmehr vollzieht er die Wende zurück

1 Der Verfasser ist Inhaber des Lehrstuhls für Unternehmenssteuerrecht und Direktor am Institut für Unternehmensrecht an der Heinrich-Heine-Universität Düsseldorf. Der Beitrag ist die vollständige, um Nachweise ergänzte Fassung seines Kommentars auf dem Fachkongress am 28.9.2010.

2 Eisendick, Das Aufteilungs- und Abzugsverbot, 1995; Scheich, Das Abzugsgebot und -verbot gemischter Aufwendungen, 1996.

3 Jakob, Einkommensteuer, 4. Aufl. 2008, Rz. 219.

4 BFH, Beschl. v. 21.9.2009 - GrS 1/06, BStBl. II 2010, 672.

5 Kaminski, Neuausrichtung der Abzugsfähigkeit von gemischt veranlassten Aufwendungen - GrS 1/06 - und die Rückbesinnung auf das Veranlassungsprinzip, Editorial, Stbg. 2/2010, M. 1; ebenso Neufang, Einkommensteuerrechtliche Behandlung von gemischten Aufwendungen, BB 2010, 2409, mit Überblick über die "neuen Grundsätze".

6 BFH, GrS 1/06, BStBl. II 2010, 672 unter C. I. 1. der Gründe. 
zur Rechtsprechung des Preußischen Oberverwaltungsgerichts. ${ }^{7}$ Dieses hatte auf die Beschwerde eines Pfarrers, der eine Viehmagd und eine Haushälterin beschäftigte, kurz und bündig entschieden: „Die Haushälterin ist zweifellos für die Landwirtschaft und den Haushalt tätig und es kann daher nur ein Teil der Kosten als Betriebskosten der Landwirtschaft berücksichtigt werden ${ }^{\prime \prime}{ }^{8}$ Die Frage der Höhe des Abzugs war bereits damals eine Frage der Plausibilität, denen das Obergericht nicht nähertrat. Auf die Frage der Justiziabilität derartiger Aufteilungen ist am Ende zurückzukommen (s. III. 2.).

Die Abkehr der Rechtsprechung von dieser altehrwürdigen Ausgangsjudikatur zeichnet der Beschluss des Großen Senats akribisch nach, ${ }^{9}$ die Kritik des Schrifttums daran vermerkt er gerafft ${ }^{10}$ und ohne Anspruch auf Vollständigkeit. ${ }^{11}$ Während die Verteidiger entweder nur die Begründung der Rechtsprechung wiederholen ${ }^{12}$ oder auf die Praktikabilität im Massenrecht Steuerrecht und allfällige Missbrauchsversuche verweisen, ${ }^{13}$ führt die lange Liste der Kritiker ganz verschiedene Argumente gegen ein allgemeines Aufteilungsverbot an. ${ }^{14}$ Historisch reichen sie vom Vorwurf unzulässiger und verdeckter "Typisierungsjudikatur"15 über die Betonung des Veranlassungsprinzips ${ }^{16}$ bis hin zur aktuellen Aktivierung des objektiven Nettoprinzips. ${ }^{17}$ Obgleich die Rechtsprechung entscheidend auf die Steuergerechtigkeit rekurrierte, hat sie nie Befriedungswirkung entfaltet. Im Gegenteil: Der Fall des allgemeinen Aufteilungs- und Abzugsgebot ist seit langem gefordert worden. Namentlich W. Drenseck

7 Ebenso Heuermann, Vom Aufteilungsverbot zum Aufteilungsgebot, StBp. 2010, 86 (87).

8 Preuß. OVG v. 26.9.1901 - J. N. XI. a. 111 - Rep. XI. A. 88/01, PrOVGE 10, 86 (87).

9 BFH, GrS 1/06, BStBl. II 2010, 672 unter C. I. der Gründe. Zuvor eingehende Analyse von Krüger, Das Aufteilungs- und Abzugsverbot in der Rechtsprechung des BFH, DB Beilage Nr. 6/2006, $39 \mathrm{ff}$.

10 Ebenda, C. II. der Gründe.

$11 \mathrm{Zu}$ ergänzen ist insbesondere aus den Reihen des BFH die frühe Kritik von Kanzler, Zum Aufteilungs- und Abzugsverbot bei sogenannten gemischten Aufwendungen, NSt 1981, Darstellung 1 Privatausgaben (Juli 1981), 1 (3ff.).

12 So z. B. Seiler in Kirchhof, EStG, 8. Aufl. 2008, § 12 Rz. 3.

13 So Crezelius, Steuerrecht II, 1991, § 9 Rz. 2 ff., 4.

14 Zusammenfassend in alphabetischer Folge der Kritiker Wissenschaftlicher Beirat des Fachbereichs Steuern bei der Ernst $\nrightarrow$ Young AG, Aufteilungs- und Abzugsverbot nach $\S 12$ Nr. 1 Satz 2 EStG?, BB 2004, 1024 (1026ff.).

15 So Kanzler, NSt 1981, Darstellung 1 Privatausgaben (Juli 1981), 1 (4, 6); kritisch zur Typisierung auch Drüen in Tipke/Kruse, AO/FGO, § 4 AO Tz. 390 (Aug. 2006) m. w. N.

16 Zuletzt Weber, Die Abgrenzung zwischen Erwerbs- und Privatsphäre nach dem Veranlassungsprinzip, StuW 2009, 184.

17 Vgl. nur Lang in Tipke/Lang, Steuerrecht, 20. Aufl. 2010, § 9 Rz. 245. 
hat sich im Schmidt-Kommentar seit der ersten Auflage aus dem Jahre 1982 für eine Wende vom Aufteilungsverbot zum Aufteilungsgebot eingesetzt. ${ }^{18}$ Steter Tropfen höhlt den Stein, ${ }^{19}$ erst im Kleinen, nunmehr ist der Boden des Aufteilungsverbotes insgesamt weggebrochen.

2. Von einem allgemeinen Aufteilungs- und Abzugsgebot konnte angesichts der vielfältigen Ausnahmefallgruppen der Rechtsprechung schon lange keine Rede mehr sein. Treffend konstatierte $H$. W. Kruse darum: „Es gibt nur ein perforiertes Aufteilungsverbot" ${ }^{20}$ Die Kritik zwang die Rechtsprechung zu immer großzügigeren Durchbrechungen des postulierten Grundsatzes. ${ }^{21}$ Dieser richterliche Weg des geringsten Widerstands führte in der Folge zu kaum mehr vorhersehbaren Einzelfallentscheidungen. ${ }^{22}$ Der Große Senat hat diesen leichteren Weg zu Recht nicht weiter beschritten. ${ }^{23}$ Denn: Aus dem Wortlaut des $\S 12$ Nr. 1 Satz 2 EStG ein allgemeines Aufteilungsverbot abzuleiten, war überschießend und konnte die Rechtsprechung selbst nicht durchhalten.

„Die Keule des Aufteilungsverbots“24 führte in den Fällen seiner Anwendung nach dem „Prinzip des Alles oder Nichts" ${ }^{\prime 25} \mathrm{zu}$ „Alles-oder-NichtsErgebnissen". ${ }^{26}$ Derartige Alles-oder-Nichts-Lösungen ohne Übergänge sind zwar einfach, aber durchweg nicht sachangemessen. ${ }^{27}$ Sie finden kaum Akzeptanz und provozieren zudem Ausweichgestaltungen. Der Große Senat hat seine Rechtsprechung unter dem Eindruck jahrzehntelanger Kritik zu Recht in Frage gestellt. Zwar sind Rechtskontinuität und -stabilität der Steuerrechtsprechung wegen ihrer Breitenwirkung im Massenfallrecht ein hohes Gut. Aber auch eine ständige Rechtsprechung kann ein ständiger Irrtum sein. Auch eine eingefahrene Rechtsprechung überzeugt nur und solange, die sie tragenden Gründe überzeugen. ${ }^{28}$ Die Überzeugungskraft der bisherigen Rechtsprechung war indes gering. Zu Recht betont der Große Senat, dass sich die bisherige Rechtsprechung angesichts permanenter Kritik nicht gewohnheitsrechtlich verfestigen konnte. ${ }^{29}$ Die

18 Zuletzt eingehend Drenseck in Schmidt, EStG, 28. Aufl., 2009, § 12 Rz. 11-16.

$19 \mathrm{Zu}$ Recht kritisch zur Dauer des Überzeugungsprozesses Leisner-Egensperger, Die Abgrenzung von privater Lebensführung und berufsbedingten Aufwendungen (§ 12 Nr. 1 EStG), DStZ 2010, 185 (187).

20 Kruse, Zur Feier des Tages, in Festschrift für Offerhaus, 1999, S. 491 (496).

21 Vgl. nur Seiler in Kirchhof, EStG, 8. Aufl. 2008, § 12 Rz. 3 m. w. N.

22 Leisner-Egensperger, DStZ 2010, 185 (186f.).

23 Dies zu Recht betonend Kanzler, Der Kommentar, NWB 3/2010, 169.

24 Plastisch Kruse, Festschrift für Offerhaus, 1999, S. 491 (496).

25 So Jakob, Einkommensteuer, 4. Aufl. 2008, Rz. 220.

26 Drenseck, Gedanken zum Aufteilungs- und Abzugsverbot - §12 Nr. 1 Satz 2 EStG im Wandel, in Festschrift für Offerhaus, 1999, S. 497 (509).

27 Tipke, Die Steuerrechtsordnung, II2, 2003, S. 769.

28 Allgemein Drüen in Tipke/Kruse, AO/FGO, § 4 AO Tz. 310 (Aug. 2006).

29 BFH, GrS 1/06, BStBl. II 2010, 672 unter C. III. 3. g) der Gründe. 
bisherige Deutung des $\S 12$ Nr. 1 Satz 2 EStG als allgemeines Aufteilungsund Abzugsverbot prägte trotz ihrer Breitenwirkung in der Praxis nicht das allgemeine Rechtsbewusstsein. Aus diesen Gründen ist der damit abschließende und inhaltlich überzeugende Beschluss des Großen Senats zu begrüßen. ${ }^{30}$

Ist das allgemeine Aufteilungsverbot verabschiedet, ${ }^{31}$ so galt der erste Blick den unmittelbaren Konsequenzen des Rechtsprechungswechsels ${ }^{32}$ speziell für gemischt veranlasste Reisekosten ${ }^{33}$ sowie Bewirtungskosten $^{34}$ und allgemein für die Abgrenzung von Kosten der privaten Lebensführung. ${ }^{35}$ Die Finanzverwaltung hat ihre bundeseinheitlich abgestimmten Grundsätze zur steuerlichen Beurteilung gemischter Aufwendungen inzwischen erarbeitet. ${ }^{36}$ An dieser Stelle sollen indes weitere Konsequenzen in den Blick genommen werden. ${ }^{37}$

\section{Seitenblick: Spezielle Aufteilungsgebote und -verbote im Steuerrecht}

1. Die grundlegende Frage liegt darin, ob der Große Senat des Bundesfinanzhofs mit seiner Kehrtwende hin zu einem Aufteilungsgebot gemischter Aufwendungen ${ }^{38}$ nicht zugleich einen allgemeinen Grundsatz der Aufteilung im Steuerrecht bestätigt oder etabliert. Denn dann läge im Rechtsprechungswechsel mehr als nur eine Abkehr vom bisherigen

30 Positiv auch Drenseck in Schmidt, EStG, 29. Aufl., 2010, § 12 Rz. 2; LeisnerEgensperger, DStZ 2010, 185 (187, 192, 194) und jüngst Jochum, Steuerliche Behandlung gemischt veranlasster Aufwendungen - Kehrtwende der Rechtsprechung, DStZ 2010, 665 (673).

31 So die übereinstimmende Deutung von Fischer, Der BFH verabschiedet das sog. Aufteilungs- und Abzugsverbot, NWB 2010, 412 und Spindler, Abschied vom allgemeinen Aufteilungs- und Abzugsverbot, DB v. 22.1.2010, Gastkommentar M. 1; ebenso Kanzler, NWB 3/2010, 169: „vollständige Abkehr vom Aufteilungs- und Abzugsverbot".

32 Dazu Pezzer, Das Aufteilungs- und Abzugsverbot ist aufgegeben; Wie geht es weiter?, DStR 2010, 93.

33 Näher Seifert, Aufteilung der Anwendungen für eine gemischt veranlasste Reise, StuB 2010, 227 sowie Neufang, BB 2010, 2409 (2410f.).

34 Eingehend Leisner-Egensperger, Anteilsmäßige Abzugsfähigkeit berufsfördernder Bewirtungskosten (§ 12 Nr. 1 Satz 2 EStG), DStZ 2010, 673.

35 Leisner-Egensperger, DStZ 2010, 185 (187ff.) und jüngst Jochum, DStZ 2010, $665 \mathrm{ff}$.

36 BMF v. 6.7.2010, BStBl. I 2010, 614.

$37 \mathrm{Zu}$ weiteren Konsequenzen außerhalb der „Arbeitnehmeraufwendungen" nunmehr auch beispielhaft Jochum, DStZ 2010, 665 (671 f.).

38 So Drenseck in Schmidt, EStG, 29. Aufl., 2010, § 12 Rz. 2 und Heuermann, StBp. 2010, 86 (87). 
„Lohnsteuer-Sonderrecht", der Bedeutung für das gesamte Steuerrecht zukäme. ${ }^{39}$ Diese Frage lässt sich nur mittels eines Seitenblicks auf Aufteilungsgebote und -verbote im Steuerrecht abseits gemischter Aufwendungen beantworten. Denn der Rechtsanwender steht im Steuerrecht verbreitet vor der Situation, ob mathematisch ohne weiteres teilbare Geldbeträge auch rechtlich aufzuteilen sind oder nicht.

Für einen allgemeinen Grundsatz der Aufteilung lassen sich zahlreiche positive Aufteilungsfälle anführen. ${ }^{40}$ An erster Stelle zu nennen ist die zutreffende Aufteilungspraxis bei verdeckten Gewinnausschüttungen, bei der nur der unangemessene Teil der Leistungsvergütung als sog. quotale vGA $^{41}$ dem Einkommen der Körperschaft hinzugerechnet wird. ${ }^{42}$ Weiteres Exempel ist die gemischte Schenkung, die im Fall einer Grundstücksschenkung für Grunderwerbsteuer und Erbschaftsteuer in einen entgeltlichen und einen unentgeltlichen Teil aufgeteilt wird. ${ }^{43}$ Es gibt auch im Ertragsteuerrecht Anwendungsfelder einer derartigen „Trennungstheorie" ${ }^{44}$ Auch bei gemischt genutzten Gebäuden greift - anders als bei gemischt genutzten beweglichen Wirtschaftsgütern ${ }^{45}$ - der "allgemeine Grundsatz der Gewinnermittlung, den betrieblichen Bereich vom privaten zu trennen" ${ }^{46}$ so dass eine Aufteilung vorzunehmen ist. Dasselbe gilt für den Vorsteuerabzug nach $\S 15$ Abs. 4 UStG, wo das Gesetz sogar explizit zur sachgerechten Schätzung der abziehbaren Teilbeträge ermächtigt (§ 15 Abs. 4 Satz 2 UStG). Im Umsatzsteuerrecht gibt es namentlich bei den Befreiungsvorschriften weitere Beispiele für eine gängige Aufteilungspraxis. ${ }^{47}$ Gesetzliche Schlüsselworte für eine Auftei-

39 In diese Richtung ,im Interesse eines möglichst konsistenten Gesamtsteuersystems" jüngst Jochum, DStZ 2010, 665 (671).

40 So wird in $\S 3 \mathrm{c}$ EStG ein Aufteilungsgebot gesehen (Hüttemann, Gemeinnützigkeits- und Spendenrecht, 2008, § 7 Rn. 50).

41 Statt vieler Gosch, KStG ${ }^{2}, 2009$, $\$ 8 \mathrm{Rz} .803 \mathrm{ff}$. zur partiellen vGA.

42 Ein Sonderfall ist der "formelle" Fremdvergleich für Leistungsbeziehungen zwischen einer Kapitalgesellschaft und ihrem beherrschenden Gesellschafter, der allein indiziellen Charakter hat, aber zur „totalen vGA“ führen kann (vgl. Gosch, KStG ${ }^{2}, 2009$, § 8 Rz. 318 ff., 798; kritisch dazu Schwedhelm in Streck, $\mathrm{KStG}^{7}, 2008$, § $\left.8 \mathrm{Rz} .320 \mathrm{ff}.\right)$.

43 Sack in Boruttau, GrEStG, 16. Aufl. 2007, §3 Rz. 228; Meincke, ErbStG, 15. Aufl. 2009, § 7 Rz. 29 jeweils m. w. N.

44 Vgl. nur BFH, Beschl. v. 4.4.2006 - IV B 12/05, BFH/NV 2006, 1460; Böhme/ Forster, Anwendbarkeit der Trennungstheorie im Rahmen von Übertragungen i.S.d. $\S 6$ Abs. 5 EStG i.d.F. des Unternehmenssteuerfortentwicklungsgesetzes, BB 2003, 1979. Zur Abgrenzung s. Note 64.

45 Dazu kritisch Heinicke in Schmidt, EStG, 29. Aufl., 2010, § 4 Rz. 206 f.

46 So Heinicke in Schmidt, EStG, 29. Aufl., 2010, § 4 Rz. 192, $206 \mathrm{ff}$.

47 So ist z. B. beim Verkauf eines Grundstücks mit Betriebsvorrichtung zwischen der nach $\S 4$ Nr.9a UStG steuerfreien Grundstückslieferung und der steuerpflichtigen Veräußerung der Betriebsvorrichtung zu unterscheiden. Dasselbe 
lung sind „insoweit" oder "soweit". Das Steuerrecht enthält zahlreiche spezielle Aufteilungsgebote und enthält zum Teil auch einen gesetzlichen Aufteilungsmaßstab. Prominentes Beispiel für letzteres sind Bewirtungsaufwendungen aus geschäftlichem Anlass, die nach $\S 4$ Abs. 5 Nr. 2 EStG seit Jahren nur noch in Höhe von 70 \% der angemessenen Aufwendungen abzugsfähig sind. Ein anderes aus dem Bereich der Einkommensteuer ist die verbilligte Vermietung, typischerweise an Familienangehörige, für die $\S 21 \mathrm{Abs}$. 2 EStG sowohl eine Relevanzschwelle als auch eine Aufteilungsvorgabe vorsieht. ${ }^{48}$ Ebenso lässt sich im Körperschaftsteuerrecht die typisierende Sonderbehandlung des Einkommens öffentlich-rechtlicher Rundfunkanstalten aus Werbesendungen nach $\S 8$ Abs. 1 Satz 2 KStG als gesetzliches Aufteilungsgebot mit Angabe der Aufteilungsquote (16\% der umsatzsteuerrechtlichen Entgelte) begreifen. ${ }^{49}$

2. Dieser Seitenblick belegt, dass Aufteilungsgebote im Steuerrecht keineswegs exzeptionell sind. Lässt sich aber daraus auf ein allgemeines Aufteilungsprinzip im Steuerrecht schließen? Gewichtige Stimmen haben sich dafür ausgesprochen. Nach dem Standardlehrbuch von Tipke/Lang ist in Fällen gemischter Veranlassung nach dem Angemessenheitsprinzip aufzuteilen. Dieses Prinzip durchziehe das gesamte Steuerrecht. ${ }^{50}$ Einsatzfelder und Ausdruck dieses allgemeinen Prinzips seien namentlich unangemessene Rechtsgestaltungen $(\S 42 \mathrm{AO})$, verdeckte Gewinnausschüttungen und Verträge zwischen Familienangehörigen. Allerdings ist die Geltung eines allgemeinen Angemessenheitsprinzips im Steuerrecht

Aufteilungsgebot gilt bei der temporären Überlassung, wo zwischen der nach $\S 4$ Nr. 12 Satz 2 UStG steuerfreien Grundstücksüberlassung und der steuerpflichtigen Überlassung von Betriebsvorrichtungen aufzuteilen ist (BFH, Urt. v. 28.5.1998 - V R 19/96, BStBl. II 2010, 307). Letztes Beispiel soll an dieser Stelle die gebotene Aufteilung nach $\S 4$ Nr. 14 a) Satz 2 UStG sein, wobei die Lieferung von Zahnprothesen nicht steuerfrei ist, soweit sie der Unternehmer in seinem Unternehmen hergestellt hat (BFH, Urt. v. 28.11.1996 - V R 23/95, BStBl. II 1999, 251).

48 Liegt die vereinbarte Miete unter 56 \% der ortsüblichen Miete ist die Nutzungsüberlassung in einen entgeltlichen und einen unentgeltlichen Teil aufzuteilen, so dass die Aufwendungen für die verbilligt überlassene Einheit nur teilweise abzugsfähig sind ( $\mathrm{zu}$ verfassungsrechtlichen Bedenken und Einzelheiten der Anwendung näher Drenseck in Schmidt, EStG, 29. Aufl., 2010, § 21 Rz. 61 ff.).

49 Diese "Art der Pauschalbesteuerung" wird mit Problemen der Ermittlung des zutreffenden Gewinns für den Betrieb gewerblicher Art, insbesondere die problematische anteilige Zuordnung der Studiokosten und sonstiger Gemeinkosten begründet (Frotscher in Frotscher/Mass, KStG/UmwStG, § 8 KStG Rn. 63a [Nov. 2005]).

50 Lang in Tipke/Lang, Steuerrecht, 20. Aufl. 2010, §9 Rz. 248. 
durchaus fraglich ${ }^{51}$ und nicht unumstritten. ${ }^{52}$ Allgemein ist methodisch vor den Gefahren der Gewinnung von Prinzipien durch den Induktionsschluss zu warnen. ${ }^{53}$ Speziell im Steuerrecht als Eingriffsrecht ist Vorsicht bei der Annahme (auch) steuerlastschaffender Prinzipien geboten. Überdies erfährt dieses Prinzip, seine Geltung unterstellt, zahlreiche gesetzliche Ausnahmen in Form spezieller Aufteilungsverbote.

Beispiele für gesetzliche Aufteilungsverbote finden sich im Einkommensteuerrecht im Katalog der nicht abziehbaren Betriebsausgaben (insbesondere $\S 4$ Abs. 5 Satz 1 Nr. 3, 4 und 6b EStG). ${ }^{54}$ Sie finden sich aber auch im Erbschaftsteuerrecht, bei dem die Steuerbefreiungen für Zuwendungen zum Zwecke eines angemessenen Unterhalts nach $\S 13$ Abs. 1 Nr. 5 und 12 ErbStG unter dem gesetzlichen Angemessenheitsvorbehalt stehen (§ 13 Abs. 2 Satz 1 ErbStG). Die Folge der Angemessenheitsprüfung ist keine Aufteilung, ${ }^{55}$ vielmehr sind das Maß übersteigende Zuwendungen in vollem Umfang steuerpflichtig (§ 13 Abs. 2 Satz 1 ErbStG). ${ }^{56}$ Weitere Beispiele wären anführbar. Derartige gesetzliche Aufteilungsverbote gelten freilich trotz der Rechtsprechungswende unverändert fort. Ihnen ist nicht mit der Kehrtwende des Großen Senats, sondern nur mit dem Verfassungsrecht beizukommen. ${ }^{57}$ Allerdings hat der Beschluss insoweit mittelbare Wirkungen, indem der Große Senat - im Kontrast zur Abstinenz des Bundesverfassungsgerichts ${ }^{58}$ - das Gewicht des objektiven Nettoprinzips zu stärken sucht. ${ }^{59}$

51 Vgl. Drüen, Typus und Typisierung im Steuerrecht, StuW 1997, 261 (273). Auch Tipke, Übertragung von Einkunftsquellen, StuW 1977, 293 (301) hielt es für sinnvoll, eine allgemeine Norm zu schaffen, die dieses Prinzip allgemein artikuliert.

52 Gegen eine autonome Angemessenheitsprüfung durch Finanzverwaltung und Rechtsprechung namentlich Arndt in Kirchhof/Söhn/Mellinghoff, EStG, § 12 Rz. A $111 \mathrm{f}$. (Okt. 2002).

53 Vgl. Kruse, Über Rechtsgefühl, Rechtsfortbildung und Richterrecht im Steuerrecht, BB 1985, 1077 (1083).

54 Demgegenüber wird in $\S 4$ Abs. 5 Nr. 7 EStG eine Grundvorschrift gesehen, die (deplatziert) das Angemessenheitsprinzip normiert, das unangemessene Aufwendungen vom steuerlichen Abzug ausschließt (Lang, in Tipke/Lang, Steuerrecht, 20. Aufl. 2010, §9 Rz. 287, 248f.).

55 Meincke, ErbStG, 15. Aufl. 2009, § 13 Rz. 69.

56 Eine weitere gesetzliche "Alles-oder-Nichts-Lösung" ist bei der Erbschaftsteuer die $50 \%$-Grenze für Verwaltungsvermögen nach $\S 13$ b Abs. 2 Satz 1 ErbStG (kritisch zu diesem „Alles oder Nichts-Prinzip“ Weinmann in Moench/ Weinmann, ErbStG, S. 13 Rz. 18 [2009]).

57 Wobei auch der Gleichheitssatz dem Gesetzgeber einen beträchtlichen Typisierungsspielraum eröffnet (vgl. nur Osterloh in Sachs, GG, 5. Aufl. 2009, Art. 3 Rz. 104 ff. m. w. N.).

58 Zuletzt den verfassungsrechtlichen Gehalt offenlassend BVerfG, Beschluss v. 6.7.2010 - 2 BvL 13/09, DStR 2010, 1563 m. w. N.

59 BFH, GrS 1/06, BStBl. II 2010, 672 unter C. III. 1. b) der Gründe. 
3. Unter dem Strich belegt unser Seitenblick, dass einer Vielzahl gesetzlicher Aufteilungsgebote einzelne spezielle Aufteilungsverbote gegenüberstehen. Für die Frage der normativen Geltung eines allgemeinen Aufteilungsprinzips ist dabei das numerische Verhältnis ohne Aussagewert. Auch punktuelle Aufteilungsverbote relativieren die Allgemeinheit des Prinzips und führen zum deutungswürdigen Verhältnis von Grundsatz und Ausnahme. Eine exakte und streitunanfällige Aussage, wann im Steuerrecht Aufwendungen aufzuteilen sind und wann nicht, fällt darum abgesehen vom Eingreifen spezieller gesetzlicher Gebote oder Verbote schwer. Dieses Manko sollte man aber nicht einfach mit dem Hinweis auf den Prinzipiencharakter überspielen. Ein überzeugenderes Erklärungsmuster liegt im Rückgriff auf $R$. Alexys Prinzipientheorie mit der Anerkennung eines prima-facie-Vorrangs eines Prinzips, welcher keinen absoluten Vorrang, aber zumindest eine Argumentationslast zugunsten dieses Prinzips begründet. ${ }^{60}$ In diesem Sinne spricht - gerade nach dem Rechtsprechungswechsel des Großen Senats - viel dafür, dem Prinzip der Aufteilung im Steuerrecht einen prima-facie-Vorrang einzuräumen. Dies begründet eine Argumentationslast zugunsten des Prinzips der Aufteilung. Nachdem sich der Große Senat grundsätzlich zur Aufteilung nach Veranlassungsbeiträgen durchgerungen hat und dabei erklärtermaßen das objektive Nettoprinzip bei der Rechtsanwendung als „Auslegungsrichtschnur" heranzieht, ${ }^{61}$ verschieben sich die Gewichte zugunsten einer Aufteilung. Es bedarf daher auch in anderen Fallgruppen als gemischter Aufwendungen einer Begründung, warum eine Aufteilung gesetzlich ausscheidet. Ordnet das Steuergesetz ein "Alles-oder-Nichts" an, scheidet eine Aufteilung selbstredend aus, sofern das Gesetz nicht (ausnahmsweise) seinerseits verfassungswidrig ist. Fehlt dagegen eine explizite Aussage zur Aufteilung, so spricht alles für eine Aufteilung. Vor allem spricht allein das Argument der Praktikabilität nicht (mehr) zwingend gegen eine Aufteilung. ${ }^{62}$ So verstanden lässt sich im Lichte der Prinzipientheorie die Ausgangsfrage bejahen: Nach der Kehrtwende des Großen Senats des Bundesfinanzhofs lässt sich das Prinzip der Aufteilung im Steuerrecht allgemein als Prinzip mit prima-facie-Vorrang verstehen, dessen Eingreifen nur mittels entsprechender Gegenargumentation ausgeräumt werden kann.

60 Vgl. Alexy, Theorie der Grundrechte, 1. Aufl. 1986, S. 87 ff., 142 f., 516 ff.

61 BFH, GrS 1/06, BStBl. II 2010, 672 unter C. III. 1. b) der Gründe.

62 Deutlich relativierend BFH, GrS 1/06, BStBl. II 2010, 672 unter C. III. 3. f) der Gründe. 


\section{Ausblick: Denkbare Konsequenzen für Steuerrecht und -vollzug}

1. Im Anschluss an die eher grundsätzlichen Überlegungen, sollen im Folgenden einige "Weiterungen" oder Sekundärfolgen materieller und verfahrensrechtlicher Natur aufgrund des Rechtsprechungswechsels exemplarisch angesprochen werden. An erster Stelle stehen materielle Konsequenzen. Der Beschluss des Großen Senats ist ein Anstoß für eine Aufteilung, wo immer diese nicht gesetzlich ausgeschlossen und sachgerecht durchführbar ist. Aus der Herleitung eines Prinzips der Aufteilung im Steuerrecht (s. II.) folgt, dass nach dem Rechtsprechungswechsel auslegungsbedingte Alles-oder-Nichts-Lösungen, die nicht gesetzlich zwingend sind, auf den Prüfstand gehören. So bedarf die herrschende Ansicht, die sich bei gemischt genutzten beweglichen Wirtschaftsgütern (anders als bei derartigen Gebäuden) auf einen Grundsatz der Unteilbarkeit beruft, einer Revision, zumal eine reale Aufteilung bilanztechnisch möglich, ${ }^{63}$ allerdings bei variierenden Nutzungsanteilen aufwändig ist. Weiterer Kandidat ist die nach Betriebs- und Privatvermögen differenzierende steuerrechtliche Behandlung teilentgeltlicher Veräußerungsgeschäfte. ${ }^{64}$ Fragwürdig erscheint auch die trotz des Wortlauts "insoweit" in $\S 371$ Abs. $1 \mathrm{AO}$ zu einem "Alles-oder-Nichts-Prinzip" führende Rechtsprechung des BGH zur Teilselbstanzeige. ${ }^{65}$ Ein weiteres Beispiel entstammt dem Gemeinnützigkeitsrecht: Der Spendenabzug setzt eine unentgeltliche Leistung des Zuwendenden voraus. ${ }^{66}$ Verbreitet wird ein Aufteilungsgebot für teilentgeltliche Leistungen gerade in Ermangelung eines geeigneten Aufteilungsmaßstabs angenommen. ${ }^{67}$ Das erscheint in dieser Generalität nunmehr fragwürdig. Wenn die Verwaltung früher die Aufteilung von Eintrittskarten für Wohltätigkeitsveranstaltungen zuließ, davon

63 Zutreffend bereits Heinicke in Schmidt, EStG, 29. Aufl., 2010, § 4 Rz. 207 m. w. N.

64 Erfolgt die Veräußerung des ganzen Gewerbebetriebes oder Teilbetriebes teilentgeltlich, entsteht ein nach $\S \S 16,34$ EStG steuerbegünstigter Gewinn, wenn das Entgelt das Kapitalkonto übersteigt. Ist das Entgelt niedriger, werden die Buchwerte fortgeführt (§ 6 Abs. 3 EStG). Der Vorgang ist also einheitlich zu beurteilen (sog. Einheitstheorie, Wacker in Schmidt, EStG, 29. Aufl., 2010, § 16 Rz. 39, 58 f.), während bei der teilentgeltlichen Übertragung von Privatvermögen (z. B. Kapitalgesellschaftsanteile i. S. d. § 17 EStG) der Vorgang nach der sog. Trennungstheorie in einen entgeltlichen und unentgeltlichen Teil getrennt wird (Weber-Grellet in Schmidt, EStG, 29. Aufl., 2010, § 17 Rz. 105).

65 Kritisch dazu Heuel, Selbstanzeigeberatung nach dem BGH-Beschluss vom 20.5.2010 - ein Himmelfahrtskommando?, AO-StB 2010, $246 \mathrm{f}$.

66 Näher Hüttemann, Gemeinnützigkeits- und Spendenrecht, 2008, § 8 Rz. 44 ff. m. w. N.

67 So Hüttemann, Gemeinnützigkeits- und Spendenrecht, 2008, §8 Rz.51 m. w. N. 
aber später mit Blick auf die frühere Rechtsprechung abrückte, ${ }^{68}$ so ist statt des Hinweises auf die Möglichkeit der alternativen Trennung in Unkostenbeiträge und Spenden über eine Rückkehr zur alten Aufteilungspraxis nachzudenken. Dasselbe gilt für andere Zuwendungen mit abgrenzbarem Entgeltanteil.

Neben derartigen Grenzverschiebungen hin zur Aufteilung im steuerrechtlichen "Mikrobereich", sind dagegen im "Makrobereich" der von der Rechtsprechung negierten privaten Sphäre von Kapitalgesellschaften keine Änderungen zu erwarten. Bekanntlich geht der Bundesfinanzhof in „mittlerweile ständiger Rechtsprechung" trotz berechtigter Kritik ${ }^{69}$ davon aus, dass Kapitalgesellschaften steuerlich gesehen über keine außerbetriebliche Sphäre verfügen. ${ }^{70}$ Danach erfolgt eine Korrektur von Aufwendungen, die eine Kapitalgesellschaft zugunsten eines Gesellschafters und seiner privaten Lebensgestaltung trägt, nicht nach Liebhabereigrundsätzen, ${ }^{71}$ sondern über das Institut der verdeckten Gewinnausschüttung. ${ }^{72}$ Für eine höchstrichterliche Neugewichtung dieses Streits gibt der Beschluss des Großen Senats zum Aufteilungsgebot gemischter Aufwendungen nichts her. Denn dessen Kernargumentation basiert auf der einkommensteuerrechtlichen Trennung zwischen Erwerbssphäre und der Sphäre der Lebensführung. ${ }^{73}$ Dass der Große Senat diese beiden Sphären eines Einkommensteuersubjekts voraussetzt, ist kein Präjudiz gegen die

68 OFD Nürnberg, Verf. v. 23.11.1990, Steuerliche Behandlung der Eintrittsgelder zu Wohltätigkeitsveranstaltungen, DStR 1991, 119; ebenso Heinicke in Schmidt, EStG, 29. Aufl., 2010, § 10b Rz. 16.

69 Eingehend Hüttemann, Liebhaberei bei Kapitalgesellschaften, Festschrift Raupach, 2006, S. 495 sowie unlängst Birk, Liebhaberei im Ertragssteuerrecht, BB 2009, 860 (865 ff.) m. w. N.

70 So BFH, Urt. v. 8.8.2001 - I R 106/99, DStR 2001, 2023 unter Hinweis auf BFH, Urt. v. 4.12.1996 - I R 54/95, DStR 1997, 492; BFH, Urt. v. 8.7.1998 - I R 123/97, DStR 1998, 1749; bestätigend trotz der Kritik BFH, Urteil v. 22.8.2007 - I R 32/06, BStBl. II 2007, 961; die neue Linie der Rechtsprechung vorbereitend Wassermeyer, Liebhaberei bei Kapitalgesellschaften, Freundesgabe Haas, 1996, S. 401.

71 Dafür Hüttemann, Festschrift Raupach, 2006, S. 495 (502 ff.); eingehend Nippert, Die außerbetriebliche Sphäre der Kapitalgesellschaft im Körperschaftsteuerrecht, 2006, S. 281 ff. und nunmehr Birk, BB 2009, 860 (865 f.) m. w. N.

72 BFH, Urt. v. 15.5.2002 - I R 92/00, DStR 2002, 1660; zur Abgrenzung BFH, Urt. v. 5.3.2008 - I R 45/07, BFH/NV 2008, 1534.

73 Wörtlich BFH, GrS 1/06, BStBl. II 2010, 672 unter C. III. 1. a) der Gründe: „Prägend für das Einkommensteuergesetz ist die Unterscheidung zwischen der durch die einzelnen Einkunftsarten definierten Erwerbssphäre und der Sphäre der Einkommensverwendung. Demgemäß bedarf es der Trennung zwischen denen den jeweiligen Einkünften zuzuordnenden Erwerbsaufwendungen (Betriebsausgaben, Werbungskosten) einerseits und den - grundsätzlich nicht absehbaren - Kosten der Lebensführung andererseits." 
Rechtsprechung zur Nichtexistenz einer Privatsphäre von Kapitalgesellschaften. Denn auf dem Boden der bisherigen Judikatur stellt sich im Körperschaftsteuerrecht das vom Großen Senat behandelte Problem gar nicht. Nach der Rechtsprechung des I. Senats ist die gesamte Tätigkeit einer Kapitalgesellschaft betrieblich veranlasst und alle ihre Ausgaben sind dem Grunde nach immer Betriebsausgaben. ${ }^{74}$ Selbst wenn nach dem Rechtssprechungswechsel grundsätzlich von der Aufteilbarkeit von Erwerbsaufwendungen und Kosten der Lebensführung auszugehen ist, so hat dies keine Konsequenz für Aufwendungen der Kapitalgesellschaft zugunsten der privaten Lebensgestaltung eines Gesellschafters. Denn der Körperschaftsteuersenat behandelt diese Aufwendungen als verdeckte Gewinnausschüttung und zugleich als Betriebsausgabe. Darin liegt der entscheidende Unterschied zum Antagonismus der wohl herrschenden Ansicht, wonach sich betriebliche Veranlassung (Betriebsausgaben) und gesellschaftliche Veranlassung (verdeckte Gewinnausschüttung) gegenseitig ausschließen. ${ }^{75} \mathrm{Da}$ aber in der Deutung der verdeckten Gewinnausschüttung als Betriebsausgabe ein "Eckpfeiler" der neueren Rechtsprechung des I. Senats liegt, ${ }^{76}$ ist nicht $z u$ erwarten, dass dieser seine Position nach dem maßgeblich auf die Gewichtung betrieblich/beruflicher und privater Veranlassungsbeiträge abhebenden Beschluss des Großen Senats revidieren wird.

2. Der Rechtsprechungswechsel kann über materielle Verschiebungen hin zu mehr Aufteilung auch Folgen für den praktischen Steuervollzug und die finanzgerichtliche Kontrolle haben. Die höchstrichterliche Erwartung, dass nach dem Wechsel zum Aufteilungsgebot viele Fälle auf die Finanzämter und Gerichte zukommen, um die Grenzen der Abziehbarkeit neu zu justieren, ${ }^{77}$ mag für die erste Zeit nach dem Beschluss des Großen Senats zutreffend sein. Mit Massen von Fällen, zumal vor den Schranken des Bundesfinanzhofs ist aber wegen der herrschenden Vollzugsbedingungen kaum zu rechnen. Die gegenwärtige Form des Steuervollzugs ist trotz des finanzbehördlichen Sicherstellungsauftrags des $\S 85 \mathrm{AO}$ auch im Ertragsteuerrecht durch einen faktischen Selbstvollzug mit risikoorientierten Kontrollen der Finanzbehörde gekennzeichnet. ${ }^{78}$

74 So Frotscher, Verdeckte Gewinnausschüttung, DStJG 20 (1997), 205 (208).

75 Vgl. nur Rengers in Blümich, EStG/KStG/GewStG, § 8 KStG Rn. 63 (Okt. 2005) m. w. N.; näher Reiß, Verdeckte Gewinnausschüttung und Steuerbilanzgewinn, StuW 2003, 21 (28, 30); Weber-Grellet, Entwicklungen im Bereich der verdeckten Gewinnausschüttung, DStZ 1998, 357 (360 f.).

76 So Wassermeyer, Verdeckte Gewinnausschüttung - Bundesfinanzhof versus Finanzverwaltung GmbHR 2002, 1 und ihm folgend Oppenländer, Verdeckte Gewinnausschüttung, 2004, S. $59 \mathrm{ff} ., 86 \mathrm{f}$.

77 So Heuermann, StBp. 2010, 86 (89).

78 Näher Seer, Reform der Steuerveranlagung, StbJb. 2004/2005, 53 (56). 
In diesem System führen Aufteilungsgebote dazu, dass die Steuerpflichtigen und ihre Berater - durchaus interessengeleitet - ihre Subsumtionsund zugleich Aufteilungsvorschläge mit der Steuererklärung der Finanzbehörde unterbreiten. Unter Anwendung finanzbehördlichen Risikomanagements ${ }^{79}$ mit Risikofilter und Zufallsauswahl kann die Aufteilung der Aufwendungen nicht flächendeckend, sondern allenfalls in Einzelfällen bei ungewöhnlichen oder unvertretbaren Aufteilungsergebnissen kontrolliert und zurückgewiesen werden. Die Weichenstellung für eine gerichtliche Kontrolle der Aufteilungspraxis hängt maßgeblich von der Intensität der Deklarationskontrolle durch die Finanzbehörde ab. Sofern es nach der Phase des Übergangs zum Aufteilungsgebot überhaupt noch zu finanzgerichtlichen Aufteilungsentscheidungen kommt, werden diese gerichtsnotorischen Fälle vermutlich nur einen kleinen Ausschnitt aus der realen Aufteilungspraxis beim Steuervollzug abbilden.

Höchstrichterliche Entscheidungen zur Umsetzung des Aufteilungsgebotes dürften in Zukunft Seltenheitswert haben. Denn die Würdigung multikausaler oder multifinaler Wirkungszusammenhänge und die Konsequenz einer Aufteilung im Wege der Schätzung durch Finanzbehörde und Finanzgericht sind als tatsächliche Feststellungen nur sehr begrenzt revisibel (§ 118 Abs. 2 FGO). Die einschlägigen Fälle werden regelmäßig schon durch die Feststellung des Sachverhalts im Finanzgerichtsverfahren entschieden und nur ausnahmsweise den Bundesfinanzhof als Revisionsinstanz erreichen. ${ }^{80}$ Selbst wenn sie dort ankommen, so beschränkt sich der Bundesfinanzhof statt einer punktgenauen Überprüfung des Schätzungsergebnisses durchweg auf eine Vertretbarkeitskontrolle der Schätzung. ${ }^{81}$ Der Streit ist im Regelfall vor dem Finanzgericht zu Ende. ${ }^{82}$

3. Der Schluss meines Ausblicks ist auf legislatorische Konsequenzen gerichtet. Nach dem Beschluss des Großen Senats stand eine mögliche Gesetzesänderung des $\S 12$ EStG zur Diskussion. ${ }^{83}$ Die Einkommensteuerreferenten des Bundes und der Länder haben im April 2010 über Reaktionen beraten. Bisher sichtbares Ergebnis ist das BMF-Anwendungsschreiben zur steuerlichen Beurteilung gemischter Aufwendungen. ${ }^{84}$ Dabei sollte es auch bleiben. Eine gesetzgeberische Intervention war zuvor mehrfach gefordert worden, aber nur für den Fall, dass der Bundesfinanzhof seine Rechtsprechung zum Aufteilungs- und Abzugsverbot

79 Dazu zuletzt Haunhorst, Risikomanagement in der Finanzverwaltung - ein Fall für die Finanzgerichte?, DStR 2010, 2105.

80 Zutreffend bereits Fischer, NWB 2010, 412 (420).

81 Seer in Tipke/Kruse, AO/FGO, § 118 FGO Tz. 74 (Okt. 2008).

82 Ebenso schon Pezzer, DStR 2010, 93 (96).

83 Vgl. z. B. Seiler in Kirchhof, EStG, 9. Aufl. 2010, § 12 Rz. 1.

84 BMF, Schr. v. 6.7.2010, BStBl. I 2010, 614. 
nach $\S 12$ Nr. 1 Satz 2 EStG nicht korrigiert. $^{85}$ Nachdem der Bundesfinanzhof unter dem Eindruck der allgemeinen Kritik die Wende vollzogen hat, ist der Gesetzgeber gut beraten die praktischen Folgen abzuwarten. Allenfalls bei gravierenden Fehlentwicklungen, die indes nicht zu erwarten sind, sollte er das Heft des Handels ergreifen. Diese Befugnis steht ihm selbstredend zu. Für eine Beschneidung des höchstrichterlichen Aufteilungsgebots bedarf der Gesetzgeber wegen des objektiven Nettoprinzips ${ }^{86}$ freilich belastbarer Gründe. ${ }^{87}$ Fiskalische Gründe allein rechtfertigen keine Korrektur der Rechtsprechungswende des Großen Senats.

85 So namentlich Wissenschaftlicher Beirat des Fachbereichs Steuern bei der Ernst \& Young AG, BB 2004, 1024 (1030) unter Hinweis auf einen Vorschlag der Bundessteuerberaterkammer.

86 Vgl. bereits Kanzler, NWB 2010, 169: „weiterer Angriff auf das objektive Nettoprinzip".

$87 \mathrm{Zu}$ tauglichen und untauglichen Rechtfertigungsgründen näher Drüen, Das Unternehmenssteuerrecht unter verfassungsgerichtlicher Kontrolle, Ubg. 2009, 23 (26f.). 



\section{Leitthema:}

\section{Mittelstand}





\title{
Aktuelle Steuerrechts- und Gestaltungsfragen zu Gesellschafterdarlehen bei Personen- und Kapitalgesellschaften
}

\author{
Dr. Martin Strahl \\ Steuerberater, Köln
}

Inhaltsübersicht

\section{Personengesellschaft}

1. Rechtsfolgen der Unverzinslichkeit

2. Fremdfinanzierung der Rückführung von Gesellschafterdarlehen

3. Einbringung gegen Gesellschafterforderung

a) Betriebliche Einheiten

b) Einzelne Wirtschaftsgüter

a) Einbringung einzelner Wirtschaftsgüter aus dem Betriebsvermögen

bb) Einbringung einzelner Wirtschaftsgüter aus dem Privatvermögen

\section{Kapitalgesellschaft}

1. Rechtsfolgen der Unverzinslichkeit
2. Ausfall von Gesellschafterdarlehen

a) Darlehensforderungen im Privatvermögen

aa) Berücksichtigung der Aufwendungen weiterhin nach $\S 17$ EStG?

bb) Berücksichtigung bei den Einkünften aus Kapitalvermögen?

(1) Berücksichtigung bei $\S 20$ Abs. 2 Satz 1 Nr. 7 EStG

(2) Berücksichtigung als Werbungskosten bei $\S 20$ Abs. 1 Nr. 7 EStG?

b) Wertminderungen von Gesellschafterdarlehen im steuerlichen Betriebsvermögen

3. Überlegungen zur Abgeltungsteuer

\section{Personengesellschaft}

\section{Rechtsfolgen der Unverzinslichkeit}

Reicht der Gesellschafter einer Personengesellschaft derselben ein unverzinsliches Darlehen aus, ist auf Seiten der Personengesellschaft das Abzinsungsgebot des $\S 6$ Abs. 1 Nr. 3 EStG nicht einschlägig. Ursächlich dafür ist nach Auffassung des $\mathrm{BFH},{ }^{1}$ dass das ausgereichte Gesellschafterdarlehen nicht nur in der Bilanz der Personengesellschaft als Fremdkapital zu passivieren, sondern korrespondierend hierzu in der Sonderbilanz des Gesellschafters zu aktivieren ist, sodass sich das durch den Gesellschafter ausgereichte unverzinsliche Darlehen in der steuerlichen Gesamtbilanz der Mitunternehmerschaft nivelliert.

1 Vgl. BFH, Urt. v. 24.1.2008 - IV R 37/06, DStR 2008, 761, Tz. II.3 der Urteilsgründe; v. 24.1.2008 - IV R 66/05, BFH/NV 2008, 1301. 
Hier wird mithin durch den BFH das Sonderbetriebsvermögen mit in die Betrachtung einbezogen. Dies ist bekanntlich - etwa im Hinblick auf die Ermittlung des maßgeblichen Kapitalkontos i. S. des § 15a EStG - nicht durchgängig der Fall. Daraus ergibt sich eine gewisse Unsystematik im Rahmen der Besteuerung der Mitunternehmerschaften, welche - zugunsten des Stpfl. - auch durch die im nächsten Abschnitt angesprochene Entscheidung zur Fremdfinanzierung der Rückführung von Gesellschafterdarlehen deutlich wird, die unter Ausblendung des Sonderbetriebsvermögens getroffen wurde.

\section{Fremdfinanzierung der Rückführung von Gesellschafterdarlehen}

Wird die Rückzahlung eines Gesellschafterguthabens durch die Personengesellschaft refinanziert, ist zu unterscheiden, ob die zurückgewährten Beträge Gesellschafter-Eigenkapital oder Gesellschafter-Fremdkapital sind. Bei einer Rückzahlung von Gesellschafter-Fremdkapital sind die Refinanzierungsentgelte vorbehaltlich der Anwendung des $\S 4$ Abs. 4a EStG Betriebsausgaben der Personengesellschaft. Dies ergibt sich aus der folgenden Entscheidung des BFH: ${ }^{2}$

An der Klägerin (einer $\mathrm{GmbH} \& \mathrm{Co}$. KG) war als alleinige Kommanditistin die I GmbH \& Co. KG beteiligt, die ca. 24 Mio. DM Guthaben auf ihrem sog. Kapitalkonto III bei der Klägerin hatte. Gemäß Gesellschaftsvertrag der Klägerin handelte es sich bei diesem Konto im Rahmen einer „Drei-Konten-Regelung“ um das jederzeit fällige Privatkonto, auf dem der entnahmefähige Gewinnanteil gutgeschrieben wurde. Nicht entnehmbare Gewinnanteile waren auf dem „Kapitalkonto II" zu erfassen, das als Rücklagekonto ausgestaltet war, auf dem auch ein etwaiger Verlust gebucht werden sollte. Neben diesen klaren Regelungen für die Kontenführung besagten die Vertragsbestimmungen über die Auseinandersetzung, das Auseinandersetzungsguthaben eines ausscheidenden Gesellschafters bestimme sich "nach dem Buchstand aller Konten des Ausgeschiedenen (Konto I - III ...)". Die I GmbH \& Co. KG ließ sich 1991 15 Mio. DM zu Lasten des Kapitalkontos III für gesellschaftsfremde Zwecke auszahlen. Den Finanzbedarf dafür deckte die Klägerin durch Ausstellung von Solawechseln, die von einer Bank durch Auszahlung an die I GmbH \& Co. KG diskontiert wurden. In der Bilanz zum 31.12.1991 wies die Klägerin unter Verminderung des Guthabens der I GmbH \& Co. KG auf dem Kapitalkonto III eine Wechselverbindlichkeit von 15 Mio. DM aus. Im Februar 1992 beglich die I GmbH \& Co. KG die Wechselverbindlichkeit durch Zahlung an die Bank, was die Klägerin veranlasste, das zwischenzeitlich verminderte Kapitalkonto III der I GmbH \& Co. KG wieder um die 15 Mio. DM zu erhöhen. Für die Wechselfinan-

2 Vgl. BFH, Urt. v. 26.6.2007 - IV R 29/06, BStB1. 2008 II, 103. 
zierung entstanden bei der Klägerin im Jahr 1991 Diskontzinsen in Höhe von 1.225.916 DM und im Jahr 1992 in Höhe von 228.119 DM. Um deren Betriebsausgabenabzug bei der Klägerin ging es im Streitfall.

Das FA meinte, die Wechselverbindlichkeit sei eine Privatschuld und die Zinsen deshalb Entnahmen. Das FG teilte diese Rechtsauffassung, im Wege der Auslegung des Gesellschaftsvertrags der Klägerin davon ausgehend, bei dem Guthaben auf dem Kapitalkonto III handele es sich um Eigenkapital (ein etwaiges positives Kapitalkonto III sei nach dem Ergebnis dieser Vertragsauslegung zur Deckung eines etwaigen negativen Saldos der Kapitalkonten I und II heranzuziehen).

Der BFH sah in der Wechselverbindlichkeit demgegenüber eine betriebliche Verbindlichkeit in der Handelsbilanz und nach dem Maßgeblichkeitsgrundsatz auch in der Steuerbilanz sowie in den Refinanzierungskosten Betriebsausgaben. Zwar werde das Maßgeblichkeitsprinzip für Wirtschaftsgüter verdrängt, die nicht der Gewinnerzielung dienen (etwa Verbindlichkeiten zur Finanzierung nicht betrieblich veranlasster Zahlungen). Deshalb seien Verbindlichkeiten zur Finanzierung von Entnahmen durch Gesellschafter keine Betriebsschulden. Keine Entnahme entstehe jedoch, wenn ein Gesellschafter Beiträge von seinem Guthaben auf seinem Gesellschafterkonto abzieht, das gesellschaftsrechtlich Fremdkapital ist. Ein solches Gesellschafterkonto sei das „Kapitalkonto III“ im Streitfall, was das FG verkannt habe.

Sachverhalt und Beurteilung stellen sich mithin wie folgt graphisch dar:

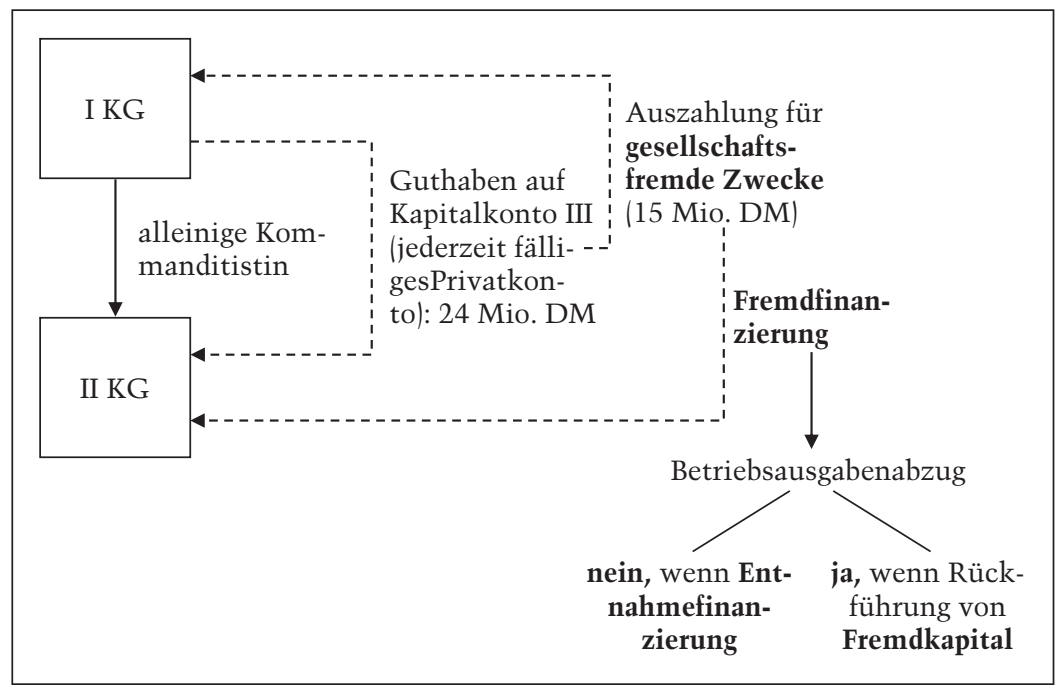


Der BFH nimmt die Abgrenzung von Gesellschaftereigenkapital- und Gesellschafterfremdkapitalkonten wie nachstehend dargetan vor: ${ }^{3}$

- Die Abgrenzung von Konten richtet sich nicht nach ihrer Bezeichnung. Führt eine Personengesellschaft für die Gesellschafter mehrere Konten mit verschiedenen Bezeichnungen, ist vielmehr anhand es Gesellschaftsvertrages zu ermitteln, welche zivilrechtliche Rechtsnatur diese Konten haben, d. h. ob sie Eigenkapital oder Forderungen und Schulden ausweisen. ${ }^{4}$

- Kennzeichnend für ein Gesellschafter-Eigenkapitalkonto ist, dass nach dem eindeutigen und klaren Willen der Gesellschafter auf dem Konto auch Verluste erfasst werden, welche die ausgewiesenen thesaurierten Gewinne aufzehren können; denn mit dem Begriff eines Fremdkapitalkontos ist eine Verlustbeteiligung des Gläubigers vereinbar.

- Maßgeblich ist die Regelung der Verlustverrechnung im Gesellschaftsvertrag. Ein Gesellschafterbeschluss, nach dem etwaige Jahresfehlbeträge aus Gesellschafterdarlehenskonten abgedeckt werden sollen, führt nicht dazu, dass es sich bei den entsprechenden Gesellschafterkonten um Gesellschafter-Eigenkapitalkonten handelt. ${ }^{5}$ Die Verlustverrechnung muss entsprechend im Gesellschaftsvertrag vorgesehen sein, damit ein entsprechendes Konto als Eigenkapitalkonto des Gesellschafters einzuordnen ist.

- Ausreichend für die Einordnung eines Kontos als Eigenkapitalkonto ist, wenn zwar eine laufende Verlustverrechnung nicht vorgesehen, für den Fall des Ausscheidens aber geregelt ist, dass sich das Abfindungsguthaben nach dem Saldo sämtlicher Gesellschafterkonten, nämlich „Kapitalkonto und Darlehenskonto abzüglich eines eventuell anteiligen Verlustvortrages" bestimmt. $^{6}$

- Bedeutung für die Einordnung als Gesellschafter-Eigenkapitalkonto oder Gesellschafter-Fremdkapitalkonto hat des Weiteren die Regelung der Entnahmefähigkeit von Guthaben, die auf den Konten ausgewiesen sind. Insoweit spricht eine Entnahmebeschränkung für das Vorliegen eines Eigenkapitalkontos. Nicht schädlich ist indes eine Entnahmemöglichkeit von Gewinnanteilen für die Einstufung eines Kontos als

3 Vgl. dazu insbesondere BFH, Urt. v. 15.5.2008 - IV R 46/05, BStBl. 2008 II, 812; vgl. auch Wendt, Stbg 2010, 145, $147 \mathrm{f}$.

4 So ausdrücklich BFH, Urt. v. 15.5.2008 - IV R 46/05, BStBl. 2008 II, 812 (unter Abschn. II.2 der Urteilsgründe).

5 Vgl. BFH, Urt. v. 15.5.2008 - IV R 46/05, BStBl. 2008 II, 812 (unter Abschn. II.3 der Urteilsgründe).

6 Vgl. BFH, Urt. v. 15.5.2008 - IV R 46/05, BStBl. 2008 II, 812 (unter Tz. 4 der Urteilsgründe). 
Eigenkapitalkonto. ${ }^{7}$ Demgegenüber ist nicht geklärt, ob eine unbeschränkte Entnahmeberechtigung der Einordnung des Kontos als Gesellschafter-Eigenkapitalkonto entgegensteht. ${ }^{8}$

Die Entscheidung des BFH zur Refinanzierung der Auszahlung von einem Gesellschafterdarlehenskonto ist verallgemeinerungsfähig; dass es sich im Streitfall um eine doppelstöckige Mitunternehmerschaft handelt und die abgezogenen Mittel alsbald zurückgeführt worden sind, war nicht entscheidungserheblich. Das folgt auch aus den Erwägungen in der Urteilsbegründung, die u.a. auf eine Entscheidung des VIII. Senats ${ }^{9}$ verweist, aus dessen Begründung sich der Betriebsausgabencharakter von Schuldzinsen zur Finanzierung der Auszahlung von Gesellschafterforderungen ergibt. Nicht anders kann die unmittelbare Auszahlung des entnahmefähigen Gewinnanteils beurteilt werden, wenn er unmittelbar nach Feststellung des Jahresabschlusses erfolgt.

Der BFH hat es nicht problematisiert, weshalb es offenkundig ohne Bedeutung ist, dass Gesellschafterforderungen steuerliches Sonderbetriebsvermögen sind, welches durch den Mittelabzug entnommen wird. Es darf mithin davon ausgegangen werden, dass die Auszahlung von Guthaben aus einem Gesellschafterkonto mit gesellschaftsrechtlichem Fremdkapitalcharakter (und die Auszahlung entnahmefähiger Gewinnanteile) fremdfinanziert werden kann, ohne dass der Betriebsausgabencharakter der Schuldzinsen bei der Gesellschaft in Frage steht. Das ist zu beachten, wenn Geldmittel für Bereiche generiert werden sollen, in denen der Schuldzinsenabzug nicht möglich ist, oder Umfinanzierungen erfolgen sollen, etwa zur Vermeidung teilentgeltlicher Übertragungen von Wirtschaftsgütern. $\S 4$ Abs. 4a EStG muss jedoch in diesen Umfinanzierungsfällen beachtet werden.

\section{Einbringung gegen Gesellschafterforderung}

a) Betriebliche Einheiten

Gestaltungsziel im Rahmen der Einbringung sowohl betrieblicher Einheiten wie auch einzelner Wirtschaftsgüter ist die steuerliche Neutralität des Einbringungsvorgangs auf Seiten des Einbringenden. Diesen

7 Vgl. BFH, Urt. v. 15.5.2008 - IV R 46/05, BStBl. 2008 II, 812 (unter Abschn. II.4 der Urteilsgründe [„,Gewinnanteile gehören nach der gesetzlichen Vorgabe des $\S 120$ Abs. 2 HGB zum Kapitalanteil des Gesellschafters. Aus den $\S \S 122$ und 167 Abs. 2 HGB lässt sich zudem entnehmen, dass es zum Wesen der Gewinnanteile gehört, zumindest teilweise entnommen zu werden."]).

8 Dies ausdrücklich offen lassend BFH, Urt. v. 15.5.2008 - IV R 46/05, BStBl. 2008 II, 812 (unter Abschn. II.4 der Urteilsgründe).

9 Vgl. BFH, Urt. v. 5.3.1991 - VIII R 93/84, BStBl. 1991 II, 516. 
Weg eröffnet für die Einbringung von Betrieben, Teilbetrieben oder Mitunternehmeranteilen $\S 24$ UmwStG. ${ }^{10}$ Zwar hat die aufnehmende Personengesellschaft das eingebrachte Betriebsvermögen gem. §24 Abs. 2 Satz 1 UmwStG als Regelwertansatz mit dem gemeinen Wert anzusetzen. Es kann jedoch gem. § 24 Abs. 2 Satz 2 UmwStG auf Antrag mit dem Buchwert oder einem Zwischenwert angesetzt werden, soweit das Recht der Bundesrepublik Deutschland hinsichtlich der Besteuerung des eingebrachten Betriebsvermögens nicht ausgeschlossen oder beschränkt wird.

Nach dem Gesetzeswortlaut (§24 Abs. 1 UmwStG) ist § 24 UmwStG nur anwendbar, wenn „der Einbringende Mitunternehmer der Gesellschaft" wird. Die Finanzverwaltung schließt daraus, §24 UmwStG sei nur anwendbar, "soweit" der Einbringende als Gegenleistung für die Einbringung Gesellschaftsrechte erwirbt; die Erfassung des Gegenwerts des eingebrachten Betriebsvermögens auf einem Darlehenskonto reiche nicht aus. ${ }^{11}$ Die Gleichstellung der im Gesetz geforderten Einräumung der Mitunternehmerstellung mit der Gewährung von Gesellschaftsrechten entspricht der h.A. und ist gerechtfertigt, wenn der Einbringende Mitunternehmer wird (oder bereit ist) und der Begriff der Gesellschaftsrechte in diesem Sinne weit dahingehend ausgelegt wird, dass bereits die Einräumung einzelner (Teil-)Gesellschaftsrechte ausreicht. Unstreitig ist, dass - abweichend vom Gesetzeswortlaut - §24 UmwStG auch anwendbar ist, wenn der Einbringende bereits zuvor Mitunternehmer ist, ihm aber zusätzliche Gesellschaftsrechte (Aufstockung seiner Mitunternehmerrechte) gewährt werden. ${ }^{12}$ Unklar ist, ob das Bewertungs-

10 Auch eine zum steuerlichen Betriebsvermögen gehörende Beteiligung zu 100 \% an einer Kapitalgesellschaft gilt als Teilbetrieb, vgl. BMF, Schr. v. 25.3.1998 IV B 7 - S 1978 -21/98/IV B 2 - S 1909 -33/98 (UmwStErlass), BStBl. 1998 I, 268, Tz. 24. Das entgegenstehende BFH-Urt. v. 17.7.2008 - I R 77/06, BStBl. 2009 II, 464, hat die FinVerw. mit einem Nichtanwendungserlass belegt, vgl. BMF, Schr. v. 20.5.2009 - IV C 6 - S 2134/07/10005 (DOK 2009/0300414), BStBl. 2009 I, 671. Mit Bezug auf dieses BMF-Schr. heißt es unter Tz. 24.03 des Formulierungsvorschlags für den neuen UmwStErlass: „Teilbetrieb i. S. von § 24 Abs. 1 UmwStG ist auch eine zu einem Betriebsvermögen gehörende $100 \%$-Beteiligung an einer Kapitalgesellschaft."

11 Vgl. BMF, Schr. v. 25.3.1998 - IV B 7 - S 1978 -21/98/IV B 2 - S 1909 -33/98 (UmwStErlass), BStBl. 1998 I, 268, Tz. 24.08; gleich lautend Tz. 24.08 des Formulierungsvorschlags für den neuen UmwStErlass.

12 Vgl. BMF, Schr. v. 25.3.1998 - IV B 7 - S 1978 -21/98/IV B 2 - S 1909 -33/98 (UmwStErlass), BStBl. 1998 I, 268, Tz. 24.02. Auch diese Sichtweise wird in Tz. 24.08 des Formulierungsvorschlags für den neuen UmwStErlass beibehalten $($ „,\$24 UmwStG ist nur anwendbar, soweit der Einbringende als Gegenleistung für die Einbringung Gesellschaftsrechte erwirbt, d. h. soweit er durch die Einbringung die Rechtsstellung eines Mitunternehmers erlangt oder seine bisherige Mitunternehmerstellung erweitert."). 
wahlrecht uneingeschränkt besteht, wenn dem Einbringenden als Gegenleistung neben Gesellschaftsrechten (Gutschrift auf den Kapitalkonten) Teilbeträge auf einem Gesellschafterkonto gutgeschrieben werden, das gesellschaftsrechtlich keinen Kapitalcharakter hat (z. B. Gesellschafterdarlehenskonto).

Für die Einbringung in Kapitalgesellschaften regelt $\S 20$ Abs. 3 Satz 3 UmwStG, dass die Gewährung „anderer Wirtschaftsgüter" die Anschaffungskosten der Gesellschaftsanteile vermindert. Eine vergleichbare Regelung oder eine Verweisung auf diese Vorschrift umschließt §24 UmwStG nicht. Deshalb wird teilweise vertreten, dass in der Gutschrift von Teilbeträgen auf einem Gesellschafterdarlehenskonto ein Teilentgelt zu sehen ist. ${ }^{13}$

Dieser Auffassung hat aber der BFH unlängst eine Absage erteilt. ${ }^{14}$ Dieser Entscheidung lag der folgende Sachverhalt zugrunde:

- Ein Arzt gründete mit Wirkung zum 1.1.1998 mit einem Berufskollegen eine GbR zum Zwecke der gemeinsamen Berufsausübung. Einnahmen und Ausgaben sollten hälftig geteilt und getragen werden. Der Arzt I brachte vereinbarungsgemäß seine Einzelpraxis in die GbR ein. Zum Ausgleich für die Hälfte des Patientenstammes und der Praxisgegenstände zahlte der Arzt II an Arzt I 200.000 DM.

- Die GbR ermittelte ihren Gewinn im Wege der Einnahmenüberschussrechnung. Die vom Arzt II geleistete Ausgleichszahlung behandelte sie als Anschaffungskosten auf Gegenstände der Praxiseinrichtung sowie auf den Praxiswert. Die sich daraus ergebende AfA berücksichtigte sie als Betriebsausgabe für den Gesamthandsbereich. Dagegen wandte sich Arzt II, der die AfA allein sich selbst zugerechnet sehen wollte. Dieser Sichtweise stimmte der BFH zu.

13 So z. B. Schmitt in Schmitt/Hörtnagl/Stratz, UmwG/UmwStG, 5. Aufl. 2009, $\S 243$ UmwStG Rz. 135; a. A. aber Widmann in Widmann/Mayer, Umwandlungsrecht, § 24 UmwStG Rz. 101.3 (August 2001); Schlößer in Haritz/Menner, UmwStG, 3. Aufl. 2010, § 24 UmwStG Anm. 78.

14 Vgl. BFH, Urt. v. 24.6.2009 - VIII R 13/07, BStBl. 2009 II, 993. 
Sachverhalt und Beurteilung seien in der folgenden Abbildung graphisch zusammengefasst:

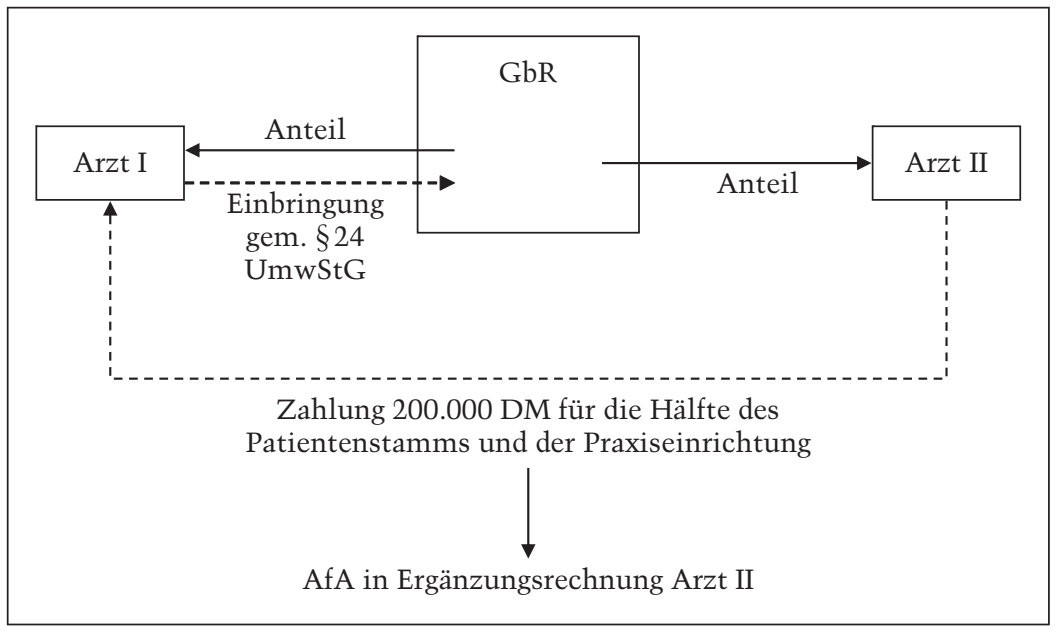

Aus dieser Entscheidung ergibt sich:

Für die Anwendung des $§ 24 \mathrm{UmwStG}$ ist es nicht erforderlich, dass die Gegenleistung für die Sacheinlage ausschließlich in der Gewährung von Gesellschaftsrechten besteht, sondern es reicht aus, dass überhaupt ein Mitunternehmeranteil eingeräumt wird. Die Zuzahlung des Klägers ist insofern unbeachtlich. Aus diesem Grunde durfte die GbR die Buchwerte des eingebrachten Praxisvermögens fortführen.

Dem Ansatz des eingebrachten Vermögens mit dem Buchwert steht auch nicht entgegen, dass einzelne Wirtschaftsgüter der Einzelpraxis zwar nicht Gesamthandsvermögen der GbR geworden sind, aber der Gesellschaft als Sonderbetriebsvermögen I zur Nutzung zur Verfügung stehen. Im Streitfall war insofern unbeachtlich, dass der seine Einzelpraxis einbringende Arzt I den zum Betriebsvermögen gehörenden Pkw nicht in das Gesellschaftsvermögen eingebracht hatte. ${ }^{15}$

15 Nach der Kodifikation des SEStEG ist fraglich geworden, ob eine Einbringung in das Sonderbetriebsvermögen neben der Gewährung von Gesellschaftsrechten der Anwendung von $\S 24$ UmwStG entgegensteht, vgl. die Anwendbarkeit von $\S 24$ UmwStG verneinend Patt in Dötsch/Jost/Pung/Witt, Die Körperschaftsteuer, § 24 UmwStG (SEStEG) Tz. 16 (Februar 2008); zutreffend a. A. hingegen Rasche in Rödder/Herlinghausen/van Lishaut, UmwStG, 2008, § 24 Rz. 59; Schmitt in Schmitt/Hörtnagl/Stratz, UmwG/UmwStG, 5. Aufl. 2009, $\S 24$ UmwStG Rz. 34 m. w. N. Nach dem Erlass des Ministeriums für Finanzen 
Die Rechtsfolgen der Einbringung gegen Gewährung von Gesellschaftsrechten und Gutschrift auf einem Gesellschafterdarlehenskonto seien anhand des folgenden Beispiels dargelegt:

A bringt sein Einzelunternehmen mit einem Buchkapital von 500 in die AB KG ein. Der gemeine Wert soll 1.000 sein. Es wird steuerlich die Buchwertfortführung gem. § 24 Abs. 2 UmwStG gewählt.

Optionen:

(a) Es erfolgt auch in der Handelsbilanz Buchwertfortführung; das Buchkapital wird auf Kapitalkonto I gutgeschrieben und das gesellschaftsrechtlich Kapitalcharakter aufweisende variable Kapitalkonto II in Höhe von je 250.

Folge: Weil in Höhe des gesamten Gegenwerts Gesellschaftsrechte gewährt werden, ist die Buchwertfortführung zweifellos zulässig.

(b) Wie (a), jedoch werden 250 auf Kapitalkonto I und 250 auf einem Darlehenskonto gutgeschrieben, das gesellschaftsrechtlich keinen Kapitalcharakter hat.

Folge: Nach h.A. ist die Gutschrift auf dem Darlehenskonto ein Teilentgelt. Eine Gewinnrealisierung tritt aber nicht ein, weil nach der maßgeblichen sog. Einheitstheorie die Gegenleistung dem Buchwert gegenüberzustellen ist und diesen nicht übersteigt. A könnte den Betrieb auch für 500 an die AB KG veräußern, ohne dass es zu einer Gewinnrealisation kommt.

(c) In der Handelsbilanz erfolgt eine Wertaufstockung auf 1.000; A wird auf Festkapitalkonto I 500 gutgeschrieben und auf dem gesellschaftsrechtlich Kapitalcharakter aufweisenden variablen Kapitalkonto II ebenfalls 500 .

Folge: Weil der Gegenwert für die Einbringung vollumfänglich in der Gewährung von Gesellschaftsrechten besteht, ist die Buchwertfortführung nach § 24 Abs. 2 UmwStG zulässig. Diese kann durch Aufstellung einer negativen steuerlichen Ergänzungsbilanz für A herbeigeführt werden (oder aber einer von der Handelsbilanz abweichenden Steuerbilanz $\operatorname{der} \mathrm{AB} K G)$.

und Energie des Landes Schleswig-Holstein v. 17.8.2008 - VI 30 - S 1978d - 005, DATEV-LEXinform Dok-Nr. 5231318, soll bis zum Ergehen einer ggf. abweichenden Verwaltungsauffassung auch bei der Anwendung des $§ 24$ UmwStG in der Neufassung durch das SEStEG von der Weitergeltung der Rz. 24.06 des UmwStErlasses ausgegangen werden. Im Formulierungsvorschlag für den neuen UmwStErlass ist unter Tz. 24.06 weiterhin die Regelung enthalten: „Im Rahmen des $\S 24$ UmwStG ist es ausreichend, wenn das eingebrachte Betriebsvermögen teilweise Sonderbetriebsvermögen des Einbringenden bei der übernehmenden Mitunternehmerschaft wird." 
(d) Wie (c), jedoch werden neben den 500 auf Kapitalkonto I die weiteren 500 auf dem Darlehenskonto gutgeschrieben, das gesellschaftsrechtlich Fremdkapitalcharakter hat.

Folge: Wenn der h.A. zu folgen ist, kommt es zu einer Gewinnrealisierung von 500, weil das gutgeschriebene Eigenkapital und das Teilentgelt in Gestalt der Darlehensforderung des A (obgleich Sonderbetriebsvermögen gem. § 15 Abs. 1 Satz 1 Nr. 2 EStG) um diesen Betrag das Buchkapital überschreiten.

Für die Einbringung gegen ein Mischentgelt, d.h. gegen Gewährung von Gesellschaftsrechten und sonstige Ausgleichsleistungen (vgl. dazu im vorstehenden Beispiel Buchst. b), sieht Tz. 24.08 des Formulierungsvorschlags für den neuen UmwStErlass Folgendes vor:

„Erfolgt die Einbringung gegen ein Mischentgelt, d.h. gegen Gewährung von Gesellschaftsrechten und sonstige Ausgleichsleistungen, kann die Einbringung auf Antrag entsprechend dem Verhältnis der jeweiligen Teilleistungen (Wert der erlangten Gesellschaftsrechte einerseits und Wert der sonstigen Gegenleistung andererseits) zum gemeinen Wert des eingebrachten Betriebsvermögens teilweise zu Buchwerten und teilweise zum gemeinen Wert vollzogen werden (BFH-Urteil vom 11. Dezember 2001, BStBl. II 2002 S. 420).“

Sollte mit dieser Formulierung gemeint sein, dass die (vollständige) Buchwertfortführung nach Maßgabe der Einheitstheorie auch dann nicht zulässig ist, wenn die sonstige Gegenleistung und die Gutschrift auf einem Gesellschaftsrechte repräsentierenden Konto das Buchkapital des eingebrachten Betriebsvermögens nicht übersteigt, wäre sie unzutreffend. Nach der für die Übertragung betrieblicher Einheiten (Betriebe, Teilbetriebe, Mitunternehmeranteile) anzuwendenden Einheitstheorie liegt ein Veräußerungsentgelt nämlich erst vor, soweit die gewährte sonstige Gegenleistung (z.B. eingeräumte Gesellschafterforderung) das Kapitalkonto der eingebrachten betrieblichen Einheit übersteigt. Im Formulierungsvorschlag zum neuen UmwStErlass wird insoweit auf das BFHUrteil VIII R 58/98 vom 11.12.2001 ${ }^{16}$ verwiesen. In diesem geht es aber gerade nicht um die Einbringung betrieblicher Einheiten gegen ein Mischentgelt, sondern um die Einbringung einzelner Wirtschaftsgüter in eine Personengesellschaft gegen ein Mischentgelt. Dies ist ein Anwendungsfall der Trennungstheorie. Zum anderen steht die Sichtweise unter Tz. 24.08 der Formulierungshilfe zum neuen UmwStErlass nicht im Einklang mit der Entscheidung des VIII. Senates des BFH vom 24.6.2009,17 wonach es für die Anwendung des $§ 24 \mathrm{UmwStG}$ ausreichend ist, wenn überhaupt ein Mitunternehmeranteil gewährt wird.

Im Falle der Entgeltlichkeit bzw. der Teilentgeltlichkeit der Einbringung kann es mithin nicht zur Gewinnrealisierung kommen, wenn die Summe

16 Vgl. BFH, Urt. v. 11.12.2001 - VIII R 58/98, BStBl. 2002 II, 420.

17 Vgl. BFH, Urt. v. 24.6.2009 - VIII R 13/07, BStBl. 2009 II, 993. 
aus Gutschrift auf Kapitalkonten und anderen Gegenleistungen den steuerlichen Buchwert der eingebrachten betrieblichen Sachgesamtheit nicht übersteigt. $^{18}$

Gestaltungshinweis: In Anbetracht der gegenwärtig nicht vollständig geklärten Rechtslage kann empfehlenswert sein, im Falle der gewünschten Buchwertfortführung oder einer anderweitigen Wahlrechtsausübung gem. § 24 Abs. 2 UmwStG zumindest im geringen Umfang das für die Beteiligung an der Gesellschaft maßgebliche Kapitalkonto (i. d. R. Festkapital- oder Kapitalkonto I) zu erhöhen und den restlichen Gegenwert für die Einbringung auf Konten gutzuschreiben, die gesellschaftsrechtlich Kapitalcharakter haben.

\section{b) Einzelne Wirtschaftsgüter}

Sollen einzelne Wirtschaftsgüter in ein Betriebsvermögen eingebracht werden, ist das Gestaltungsziel überwiegend nach der steuerlichen Verhaftung der Wirtschaftsgüter vorgegeben. Insoweit kann wie folgt differenziert werden:

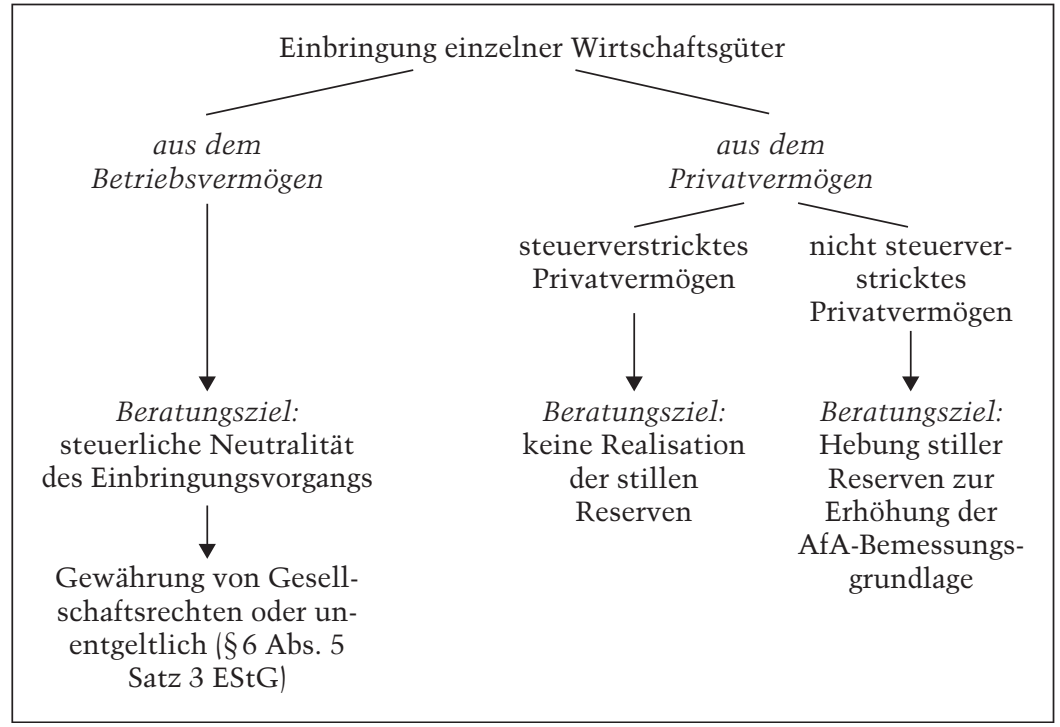

18 Vgl. zur Anwendung der Einheitstheorie z.B. BFH, Urt. v. 22.9.1994 IV R 61/93, BStBl. 1995 II, 367 m. w. N.; v. 10.7.1986 - IV R 12/81, BStBl. 1986 II, 811; Korn/Strahl in Korn, EStG, § 6 EStG Rz. 107 (Dezember 2005), sowie Rz. 477.2 (Dezember 2005) m. w. N. 


\section{aa) Einbringung einzelner Wirtschaftsgüter aus dem Betriebsvermögen}

Das Gestaltungsziel, die Einbringung einzelner Wirtschaftsgüter aus einem Betriebsvermögen in eine Personengesellschaft steuerlich neutral auszugestalten, ist nach Maßgabe des $\S 6$ Abs. 5 Satz 3 EStG erreichbar. Danach darf die Einbringung einzelner Wirtschaftsgüter aus einem Einzelbetriebsvermögen oder einem Sonderbetriebsvermögen bei derselben oder einer anderen Mitunternehmerschaft nur gegen die Gewährung von Gesellschaftsrechten und/oder unentgeltlich erfolgen. ${ }^{19}$ Die Einbringung eines einzelnen Wirtschaftsgutes aus einem Betriebsvermögen darf aber auch nicht teilweise mit der Gewährung einer Gesellschafterforderung verbunden sein, weil insoweit ein Teilentgelt vorliegt, welches nach Anwendung der Trennungstheorie zur Realisation stiller Reserven führt.

Die Trennungstheorie kann nach der jüngeren Rspr. des BFH auch bei der Übertragung einer Vielheit einzelner Wirtschaftsgüter, die sich indes nicht zu einer betrieblichen Einheit in Gestalt eines Betriebes, Teilbetriebs oder Mitunternehmeranteils verdichten, Anwendung finden. ${ }^{20}$ Es ging um die Beurteilung der folgenden Konstellation:

Im Jahre 1995 übertrug A seine Kommanditbeteiligung an einer gewerblich tätigen KG sowie die überwiegenden Geschäftsanteile an der Komplementär-GmbH jeweils zur Hälfte in zwei Tranchen auf seine Söhne. Er behielt sich ein lebenslanges Nießbrauchsrecht an dem auf die übertragenen Kommanditbeteiligungen entfallenden Gewinnanteil abzüglich der einkommensteuerlichen Belastung im Spitzensteuersatz vor. Zeitgleich mit der Übertragung der zweiten Tranche brachte er das zu seinem Sonderbetriebsvermögen rechnende Grundstück mit aufstehendem Gebäude, in dem die KG ihren Betrieb ausübte, zu Buchwerten in eine

$19 \S 6$ Abs. 5 Satz 3 EStG soll nach der Auffassung des I. Senates nicht auf die Einbringung einzelner Wirtschaftsgüter aus dem Betriebsvermögen einer Schwester-Mitunternehmerschaft anwendbar sein, vgl. BFH, Urt. v. 25.11.2009 - I R 72/08, BStB1. 2010 II, 471. Sofern Beteiligungsidentität mit der Schwester-Personengesellschaft besteht, sieht hingegen der IV. Senat des BFH die Anwendung von $\S 6$ Abs. 5 Satz 3 EStG nicht als geboten an, da sich bereits aus der Transparenz der Personengesellschaft ergibt, dass es in diesem Falle auf Grund des Transfervorgangs nicht zur Realisation stiller Reserven kommen könne (Rechtsgedanke des § 6 Abs. 5 Satz 1 EStG), vgl. BFH, Beschl. v. 28.2.2010 - IV B 105/09, BStBl. 2010 II, 971; dazu kritisch Gosch, DStR 2010, 1173; vgl. auch Siegmund/Ungemach, NWB 2010, 206; Olgemöller/Esteves Gomes, Stbg. 2010, 312. Die Finanzverwaltung hat den Beschluss des IV. Senats des BFH mit einem Nichtanwendungserlass belegt, vgl. BMF, Schr. v. 29.10.2010 - IV C 6 S 2241/10/10002:001 (Dok 2010/0823464), BStBl. 2010 I, 1206, dessen Begründung indes fehl geht, weil sie darauf gerichtet ist, § 6 Abs. 5 Satz 3 EStG weise keine planwidrige Regelungslücke auf, die einen Analogieschluss zulasse. Auf jene hatte der IV. Senat des BFH auch nicht erkannt.

20 Vgl. BFH, Urt. v. 6.5.2010 - IV R 52/08, DStR 2010, 1374. 
gewerblich geprägte KG ein. Diese überließ das Grundstück mit dem aufstehenden Gebäude fürderhin der KG zur Nutzung. Der Sachverhalt stellt sich mithin graphisch wie folgt dar:

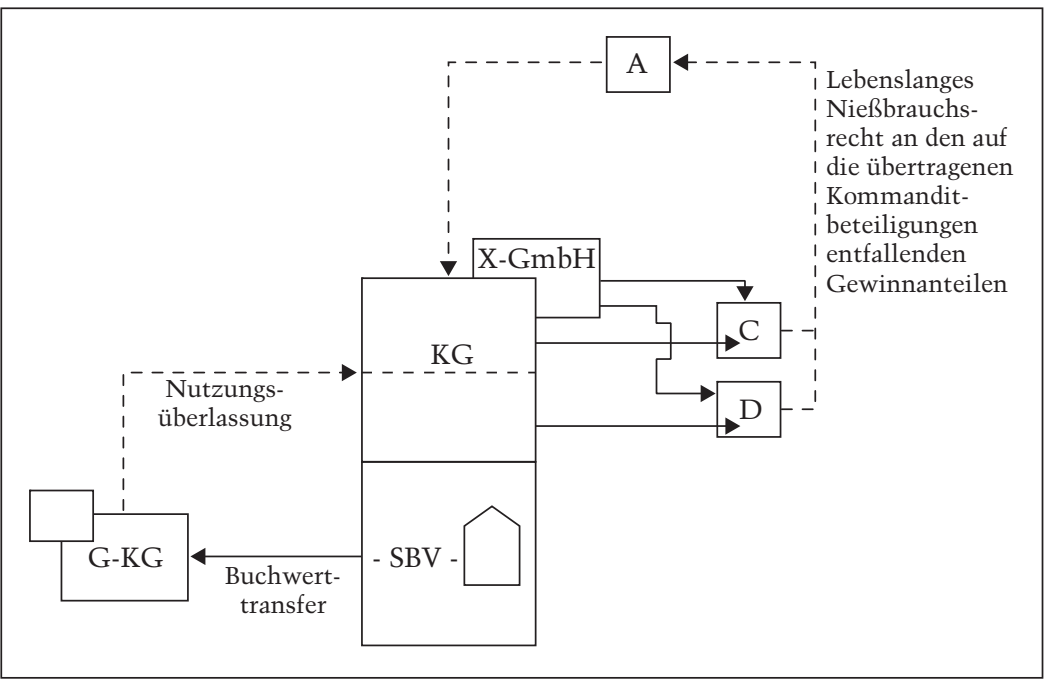

Die für die Übertragung der Kommanditbeteiligung beanspruchte Buchwertfortführung nach Maßgabe von $\S 7$ Abs. 1 EStDV a.F. (§6 Abs. 3 EStG) gewährte die FinVerw. nicht und erhielt damit vom BFH Recht. Dieser sah in der Übertragung keine Übertragung eines begünstigten Mitunternehmeranteils, sondern wegen der erfolgten Ausgliederung des Grundstückes die Übertragung eines bloßen Kommanditanteils. Anders als das FG gelangte der BFH aber zu dem Ergebnis, der grundsätzlich anzusetzende Entnahmegewinn werde im Hinblick auf die in Bruchteilsbetrachtung übertragenen anteiligen Wirtschaftsgüter der KG durch den vorrangigen Tatbestand der Veräußerung verdrängt. Von einem solchen vorrangigen Veräußerungsentgelt ist im Streitfall nicht nur auf Grund der Übernahme der auf den Kommanditanteil anteilig entfallenden Verbindlichkeiten der KG auszugehen, sondern Gleiches gilt für die fortdauernde Gewinnbeteiligung des A.

Die Übertragung der anteiligen Wirtschaftsgüter ist nach Sicht des BFH im Streitfall mit einem Veräußerungsentgelt einerseits auf Grund der Übernahme der auf den Kommanditanteil des A anteilig entfallenden Verbindlichkeiten und andererseits hinsichtlich der Abrede über die fortdauernde Gewinnbeteiligung verbunden. 
Diesbezüglich gibt der BFH dem FG, an welches die Sache zurückverwiesen worden ist, Folgendes auf:

- Es ist zu ermitteln, ob die Summe aus den übernommenen Verbindlichkeiten sowie den im Schätzwege zu ermittelnden Barwert der fremdüblichen Gewinnbeteiligung des A den tatsächlichen Wert der übertragenen anteiligen Wirtschaftsgüter erreicht. Ist das so ermittelte Veräußerungsentgelt niedriger als der Verkehrswert der übertragenen Aktiva, wäre für den verbleibenden nicht durch die Veräußerungstatbestände (Schuldübernahme; Barwert der Gewinnbeteiligung) aufgedeckten Wert der anteiligen Aktiva ein Entnahmegewinn anzusetzen.

- Entspricht die Höhe der vereinbarten Gewinnbeteiligung bereits dem unter Fremden üblichen Entgelt nicht, wäre im Hinblick auf den überhöhten nicht fremdüblichen Teil der Gewinnbeteiligung von privat veranlassten und nicht der Einkommenssphäre des A zuzurechnenden Zuwendungen auszugehen.

- Das Schlusskapital des A im Jahre der Übertragung ist aufzugliedern und beiden Veräußerungstatbeständen sowie dem Entnahmetatbestand anteilig zuzuordnen.

Da nach Sicht des BFH der Veräußerungstatbestand erfüllt ist, ist auch zu ermitteln, ob ein Firmenwert vorhanden ist und dementsprechend erworben wird.

Die Sichtweise des BFH macht es deswegen erforderlich, dass der Verkehrswert sämtlicher auf die übertragene Beteiligung entfallenden anteiligen - Wirtschaftsgüter ermittelt wird, seien sie bislang aktiviert oder nicht aktiviert gewesen. Erreicht das Veräußerungsentgelt diese Verkehrswerte nicht, kommt es gleichwohl zur Gewinnrealisation, da dann in Höhe der Differenz zwischen den Verkehrswerten und den Entgelten ein Entnahmegewinn anzunehmen sein soll. Damit gilt die Einheitstheorie nicht in Fällen der Übertragung eines Kommanditanteils, die nicht zugleich die Übertragung eines Mitunternehmeranteils darstellt. Die Einheitstheorie gilt aber bei Übertragung eines Mitunternehmeranteils fort.

Diese Anwendung der Trennungstheorie bei der Übertragung einer Vielheit von Wirtschaftsgütern führt zu erheblichen, bis zur Unpraktikabilität reichenden Rechtsfolgen. So hat der Erwerber Anschaffungskosten in Höhe seines Teilentgeltes, das für jedes einzelne Wirtschaftsgut zu ermitteln ist. In Höhe des unentgeltlich übertragenen Teiles, welcher beim Veräußerer dem Entnahmetatbestand unterliegt, ist eine Einlage gegeben, die nach $\S 6$ Abs. 1 Nr. 5 EStG zu bewerten ist. Es ist somit nicht damit getan, in rein summarischer Betrachtung den tatsächlichen Wert der Aktiva den Veräußerungsentgelten gegenüberzustellen. Vielmehr muss das Veräußerungsentgelt auf die einzelnen Wirtschaftsgüter aufgeteilt und für diese jeweils nach Maßgabe der Relation des Veräuße- 
rungsentgeltes zum tatsächlichen Wert die Quote der Entgeltlichkeit ermittelt werden.

\section{bb) Einbringung einzelner Wirtschaftsgüter aus dem Privatvermögen}

Sollen Wirtschaftsgüter des steuerverstrickten Privatvermögens eingebracht werden (z. B. Beteiligungen i. S. des $§ 17$ EStG, Grundstücke innerhalb der Zehnjahresfrist des $\$ 23$ Abs. 1 Satz 1 EStG oder nach dem 31.12.2008, aber ohne Wertpapiere), ist $\S 6$ Abs. 5 Satz 3 EStG nicht anwendbar. Nach Maßgabe der FinVerw. ist insoweit nur der Weg der unentgeltlichen Einlage durch Gutschrift auf einem gesamthänderisch gebundenen Rücklagekonto eröffnet. ${ }^{21}$ Eine Gegenleistung darf nicht gewährt werden, da es anderenfalls zur Gewinnrealisation nach Maßgabe der Trennungstheorie käme oder - wenn die Gegenleistung zumindest teilweise auch in Gesellschaftsrechten besteht - nach der Rspr. des BFH von einem vollentgeltlichen Vorgang auszugehen wäre. ${ }^{22}$

Rechnen die einzubringenden Wirtschaftsgüter demgegenüber zum nicht steuerverstrickten Privatvermögen, lässt sich durch eine Einbringung gegen Gutschrift auch auf einem Gesellschafterdarlehenskonto eine Vollentgeltlichkeit des Transfervorgangs herbeiführen, die der Generierung einer zusätzlichen AfA-Bemessungsgrundlage dient. Nach der Rspr. des $\mathrm{BFH}$ ist von einer Vollentgeltlichkeit des Einbringungsvorgangs daneben stets auszugehen, wenn der Gegenwert der eingebrachten Wirtschaftsgüter neben der Gewährung von Gesellschaftsrechten auch im Rahmen des Kapitalkontos II oder der gesamthänderisch gebundenen Rücklage ausgewiesen wird. ${ }^{23}$

$\S 7$ Abs. 1 Satz 5 EStG a. F., wonach sich bei Wirtschaftsgütern, die nach einer Verwendung im Rahmen der Überschusseinkunftsarten „in ein Betriebsvermögen eingelegt" werden, die "Anschaffungs- oder Herstellungskosten" um die bis zum Zeitpunkt der Einlage vorgenommenen Abschreibungen mindern, ist auf eine Einbringung nicht anwendbar. Der BFH begründet dies damit, dass der Gesetzgeber sich mit der Verwendung des Einlagebegriffs nicht für eine offene Tatbestandsfassung entschieden habe. Vielmehr habe ihm bewusst sein müssen, dass nach ständiger Rspr. des BFH sowohl Einbringungsvorgänge als auch die Übertragung von Einzelwirtschaftsgütern in ein betriebliches Gesamthandsvermögen gegen sonstige Gegenleistungen nicht dem Merkmal der Einlage entsprechen

21 Vgl. dazu BMF, Schr. v. 26.11.2004 - IV B 2 - S 2178 - 2/04, BStB1. 2004 I, 1190, Tz. 2 Buchst. b.

22 Vgl. BFH, Urt. v. 24.1.2008 - IV R 37/06, DStR 2008, 761; v. 24.1.2008 IV R 66/05, BFH/NV 2008, 1302.

23 Vgl. BFH, Urt. v. 24.1.2008 - IV R 37/06, DStR 2008, 761; v. 24.1.2008 IV R 66/05, BFH/NV 2008, 1302. 
und damit auch nicht dem Tatbestand des $\S 7$ Abs. 1 Satz 5 EStG zu subsumieren sein können. Dabei komme es nicht darauf an, ob das eingebrachte Wirtschaftsgut vor der Übertragung zu einem Betriebsvermögen oder zum (steuerlich nicht verstrickten) Privatvermögen des Einbringenden gehört. Durch die Einbringung steuerlich nicht verstrickten Privatvermögens etwa in eine gewerblich geprägte Personengesellschaft kann mithin nach wie vor eine höhere AfA-Bemessungsgrundlage generiert werden, ohne dass der Einbringungsvorgang der Besteuerung unterläge.

Im Rahmen des JStG 2010 ist $\S 7$ Abs. 1 Satz 5 EStG geändert worden; indes kommt es dadurch nicht zu einer Einschränkung der vorstehend geschilderten Gestaltungsmöglichkeit. Vielmehr hat die Norm den folgenden Wortlaut erhalten: ${ }^{24}$

„Bei Wirtschaftsgütern, die nach einer Verwendung zur Erzielung von Einkünften im Sinne des $\S 2$ Abs. 1 Nummer 4 bis 7 in ein Betriebsvermögen eingelegt wurden, mindert sich der Einlagewert um die Absetzungen für Abnutzung oder Substanzverringerung, Sonderabschreibungen oder erhöhte Absetzungen, die bis zum Zeitpunkt der Einlage vorgenommen worden sind, höchstens jedoch bis zu den fortgeführten Anschaffungs- oder Herstellungskosten; ist der Einlagewert niedriger als dieser Wert, bemisst sich die weitere Absetzung für Abnutzung vom Einlagewert."

Damit wird lediglich die Rechtsprechung des BFH nachvollzogen. ${ }^{25}$

\section{Kapitalgesellschaft}

\section{Rechtsfolgen der Unverzinslichkeit}

Anders als auf ein unverzinsliches Darlehen, welches der Gesellschafter einer Personengesellschaft an die Gesellschaft ausreicht (s. dazu oben Abschn. I. 1), ist nach der Rspr. des I. Senats das Abzinsungsgebot des $§ 6$ Abs. 1 Nr. 3 EStG auf unverzinsliche Gesellschafterdarlehen an Kapitalgesellschaften anwendbar. ${ }^{26}$ Insbesondere könne ein Absehen von der Abzinsung nicht auf die Annahme gestützt werden, dass die Unverzinslichkeit wirtschaftlich durch erhöhte Ausschüttungen an die Gesellschafter ausgeglichen werde. Auch sei der Ansatzpunkt verfehlt, dass

24 Vgl. Stellungnahme des Bundesrates zum Entwurf eines Jahressteuergesetzes 2010 (JStG 2010), BT-Drucks. 318/10 (Beschluss) v. 9.7.2010, 17.

25 Vgl. dazu auch BMF, Schr. v. 27.10.2010 - IVC 3 - S 2190/09/10007 (DOK 2010/0764153), BStBl. 2010 I, 1204.

26 Vgl. BFH, Urt. v. 6.10.2009 - I R 4/08, BStBl. 2010 II, 177; v. 27.1.2010 - I R 35/09, BStBl. 2010 II, 478. Der IV. Senat des BFH hatte es hingegen im Urt. v. 10.11.2005 - IV R 13/04, BStBl. 2006 II, 618, 623 (unter Abschn. II.2 Buchst. der Urteilsgründe), noch als fraglich bezeichnet, ob $\S 6$ Abs. 1 Nr. 3 EStG auf unverzinsliche eigenkapitalersetzende Darlehen überhaupt Anwendung findet oder die Vorschrift insoweit teleologisch zu reduzieren sei. 
durch das Gesellschaftsverhältnis veranlasste Vorgänge generell das Einkommen der Kapitalgesellschaft nicht beeinflussen dürfen. Tragend dafür sei, dass Nutzungsvorteile nicht Gegenstand einer verdeckten Einlage sein können, und dass deshalb die Veranlassung durch das Gesellschaftsverhältnis kein Anknüpfungspunkt für eine Differenzierung zwischen Gesellschafterdarlehen und Fremddarlehen sein kann.

Der BFH betont des Weiteren, eine besondere Zweckbindung eines unverzinslichen (Gesellschafter-)Darlehens stehe einer Verzinsungspflicht nicht gleich, die dazu führte, dass das Abzinsungsgebot nach $\S 6$ Abs. 1 Nr. 3 EStG keine Anwendung fände. Der BFH gesteht zwar zu, dass es für die Verzinslichkeit eines Darlehens nicht nur auf die Nominalverzinsung ankommt, sondern insoweit auch andere, mit der Darlehensgewährung verbundene Leistungsverpflichtungen des Darlehensnehmers bedeutsam sein können. Einer Abzinsung steht eine Zweckbindung des Darlehens aber nur dann entgegen, wenn sie einen die Verzinsung ersetzenden Nachteil des Darlehensnehmers begründet.

Ausdrücklich hervorgehoben wird, das Abzinsungsgebot erfasse auch eigenkapitalersetzende Gesellschafterdarlehen i.S. von §32a GmbHG a. F. bei Unverzinslichkeit, da sie sich aus steuerrechtlicher ebenso wie aus zivilrechtlicher Sicht für die Kapitalgesellschaft als Fremdkapital darstellen. Eine Gleichstellung der Darlehensgewährung mit der Zuführung von Eigenkapital kommt nur dann in Betracht, wenn die Darlehensgewährung in einer Weise ausgestaltet ist, dass sie nach den Grundsätzen des Zivilrechts als Zuführung von Eigenkapital anzusehen ist („gesplittete Einlage").

In beiden Urteilsfällen ist von Klägerseite vorgetragen worden, die Abzinsung sei deswegen nicht geboten, weil es sich um Darlehen mit unbestimmter Laufzeit handele. Diese können nach den Vorschriften des BGB mit einer Frist von drei Monaten gekündigt werden (§ 609 BGB a. F.; $§ 488$ Abs. 3 Satz 2 BGB n. F. - seit dem 1.1.2002 geltend -l, so dass die Anwendung von $\S 6$ Abs. 1 Nr. 3 Satz 2 EStG geboten sei, wonach die Abzinsung u. a. bei Verbindlichkeiten, deren Laufzeit am Bilanzstichtag weniger als zwölf Monate beträgt, unterbleibt. - Der BFH folgt diesem zivilrechtlichen Ansatz nicht, indem er feststellt, die Anwendung des $\S 6$ Abs. 1 Nr. 3 Satz 2 EStG sei vorrangig am Gesichtspunkt der tatsächlichen wirtschaftlichen Belastung auszurichten. Diese aber hänge nicht von der zivilrechtlichen Ausgangslage, sondern davon ab, auf eine wie lange Zeit der Schuldner nach den tatsächlichen Verhältnissen mit der Überlassung des Kapitals rechnen könne.

Von allgemeiner Bedeutung ist, dass der BFH das Vorbringen des Klägers im Urteil I R 4/08 verwirft, bei einem früheren Bekanntwerden der Verwaltungssicht wären Rechtsnachteile ohne Schwierigkeiten durch die 
Vereinbarung einer geringfügigen Verzinsung vermieden worden. Die FinVerw. hatte auf das Steuerentlastungsgesetz 1999/2000/2002 vom 24.3.1999 erst durch das BMF-Schreiben vom 26.5.2005 (IV B 2 S 2175-7/05/27 reagiert. Der BFH dazu in Rz. 20 des Urteils I R 4/08:

„Denn das Fehlen einer zeitnahen Verwaltungsäußerung kann kein Grund sein, die Vorschrift in einem für die Klägerin günstigen Sinne auszulegen." (Hervorhebung nicht im Original.)

\section{Ausfall von Gesellschafterdarlehen}

a) Darlehensforderungen im Privatvermögen

Gewährt ein Gesellschafter „seiner" GmbH aus dem Privatvermögen ein Darlehen und fällt die Darlehensrückzahlung auf Grund wirtschaftlicher Schwierigkeiten der $\mathrm{GmbH}$ aus, so konnte der Forderungsfall nach bisheriger Auffassung zu nachträglichen Anschaffungskosten des Gesellschafters für seine im Privatvermögen gehaltene Beteiligung der $\mathrm{GmbH}$ führen. Entsprechendes galt für die Übernahme einer Bürgschaft durch den Gesellschafter. Wurde der Gesellschafter aus einer für die GmbH gewährten Bürgschaft in Anspruch genommen und war die Rückgriffsforderung gegenüber der $\mathrm{GmbH}$ wertlos, so konnte dies gleichfalls zu nachträglichen Anschaffungskosten der Beteiligung führen.

Die Aufwendungen konnten jedoch grundsätzlich nur dann als nachträgliche Anschaffungskosten dem Grunde nach berücksichtigt werden, wenn es sich bei dem Darlehen oder der Bürgschaft um Eigenkapitalersatz im gesellschaftsrechtlichen Sinne handelte. Waren danach nachträgliche Anschaffungskosten dem Grunde nach gegeben, so war in einem zweiten Schritt bezüglich der Höhe nach den vier Fallgruppen "Darlehensgewährung in der Krise" , „stehen gelassenes Darlehen“, „krisenbestimmtes Darlehen" und „Finanzplandarlehen“ zu differenzieren. Entsprechendes galt für Verluste aus einer Bürgschaft. Die so ermittelten nachträglichen Anschaffungskosten waren nach § 17 EStG grundsätzlich im Teileinkünfteverfahren (bis 2008: Halbeinkünfteverfahren) steuerlich zu berücksichtigen. Ausnahmsweise erfolgt eine Berücksichtigung in voller Höhe, wenn der Gesellschafter keine Ausschüttungen oder sonst Erträge im Rahmen des Teileinkünfteverfahrens oder Halbeinkünfteverfahrens aus der Beteiligung bezogen hat. ${ }^{28}$

27 Vgl. BMF, Schr. v. 26.5.2005 - IV B 2 - S 2175 - 7/05, BStBl. 2005 I, 699.

28 Vgl. BFH, Urt. v. 25.6.2009 - IX R 42/08, BStBl. 2010 II, 220; dagegen BMF, Schr. v. 15.2.2010 - IV C 6 - S 2233/09/10002 (DOK 2009/0722841), BStB1. 2010 I, 181; dieser Nichtanwendungserlass außer Kraft gesetzt mit BMF, Schr. v. 28.6.2010 - IV C 6 - S 2244/09/10002 (DOK 2010/0464101), BStB1. 2010 I, 599, nach Ergehen des BFH, Beschl. v. 18.3.2010 - IX B 227/09, BStBl. 2010 II, 627. Im Entwurf des JStG 2010 ist mit $\S 3 c$ Abs. 2 Satz 2 EStG eine Nicht- 
Es stellt sich die Frage, ob und inwieweit diese Beurteilung weiterhin Geltung hat. Dies ist deshalb fraglich, weil sich zivilrechtliche Änderungen durch das MoMiG (Abschaffung des Eigenkapitalersatzrechts) und ertragsteuerliche Veränderungen durch das Unternehmensteuerreformgesetz 2008 (Steuerbarkeit von Forderungsverkäufen im Privatvermögen) ergeben haben. ${ }^{29}$

Nach der Änderung des § 20 EStG durch das Gesetz zur Unternehmensteuerreform 2008 kommt ab 2009 eine Berücksichtigung der Aufwendungen des Gesellschafters nicht mehr nur nach § 17 EStG in Betracht, sondern grundsätzlich auch nach $\S 20$ Abs. 2 Nr.7 EStG. Nach dieser Vorschrift rechnet nunmehr auch der Gewinn aus der Veräußerung von sonstigen Kapitalforderungen jeder Art i. S. des § 20 Abs. 1 Nr. 7 EStG zu den Einkünften aus Kapitalvermögen. Damit unterliegen nicht nur laufende Zahlungen, sondern auch Gewinne aus der Veräußerung von Forderungen der Steuerpflicht. Vom Wortlaut der Vorschrift erfasst ist damit die Veräußerung einer Darlehensforderung durch den Gesellschafter ebenso wie die Veräußerung einer Rückgriffsforderung des Bürgen. Setzt man den Forderungsausfall mit einer Veräußerung der Forderung gleich, käme ab 2009 eine Berücksichtigung der Aufwendungen nach $\S 20$ Abs. 2 Nr. 7 EStG in Betracht. Ferner ist es denkbar, die aus einem Forderungsausfall resultierenden Aufwendungen als Werbungskosten (Absetzung für außergewöhnliche Abnutzung) bei den Einkünften aus Kapitalvermögen nach $\S 20$ Abs. 1 Nr. 1 oder Nr. 7 EStG zu berücksichtigen.

Bezüglich des Verhältnisses von §20 EStG und § $17 \mathrm{EStG}$ regelt $\S 20$ Abs. 8 EStG den Vorrang von $\S 17$ EStG. Ist daher der Gesellschafter zu mindestens $1 \%$ am Nennkapital der Kapitalgesellschaft beteiligt, gelangt vorrangig § 17 EStG zur Anwendung. In diesem Fall ist zunächst zu prüfen, ob der Ausfall der Darlehensforderung oder der Ausfall der Rückgriffsforderung des Bürgen zu nachträglichen Anschaffungskosten i.S. von $\S 17$ Abs. 2 Satz 1 EStG führt. Nur wenn diese Voraussetzungen nicht gegeben sind, kann sich die Abzugsfähigkeit der Aufwendungen aus $\S 20$ EStG ergeben.

\section{aa) Berücksichtigung der Aufwendungen weiterhin nach § 17 EStG?}

Nach der bisherigen Rspr. können zu den nachträglichen Anschaffungskosten i. S. von $\S 17$ EStG auf eine im Privatvermögen gehaltene Kapitalbeteiligung auch solche nachträglichen Aufwendungen gehören, die durch das Gesellschaftsverhältnis veranlasst und weder Werbungskosten

anwendungsnorm vorgesehen, die erstmals ab dem VZ 2011 anzuwenden sein soll (§ 52 Abs. 8a Satz 3 EStG-Entw.).

29 Vgl. dazu auch Schwenker/Fischer, FR 2010, 643; Fuhrmann, NWB 2009, 3990; Heuermann, DB 2009, 2173. 
bei den Einkünften aus Kapitalvermögen noch Veräußerungskosten sind. Voraussetzung für die Berücksichtigung der Aufwendungen dem Grunde nach war, dass es sich bei dem Darlehen oder der Bürgschaft zivilrechtlich um Eigenkapitalersatz handelt. Allein die Veranlassung der Darlehenshingabe oder der Bürgschaftsübernahme durch das Gesellschaftsverhältnis reichte für die Begründung von nachträglichen Anschaffungskosten nicht aus.

Diese vom VIII. Senat begründete Rspr. hat der IX. Senat - in dessen Zuständigkeit diese Fragen zwischenzeitlich gelangt sind - fortgeführt. ${ }^{30}$ Diese am Zivilrecht orientierte Beurteilung hat ferner zur Folge, dass bei Minderheitsgesellschaftern ohne Geschäftsführungsbefugnis grundsätzlich keine nachträglichen Anschaffungskosten entstehen können, weil insoweit das Eigenkapitalersatzrecht keine Anwendung findet. Eine Ausnahme hat der BFH zugelassen, wenn nur deshalb kein Kapitalersatz vorliegt, weil das Sanierungsprivileg des $\S 32$ a Abs. 3 Satz 3 GmbHG a.F. greift, welches nach $\S 39$ Abs. 4 Satz 2 InsO fortgilt. ${ }^{31}$ Die FinVerw. ist der Rspr. gefolgt, erkennt aber nachträgliche Anschaffungskosten nicht an, wenn nach $\S 32 \mathrm{a}$ Abs. 3 Satz 2 GmbHG a. F. kein Kapitalersatz vorliegt, weil die Beteiligung $10 \%$ nicht übersteigt und der Gesellschafter nicht Geschäftsführer der $\mathrm{GmbH}$ ist. ${ }^{32}$

Die Neuregelung des GmbHG durch das MoMiG hat zur Abschaffung der Rechtsfigur des eigenkapitalersetzenden Darlehens und der eigenkapitalersetzenden Bürgschaft geführt. Nach dem neuen Konzept gibt es keine kapitalersetzenden Gesellschafterleistungen mehr. Der Wegfall eigenkapitalersetzender Darlehen nach der Neuregelung könnte dafür sprechen, dass auch die Voraussetzungen für nachträgliche Anschaffungskosten i. S. von $\S 17$ Abs. 2 Satz 1 EStG neu zu bestimmen sind. Zwingend ist eine solche Neubestimmung allerdings nicht. Es ist nicht ausgeschlossen, dass die Rspr. auch zukünftig den Umfang nachträglicher Anschaffungskosten in Anlehnung an die bisherige - durch das MoMiG überholte-Zivilrechtslage bestimmt.

Wie die Rspr. des BFH zur Pensionszusage zeigt, greift sie zur Auslegung steuerlicher Tatbestände durchaus auf bereits überholte zivilrechtliche Regelungen zurück. So prüft der BFH die Erdienbarkeitsfristen zur Anerkennung einer Pensionszusage noch heute auf Basis einer seit vielen Jahren nicht mehr anwendbaren Fassung des Betriebsrentengesetzes. Zur Begründung führt der BFH an, bei der Bezugnahme auf das Zivilrecht handele es sich lediglich um Leitlinien zur Konkretisierung der Rechts-

30 Vgl. BFH, Urt. v. 2.4.2008 - IX R 76/06, DStR 2008, 1424.

31 Vgl. BFH, Urt. v. 19.8.2008 - IX R 63/05, BStBl. 2009 II, 5.

32 Vgl. Kurzinformation der OFD Münster v. 10.2.2009 - ESt 005/2009, DB 2009, 368. 
anwendung. ${ }^{33}$ In diesem Sinne wären FinVerw. und Rspr. nicht gehindert, die bisher maßgeblichen vier Fallgruppen Darlehensgewährung in der Krise, stehen gelassene Darlehen, krisenbestimmte Darlehen und Finanzplandarlehen auch nach der Neuregelung durch das MoMiG zur Bestimmung der nachträglichen Anschaffungskosten i.S. des $§ 17$ Abs. 2 Satz 1 EStG heranzuziehen. ${ }^{34}$

Diesen Weg geht die Finanzverwaltung, wonach wie folgt differenziert werden soll: ${ }^{35}$

(a) Ein Darlehen ist durch das Gesellschaftsverhältnis veranlasst, wenn im Zeitpunkt seiner Gewährung oder Weitergewährung die Rückzahlung des Darlehens angesichts der finanziellen Situation der Gesellschaft in dem Maße gefährdet ist, dass ein ordentlicher Kaufmann das Risiko einer Kreditgewährung $z u$ denselben Bedingungen wie der Gesellschafter nicht mehr eingegangen wäre. Dieser Krisenbegriff und die steuerliche Anknüpfung an die Krise bleiben unverändert Grundlage für die steuerrechtliche Beurteilung, so dass unverändert die maßgebliche gesellschaftsrechtliche Veranlassung der Kreditgewährung danach zu beurteilen ist, ob die Gesellschaft unter den bestehenden Verhältnissen von einem Dritten noch ein Darlehen zu marktüblichen Bedingungen erhalten hätte. Wird ein Darlehen in der Krise gewährt, ist dessen Verlust nachträglicher Anschaffungsaufwand in Höhe des Nennwerts.

(b) Stehengelassene Darlehen, die bei Eintritt der Krise hätten abgezogen werden können, werden mit dem Wert im Zeitpunkt des Stehenlassens bewertet, der erheblich unter dem Nennwert liegen und möglicherweise 0 Euro betragen kann. Unter der Herrschaft des MoMiG kann ein „stehen gelassenes" Darlehen begrifflich nur noch vorliegen, wenn die Krise zeitlich vor dem Beginn des Anfechtungszeitraums nach §6 AnfG (Darlehen wurde im Jahr vor Erlangung eines vollstreckbaren Schuldtitels zurückgezahlt oder 10 Jahre vor diesem Zeitpunkt besichert) entstanden ist. Ist die Krise erst nach dem Beginn des Anfechtungszeitraums entstanden, gelten die Grundsätze für krisenbestimmte Darlehen.

(c) Der Ausfall von Finanzplandarlehen führt unverändert zu nachträglichen Anschaffungskosten in Höhe des Nennwerts.

(d) Das gilt grundsätzlich auch für krisenbestimmte Darlehen, wobei die FinVerw. differenziert. Bei vertraglicher Krisenbestimmung gegenüber

33 Vgl. BFH, Urt. I R 80/02, BStB1. 2003 II, 926.

34 Vgl. Fuhrmann, NWB 2008, 3745, F 4, 5391.

35 Vgl. BMF, Schr. v. 21.10.2010 - IV C 6 - S 2244/08/10001 (DOK 2010/0810418), BStBl. 2010 I, 832. 
der Gesellschaft oder den Gesellschaftsgläubigern führt der Ausfall in Höhe des Nennwerts zu nachträglichen Anschaffungskosten. Beruht die Krisenbindung auf den gesetzlichen Neuregelungen der InsO und des AnfG, ist eine Krisenbindung mit Beginn des Anfechtungszeitraums anzunehmen; die nachträglichen Anschaffungskosten bemessen sich nach dem gemeinen Wert im Zeitpunkt des Beginns des Anfechtungszeitraums.

\section{bb) Berücksichtigung bei den Einkünften aus Kapitalvermögen?}

Soweit es sich um Forderungen handelt, die unter das Kleinbeteiligungsprivileg nach $\S 39$ Abs. 5 InsO fallen, scheidet unter Zugrundelegung obiger Beurteilung eine Berücksichtigung bei $§ 17$ EStG aus. Eine Berücksichtigung des Forderungsausfalls scheidet auch dann nach § $17 \mathrm{EStG}$ aus, wenn der Gesellschafter mit weniger als $1 \%$ an der Gesellschaft beteiligt ist. Eine Berücksichtigung nach $\S 17$ EStG würde zudem generell ausscheiden, wenn man abweichend von obiger Auffassung eine Berücksichtigung bei § 17 EStG auf Grund des Wegfalls des Eigenkapitalersatzrechts zukünftig für ausgeschlossen erachten würde. In all diesen Fällen stellt sich die Frage, ob die Verluste aus den Finanzierungshilfen bei den Einkünften aus Kapitalvermögen berücksichtigt werden können. Denkbar ist einerseits eine Berücksichtigung im Rahmen der Ermittlung eines Veräußerungsgewinns nach $\S 20$ Abs. 4 i. V.m. Abs. 2 Satz 1 Nr. 7 EStG und andererseits eine Berücksichtigung als Werbungskosten bei den Einkünften nach $\S 20$ Abs. 1 Nr. 1 oder 7 EStG.

\section{(1) Berücksichtigung bei § 20 Abs. 2 Satz 1 Nr. 7 EStG}

Nach $\S 20$ Abs. 2 Satz 1 Nr. 7 EStG rechnet zu den Einkünften aus Kapitalvermögen der Gewinn aus der Veräußerung von sonstigen Kapitalforderungen jeder Art i. S. von $\S 20$ Abs. 1 Nr. 7 EStG. Als Veräußerung gilt auch die Einlösung oder Rückzahlung der Kapitalforderung. Gewinn ist nach $\S 20$ Abs. 4 Satz 1 EStG der Unterschied zwischen den Einnahmen aus der Veräußerung und den Anschaffungskosten abzüglich der veräußerungsbedingten Aufwendungen. Der Gewinn kann daher auch negativ und damit ein Verlust sein.

Eine Berücksichtigung nach dieser Vorschrift kommt also nur dann in Betracht, wenn der Forderungsausfall einer Forderungsveräußerung im Sinne der Vorschrift gleichzustellen ist. Nach Auffassung der FinVerw. soll der Ausfall der Forderung oder ein Forderungsverzicht aber keine Veräußerung i.S. des $\S 20$ Abs. 2 EStG darstellen. ${ }^{36}$ Damit führt ein For-

36 Vgl. BMF, Schr. IV C 1 - S 2252/08/10004 (DOK 2009/0860687), BStBl. 2010 I, 94, Rz. 60 f. 
derungsverlust - auch bei Begründung der Forderung nach dem 31.12.2008 - nicht zu einem steuerrechtlich relevanten Aufwand, sofern die Forderung nicht zu einem Betriebsvermögen zählt.

Anders ist der Forderungsverzicht gegenüber einer Kapitalgesellschaft zu beurteilen, mit der ein Beteiligungsverhältnis besteht. Hier führt der Forderungsverzicht nach $\S 20$ Abs. 2 Satz 2 EStG zu einer grundsätzlich steuerlich erheblichen verdeckten Einlage, die jedoch ebenfalls nicht zu steuerlichen Konsequenzen führen soll, weil dem gemeinen Wert der Forderung als Wertmaßstab für die verdeckte Einlage (§ 20 Abs. 4 Satz 2 Halbsatz $1 \mathrm{EStG}$ ) (nachträgliche) Anschaffungskosten in selber Höhe (statt in Höhe der historischen Anschaffungskosten) gegenüberstehen, so dass sich der Veräußerungsgewinn auf 0 Euro beläuft. Dies gilt auch in Fällen des Forderungsverzichts gegen Besserungsschein. ${ }^{37}$

Auch die Liquidation einer Kapitalgesellschaft soll nach Auffassung der FinVerw. ${ }^{38}$ nicht einer Veräußerung der Anteile an dieser Kapitalgesellschaft gleichstehen (in Fällen der Beteiligung i.S. des $\S 17$ Abs. 1 Satz 1 EStG bleibt $\S 17$ Abs. 4 EStG allerdings unberührt). ${ }^{39}$ Weil nach Auffassung der FinVerw. mit der Liquidation einer Kapitalgesellschaft, einem Forderungsausfall oder einem Forderungsverzicht nicht der Begriff „Veräußerung" erfüllt wird, führt der jeweilige Vorgang insbesondere nicht zu einem im Rahmen des $\S 20$ Abs. 6 EStG zu berücksichtigenden Verlust.

Gestaltungshinweis: Es gilt mithin - sofern gestaltbar -, die Liquidation einer Kapitalgesellschaft, einen Forderungsausfall oder -verzicht zu vermeiden, um - bei Erwerb der Anteile oder der Forderung nach dem 31.12.2008 - einen im Rahmen des § 20 Abs. 6 EStG verrechenbaren Verlust zu generieren. Als Gestaltungsweg bietet sich die Veräußerung zu einem niedrigen Kaufpreis (z. B. 1 Euro) an. Ein Gestaltungsmissbrauch kann darin nach der jüngeren Rspr. nicht gesehen werden, welche die bewusste - Realisation von Verlusten als mit dem Leistungsfähigkeitsprinzip in Einklang stehend einstuft. ${ }^{40}$ Das BMF-Schreiben schweigt zu dieser Gestaltungsmöglichkeit; sie wird insbesondere nicht von vornherein als gestaltungsmissbräuchlich eingeordnet.

37 Vgl. BMF, Schr. IV C 1 - S 2252/08/10004 (DOK 2009/0860687), BStB1. 2010 I, 94, Rz. $61 \mathrm{f}$.

38 Vgl. BMF, Schr. IV C 1 - S 2252/08/10004 (DOK 2009/0860687), BStB1. 2010 I, 94, Rz. 63.

39 Vgl. dazu zutreffend kritisch Dinkelbach, DB 2009, 870, 872.

40 Vgl. z. B. BFH, Urt. v. 25.8.2009 - IX R 60/07, BStBl. 2009 II, 999; v. 25.8.2009 IX R 55/07, BFH/NV 2010, 387; v. 29.5.2008 - IX R 77/06, BStBl. 2008 II, 789; FG Saarland, Urt. v. 17.6.2008 - 2 K 1179/04, EFG 2008, 1803 (rkr.); Korn/Strahl, in StF 29, 2010, Tz. B/1. 
Bejaht man eine Berücksichtigung bei $\S 20$ Abs. 2 Satz 1 Nr. 7 EStG, so liegen negative Einkünfte aus Kapitalvermögen vor. Es ist dann aber das Verlustverrechnungsverbot in $\S 20$ Abs. 6 EStG zu beachten.

(2) Berücksichtigung als Werbungskosten bei § 20 Abs. 1 Nr. 7 EStG?

Nach teilweise vertretener Auffassung soll eine Berücksichtigung der Aufwendungen auch bei $\S 20$ Abs. 1 Nr. 1 oder Nr. 7 EStG möglich sein. ${ }^{41}$ Auf Grund des grundsätzlichen Abzugsverbots für Werbungskosten nach $\S 20$ Abs. 9 EStG setzt eine solche Berücksichtigung freilich voraus, dass die Anwendung der genannten Vorschrift suspendiert ist.

Liegt ein fremdüblich verzinstes Darlehen vor, so richtet sich ein etwaiger Abzug nach $\S 20$ Abs. 1 Nr. 7 i. V. m. § 9 EStG. Die Berücksichtigung des Forderungsverlustes ist denkbar als Werbungskosten in Form der Absetzung für außergewöhnliche Abnutzung. ${ }^{42}$ Das Abzugsverbot für Werbungskosten gem. § 20 Abs. 9 EStG kommt bei den Einkünften nach $\S 20$ Abs. 1 Nr. 7 EStG nicht zur Anwendung, wenn die Beteiligungsquote des Kreditgebers über $10 \%$ liegt oder sonst die Voraussetzungen von $\S 32$ d Abs. 2 Nr. 1 EStG gegeben sind. Die Suspendierung des $\S 20$ Abs. 9 EStG gilt automatisch und bedarf keines Antrags. Die Aufwendungen sind in voller Höhe $z u$ berücksichtigen. Das Teileinkünfteverfahren gelangt nicht zur Anwendung.

Fehlt es an einem fremdüblich verzinslichen Darlehen, so ist es denkbar, die Aufwendungen als Werbungskosten (Absetzung für außergewöhnliche Abnutzung) bei den Dividendeneinkünften anzusetzen. ${ }^{43}$ Ein Werbungskostenabzug kann hier erreicht werden, wenn der Gesellschafterkreditgeber nach $\S 32 \mathrm{~d}$ Abs. 2 Nr. 3 Satz 1 EStG auf die Anwendung der Abgeltungsteuer verzichtet und zur Regelbesteuerung optiert. Die Option kann nur ausgeübt werden, wenn der Gesellschafterkreditgeber entweder zu mindestens $25 \%$ an der Gesellschaft beteiligt ist oder zu mindestens $1 \%$ und überdies beruflich für die Gesellschaft tätig ist. Die Wahlrechtsausübung unterliegt ferner den Restriktionen des $\S 32 \mathrm{~d}$ Abs. 2 Sätze 3 bis 6 EStG. Ist die Option wirksam ausgeübt, so kommt eine Berücksichtigung des Forderungsverlustes als Werbungskosten nur nach dem Teileinkünfteverfahren in Betracht.

41 Vgl. Heuermann, DB 2009, 2173, 2177.

42 Vgl. dazu Heuermann, DB 2009, 2173, 2177.

43 Vgl. dazu Heuermann, DB 2009, 2173, 2177. 
b) Wertminderungen von Gesellschafterdarlehen im steuerlichen Betriebsvermögen

Gehören wertgeminderte Gesellschafterdarlehen zum steuerlichen Betriebsvermögen des Gesellschafters, handelt es sich um ein selbständiges Wirtschaftsgut neben der Beteiligung. ${ }^{44}$ Es sind zwei Fallgruppen zu unterscheiden.

(1) Gesellschafter und Darlehensgeber ist eine Kapitalgesellschaft (oder ein anderer Körperschaftsteuerpflichtiger):

- Seit dem VZ 2008 (§ 34 Abs. 1 KStG i. d. F. des JStG 2008) bleibt eine Gewinnminderung (z.B. durch Teilwertabschreibung) gem. $\S 8 \mathrm{~b}$ Abs. 3 Sätze 4 ff. KStG i.d.F. des JStG 2008 bei der Einkommensermittlung unberücksichtigt, wenn folgende Voraussetzungen vorliegen: Der Darlehensgeber ist oder war zu mehr als $25 \%$ unmittelbar oder mittelbar am Grund- oder Stammkapital der darlehensnehmenden Körperschaft beteiligt (gleichgestellt sind einem solchen Gesellschafter i.S. des $\S 1$ Abs. 2 AStG nahestehende Personen oder Gewinnminderungen aus Rückgriffen dritter Darlehensgeber auf den Gesellschafter oder diesem nahestehende Personen). Das Abzugsverbot entfällt nach $\S 8$ b Abs. 3 Satz 6 KStG, wenn auch ein fremder Dritter das Darlehen unter sonst gleichen Umständen gewährt oder noch nicht zurückgefordert hätte (dabei sind nur eigene Sicherungsmöglichkeiten der Gesellschaft zu berücksichtigen).

- In anderen Fällen (also soweit $\S 8$ b Abs. 3 Sätze 4 ff. KStG sachlich oder [vor 2008] zeitlich nicht anwendbar ist), greift das Abzugsverbot des $\S 8$ b Abs. $3 \mathrm{KStG}$ nicht. ${ }^{45}$ Durch Veröffentlichung im BStBl. II hat die FinVerw. zum Ausdruck gebracht, dass sie das BFH-Urteil anwendet /gem. Mitteilung v. 13.10.2009 auf der Homepage des BMF soll allerdings zur steuerlichen Behandlung von Teilwertabschreibungen auf Darlehen an verbundene ausländische Unternehmen und zur Anwendung des $\S 3 \mathrm{c}$ Abs. 2 EStG im Rahmen gesonderter BMFSchreiben Stellung genommen werden).

(2) Gesellschafter und Darlehensgeber ist Einzelunternehmer oder eine Mitunternehmerschaft (soweit daran unmittelbar oder mittelbar natürliche Personen beteiligt sind): Weil das Darlehen und die Beteiligung selbständige Wirtschaftsgüter sind, müssten die Wertminderungen die betrieblichen Einkünfte ohne Einschränkung durch $\S 3 \mathrm{c}$ Abs. 2 EStG mindern (eine Gesetzesänderung wie in $\S 8$ b Abs. 3 KStG

44 Vgl. BFH, Urt. v. 14.1.2009 - I R 52/08, BStBl. 2009 II, 674.

45 Vgl. BFH, Urt. v. 14.1.2009 - I R 52/08, BStBl. 2009 II, 674. 
ist nicht erfolgt). ${ }^{46}$ Die FinVerw. wendet jedoch $\S 3 \mathrm{c}$ Abs. 2 EStG, also das Halb- bzw. Teilabzugsverbot (Letzteres ab 2009), soweit an, wie das Darlehen nicht fremdüblich gewährt wurde. ${ }^{47}$

\section{3. Überlegungen zur Abgeltungsteuer}

Haben Gesellschafter einer Mitunternehmerschaft ein Darlehen gewährt, sind die daraus resultierenden Zinsen Sonderbetriebseinnahmen und infolgedessen gem. §32d Abs. 1 Satz 1 i. V.m. § 20 Abs. 8 EStG von der Anwendung des besonderen Steuersatzes ausgenommen. Gleiches gilt nach $\S 32$ d Abs. 2 Nr. 1 Satz 1 Buchst. b EStG mit Bezug auf Gesellschafter an Kapitalgesellschaften, die zu mindestens $10 \%$ beteiligt sind. Es gelangt in beiden Fällen auf die Zinsen in der Spitze ein Grenzsteuersatz von $47,475 \%$ statt des besonderen Steuersatzes von $26,375 \%$ (jeweils inkl. SolZ) zur Anwendung. Zur Steuerminderung kommen folgende Gestaltungsansätze in Betracht: ${ }^{48}$

- Verfügt die Personen- oder Kapitalgesellschaft über ausreichend freie Liquidität, kann das Gesellschafterdarlehen ganz oder partiell zurückgezahlt werden. Der Gesellschafter kann die Mittel dann zum begünstigten Steuersatz anlegen.

- Verfügt die Personen- oder Kapitalgesellschaft nicht über hinreichende Liquidität, muss sie eine etwaige Rückzahlung des Gesellschafterdarlehens refinanzieren. Es ist dann einerseits zu berücksichtigen, dass die Refinanzierung nicht im Zusammenhang mit der Kapitalanlage des Gesellschafters nach Rückzahlung des Darlehens erfolgen darf, weil anderenfalls die Zinserträge auf Grund der Regelung der Back-to-BackFinanzierung in $\S 32 \mathrm{~d}$ Abs. 2 Nr. 1 Satz 1 Buchst. c EStG erneut von der Anwendung des besonderen Steuersatzes ausgenommen wären. Bereits eine Vereinbarung marktüblicher Zinssätze schließt indes die Anwendung dieser Missbrauchsvorschrift aus. ${ }^{49}$ Schwerer wiegt, dass die Gestaltung wirtschaftlich nur vorteilhaft ist, wenn der Zinssatz für das Drittdarlehen (den die Mitunternehmerschaft resp. Kapitalgesellschaft $\mathrm{zu}$ entrichten hat) nicht zu stark vom Zinssatz für die Geldanlage abweicht (den der Gesellschafter erhält). Bei Stpfl., die dem Spitzen-

46 So z. B. auch Gosch in StF 28, 2009, Tz. A/17; Kleinert/Podewils, GmbHR 2009, 849, 850; Schulze zur Wiesche, GmbHR 2007, 847, 851; Fuhrmann/Strahl, DStR 2008, 125; Hoffmann, DStR 2008, 857, 860; Stahl, KÖSDI 2008, 15905; Schmidt/Schwind, NWB F 4, 5223, 5231 (Heft 3/2008); a. A. Dötsch/Pung in Dötsch/Pung/Jost/Witt, Die Körperschaftsteuer, § 8 b KStG Rz. 141 (Juni 2008).

47 Vgl. BMF, Schr. v. 8.11.2010 - IV C 6 - S 2128/07/10001 (DOK. 2010/0805444), BStBl. 2010 I, 1292.

48 Vgl. ausführlich Strahl, Ubg 2008, 143; Kollruss, GmbHR 2007, 1133.

49 Siehe Strahl, KÖSDI 2008, 15896, 15898 f. 
steuersatz-Zuschlag unterliegen, darf der Zinssatz für das Drittdarlehen den Zinssatz für die Geldanlage nicht um das 1,354-fache überschreiten (bei geringeren Grenzsteuersätzen schließt sich diese Schere weiter). ${ }^{50}$

- Ein weiterer Ansatz könnte in einem Zinsverzicht liegen. Für Mitunternehmerschaften findet die Abzinsungsregel des $\S 6$ Abs. 1 Nr. 3 EStG keine Anwendung. ${ }^{51}$ Bei Kapitalgesellschaften verbietet sich unter Berücksichtigung der Auffassung der FinVerw. ein völliger Zinsverzicht; stattdessen kann die Absenkung des Zinssatzes auf eine marginale Größe erwägenswert sein.

Beratungshinweise:

- Der auf Seiten der Personengesellschaft eingesparte Zinsaufwand kann als Ertrag der nach §34a EStG begünstigten Thesaurierungsbesteuerung zugeführt werden und unterliegt dann (zunächst) nur einem Steuersatz von $29,8 \%$. Das gleiche Ergebnis wird erreicht, wenn der Zinsertrag nicht entnommen, sondern einem Verrechnungskonto gutgebracht und insoweit die Anwendung des §34a EStG beantragt wird. In beiden Fällen ist jedoch bei einer späteren Überentnahme die Nachversteuerung (zum festen Steuersatz von 26,375 \%) zu gegenwärtigen.

- Bei einer Kapitalgesellschaft wird der ersparte Zins mit der niedrigeren ertragsteuerlichen Gesamtbelastung belegt $(29,8 \%$ bei einem GewStHebesatz von $400 \%$ ); eine Nachbelastung erfolgt erst bei Ausschüttung. Hier kann sich aber eine Sonderproblematik ergeben, wenn der Gesellschafter das gewährte Darlehen refinanziert hat, weil die Schuldzinsen nur nach Maßgabe des Teileinkünfteverfahrens abzugsfähig sind, soweit die Darlehensfinanzierung unentgeltlich erfolgt. ${ }^{52}$

50 Vgl. dazu ausführlich Strahl, Ubg 2008, 143, 146.

51 Vgl. BFH, Urt. v. 24.1.2008 - IV R 37/06, DStR 2008, 761 (unter Tz. II.3 der Urteilsgründe).

52 Vgl. BFH, Urt. v. 25.7.2000 - VIII R 35/99, BStBl. 2000 II, 701; OFD Frankfurt, Vfg. v. 18.10.2007 - S 2128 A - 4 - St 219, DB 2008, 92. 



\title{
Abfindungsklauseln in Gesellschaftsverträgen - Zivil- und Steuerrecht
}

\author{
Dr. Eckhard Wälzholz \\ Notar, Füssen
}

Inhaltsübersicht

I. Einführung

II. Aktuelle gesellschaftsrechtliche Probleme von Abfindungsklauseln

1. Die gesetzliche Ausgangslage, $\S 738$ BGB

a) Schuldner der Abfindung

b) Höhe der Abfindung und Bewertungsverfahren

c) Gesamtabrechnung per Abschichtungsbilanz

2. Übliche gesellschaftsvertragliche Regelungen

3. Beschränkungen der Abfindungszahlung und deren Grenzen

a) Der Höhe nach

b) Zeitliche Streckung

c) Unzulässige Kündigungserschwerung

d) Weitere Besonderheiten bei Kapitalgesellschaften

4. Vollständiger Ausschluss der Abfindung

5. Empfehlungen zur Gestaltung von Gesellschaftsverträgen

III. Steuerliche Folgen von Abfindungsklauseln

1. Einkommensteuer

a) Unentgeltlicher Erwerb

b) Teilentgeltliches Ausscheiden - Abfindung unter oder gleich Buchwert

c) Teilentgeltliches oder vollentgeltliches Ausscheiden Abfindung über dem Buchwert d) Verlust und negatives Kapitalkonto

e) Vermögensverwaltende Personengesellschaft

f) Probleme des Sonderbetriebsvermögens

g) Ausscheiden gegen Sachwertabfindung

h) Nachträglicher Forderungsausfall, § 175 Abs. 1 S. 2 Nr. 2 AO

2. Schenkungsteuerliche und erbschaftsteuerliche Auswirkungen des Ausscheidens eines Gesellschafters

a) Die maßgeblichen gesetzlichen Regelungen

b) Das grundsätzliche Besteuerungsproblem

c) Gestaltungsüberlegungen

d) Probleme der qualifizierten Nachfolgeklausel

e) Anpassung von gesellschaftsvertraglichen Abfindungsklauseln aufgrund der Erbschaftsteuerreform

f) Formulierungsvorschlag einer Abfindungsklausel

g) Zur Auslegung des $\S 10$ Abs. 10 ErbStGn. F., $§ 7$ Abs. 7 S. 3 ErbStG

IV. Exkurs: Die neue steuerliche Behandlung der qualifizierten Nachfolgeklausel

V. Zusammenfassung 


\section{Einführung}

Abfindungsklauseln beschäftigen die Gestaltungspraxis sowohl aus gesellschaftsrechtlicher als auch aus steuerrechtlicher Hinsicht immer wieder. ${ }^{1}$ In gesellschaftsrechtlicher Hinsicht geht es dabei insbesondere um folgende Fragestellungen:

1 Siehe insbes. Bacher/Spieth, Fehlerhafte Abfindungsklauseln in GmbH-Satzungen, GmbHR 2003, 517; Boujong, Abfindungsklauseln nach dem Tod eines Gesellschafters einer OHG und Pflichtteilsergänzungsansprüche, Festschrift Ulmer, 2003, S. 41 ff.; Brückner, Die Kontrolle von Abfindungsklauseln in Personengesellschafts- und GmbH-Verträgen, Diss. Berlin 1995; Casper/Altgen, Gesellschaftliche Abfindungsklauseln - Auswirkungen der Erbschaftsteuerreform, DStR 2008, 2319; Ebenroth/Müller, Die Abfindungsklauseln im Recht der Personengesellschaften, BB 1993, 1153; Engel, Abfindungsklauseln - eine systematische Übersicht, NJW 1986, 345; Geißler, Rechtsgrundsätze und Bewertungsfragen zur angemessenen Abfindung des ausscheidenden Gesellschafters, GmbHR 2006, 1173; Götzenberger, Konsequenzen des neuen Erbschaftsteuerund Bewertungsrechts bei Ausscheiden eines Gesellschafters aus einer Personen- oder Kapitalgesellschaft, BB 2009, 131; Groß, Gesellschaftsvertragliche Abfindungsklausel im Lichte der Erbschaftsteuerreform, ErbStB 2009, 154; Heckschen, Einziehung, Zwangsabtretung und Ausschluss in der Insolvenz eines GmbH-Gesellschafters, NZG 2010, 521; Hübner/Maurer, Erbschaft- und Schenkungsteuerliche Folgen gesellschaftsvertraglicher Abfindungsbeschränkungen für die verbleibenden Gesellschafter, ZEV 2009, 361 und 428; Hülsmann, GmbH-Abfindungsklausel: Stuttgarter Verfahren kein geeigneter Berechnungsmodus, GmbHR 2007, 290; Krumm, Gesellschaftsvertragliche Abfindungsklauseln und erbschaftsteuerliche Schenkungsfiktion - veränderte steuerliche Rahmenbedingungen nach der Erbschaftsteuerreform, NJW 2010, 187; Lange, Neues zu Abfindungsklauseln, NZG 2001, 635; Leitzen, Abfindungsklauseln bei Personengesellschaften und GmbHs - aktuelle Entwicklungen und Auswirkungen der Erbschaftsteuerreform, RNotZ 2009, 315; Milatz/ Kämper, GmbHR 2009, 470; Mohr, Abfindung an ausscheidende Gesellschafter, GmbH-StB 2010, 73; Neumayer/Imschweiler, Schenkungsteuer beim Ausscheiden eines Gesellschafters auf Basis gesellschaftsvertraglicher Abfindungsklauseln, DStR 2010, 201; Piltz, Rechtspraktische Überlegungen zu Abfindungsklauseln in Gesellschaftsverträgen, BB 1994, 1021; Piltz, Die Besteuerung beim Ausscheiden aus einer Personengesellschaft mit dem Tode, ZEV 2006, 205; Riedel, Gesellschaftsvertragliche Nachfolgeregelungen im Lichte der neuen Erbschaftsteuer, ZErb 2009, 2; Riedel, Zur erbschaftsteuerrechtlichen Behandlung von Einziehungs- und Zwangsabtretungsklauseln bei Kapitalgesellschaften, ZErb 2009, 113; Schwind/Schmidt, Gesellschaftsvertragliche Abfindungsklauseln - neue Wertansätze führen zur Steuerpflicht, NWB 2009, 297; Sigle, Gedanken zur Wirksamkeit von Abfindungsklauseln in Gesellschaftsverträgen, ZGR 1999, 659; Sörgel/Engelmann, Möglichkeiten der Anpassung von Buchwertabfindungen an den niedrigeren Verkehrswert bei der GmbH, DStR 2003, 1260; Volmer, Vertragspaternalismus im Gesellschaftsrecht? - Neues zu Abfindungsklauseln, DB 1998, 2507; Wälzholz, Auswirkungen der Erbschaftsteuerreform 2008/2009 auf Gesellschaftsverträge und die Besteuerung der Vererbung von Gesellschaftsanteilen, DStZ 2009, 591; Wangler, Abfindungsregelungen in 
- Was gilt bei fehlender Bestimmung im Gesellschaftsvertrag oder in der Satzung?

- Inwieweit können Abfindungsansprüche beim Ausscheiden eines Gesellschafters beschränkt oder gar ganz ausgeschlossen werden? ${ }^{2}$

- Wie ist der Wert des Abfindungsanspruchs zu ermitteln?

- Wann ist die Abfindung zu zahlen und inwieweit lassen sich Abfindungsansprüche stunden?

- Welche Regelungen sind im Gesellschaftsvertrag/in der Satzung empfehlenswert und welcher aktuelle Anpassungsbedarf besteht? ${ }^{3}$

- Lassen sich durch Abfindungsbeschränkungen pflichtteilsreduzierende Gestaltungen erreichen? ${ }^{4}$

- Lässt sich durch Abfindungsbeschränkung im Falle des Vermögensverfalls eines Gesellschafters der Gläubigerzugriff einschränken?

Als steuerrechtliche Fragestellungen ${ }^{5}$ sind insbesondere hervorzuheben:

- Wann werden im Falle des Ausscheidens gegen Abfindung Einkommensteuerbelastungen beim Ausscheidenden ausgelöst und wie werden diese besteuert? ${ }^{6}$

- Welche ertragsteuerlichen Konsequenzen hat die Leistung der Abfindung bei der Gesellschaft bzw. den erwerbenden Mitgesellschaftern?

- Wann werden beim Ausscheiden gegen eine unter dem gemeinen Wert liegende Abfindung Schenkungsteuer- oder Erbschaftsteuertatbestände erfüllt?

- Wer ist jeweils Steuerschuldner?

- Inwieweit lassen sich die Steuerbelastungen durch Gestaltungen vermeiden?

Die genaue Analyse der vorstehend geschilderten Fragestellungen führt zu dem Ergebnis, dass die wirtschaftlichen Zielsetzungen der Gesellschaft, nämlich die Liquidität der Gesellschaft zu schonen, häufig den

Gesellschaftsverträgen: Zum aktuellen Stand in Literatur, Rechtsprechung und Vertragspraxis, DB 2001, 1763; Wangler, Einfluss des neuen Bewertungs- und Erbschaftsteuerrechts auf Abfindungsregelung in Gesellschaftsverträgen, DStR 2009, 1501; Wangler/Dierkes, Gesellschaftsvertragliche Abfindungsregelungen: Rechtsprechung und Vertragspraxis, DS 2007,94.

2 Sigle, Gedanken zur Wirksamkeit von Abfindungsklauseln in Gesellschaftsverträgen, ZGR 1999, 659; Brückner, Die Kontrolle von Abfindungsklauseln in Personengesellschafts- und GmbH-Verträgen, Diss. Berlin 1995.

3 Speziell zu insolvenzbezogenen Problemen siehe Heckschen, NZG 2010, $521 \mathrm{ff}$.

4 Siehe Boujong, Festschrift Ulmer, 2003, S. 41 ff.; Wälzholz, NWB 2008, 4329.

5 Siehe insbes. Piltz, ZEV 2006, 205.

6 Siehe Mohr, GmbH-StB 2010, 73 ff. 
steuerlichen Zielsetzungen zuwiderlaufen. Die steuerlichen Fragestellungen haben insbesondere im Hinblick auf die erbschaftsteuerrechtliche Relevanz von Abfindungsklauseln wesentlich zugenommen. Dies liegt weniger an ausdrücklichen Gesetzesänderungen, die im Rahmen der Erbschaftsteuerreform 2010 in Kraft getreten sind, als vielmehr daran, dass der Erbschaftsteuertatbestand des $\S 3$ Abs. 1 Nr. 2 S. 2 ErbStG und der entsprechende schenkungsteuerliche Tatbestand des $\S 7$ Abs. 7 ErbStG immer schon auf die Differenz des Abfindungsbetrages gegenüber dem steuerlich maßgeblichen gemeinen Wert abgestellt hat. Durch die Hochbewertung in $\S \S 11,199 \mathrm{ff}$. BewG ist dieser bisher nur in seltenen Fällen maßgebliche Steuertatbestand mit neuem Leben erfüllt worden. ${ }^{7}$ Dies verleiht dem Thema eine besondere Aktualität.

Zur Einführung in die Problematik seien an dieser Stelle drei Beispiele geschildert, anhand derer die gesellschaftsrechtlichen und steuerlichen Probleme verdeutlicht werden.

Ausgangsbeispiel 1:

A ist an einer $\mathrm{GmbH}$ mit einem Geschäftsanteil zu nominal 50.000 Euro beteiligt; der gemeine Wert des Geschäftsanteils beträgt ca. 10 Mio. Euro. Der Gesellschafter A verstirbt und hinterlässt ein Testament, mit dem er seine nichteheliche Lebensgefährtin zur Alleinerbin eingesetzt hat. Die Mitgesellschafter können nach der Satzung den Geschäftsanteil einziehen oder zwangsabtreten und wollen wissen, welche zivilrechtlichen und steuerlichen Folgen eintreten.

Ausgangsbeispiel 2:

A ist an einer Einheits-GmbH \& Co. KG mit einem Kommanditanteil zu nominal 50.000 Euro beteiligt, gemeiner Wert ca. 10 Mio. Euro. Der Gesellschafter A verstirbt und hinterlässt ein Testament, mit dem er seine nichteheliche Lebensgefährtin zur Alleinerbin eingesetzt hat. Im Gesellschaftsvertrag der KG ist eine qualifizierte Nachfolgeklausel geregelt, bei der nur Abkömmlinge nachfolgeberechtigt sind.

Ausgangsbeispiel 3:

A ist an einer $\mathrm{GmbH}$ mit einem Geschäftsanteil zu nominal 50.000 Euro beteiligt; der gemeine Wert beträgt ca. 10 Mio. Euro. Der Gesellschafter A soll im Wege der Einziehung oder Zwangsabtretung aus der Gesellschaft ausgeschlossen werden gegen eine Abfindung, weil er nachhaltig gegen ein gesellschaftsvertraglich normiertes Wettbewerbsverbot verstoßen hat und daher der weitere Verbleib in der Gesellschaft nicht zumutbar ist.

7 Casper/Altgen, DStR 2008, 2319; Götzenberger, BB 2009, 131; Groß, ErbStB 2009, 154; Hübner/Maurer, ZEV 2009, 361 und 428; Krumm, NJW 2010, 187; Leitzen, RNotZ 2009, 315; Milatz/Kämper, GmbHR 2009, 470; Neumayer/ Imschweiler, DStR 2010, 201; Riedel, ZErb 2009, 2; Riedel, ZErb 2009, 113; Schwind/Schmidt, NWB 2009, 297; Wälzholz, DStZ 2009, 591; Wangler, DStR 2009, 1501. 


\section{Aktuelle gesellschaftsrechtliche Probleme von Abfindungsklauseln}

\section{Die gesetzliche Ausgangslage, $§ 738$ BGB}

Für alle Personengesellschaften und Personenhandelsgesellschaften ist $\S 738$ BGB die Ausgangsnorm. Sie findet auch auf offene Handelsgesellschaften, Kommanditgesellschaften und Partnerschaftsgesellschaften Anwendung. Nach dieser Bestimmung sind beim Ausscheiden eines Gesellschafters die verbleibenden Gesellschafter verpflichtet, dem Ausscheidenden dasjenige zu zahlen, was er bei der Auseinandersetzung erhalten würde, wenn die Gesellschaft zur Zeit seines Ausscheidens aufgelöst worden wäre. Der Abfindungsanspruch entsteht mit dem Zeitpunkt des Ausscheidens. ${ }^{8}$

\section{a) Schuldner der Abfindung}

Der Wortlaut dieser Norm spricht einerseits dafür, dass die Mitgesellschafter zur entsprechenden Zahlung verpflichtet wären. Dies ist jedoch nach herrschender Meinung nicht zutreffend. Schuldner der Abfindung ist vielmehr die jeweilige Gesellschaft. ${ }^{9}$ Allerdings haften bei einer GbR und einer OHG oder Partnerschaftsgesellschaft die jeweiligen Gesellschafter für alle Verbindlichkeiten der Gesellschaft. ${ }^{10}$ Insoweit kann bei Nichtzahlung der Abfindung durch die Gesellschaft selbst der ausgeschiedene Gesellschafter auch auf die Mitgesellschafter zurückgreifen. Aus den Erwägungen des gesellschaftsrechtlichen Treuegrundsatzes ist er jedoch regelmäßig zunächst verpflichtet, Befriedigungen bei der Gesellschaft selbst zu erlangen. Lediglich der Kommanditist haftet nur in den Grenzen der $§ 171 \mathrm{f}$. HGB für entsprechende Abfindungsansprüche.

Bei der GmbH oder AG entspricht es ganz herrschender Meinung, dass ohne abweichende Satzungsbestimmungen lediglich die Kapitalgesellschaft selbst Schuldner der Abfindung ist.

8 BGH v. 14.7.1997 - II ZR 122/96, NJW 1997, 3370.

9 Lorz in Ebenroth/Boujong/Joost/Strohn, HGB, 2. Auflage 2008, § 131 Rz. 65.

10 Soweit beim Ausscheiden eines Freiberuflers eine Altersversorgung anstelle der Abfindung vereinbart wird, ist das OLG Hamm hingegen davon ausgegangen, dass einen ausscheidenden Gesellschafter aus der verbleibenden GbR keine Haftung mehr für die Altersversorgung treffe, wohl auch nicht nach Nachhaftungsgrundsätzen, Siehe OLG Hamm v. 9.11.2009 - 8 U 46/09, MDR 2010, 476. 


\section{b) Höhe der Abfindung und Bewertungsverfahren}

Der Wortlaut des $\S 738$ BGB scheint wiederum dafür zu sprechen, dass der Abfindungsanspruch sich nach dem gedachten Liquiditationserlös des ausgeschiedenen Gesellschafters richtet. Nach ganz herrschender Meinung ist dem jedoch nicht so. Als Abfindung ist vielmehr der volle Wert des Gesellschaftsanteils einschließlich aller stiller Reserven geschuldet. ${ }^{11} \mathrm{Zu}$ diesem Zweck ist nach überwiegender Auffassung zunächst der Wert der Gesamtgesellschaft als gemeiner Wert zu ermitteln, aus dem anschließend der Wert des Gesellschaftsanteils des ausgeschiedenen Gesellschafters abzuleiten ist. Maßgeblicher Bewertungsstichtag ist derjenige des Ausscheidens. ${ }^{12}$ Nach $\S 740$ BGB nimmt der ausgeschiedene Gesellschafter grundsätzlich auch an schwebenden Geschäften teil, was üblicherweise allerdings abbedungen wird. Nach den vorstehenden Ausführungen hat ein ausscheidender Gesellschafter also grundsätzlich auch am good will teil.

Maßgeblicher Bewertungszeitpunkt ist der Stichtag des Ausscheidens.

Besonders problematisch und immer streitanfällig ist die Wahl des zutreffenden Bewertungsverfahrens. Während früher üblicherweise ein substanzwertorientierter Ansatz dominierend war, hat sich entsprechend den betriebswirtschaftlichen Erkenntnissen durchgesetzt, dass entweder ein so genannten Ertragswertverfahren ${ }^{13}$ oder aber ein Discounted-CashFlow-Verfahren ${ }^{14}$ maßgeblich ist. Der Substanzwert ist regelmäßig entsprechend den Grundsätzen von IDW S1 ${ }^{15}$ lediglich als Untergrenze eines gemeinen Wertes zu berücksichtigen, wenn bei ertragslosen Gesellschaften der Substanzwert höher als der Ertragswert ist. ${ }^{16}$ Ein Bewertungsverfahren nach IDW S1 wird üblicherweise als zutreffend anerkannt. In der Praxis entstehen regelmäßig Streitigkeiten über die Bewertung des Gesellschaftsanteils des ausgeschiedenen Gesellschafters. Zur Lösung dieses Streites wird regelmäßig der gemeine Wert geschätzt und hierbei entweder von den Beteiligten als Schiedsgutachter oder aber vom Gericht als Sachverständiger ein Wirtschaftsprüfer eingeschaltet, der anschlie-

11 BGH v. 21.4.1955 - II ZR 227/53, BGHZ 17, 130 ff.; BGH v. 16.12.1991 - II ZR 58/91, NJW 1992, 892; Hopt in Baumbach/Hopt, 34. Auflage 2010, § 131 Rz. 49; Mohr, GmbH-StB 2010, 73, 74; Leitzen, RNotZ 2009, 315.

12 Lorz in Ebenroth/Boujong/Joost/Strohn, HGB, 2. Auflage 2008, § 131 Rz. 74.

13 Lutter in Lutter/Hommelhoff, GmbHG, 17. Auflage 2009, § 34 Rz. 79.

14 Zur Bewertungsmethode des Discounted Cash Flow siehe Barthels, DStR 1995, 343, 348; Ballwieser, WPg 1995, 119, 121; siehe auch Lorz in Ebenroth/Boujong/ Joost/Strohn, HGB, 2. Auflage 2008, § 131 Rz. 91.

15 Grundsätze zur Durchführung von Unternehmensbewertungen, IDW Fachnachrichten, 2008, 271-292.

16 Lutter in Lutter/Hommelhoff, GmbHG, 17. Auflage 2009, § 34 Rz. 79; Piltz, Die Unternehmensbewertung in der Rechtsprechung, 3. Aufl. 1994, S. $181 \mathrm{ff}$. 
ßend das Unternehmen bewertet und hierbei auch die Bewertungsmethode festlegt, $\S \S 317 \mathrm{ff}$. BGB. ${ }^{17}$ Reine Substanzwertverfahren oder auch das so genannte Stuttgarter Verfahren nach R 98 ff. der Erbschaftsteuerrichtlinien 2003 gelten gesellschaftsrechtlich als ungeeignet ${ }^{18}$ und werden von der Rechtsprechung grundsätzlich nicht angewandt, sondern sind allenfalls im Falle der entsprechenden gesellschaftsvertraglichen Bestimmungen heranzuziehen.

Für das GmbHG und das AktG existieren keine ausdrücklichen Bestimmungen über die Abfindung eines Gesellschafters, der aus der Gesellschaft ausgeschlossen wird. Nach ganz herrschender Meinung ist als Abfindung auch hier der Verkehrswert des Geschäftsanteils geschuldet. ${ }^{19}$ Ein Durchgriff auf Mitgesellschafter scheidet regelmäßig aus. Die Bewertung des Gesellschaftsanteils erfolgt entsprechend.

Für die Ermittlung des gemeinen Wertes des Gesellschaftsanteils ist die indirekte Methode ${ }^{20}$ nach der zunächst der Wert der Gesellschaft ermittelt wird und dieser Gesamtwert anschließend auf die einzelnen Gesellschaftsanteile verteilt wird.

\section{c) Gesamtabrechnung per Abschichtungsbilanz}

Im Rahmen der Ermittlung des Abfindungswertes sind einzelne Forderungen eines Gesellschafters gegen die Gesellschaft regelmäßig nicht selbständig durchsetzbar, sofern gesellschaftsvertraglich nichts Abweichendes bestimmt ist. Es erfolgt hingegen über eine so genannte $\mathrm{Ab}$ schichtungsbilanz ${ }^{21}$ eine Gesamtabrechnung, in die auch die wechselseitigen Forderungen und Verbindlichkeiten zwischen Gesellschaft und ausscheidendem Gesellschafter mit einbezogen werden. ${ }^{22}$ Mit deren Feststellung ist der Abfindungsanspruch fällig. ${ }^{23}$

17 Hopt in Baumbach/Hopt, 34. Auflage 2010, HGB, § 131 Rz. 53.

18 So dezidiert Hülsmann, GmbHR 2007, $290 \mathrm{ff} . ;$ Lutter in Lutter/Hommelhoff, GmbHG, 17. Auflage 2009, § 34 Rz. 79 m. w. N.

19 BGH v. 16.12.1991 - II ZR 58/91, NJW 1992, 892; BGH v. 24.5.1993 - II ZR 36/92, NJW 1993, 2101; Geißler, GmbHR 2006, 1173; Altmeppen in Roth/Altmeppen, GmbHG, 6. Auflage 2009, § 34 Rz. 44; Leitzen, RNotZ 2009, 315.

20 Siehe BGH v. 18.4.2002 - IX ZR 72/99, ZIP 2002, 1144, 1149; BGH v. 16.12.1991 - II ZR 58/91, NJW 1992, 892.

21 Kritisch zur Abschichtungsbilanz Beck'sches Handbuch Personengesellschaften/Sauter, 3. Auflage 2009, § 7 Rz. 139 ff. (eher für eine Gesamtabrechnung ohne zwingende BIlanzierung); Lorz in Ebenroth/Boujong/Joost/Strohn, HGB, 2. Auflage 2008, § $131 \mathrm{Rz} .102$.

22 BGH v. 12.7.1999 - II ZR 4/98, WM 1999, 1827; BGH v. 15.5.2000 - II ZR 6/99, NZG 2000, 832, 833. Kritisch zur Abschichtungsbilanz: Lorz in Ebenroth/Boujong/Joost/Strohn, HGB, 2. Auflage 2008, § 131 Rz. 102.

23 Förstel, NJW 1994, 2268, 2269. 
Soweit der Abfindungswert des ausscheidenden Gesellschafters negativ ist, besteht bei GbR, OHG und Partnerschaftsgesellschaft eine Ausgleichspflicht nach $\S 739$ BGB und damit eine faktische Nachschusspflicht. ${ }^{24}$ Diese verstößt nach ganz herrschender Meinung auch nicht gegen das Verbot von Nachschusspflichten gem. § 707 BGB. ${ }^{25}$ Für den Kommanditisten gilt diese Verpflichtung zu Ausgleich eines negativen Kapitalkontos hingegen nicht, sofern er seine Einlage geleistet hat, § 167 Abs. 3 HGB. ${ }^{26}$

\section{2. Übliche gesellschaftsvertragliche Regelungen}

Üblicherweise werden in Gesellschaftsverträgen Regelungen zur Ermittlung und Zahlung der Abfindung im Falle des Ausscheidens eines Gesellschafters vorgesehen. Der Zweck entsprechender Bestimmungen in Gesellschaftsverträgen von Personengesellschaften und Satzungen von Kapitalgesellschaften besteht vor allem in der Bestandserhaltung, dem Liquiditätsschutz und der Streitvermeidung. ${ }^{27}$ Die entsprechenden Satzungsbestimmungen setzen dabei die Interessen der Gesellschaft meist über diejenigen des Gesellschafters. Wichtigstes Kriterium der Streitvermeidung ist häufig die Festlegung der Bewertungsmethode. Bei mittelständischen Gesellschaften wurde in der Vergangenheit häufig auf das Stuttgarter Verfahren nach R $98 \mathrm{ff}$. ErbStR 2003 verwiesen. Entsprechende Klauseln sollten schleunigst geändert werden, da ihre Auslegung seit dem Inkrafttreten der Erbschaftsteuerreform 2010 erhebliche Schwierigkeiten mit sich bringen. Ob es sinnvoll ist, im Gesellschaftsvertrag eine Bewertungsmethode festzulegen, hängt ganz von den Umständen des Einzelfalles ab. Einerseits besteht eine Vielzahl branchenspezifischer Bewertungsmethoden ${ }^{28}$ und eine Vielzahl sonstiger Bewertungsmethoden vom Substanzwert über allgemeine Ertragswertverfahren, das Verfahren nach IDW S1 oder Discounted-Cash-Flow-Verfahren. ${ }^{29}$ Gleichzeitig existieren beispielsweise im Bereich der DCF-Verfahren oder im Bereich der Ertragswertverfahren zahlreiche Unterspielarten, so dass die bloße Festlegung der Bewertungsart noch wenig aussagekräftig sein kann. Ferner sollte man sich auf ein Bewertungsverfahren nur dann festlegen, wenn man hinreichende Kenntnisse betriebswirtschaftlicher Bewertungsverfahren hat, um das für die jeweilige Gesellschaft zutreffende

24 BGH v. 19.12.1974-II ZR 27/73, NJW 1975, 1022.

25 Lorz in Ebenroth/Boujong/Joost/Strohn, HGB, 2. Auflage 2008, § 131 Rz. 114.

26 Beck'sches Handbuch Personengesellschaften/Sauter, 3. Auflage 2009, §7 Rz. 147.

27 Lorz in Ebenroth/Boujong/Joost/Strohn, HGB, 2. Auflage 2008, § 131 Rz. 115.

28 Siehe die ausführliche Übersicht in FM Bayern v. 30.12.2009 34 - S 3715 - 009 36659/09.

29 Siehe Großfeld, Recht der Unternehmensbewertung, 5. Aufl. 2009, Rz. 1012 ff. 
Bewertungsverfahren angemessen bestimmen zu können. Eine gesellschaftsvertragliche Klausel, die für jede Gesellschaft passt ist gewiss fehl am Platze. Vor dem Hintergrund ist in der Gestaltungspraxis eher Zurückhaltung anzuraten. Eine sinnvollere, wenn auch nicht Streit vermeidende Gestaltung kann darin bestehen, die Bewertungsmethode dem jeweiligen Schiedsgutachter zu überlassen.

Da eine Bewertung des Geschäftsanteils oder Gesellschaftsanteils ohne Einschaltung eines Sachverständigen meist nicht möglich ist, ist es regelmäßig empfehlenswert, zur Vermeidung eines Gerichtsverfahrens, den gemeinen Wert des Gesellschaftsanteils des Ausscheidenden durch einen Schiedsgutachter ermitteln zu lassen, der auch die Bewertungsmethode festlegt. Im Gesellschaftsvertrag sollten insoweit einerseits die Auswahl des Schiedsgutachters festgelegt werden, die Kostentragung sowie die Verbindlichkeit des Schiedsgutachterspruches nach § 317 BGB vereinbart werden. ${ }^{30} \mathrm{Um}$ die Einigung auf einen Parteischiedsgutachter zu vermeiden ist es empfehlenswert, den örtlich zuständigen Landgerichtspräsidenten oder IHK-Präsidenten mit der Auswahl des Schiedsgutachters zu beauftragen.

Ohne entsprechende gesellschaftsvertragliche Regelung ist es zweifelhaft, ob die Gesellschaft verpflichtet ist, dem ausgeschiedenen Gesellschafter bei langfristiger Stundung der Abfindungszahlung eine Sicherheit $\mathrm{zu}$ leisten. ${ }^{31}$ Gesellschaftsvertraglich wird daher ein Anspruch auf Sicherheitsleistung üblicherweise ausgeschlossen. Ferner wird die ansonsten geschuldete Fälligkeit mit Ausscheiden und Feststehen des Anspruches ${ }^{32}$ durch eine längerfristige Stundung ersetzt. In diesem Fall ist der Anspruch üblicherweise zu verzinsen, um von der Rechtsprechung Anerkennung zu finden. Um die Gesellschafter zu ermutigen, der Gesellschaft auch Kredit zu geben oder entnahmefähige Gewinnansprüche auf dem so genannten Privatkonto oder Forderungskonto stehen zu lassen, wird häufig vereinbart, dass Forderungen des Gesellschafters gegen die Gesellschaft auf entsprechenden Konten sofort auszuzahlen sind. Auf diese Weise werden sie aus der Gesamtabrechnung herausgenommen.

Regelungen zur Höhe der Abfindung können auch in einem Side-letter, also einer Nebenvereinbarung ${ }^{33}$ getroffen werden. Einen derartigen Fall

30 Siehe zu §§317-319 HGB Hopt in Baumbach/Hopt, 34. Auflage 2010, HGB, $\S 131 \mathrm{Rz} .53$.

31 Gegen einen Anspruch auf Sicherheitsleistung Leitzen, RNotZ 2009, 315, 318.

32 Fälligkeit des Abfindungsanspruches mit dem Zeitpunkt der Feststellung der Abschichtungsbilanz: Förstel, NJW 1994, 2268, 2269.

33 Siehe dazu Baumann/Reiss, ZGR 1989, $157 \mathrm{ff.}$; Duhnkrack/Hellmann, ZIP 2003, 1425 ff.; Dürr, BB 1995, 1365 ff.; Ehricke, Schuldvertragliche Nebenabreden zu GmbH-Gesellschaftsverträgen, 2004; Görgemanns, GmbHR 2004, 170 ff.; Habersack, ZGR 1994, 134 ff.; Hoffmann-Becking, ZGR 1994, 442 ff.; 
hatte der BGH in seiner Entscheidung vom 15.3.2010 zu entscheiden. ${ }^{34}$ Während die Satzung der $\mathrm{GmbH}$ eine allgemeine Abfindung vorsah, war in einer als Nebenvereinbarung der Gesellschafter auszulegenden Regelung bestimmt worden, dass die Abfindung wegen des Vorliegens eines Mitarbeiter-/Geschäftsführermodells auf den Nominalwert des Geschäftsanteils beschränkt werde. Diese Abrede wurde als echter Vertrag zugunsten der $\mathrm{GmbH}$ ausgelegt und konnte daher im Abfindungsprozess zwischen der $\mathrm{GmbH}$ und dem Ausscheidenden entgegengehalten werden.

\section{Beschränkungen der Abfindungszahlung und deren Grenzen}

a) Der Höhe nach

Der gesetzliche Ausgangspunkt der Abfindung zum vollen gemeinen Wert im Bereich der Personengesellschaften nach $\S 738$ BGB und im Bereich der Kapitalgesellschaften ${ }^{35}$ ist nicht zwingend, sondern abdingbar. Gleichzeitig entspricht es ganz herrschender Meinung, dass die Abfindung nicht beliebig herabgesetzt oder eingeschränkt werden kann. Im Bereich der Personengesellschaften folgt das Verbot von übermäßigen Abfindungsbeschränkungen einerseits aus dem Verbot von Kündigungserschwerungen nach $\S 723$ Abs. 3 BGB und aus $\S 138$ BGB, ${ }^{36}$ im Bereich der Kapitalgesellschaften ausschließlich aus $\S 138$ BGB. Ein ausscheidender Gesellschafter darf nicht sittenwidrig benachteiligt werden. Nach herrschender Meinung und ständiger Rechtsprechung ist eine Abfindungsklausel sittenwidrig und damit unwirksam, wenn im Zeitpunkt der Vereinbarung dieser gesellschaftsvertraglichen Klausel ein krasses Missverhältnis zwischen dem gemeinen Wert des Gesellschaftsanteils des ausscheidenden Gesellschafters und dem Abfindungsbetrag besteht. ${ }^{37}$ Liegt im Zeitpunkt der entsprechenden Vereinbarung ein solches krasses Missverhältnis nicht vor, sondern entwickelt sich dieses erst durch späte-

Jäger, DStR 1996, 1935 ff.; Joussen, Gesellschafterabsprachen neben Satzung und Gesellschaftsvertrag, 1995; Joussen, GmbHR 1996, 574 ff.; Mayer, MittBayNot 2006, 281 ff.; Noack, Gesellschaftervereinbarungen bei Kapitalgesellschaften, 1994; Priester, FS Claussen, 1997, S. 319 ff.; Stöhr, MittRhNotK 1996, 390 ff.; Ullrich, ZGR 1985, 235 ff.; Ulmer, FS Röhricht, 2005, S. 633 ff.; Ulmer, NJW 1987, 1849 ff.; Weber, Der side-letter zum GmbH-Vertrag als Grundlage und Grenze von Gesellschafterbeschlüssen, 1996; Weber, DStR 1997, $824 \mathrm{ff}$; Werner, GmbHR 2005, 1554 ff.; Wicke, DNotZ 2006, 419 ff.; Wicke, DStR 2006, 1137 ff.; Winter, ZHR 154 (1990), 259 ff.; Zöllner, FS Ulmer, 2003, S. 725 ff.; Wälzholz, GmbHR 2009, $1020 \mathrm{ff}$.

34 BGH v. 15.3.2010 - II ZR 4/09, GmbHR 2010, 980 ff. m. Komm. Podewils.

35 Altmeppen in Roth/Altmeppen, GmbHG, 6. Auflage 2009, § 34 Rz. 44.

36 Mohr, GmbH-StB 2010, 73, 74.

37 BGH v. 16.12.1991 - II ZR 58/91, DStR 1992, 652 = BGHZ 116, 359, 376; Leitzen, RNotZ 2009, 315. 
res Auseinanderdriften von Abfindungswert und gemeinem Wert, so wendet die Rechtsprechung ${ }^{38}$ eine Anpassung der gesellschaftsvertraglichen Klausel nach Treu und Glauben im Wege der ergänzenden Vertragsauslegung an, § 157 BGB. Diese Methode ist kritikwürdig, ${ }^{39}$ weil in vielen Fällen selbst in Kenntnis des krassen Auseinanderfallens die Vertragsteile gleichwohl die entsprechende Klausel gewollt hätten.

Nach herrschender Meinung gelten die vorstehenden Grenzen von Abfindungsbeschränkung grds. unabhängig vom Rechtsgrund des Erwerbs (zu Ausnahmen s. unten); selbst bei unentgeltlichem Erwerb eines Geschäftsanteils oder Gesellschaftsanteils soll also grundsätzlich die entsprechende gesellschaftsvertraglich geschuldete Abfindung an den vorstehenden Maßstäben gemessen werden. Auch ein unentgeltlicher Erwerber eines Geschäftsanteils ist grundsätzlich kein Gesellschafter minderen Rechts. ${ }^{40}$

Ein krasses Missverhältnis von gemeinem Wert und Abfindungswert wird üblicherweise angenommen, wenn die Abfindung nur $50 \%$ des gemeinen Wertes oder weniger beträgt. ${ }^{41}$ Die Beschränkung der Abfindung auf die Hälfte des Buchwertes ist daher regelmäßig unwirksam, $\S 138$ BGB. ${ }^{42}$ Auch wenn die $50 \%$-Grenze einen gewissen Anhaltspunkt gewährt, so kommt es doch jeweils auf alle Umstände des Einzelfalls an. Hierbei werden insbesondere die Dauer der Mitgliedschaft, der Anlass des Ausscheidens und die Leistungen des Ausscheidenden bei der Gründung, dem Aufbau und der Führung der Gesellschaft berücksichtigt. Sonstige weitere im Einzelfall relevante Belange können ebenfalls Einfluss nehmen.

Als problematisch haben sich die Fälle erwiesen, in denen zunächst beispielsweise Buchwertklauseln vereinbart wurden und später ein krasses Missverhältnis zwischen Abfindungswert und gemeinem Wert sich ergeben hat. Ohne Anpassung des Gesellschaftsvertrages findet dann eine Anpassung dieser Vereinbarung im Wege der ergänzenden Vertragsauslegung statt. Wird in dieser Situation jedoch die Abfindungsklausel nach oben korrigiert, verbleibt jedoch gleichwohl ein krasses Missverhältnis,

38 Bei späterem Entstehen eines krassen Missverhältnisses BGH v. 24.5.1993 II ZR 36/92, NJW 1993, 2101, 2102; BGH v. 20.9.1993 - II ZR 104/92, NJW 1993, 3193 = DB 1993, $2275=$ GmbHR 1993, 806.

39 Siehe die Nachweise bei Lutter in Lutter/Hommelhoff, GmbHG, 17. Auflage 2009, § 34 Rz. 89.

40 Siehe BGH v. 17.4.1989 - II ZR 258/88, ZIP 1989, 768, 772; Beck'sches Handbuch Personengesellschaften/Sauter, 3. Auflage 2009, § 7 Rz. 152.

41 Beck'sches Handbuch Personengesellschaften/Sauter, 3. Auflage 2009, § 7 Rz. 159; Lorz in Ebenroth/Boujong/Joost/Strohn, HGB, 2. Auflage 2008, § 131 Rz. 133; Leitzen, RNotZ 2009, 315, 319.

42 BGH v. 9.1.1989 - II ZR 83/88, NJW 1989, 2685; Lange, NZG 2001, 635, 642. 
so hat das OLG Hamm ${ }^{43}$ die Auffassung vertreten, dass die Änderung über den Gesellschaftsvertrag unwirksam sei und daher der volle gemeine Wert geschuldet sei. Ein Rückgriff auf die abgeänderte, anzupassende Buchwertklausel schied nach Auffassung des Gerichtes aus. Maßgeblich für die Inhaltskontrolle nach $\S 138$ BGB ist nach ganz h. M. der Zeitpunkt von deren Vereinbarung ${ }^{44}$ Diese Auffassung des OLG Hamm ist m. E. unzutreffend. Für die Gestaltungspraxis sollte in entsprechenden Konstellationen zur Vermeidung einer Abfindung zum vollen gemeinen Wert gleichwohl die ursprünglich wirksame, nunmehr aber unangemessene Klausel erhalten bleiben oder durch entsprechende Gestaltungen mit „Netz und doppeltem Boden" in jedem Fall eine Beschränkung der Abfindung auf ca. $60 \%$ des gemeinen Wertes zusätzlich vereinbart werden. ${ }^{45}$

Liegt bei Anwendung der gesellschaftsvertraglich vereinbarten Abfindungsklausel kein krasses Missverhältnis vor, so ist die entsprechende Klausel anzuwenden, selbst wenn sie nicht zum vollen gemeinen Wert führt.

Soweit eine Klausel eine herabgesetzte Abfindung ausschließlich für den Fall der Insolvenz des Gesellschafters oder der Zwangsvollstreckung in dem Gesellschaftsanteil vorsieht, so ist diese gesellschaftsvertragliche Klausel wegen beabsichtigter Gläubigerbenachteiligung nach § 138 BGB unwirksam. ${ }^{46}$ An die Stelle dieser Klausel tritt die Abfindung zum vollen Wert.

\section{b) Zeitliche Streckung}

Auch wenn die Abfindung der Höhe nach angemessen ist, so darf die Auszahlung des Abfindungsbetrages nicht unangemessen zeitlich gestreckt werden. Eine Streckung auf 5 Jahre ab dem Zeitpunkt des Ausscheidens wird bei angemessener Verzinsung üblicherweise anerkannt. ${ }^{47}$ Eine zeitliche Streckung auf 15 Jahre wird üblicherweise hingegen als unzulässig angesehen. ${ }^{48}$ An die Stelle dieser unwirksamen Klausel tritt dann die

43 OLG Hamm v. 4.12.2002 - Az: 8 U 40/02, DStR 2003, 1178 m. Anm. Wälzholz.

44 BGH v. 16.12.1991, II ZR 58/91, DStR 1992, 652; Bacher/Spieth, GmbHR 2003, 517,519 .

45 Siehe zu dieser Problematik auch Lorz in Ebenroth/Boujong/Joost/Strohn, HGB, 2. Auflage 2008, § $131 \mathrm{Rz} .127$.

46 BGH v. 12.6.1975 - II ZB 12/73, NJW 1975, 1835; eventuell abweichend BGH v. 19.6.2000 - II ZR 73/99, NZG 2000, 1027, 1028. Keine Gläubigerbenachteiligung und Sittenwidrigkeit wenn auch wichtiger Grund geregelt ist: BGH v. 12.6.1975 - II ZB 12/73, NJW 1975, 1835.

47 Koller in Koller/Roth/Morck, § $131 \mathrm{Rz} .19$; Hannes in Hesselmann/Tillmann/ Müller-Thuns, GmbH \& Co. KG, § 10 Rz. 261; Lange, NZG 2001, 635, 637; Lorz in Ebenroth/Boujong/Joost/Strohn, HGB, 2. Auflage 2008, § $131 \mathrm{Rz} .142$.

48 BGH v. 9.1.1989-II ZR 83/88, NJW 1989, 2685. 
gesetzliche Regelung der sofortigen Fälligkeit des Abfindungsguthabens. Ob eine zeitliche Streckung der Auszahlung auf 10 Jahre noch anzuerkennen ist, hängt von den jeweiligen Umständen des Einzelfalles ab. ${ }^{49}$ Diese Ungewissheit sollte üblicherweise in der Gestaltungspraxis vermieden werden.

In bestimmten Fällen wendet die Rechtsprechung ein strengeres Kontrollkriterium an, nach denen der volle gemeine Wert im Wesentlichen erreicht werden muss. Die allgemeinen Grundsätze gelten üblicherweise vor allem, wenn der Gesellschafter selbst ohne besonderen Grund den Austritt oder die Kündigung der Gesellschaft erklärt. Sofern der Gesellschafter hingegen seinen Austritt aus der Gesellschaft aus wichtigem Grund erklärt, den die Mitgesellschafter verursacht haben, so soll nach der Rechtsprechung und herrschenden Meinung hingegen eine Abfindungsklausel nur dann anzuerkennen sein, wenn sie im Wesentlichen eine Abfindung zum vollen gemeinen Wert vorsieht. ${ }^{50}$ Das gleiche gilt in Fällen, wenn ein Gesellschafter ausnahmsweise hinausgekündigt werden kann, ohne dass es eines wichtigen Grundes oder sachlichen Grundes bedarf. ${ }^{51}$ Diese Konstellationen sind nur selten, erfordern jedoch einen besonderen Schutz des Gesellschafters.

\section{c) Unzulässige Kündigungserschwerung}

Bei den Personengesellschaften spielt bei den vorstehenden Erwägungen stets auch die Norm des $\S 723$ Abs. 3 BGB entsprechend eine besondere Rolle, da das Recht zum Ausscheiden aus der Gesellschaft durch diese Norm besonders geschützt wird. Bei Kapitalgesellschaften wie der $\mathrm{GmbH}$ oder der AG besteht kein gesetzlich vorgesehenes Recht zur jederzeitigen Kündigung des Gesellschaftsverhältnisses durch Ausscheiden des Gesellschafters. Daher findet $\S 723$ Abs. 3 BGB hier keine Anwendung. Gleichwohl sind die Maßstäbe für die Anerkennung von Abfindungsbeschränkungen im Bereich der Personengesellschaften und der Kapitalgesellschaften grundsätzlich identisch. ${ }^{52}$

49 Unzulässig mit geltungserhaltender Reduktion OLG Karlsruhe v. 10.1.2006 8 U 27/05, NJOZ 2006, 3001; unzulässig mit sofortiger Auszahlung ohne geltungserhaltende Reduktion OLG Dresden v. 18.5.2000 - 21 U 3559/99, NZG 2000, 1042.

50 Siehe Lorz in Ebenroth/Boujong/Joost/Strohn, HGB, 2. Auflage 2008, § 131 Rz. 129.

51 Besonders strenger Maßstab bei Ausschluss eines Gesellschafters ohne wichtigen Grund nach BGH v. 29.5.1978 - II ZR 52/77, NJW 1979, 104.

52 Altmeppen in Roth/Altmeppen, GmbHG, 6. Auflage 2009, § 34 Rz. 48; BGH v. 16.12.1991 - II ZR 58/91, NJW 1992, 892; Wangler/Dierkes, DS 2007, 94, 95; Leitzen, RNotZ 2009, 315; siehe auch Lutter in Lutter/Hommelhoff, GmbHG, 17. Auflage 2009, § $34 \mathrm{Rz} .81 \mathrm{ff}$. 


\section{d) Weitere Besonderheiten bei Kapitalgesellschaften}

Bei der GmbH ist nach $\S 34$ Abs. 2 GmbHG zusätzlich zu beachten, dass die nachträgliche Einführung oder Verschärfung einer Abfindungsbeschränkung im Wege der Satzungsänderung der Zustimmung aller betroffenen Gesellschafter bedarf..$^{53}$

Soweit bei der $\mathrm{GmbH}$ eine satzungsmäßige Abfindungsbeschränkung grundsätzlich unwirksam ist, ist zusätzlich die Heilungswirkung des $\S 242$ Abs. 2 AktG zu berücksichtigen. § 242 Abs. 2 AktG findet auf die $\mathrm{GmbH}$ entsprechende Anwendung. ${ }^{54}$ Soweit eine Satzungsbestimmung entweder bei der Gründung der Gesellschaft oder bei einer späteren Satzungsänderung unwirksam ist, aber ins Handelsregister eingetragen wurde, so tritt mit Ablauf von 3 Jahren eine Heilung ein. In diesem Fall ist die entsprechende Satzungsbestimmung gleichwohl anzuerkennen. Dies hinderte den BGH jedoch nicht daran, eine Anpassung des nach der Satzung geschuldeten Betrages nach $\S 242$ BGB für möglich zu halten. ${ }^{55}$

BGH wörtlich: 56

„Ist ein Hauptversammlungsbeschluss nichtig i. S. d. § 241 Nr. 1, 3 und 4 AktG, so kann nach dieser Vorschrift seine Nichtigkeit dann nicht mehr geltend gemacht werden, wenn der Beschluss in das Handelsregister eingetragen worden ist und seitdem drei Jahre vergangen sind. Da das Gesetz die Heilung generell für Beschlüsse vorsieht, die wegen ihrer Bedeutung in das Handelsregister einzutragen sind, umfasst die Regelung auch nichtige Beschlüsse über Satzungsänderungen (BGHZ 99, 211 [217]). Nach dem Wortlaut der Bestimmung erstreckt sich die Heilung zwar nicht auf nichtige Regelungen der ursprünglichen Satzung. Darin ist jedoch zu Recht eine Ungleichbehandlung der durch Beschluss der Gründer festgestellten und der durch Hauptversammlungsbeschluss geänderten Satzungsbestimmungen gesehen worden, die sich weder rechtsdogmatisch noch rechtssystematisch rechtfertigen lässt (vgl. Geßler, ZGR 1980, 427 [453]). Da Sinn der Regelung die Herbeiführung von Rechtssicherheit ist, die bei gleicher Sachlage für alle Satzungsbestimmungen im Rechtsverkehr der Gesellschaften erforderlich ist und nicht davon abhängt, ob die Regelung bereits in der Ursprungssatzung getroffen oder später durch Hauptversammlungsbeschluss eingefügt worden ist, erscheint es geboten, den Rechtsgedanken dieser Vorschrift auch auf nichtige Bestimmungen der Ursprungssatzung anzuwenden..."

53 Altmeppen in Roth/Altmeppen, GmbHG, 6. Auflage 2009, § 34 Rz. 46; BGH v. 16.12.1991 - II ZR 58/91, NJW 1992, 892; Lutter in Lutter/Hommelhoff, GmbHG, 17. Auflage 2009, § 34 Rz. 81.

54 BGH v. 19.6.2000 - II ZR 73/99, NJW 2000, 2819; siehe auch Bacher/Spieth, GmbHR 2003, 517.

55 Leitzen, RNotZ 2009, 315, 319.

56 BGH vom 19.6.2000 - II ZR 73/99, GmbHR 2000, 822, 823. Zustimmend Geißler, GmbHR 2006, 1173, 1179 auch mit Hinweisen zu Gegenstimmen aus der Rechtslehre. 
Nach §398 FamFG kann jedoch die Amtslöschung der entsprechenden Klausel verlangt werden. ${ }^{57}$ Es sei also nach BGH keineswegs so, dass ewig sittenwidriges Satzungsrecht so sanktioniert werde. Damit sei der Rechtsverkehr hinreichend geschützt.

\section{Vollständiger Ausschluss der Abfindung}

Ein vollumfänglicher Ausschluss einer Abfindung ist gesellschaftsverträglich grundsätzlich nicht möglich. In folgenden Ausnahmefällen ist gleichwohl der vollständige Ausschluss der Abfindung anerkannt.

- Im Todesfall kann eine Abfindung nach herrschender Meinung in vollem Umfang ausgeschlossen werden. ${ }^{58}$ Für die Personengesellschaften gilt dies uneingeschränkt, während dies bei der $\mathrm{GmbH}$ umstritten aber h. M. ist ${ }^{59}$ und bei der Aktiengesellschaft nur selten problematisiert wird. 60

- Bei gemeinnützigen oder sonst nicht erwerbsorientierten, ideellen Gesellschaften kann eine Abfindung voll umfänglich ausgeschlossen werden. ${ }^{61}$

- Soweit für den Fall der Kündigung die Liquidation mit anschließender Auflösung der Gesellschaft und Verteilung des Liquidationsguthaben angeordnet wird, wird ebenfalls nicht der gemeine Wert des Gesellschaftsanteils als solcher abgefunden, sondern lediglich der verbleibende Liquidationswert verteilt.

- Anzuerkennen ist meines Erachtens ferner in Ausnahmefällen eine Klausel, die vor allem in Freiberuflergesellschaften von Bedeutung sein kann, wenn der ausscheidende Gesellschafter befugt ist, die von ihm bisher in der Gesellschaft betreuten Kunden/Mandanten anstelle einer Barabfindung zu übernehmen, wobei typischerweise die Gesellschaft verpflichtet wird, sich jeglichen Wettbewerbs- oder Abwerbungsbemü-

57 Siehe Altmeppen in Roth/Altmeppen, GmbHG, 6. Auflage 2009, § 34 Rz. 54; OLG München v. 3.12.2009 - 23 U 2863/09; BGH v. 19.6.2000 - II ZR 73/99, NJW 2000, $2819 \mathrm{f} . ;$ kritisch Geißler, NZG 2006, 527.

58 BGH v. 14.7.1971 - III ZR 91/70, WM 1971, 1338; Koller in Koller/Roth/Morck, HGB, § $131 \mathrm{Rz} .17$.

59 Lutter in Lutter/Hommelhoff, GmbHG, 17. Auflage 2009, § 34 Rz. 96 m. w. N.; Wicke, GmbHG, 2008, Anh. § 34 Rz. 19; Müller/Maul in Beck`sches Handbuch der GmbH, 4. Auflage 2009, § 13 Rz. 122; Mohr, GmbH-StB 2010, 73, 75 - alle vorstehenden für die Zulässigkeit des Ausschlusses jeder Abfindung.

60 Siehe dazu Jäger, Aktiengesellschaft, 2004, §52 Rz. 27; siehe auch Hüffer, AktG, 9. Auflage 2010, § 237 Rz. 18.

61 BGH v. 2.6.1997 - II ZR 81/96, NZG 1998, 25; OLG Hamm v. 26.5.1997 - 8 U 163/96, DB 1997, 1612; Mohr, GmbH-StB 2010, 73, 75; Beck'sches Handbuch Personengesellschaften/Sauter, 3. Auflage 2009, § 7 Rz. 153. 
hungen hinsichtlich der übernommenen Kunden/Mandanten zu enthalten. ${ }^{62}$ Diese Gestaltung wird auch anerkannt, wenn jeder Gesellschafter und die Gesellschaft sich nach dem Ausscheiden frei um die Mandate bemühen kann - ohne jegliches Wettbewerbsverbot. Ebenso kann der Abfindungsausschluss angemessen sein, wenn stattdessen eine Altersversorgung gewährt wird. ${ }^{63}$

- Soweit insbesondere bei Personengesellschaften die Abfindung für den Todesfall vollständig ausgeschlossen wird, so bietet sich hierdurch eine wirksame und bisher von der Rechtsprechung regelmäßig anerkannte Möglichkeit der Beschränkung von Abfindungsansprüchen. Zu diesem Zweck sollte gleichmäßig für alle Gesellschafter mit ungefähr gleichmäßig verteiltem Risiko eine Fortsetzungsklausel mit vollständigem Abfindungsausschluss vereinbart werden. Verstirbt ein Gesellschafter, so wächst der Gesellschaftsanteil des Verstorbenen den Mitgesellschaftern an. Diese haben keine Abfindung zu zahlen. Hierbei handelt es sich nach herrschender Meinung nicht um einen Fall des $\S 2301$ BGB. Da weder ein Gesellschaftsanteil noch ein Abfindungsanspruch im Nachlass entsteht, können Pflichtteilsansprüche hinsichtlich des Gesellschaftsanteils nicht entstehen. Gleichzeitig liegt nach bisher herrschender Meinung keine pflichtteilsergänzungsbedürftige unentgeltliche Zuwendung nach $\S 2325$ BGB vor, sofern die entsprechende Gestaltung gleichmäßig und mit ähnlichem Risiko für alle Gesellschafter gilt. Dann handelt es sich vielmehr um ein aleatorisches Rechtsgeschäft.

\section{Empfehlungen zur Gestaltung von Gesellschaftsverträgen}

Nach den vorstehenden Ausführungen gelten folgende Empfehlungen für die Gestaltung von Gesellschaftsverträgen.

- Buchwertklauseln sollten grundsätzlich nur bei Neugründung einer Gesellschaft verwandt werden, soweit bereits ein laufendes Unternehmen mit erheblichem Gewinnpotential vorliegt, können sie zur Nichtigkeit führen. In derartigen Fällen oder bei nachträglicher Einführung einer Buchwertklausel sollte stets mit "Netz und doppeltem Boden" gehandelt werden, also für den Fall der Unwirksamkeit der Klausel eine Kappung der Abfindung auf beispielsweise $60 \%$ des gemeinen Wertes hilfsweise vorgesehen werden.

62 So BGH v. 31.5.2010 - II ZR 29/09, ZIP 2010, 1595; siehe auch BGH v. 6.12.1993 - II ZR 242/92, DStR 1994, 401; BGH v. 6.3.1995 - II ZR 97/94, DStR 1995, 856; Beck'sches Handbuch Personengesellschaften/Sauter, 3. Auflage 2009, § 7 Rz. 161; Leitzen, RNotZ 2009, 315, 319.

63 Siehe OLG Hamm v. 9.11.2009-8 U 46/09, MDR 2010, 476. 
- Buchwertklauseln sollten ferner begrenzt werden auf den niedrigeren gemeinen Wert, da es nicht ausgeschlossen werden kann, dass bei ertragschwachen Gesellschaften der Buchwert im Einzelfall höher ist als der geschuldete gemeine Wert.

- Eine Bezugnahme auf das Stuttgarter Verfahren nach R $98 \mathrm{ff}$. ErbStR 2003 sollte in Zukunft vermieden werden, da dieses Verfahren von der Finanzverwaltung und vom Gesetzgeber nicht mehr angewandt wird.

- Soweit für die Bewertung auf den gemeinen Wert abgestellt wird, könnte nach $\S \S 9,11,199 \mathrm{ff}$. BewG auf das so genannte vereinfachte Ertragswertverfahren des Bewertungsgesetzes verwiesen werden. ${ }^{64} \mathrm{Um}$ insoweit Zweifel zu vermeiden empfiehlt es sich, für die Ermittlung des gemeinen Wertes stattdessen auf betriebswirtschaftliche Grundsätze Bezug zu nehmen.

- Zur Vermeidung gerichtlicher Prozesse empfiehlt sich die Festlegung des gemeinen Wertes durch einen Schiedsgutachter; der Bestellung eines Schiedsgerichtes bedarf es hierzu nicht, auch wenn dessen Möglichkeit zwischenzeitlich durch den BGH eindeutig anerkannt ist. ${ }^{65}$

Soweit es sich um ertragstarke Unternehmen handelt und nicht beispielsweise vermögensverwaltende Immobiliengesellschaften, so sollte

64 Soweit dies im Einzelfall gewünscht wird, sollte jedoch der Kapitalisierungsfaktor abweichend vom Gesetz mit einer festen Zahl festgelegt werden oder der Kapitalisierungsfaktor individuell nach betriebswirtschaftlichen Grundsätzen ermittelt werden.

65 BGH v. 6.4.2009 - II ZR 255/08, DStR 2009, 1043 = NJW 2009, 1962; dazu siehe Goette, Neue Entscheidung des Bundesgerichtshofs: Beschlussmängelstreitigkeiten im GmbH-Recht sind schiedsfähig, GWR 2009, 282088; Wagner, Anmerkungen zu Beschlussmängelstreitigkeiten im GmbH-Recht sind grundsätzlich schiedsfähig - „schiedsfähig II", GWR 2009, 281971. Götz/Peitsmeyer, Schiedsfähigkeit von Beschlussmängelklagen bei der $\mathrm{GmbH}$ - zugleich Besprechung des BGH, Urt. v. 6.4.2009, DB 2009, 1171; Böttcher/Helle, Zur Schiedsfähigkeit von Beschlussmängelstreitigkeiten - Schiedsfähigkeit II, NZG 2009, 700; Anm. zu BGH, Schiedsfähigkeit von Beschlussmängelstreitigkeiten bei der GmbH, NJW-Spezial 2009, 335; Borris, Die ergänzenden Regeln für gesellschaftsrechtliche Streitigkeiten der DIS, SchiedsVZ 2009, 299; Nietsch, Schiedsfähigkeit von Beschlussmängelstreitigkeiten in der GmbH, ZIP 2009, 2269; Lilja/Schaper/Schwedt, Schiedsfähigkeit von Beschlussmängelstreitigkeiten: Die neuen ergänzenden Regeln für gesellschaftsrechtliche Streitigkeiten der DIS, NZG 2009, 1281; Hafner/Witte, Schiedsfähigkeit von Beschlussmängelstreitigkeiten im Recht der $\mathrm{GmbH}$ am Maßstab der neuen BGH-Rechtsprechung und ihre Auswirkungen, DStR 2009, 2052; Nolting, Schiedsfähigkeit von Beschlussmängelstreitigkeiten, NotBZ 2009, 241; Werner, Schiedsfähigkeit von Beschlussmängelstreitigkeiten im Recht der GmbH, MDR 2009, 842; Wolff, Beschlussmängelstreitigkeiten im Schiedsverfahren, NJW 2009, 2021. 
die gesellschaftsvertraglich geschuldete Abfindung den Betrag von $60 \%$ des gemeinen Wertes des Gesellschaftsanteiles grundsätzlich nicht unterschreiten, anderenfalls droht die Nichtigkeit der Klausel nach $\S 138$ BGB.

- Für die Fälle des Austritts eines Gesellschafters aus der Gesellschaft aus wichtigem Grund sollte stets der volle gemeine Wert geschuldet sein.

- Die Stundung der Abfindung sollte auf nicht mehr als 5 Jahre verteilt werden und mit einem angemessenen Zinssatz wie beispielsweise $3 \%$ über dem Basiszinssatz verzinst werden.

- Soweit die Abfindung in Insolvenz- und Zwangsvollstreckungsfällen in das Vermögen des Gesellschafters beschränkt werden soll, darf die Abfindungsklausel sich nicht ausschließlich auf diese beiden Fälle beschränken, sondern sollte zusätzlich einen weiteren vergleichbaren Fall, insbesondere für den Fall des Ausscheidens aus wichtigem Grund erfassen. Dann liegt keine sittenwidrige Gläubigerbenachteiligung nach $\S 138$ BGB vor. ${ }^{66}$

- Das Ausscheiden des Gesellschafters sollte von der Leistung der Abfindung abgekoppelt werden. Diese Problematik stellt sich vor allem bei der GmbH. ${ }^{67}$ Die Grenzen der Zulässigkeit entsprechender Gestaltungen sind im Detail derzeit noch nicht abschließend geklärt, die grds. Anerkennung dieser Möglichkeit jedoch gesichert. Um die Einziehung bzw. Zwangsabtretung des Geschäftsanteiles zu ermöglichen, ist es empfehlenswert, 68 bei entsprechender Zustimmung der erwerbenden Gesellschafter deren persönliche Mithaftübernahme für die Leistung der Abfindung zu vereinbaren. Dies reduziert das Ausfallrisiko des ausscheidenden Gesellschafters und steigert daher die Wahrscheinlich-

66 BGH v. 19.6.2000 - II ZR 73/99, NJW 2000, 2819; BGH v. 12.6.1975 - II ZB 12/73, NJW 1975, 1835.

67 BGH v. 8.12.2008 - II ZR 263/07, GmbHR 2009, 313; BGH v. 17.7.2006 - II ZR 313/05, DStR 2006, 1900; BGH v. 30.6.2003, II ZR 326/01, GmbHR 2003, 1062 m. Komm. Blöse/Kleinert = BB 2003, 1749 f. = MDR 2003, $1188=$ NotBZ 2003, $351=$ DStR 2003, 1717 = NZG 2003, 871; KG Berlin v. 18.10.2005 - 1 W 27/05, GmbHR 2005, 1612; KG Berlin v. 6.2.2006 - 23 U 206/04, NZG 2006, 436 m. w. N.; Peetz, GmbHR 2000, 749 ff.; Lindeman/Imschweiler; GmbHR 2009, 423; Fromm, GmbHR 2005, 1477; Goette, FS Lutter, 2000, S. 399 ff.; Heckschen, GmbHR 2006, 1254; Heidinger/Blath, GmbHR 2007, 1184; Löwe/Thoß, NZG 2003, 1005; Goette, DStR 2001, 533; Wehrstedt/Füssenich, GmbHR 2006, 698; Braun, Einziehung von GmbH-Geschäftsanteilen nach dem MoMiG, GmbHR 2010, 82.

68 So ausdrücklich Goette, DStR 2006, 1901 ff. - Anm. zu BGH v. 17.7.2006 II ZR 313/05, DStR 2006, 1900. 
keit der Anerkennung einer entsprechenden sofortigen Ausscheidensklausel.

- Der Anspruch auf gegebenenfalls bestehende Sicherheitsleistung sollte abbedungen werden, ebenso der Anspruch auf Teilhabe an schwebenden Geschäften nach $\S 740$ BGB bei Personengesellschaften, da anderenfalls dauerhafte Streitigkeiten mit dem ausgeschiedenen Gesellschafter drohen.

- Bei Austritt aus wichtigem Grund oder Hinauskündigung ohne sachlichen Grund sollte regelmäßig eine Abfindung zum vollen Wert vorgesehen werden; ${ }^{69}$ bei unentgeltlicher Hinübertragung hat der BGH jedoch auch eine unentgeltliche Rückübertragung oder zum Nominalwert anerkannt (Managermodell). ${ }^{70}$

\section{Steuerliche Folgen von Abfindungsklauseln}

\section{Einkommensteuer}

Das Ausscheiden eines Gesellschafters aus einer Gesellschaft gegen Abfindung gilt als entgeltliches Veräußerungsgeschäft. Dies gilt sowohl für Mitunternehmeranteile ${ }^{71}$ als auch für steuerverstrickte Kapitalgesellschaftsanteile i. S. d. $\S \S 17,20$ Abs. 2 EStG. ${ }^{72}$ Soweit bei der Kapitalgesellschaft der Veräußerungsgewinn einer Kapitalgesellschaft entfällt, so greift $\S 8 \mathrm{~b}$ KStG ein, so dass grds. nur $5 \%$ des Gewinns pauschaliert

69 BGH v. 24.5.1993 - II ZR 36/92, MittBayNot 1994, 157; BGH v. 9.1.1989 - II ZR 83/88, ZIP 1989, 770, 772 = MittBayNot 1989, 223; Leitzen, RNotZ 2009, 315 , $316 \mathrm{~m} . \mathrm{w} . \mathrm{N}$.

70 BGH v. 19.9.2005 - II ZR 342/03, GmbHR 2005, $1561=$ DB 2005, $2404=$ BB 2005, $2427 \mathrm{~m}$. Anm. Gehrlein = DStR 2005, $1910=$ NotBZ 2005, $442=$ MDR 2006, 100. Zum Nominalwert BGH v. 15.3.2010 - II ZR 4/09, GmbHR 2010, 980 ff. m. Komm. Podewils. Vgl. dazu Böttcher, NZG 2005, 992; Bütter/Tonner, BB 2005, 283; Bütter/Tonner, MDR 2006, 61; Heckschen/Voigt, NotBZ 2005, 427; Hinderer, RNotZ 2005, 416; Hohaus/Weber, NZG 2005, 961; Kowalski/Bormann, GmbH-StB 2005, 380; Schneider/Wiechers, DB 2005, 2450; Sosnitza, DStR 2006, 99. So OLG Celle, GmbHR 2003, 1428 ff. mit kritischem Komm. von Schröder. Das OLG stützt sich dabei auf ein Rechtsprechung des BGH aus dem Jahre 1976, DB 1977, 342 = GmbHR 1977, 81.

71 Beck'sches Handbuch Personengesellschaften/Sauter, 3. Auflage 2009, § 7 Rz. 174.

72 Lutter in Lutter/Hommelhoff, GmbHG, 17. Auflage 2009, § 34 Rz. 98; siehe auch BMF v. 27.11.1998, IV C 6 - S 2741 - 12/98, BStBl. I 1998, 1509, Tz. 19, 24 (zum vergleichbaren Fall des Erwerbs eigener Anteile). A. A. Carlé in Carle/ Korn/Stahl/Strahl, EStG, Loseblatt, § 23 Rz. 46.8.5 (Mindermeinung). $\S 23$ EStG wird nach dessen Abs. 2 inzwischen stets durch Einkünfte anderer Einkunftsarten verdrängt. 
steuerpflichtig sind nach $\S 8$ b Abs. 3 KStG. Die Einziehung begründet für die Mitgesellschafter keine Anschaffung, ${ }^{73}$ wohl aber die entgeltliche Zwangsabtretung.

\section{a) Unentgeltlicher Erwerb}

Soweit der Übergang des Gesellschaftsanteils ohne jegliche Abfindung folgt, so liegt ein unentgeltlicher Rechtsübergang nach $\$ 6$ Abs. 3 EStG, $\S 17$ Abs. 1 S. 4 EStG vor. Der Rechtsnachfolger führt insoweit die Buchwerte des ausscheidenden Gesellschafters fort. Der Vorgang ist daher für den ausscheidenden Gesellschafter nicht steuerpflichtig und führt beim übernehmenden Gesellschafter nicht zu neuen Anschaffungskosten. Die Frage eines Schuldzinsenabzuges stellt sich insoweit nicht. Soweit ein $\mathrm{GmbH}$-Anteil sind allerdings in einem Betriebsvermögen befand wird der Anteil aus dem Betriebsvermögen entnommen und kann dadurch eine Entnahmebesteuerung nach $\S 6$ Abs. 1 Nr. 4 EStG auslösen.

\section{b) Teilentgeltliches Ausscheiden - Abfindung unter oder gleich Buchwert}

Ertragsteuerlich problematisch hingegen ist das Ausscheiden eines Gesellschafters gegen Abfindung. Dies führt zu einem Veräußerungstatbestand i.S.d. $\S \S 14,16$ Abs. 1, 18 Abs. 3 EStG, soweit es sich um Mitunternehmeranteile an der Personengesellschaft handelt. Bei Kapitalgesellschaften sind hingegen die $\S \S 17, \S 20$ Abs. 2 EStG einschlägig ${ }^{74}$ teilweise wird die Einziehung gegen Abfindung auch nach $\S 17$ Abs. 4 EStG nach den Grundsätzen entsprechend einer Kapitalherabsetzung behandelt; dies ist überzeugend, soweit die Einziehung tatsächlich mit einer Kapitalherabsetzung einhergeht. Dies würde zu Einkünften nach $\S 20$ Abs. 1 Nr. 2 EStG führen. ${ }^{75}$

Soweit bei Mitunternehmeranteilen der Abfindungsbetrag kleiner als der Buchwert des Mitunternehmeranteils oder gleich groß wie der Buchwert des Mitunternehmeranteils ist, so findet weiterhin grds. § 6 Abs. 3 EStG

73 Lutter in Lutter/Hommelhoff, GmbHG, 17. Auflage 2009, § 34 Rz. 98.

74 Gosch in Kirchhof, EStG, 9. Auflage 2010, § 17 Rz. 54; Stuhrmann in Blümich, EStG, § 17 Rz. 208; Lutter in Lutter/Hommelhoff, GmbHG, 17. Auflage 2009, $\S 34$ Rz. 98 m. w. N.; Schwetlik, GmbHR 2006, 752, 753. Auf Ebene der Kapitalgesellschaft ist die Leistung der Abfindung ergebnis-, also gewinnneutral (BFH v. 29.7.1992 - I R 31/91, BStBl. II 1993, 369 = GmbHR 1993, 380). Nur bei Zahlung einer überhöhten Abfindung liegt eine ergebnisrelevante vGA vor, siehe Weber-Grellet in Schmidt, EStG, 29. Auflage 2010, § $17 \mathrm{Rz} .101$; Gosch in Kirchhof, EStG, 9. Auflage 2010, § 17 Rz. 79; Strahl in Carle/Korn/Stahl/Strahl, EStG, Loseblatt, § 17 Rz. 53.

75 So Fromm, GmbHR 2005, 1477, 1481; Weber-Grellet in Schmidt, EStG, 2010, $\S 17 \mathrm{Rz} .101 \mathrm{ff}$. 
Anwendung. ${ }^{76}$ Der Aufteilungsgrundsatz, der ansonsten im Bereich des Kapitalgesellschaftsrechts anwendbar ist, ${ }^{77}$ ist hier m. E. nicht anzuwenden. Diese Bestimmung ist nur anwendbar bei einander nahestehenden Personen oder wenn sonst der Wille zur unentgeltlichen oder teilentgeltlichen Zuwendung nachweisbar ist. ${ }^{78}$ Bei gleichmäßiger Vereinbarung zwischen mehreren, einander fremden Gesellschaftern wird daher sogar bei gezielt niedriger Abfindung ein entgeltliches Veräußerungsgeschäft anerkannt, bei dem durch den ausscheidenden Gesellschafter ein Veräußerungsverlust ${ }^{79}$ oder ungewöhnlich niedriger Gewinn erzielt wird, ${ }_{i}^{80}$ die erwerbenden Mitgesellschafter erzielen durch den vergünstigten Erwerb hingegen keinen betrieblichen Gewinn, sondern haben wegen des damit verbundenen Anschaffungsvorgangs ihre Buchwerte dementsprechend im Rahmen einer Ergänzungsbilanz abzustocken. ${ }^{81}$ Bei Erwerb eines negativen Kapitalkontos erleiden die verbleibenden Gesellschafter auch keinen Erwerbsverlust. ${ }^{82}$

Im Bereich der Kapitalgesellschaftsanteile ${ }^{83}$ könnten auch derartige Vorgänge aufgrund des Aufteilungsgrundsatzes steuerpflichtig sein.

Beispiel: A hat einen Geschäftsanteil zu nominal 50.000,-Euro, gemeinem Wert von 100.000,- Euro und scheidet gegen Abfindung in Höhe von 50.000,- Euro aus der Gesellschaft aus. Nach dem Aufteilungsgrundsatz wäre der einheitliche Vorgang in einen entgeltlichen und einen unentgeltlichen Teil aufzuteilen. Den hälftigen Anschaffungskosten von 25.000,- Euro wären dann 50.000,- Euro Gegenleistung gegenüberzustellen. Richtigerweise kann dies jedoch nicht bei einem entsprechenden Vorgang zwischen fremden Dritten gelten, die einander nichts unentgeltlich zuwenden wollen. ${ }^{84}$

76 Beck'sches Handbuch Personengesellschaften/Sauter, 3. Auflage 2009, §7 Rz. 175.

77 Siehe Weber-Grellet in Schmidt, EStG, 29. Auflage 2010, § 17 Rz. 82, 105.

78 Siehe Korn/Strahl in Korn, EStG, § 6 Rz. 474.2 f. Zur Abgrenzung bei negativem Kapitalkonto siehe auch BFH v. 10.3.1998 - VIII R 76/96, BStBl. II 1999, 269.

79 So BFH v. 12.12.1996 - IV R 77/93, BStBl. II 1998, 180; BFH v. 24.10.1996 - IV R 90/94, BStBl. II 1997, 241; BFH v. 21.4.1994, IV R 70/92, BStBl. II 1994, 745.

80 Wacker in Schmidt, EStG, 29. Auflage 2010, § 16 Rz. 663 m. w. N.

81 BFH v. 12.12.1996 - IV R 77/93, BStBl. II 1998, 180 (dort für eine Abstockung in der Bilanz der KG selbst).

82 BFH v. 21.4.1994 - IV R 70/92, BStBl. II 1994, 745 mit Hinweisen auf anderslautende frühere Urteile des BFH.

83 Zur Behandlung des Erwerbs eigener Anteile bei der $\mathrm{GmbH}$ siehe Müller/Maul in Beck`sches Handbuch der $\mathrm{GmbH}$, 4. Auflage 2009, § 13 Rz. 122; wohl Mindermeinung Weber-Grellet in Schmidt, EStG, 2010, §17 Rz. 101; siehe auch BMF v. 27.11.1998, IV C 6 - S 2741 - 12/98, BStBl. I 1998, 1509.

84 Siehe auch BFH v. 22.7.2008 - IX R 15/08, BStBl. II 2008, 927 (zum Zeitpunkt der Verlustrealisierung), der grds. auch von einem Veräußerungsverlust ausgeht; der Aufteilungsgrundsatz gilt nur bei teilentgeltlichen Vorgängen, siehe Weber-Grellet in Schmidt, EStG, 29. Auflage 2010, § 17 Rz. 82, 105. Dies ist bei 
Teilweise wird die Einziehung gegen Abfindung auch nach den Grundsätzen einer Kapitalherabsetzung behandelt.

\section{c) Teilentgeltliches oder vollentgeltliches Ausscheiden - Abfindung über dem Buchwert}

Soweit die Abfindung größer ist als der Buchwert des übergehenden Gesellschaftsanteils, so liegt beim ausscheidenden Gesellschafter ein entgeltliches Veräußerungsgeschäft vor. ${ }^{85}$ Dieses ist nach $\S 16$ Abs. 1, Abs. 4, § 34 EStG steuerpflichtig. Soweit die Voraussetzungen der $\S \S 16$ Abs. 4, 34 Abs. 3 EStG erfüllt sind, ist einerseits ein Freibetrag als auch die Besteuerung mit $56 \%$ des sonst maßgeblichen Steuersatzes anwendbar, mindestens aber $16 \%$. Soweit diese Voraussetzungen nicht anwendbar sind, erfolgt eine Besteuerung nach $\S 34$ Abs. 1 EStG, die jedoch häufig keine steuerliche Entlastung mit sich bringt. Die vorstehenden Grundsätze der Besteuerung gelten sowohl bei Ausscheiden eines Gesellschafters bei Erwerben unter Lebenden, also insbesondere bei Ausschließung oder Kündigung eines Gesellschafters als auch bei Erwerben von Todes wegen. Der Veräußerungsvorgang im Falle des Ausscheidens eines Erblassers im Todesfall ist dabei der letzte rechtsgeschäftliche Vorgang des Erblassers. Die steuerlichen Wirkungen treten daher noch beim Erblasser ein. Dies ermöglicht durch geschickte Gestaltung, beim Erblasser gegebenenfalls vorhandene Verlustvorträge i.S.d. § $10 \mathrm{~d}$ EStG, die anderenfalls untergehen würden, noch beim Erblasser zu nutzen und gleichzeitig bei den durch Anwachsung erwerbenden Mitgesellschaftern erhöhtes Abschreibungspotential durch Anschaffungskosten zu erzielen. ${ }^{86}$

Dem Vorliegen eines entgeltlichen Veräußerungsgeschäftes steht nicht entgegen, dass das Ausscheiden des Gesellschafters zu Lebzeiten gegebenenfalls auf einer zwangsweisen Hinauskündigung des ausscheidenden Gesellschafters beruhen kann.

Bei Personengesellschaften wächst der Anteil des ausscheidenden Gesellschafters den übrigen Gesellschaftern im Wege der Anwachsung im Verhältnis ihrer Beteiligung an den Kapitalkonten I der Gesellschaft an. Diese Gesellschafter haben Anschaffungskosten auf die neu hinzu erworbenen Teile an der Gesellschaft. Zinsen, die die Gesellschafter zu zahlen haben, um die Abfindungsleistungen zu erbringen, sind Betriebsausgaben im Sonderbetriebsvermögen bei der Mitunternehmerschaft.

Einziehungsvorgängen hingegen regelmäßig nicht der Fall. Dort fehlt es regelmäßig an der Einigung über eine teilweise Unentgeltlichkeit.

85 Siehe BFH v. 12.12.1996 - IV R 77/93, BStB1. II 1998, 180.

86 Piltz, ZEV 2008, 376, 378; Wälzholz, DStR 2008, 1769, 1770. 


\section{d) Verlust und negatives Kapitalkonto}

Soweit den Gesellschafter insbes. bei einer OHG, GbR oder als Komplementär einer KG eine Nachschusspflicht nach § 739 BGB trifft, weil er ein negatives Abfindungsguthaben hat, so führt dies regelmäßig zu einem steuerrelevanten Verlust i. S. d. § 15 EStG. ${ }^{87}$

Liegt bei dem ausscheidenden Gesellschafter ein negatives Kapitalkonto vor, dass der Gesellschafter beispielsweise als Kommanditist nicht auszugleichen hat, so ist die Differenz zwischen dem Abfindungsbetrag und dem negativen Kapitalkonto der Gewinn. Eine Abfindung von 1,- Euro kann bei einem negativen Kapitalkonto von 500.000,- Euro also zu einem Gewinn von 500.001,- Euro führen. ${ }^{88}$

Soweit das negative Kapitalkonto bei einem Kommanditisten vorliegt und $\S 15$ a EStG eingreift, so gelten die vorstehenden Grundsätze grds. ebenso. ${ }^{89}$ Soweit allerdings das Entstehen des negativen Kapitalkontos sich steuerlich nach $\S 15$ a EStG nicht auswirken konnte, sondern nur $\mathrm{zu}$ verrechenbaren Verlusten geführt hat, so ist die Versteuerung des Gewinns aus der Auflösung des negativen Kapitalkontos um die nur verrechenbaren Verluste zu kürzen. ${ }^{90}$ Soweit das Ausscheiden hingegen unentgeltlich erfolgt, § 6 Abs. 3 EStG, so kann der verbleibende Gesellschafter den verrechenbaren Verlust fortführen. ${ }^{91}$

Gewerbesteuerliche Verlustvorträge gehen wegen des Erfordernis des Unternehmens- und Unternehmeridentität mit dem Ausscheiden eines Gesellschafters unter, soweit diese auf den ausscheidenden Gesellschafter entfallen sind. ${ }^{92}$

\section{e) Vermögensverwaltende Personengesellschaft}

Soweit es sich bei den betroffenen Personengesellschaften um vermögensverwaltende Gesellschaften handelt, wird gleichwohl der Tatbestand des $§ 23$ EStG verwirklicht, sofern die Gesellschaften mit Privatvermögen ausgestattet sind. Soweit also die Gesellschaft, aus der der ausscheidende Gesellschafter ausscheidet, innerhalb der letzten 10 Jahre Grundbesitz angeschafft hat, so gelten die im Gesamthandsvermögen der Gesellschaft befindlichen Grundstücke nach einer nicht zweifelsfreien

87 Beck'sches Handbuch Personengesellschaften/Sauter, 3. Auflage 2009, § 7 Rz. 179.

88 Wacker in Schmidt, EStG, 29. Auflage 2010, § 15a Rz. 215.

89 Siehe auch BFH v. 21.4.1994 - IV R 70/92, BStBl. II 1994, 745.

90 Siehe Beck'sches Handbuch Personengesellschaften/Sauter, 3. Auflage 2009, $\S 7$ Rz. 183; Wacker in Schmidt, EStG, 29. Auflage 2010, § 15a Rz. 224; von Beckerath in Kirchhof, EStG, 9. Auflage 2010, § 15 a Rz. 23.

91 BFH v. 10.3.1998 - VIII R 76/96, BStBl. II 1999, 269.

92 BFH v. 3.5.1993 - GrS 3/92, BStBl. II 1993, 616. 
Ansicht durch das Ausscheiden des Gesellschafters gegen Entgelt als veräußert, § 23 Abs. 1 S. 4 EStG. ${ }^{93}$ Im Bereich des $§ 23$ EStG gilt insoweit der Aufteilungsgrundsatz. ${ }^{94}$

Fälle des gewerblichen Grundstückshandels können auf diese Art und Weise m. E. hingegen nicht verwirklicht werden, weil im Regelfall die Vermutung der Anschaffung in zumindest bedingter Veräußerungsabsicht widerlegbar ist.

\section{f) Probleme des Sonderbetriebsvermögens}

Die Hinauskündigungsfälle oder Kündigungsfälle bei Personengesellschaften erstrecken sich gesellschaftsrechtlich ausschließlich auf den Gesellschaftsanteil selbst. Soweit wesentliche Betriebsgrundlagen sich im Sonderbetriebsvermögen befinden, bleibt dieses Sonderbetriebsvermögen regelmäßig beim ausscheidenden Gesellschafter und wird bei ihm in das Privatvermögen überführt. In entsprechenden Fällen handelt es sich daher nicht um einen Fall der Veräußerung eines Mitunternehmeranteils nach $\S 16$ Abs. 1 EStG, sondern um die Aufgabe eines Mitunternehmeranteils, §§ 16 Abs. 3 S. 1, Abs. 4, § 34 EStG. Soweit hingegen der Gesellschafter sein Sonderbetriebsvermögen in ein anderes Betriebsvermögen nach $\S 6$ Abs. 5 S. 2 EStG überführt, können $\S \S 16$ Abs. 4, $\S 34$ EStG nicht zur Anwendung gelangen, wenn nicht sämtliche stillen Reserven des Mitunternehmeranteils in einem Zuge aufgelöst werden. ${ }^{95}$ Bei entsprechenden Besteuerungskonstellationen, die einer Gestaltung noch zugänglich sind, sollte daher stets auf das Schicksal des Sonderbetriebsvermögens geachtet werden. Diese Probleme lassen sich vermeiden, indem das Sonderbetriebsvermögen in eine selbständige gewerblich geprägte $\mathrm{GmbH} \&$ Co. KG eingebracht wird.

Sonderbetriebsvermögen kann auch der Anwendung der $\S \S 13 \mathrm{a}, 13 \mathrm{~b}$, 19 a ErbStG entgegenstehen.

\section{g) Ausscheiden gegen Sachwertabfindung}

Besonderheiten gelten, wenn die Gesellschafter sich aus Anlass des Ausscheidens eines Gesellschafters darauf verständigen, oder dies bereits im Gesellschaftsvertrag abstrakt vorgesehen ist, dass der ausscheidende

93 So wohl Weber-Grellet in Schmidt, EStG, § 23 Rz. 47 unter Berufung auf BRDrs. 612/93, 61; ebenso Kuhlmann in Frotscher, EStG, § 23 Rz. 8; vgl. dazu ausführlich Peter, DStR 1999, $1337 \mathrm{ff}$.

94 Siehe BMF v. 5.10.2000 - IV C 3 - S 2256-263/00, DStR 2000, $1867=$ FR 2000,1158 = BStBl. I 2000, 1383, Tz. 30 f.; siehe dazu auch Tiedtke/Wälzholz, ZEV 2000, $293 \mathrm{ff}$.

95 BFH v. 12.4.2000 - XI R 35/99, BStBl. II 2001, 26; BFH v. 31.8 .1995 - VIII B 21/93, BStBl. II 1995, 890. 
Gesellschafter keine Barabfindung erhält, sondern stattdessen Wirtschaftsgüter des Gesamthandsvermögen auf diesen übertragen werden. Ein Fall der Realteilung nach $\S 16$ Abs. 3 S. 2 ff. EStG greift hier nicht ein, weil die Mitunternehmerschaft als solche fortbesteht. ${ }^{96}$ Stattdessen behandelt die Finanzverwaltung und herrschende Meinung einen Fall des Ausscheidens gegen Sachwertabfindung als entgeltliche Veräußerung des Mitunternehmeranteils, wobei die Gegenleistung für den Mitunternehmeranteil in dem gemeinen Wert des Sachwertes zu sehen ist. ${ }^{97}$ Ausnahmsweise lässt sich das Ausscheiden eines Gesellschafters gegen Sachwertabfindung nach $\S 6$ Abs. 5 S. 3 Nr. 1 EStG unter Buchwertfortführung darstellen, soweit das als Sachwertabfindung hingegebene Vermögen in ein Sonderbetriebsvermögen oder Betriebsvermögen des ausscheidenden Gesellschafters überführt wird und keine Schuldübernahme dabei erfolgt.

Die Behandlung bei der Gesellschaft bzw. den verbleibenden Mitgesellschaftern ist jeweils korrespondierend.

\section{h) Nachträglicher Forderungsausfall, § 175 Abs. 1 S. 2 Nr. 2 AO}

Soweit eine gestundete Abfindungsforderung nachträglich uneinbringlich wird, so handelt es sich insoweit um ein rückwirkendes Ereignis. ${ }^{98}$ Die ursprünglich bestandskräftige Veranlagung ist dementsprechend zu berichtigen.

\section{Schenkungsteuerliche und erbschaftsteuerliche Auswirkungen des Ausscheidens eines Gesellschafters}

Die maßgeblichen Normen der $\S 3$ Abs. 1 Nr. 2 S. 2, § 7 Abs. 7 ErbStG wurden bereits 1974 vom Gesetzgeber ins ErbStG eingefügt, ${ }^{99}$ um eine vom Gesetzgeber so wahrgenommene Gesetzeslücke zu schließen. Nach $\S 3$ Abs. 1 Nr. 2 S. 2 ErbStG gilt als steuerpflichtige Schenkung auf den Todesfall auch der auf dem Ausscheiden des Gesellschafters beruhende Übergang des Anteils eines Gesellschafters einer Personengesellschaft oder Kapitalgesellschaft, bei dessen Tod auf die anderen Gesellschafter oder die Gesellschaft, soweit der Wert, der sich für seinen Anteil zur Zeit seines Todes nach $\S 12$ ErbStG ergibt, die Abfindungsansprüche Dritter

96 BMF v. 28.2.2006 - IV B 2 - S 2242 6/06, BStBl. I 2006, 228 unter II.; BMF v. 27.3.2007 - IV B 2-S 2242/07/0002.

97 BMF v. 28.2.2006 - IV B 2 - S 2242 6/06, BStBl. I 2006, 228 unter II.; BMF v. 27.3.2007 - IV B 2-S 2242/07/0002.

98 BFH v. 14.12.1994 - X R 128/92, BStBl. II 1995, 465.

99 Siehe Kapp/Ebeling, ErbStG, § 3 Rz. 239 ff. und § 7 Rz. $191 \mathrm{ff}$. Anpassungen hat die Norm im Wesentlichen nur noch durch Art. 10 des StEntlG 1999/2000/2002 erfahren. Milatz/Kämper, GmbHR 2009, 470, $471 \mathrm{f}$. 
übersteigt. Das gleiche gilt für den Fall, dass bei einer Gesellschaft mit beschränkter Haftung der Geschäftsanteil eines Gesellschafters bei dessen Tod eingezogen wird und der sich nach $\S 12$ ergebende Wert ${ }^{100}$ seines Anteils zur Zeit seines Todes die Abfindungsansprüche Dritter übersteigt.

Im Bereich des Schenkungsteuerrechts gibt es in $\S 7$ Abs. 7 ErbStG eine dementsprechende Fiktion einer Schenkung. Danach gilt als Schenkung auch der auf dem Ausscheiden eines Gesellschafters beruhende Übergang des Anteils eines Gesellschafters einer Personengesellschaft oder Kapitalgesellschaft auf die anderen Gesellschafter oder die Gesellschaft, soweit der Abfindungswert niedriger ist als der nach § 12 ErbStG maßgebliche Wert des Gesellschaftsanteils. Das gleiche gilt in Fällen der Einziehung eines Geschäftsanteils einer Gesellschaft mit beschränkter Haftung. In den Fällen des $\S 7$ Abs. 7 gilt $\S 10$ Abs. 10 ErbStG sinngemäß.

\section{a) Die maßgeblichen gesetzlichen Regelungen}

Durch die Erbschaftsteuerreform 2008/2009 wurde ein neuer $\S 10$ Abs. 10 ErbStG eingefügt. Durch diese neue Norm, auf die auch $\S 7$ Abs. 7 S. 3 ErbStG verweist, soll sichergestellt werden, dass ein Erbe, der zunächst einen Gesellschaftsanteil erwirbt, diesen später jedoch herauszugeben hat, nicht den vollen Gesellschaftsanteil ohne die Begünstigungen nach $\S \S 13 \mathrm{a}, 13 \mathrm{~b}, 19 \mathrm{a}$ ErbStG zu versteuern hat, sondern nur den endgültig ihm zufallenden Abfindungsanspruch. Die Vergünstigungen nach $\S \S 13 a, 13 b, 19$ a ErbStG stehen dem Empfänger des Abfindungsanspruches nicht $z u$, da es sich um einen reinen Baranspruch handelt. ${ }^{101}$ Die beim Erblasser durch das Ausscheiden gegen Abfindung ausgelöste Einkommensteuerlast bei der Fortsetzungsklausel kann bei der Erbschaftsteuer des Erben nur nach $\S 10$ Abs. 5 Nr. 1 ErbStG als bereicherungsmindernder Posten geltend gemacht werden. ${ }^{102}$

100 Siehe zur Bewertung von Betriebsvermögen und Gesellschaften nach neuem Recht Creutzmann, DB 2008, 2784; Balmes/Felten, FR 2009, 258; Brüggemann, ErbBstg 2009, 74; Halaczinsky, UVR 2009, 44; Höne, BBEV 2009, 28; Höne, BBEV 2009, 62; Hübner, Ubg 2009, 1; Knief, DStR 2009, 604; Kohl/ Schilling, StuB 2008, 909; Philipp/Richter/Viskorf, DB Beilage 2, S. 1 ff.; Rohde/Gemeinhardt, StuB 2009, 167; Piltz, DStR 2009, 1829; Piltz, Brennpunkte aus Unternehmenssicht - Unternehmensbewertung, JbFfSt 2008/2009, 106; Kühnold/Mannweiler, BB 2008, 1879.

101 R 55 Abs. 2 S. 5 ErbStR 2003; Mohr, GmbH-StB 2010, 73, 78; Riedel, ZErb 2009, 2, 5; siehe zur Besteuerung des Abfindungsanspruchs mit Gestaltungshinweisen Piltz, ZEV 2006, $205 \mathrm{ff}$.

102 Piltz, ZEV 2006, 205, 206. 
b) Das grundsätzliche Besteuerungsproblem

Die vorstehend genannten Normen des $\S 3$ Abs. 1 Nr. 2 S. 2, 3 ErbStG und des $\S 7$ Abs. 7 ErbStG führen zu einer Besteuerung der Bereicherung der verbleibenden Gesellschafter, die dadurch eintritt, dass ein Gesellschafter ausscheidet - gleichgültig auf welche Art und Weise ${ }^{103}$ - und die Abfindung niedriger ist als der Steuerwert des Gesellschaftsanteils des ausscheidenden Gesellschafters. Beide Sondertatbestände des ErbStG spielen keine Rolle, wenn der Gesellschaftsanteil als solcher fortbesteht und nur auf eine andere Person übergeht wie bei der Nachfolgeklausel. ${ }^{104}$ Auch wenn $\S 7$ Abs. 1 Nr. 1 grundsätzlich eine freigebige Zuwendung voraussetzt und damit auch ein subjektives Tatbestandsmerkmal enthält, ist dies bei $\S 7$ Abs. 7 ErbStG nach herrschender Meinung nicht erforderlich. ${ }^{105}$ Es handelt sich um Fiktionstatbestände, mit denen der Gesetzgeber sicherstellen wollte, dass die durch herabgesetzte Abfindung eintretende Bereicherung in jedem Fall der Besteuerung unterliegt. Aus diesem Grunde sind Gestaltungen zur Vermeidung der entsprechenden Besteuerung nur eingeschränkt möglich. Gleichwohl hat die Praxis Gestaltungsüberlegungen entwickelt, mit deren Hilfe die Steuertatbestände der $\S \S 3$ Abs. 1 Nr. 2 S. 2, 3 ErbStG und des $§ 7$ Abs. 7 ErbStG sich vermeiden lassen.

\section{c) Gestaltungsüberlegungen}

Die wichtigsten Gestaltungsüberlegungen knüpfen an den gesetzlichen Wortlaut und die durch diesen gerissenen Lücken im Gesetz an. Nach einer teilweise in der Rechtslehre vertretenen Auffassung erfassen $\S 7$ Abs. 7 ErbStG und $\S 3$ Abs. 1 Nr. 2 S. 2, 3 ErbStG lediglich die Übertragung von Gesellschaftsanteilen auf die Gesellschaft selbst ${ }^{106}$ oder auf Mitgesellschafter. Demgegenüber soll sich der Steuertatbestand jeweils vermeiden lassen, wenn anstelle der Einziehung oder Übertragung auf

103 Also auch bei unfreiwilligem Ausscheiden.

104 Hübner/Maurer, ZEV 2009, 361, 363.

105 BFH v. 1.7.1992 - II R 20/90, BStBl. II 1992, 912 zu § 3 Abs. 1 Nr. 1 ErbStG, BFH v. 1.7.1992 - II R 12/90, BStBl. II 1992, 925; gleich lautende Erlasse der obersten Finanzbehörden der Länder 25.6.2009, z. B. FinMin Baden-Württemberg 25.6.2009 - 3 - S 3715/9, BStB1. I 2009, 713 Abschnitt 2 Abs. 3; Gebel in Troll/Gebel/Jülicher, ErbStG, § 7 Rz. 400; Groß, ErbStB 2009, 154, 155; Milatz/Kämper, GmbHR 2009, 470, 472; rechtspolitisch (de lege ferenda) jedoch kritikwürdig; siehe zur Kritik Meincke, ErbStG, 15. Aufl. 2009, § 7 Rz. 149.

106 In diesem Fall des Erwerbs eigener Anteile durch die GmbH soll bei der $\mathrm{GmbH}$ die $\mathrm{GmbH}$ selbst bereichert und damit Steuerschuldner sein mit der Folge der Steuerklasse III, sofern die $\S \S 13$ a, 13 b, 19 a ErbStG nicht eingreifen, siehe R 7 Abs. 3 ErbStR 2003. Bei der Einziehung sind hingegen die Mitgesellschafter bereichert. 
Mitgesellschafter die Übertragung an Dritte erfolgt. ${ }^{107}$ Dieser Gestaltungsansatz wird teilweise auch für Personengesellschaften empfohlen und ist dort gestaltbar. ${ }^{108}$ Es werden jedoch auch Bedenken gegen die Anerkennung dieser Gestaltung geltend gemacht. Dies beruht vor allem darauf, dass der jeweilige Dritte mit dem Erwerb des Gesellschaftsanteils zum Mitgesellschafter wird und damit gleichwohl in den Anwendungsbereich der $\S \S 3$ Abs. 1 Nr. 2 ErbStG und $\S 7$ Abs. 7 ErbStG fallen könnte. Gebel geht im Übrigen davon aus, dass bei Weitergabe des Erwerbsrechts an einen Dritten regelmäßig eine Abkürzung des Leistungsweges vorliege, so dass die Gesellschaft als Erwerber im steuerlichen Sinne anzusehen sei. ${ }^{109}$ Ferner besteht die Gefahr, dass dann $\S 7$ Abs. 1 Nr. 1 ErbStG erfüllt wird. ${ }^{110}$ Klärende Rechtsprechung hier ist nicht ersichtlich. Soweit jedoch die Abtretung an einen Nichtgesellschafter, also Dritten nicht auf dem Gesellschaftsvertrag, sondern auf einem selbständigen schuldrechtlichen Rechtsgeschäft beruht, so ist nicht mehr § 7 Abs. 7 ErbStG, sondern $\S 7$ Abs. 1 Nr. 1 ErbStG einschlägig. ${ }^{111}$

Soweit es um die Einziehung von Geschäftsanteilen geht ist ferner nur die Gesellschaft mit beschränkter Haftung erfasst und damit auch die UG (haftungsbeschränkt). Demgegenüber ist die Aktiengesellschaft oder auch vergleichbare ausländische Gesellschaftsformen vom Wortlaut der Norm nicht erfasst, so dass insoweit die Einziehung gegen herabgesetzte Abfindung nicht tatbestandsmäßig ist. ${ }^{112}$

Als dritter Gestaltungsansatz wird von Neumayer/Imschweiler ein weiteres interessantes Gestaltungsmodell vorgeschlagen. Anstelle von Einziehungs- oder Zwangsabtretungsklauseln soll stattdessen durch Gestaltung bedingter Kaufoptionen die Tatbestandsmäßigkeit ausgeschlossen werden. Diese Regelungen dürfen also nicht auf gesellschaftsvertraglichen Bestimmungen beruhen, sondern auf wechselseitigen Kaufangeboten, die später angenommen werden können. ${ }^{113}$ Bedenken bestehen gegen diese Gestaltung jedoch in der Weise, als die gezielte Vereinbarung eines besonders niedrigen Kaufpreises zur Erfüllung des Tatbestandes

107 Siehe dazu Gebel in Troll/Gebel/Jülicher, ErbStG, §7 Rz.410; Meincke, ErbStG, 15. Aufl. 2009, §7 Rz. 143; Beck'sches Handbuch Personengesellschaften/Sauter, 3. Auflage 2009, § 7 Rz. 139; Hübner/Maurer, ZEV 2009, 428, $40 \mathrm{f}$.

108 Hübner/Maurer, ZEV 2009, 428, 434.

109 Gebel in Troll/Gebel/Jülicher, ErbStG, § 3 Rz. 259 ff.

110 Siehe Neumayer/Imschweiler, DStR 2010, 201, 203 a. E.

111 BFH v. 1.7.1992 - II R 70/88, BStBl. II 1992, 921.

112 Hübner/Maurer, ZEV 2009, 428 a. E.; Neumayer/Imschweiler, DStR 2010, 201, 204. Siehe auch Milatz/Kämper, GmbHR 2009, 470, 475; Schwind/ Schmidt, NWB 2009, 297, 298 - zu § 10 Abs. 10 ErbStG.

113 Siehe Neumayer/Imschweiler, DStR 2010, 201, 204 unter Hinweis auf Meincke, ErbStG, § 7 Rz. 146; Gebel in Troll/Gebel/Jülicher, ErbStG, § 7 Rz. 407. 
nach $\S 7$ Abs. 1 Nr. 1 ErbStG führt, da jeweils die entsprechende Gestaltung freiwillig und dann auch mit dem Bewusstsein der Bereicherung erfolgt. ${ }^{114} \mathrm{Ob}$ die bloße Gegenseitigkeit dieser Vereinbarung dem entgegensteht, ist zweifelhaft.

Der wohl wichtigste praktische Gestaltungsansatz zur Vermeidung übermäßiger Steuerbelastungen im Anwendungsbereich der $\S \S 3$ Abs. 1 Nr. 2 S. 2, 3 ErbStG, $§ 7$ Abs. 7 ErbStG besteht darin, regelmäßig sicherzustellen, dass für den jeweiligen Erwerb durch die Mitgesellschafter die $\S \S 13 \mathrm{a}, 13 \mathrm{~b}, 19 \mathrm{a}$ ErbStG zur Anwendung gelangen. Ist dies der Fall, so können regelmäßig die steuerlichen Folgen auch bei einander nicht verwandten Personen noch hingenommen werden. Nach herrschender Meinung finden die Begünstigungen für Betriebsvermögen bei Personengesellschaften sowohl für die Fortsetzungsklausel, als auch für den Ausschluss eines Gesellschafters aus einer Personengesellschaft durch Hinauskündigung oder auch im Falle der Kündigung durch den Gesellschafter selbst Anwendung. ${ }^{115}$

Die Begünstigung nach $\S \S 13 \mathrm{a}, 13 \mathrm{~b}$ ErbStG kann jedoch gefährdet werden, wenn bei der Fortsetzungsklausel der Gesellschaftsanteil den Mitgesellschaftern anwächst, das wesentliche Sonderbetriebsvermögen jedoch wiederum den Erben zufällt. Dann liegt nämlich keine begünstigungsfähige Wirtschaftseinheit mehr vor. ${ }^{116}$

Weitere Voraussetzungen für die Anwendung des $\S 19$ a ErbStG ist ausweislich des eindeutigen Wortlautes ferner, dass es sich bei dem jeweiligen Erwerber um eine natürliche Person handelt. ${ }^{117}$ Für Kapitalgesellschaften als Mitgesellschafter einer Personengesellschaft scheidet daher beispielsweise die Anwendung des $§ 19$ a ErbStG aus. Dies hindert jedoch nicht die Gewährung der $\S 13 \mathrm{a}, \mathrm{b}$ ErbStG.

114 Siehe BFH v. 1.7.1992 - II R 70/88, BStBl. II 1992, 921, wo der BFH nach der Verneinung des $\S 7$ Abs. 7 ErbStG die Tatbestandsmäßigkeit nach $\S 7$ Abs. 1 Nr. 1 ErbStG prüfte.

115 Gleich lautende Erlasse der obersten Finanzbehörden der Länder 25.6.2009, z. B. FinMin Baden-Württemberg 25.6.2009 - 3 - S 3715/9, BStBl. I 2009, 713 Abschnitt 2 Abs. 3; Milatz/Kämper, GmbHR 2009, 470, 474 (für die Fortsetzungsklausel); Mohr, GmbH-StB 2010, 73, 78 (sowohl für Fortsetzungs- als auch für Ausschlussklausel); Schwind/Schmidt, NWB 2009, 297, 300. Auch für den Fall der Eintrittsklausel mit Ausübung des Eintrittsrechts werden $\S 13$ a, 13 b, 19 a ErbStG angewandt, Hübner/Maurer, ZEV 2009, 361, 365; R 55 Abs. 2 S. 4 ErbStR 2003.

116 Siehe Riedel, ZErb 2009, 2, 5; gleich lautende Erlasse der obersten Finanzbehörden der Länder 25.6.2009, z. B. FinMin Baden-Württemberg 25.6.2009, 3 S 3715/9, BStB1. I 2009, 713 Abschnitt 20 Abs. 3.

117 Tiedtke/Wälzholz in Tiedtke, ErbStG, 2009, §19a Rz. 4; Milatz/Kämper, GmbHR 2009, 470, 475 f.; Neumayer/Imschweiler, DStR 2010, 201, 205. 
Ebenso sollen die Fälle der satzungsgemäßen Zwangsabtretung eines GmbH-Geschäftsanteils an die Gesellschaft oder einen Mitgesellschafter zur Anwendung der $\S \S 13 \mathrm{a}, 13 \mathrm{~b}, 19 \mathrm{a}$ ErbStG führen, sofern der Abtretende unmittelbar zu mehr als $25 \%$ an der Kapitalgesellschaft beteiligt ist. ${ }^{118}$ Das dauerhafte Aufrechterhalten von Poolvereinbarungen und die Vermeidung von Verstößen gegen die Poolvereinbarung ist insoweit essentiell. Problematisch ist hingegen die Einziehung von GmbH-Geschäftsanteilen, da hierbei der Geschäftsanteil nicht auf dritte Personen übergeht, sondern erlischt. Aus diesem Grunde lehnt die Finanzverwaltung die Gewährung der $\S \S 13 a, 13$ b, 19 a ErbStG für Einziehungsfälle ab. ${ }^{119}$ In der Gestaltungspraxis sollten daher GmbH-Satzungen stets anstelle der Zwangseinziehung auch die Zwangsabtretung vorsehen. Hierbei sollte der jeweilige Geschäftsführer ermächtigt werden, alle hierzu erforderlichen Maßnahmen vorzunehmen. Dies ist auch die rechtskonstruktiv einfachere Gestaltung als die Einziehung, die stets mit vielen Tücken und Gefahren verbunden ist. ${ }^{120}$

\section{d) Probleme der qualifizierten Nachfolgeklausel}

Die qualifizierte Nachfolgeklausel kann zwar zu Auszahlungsverpflichtungen des den Gesellschaftsanteil erwerbenden Erben führen, dabei geht es rechtskonstruktiv jedoch um Ausgleichsansprüche innerhalb der Erbengemeinschaft und nicht um eine Abfindung i. S. d. § 738 BGB. Dieser Fall ist daher dogmatisch selbständig zu behandeln. Der Erwerber des Gesellschaftsanteils kommt in den Genuss der Betriebsvermögensvergünstigungen, der Miterbe verliert jedoch die entsprechenden Vergünstigungen nach $\S \S 13$ a Abs. 3, 13 b Abs. 3 S. 1 ErbStG. Soweit durch die qualifizierte Nachfolgeklausel dem qualifizierten Nachfolger ein Mehrwert zuwächst, als ihm nach seiner Beteiligungsquote an dem Nachlass zusteht und eine Ausgleichszahlung zu leisten hat, so wird dies zwar nach herrschender Meinung ertragsteuerlich als unentgeltlich behandelt. Der qualifizierte Nachfolger kann diese Aufwendungen weder als Anschaffungskosten geltend machen, noch die dazu gehörigen Schuldzinsen als Betriebsausgaben geltend machen. ${ }^{121}$ Erbschaftsteuerrechtlich bekommt der qualifizierte Nachfolger die Betriebsvermögensvergünstigungen jedoch nur insoweit, als er den zusätzlichen Erwerb des Gesellschaftsanteils durch Hingabe von weiterem Vermögen aus demselben Nachlass erwirbt. Soweit er eigenes Vermögen aufwenden muss, um den

118 R 7 Abs. 3 ErbStR 2003; Neumayer/Imschweiler, DStR 2010, 201, 205.

119 Gleich lautende Erlasse der obersten Finanzbehörden der Länder 25.6.2009, z. B. FinMin Baden-Württemberg 25.6.2009 - 3 - S 3715/9, BStBl. I 2009, 713 Abschnitt 2 Abs. 3. Ebenso Schwind/Schmidt, NWB 2009, 297, 301.

120 Siehe Heckschen, NZG 2010, $521 \mathrm{ff}$.

121 Wacker in Schmidt, EStG, § 16 Rz. 673 m. w. N. 
zusätzlichen Werterwerb auszugleichen, kommen die $\S \S 13 \mathrm{a}, 13 \mathrm{~b}$, 19 a ErbStG nicht zur Anwendung.

Einen eventuell zu zahlenden Ausgleichsanspruch konnte der qualifizierte Nachfolgeerbe früher nicht gemäß § 10 Abs. 5, Abs. 6 ErbStG bereicherungsmindernd geltend machen. Die durch den Ausgleichsanspruch begünstigten Miterben hatten den Ausgleichsanspruch damals nicht mit ihrem Nominalwert zu versteuern. Die Finanzverwaltung hält an dieser Ansicht wohl weiter fest. ${ }^{122}$

Scheitert die qualifizierte Nachfolgeklausel, weil keine qualifizierte Person zum Kreis der Erben gehört, dann wirkt die qualifizierte Nachfolgeklausel wiederum wie eine Fortsetzungsklausel und für diese ist die Geltung der $\S \S 13 \mathrm{a}, 13$ b, 19 a ErbStG grds. anerkannt. ${ }^{123}$

\section{e) Anpassung von gesellschaftsvertraglichen Abfindungsklauseln aufgrund der Erbschaftsteuerreform}

Aufgrund der vorstehend geschilderten geänderten steuerlichen Bedeutung von Abfindungsklauseln stellt sich die Frage, inwieweit sich Änderungsbedarf bei der Abfassung von Abfindungsklauseln in Gesellschaftsverträgen ergibt. ${ }^{124}$

Zunächst ist festzuhalten, dass trotz der nunmehr verschärft eingreifenden Erbschaftsbesteuerung Buchwertklauseln in gleichem Umfang wie bisher weiterhin verwandt werden können. Der bloße Eintritt einer entsprechenden Besteuerung steht dem nicht entgegen. Einerseits wird das Ziel der Liquiditätsschonung der Gesellschaft ebenso erreicht wie bisher, weil die Besteuerung (Steuerschuldnerschaft) üblicherweise die erwerbenden Gesellschafter und nicht die Gesellschaft trifft. ${ }^{125}$ Gleichzeitig wäre es „ökonomischer Harakiri“, zum Zwecke der Steuerersparnis bei der Schenkungsteuer bzw. Erbschaftsteuer den vollen gemeinen Wert auszahlen zu müssen. Denn die Erbschaftsteuerbelastung kann max. $50 \%$ in der Steuerklasse III betragen und bei Anwendung der $\S \S 13 \mathrm{a}, 13 \mathrm{~b}$ und 19 a ErbStG max. eine Steuerbelastung von 4,5\%. Soweit also Buch-

122 Gleich lautende Erlasse der obersten Finanzbehörden der Länder 25.6.2009, z. B. FinMin Baden-Württemberg 25.6.2009 - 3 - S 3715/9, BStBl. I 2009, 713 Abschnitt 7 Abs. 2 S. 5; a. A. Wälzholz, ZEV 2009, 113 ff. - im Ergebnis aber gleich.

123 Siehe bereits oben und Milatz/Kämper, GmbHR 2009, 470, 474.

124 Siehe beispielsweise Götzenberger, BB 2009, 131 f.; Casper/Altgen, DStR 2008, $2319,2321 \mathrm{f}$.

125 BFH v. 1.7.1992 - II R 20/90, BStBl. II 1992, 912; Groß, ErbStB 2009, 154, 156; siehe auch Milatz/Kämper, GmbHR 2009, 470, 476; Schmidt/Schwind, NWB 5/2009, 297, 305 mit entsprechendem Formulierungsvorschlag. 
wertklauseln bisher wirksam waren, können diese unverändert verwandt werden. Die Steuerbelastung ist insoweit das geringere Übel.

Soweit in der Vergangenheit Abfindungsklauseln die Bewertung nach dem so genannten Stuttgarter Verfahren vorsahen, so ist dies für zukünftige Gesellschaftsverträge nicht mehr empfehlenswert, da das Stuttgarter Verfahren gesetzlich nicht mehr aktuell ist und damit in Zukunft altes Recht angewandt werden müsste. Darüber hinaus wurde es von der Rechtsprechung stets skeptisch betrachtet, da es auch einen gewichteten Substanzwertanteil enthält und damit betriebswirtschaftlich im Ergebnis zweifelhaft sein kann. ${ }^{126}$ Soweit in Altgesellschaftsverträgen auf das Stuttgarter Verfahren verwiesen wurde, ist dieser Verweis hinsichtlich der Auslegung kritisch. ${ }^{127}$ Das Stuttgarter Verfahren ist bisher das von der Finanzverwaltung anzuwendende Verfahren zur Ermittlung des gemeinen Wertes von nichtbörsennotierten Kapitalgesellschaftsanteilen gewesen. Die entsprechende Klausel könnte so ausgelegt werden, dass an die Stelle des Stuttgarter Verfahrens nunmehr nach $\S \S 11,199 \mathrm{ff}$. BewG das so genannte vereinfachte Ertragswertverfahren getreten ist. Damit würden typischerweise Überbewertungen erreicht, die keinesfalls von den Vertragsteilen gewollt waren. ${ }^{128}$ Diese Problematik stellt sich noch deutlicher, sofern es sich nicht um die statische Verweisung auf ein Stuttgarter Verfahren zu einem bestimmten Zeitpunkt handelt, sondern auf die Bewertung nach dem Stuttgarter Verfahren in der jeweils gültigen Fassung. ${ }^{129}$ Die entsprechenden Auslegungen sind zwar abzulehnen, da bei der Ermittlung des tatsächlichen Willens der Gesellschafter nicht angenommen werden kann, dass sie das vereinfachte Ertragswertverfahren nach den $\S \S 199 \mathrm{ff}$. BewG gewollt hätten. ${ }^{130}$ Um entsprechende Streitigkeiten und Auslegungsschwierigkeiten jedoch zu vermeiden, sollte eine entsprechende Klausel dahingehend geändert werden, dass eine Bewertung des Gesellschaftsanteils zum gemeinen Wert ohne Bindung an die Vorgaben des Bewertungsgesetzes erfolgen soll. Von dem so ermittelten gemeinen Wert kann beispielsweise ein herabgesetzter Prozentsatz als Abfindung geschuldet sein. Ein Verweis auf die $\S \S 11,199 \mathrm{ff}$. BewG in Gesellschaftsverträgen sollte vermieden werden.

126 So dezidiert Hülsmann, GmbHR 2007, 290 ff.; Lutter in Lutter/Hommelhoff, GmbHG, 17. Auflage 2009, § 34 Rz. 79 m. w. N.

127 Siehe insbes. Casper/Altgen, DStR 2008, $2319 \mathrm{ff}$.

128 Daher eine entsprechende Auslegung zu Recht ablehnend Casper/Altgen, DStR 2008, 2319, 2323.

129 Siehe dazu Hülsmann, GmbHR 2007, 290, 292; Piltz, BB 1994, 1021, 1026; Casper/Altgen, DStR 2008, 2319, $2322 \mathrm{f}$.

130 Leitzen, RNotZ 2009, 315, 321. 


\section{f) Formulierungsvorschlag einer Abfindungsklausel}

\section{$\S^{\star \star \star}$ Abfindung}

1. Scheidet ein Gesellschafter-gleich aus welchem Grund-aus der Gesellschaft aus, so erhält er eine Abfindung nach Maßgabe der nachfolgenden Bestimmungen, soweit nicht abweichende Spezialregelungen in diesem Vertrag

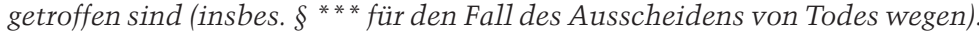

2. Zunächst ist der gemeine Wert des Gesellschaftsanteils nach den im Zeitpunkt des Ausscheidens geltenden Bewertungs-Grundsätzen des IDW auf diesen Zeitpunkt zu ermitteln. Ggfs. ist eine Zwischenbilanz zu erstellen.

Alternativ:

Zunächst ist der gemeine Wert des Gesellschaftsanteils nach einem geeigneten Bewertungsverfahren ohne Bindung an steuerliche Bewertungsverfahren auf diesen Zeitpunkt zu ermitteln. Bei Bedarf bestimmt das anzuwendende Bewertungsverfahren der Schiedsgutachter. Ggfs. ist eine Zwischenbilanz zu erstellen.

Alternativ:

Zunächst ist der gemeine Wert des Gesellschaftsanteils nach dem vereinfachten Ertragswertverfahren nach den § 199ff. BewG auf diesen Zeitpunkt zu ermitteln, abweichend von den gesetzlichen Bestimmungen ist jedoch der Kapitalisierungsfaktor nach betriebswirtschaftlichen Grundsätzen zu ermitteln; soweit die Vergangenheitserträge im Einzelfall keine angemessene Prognose der zu erwartenden zukünftigen Gewinne wiederspiegeln, sind die zukünftigen Gewinne zu schätzen und der Bewertung zugrunde zu legen. Ggfs. ist eine Zwischenbilanz zu erstellen.

3. Können die Gesellschaft und der ausscheidende Gesellschafter oder seine Rechtsnachfolger sich nicht auf den Wert des Gesellschaftsanteils des ausscheidenden Gesellschafters innerhalb von zwei Monaten nach dem Ausscheiden des Gesellschafters einigen, so ermittelt diesen Wert für alle Beteiligten verbindlich als Schiedsgutachter der im Zeitpunkt des Ausscheidens des Gesellschafters für die Gesellschaft tätige Wirtschaftsprüfer, hilfsweise Steuerberater. Dessen Kosten tragen Gesellschaft und ausgeschiedener Gesellschafter je zur Hälfte. Auf Verlangen des Ausscheidenden kann dieser auf eigene Kosten eine Überprüfung der Abfindungsermittlung durch einen für die Gesellschaft bisher nicht tätigen Wirtschaftsprüfer/WP-Gesellschaft verlangen. Dessen Ergebnis ist dann für alle Beteiligten nach \$ 317 BGB maßgebend.

4. Von dem so ermittelten Wert des Gesellschaftsanteils sind lediglich $60 \%$ auszuzahlen. Für den Fall des Ausscheidens wegen Insolvenzeröffnung, Ablehnung mangels Masse, Kündigung nach § 135 HGB, Pfändung von Gesellschafterrechten und wegen Unzumutbarkeit des ausscheidenden Gesellschafters bzw. von dessen Handeln ist jedoch vorrangig nur der Buchwert als Abfindung geschuldet, begrenzt auf den Verkehrswert des Gesellschaftsanteils in jedem Fall höchstens $60 \%$ des Wertes von dessen Gesellschaftsanteil. Mit diesem Abfindungswert sind das gesamthänderische Rücklagenkonto, das Kapitalkonto I und II abgefunden. Soweit das Ausscheiden des Gesellschafters auf einem wichtigen Grund beruht, den die Gesellschaft oder ein Mitgesellschafter zu vertreten hat, so ist eine Abfindung in Höhe von $90 \%$ des so ermittelten Wertes des Gesellschaftsanteils geschuldet. 
5. Der Abfindungsbetrag ist in drei/alternativ fünf gleichen Jahresraten auszuzahlen, erstmals zum 31.07., nachdem der Gesellschafter aus der Gesellschaft ausgeschieden ist. Das Abfindungsguthaben ist ab dem Ausscheiden mit jährlich 3,5\% zu verzinsen, beginnend mit dem Zeitpunkt des Ausscheidens, fällig mit der jeweiligen Jahresrate. Der Abfindungsbetrag wird in voller Höhe fällig, sowie die Gesellschaft mit einem Betrag in Höhe von mindestens einer halben Jahresrate für mehr als vier Monate in Verzug geraten ist.

6. Sicherstellung des Abfindungsbetrages kann nicht verlangt werden. Vorzeitige Zahlung der Abfindung unter Wegfall der Verzinsungspflicht ist zulässig.

7. Zum Zeitpunkt des Ausscheidens steht dem ausscheidenden Gesellschafter sein Guthaben auf seinem Privatkonto und den Darlehenskonten zu und ist mit dem Ausscheiden auszuzahlen, soweit nicht in einzelnen Darlehensvereinbarungen abweichende Bestimmungen getroffen wurden. Die Gesellschaft ist befugt, die Auszahlung zu verweigern, soweit sie aufgrund des Ausscheidens des Gesellschafters befugt ist, Zahlungen vom Gesellschafter zu verlangen, insbes. bei negativem Kapitalkonto. Insoweit gilt die vorstehende Stundungsregelung nicht. Ist das Privatkonto eines Gesellschafters im Zeitpunkt des Ausscheidens negativ, ist der Gesellschafter zum Ausgleich unverzüglich verpflichtet.

8. §740 BGB wird ausgeschlossen; an schwebenden Geschäften hat ein ausscheidender Gesellschafter also nicht Teil. Spätere Bilanzänderungen, insbesondere aufgrund einer Betriebs- bzw. Außenprüfung führen nicht zu einer Anpassung der Abfindung.

9. Sollte ein (Schieds-)Gericht feststellen, dass die hier getroffene Abfindungsregelung ganz oder teilweise unwirksam oder anpassungsbedürftig ist, so wird für diesen Fall die niedrigste noch zulässige Abfindung vereinbart.

10. Haftet ein ausscheidender Gesellschafter für die Verbindlichkeiten der Gesellschaft aus anderen Gründen als der Nichtaufbringung oder Rückzahlung der Haftsumme i. S. d. $\S \S 171-\S 172$ HGB, so hat die Gesellschaft den ausscheidenden Gesellschafter von einer Inanspruchnahme freizustellen, dies allerdings erst und nur für den Fall einer unmittelbar bevorstehenden/drohenden Inanspruchnahme durch den Drittgläubiger.

g) Zur Auslegung des § 10 Abs. 10 ErbStG n. F., § 7 Abs. 7 S. 3 ErbStG

$\S 10$ Abs. 10 ErbStG n.F. und $\S 7$ Abs. 7 S. 3 ErbStG gelten nur dann, wenn ein Gesellschaftsanteil zunächst auf einen Dritten übergeht und anschließend aufgrund einer gesellschaftsvertraglichen Bestimmung im Zeitpunkt der Entstehung des Steuertatbestandes wieder herausgegeben werden muss. ${ }^{131}$ Bei Personengesellschaften erfasst $\S 10$ Abs. 10 S. 1 ErbStG daher nicht die Fortsetzungsklausel, bei der der Gesellschafts-

131 Gleich lautende Erlasse der obersten Finanzbehörden der Länder 25.6.2009, z. B. FinMin Baden-Württemberg 25.6.2009 - 3 - S 3715/9, BStBl. I 2009, 713 Abschnitt 2. 
anteil erst gar nicht in den Nachlass fällt. ${ }^{132}$ Diese Norm ist vielmehr anwendbar, wenn der Gesellschaftsanteil sich zunächst vererbt und auf einen oder mehrere Erben übergeht und anschließend unverzüglich aufgrund einer gesellschaftsvertraglichen Regelung an die Mitgesellschafter $\mathrm{zu}$ einem unter dem gemeinen Wert liegenden Abfindungsbetrag herauszugeben ist. Dabei handelt es sich regelmäßig um Hinauskündigungsklauseln oder gesellschaftsvertraglich begründete Abtretungsverpflichtungen, die hier maßgeblich sind. $\S 10$ Abs. 10 ErbStG greift hingegen nicht ein, wenn die Übertragungsverpflichtung nicht auf einem Gesellschaftsvertrag beruht, sondern auf anderen schuldrechtlichen Rechtsgründen. Auf die Bereicherung die bei dem jeweiligen Mitgesellschafter als Erwerber eintritt, ist insoweit $\S 7$ Abs. 7 S. 3 ErbStG anzuwenden. ${ }^{133}$ Diese Anordnung ist insoweit problematisch, weil dieser Erwerbsfall bei den Mitgesellschaftern auch den Tatbestand des $\S 3$ Abs. 1 Nr. 2 ErbStG erfüllt. ${ }^{134}$ Diese Tatbestandskonkurrenz scheint dem Gesetzgeber nicht bewusst geworden zu sein.

$\S 10$ Abs. 10 ErbStG erfasst nur Erwerbe von Todes wegen. ${ }^{135}$

$\S 10$ Abs. 10 S. 2 ErbStG erfasst die vergleichbare Konstellation bei dem Erwerb eines GmbH-Geschäftsanteils, wenn anschließend eine Zwangsabtretung aufgrund einer gesellschaftsvertraglichen Bestimmung oder eine Einziehung nachfolgen. ${ }^{136}$ Nach dem klaren Wortlaut greift $\S 10$ Abs. 10 ErbStG nur bei Übertragungen an Mitgesellschafter ein. Erfolgt die Übertragung hingegen auf eine dritte Person, wie dies im Anwendungsbereich des $\S 3$ Abs. 1 Nr. 2 S. 2 ErbStG als Gestaltungsvariante angedacht wird, so könnte dies beim ursprünglichen Erben zu einer ungekürzten und ungeschmälerten Besteuerung des ursprünglich erworbenen Gesellschaftsanteiles führen. Gleiches gilt bei einer Zwangsabtretung an die Gesellschaft. ${ }^{137}$ Dies wird jedoch kaum dem Regelungsziel des Gesetzgebers zu $\S 10$ Abs. 10 ErbStG entsprechen, so dass insoweit $\S 10$ Abs. 10 ErbStG entsprechend anwendbar sein könnte. ${ }^{138}$

132 Siehe auch Gebel in Troll/Gebel/Jülicher, ErbStG, § 10 Rz. 274 ff.; Kapp/Ebeling, ErbStG, § 10 Rz. $200 \mathrm{ff}$.

133 Balmes/Felten, FR 2009, 258.

134 Hübner/Maurer, ZEV 2009, 428, 429 (dort auch mit Hinweis auf die Besteuerungsunterschiede, wenn man im Fall des $\S 7$ Abs. 7 S. 3 ErbStG einen Erwerb vom Erben und nicht vom Erblasser annimmt!); Gebel in Troll/Gebel/Jülicher, ErbStG, § 10 Rz. 278.

135 Kapp/Ebeling, ErbStG, § 10 Rz. 201.

136 Götzenberger, BB 2009, 131, 132; Kapp/Ebeling, ErbStG, § 10 Rz. 204.

137 Siehe Hübner/Maurer, ZEV 2009, 428, 431.

138 Ablehnend Riedel, ZErb 2009, 113, 115. 
Im Gesetz ist klargestellt, dass der oder die Mitgesellschafter und nicht die $\mathrm{GmbH}$ im Fall der Einziehung als bereichert anzusehen sind. ${ }^{139}$

$\S 10$ Abs. 10 ErbStG erwähnt dem Wortlaut nach ausschließlich den Erben, nicht aber den Vermächtnisnehmer, der zunächst den Gesellschaftsanteil erworben hat und ihn unverzüglich nachfolgend herauszugeben hat. $\S 10$ Abs. 10 ErbStG ist jedoch entsprechend auf andere Erwerbe von Todes wegen anzuwenden wie einen Vermächtnisweisen oder Auflageerwerb, weil nur so sichergestellt ist, dass die bei dem Erben, Vermächtnisnehmer oder Auflagenbegünstigten tatsächlich eintretende und verbleibende Bereicherung der Besteuerung unterworfen wird. ${ }^{140}$ Jede andere Auslegung des $\S 10$ Abs. 10 ErbStG würde zu einer verfassungswidrigen Übermaßbesteuerung führen.

$\S 10$ Abs. 10 ErbStG erfasst ausschließlich gesellschaftsvertragliche Einziehungs-, Hinauskündigungs- und Zwangsabtretungsregelungen. Andere schuldrechtliche Rechtsgründe führen die Wirkung des $\S 10$ Abs. 10 ErbStG hingegen nicht herbei. Die entsprechende gesellschaftsvertragliche Bestimmung muss bereits im Todeszeitpunkt bestanden haben. Spätere freiwillige oder aufgrund nachträglich vereinbarter gesellschaftsvertraglicher Klauseln erfolgende Abtretungen bewirken die Rechtsfolge des $\S 10$ Abs. 10 ErbStG hingegen nicht.

Die jeweilige Einziehung oder Abtretung hat unverzüglich zu erfolgen. Unverzüglich heißt ohne schuldhaftes Zögern. Soweit eine unklare Rechtslage besteht und daher entsprechende Beschlüsse und Maßnahmen noch nicht sicher durchgeführt werden können, kann eine daraus resultierende Verzögerung nicht schuldhaft sein. ${ }^{141}$

Unklar ist, welche Rechtsfolgen eintreten sollen, wenn das Gebot der Unverzüglichkeit nicht eingehalten wird. Hübner/Maurer ${ }^{142}$ betrachten $\S 10$ Abs. 10 ErbStG als Steuertatbestand und gehen davon aus, dass die Steuerbarkeit bei Verstoß gegen die Unverzüglichkeit entfällt. Dies vermag jedoch nicht zu überzeugen, da § 10 Abs. 10 ErbStG keinen Steuertatbestand regelt, sondern lediglich den Erwerbsgegenstand zugunsten des steuerpflichtigen Erben modifiziert. Es ist wohl anzunehmen, dass der Erbe bei Verstoß gegen die Unverzüglichkeit zunächst den Gesellschaftsanteil mit der Nachversteuerung des $\S 13$ a Abs. 5 ErbStG ungeschmälert $\mathrm{zu}$ versteuern hat und die nachfolgende Zwangseinziehung oder -abtretung als selbständiger neuer Steuerfall behandelt wird. Beim

139 Kapp/Ebeling, ErbStG, § 10 Rz. 204.

140 Ebenso Szczesny in Tiedtke, ErbStG, 2009, § 10 Rz. 96. Ohne Aussage dazu Gebel in Troll/Gebel/Jülicher, ErbStG, § 10 Rz. 276; a. A. hingegen wohl Hübner/Maurer, ZEV 2009, 428, 432.

141 Gebel in Troll/Gebel/Jülicher, ErbStG, § 10 Rz. 276.

142 Hübner/Maurer, ZEV 2009, 428, 431. 
Erben ließe sich dann die harte Nachversteuerung nach $\S 13$ a Abs. 5 ErbStG vermeiden, wenn man mit der Einziehung bzw. Zwangsabtretung mehr als fünf Jahre nach dem Todestag warten würde, da dann im Regelfall die Haltefrist des $\S 13$ a Abs. 5 ErbStG abgelaufen wäre. Der spätere Erwerb des Abfindungsanspruchs wäre beim Erben dann m. E. gar nicht erbschaftsteuerpflichtig, sondern nur einkommensteuerpflichtig.

Als Rechtsfolge hat der Erbe nur den Baranspruch zu versteuern, der ihm aufgrund der gesellschaftsvertraglichen Regelung verbleibt - allerdings ohne jegliche Begünstigungen für Betriebsvermögen. ${ }^{143}$

\section{Exkurs: Die neue steuerliche Behandlung der qualifizierten Nachfolgeklausel}

Die qualifizierte Nachfolgeklausel bei einer Personengesellschaft ist kein unmittelbares erbschaftsteuerliches Problem der Abfindung. Denn bei der qualifizierten Nachfolgeklausel entsteht im Regelfall kein Abfindungsanspruch, den die Gesellschaft an einen bisherigen Gesellschafter auszuzahlen hätte. Ist mindestens ein Erbe des verstorbenen Gesellschafters qualifizierter Nachfolger, so geht der Gesellschaftsanteil auf diesen oder alle qualifizierten Nachfolger im Wege der automatisch wirkenden Erbauseinandersetzung über. Eine Abfindungsleistung hat daher auf gesellschaftsvertraglicher Grundlage nur dann zu erfolgen, wenn die qualifizierte Nachfolgeklausel scheitert, weil keiner der Erben des Gesellschafters die gesellschaftsvertraglich vorgesehenen Bedingungen erfüllt. In diesem Fall wirkt die qualifizierte Nachfolgeklausel wie eine Fortsetzungsklausel, wobei der versterbende Gesellschafter mit seinem Ableben aus der Gesellschaft ausscheidet und seine Erben eine Barabfindung bekommen.

Neu ist an der steuerlichen Behandlung der qualifizierten Nachfolgeklausel hingegen, dass die Wirkung wie eine Erbauseinandersetzung nunmehr erbschaftsteuerrechtlich relevant wird. Geht beispielsweise ein Gesellschaftsanteil von 1 Mio. Euro gemeinem Wert auf einen qualifizierten Miterben über, während der andere Miterbe entsprechendes Barvermögen erwirbt, so führt die Wirkung der $\S \S 13$ a Abs. 3, § 13 b Abs. 3 dazu, dass der das Betriebsvermögen Erwerbende in den uneingeschränkten Genuss der $\S \S 13 \mathrm{a}, 13 \mathrm{~b}$ und $19 \mathrm{a}$ ErbStG gelangt und daher im genannten Beispielsfall grundsätzlich keinerlei Steuerlast zu tragen hat, während der andere Erbe ausschließlich das auf ihn entfallende Barvermögen des Nachlasses zu versteuern hat. Während die qualifizierte Nachfolgeklau-

143 Mohr, GmbH-StB 2010, 73, 78; Riedel, ZErb 2009, 2, 5; siehe zur Besteuerung des Abfindungsanspruchs mit Gestaltungshinweisen Piltz, ZEV 2006, 205 ff. 
sel bis zum Inkrafttreten der Erbschaftsteuerreform 2008/2009 erbschaftsteuerlich unbeachtlich war, führt sie nunmehr zu einer Verschiebung der Steuerbelastung zwischen den Erben. ${ }^{144}$

Diese steuerliche Behandlung hat den Vorteil, dass das tatsächlich begünstigungswürdige Betriebsvermögen ausschließlich dem Unternehmensnachfolger zugute kommt. Die vom Bundesverfassungsgericht kritisierte Fehlallokation von Steuerbegünstigungstatbeständen wird dadurch vermieden. Gleichzeitig besteht der Vorteil dieser Regelung darin, dass im Gegensatz zum bisherigen Recht - ein Verstoß gegen die Haltefrist des $\S 13$ a Abs. 5 ErbStG oder gegen die Lohnsummenregelung nach $\S 13$ a Abs. 1 S. 2 ErbStG lediglich den qualifizierten Nachfolger des Gesellschaftsanteiles betrifft, die Nachversteuerungssanktion hingegen nicht den anderen Miterben betrifft, der den Gesellschaftsanteil gar nicht erworben hat und daher keinen Einfluss auf das steuerliche Schicksal dieses Gesellschaftsanteils nehmen kann.

\section{Zusammenfassung}

Abfindungsklauseln in Gesellschaftsverträgen sind ein hochaktuelles Thema, das die Gestaltungspraxis stets fordert. Gesellschaftsvertraglich besteht in der Regel das wichtigste Ziel, die Gesellschaft in ihrem Bestand und Liquiditätsinteresse hinreichend zu schützen. Die Grundsätze der Anerkennung entsprechender Satzungsgestaltungen sind inzwischen weitgehend gefestigt. Bis zur Grenze von 50-60\% des gemeinen Wertes werden herabgesetzte Abfindungen regelmäßig anerkannt, es sei denn ein Gesellschafter würde selbst aus wichtigem Grund den Austritt oder die Kündigung der Gesellschaft erklären. Ein vollständiger Ausschluss der Abfindung ist nur in Ausnahmefällen wie dem Todesfall oder bei gemeinnützigen Gesellschaften anzuerkennen.

Ertragsteuerlich führt das Ausscheiden aus einer Gesellschaft gegen Abfindung regelmäßig $\mathrm{zu}$ einem entgeltlichen Veräußerungsgeschäft nach $\S \S 14,16,18$ Abs. 3, 34 EStG und bei Kapitalgesellschaften nach $\S \S 17,20$ Abs. 2 EStG. Erbschaftsteuerlich gewinnen die Steuertatbestände des $\S 3$ Abs. 1 Nr. 2, $\$ 7$ Abs. 7 ErbStG wesentlich an Bedeutung, weil durch die Anhebung der erbschaftsteuerlichen Werte viel häufiger ein Unterschied zwischen dem bewertungsrechtlich maßgeblichen Wert und dem gesellschaftsvertraglich maßgeblichen Abfindungsbetrag eintritt. Diese bei den verbleibenden Mitgesellschaftern eintretende Bereicherung wird nunmehr häufiger über $\S 3$ Abs. 1 Nr. 2 S. 2 ErbStG und über $\S 7$ Abs. 7 ErbStG erfasst. Durch geschickte Gestaltungen lässt sich

144 Siehe dazu insbes. Wälzholz, ZEV 2009, 113; Wälzholz, NWB 2009, 2803 ff. 
diese Steuerpflicht jedoch vermeiden, nach einer häufig vertretenen Auffassung in der Rechtslehre insbesondere durch Zwangsabtretungsklauseln an Nichtgesellschafter. Bei GmbH-Anteilen sollte die Einziehung des Geschäftsanteils regelmäßig vermieden werden, weil anderenfalls die Betriebsvermögensprivilegien der $\S \S 13 \mathrm{a}, 13 \mathrm{~b}, 19$ a ErbStG nach herrschender Meinung nicht anwendbar wären. Bei entsprechenden Zwangsabtretungsgestaltungen könnte die Besteuerung der Bereicherung zumindest über $\S \S 13$ a, 13 b, 19 a ErbStG abgemildert werden.

Die Vertragsgestaltungspraxis wird sich auch auf eine geänderte steuerliche Behandlung von qualifizierten Nachfolgeklauseln im Bereich des Erbschaftsteuerrechts einzustellen haben.

Die in früheren Gesellschaftsverträgen vorgesehenen Abfindungsklauseln sollten insbesondere hinsichtlich der Zielvorgabe und Bewertungsmethode überprüft und regelmäßig angepasst werden. Dabei sollten Bezugnahmen auf das Stuttgarter Verfahren vermieden werden. Bei einer Bezugnahme auf die Ermittlung des gemeinen Wertes sollte eine Loslösung von den Vorgaben des Bewertungsgesetzes klarstellend aufgenommen werden. 



\title{
Praxiserkenntnisse zur neuen Erbschaftsteuer
}

\author{
Dr. Reinhard Geck \\ Rechtsanwalt, Notar und Steuerberater, Hannover
}

Inhaltsübersicht

1. Einleitung

2. Renaissance der Übertragung von Unternehmen

3. Die Personengesellschaft im Aufwind
a) Quotenunabhängige Begüns- tigung
b) Sonderbetriebsvermögen als Entscheidungshilfe
c) Abstecher ins Ertragsteuer- recht

4. Übertragung unter Nießbrauchsvorbehalt
a) Geänderte Rahmenbedin- gungen ab 1.1.2009
b) Tendenzen in der Beratungs- praxis
c) Betriebliche Einheiten und Nießbrauch
d) Begrenzung des Schulden- abzugs
e) Einfluss der Vermögensüber- gabe gegen Versorgungsleis- tungen auf die Entscheidung, unter Nießbrauch zu übertragen
f) Zivilrechtliche Überlegungen

5. Erwerb des Familienheims, insbesondere durch den Ehegatten
a) Lebzeitige Zuwendung an Ehepartner
b) Einfluss des begünstigten Erwerbes von Todes wegen auf die Beratungspraxis

6. Resümee

\section{Einleitung}

Im Vorfeld des ErbStRG $2009^{1}$ wurde erbittert um ein in sich schlüssiges, aber auch den jeweiligen Klientelinteressen genügendes Erbschaftsteuerrecht gestritten. Insbesondere die vom $\mathrm{BVerfG}^{2}$ gesetzte relativ enge Frist bis zum 31.12.2008, innerhalb welcher der Gesetzgeber tätig zu werden hatte, versetzte die Praxis in Unruhe. Vornehmlich die im Vorfeld von Gesetzesänderungen stets zu beobachtenden Gerüchte sowie später nicht realisierte Vorschläge etc. haben bei den Steuerpflichtigen leider in manchen Fällen zu übereilten Entscheidungen geführt, die nachträglich nur mühsam über Rückabwicklungsklauseln „repariert" werden könnten. Das Ergebnis des ErbStRG ist bekannt: die beabsichtigte Aufkommensneutralität der Erbschaftsteuer auf das Niveau vor der Reform wird überwiegend durch die Erwerber der Steuerklassen II und III finanziert. Diese tragen letztlich die Last der Steuerausfälle im unternehmerischen Bereich, aber auch der erhöhten Freibeträge im Bereich der Steuerklasse I.

1 ErbStRG v. 24.12.2008 - BGBl. I 2008, 3018.

2 BVerfG v. 7.11.2006 - 1 BvL 10/02, BStBl. II 2007, 192. 
Hieran hat auch die Absenkung der Steuersätze im Bereich der Steuerklasse II durch das Wachstumsbeschleunigungsgesetz 2009 (WaBeschG) ${ }^{3}$ nichts geändert. Auffallend ist, dass nach der "literarischen Unruhe" im Jahre 2009 mit durchschnittlich drei bis vier Aufsätzen pro Woche eine deutliche Beruhigung eingetreten ist. Auch die betroffenen Steuerpflichtigen sehen die Entwicklung mittlerweile gelassener. Gleichwohl mag dies nur Ruhe vor dem Sturm sein. Auch nur eine untere Gerichtsentscheidung, die die Verfassungsmäßigkeit der Neuregelung in Frage stellt, wird im „steuersensiblen" Deutschland zu erneuten Diskussionen, insbesondere auch Reaktionen führen. ${ }^{4}$

Dies ändert nichts daran, dass natürlich der Alltag der vorweggenommenen Erbfolge und Nachlassplanung "abgearbeitet" werden muss. Schon nach relativ kurzer Zeit lassen sich erste Praxiserkenntnisse feststellen, die die Schwerpunkte der Beratung teilweise neu justieren. Auf diese Aspekte soll nachfolgend eingegangen sein, und zwar ohne Rücksicht auf Vollständigkeit. Ein gewisser subjektiver Eindruck kann bei diesem Thema nicht ausbleiben.

\section{Renaissance der Übertragung von Unternehmen}

Seit gewisser Zeit ist wieder eine verstärkte Neigung zu beobachten, Unternehmen zu übertragen. Dies beruht darauf, dass zwar zum Einen die Ermittlung des Unternehmenswertes nach neuem Recht zu mitunter sehr hohen Werten ${ }^{5}$ führt, zum Anderen aber auf den sehr weitreichenden Verschonungsregelungen der $\S \S 13 \mathrm{a}, 13 \mathrm{~b}, 19 \mathrm{a}$ ErbStG, die mit der Erholung der Wirtschaft und der damit verbundenen Furcht vor noch höherer Bewertung einhergehen.

Bekanntlich wird bei gewerblichen Unternehmen, die nicht mehr als $50 \%$ sog. Verwaltungsvermögen aufweisen, nur $15 \%$ des Unternehmenswertes angesetzt, in Fällen des Optionsmodells sogar nur $0 \%$, so dass der Erwerb in großem Umfang entlastet wird, wenn nicht sogar in voller Höhe steuerfrei bleibt (§ 13 a Abs. 1, Abs. 8 ErbStG). Voraussetzung ist allerdings, dass im Nachsteuerzeitraum von fünf bzw. sieben Jahren weder die sog. Lohnsummenklausel als auch die allgemeinen Behaltenstatbestände der $\S 13$ a Abs. 4, 5 ErbStG missachtet werden.

Für das gestiegene Interesse an Übertragungen von Unternehmen sind i. d. R. folgende Gründe anzuführen:

3 WaBeschG v. 22.12.2009, BGB1. I 2009, 3950.

4 Vgl. zur Frage der Aussetzung der sofortigen Vollziehung BFH v. 1.4.2010 - II B 168/09, ZEV 2010, 317.

$5 \mathrm{Zu}$ den Bewertungsmethoden und ihrem Rangverhältnis Viskorf, ZEV 2009, 591. 
a) Bei der Unternehmensbewertung kann insbesondere bei Personenunternehmen ein Gestaltungsspielraum durch den Abzug des Unternehmerlohnes (vgl. § 202 Abs. 1 Satz 2 Nr. 1d BewG) genutzt werden. Gerade bei vom Inhaber geführten Unternehmen besteht die Aussicht, einen Großteil des Jahresergebnisses durch den Unternehmerlohn zu kompensieren, so dass auch der hohe Vervielfältiger von 11,79 $(2010)^{6}$ kein erschreckendes Hindernis sein muss.

b) Bestanden anfänglich noch Bedenken, die maßgebliche Lohnsumme sei ein Hindernis für die Unternehmensnachfolge, hat dieser Aspekt an Bedeutung verloren. Zum Einen hat der Gesetzgeber durch das WaBeschG 2009 bereits mit Wirkung ab 1.1.2009 die Erleichterungen insbesondere für kleine und mittlere Unternehmen erweitert. Die Lohnsummenklausel ist nur für solche Betriebe zu beachten, die mehr als 20 Arbeitnehmer beschäftigen (§ 13 a Abs. 1 Satz 4 ErbStG). Selbst die sehr restriktive Auffassung der Finanzverwaltung in A 8 Abs. 2 Satz 2 des Ländererlasses vom 25.6.2009,7 die auch Teilzeitkräfte, Auszubildende etc. in die Mitarbeiterzahl einbezieht, ändert nichts daran, dass vermutlich 75 bis $80 \%$ der deutschen Unternehmen übertragen werden können, ohne dass es auf die maßgebende Mitarbeiterzahl zwecks Beachtung der Lohnsummenklausel überhaupt ankommt. Die durch kleinere mittelständische Unternehmen geprägte Unternehmenslandschaft, aber auch der hohe Grad an Diversifizierung durch Einschaltung von Subunternehmern hat in der Praxis zu einer erheblichen Erleichterung im Rahmen der Unternehmensnachfolge geführt. Gerade die emotionale Belastung der Unternehmensnachfolger, bei durch vom Markt erzwungenen Anpassungen der Lohnsumme Erbschaftsteuer in schlechter Zeit nachzahlen zu müssen, ist hierdurch beseitigt worden. Außerdem sind die Nachsteuerfristen von sieben auf fünf bzw. zehn auf sieben Jahre verkürzt worden.

c) Von ganz entscheidender Bedeutung ist jedoch die Interpretation des im Rahmen der Vermögensnachfolge schädlichen sog. Verwaltungsvermögens durch den Ländererlass vom 25.6.2009. ${ }^{8}$ Dieser enthält in Abschn. 32 die Anweisung, dass Liquidität nur unter sehr engen Voraussetzungen Verwaltungsvermögen ist. Gerade die in der Vergangenheit sehr erfolgreichen Unternehmen, die ihre Eigenkapitalfinanzierung auf einem hohen Sockel an Eigenkapital in Form von Liquidität aufgebaut haben, sahen sich vor der Veröffentlichung des Erlasses

6 BMF v. 5.1.2010, BStBl. I 2010, 14; für 2011 beträgt der Vervielfältiger sogar 12,61, vgl. BMF v. 5.1.2011, BStBl. I 2011, 5.

7 Ablehnend Geck in Kapp/Ebeling, ErbStG, § 13 a Rz. 24.

8 Ländererlass v. 25.6.2009, BStBl. I 2009, 713. 
in einer Zwickmühle. Einerseits ersparte der hohen Eigenkapitalanteil unangenehme Verhandlungen mit Kreditinstituten, die auch unerwünschten Einfluss auf die Geschäftspolitik hätten nehmen können, andererseits drohte jedoch eine massive Erbschaftsteuerbelastung, weil der Unternehmenswert eben nicht durch die Betriebsvermögensverschonungen reduziert wurde. Diese Sorgen sind zumindest derzeit verflogen. Durch geschickte Gestaltung wie Umschichtung von Wertpapieren in Festgeldgeldanlagen oder ähnliche Portofolio-Bestände kann der Anteil an Verwaltungsvermögen sogar auf ein Niveau gesenkt werden, welches die Totalverschonung von $100 \%$ gem. $\S 13$ a Abs. 8 ErbStG ermöglicht. Nach Beobachtungen der Beratungspraxis gibt es außerhalb von vermögensverwaltenden Gesellschaften, die über Grundbesitz verfügen, nur wenige Unternehmen, die an der Quote des Verwaltungsvermögens von mehr als $50 \%$ und damit an der Regeloption scheitern. Dies ist umso erfreulicher, als anfänglich befürchtet wurde, die unsägliche Regelung in $\S 13 \mathrm{~b}$ Abs. 2 Satz 4 ErbStG, wonach Verbindlichkeiten des Verwaltungsvermögens dieses nicht vermindern, hätte unerfreulichen, weil Übertragungen hemmenden Einfluss auf die Unternehmensnachfolge.

d) Hinzu kommt die gezielte Auslagerung von Verwaltungsvermögen in nachgelagerte Tochtergesellschaften. ${ }^{9}$ Wird Verwaltungsvermögen in eine Tochtergesellschaft übertragen und beträgt deren anteiliges Verwaltungsvermögen max. 50\%, bleibt der Beteiligungsansatz an der Tochtergesellschaft bei Beurteilung der Verwaltungsvermögensquote des übertragenden Rechtsträgers vollständig außer Ansatz (§13b Abs. 2 Nr. 2 ErbStG).

Beispiel:

A überlegt, Anteile an der X-KG unentgeltlich zu übertragen. Die X-KG verfügt über Verwaltungsvermögen. Sie überträgt Verwaltungsvermögen auf eine von ihr gegründete $100 \%$ ige Tochtergesellschaft in der Rechtsform der GmbH und stattet diese mit weiteren Vermögensgegenständen aus, die kein Verwaltungsvermögen sind.

Die Verwaltungsvermögensquote der $\mathrm{GmbH}$ soll nicht mehr als $50 \%$ betragen.

Rechtsfolge:

Der Anteil an der Tochtergesellschaft gilt nicht als Verwaltungsvermögen, so dass das dort enthaltene Verwaltungsvermögen bei der Ermittlung des Verwaltungsvermögensanteils der Spitzeneinheit unberücksichtigt bleibt.

Die sehr enge Auslegung des Begriffes des Verwaltungsvermögens bezüglich Wertpapieren und vergleichbaren Forderungen begünstigt die Übertragung von Unternehmen. Letztlich kann auch in diesem Bereich durch gezielte Gestaltungen Verwaltungsvermögen vermieden werden.

9 Vgl. Scholten/Korezkij, DStR 2010, 147. 
Beispiel:

Im Betriebsvermögen von A befindet sich ein Wertpapier. A veräußert dieses Wertpapier an eine $100 \%$ ige Tochtergesellschaft und stundet den Kaufpreis. Es handelt sich bei A nicht mehr um Verwaltungsvermögen, da die Forderung gegen ein verbundenes Unternehmen keine einem Wertpapier vergleichbare Forderung ist. Die Beteiligung an der Tochtergesellschaft ist aller Wahrscheinlichkeit nach mit 0 anzusetzen, da sich Aktiv- und Passivvermögen aufheben.

e) Mittlerweile hat die Praxis auch realisiert, dass die am 31.12.2008 ausgelaufenen Vergünstigungen der $\S \S 13$ a, 19a ErbStG a. F. nicht durch das Abschmelzungsmodell, sondern eine „Entweder-Oder-Betrachtung" gekennzeichnet waren. Verstieß der "Erwerber alten Rechts" kurz vor Ablauf der fünfjährigen Frist gegen die Behaltenstatbestände, wurde die Steuer so festgesetzt, als hätten die Vergünstigungen im Zeitpunkt des Erwerbs nicht gewährt werden dürfen. Dies ist mit Ausnahme der Überentnahmeregelung des $\S 13$ a Abs. 5 Nr. 3 ErbStG ${ }^{10}$ bekanntlich seit 1.1.2009 anders. Durch das Abschmelzungsmodell reduzieren sich die steuerlichen Auswirkungen der Nachsteuertatbestände auf den Anteil des fünfjährigen Zeitraums, für welchen die Vergünstigungen nicht dauerhaft zu gewähren sind.

Beispiel:

Kurz vor Ablauf der fünfjährigen Frist veräußert A unter Druck der Kreditinstitute das begünstigt erworbene Unternehmen. Die Nachsteuer ist nur im Umfang von einem Fünftel festzusetzen. Im Übrigen kommt es (leider) nicht darauf an, aus welchen Gründen A veräußert hat. Auch die Veräußerung unter Druck oder gar die Insolvenz ist ein Verstoß gegen den Nachsteuertatbestand. ${ }^{11}$

Da der Verschonungsabschlag mit $85 \%$ wesentlich höher als nach altem Recht (35\%) ist, wirkt sich somit die Neuregelung selbst dann als vorteilhaft aus, wenn ein Verstoß innerhalb der fünfjährigen Behaltensfrist erfolgt. Die Rechtslage ist insoweit günstiger als nach altem Recht, zumindest wenn man davon absieht, dass mit der Lohnsummenklausel ein neuer Nachsteuertatbestand eingeführt ist. Wie ausgeführt, unterliegt jedoch nur ein kleinerer Teil der Unternehmen dieser Form der Nachbelastung, da die durchschnittliche Mitarbeiterzahl meist die Anzahl von 20 nicht übersteigt.

Im Ergebnis wird daher die Unternehmensnachfolge primär nach betriebswirtschaftlichen und familiären Aspekten, weniger aber unter erbschaftsteuerlichen Gesichtspunkten betrieben. Dies basiert letztlich darauf, dass anders als nach altem Recht davon auszugehen ist, dass eine lebzeitige Übertragung ohne Steuerbelastung möglich ist.

10 Meincke, ErbStG, 15. Aufl. 2009, § 13 a Rz. 33.

11 Leider ständige Rspr., zuletzt sogar hinsichtlich eines Erlasses der Steuer bei Insolvenz BFH v. 4.2.2010 - II R 25/08, ZEV 2010, 322 m. w. N. 
Diese Entwicklung ist sicherlich volkswirtschaftlich zu begrüßen, verhindert sie doch Fehlallokationen.

f) Bei Planung letztwilliger Verfügungen auch betr. unternehmerischen Vermögens kommt der Teilungsanordnung anders als nach altem Recht ${ }^{12}$ größere Bedeutung zu. War nach altem Recht der Erwerber nur dann in der Lage, die Betriebsvermögensvergünstigungen in vollem Umfang in Anspruch zu nehmen, wenn er die Beteiligung als Alleinerbe oder im Wege des Vermächtnisses/Vorausvermächtnisses erhalten hatte, eröffnen die $\S \S 13$ a Abs. 3, 13b Abs. 3 ErbStG neue Optionen. Danach kann selbst im Rahmen der freien Erbauseinandersetzung - erst recht dann bei Teilungsanordnung - iaR. jedenfalls der Vorteil der steuerlichen Entlastung auf denjenigen übertragen werden, welcher das Unternehmen fortführt. ${ }^{13}$

Beispiel:

Erblasser A ordnet in seiner letztwilligen Verfügung an, dass Sohn S und Tochter T seine Erben zu je ein Halb werden. Im Rahmen einer Teilungsanordnung weist er S das Unternehmen, $\mathrm{T}$ das restliche Vermögen zu. Da letzteres den Wert des Unternehmens übersteigt, leistet $\mathrm{T}$ noch eine Ausgleichszahlung. Durch den Vollzug dieser Regelung werden die Betriebsvermögensvergünstigungen nunmehr S zugewiesen. Nach altem Recht hätten sie S und T im Verhältnis der Erbquoten zugestanden. Nachsteuertatbestände, die S als Fortführender verwirklicht hätte, hätten damit auch auf $\mathrm{T}$ in Form einer Nachsteuer "durchgeschlagen".

\section{Die Personengesellschaft im Aufwind}

$\mathrm{Zu}$ beobachten ist eine Renaissance der Personengesellschaft als Träger unternehmerisch gebundenen Vermögens, welches unentgeltlich zu Lebzeiten oder von Todes wegen übertragen wird. Dies hat vermutlich folgende Gründe:

\section{a) Quotenunabhängige Begünstigung}

Ist bei Kapitalgesellschaften wie schon nach altem Recht die Mindestbeteiligungsquote des Übertragenden von mehr als 25 \% ein Gestaltungshindernis, welches auch durch die Poolvereinbarungen nicht endgültig beseitigt wird, besteht bei Personenunternehmen der Vorteil darin, dass diese quotenunabhängig begünstigt übertragen werden können. Dies ist dem Fachmann nicht neu, durch die Diskussion um Poolverträge und ihre Gestaltung bei Kapitalgesellschaften aber bekannter geworden.

12 Vgl. BFH v. 1.4.1992 - II R 21/89, BStBl. II 1992, 669, sowie R 5 ErbStR, BStBl. I 2003, Sondernummer 1.

13 Riedel in Daragan u. a., ErbStG, 2009, § 13 b Rz. 235 m. w. N. 
Dies gilt auch hinsichtlich der unterschiedlichen Behandlung von Gesellschaftsanteilen und Sonderbetriebsvermögen. Nach Auffassung der Finanzverwaltung ${ }^{14}$ ist ein begünstigter Tatbestand auch dann gegeben, wenn das Sonderbetriebsvermögen nicht in gleicher Höhe, sondern in geringerem oder größerem Umfang übertragen wird, zumindest wenn der Übertragende Mitunternehmer der Personengesellschaft bleibt. Problematisch erscheint es allerdings auf der Grundlage der ertragsteuerlichen Rechtsprechung, insbesondere des IV. Senates im Urteil vom 6.5.2010,15 wenn das Sonderbetriebsvermögen unmittelbar vor Übertragung des Gesellschaftsanteils in einen anderen gewerblichen Rechtsträger ausgegliedert wird. Selbst unter Berücksichtigung des strengen Stichtagsprinzips, wie es in $\S 11$ ErbStG statuiert ist, bestehen Zweifel, ob der BFH in diesem Fall die Begünstigungsregelungen zur Anwendung bringen würde. Denn er könnte geneigt sein, entsprechend der ertragsteuerlichen Beurteilung nicht von der Übertragung eines Mitunternehmeranteils auszugehen. Die Finanzverwaltung vertritt eine ähnliche Tendenz in H 51 Abs. 3 der Erbschaftsteuerhinweise. ${ }^{16}$ Dort ist zwar nur der Fall angesprochen, dass eine wesentliche Betriebsgrundlage zurückbehalten und in das Privatvermögen überführt wird. Gleiches dürfte jedoch auch dann gelten, wenn die wesentliche Betriebsgrundlage Betriebsvermögen in einem anderen Betrieb des Übergebers wird. Gleichwohl bleibt der Vorteil, dass Beteiligungen an Personengesellschaften unabhängig von ihrer Höhe und sogar mit disquotaler Übertragung des Sonderbetriebsvermögens Gegenstand der begünstigten Vermögensübergabe sein können. All diese Vorteile bietet die Kapitalgesellschaft nicht.

Soweit auf die möglichen Poolvereinbarungen bei Kapitalgesellschaften (§ 13 b Abs. 1 Nr. 3 Satz 2 ErbStG) verwiesen wird, ist dies nur ein schwacher Trost. Denn die Finanzverwaltung hat sich im Anwendungserlass vom 25.6.200917 elegant vor der Frage gedrückt, was unter den „Grundsätzen der einheitlichen Verfügung" i. S. d. § 13 b Abs. 1 Nr. 3 ErbStG zu verstehen sei. Bekanntlich werden in der Literatur ${ }^{18}$ die enge und die weite Auslegung vertreten. Die weite Auslegung - die als strengste zumindest der Gestaltungsberatung zugrunde zu legen ist - hätte zur Folge, dass jeder poolgebundene Anteil nur gemeinsam mit den anderen poolgebundenen Anteilen übertragen werden könnte. All diese als lästig empfundenen Restriktionen sind auf die Ebene der Personengesellschaft nicht übertragbar. Daher ist in der Praxis zu beobachten, dass Anteile an Kapi-

14 R 51 Abs. 3 ErbStR 2003, BStBl. I 2003, Sondernummer 1, S. 2.

15 BFH v. 6.5.2010 - IV R 52/08, DStR 2010, 1374.

16 BStBl. I 2003, Sondernummer 1, 91.

17 BStBl. I 2009, 713.

18 Überblick bei Viskorf in Viskorf/Knobel/Schuck, ErbStG, 3. Aufl. 2009, § 13 b Rz. 133 ff. 
talgesellschaften verdeckt in eine Personengesellschaft eingelegt werden. Anschließend werden die Anteile an der Personengesellschaft unentgeltlich übertragen. Da die Einlage ertragsteuerlich zum Buchwert erfolgt, ${ }^{19}$ mithin nicht mit einer Gewinnrealisierung verbunden ist, ergeben sich auf dieser Ebene zumindest keine kurzfristigen Nachteile. Lediglich in bestimmten Fällen mag der Abgeltungsteuersatz auf die Gewinnausschüttungen ( $\$ 32 \mathrm{~d} E S t G)$ durch die persönliche Tarifbelastung ersetzt werden. Dies mag ein Nachteil, kann aber auch ein Vorteil sein, je nach persönlicher steuerlicher Situation des Gesellschafters.

Insofern wird sich der Trend bei mehrgliedrigen Einheiten zu den Personengesellschaften, insbesondere zur Holdinggesellschaften verstärken, um auf diese Weise die Restriktionen des $\S 13$ b Abs. 1 Nr. 3 ErbStG zu vermeiden.

Damit keine Missverständnisse entstehen: Selbstverständlich ist auf der Ebene der Steuerfestsetzung für die Übertragung des Mitunternehmeranteils an der Holding inzident zu prüfen, ob und in welchem Umfang die (Tochter-)Kapitalgesellschaft über Verwaltungsvermögen verfügt $(\S 13 \mathrm{~b}$ Abs. 2 Nr. 2 ErbStG). Gleichwohl liegt der Vorteil der Gestaltung darin, dass die Mindestbeteiligungsquote von 25,1 \% bei Übertragung eines Personengesellschaftsanteils ohne Bedeutung ist. Denn in der vorgeschlagenen Konstruktion schließen sich Gesellschafter zusammen, deren Anteile an der Ausgangskapitalgesellschaft eben nicht mindestens 25,1\% des Grund- bzw. Stammkapitals betragen. Die auf gesellschaftsrechtlicher Ebene der $\mathrm{GmbH}$ vorhandenen Regelungen, wie etwa freie Übertragbarkeit, können auf der Ebene der Personengesellschaft perpetuiert werden, was die Praxis als erhebliche Erleichterung ansieht. Denn in die bewährte interne Optionsstruktur der Gesellschaft muss nicht eingegriffen werden.

Beispiel:

Der Gesellschaftsvertrag der ABC-GmbH sieht die freie Übertragbarkeit der Geschäftsanteile vor. Gesellschafter A und B, die jeweils mit $25 \%$ am Kapital beteiligt sind, möchten ihre Anteile aus erbschaftsteuerlichen Gründen „poolen“, gleichwohl die freie Übertragbarkeit erhalten. Zu diesem Zweck gründen sie die XY-GmbH \& Co. KG und übertragen auf diese ihre Anteile an der GmbH im Wege verdeckter Einlage. Auf der Ebene des Gesellschaftsvertrages der KG kann durch freie Übertragung der Geschäftsanteile an der Kommanditgesellschaft das gleiche Ergebnis wie auf der Ebene der GmbH hergestellt werden. Auf die Poolbindung kommt es damit nicht an.

Der naheliegende Einwand, es handele sich um eine gem. $\S 42 \mathrm{AO}$ unbeachtliche Gestaltung, überzeugt nicht, da sich auch außersteuerliche Gründe finden lassen. Sinnvoll ist es, weitere Beteiligungen in die Personengesellschaft einzulegen. Alternativ können auch weitere Betei-

19 Vgl. § 6 Abs. 1 Nr. 5 Satz 1 Nr. b EStG, s. auch BFH v. 19.10.1998 - VIII R 69/95, BStBl. II 2000, 230. 
ligungen durch die Personengesellschaft erworben werden. Außerdem lässt sich vortragen, durch die Vorschaltung der Personengesellschaft solle ein Auseinanderfallen von Anteilen an der Tochterkapitalgesellschaft vermieden werden, indem sich die Entscheidungsbildung auf der vorgelagerten Ebene der Personengesellschaft vollziehe.

Ein weiterer Vorteil der Personengesellschaft besteht darin, dass mittlerweile durch den $\mathrm{BFH}^{20}$ geklärt ist, dass der Nießbrauchsvorbehalt bei sachkundiger Ausgestaltung die Anwendung der Betriebsvermögensvergünstigungen nicht hindert. Hatte die Finanzverwaltung in H51 Abs. 5 ErbStH $2003^{21}$ mit gewissem Recht, jedoch nicht präzise, darauf hingewiesen, dass die Übertragung unter Nießbrauchsvorbehalt eine Mitunternehmerstellung des Erwerbers vermitteln musste, hat der BFH für Rechtssicherheit gesorgt. Entspricht der Inhalt der vertraglichen Abreden zwischen Schenker und Beschenktem/Nießbrauchsbesteller in etwa dem gesetzlichen Regelstatut, werden insbesondere die Stimmrechte des Bestellers in Grundlagengeschäften nicht durch Vollmachten ausgeschlossen und wird sein Anteil an Altrücklagen beschränkt, vermittelt der Nießbrauchsvorbehalt eine Mitunternehmerstellung des Erwerbers. ${ }^{22}$

\section{b) Sonderbetriebsvermögen als Entscheidungshilfe}

Bei der Personengesellschaft besteht ferner der Vorteil, dass der von der Personengesellschaft zu eigenen gewerblichen Zwecken genutzte Grundbesitz im Sonderbetriebsvermögen kein Verwaltungsvermögen ist ( $§ 13 \mathrm{~b}$ Abs. 2 Satz 2 Nr. 1 Satz 2 ErbStG), sofern er mit dem Mitunternehmeranteil auf den Erwerber übergeht. Die unangenehme Konsequenz, dass die mit dem Verwaltungsvermögen verbundenen Schulden nicht abzugsfähig sind, wird vermieden.

Beispiel:

An der A-KG ist C mit $30 \%$ beteiligt. Gegenstand der A-KG ist die Erbringung von Dienstleistungen im Bereich des Facility-Management. C überlässt der Gesellschaft ein im Umfang von $80 \%$ fremdfinanziertes bebautes Grundstück zur Nutzung, welches jedenfalls gewillkürtes Betriebsvermögen ist. Rechtsfolge: Unabhängig von Einordnung des Grundstücks als Verwaltungsvermögen können jedenfalls die Verbindlichkeiten bei der Ermittlung der Verwaltungsvermögensquote mindernd abgezogen werden, so dass eine sehr hohe Wahrscheinlichkeit für die Inanspruchnahme der Betriebsvermögensvergünstigungen besteht.

Zwar ist die Einordnung des Grundstücks als Betriebsvermögen mit der Folge der Begründung einer Betriebsaufspaltung nur davon abhängig, dass das Grundstück aus Sicht der GmbH eine wesentliche Betriebsgrundlage

20 BFH v. 10.12.2008 - II R 55/07, BStBl. II 2009, 473.

21 BStB1. I 2003, Sondernummer 1, 2.

22 Aktuell jetzt auch BFH v. 23.2.2010 - II R 42/08, ZEV 2010, 320. 
ist. Dies ist regelmäßig der Fall. Jedoch droht bei einer Personengesellschaft bei der Beendigung des Nutzungsverhältnisses keine Totalbeendigung der Mitunternehmerschaft.

\section{c) Abstecher ins Ertragsteuerrecht}

Im Rahmen eines Exkurses zum Einkommensteuerrecht, jedoch als wichtiger Teil der Planung der vorweggenommenen Erbfolge ist zu betonen, dass die Personengesellschaft auch unter dem Aspekt der Vermögensübergabe gegen Versorgungsleistungen Vorteile bietet. Denn die verschärfte Rechtslage nach dem JStG $2008^{23}$ schließt bekanntlich die Übertragung von Geschäftsanteilen an einer $\mathrm{GmbH}$ von einer Vermögensübergabe gegen Versorgungsleistungen selbst dann aus, wenn der Übergeber zwar mindestens $50 \%$ des Stammkapitals überträgt, der Übernehmer jedoch nicht dauerhaft Geschäftsführer der Kapitalgesellschaft bleibt. Aktien können außerhalb von Betriebsvermögen unter keinen Umständen Gegenstand einer Vermögensübergabe gegen Versorgungsleistungen sein. Spätestens mit Aufgabe der Geschäftsführerstellung durch den Übernehmer endet selbst bei qualifizierten Anteilen an GmbHs der Abzug der Versorgungszahlungen als Sonderausgaben. ${ }^{24}$ Ist bereits im Zeitpunkt der Übergabe absehbar, dass der Übernehmer aus welchen Gründen auch immer nicht dauerhaft Geschäftsführer bleiben wird, empfiehlt es sich, vor der geplanten Übertragung die Kapitalgesellschaft in eine Personengesellschaft - idealerweise eine GmbH \& Co. KG - formzuwechseln, um damit diesen Restriktionen nicht zu unterliegen. Denn bei der Personengesellschaft gibt es insoweit keine Anforderungen an die fortdauernde Tätigkeit des Übernehmers im Unternehmen. Natürlich ist eine Gesamtbetrachtung durchzuführen. Die Gewinnrücklagen der $\mathrm{GmbH}$ gelten gem. $§ 7$ UmwStG im Zeitpunkt des Formwechsels als ausgeschüttet. Ergeben sich hieraus erhebliche steuerliche Mehrbelastungen, sollte trotz der Vorteile im Rahmen der Vermögensübergabe gegen Versorgungsleistungen dieser Weg nicht beschritten werden. Er zeigt jedoch die zunehmende Attraktivität der Personengesellschaften.

\section{4. Übertragung unter Nießbrauchsvorbehalt}

a) Geänderte Rahmenbedingungen ab 1.1.2009

Die Übertragung unter Nießbrauchsvorbehalt zugunsten des Schenkers bzw. dessen Ehepartner unterlag bis zum 31.12.2008 den Restriktionen des $\S 25$ ErbStG a. F. Danach konnte die Nießbrauchslast nicht bereicherungsmindernd abgezogen werden, obwohl es sich - wie jeder "Zivilist"

23 Jahressteuergesetz 2008 v. 20.12.2007, BGBl. I 2007, 3150.

24 BMF v. 11.3.2010, BStBl. I 2010, 227, Tz. 15 ff. 
bestätigen wird - um eine wertmindernde Belastung handelt. Hintergrund war die Sorge des Gesetzgebers, infolge der niedrigen Bemessungsgrundlage der Werte der übertragenen Wirtschaftsgüter käme es bei Abzug der Nießbrauchslast zu keiner steuerlich relevanten Bemessungsgrundlage und damit keiner Steuerfestsetzung mehr. ${ }^{25}$ Dieser bereits nach altem Recht jedenfalls dogmatisch nicht überzeugende Gedanke hat nunmehr durch die Neuregelung der Bewertung ab 2009 jede Rechtfertigung verloren. Es ist daher zu begrüßen, dass der Gesetzgeber $\S 25$ ErbStG mit Wirkung ab dem 1.1.2009 aufgehoben hat. Die Rahmenbedingungen für die Übertragung unter Nießbrauchsvorbehalt haben sich daher grundlegend verschoben.

\section{b) Tendenzen in der Beratungspraxis}

Dies spürt auch die Beratungspraxis, die die Steuerpflichtigen auf Folgendes hinweist:

- Der Übertragungsgegenstand ist gegenüber dem alten Rechtszustand u. U. höher zu bewerten. Dies gilt insbesondere für Grundbesitz, aber auch die bereits eingangs angesprochenen Unternehmensbeteiligungen.

- Andererseits wird die Höherbewertung dadurch teilweise kompensiert, als auch die Nießbrauchslast nunmehr einen höheren und zudem abzugsfähigen Wert hat. Denn die Nießbrauchslast ermittelt sich aus dem Steuerwert des übertragenen Gegenstandes dividiert durch 18,6 (vgl. §16 BewG, sog. Kappung) multipliziert mit dem Vervielfältiger gem. Anlage $9 \mathrm{zu} \S 14$ BewG. Ferner wirkt sich entlastend aus, dass der Vervielfältiger aufgrund der Gesetzesänderung des $\S 14$ Abs. 1 Satz 2 BewG durch das ErbStRG 2009 aus der Sterbetafel des Statistischen Bundesamtes zu ermitteln und ab dem 1.1. des folgenden Jahres anzuwenden ist. ${ }^{26}$

Verglichen mit der bis zum 31.12.2008 geltenden Rechtslage ergeben sich für die Nießbrauchslast erheblich höhere Abzugsbeträge, was in erster Linie auf der gestiegenen Lebenserwartung der Bevölkerung beruht. ${ }^{27}$

In Verbindung mit den zumindest in der Steuerklasse I deutlich erhöhten Freibeträgen bei unveränderten Steuersätzen ergibt sich schon auf den ersten Blick der aus Sicht des Erwerbers erfreuliche Befund, dass zumindest bei nur moderater Erhöhung der steuerlichen Werte des Übertragungsgegenstandes die Bemessungsgrundlage für die Erbschaftsteuer

25 Überblick bei Kapp/Ebeling, ErbStG, § 25 a. F. Rz. 1.1.ff.

26 Die aktuellen Tabellen sind über das Statistische Bundesamt abrufbar.

27 Beispiele und weiterführende Hinweise bei Geck, DStR 2009, 1005, 1006. 
tendenziell sinkt, weil der Erhöhung der Bemessungsgrundlage die entlastenden Faktoren der abziehbaren Nießbrauchslast sowie der regelmäßig erhöhten Freibeträge gegenüberstehen. Nur im Bereich der Steuerklassen II und III muss aufgrund der dort erhöhten Steuersätze im Detail gerechnet werden. Dies führt in der Praxis dazu, dass zunehmend eine Übergabe abweichend von der bisherigen Praxis unter Nießbrauchsvorbehalt angestrebt wird. Soweit der Nießbraucher nicht auf sämtliche Erträge verzichten möchte, kann er mittels Quotennießbrauches einen Teil der Erträge beim Nießbrauchsbesteller/Beschenkten belassen. Damit einhergehen sollte auch die anteilige Übernahme der dinglichen und schuldrechtlichen Belastungen durch den Beschenkten, um diese sofort von der Bemessungsgrundlage des zu übertragenden Gegenstandes abziehen zu können. Ob dies nach den Grundsätzen der gemischten Schenkung nur in dem Verhältnis möglich ist, in welchem der Steuerwert zum Verkehrswert des Übertragungsgegenstandes steht oder ob die Belastung voll abgezogen werden kann, ist noch nicht geklärt. Die Finanzverwaltung ${ }^{28}$ vertritt die Meinung, es sei nur ein quotaler Abzug möglich.

\section{c) Betriebliche Einheiten und Nießbrauch}

Ist Gegenstand der Übergabe ein Betrieb, Teilbetrieb oder Mitunternehmeranteil, wurde bereits in anderem Zusammenhang erläutert, dass die Sorge der Beteiligten davor, die Nießbrauchslast könne zwar abgezogen werden, eröffne aber mangels Mitunternehmerstellung des Beschenkten nicht den Weg in die Betriebsvermögensverschonung, regelmäßig unbegründet ist. Auf die einschlägige Rechtsprechung des BFH wurde bereits verwiesen. Wichtig ist in diesem Zusammenhang, dass der BFH ebenfalls entschieden hat, dass eine Mitunternehmerstellung selbst dann vermittelt werden muss, wenn der Beschenkte bereits Mitunternehmer der Personengesellschaft ist, deren weitere Anteile er unter Nießbrauchsvorbehalt erhält. ${ }^{29}$

\section{d) Begrenzung des Schuldenabzugs}

Ist Gegenstand der Übertragung ein zu privaten Wohnzwecken vermietetes Grundstück, können Nießbrauchslast und weitere Gegenleistungen nach $\S 13$ c Abs. 1, 3 ErbStG nur im Umfang von 90 \% abgezogen werden. Denn im Umfang von $10 \%$ ist der Übertragungsgegenstand steuerbefreit, so dass auch die Gegenleistungen nur gekürzt um $10 \%$ bereicherungsmindernd abgezogen werden können (vgl. § 10 Abs. 6 Sätze 4, 5 ErbStG).

28 Abschn. 1 des Ländererlasses v. 25.6.2009, BStBl. I 2009, 713.

29 So BFH v. 23.2.2010 - II R 42/08, ZEV 2010, 320 m. Anm. Wachter, hierzu auch Hochheim/Wagenmann, ZEV 2010, 109. 
e) Einfluss der Vermögensübergabe gegen Versorgungsleistungen auf die Entscheidung, unter Nießbrauch zu übertragen

Einher mit der verstärkten Attraktivität des Nießbrauchsrechtes auf erbschaftsteuerlicher Ebene verblasst der Stern der Vermögensübergabe gegen Versorgungsleistungen zumindest hinsichtlich Privatvermögens. Bekanntlich kann dieses seit 1.1.2008 zumindest in Neufällen nicht mehr Gegenstand einer Übergabe gegen Versorgungsleistungen sein. Rechtsfolge ist zumindest nach allerdings umstrittener Auffassung der Finanzverwaltung ${ }^{30}$ ein teilentgeltliches Rechtsgeschäft mit u. U. unangenehmen Rechtsfolgen für den Übergeber, sofern es sich nämlich um ein ertragsteuerlich verstricktes Wirtschaftsgut mit geringen Anschaffungskosten handelt. Angesprochen ist insbesondere die Beteiligung an einer Kapitalgesellschaft i.S. d. § 17 EStG, bei welcher sich die Anschaffungskosten häufig auf den Nennbetrag des übernommenen Geschäftsanteils bei Übernahme der Beteiligung beschränken. In diesen Fällen kann es sich auch unter dem ertragsteuerlichen Aspekt anbieten, die Beteiligung in ein Betriebsvermögen, etwa einer Personengesellschaft, zu übertragen und anschließend die Anteile an dieser Personengesellschaft gegen Versorgungsleistungen in die nächste Generation $\mathrm{zu}$ transferieren. Rechtsfolge ist vorbehaltlich des sog. Verwaltungsvermögenstestes die Betriebsvermögensvergünstigung der $\S \S 13 \mathrm{a}, 13 \mathrm{~b}, 19 \mathrm{a}$ ErbStG und ertragsteuerlich der Abzug der Zahlungen als Versorgungsleistungen, sofern es sich nicht um eine gewerblich geprägte Personengesellschaft handelt. Dies gilt unabhängig vom Umfang der Beteiligung an der Personengesellschaft.

\section{f) Zivilrechtliche Überlegungen ${ }^{31}$}

Als Nachteil des Nießbrauchs ist darauf hinzuweisen, dass die Frist zur Abschmelzung des Pflichtteilsergänzungsanspruchs gem. § 2325 Abs. 3 BGB auch nach der Erbrechtsreform erst mit Erlöschen des Nießbrauchsrechtes beginnt. Erlischt dieses mit dem Tode des Nießbrauchers, sind die Pflichtteilsergänzungsanspruche ungeschmälert um eine etwaige Abschmelzung in den fiktiven Nachlass mit einzubeziehen. Dieser Nachteil besteht bei der Vermögensübergabe gegen Versorgungsleistungen nicht. Die Frist beginnt mit zivilrechtlichem Vollzug der Zuwendung. ${ }^{32}$ Die Versorgungsleistungen haben außerdem eine gewisse Attraktivität auch bei der älteren Generation behalten, da die gesamte

30 BMF v. 11.3.2010, BStBl. I 2010, 227, Tz. 65; ablehnend Spiegelberger, DStR $2008,1065$.

31 Zur Erbrechtsreform informativ Mayer, ZEV 2010, 2.

32 Regelmäßig Grundbuchumschreibung, Lange in MüKo/BGB, 5. Aufl. 2010, $\S 2325 \mathrm{Rz} .58 \mathrm{~m} . \mathrm{N}$. 
Verwaltung des übertragenen Vermögensgegenstandes Aufgabe des Übernehmers ist. Der Übergeber erhält unabhängig von dem konkreten Ertrag des übergebenen Vermögens abgesehen von Ausnahmefällen einen festen Betrag. Gleichwohl kann dem Nießbraucher zumindest die Last der Verwaltung des Vermögensgegenstandes abgenommen werden, indem durch eine Regelung mit dem Nießbrauchsbesteller diesem die Verwaltung übertragen wird. Dies ist insbesondere bei einem Quotennießbrauch anzuraten, da nach $\S 741 \mathrm{BGB}$ eine entsprechende Verwaltungsvereinbarung möglich ist und auch Dritten gegenüber wirkt. ${ }^{33}$

\section{Erwerb des Familienheims, insbesondere durch den Ehegatten}

a) Lebzeitige Zuwendung an Ehepartner

Bereits seit 1994 ist der Erwerb des Familienheims (früher Familienwohnheims) aufgrund freigebiger lebzeitiger Zuwendung durch den Ehepartner steuerbefreit (§ 13 Abs. 1 Nr. 4a ErbStG). Die Finanzverwaltung hat die Anwendung dieser Norm wesentlich erleichtert, indem auch mittelbare Erwerbsvorgänge, etwa in Form mittelbarer Schenkungen von der Besteuerung kraft sachlicher Befreiung ausgenommen sind. ${ }^{34}$ Bekanntlich kennt die Norm keinen Objektverbrauch. Es muss sich lediglich im Zeitpunkt der Ausführung der Zuwendung (§9 Abs. 1 Nr. 2 ErbStG) um das Familienheim handeln, in welchem zumindest einer der Ehepartner seinen Lebensmittelpunkt hat. Daher ist auch der Erwerb des Familienheims in den Fällen, in denen die Eheleute getrennt leben und nur ein Ehepartner das Objekt nutzt, steuerbefreit. ${ }^{35}$

Die unmittelbare und mittelbare Zuwendung des Familienheims war seit Langem ein Klassiker der Gestaltungsberatung. Dies hat sich durch das ErbStRG 2009 nicht verändert. Gleichwohl ist zu beobachten, dass die Zahl der lebzeitigen freigebigen Zuwendungen zwischen Ehegatten steigt. Woran liegt dies?

b) Einfluss des begünstigten Erwerbes von Todes wegen

auf die Beratungspraxis

Der Gesetzgeber hat durch $\S 13$ Abs. 1 Nr. 4b ErbStG mit Wirkung ab 2009 auch den Erwerb des Familienheims von Todes wegen durch den Ehegatten oder gleichgestellt den Partner einer gleichgeschlechtlichen eingetragenen Lebenspartnerschaft von der Erbschaftsteuer befreit. ${ }^{36}$

33 Instruktiv Amann, in FS Spiegelberger, 2009, 1161.

34 R 43 ErbStR 2003, BStBl. I 2003, Sondernummer 1, 2 ff.

35 BFH v. 26.2.2009 - II R 69/06, BStBl. II 2009, 480.

36 Wertvolle Gestaltungshinweise enthält der Beitrag von Reimann, ZEV 2010, 174. 
Allerdings enthält diese Norm zahlreiche Restriktionen. So ist Voraussetzung, dass der Erblasser im Zeitpunkt des Todes das maßgebliche Familienheim zu eigenen Wohnzwecken genutzt hat oder aus zwingenden Gründen hieran gehindert war.

Ferner muss der Erwerber - will er die Vergünstigung dauerhaft behalten das Familienheim für die Dauer von zehn Jahren ab Erwerb selbst zu eigenen Wohnzwecken nutzen oder hieran aus zwingenden Gründen gehindert sein. Die Finanzverwaltung legt anders als bei $\S 13$ Abs. 1 Nr. 4a ErbStG den Befreiungstatbestand - nach meiner Meinung über Gebühr - eng aus. So soll insbesondere die Aufgabe des Familienheims nach dem Erwerb aus beruflichen Gründen keinen zwingenden Grund für den Wegfall der Selbstnutzung darstellen. Die Weitergabe innerhalb der zehnjährigen Frist an Kinder soll selbst dann schädlich sein, wenn dies unter dem Vorbehalt des Nießbrauchs erfolgt. Die Beispiele ließen sich fortsetzen. Dies hat in der Bevölkerung dazu geführt, dass die Vorteile der lebzeitigen Zuwendung des Familienheims an den Ehepartner stärker in das Bewusstsein getreten sind. Diese haben zusammengefasst folgenden Inhalt:

- Keine Beschränkung auf ein Objekt; vielmehr sind mehrere nacheinander folgende Zuwendungen steuerbefreit, wenn die sachlichen Voraussetzungen vorliegen.

- Keine zwingende Selbstnutzung durch den Schenker bei Ausführung der Schenkung.

- Keine nachhängende Frist zur Selbstnutzung durch den Erwerber.

- Veräußerung an Dritte oder Weitergabe an Angehörige begünstigungsunschädlich möglich.

Dies führt zu einer deutlichen Konjunktur im Rahmen der Übergabe von Familienheimen. Insbesondere wenn absehbar ist, dass der erwerbende Ehepartner nach dem Tode des übertragenden Ehepartners keine zehn Jahre mehr in dem Objekt wohnen bleiben wird, etwa weil das Familienheim für eine Person zu groß ist oder er es aus Altersgründen vermutlich räumen wird, ist der lebzeitigen Übertragung zuzuraten, da dann die Weitergabe des Familienheims im nächsten Schritt durch den überlebenden Ehepartner an Kinder die Vergünstigung des Erwerbes nicht entfallen lässt. Wird das Familienheim durch lebzeitige Zuwendung gegen Wohnrecht und/oder Nießbrauch übertragen, kann die Nießbrauchslast abgezogen werden. Der danach verbleibende Wert wird sich regelmäßig im Bereich der persönlichen Freibeträge halten, so dass der Gesamterwerb zu keiner Steuerbelastung führt.

Der Sorge der übertragenden Ehepartner, bei einer unerwarteten Reihenfolge des Versterbens sei der erbrechtliche Rückerwerb an den Schenker 
bei diesem nur mit den Restriktionen des $\S 13$ Abs. 1 Nr. 4b ErbStG steuerbefreit, lässt sich mit einem Rückforderungsrecht begegnen, welches zumindest nach allgemeiner Auffassung ${ }^{37}$ dazu führt, dass das Familienheim erbschaftsteuerlich außerhalb des Erwerbes von Todes wegen als Rückerwerb gem. §29 Abs. 1 Nr. 1 ErbStG wieder dem seinerzeitigen Schenker zugewiesen wird. In diesem Zusammenhang sind Anwendungsprobleme in der Praxis nicht bekannt.

\section{Resümee}

Das Erbschaftsteuerrecht hat in einigen Bereichen zu einem veränderten "Verbraucherverhalten" geführt. Dies ist vom Gesetzgeber entweder dem Grunde nach angestrebt, wie dies in der Absicht zum Ausdruck kommt, Vermögensübergaben über Unternehmen zu erleichtern, oder es ist eine Folgewirkung nunmehr beendeter Restriktionen im Bereich der Nießbrauchslast. Bezogen auf Familienheime sind durch Erleichterungen bei Erwerben von Todes wegen, die aber mit Einschränkungen verbunden sind, die Vorteile der lebzeitigen Zuwendung wieder in den Blick der interessierten Öffentlichkeit getreten.

Es bleibt abzuwarten, welches Schicksal die Erbschaftsteuer in den nächsten Jahren nehmen wird.

37 Hardt, ZEV 2004, 408. 
4. Leitthema:

Internationales Steuerrecht 



\title{
Neues zu Betriebsstättenbegriff und Gewinnermittlung
}

\author{
Dr. Andreas Roth \\ Mannheim
}

Inhaltsübersicht

\section{Einleitung}

2. Auflösungstendenzen beim Betriebsstättenbegriff
a) Geschäftseinrichtung - Mittel versus Gegenstand der Tätig- keit
b) „Feste“ Geschäftseinrich- tung - örtlich und zeitlich
c) Anlagenbau - auch ohne Tätigkeit vor Ort?
d) Vertreterbetriebsstätte - was bedeutet Abschlussvollmacht?
e) Dienstleistungsbetriebsstätte

3. Potenzielle Betriebsstätten bei Konzernstrukturen
a) Supply Management
b) Vertriebsstruktur
c) Personalentsendung
d) Tochtergesellschaft
e) Matrixorganisation

4. Gewinnabgrenzung zwischen $\S 4$ Abs. 1 Satz 3 EStG, BFH und dem Authorized OECD Approach

a) Gewinnabgrenzung nach BFH - Vorrang der Einheit des Unternehmens

b) Entstrickung nach $\S 4$ Abs. 1 Satz 3 EStG - begrenzte Anwendung

c) Der AOA in Art. 7 OECD-MA - Vorrang der wirtschaftlichen Selbständigkeit der Betriebsstätte

aa) Functionally Separate Entity Approach

bb) Interne "Dealings"

cc) Kapitalausstattung

dd) Korrespondierende Gewinnberichtigung

5. Ausblick

\section{Einleitung}

Die Betriebsstätte war schon verschiedentlich Gegenstand des Fachkongresses, so beispielsweise in den Jahren 1988, ${ }^{1} 1997,{ }^{2} 1999,{ }^{3} 2000,{ }^{4} 2004^{5}$

1 Kumpf, Ergebnis- und Vermögenszuordnung bei Betriebsstätten, StbJb. 1988/89, 399.

2 Roth, Aktuelle Fragen der Betriebsstättenbesteuerung unter Berücksichtigung des Entwurfs eines Betriebsstättenerlasses, StbJb. 1997/98, 427.

3 Kroppen, Ausgewählte Fragen zum Betriebsstättenerlass, StbJb 1999/2000,137.

4 Kraft, Erfolgsabgrenzung bei Betriebsstätten nach den Betriebsstätten-Verwaltungsgrundsätzen, StbJb. 2000/2001, Köln 2001, 205.

5 Görl, Aktuelle Aspekte des Betriebsstättenbegriffs unter Berücksichtigung der Präsenzanforderung, StBJb 2004/2005, 81-91; Wichmann, Aktuelle Tendenzen der OECD-Arbeiten zur Betriebsstätte, insbesondere bei Vertretern und Dienstleistungen, StBJb 2004/2005, 93-108. 
und zuletzt 2005. ${ }^{6}$ Dabei standen regelmäßig der Begriff der Betriebsstätte und die Abgrenzung des Gewinns, insbesondere bei internen Transaktionen zwischen Stammhaus und Betriebsstätte im Zentrum.

Mit zunehmender Globalisierung der Unternehmen bei gleichzeitiger Virtualisierung der Geschäftstätigkeiten werden die Begrenzungen, die das Betriebsstättenkonzept für Quellenstaaten mit sich bringt, zunehmend kritisch diskutiert, und es wird versucht, den Betriebs-stättenbegriff den geänderten Gegebenheiten anzupassen. Dies hat zu erheblichen Auflösungstendenzen des Betriebsstättenbegriffs, insbesondere bei der OECD, geführt, und zwar ohne dass der Text des Art. 5 OECD-MA geändert worden wäre. Hierauf ist im nächsten Abschnitt einzugehen.

Nachfolgend werde ich einige Situationen im Konzern beispielhaft aufzeigen, die eine Auseinandersetzung mit der Betriebsstätte notwendig machen. Es wird sich zeigen, dass Betriebsstätten an Ecken lauern können, wo man sie auf den ersten Blick nicht vermuten würde.

Andererseits hat sich international bei der Gewinnabgrenzung immer mehr die Meinung gefestigt, dass die Betriebsstätte faktisch wie ein eigenständiges Unternehmen zu behandeln sei, was insbesondere auf das Innenverhältnis zwischen Betriebsstätte und Stammhaus wirkt. Deshalb ist auf die Entwicklungen bei der Gewinnabgrenzung zwischen Stammhaus und Betriebsstätte einzugehen. Hier hat sich bekanntlich seit dem SEStEG ${ }^{7}$ sowohl national durch die Rechtsprechung des $\mathrm{BFH}^{8}$ als auch ganz aktuell durch die Veröffentlichung des OECD-MA $2010^{9}$ - auf Seiten der OECD einiges geändert.

\section{Auflösungstendenzen beim Betriebsstättenbegriff}

Wichmann und Görl ${ }^{10}$ hatten bereits vor sechs Jahren über die Änderungen im OECD-MK zu Art. 5 aus dem Jahr 2003 berichtet. Die damals eingetretenen Änderungen im Verständnis OECD dessen, was eine Betriebsstätte ausmacht, sind m.E. so grundlegend, dass auf einige zentrale Punkte nochmals eingegangen werden muss. Hierzu die folgenden Beispiele.

6 Remberg, Betriebsstätten-Gewinnermittlung im Blickpunkt der OECD Fallbeispiel: Großanlagenbau -, StBJb 2005/2006, 179-189.

7 Gesetz über steuerliche Begleitmaßnahmen zur Einführung der Europäischen Gesellschaft und zur Anderung weiterer steuerrechtlicher Vorschriften, BStBl. I, 2782.

8 BFH, Urt. v. 17.7.2008 - I R 77/06, BStBl. II 2009, 464 und BFH, Urt. v. 28.10.2009 - I R 99/08, GmbHR 2010, 219.

9 OECD, Model Tax Convention on Income and on Capital as of 17 July 2010.

10 S. Fn. 5. 
a) Geschäftseinrichtung - Mittel versus Gegenstand der Tätigkeit

Nach traditionellem Verständnis war die feste Geschäftseinrichtung, die für die Begründung einer Betriebsstätte notwendig ist, ein Mittel zur Ausübung der Tätigkeit. Dieser Mittelcharakter kommt auch in den Formulierungen sowohl des $\S 12 \mathrm{AO}$ (,die der Ausübung ... dient") wie auch des Art. 5 Abs. 1 OECD-MA („,durch die die Tätigkeit ... ausgeübt wird") zum Ausdruck. Die OECD hat dieses Verständnis aufgegeben und lässt nun auch den Gegenstand der Tätigkeit selbst als Anknüpfungspunkt ausreichen. Dies wird an den Beispielen des Anstreichers ${ }^{11}$ und des Straßenbaus $^{12}$ deutlich. Damit wurde die Betriebsstättendefinition wesentlich ausgeweitet und schließt nunmehr zwanglos die Bau- und Montagetätigkeit, aber auch eine ganze Reihe von ortsgebundenen Leistungen mit ein, wie das folgende Beispiel zeigt:

Die französische Tochtergesellschaft $F$ eines deutschen Energieversorgers $\mathrm{D}$ ist mit Wartungsarbeiten an einer Kraftwerksanlage im Inland beauftragt und führt dabei auch Reparaturarbeiten aus. Zur Ausführung der Tätigkeiten sind an mindestens sieben Monaten während eines Jahres Mitarbeiter des Unternehmens beim Kunden vor Ort. F verfügt nicht über Büro- oder Besprechungsräume bei D.

Nach deutscher Auffassung unterhält die ausländische Tochtergesellschaft keine feste Geschäftseinrichtung im Sinne einer Mittel/ZweckRelation. Eine Bauausführung bzw. Montage liegt ebenfalls nicht vor, da die Tätigkeiten nicht auf die Errichtung der Anlage bzw. den erstmaligen Zusammenbau gerichtet sind. ${ }^{13}$ Danach hat $\mathrm{F}$ keine Betriebsstätte im Inland.

Die Lösung nach OECD sieht jedoch ganz anders aus: Der Gegenstand der Tätigkeit, die Kraftwerksanlage, wird als feste Geschäftseinrichtung der $\mathrm{F}$ angesehen, Bauausführungen/Montagen stellen hiernach lediglich Anwendungsfälle der festen Geschäftseinrichtung mit erweiterter zeitlicher Voraussetzung, nämlich 12 statt 6 Monate Mindestdauer, dar. Da die Reparatur- und Wartungsarbeiten keine Montage i.S. des Art. 2 Abs. 1 Nr. 7 Buchst. a Doppelbuchst. (gg) DBA-Frankreich darstellen, ist nicht die dort genannte 12-Monatsfrist, sondern die allgemeine 6-Monatsfrist für eine feste Geschäftseinrichtung maßgeblich. F hätte nach diesem Verständnis eine Betriebsstätte im Inland.

Mit dieser Neuinterpretation mutiert die Regelung des Art. 5 Abs. 3 von einer Definitionserweiterung zu einer Einschränkung: denn ohne diese

11 OECD-MK zu Art. 5, Tz. 4.5.

12 OECD-MK zu Art. 5, Tz. 4.6.

13 Vgl. BFH, Urt. v. 16.5.1990 - I R 113/87 BStBl. 1990 II, 983. 
Vorschrift wären Bau- und Montagetätigkeiten bereits nach sechs Monaten Dauer als Betriebsstätten anzusehen.

Im Übrigen ist fraglich, ob diese Auslegung auf bestehende DBA, wie das DBA Frankreich, anwendbar ist, oder ob sie sich auf neu abzuschließende DBA beschränkt. Handelt es sich doch, wie das Beispiel zeigt, nicht um eine klarstellende Auslegung, sonder um eine wesentliche Neuinterpretation des Musterabkommens. ${ }^{14}$

\section{b) „Feste“ Geschäftseinrichtung - örtlich und zeitlich}

Bezüglich der zeitlichen Komponente können - anders als nach $\S 12 \mathrm{AO}$ nach wie vor Tätigkeiten nur dann zusammengerechnet werden, wenn sie sowohl geografisch als auch wirtschaftlich zusammenhängen. Eine nur geographische oder nur wirtschaftliche Einheit reicht nicht aus. Insoweit steht der Damm noch. Allerdings sind erste Schadstellen zu erkennen, wenn nicht mehr die Nutzung derselben Einrichtung während der Mindestdauer gefordert wird, sondern die Nutzung unterschiedlicher Räume/Einrichtungen ausreichend sein soll. Die Angst vor Umgehung durch entsprechende tatsächliche Gestaltungen ist nachzuvollziehen. Andererseits aber verliert der Betriebsstättenbegriff weiter an Kontur.

Dies zeigt das Beispiel des sogenannten Bürohotels. ${ }^{15}$ Danach soll es unschädlich sein, wenn nicht derselbe Raum, sondern ggf. unterschiedliche Räume in einem Gebäude genutzt werden. Mietet ein Dienstleister im Zusammenhang mit einem Auftrag für die jeweiligen Ortstermine Büroräume in einem sogen. Bürohotel an, dann wird häufig für den jeweiligen Aufenthalt nicht der gleiche Raum zur Verfügung stehen. Dies soll nunmehr nach Auffassung der OECD auch nicht mehr notwendig sein. Fraglich ist allerdings, ob dies nur auf Räume im gleichen Gebäude zutrifft oder ob auch unterschiedliche Räume in benachbarten Gebäuden mitzählen; wenn ja, bis zu welchem Umkreis? Wie, wenn Büroräume bei verschiedenen Vermietern im selben Gebäude angemietet werden? Und wie steht es mit Unterbrechungen des Aufenthalts?

Schließlich ist unklar, wie dies alles mit der Rechtsprechung des BFH in Einklang gebracht werden kann. Das Hotelmanagement-Urteil aus

14 Nach h. M. können OECD-MA und MK zur Auslegung von Abkommen nur beschränkt und auch nur in der Fassung herangezogen werden, die im Zeitpunkt des Abschlusses des betreffenden DBA gegolten haben. Vgl. hierzu Schaumburg, Internationales Steuerrecht, 3. Aufl., Köln 2011, Rz. 16.77; vgl ferner Vogel in Vogel/Lehner, DBA, 5. Aufl., München 2008, Einleitung Rz. 123 ff.; Wassermeyer in Debatin/Wassermeyer, DBA (2008), vor Art. 1 Rz. 60.

15 Vgl. OECD-MK zu Art. 5 Tz. 5.2. 
$1993^{16}$ hatte bereits Diskussionen darüber ausgelöst, was unter Verfügungsmacht $\mathrm{zu}$ verstehen ist. Allerdings enthält das veröffentlichte Urteil keine Hinweise darauf, dass der BFH wechselnde Räumlichkeiten als feste Geschäftseinrichtungen i. S. des $\S 12 \mathrm{AO}$ anerkannt hätte. Im Falle eines Unternehmensberaters ${ }^{17}$ hatte der $\mathrm{BFH}$ entschieden, dass eine Betriebsstätte bei nicht durchgehendem Aufenthalt nur dann begründet wird, wenn die Geschäftseinrichtung auch während der Abwesenheit des Unternehmens diesem zur Verfügung steht, d.h. nicht an andere Personen zur Nutzung überlassen wird.

Aber auch die Rechtsprechung des BFH erscheint in sich nicht spannungsfrei. Vor allem sind aus meiner Sicht die beiden genannten Urteile nicht ohne weiteres mit der Marktstandrechtsprechung ${ }^{18}$ in Übereinklang zu bringen. Wenn es richtig ist, dass der Unternehmer durchgehend über die Geschäftseinrichtung verfügen können muss und eine zwischenzeitliche anderweitige Nutzung schädlich ist, dann muss dies für den Standplatz auf dem Wochenmarkt gelten, wenn der Händler nur an bestimmten Wochentagen seinen mobilen Marktstand aufstellt, der Platz jedoch zwischen den Markttagen anderweitig, z. B. als öffentlicher Parkplatz genutzt wird.

\section{c) Anlagenbau - auch ohne Tätigkeit vor Ort?}

Bekanntlich werden dem Generalunternehmer einer Bauausführung bzw. Montage auch die Zeiten der Subunternehmer zugerechnet, wenn er einzelne Gewerke nach außen vergeben hat und selbst mit eigenem Personal nur weniger als die nach dem DBA erforderliche Frist vor Ort anwesend ist. Diese Hinzurechnung bezieht sich allerdings nur auf die Berechnung der Mindestfrist. Daran hat sich bis heute auch nichts geändert. Allerdings hatte Wichmann ${ }^{19}$ bereit 2004 darauf hingewiesen, dass einige Mitgliedsstaaten der OECD eine Änderung des MK zu Art. 5 oder ggf. das Abkommen selbst dahingehend fordern, dass eine Betriebsstätte des Generalunternehmers auch dann unterstellt wird, wenn dieser selbst nicht vor Ort tätig wurde, sondern alle Gewerke, einschließlich der Bauüberwachung vor Ort an Subunternehmer vergeben hat.

16 Vgl. BFH, Urt. v. 3.2.1993 - I R 80-81/91, BStBl. II 1993, 462.

17 Vgl. BFH, Urt. v. 28.6.2006 - I R 92/05, BStBl. II 2007, 100.

18 Vgl. BFH, Urt. v. 9.10.1974 - I R 128/73, BStBl. II 1975, 203, danach bedürfe es „keiner Begründung“, dass es für die Annahme einer Betriebsstätte ausreiche, wenn dem Händler für die jeweilige Marktveranstaltung ein Platz zugewiesen sei und die Marktveranstaltungen „sich ständig in mehr oder weniger großen zeitlichen Abständen an meist auch gleicher Stelle wiederholen".

19 Vgl. Wichmann, StBJb 2004/2005, $102 \mathrm{f}$. 
Da der Generalunternehmer in diesem Fall keine Bau- bzw. Montageleistungen vor Ort erbringt, zielt dieser Vorstoß darauf ab, Gewinne aus Leistungen - insbesondere Planungsleistungen und Projektkoordination-, die außerhalb des Staates der Bauausführung bzw. Montage erbracht werden, dort zu besteuern. Dies aber wäre der Einstieg in die Liefergewinnbesteuerung und wird deshalb von Deutschland nach wie vor vehement bekämpft.

Diese Diskussion scheint innerhalb der Working Party 1 noch nicht abgeschlossen. Jedenfalls konnte eine diesbezügliche Änderung des MK bisher verhindert werden.

\section{d) Vertreterbetriebsstätte - was bedeutet Abschlussvollmacht?}

Vertreterbetriebsstätten gewinnen, wie die Beispiele im nächsten Abschnitt zeigen werden, zunehmend an praktischer Bedeutung. Deshalb sind hier eindeutige und leicht handhabbare Abgrenzungskriterien für die Praxis wichtig. Das Innehaben und die nachhaltige Ausübung einer Abschlussvollmacht für das ausländische Unternehmen erfüllt diese Anforderung im Grundsatz. Allerdings sind, wie das folgende Beispiel zeigt, an der einen oder anderen Stelle Überraschungen zu erwarten.

Ein deutscher Fahrzeughersteller beschäftigt in Serbien einen angestellten Vertreter, dessen Aufgabe es ist, die für den Verkauf in Serbien bestimmten Fahrzeuge zu homologieren. Der Mitarbeiter verfügt über eine entsprechende Vollmacht, die er gewöhnlich im Verkehr mit den Behörden nutzt.

Liest man die Erläuterungen des MK in Tz. 33 mit Blick auf den geschilderten Sachverhalt, dann stellt sich zunächst die Frage, ob die Vollmacht zum Abschluss von Verträgen auch die Vertretung des ausländischen Unternehmens gegenüber Behörden umfasst, oder ob nur der Abschluss privatrechtlicher Verträge gemeint ist. Wird ersteres bejaht, dann ist weiter zu fragen, ob das Homologieren zum Kernbereich der Unternehmenstätigkeit gehört, oder nur zum unschädlichen internen Geschäftsbetrieb. Dabei ist zu berücksichtigen, dass das Homologieren unmittelbare Voraussetzung für die Zulassung und damit für den Absatz von Fahrzeugen in einem Land ist. Die Gefahr einer Vertreterbetriebsstätte ist nicht auszuschließen.

\section{e) Dienstleistungsbetriebsstätte}

Wie wir gesehen haben, wurde der Einstieg in die Dienstleistungsbetriebsstätte bei ortsgebundenen Leistungen bereits mit der Änderung des OECD-MK im Jahr 2003 gemacht. ${ }^{20}$ Einige Mitgliedsstaaten hatten

20 Insbesondere das Anstreicherbeispiel in OECD-MK Tz. 4.5; Wichmann, StBJb 2004/2005, 96 nennt dies die "kleine Dienstleistungsbetriebsstätte". 
in ihren DBAs bisher schon Dienstleistungen als Betriebsstätten anerkannt. Für Deutschland sind dies die DBA mit China, Liberia und den Philippinen.

Mit dem MK 2008 wurde in den Tz. 42.11 bis 42.48 zu Art. 5 erstmals ein Vorschlag zur Dienstleistungsbetriebsstätte vorgestellt. In den Text des MA selbst wurde jedoch keine Formulierung aufgenommen, um den Ausnahmecharakter dieses Tatbestandes zu unterstreichen. Die Regelung sieht für folgende Tatbestände eine Betriebsstätte vor:

- Mindestaufenthalt 183 Tage innerhalb von 12 Monaten und

- Mehr als 50 \% der Einkünfte aus dieser Tätigkeit im Quellenstaat, unabhängig von Ort der Leistung (Kleinunternehmer) oder

- Dienstleistung für ein bestimmtes (ortsfestes) Projekt oder mehrere zusammenhängende Projekte

Man kann für diese Regelung durchaus Verständnis haben, da internationale Dienstleistungen mit zunehmender Globalisierung wichtiger werden und erhebliche Wertschöpfung erzielen, an denen insbesondere die Empfängerstaaten der Dienstleistungen partizipieren wollen. Allerdings wird dies erkauft mit einer weiteren Auflösung des Betriebsstättenprinzips. Je nachdem, wie extensiv man das weiter oben genannte Bürohotelbeispiel auslegt, kann man damit allerdings auch ohne besondere Regelung in die Nähe der Dienstleistungsbetriebsstätte kommen.

Schließlich sollte bedacht werden, dass die wirtschaftliche Entwicklung in einigen Fällen bereits weiter fortgeschritten ist und es zur Erbringung von Dienstleistungen oft gar nicht mehr der physischen Anwesenheit bedarf oder Leistungen durch virtuelle Gruppen oder Organisationen erbracht werden. Hier greift naturgemäß auch die von der OECD vorgeschlagene Formulierung zu kurz. Das könnte über kurz oder lang zur Grundsatzfrage führen, ob die Betriebsstätte künftig noch das richtige Anknüpfungsmerkmal ist, oder ob ggf. ein ganz anderes Merkmal entwickelt werden muss um die Wertschöpfungsströme der Zukunft sachgerecht einzelnen Steuerhoheiten zuzuordnen.

\section{Potenzielle Betriebsstätten bei Konzernstrukturen}

Multinationale Konzerne sehen sich zunehmend mit Betriebsstättenfragen konfrontiert. Dies ist vor allem geänderten Konzernstrukturen geschuldet, in denen Funktionen im Bereich des Engineering, des Supply Management oder des Marketing organisatorisch, nicht aber notwendigerweise auch physisch gebündelt, und dadurch Matrixorganisationen quer über rechtliche Einheiten und Jurisdiktionen hinweg gebildet werden. Die folgenden Beispiele mögen einige Hinweise zu möglichen Gefah- 
renherden geben und insbesondere zur Überprüfung der eigenen Konzernstrukturen anregen.

\section{a) Supply Management}

Im ersten Beispiel hat der ausländische M-Konzern die Beschaffungsfunktion zentral von der ausländischen Konzernspitze gesteuert. Für bestimmte Materialgruppen sind bei der inländischen TG angestellte strategische Einkäufer zuständig, die jedoch organisatorisch der zentrale Supply Management-Funktion bei der Muttergesellschaft MG zugeordnet sind. Diese Mitarbeiter ernennen und betreuen deutsche Lieferanten und verhandeln Lieferpreise für den Konzern; ausländische Lieferanten werden entsprechend von örtlichen Mitarbeitern der jeweiligen ausländischen TG ernannt und betreut, und zwar auch, soweit sie die deutsche Gesellschaft beliefern.

Bei der Lösung dieses Falles sind die folgenden Fragen zu beantworten. Im Rahmen dieses Beitrags sollen lediglich die Fragen benannt werden, ohne sie im Einzelnen zu diskutieren.

- Begründet MG durch die örtlichen Supply Manangement-Mitarbeiter feste Geschäftseinrichtungen bei den verschiedenen Tochtergesellschaften? Dies hängt davon ab, ob man die bei den Tochtergesellschaften angestellten Mitarbeiter wirtschaftlich der MG zuordnen kann.

- Oder sind die Tochtergesellschaften als Vertreter für andere Konzernunternehmen anzusehen? Schließlich besorgen Mitarbeiter der Tochtergesellschaften den Einkauf für MG und Schwestergesellschaften und zwar mit Vollmacht und nachhaltig.

- Handelt es sich ggf. um eine Hilfstätigkeit? Wohl kaum, da die Tätigkeit auch für andere Konzernunternehmen ausgeübt wird.

- Bezieht sich die Abschlussvollmacht auf den Kernbereich oder auf den internen Geschäftsbetrieb?

- Kommt man zur Annahme einer Betriebsstätte so stellt sich die Folgefrage nach dem angemessenen Gewinn.

\section{b) Vertriebsstruktur}

Ein deutsches Vertriebsunternehmen beschäftigt im Inland und in verschiedenen europäischen Ländern sogenannte Territory Manager ein, deren Aufgabe es ist, Vertragshändler hinsichtlich deren Marktauftritt zu beraten und zu unterstützen und sicherzustellen, dass die von dem Vertriebsunternehmen vorgegebenen Standards bezüglich Auftritt, Qualität, Management und Ausbildung sowie hinsichtlich Umsatzziele erreicht werden. Bestellungen geben die Händler über ein Internetportal direkt 
beim Vertriebsunternehmen ein. Außerdem unterstützen die Territory Manager das Unternehmen bei der Akquisition neuer Händler, ohne allerdings Abschlussvollmacht zu besitzen.

Auch hier stellt sich die Frage, ob die Territory Manager nicht VertreterBetriebsstätten für das Unternehmen begründen. Zwar nehmen diese Mitarbeiter keine Aufträge entgegen und sie besitzen regelmäßig auch keine Abschlussvollmacht für Aufträge. Dennoch können sie in begrenztem Umfang über Verkaufshilfen entscheiden ${ }^{21}$ und tragen durch die Unterstützung und Entwicklung der Vertragshändler wesentlich zur Wertschöpfung bei.

\section{c) Personalentsendung}

Die U. S. Inc. stellt Produkte her, die sie im Inland über die T-GmbH vertreibt. Für die Beratung von Kunden, Begutachtung von Mängeln sowie für den Aufbau eines europäischen Kompetenzzentrums für die in USA hergestellten Produkte entsendet die U. S. Inc. einen Produktspezialisten nach Deutschland. Der Mitarbeiter erhält von der inländischen T-GmbH einen Anstellungsvertrag und ein Büro, fachlich und disziplinarisch ist er jedoch der U. S. Inc. weiterhin unterstellt. Auch werden sämtliche Bedingungen des Arbeitsverhältnisses, einschließlich der Gehaltsbemessung von U.S. Inc. vorgegeben. $M$ hat Vertretungsvollmacht für U.S. Inc. bezüglich Garantiezusagen, Preisnachlässen sowie zum Einkauf von Beratungsleistungen und übt diese regelmäßig bei Kundenbesuchen im In- und Ausland aus.

Auch hier sollen nur Fragen formuliert werden:

- Begründet die U.S. Inc. durch Büro das M von der T-GmbH zur Verfügung gestellt wird, eine feste Geschäftseinrichtung im Inland? Die Antwort hierauf ist abhängig von der Folgefrage: Ist die Tätigkeit des M funktional der U. S. Inc. oder der T-GmbH zuzuordnen?

- Ist M ggf. aufgrund seiner Abschlussvollmacht als Vertreter der U.S. Inc. anzusehen? Wer kommt als Vertreter in Betracht: $M$ oder $\mathrm{T}-\mathrm{GmbH}$ ?

- Reicht der Umfang der Vollmacht - Zusage von Gewährleistungen, Preisnachlässen, Einkauf von Beratungsleistungen - für eine Vertreterbetriebsstätte aus?

$21 \mathrm{Ob}$ eine solche begrenzte Vollmacht zur Vereinbarung einzelner Konditionen für die Begründung einer Vertreterbetriebsstätte ausreicht erscheint angesichts des Hinweises in Tz. 33, darauf, dass die Person „alle Einzelheiten eines Vertrags" unterschriftsreif aushandelt, eher zweifelhaft. 


\section{d) Tochtergesellschaft}

Eine deutsche GmbH D hat mit einem italienischen Hersteller $\mathrm{H}$ von Konsumgütern eine Lizenzvereinbarung abgeschlossen, wonach $\mathrm{H}$ für das Recht, Waren unter der Marke von D zu produzieren und zu vertreiben, gegen Zahlung einer Lizenzgebühr erhält. Die italienische Tochtergesellschaft $\mathrm{T}$ von $\mathrm{D}$, die Komponenten und Vorprodukte u. a. für D sowie für den Lizenznehmer herstellt, wird von D beauftragt, die Durchführung des Lizenzvertrags zu überwachen. Außerdem hatten Mitarbeiter der T an den Vertragsverhandlungen zwischen D und I teilgenommen.

Es handelt sich hier um den bekannten Philipp Morris Fall in Italien. Der italienische Steuergerichtshof ${ }^{22}$ sah $\mathrm{T}$ als Vertreterbetriebsstätte von D an mit der Folge, dass die Lizenzgebühren der ungemilderten Besteuerung in Italien unterlagen. Dabei sah er in der Teilnahme der T an Verhandlungen ein Indiz für deren Vertretervollmacht; außerdem begründete T nach Ansicht des Gerichtshofs durch Überwachung der Durchführung eine Vertreterbetriebsstätte für D.

Zwar hat die OECD diese Rechtsprechung als nicht konform mit Art. 5 OECD-MA eingestuft. ${ }^{23}$ Der italienische Gerichtshof hat sich davon allerdings nicht beeindrucken lassen und seine bisherige Ansicht in einem späteren Verfahren ${ }^{24}$ bestätigt. Dieses Beispiel zeigt eindrücklich, welchen Gefahren international agierende Unternehmen ausgesetzt sein können.

\section{e) Matrixorganisation}

Ein U.S. Konzern mit deutscher Tochtergesellschaft T möchte ein Entwicklungszentrum in Deutschland errichten. Es soll als Niederlassung der $\mathrm{T}$ im Inland errichtet und betrieben werden. Die leitenden Ingenieure sind bei $\mathrm{T}$ angestellt, berichten jedoch nicht an deren Geschäftsführer, sondern direkt an Vorgesetzte in USA. Das Entwicklungsbudget sowie sämtliche Entscheidungen bzgl. der Entwicklungsprojekte werden direkt bei der Muttergesellschaft M in USA verantwortet; T hat kein Mitspracherecht. Die Kosten werden mit einem angemessenen Gewinnaufschlag an $\mathrm{M}$ belastet.

- Führt die Organisationsstruktur dadurch zur Annahme einer Geschäftsleitungsbetriebsstätte von T in USA, dass die verantwortliche

22 Vgl. Kassationsgerichtshof v. 25.5.2002, Nr. 7682, zitiert bei IBFD, Italy, Permanent Establishments Tz. 2.1.6.1; vgl. auch Ditz, IStR 2010, 553.

23 Vgl. Ditz, IStR 2010,553 (554) mit Hinweis auf die geänderten Tz. 33, 41, 41.1 und 42 OECD-MK zu Art. 5.

24 Vgl. Kassationsgerichtshof v. 28.7.2006, Nr. 17206, zitiert bei IBFD, Italy, Permanent Establishments, Tz. 2.1.6.1. 
Leitung des Entwicklungsbereichs durch M erfolgt und der Geschäftsführer der T keine Befugnisse bzgl. Budget und Entwicklungsprogramm hat?

- Kann umgekehrt aufgrund der tatsächlichen Entscheidungsgewalt der $M$ das Entwicklungszentrum als Betriebsstätte von $M$ bei $T$ angesehen werden? Ist $M$ als wirtschaftlicher Arbeitgeber der inländischen Entwicklungsingenieure anzusehen und vermittelt ihr dies zusammen mit der Budgethoheit die ausreichende Verfügungsmacht über die Einrichtung?

\section{Gewinnabgrenzung zwischen $₫ 4$ Abs. 1 Satz 3 EStG, BFH und dem Authorized OECD Approach}

Im Bereich der Gewinnabgrenzung zwischen Stammhaus und Betriebsstätte hat sich in den letzten Jahren Wesentliches geändert. Die jüngste Entwicklung betrifft die im Juli 2010 verabschiedete Neufassung von Art. 7 ECD-MA und des dazugehörigen MK. Aber auch Gesetzgebung und Rechtsprechung haben einiges auf nationaler Ebene verändert.

\section{a) Gewinnabgrenzung nach BFH - Vorrang der Einheit des Unternehmens}

Mit seinem vielbeachteten Urteil vom 17.7.2008 ${ }^{25}$ hat der BFH sich klar und eindeutig von der früher vertretenen sog. "finalen Entnahmetheorie" verabschiedet. Diese war bereits im Schrifttum ${ }^{26}$ weitestgehend abgelehnt worden, diente aber im Betriebsstättenerlass vom 24.12.199927 als unausgesprochene Rechtfertigung für die Gewinnzuordnung und -realisierung bei internen Leistungsbeziehungen zwischen Stammhaus und Betriebsstätte.

Der BFH hat demgegenüber in seinem o. g. Urteil für die Zeit vor SEStEG klargestellt, dass durch die Überführung eines Wirtschaftsguts vom inländischen Stammhaus an die ausländische Betriebsstätte kein gesetzlicher Gewinnrealisierungstatbestand erfüllt ist. Vielmehr sei erst im Zeitpunkt der Weiterveräußerung des Wirtschaftsguts durch die Betriebsstätte am Markt oder seines Verbrauchs ein Gewinn realisiert. Dem Stammhaus sei folglich - mangels anderweitiger Rechtsgrundlage - erst

25 I R 77/06, BStBl. II 2009, 464.

26 Vgl. z. B. Schaumburg, Internationales Steuerrecht, 3. Aufl., Köln 2011, Rz. 18.49, ferner Wassermeyer in Debatin/Wassermeyer, DBA (2009), Art. 7 Rz. 246 m. w. N.

27 BMF, Schr. v. 24.12.1999 - IV B 4 - S1300 - 111/99, BStB1. 1999 I, 1076, das allerdings nicht folgerichtig statt des Teilwerts, den Fremdvergleichspreis als Bewertungsmaßstab zugrunde legt. 
in diesem Zeitpunkt ein fremdüblicher Anteil an dem Gewinn zuzurechnen und im Inland zu versteuern. Das Urteil wie auch das Folgeurteil vom 28.10.200928 wurde in der Fachwelt überwiegend begrüßt. Gleichwohl hat die Finanzverwaltung auf die geänderte Rechtsprechung des $\mathrm{BFH}$ zunächst mit einem Nichtanwendungserlass reagiert. ${ }^{29}$

Dieser maßgeblich von Wassermeyer, ${ }^{30}$ aber auch anderen Autoren ${ }^{31}$ vertretene Denkansatz stellt die Einheit des Unternehmens in den Vordergrund. Allerdings wirft er aus praktischer Sicht Fragen auf, zu denen das Gericht in den zu genannten Verfahren nicht zu entscheiden hatte. So ist insbesondere unklar, welche Wertverhältnisse der Gewinnabgrenzung zugrunde zu legen sind: diejenigen im Zeitpunkt des internen Vorgangs oder diejenigen im Zeitpunkt der Realisation? Man denke insbesondere an den Untergang oder die Beschädigung eines übertragenen Wirtschaftsguts oder an Wertschwankungen von Edelmetallbeständen.

Praktische Schwierigkeiten können in der Abrechnungstechnik im Umlaufvermögen auftreten. Hier müssten ggf. Verbrauchsfolgeverfahren im Rahmen der aufgeschobenen Gewinnverwirklichung angewandt werden. Beim Anlagevermögen wären ggf. Wertanpassungen bezüglich des Verbrauchs nachträglich zu berücksichtigen. Für die Praxis wäre eine rasche Klärung wichtig.

\section{b) Entstrickung nach § 4 Abs. 1 Satz 3 EStG-begrenzte Anwendung}

Mit dem SEStEG ${ }^{32}$ hatte der Gesetzgeber auf die Kritik an der mangelnden gesetzlichen Grundlage reagiert und mit Wirkung vom 1.1.2006 in $\S 4$ Abs. 1 Satz 3 EStG und $\S 12$ Abs. 1 KStG einen neuen Entstrickungstatbestand für die Überführung bzw. Nutzungsüberlassung von Wirtschaftsgütern in das Ausland geschaffen. ${ }^{33}$ Ganz im Denkmuster der finalen Entnahmetheorie wird eine Entnahme fingiert, die allerdings mit einer eigenen Bewertungsregel- dem gemeinen Wert - in $\S 6$ Abs. 1 Nr. 4 Satz 2 1. Halbsatz EStG versehen wurde.

28 I R 99/08, DStR 2010, 40.

29 Vgl. BMF, Schr. v. 20.5.2009 - IV C 6 - S 2134/07/10005, BStB1. I 2009, 671

30 Vgl. Wassermeyer in Debatin/Wassermeyer, DBA (2009), Art. 7 Rz. 248.

31 Vgl. Debatin, BB 1989, $1692 \mathrm{ff}$. und $1739 \mathrm{ff}$.

32 Gesetz über steuerliche Begleitmaßnahmen zur Einführung der Europäischen Gesellschaft und zur Änderung weiterer steuerrechtlicher Vorschriften, BGBl. I 2006, 2782.

33 Die parallele Verstrickungsvorschriften für vom Ausland in das Inland verbrachte Wirtschaftsgüter findet sich in $\S 4$ Abs. 1 Satz 72 . Halbsatz und $\S 6$ Abs. 1 Nr. 5a EStG. 
Diese Gesetzesänderung hat viel Kritik erfahren: ${ }^{34}$ Entgegen der Auffassung der Finanzverwaltung ist sie nicht klarstellend, sondern anspruchsbegründend. Dies ist spätestens seit dem genannten BFH-Urteil vom 17.7.2008 unbestreitbar. Damit ist die Regelung für Zeiträume vor dem 1.1.2006 nicht anzuwenden, der Betriebsstättenerlass im Übrigen auch nicht, denn er entbehrt ebenfalls der Rechtsgrundlage. Für spätere Jahre ist fraglich, ob die Gesetzesregelung überhaupt einen nennenswerten Anwendungsbereich hat: Zum einen, weil sie potenziell EU-widrig ist sie behandelt die Überführung von Wirtschaftsgütern in inländische Betriebsstätten anders, d.h. besser als in ausländische. ${ }^{35}$ Zum anderen spricht einiges dafür, dass, wenn der BFH seine Überlegungen und Begründungen in den zitierten Urteilen künftig aufrechterhält, die Entstrickungsregeln weitestgehend leerlaufen. ${ }^{36}$ Denn wo im Zeitpunkt des Verbringens noch gar kein Besteuerungsrecht entstanden ist, kann auch nichts entzogen oder beschränkt werden.

Schließlich ist die Regelung insofern lückenhaft und nicht konsequent, als sie interne Dienstleistungen zwischen Stammhaus und Betriebsstätte nicht erfasst. Hier sollen nach Auffassung der Finanzverwaltung die Regelungen des Betriebsstättenerlasses weiter gelten. ${ }^{37}$ Dies ist m.E. schon deshalb falsch, weil der Gesetzgeber ohne Weiteres sonstige Leistungen hätte aufnehmen können, wie er dies in $\S 4$ Abs. 1 Satz 2 EStG der Fall ist.

Bleibt noch darauf hinzuweisen, dass im JStG 2010 eine "klarstellende" Ergänzung in $\S 4$ Abs. 1 EStG dahingehend aufgenommen werden soll, ${ }^{38}$ dass das Verbringen eines Wirtschaftsguts in eine ausländische Betriebsstätte immer zum Ausschluss bzw. zur Beschränkung des deutschen Besteuerungsrechts führen soll. Ob dies allerdings den verunglückten Denkansatz der Vorschrift heilen kann, ist fraglich. M.E. wäre eine grundsätzliche Neukonzeption ähnlich der österreichischen Entstrickungsregelung notwendig.

34 Vgl. zuletzt und ausführlich Wissenschaftlicher Beirat von Ernst \& Young tax, DB 2010, $1776 \mathrm{ff}$.

35 Vgl. z. B. Förster, DB 2007, 72 (75); Rödder/Schumacher, DStR 2007, 369 (372); a. A. Musil in HHR, EStG, § 4 Anm. 211.

36 Vgl. ebenda, Fn. 34, Glnr. 2, Wassermeyer, DB 2006, 1176 (1180), Ditz, IStR 2009, 120.

37 Vgl. BMF, Schr. v. 25.8.2009 - IV B 5-S 2118-a/07/10011, BStBl. II 2009, 835 durch das der Betriebsstättenerlass vom 24.12.1999 bezüglich der Überführung von Wirtschaftsgütern, nicht aber in Bezug auf interne Dienstleistungen geändert wurde.

38 Antrag des Bundesrats v. 9.7.2010, BT-Drucks. 17/2823, 3; sowie Gegenäußerung der Bundesregierung ebenda, S. 37. 
c) Der AOA in Art. 7 OECD-MA - Vorrang der wirtschaftlichen Selbständigkeit der Betriebsstätte

Die OECD hat im Juli dieses Jahres eine Aktualisierung des Musterabkommens und des Kommentars beschlossen und veröffentlicht. ${ }^{39}$ Ein zentraler Punkt dabei war die Neufassung von Art. 7 und des dazu gehörigen Kommentars. Der Verabschiedung des Textes gingen jahrelange Arbeiten und z. T. kontroverse Diskussionen voraus. So sah der Ende 2009 vorliegende Entwurf noch eingehende Regelungen zur Kapitalausstattung vor, die in der endgültigen Fassung durch einen umfassenden Gegenberichtigungsanspruch bezüglich der Gewinnabgrenzung ersetzt wurde.

Insgesamt wurde Art. 7 entschlackt: so wurden die bisherigen Absätze 3 bis 6 gestrichen. Dies bedeutet insbesondere, dass die formelmäßige Gewinnaufteilungsmethode (Abs. 4) nicht mehr als eine Regelmethode anerkannt wird. Sie ist nach Ansicht der OECD entbehrlich, weil die direkte Methode auch in schwierigen Fällen zu Lösungen gelangt und die indirekte Methode bisher schon auf Ausnahmefälle beschränkt war. Dementsprechend war auch Abs. 5 (Methodenkontinuität) obsolet geworden. Ebenso wurde Abs.3, der die Kostenzuordnung regelte, als überflüssig und als eher irreführend angesehen.

Auch Abs. 6, der die Gewinne aus der Einkaufstätigkeit für andere Unternehmensteile künftig von der Gewinnzuordnung ausgenommen hatte, wurde gestrichen. Diese Leistungen muss, wie jede andere Dienstleistung auch, funktionsgerecht entgolten werden.

\section{aa) Functionally Separate Entity Approach}

Ziel der OECD ist es die Betriebsstätte hinsichtlich der Gewinnabgrenzung zum Stammhaus weitestgehend mit verbundenen Unternehmen gleichzusetzen. Die Formulierung des Abs. 2 stellt klarer als bisher den sogen. „Functionally Separate Entity Approach" ${ }^{\prime 40}$ heraus. Dabei wird insbesondere die Funktionsanalyse entsprechend der „significant people function "41 für die Zuordnung von Wirtschaftsgütern und Risiken in den Fokus gestellt. Im Wesentlichen entspricht der Ansatz dem für verbundene Unternehmen. Wegen der mangelnden rechtlichen Abgrenzung der Betriebsstätte können Funktionen und Risiken nicht per Vertrag zugeordnet werden wie dies zwischen selbständigen Rechtssubjekten möglich ist. Deshalb wird der tatsächlichen Substanz der Gestaltung erhöhte Bedeutung zukommen müssen. Gleichwohl muss man davon ausgehen,

39 The 2010 Update tot the Model Tax Convention, 22.7.2010, OECD.

40 Vgl. OECD, 2010 Report on the Attribution of Profits to Permanent Establishments, 22.7.2010, Tz. $8 \mathrm{ff}$.

41 Vgl. Tz. 20 OECD-MK zu Art. 7 (2010). 
dass im Gegensatz zur bisherigen Auffassung der Verwaltung unter dem neuen Regime Betriebsstätte als Beteiligungsholding, als Patentverwertungsholding oder als Cash Pool bei entsprechender tatsächlicher Gestaltung möglich sein sollten.

\section{bb) Interne „Dealings“}

In Abs. 2 wird ein ausdrücklicher Hinweis auf die internen Leistungen zwischen verschiedenen Unternehmensteilen aufgenommen. Demnach sind solche „internal dealings" zwischen Stammhaus und Betriebsstätte zu beachten. Der MK nennt in diesem Zusammenhang insbesondere Miet- und Zinsverrechnungen für die interne Überlassung von Sach- bzw. Geldkapital. Nach der bisherigen Auffassung der OECD waren solche internen Leistungen nur insoweit zuzuordnen als tatsächliche Aufwendungen ggü. Dritten eingetreten waren. Zinsen für Darlehen des Stammhauses an die Betriebsstätte waren daher grundsätzlich nicht nach Fremdvergleichsentgelten, sondern nach tatsächlich entstandenen Kosten infolge von externen Darlehen zu verrechnen. ${ }^{42}$

Fraglich ist allerdings, ob dies auch für die Nutzung von immateriellen Wirtschaftsgütern gelten soll. Der MK schweigt hierzu. Indirekt könnte man aus der Tatsache, dass Tz. 28 und 29 nur Mieten und Zinsen anführen, nicht aber Lizenzen, darauf schließen, dass nur die ersteren als interne Leistungen zum Fremdvergleichspreis abrechenbar sein sollten. Auf den zweiten Blick ist dies allerdings nicht überzeugend, denn die entsprechende Tz. des bisherigen MK, in der die Verrechnung interner Nutzungsüberlassungen $\mathrm{zu}$ fremdüblichen Preisen untersagt und nur eine Verteilung des tatsächlichen Aufwandes zugelassen wurde, ist ersatzlos gestrichen worden. Und es ist kein Grund ersichtlich, weshalb dies nur für die Überlassung von Sach- und Geldkapital, nicht aber für immaterielle Wirtschaftsgüter gelten sollte.

Anzumerken ist, dass der Functionally Separate Entity Approach sich ausschließlich auf die Zuordnung von Unternehmensgewinnen bezieht, nicht jedoch diese umzuqualifizieren vermag, z. B. in Zins- oder Vermietungseinkünfte. ${ }^{43}$

Somit bleibt festzuhalten, dass Art. 5 Abs. 2 nunmehr die Selbständigkeitsfiktion der Betriebsstätte umfassend manifestiert und bisherige Ausnahmen eliminiert hat.

42 Eine Ausnahme galt lediglich für Finanzinstitute bezüglich ihres laufenden Geschäftsverkehrs.

43 Vgl. Tz. 29 OECD-MK zu Art. 7 (2010). 


\section{cc) Kapitalausstattung}

Eine bedeutsame Änderung ggü. dem Entwurf zu Art. 7 betrifft Abs. 3 . Entgegen der endgültigen Fassung enthielt der Entwurf noch detaillierte Regelungen zur Allokation von Eigenkapital (free capital). Die ursprünglich vorgesehenen Regelungen waren kritisch kommentiert worden. Sie waren letztlich auch überflüssig, denn die angemessene Kapitalausstattung ist letztlich als Ergebnis einer funktions- und risikoadäquaten Zuordnung von Wirtschaftsgütern, ${ }^{44}$ und zwar sowohl der aktiven als auch der passiven.

\section{dd) Korrespondierende Gewinnberichtigung}

Die Korrespondierende Gewinnberichtigung wurde als Pendant zu Art. 9 auch für die Unternehmensgewinne neu eingeführt. Art. 7 Abs. 3 bietet künftig hierfür eine eigenständige Grundlage. Das Ziel der Vorschrift ist es, sicherzustellen, dass Doppelbesteuerungen aufgrund von unterschiedlichen Gewinnabgrenzungen durch die beteiligten Staaten vermieden werden.

\section{Ausblick}

Zusammenfassend lässt sich sagen: Die Betriebsstätte wird auch in Zukunft eine wichtige Rolle spielen, einmal wegen der ausgeweiteten Regelungen des Art. 5, aber auch wegen sich ändernder Organisationsstrukturen in international agierenden Konzernen.

Was die Gewinnabgrenzung zwischen Stammhaus und Betriebsstätte anbetrifft, so ist die OECD auf dem Wege zur steuerlichen Verselbständigung weiter fortgeschritten; es bestehen faktisch kaum noch Unterschiede zu verbundenen Unternehmen, wenn man einmal von der Qualifikation der Einkünfte absieht. Die steuerliche Gewinnzuordnung wird im Zeitpunkt der internen Leistung dem Grunde und der Höhe nach endgültig fixiert.

Die Rechtsprechung des BFH mit ihrer Betonung der Einheit des Unternehmens steht dem diametral entgegen.

Der deutsche Gesetzgeber hat die Frage der Gewinnabgrenzung bislang nur sehr unzureichend geregelt. Eine umfassende Neuregelung entsprechend des OECD-Ansatzes erscheint dringend notwendig, nicht zuletzt um der deutschen Wirtschaft im internationalen Steuerwettbewerb keine Nachteile erwachsen zu lassen.

44 Tz. 21 OECD-MK. 


\title{
Die Besteuerung von Funktionsverlagerungen - neue Rechtslage
}

\author{
Professor Dr. Hubertus Baumhoff \\ Steuerberater, Wirtschaftsprüfer, Bonn
}

Inhaltsübersicht

I. Änderung der Funktionsverlagerungsbesteuerung durch das EUUmsetzungsgesetz

1. Einleitung

2. Funktionsbegriff

3. Definition des Transferpakets

4. Hauptkritikpunkte an der Funktionsverlagerungsbesteuerung

5. Politische Vorgaben und Entwicklung der Rechtslage

II. Redaktionelle Änderungen

1. Änderung von $\S 1$ Abs. 3 Satz 9 AStG

2. Änderung von $\S 1$ Abs. 3 Satz 10, 1. HS AStG
III. Die neue „Escape-Klausel“ des § 1 Abs. 3 Satz 10, 2. HS AStG

1. Die drei „Escape-Klauseln" des $\S 1$ Abs. 3 Satz 10 EStG

2. Tatbestandsvoraussetzungen der neuen (dritten) „Escape-Klausel“

3. Rechtsfolgen

a) Einzelbewertung der Bestandteile eines Transferpakets statt Gesamtbewertung

b) Berücksichtigung eines funktionsbezogenen Geschäftsoder Firmenwertes?

IV. Praktische Relevanz der Neuregelung und zeitliche Anwendung

\section{I. Änderung der Funktionsverlagerungsbesteuerung durch das EU-Umsetzungsgesetz}

\section{Einleitung}

Im Rahmen des UntStRefG $2008^{1}$ wurden bekanntlich Regelungen in $\S 1$ Abs. 3 Satz 9 f. AStG aufgenommen, die die Besteuerung von Funktionsverlagerungen zum Gegenstand haben. ${ }^{2}$ Kern der damaligen Regelungen, die seit dem VZ 2008 gelten $^{3}$ und durch die sog. Funktionsverlagerungsverordnung (FVerlV) ${ }^{4}$ konkretisiert wurden, ist die Bewertung des im Zusammenhang mit der Funktionsverlagerung übergehenden Transferpakets als Ganzes unter Berücksichtigung des mit der Funktion verbunde-

1 Vgl. UntStRefG 2008 v. 14.8.2007, BGBl. I 2007, 1912.

2 Vgl. zu Einzelheiten etwa Baumhoff/Ditz/Greinert, DStR 2007, 1649 ff.; Kroppen/Rasch/Eigelshoven, IWB 2007 Fach 3 Gruppe 1, $2201 \mathrm{ff}$.

3 Vgl. $\S 21$ Abs. 16 AStG.

4 Vgl. FVerlV v. 12.8.2008, BGBl. I 2008, 1680 und dazu im Einzelnen Baumhoff/ Ditz/Greinert, DStR 2008, $1945 \mathrm{ff}$. 
nen "Gewinnpotentials". Eine Einzelbewertung der im Zuge der Funktionsverlagerung auf das ausländische verbundene Unternehmen übergehenden Wirtschaftsgüter sollte nach dieser Regelung - außerhalb der Escape-Klauseln des $§ 1$ Abs. 3 Satz 10 AStG - nicht mehr stattfinden.

Die aus der Funktionsverlagerungsbesteuerung resultierenden Steuermehreinnahmen sollten zur (teilweisen) Gegenfinanzierung der Körperschaftsteuersatzsenkung von $25 \%$ auf $15 \%$ verwendet werden.

\section{Funktionsbegriff}

Bevor die Einzelheiten einer Funktionsverlagerungsbesteuerung und der aktuellen Änderungen diskutiert werden, muss zunächst geklärt werden, was der Gesetzgeber eigentlich unter einer Funktionsverlagerung versteht. Der Gesetzgeber definiert den Begriff der "Funktionsverlagerung" in $\S 1$ Abs. 3 Satz 9 AStG n. F. tautologisch durch sich selbst. Demnach liegt eine Funktionsverlagerung vor, wenn „eine Funktion einschließlich der dazugehörigen Chancen und Risiken und der mit übertragenen oder überlassenen Wirtschaftsgüter und sonstigen Vorteile verlagert" wird.

Das Gesetz enthält allerdings keine Definition des Begriffs „Funktion“. Lediglich in $\S 1$ Abs. 1 der FVerlV wird dieser Begriff wie folgt normiert: „Eine Funktion ist eine Geschäftstätigkeit, die aus einer Zusammenfassung gleichartiger betrieblicher Aufgaben besteht, die von bestimmten Stellen oder Abteilungen erledigt werden. Sie ist ein organischer Teil eines Unternehmens, ohne dass ein Teilbetrieb im steuerlichen Sinn vorliegen muss."

Diese grundsätzlich betriebswirtschaftlich geprägte Begriffsdefinition ${ }^{5}$ grenzt die Funktion vom steuerlichen Teilbetrieb ab, dessen Voraussetzungen hierbei nicht kumulativ erfüllt sein müssen. ${ }^{6}$

\section{Definition des Transferpakets}

Der Gesetzgeber verknüpft den Begriff des Transferpakets eng mit dem der Funktionsverlagerung. Dies ergibt sich indirekt aus $\S 1$ Abs. 3 Satz 9 AStG n. F., weil darin gefordert wird, dass für den Fall, dass für das Transferpaket als Ganzes keine zumindest eingeschränkt vergleichbaren Fremdvergleichswerte vorliegen, der sog. hypothetische Fremdvergleich anzuwenden ist. Danach hat der Steuerpflichtige den Einigungsbereich auf der Grundlage des Transferpakets unter Berücksichtigung funktionsund risikoadäquater Kapitalisierungszinssätze zu bestimmen. Dabei besteht das Transferpaket als Gesamtbewertungsobjekt aus einer Funk-

5 Vgl. dazu Eisele, 2003, S. 9 ff.; Lange/Rohler, 2007, S. 342.

6 Hier $\S 1$ Abs. 1 Satz 2 FVerlV. 
tion und den ihr zugehörigen Chancen und Risiken sowie Wirtschaftsgütern, Vorteilen und den in diesem Zusammenhang erbrachten Dienstleistungen. ${ }^{7}$ Hintergrund dieser Regelung ist, dass der Wert der einzelnen Wirtschaftsgüter und Dienstleistungen regelmäßig nicht dem Wert der Gesamtheit (also des gesamten Transferpakets) entspricht, sondern dass i. d. R. mehr als die Summe der einzeln verlagerten Wirtschaftsgüter übertragen wird; m.a.W., dass die Differenz zwischen der Summe der Einzelverrechnungspreise und dem Gesamtwert einen (anteiligen) Geschäftsoder Firmenwert darstellt.

\section{Hauptkritikpunkte an der Funktionsverlagerungsbesteuerung}

Die Besteuerung von Funktionsverlagerungen gem. $\S 1$ Abs. 3 Satz $9 \mathrm{f}$. AStG und der FVerlV waren von Beginn an heftig umstritten. Hauptkritikpunkte der Regelungen waren und sind insbesondere die aus den zahlreichen unbestimmten Rechtsbegriffen resultierenden Rechtsunsicherheiten, das (praktisch sehr aufwändige) Bewertungsmodell des Transferpakets, die Besteuerung von im Ausland erst zukünftig entstehenden Gewinnpotentialen unter Berücksichtigung von Standortvorteilen und Synergieeffekten, die Besteuerung von Funktionsverdoppelungen, die unpraktikablen Escape-Klauseln des $\S 1$ Abs. 3 Satz 10 AStG sowie die Preisanpassungsklausel des $\S 1$ Abs. 3 Satz $11 \mathrm{f}$. AStG. ${ }^{8}$ Auch die soeben erschienenen Verwaltungsgrundsätze Funktionsverlagerung v. 13.10.20109 (nachfolgend „VWG-FVerl“) können diese Kritikpunkte nicht vollständig beheben; vielmehr zeichnet sich das BMF-Schreiben zur Funktionsverlagerungsbesteuerung durch zahlreiche verschärfende Regelungen aus, die das Thema „Funktionsverlagerungsbesteuerung" weiterhin zu einem der umstrittensten Themen des internationalen Steuerrechts machen. ${ }^{10}$

\section{Politische Vorgaben und Entwicklung der Rechtslage}

Vor diesem Hintergrund hatte es sich die neue CDU/CSU/FDP-Regierungskoalition zum Ziel gesetzt, die Funktionsverlagerungsbesteuerung zu entschärfen. So sieht das im Koalitionsvertrag vorgesehene „Sofortpro-

7 Vgl. § 1 Abs. 3 FVerlV; Baumhoff/Ditz/Greinert, 2008, 1947 f.

8 Vgl. zur Kritik an der Funktionsverlagerungsbesteuerung auch Baumhoff/ Ditz/Greinert, DStR 2007, $1649 \mathrm{ff} . ;$ dies., DStR 2008, $1945 \mathrm{ff} . ;$ Kroppen/ Rasch/Eigelshoven, IWB 2007 Fach 3 Gruppe 1, $2201 \mathrm{ff}$.; Frischmuth in FS Schaumburg, S. 647 ff.; Welling in FS Schaumburg, S. 985 ff.

9 BStBl. I 2010, 774.

10 Vgl. Kroppen/Rasch, IWB 2010, 824 ff. Zum Entwurf der VWG-Funktionsverlagerung vgl. auch Kroppen/Rasch, IWB 2009, Fach 3 Gruppe 1, $2439 \mathrm{ff}$. und 2455 ff.; Kaminski/Strunk, RIW 2009, 706 ff. 
gramm krisenentschärfender Maßnahmen"11 vor, dass bei grenzüberschreitenden Leistungsbeziehungen unverzüglich die negativen Auswirkungen der Neuregelung zur Funktionsverlagerungsbesteuerung auf den Forschungs- und Entwicklungsstandort Deutschland zu beseitigen sind. Diese Vorgabe des Koalitionsvertrages wurde nunmehr durch die Änderungen des $\S 1$ Abs. 3 Sätze 9 und 10 AStG durch das „Gesetz zur Umsetzung steuerlicher EU-Vorgaben sowie zur Änderung steuerlicher Vorschriften" $" 12$ umgesetzt. Dabei bezieht sich die wesentliche Änderung des $\S 1$ Abs. 3 AStG auf die Aufnahme einer dritten Escape-Klausel in Satz 10 der Vorschrift. $\S 1$ Abs. 3 Satz 10 AStG definierte bereits bisher zwei Fälle, in denen ausnahmsweise von der in der Grundregel des $\S 1$ Abs. 3 Satz 9 AStG vorgesehenen Transferpaketbewertung abgewichen und stattdessen einzelne Verrechnungspreise für die verlagerungsbedingt übergehenden materiellen und immateriellen Wirtschaftsgüter angesetzt werden konnten. Mithin sah die bisherige Escape-Klausel vor, dass bei einer Funktionsverlagerung einzelne Verrechnungspreise anstatt des Transferpakets für alle betroffenen Wirtschaftsgüter und Dienstleistungen angesetzt werden können, wenn der Steuerpflichtige glaubhaft macht, dass keine wesentlichen immateriellen Wirtschaftsgüter übertragen werden (1. Alternative) oder die Summe der angesetzten Einzelverrechnungspreise gemessen an der Bewertung des Transferpakets als Ganzes dem Fremdvergleich entspricht (2. Alternative). Beide Alternativen sind umstritten und kaum praktikabel. Sie werden nunmehr um eine 3. Alternative ergänzt, wonach der Ansatz einzelner Verrechnungspreise dann statthaft ist, wenn der Steuerpflichtige glaubhaft macht, dass zumindest ein wesentliches immaterielles Wirtschaftsgut Gegenstand der Funktionsverlagerung ist und er es genau bezeichnet. Neben dieser zentralen Änderung des Satzes 10 wurden (mehr oder weniger) redaktionelle Änderungen in den Sätzen 9 und 10 des $\S 1$ Abs. 3 AStG vorgenommen.

\section{Redaktionelle Änderungen}

\section{1. Änderung von $§ 1$ Abs. 3 Satz 9 AStG}

$\S 1$ Abs. 3 Satz 9 AStG wurde wie folgt neu gefasst (neue Bestandteile sind kursiv gedruckt und gelöschte Passagen in eckige Klammern gesetzt):

„Wird [in den Fällen des Satzes 5] eine Funktion einschließlich der dazugehörigen Chancen und Risiken und der mitübertragenen und überlassenen Wirtschaftsgüter und sonstigen Vorteile verlagert (Funktionsverlage-

11 Koalitionsvertrag zwischen CDU, CSU und FDP, 17. Legislaturperiode, S. 3.

12 Vgl. Gesetz zur Umsetzung steuerlicher EU-Vorgaben sowie zur Änderung steuerlicher Vorschriften v. 8.4.2010, BGBl. II 2010, 386. 
rung) und ist auf die verlagerte Funktion Satz 5 anzuwenden, weil für das Transferpaket als Ganzes keine zumindest eingeschränkt vergleichbaren Fremdvergleichswerte vorliegen, hat der Steuerpflichtige den Einigungsbereich auf der Grundlage [einer Verlagerung der Funktion als Ganzes (Transferpaket)] des Transferpakets unter Berücksichtigung funktionsund risikoadäquater Kapitalisierungszinssätze zu bestimmen."

Nach der Gesetzesbegründung soll die Neufassung des Satzes 9 in $\S 1$ Abs. 3 AStG lediglich klarstellenden Charakter haben und sich inhaltlich nicht auswirken. Ob das Ziel der Änderungen in Satz 9 "möglichen Missverständnissen vorzubeugen" allerdings tatsächlich erreicht wird, ist zu bezweifeln: Bisher befand sich im Gesetz die Formulierung "Verlagerung der Funktion als Ganzes (Transferpaket)". Damit enthielt bereits das Gesetz eine Definition des „Transferpakets", nämlich eine ganzheitliche Betrachtung der übergehenden Funktionen. Nach der Neufassung des $\S 1$ Abs. 3 Satz 9 AStG ist der Ausdruck "Transferpaket" nicht mehr weiter im Gesetz erläutert. Dies ist insofern unbefriedigend, als es sich bei dem "Transferpaket" um einen Ausdruck handelt, der weder national noch international bekannt ist und insofern einer gesetzlichen Konkretisierung bedarf. Eine solche findet sich jetzt nur noch in $\S 1$ Abs. 3 FVerlV, wonach ein Transferpaket "aus einer Funktion und den mit dieser Funktion zusammenhängenden Chancen und Risiken sowie den Wirtschaftsgütern und Vorteilen, die das verlagernde Unternehmen dem übernehmenden Unternehmen zusammen mit der Funktion überträgt oder zur Nutzung überlässt, und den in diesem Zusammenhang erbrachten Dienstleistungen" besteht. $^{13}$

Schließlich zeigen die folgenden Punkte, dass die Neufassung des $\S 1$ Abs. 3 Satz 9 AStG - wie indessen in der Gesetzesbegründung vorgesehen - nicht unbedingt zur Klarstellung beiträgt:

- In der Vorschrift finden sich sowohl die Formulierungen „Transferpaket als Ganzes" als auch schlicht "Transferpaket". Es ist davon auszugehen, dass mit beiden Ausdrücken das Gleiche gemeint ist.

- Auch in der Neufassung des Satzes 9 ist die Formulierung "Wirtschaftsgüter und sonstige Vorteile" enthalten. Es besteht indessen auch nach zwei Jahren Anwendung des $\S 1$ Abs. 3 Satz 9 AStG noch Unsicherheit darüber, was konkret unter "sonstigen Vorteilen“ zu verstehen ist.

13 Zum daraus resultierenden Widerspruch zur Definition der Funktionsverlagerung gem. § 1 Abs. 2 FVerlV vgl. Oestreicher, Ubg 2009, 83; Oestreicher/Wilcke, Ubg 2010, 227. 


\section{2. Änderung von § 1 Abs. 3 Satz 10, 1. HS AStG}

$\S 1$ Abs. 3 Satz 10, 1. HS AStG hat folgenden neuen Wortlaut (neue Bestandteile sind kursiv gedruckt und gelöschte Passagen in eckige Klammern gesetzt):

„In den Fällen des Satzes 9 ist die Bestimmung von Einzelverrechnungspreisen für alle betroffenen Wirtschaftsgüter und Dienstleistungen nach Vornahme sachgerechter Anpassungen anzuerkennen, wenn der Steuerpflichtige glaubhaft macht, dass keine wesentlichen immateriellen Wirtschaftsgüter und Vorteile [mit der Funktion übergegangen sind oder zur Nutzung überlassen wurden] Gegenstand der Funktionsverlagerung waren, oder dass [das Gesamtergebnis der Einzelpreisbestimmungen] die Summe der angesetzten Einzelverrechnungspreise, gemessen an der [Preisbestimmung für das Transferpaket] Bewertung des Transferpakets als Ganzes, dem Fremdvergleichsgrundsatz entspricht; [...]".

Die Korrekturen im ersten Halbsatz von Satz 10 des $\S 1$ Abs. 3 AStG werden in der Gesetzesbegründung ebenfalls als rein „sprachlich" und "ohne inhaltliche Auswirkung" eingestuft. Auch hier gibt es Zweifel, ob dieses Vorhaben gelungen ist:

- Neu ist die Formulierung „Einzelverrechnungspreis“. Es ist unklar, was damit gemeint ist. Denn für die Verrechnungspreisermittlung ist grundsätzlich eine Einzelbewertung vorzunehmen. Die bisherige Formulierung „Verrechnungspreise für alle betroffenen einzelnen Wirtschaftsgüter" traf den Sachverhalt besser.

- Bisher wurden im Gesetzestext die beiden Fälle der Übertragung und der Nutzungsüberlassung unterschieden. Diese Differenzierung ist nun nicht mehr aus dem Gesetzestext unmittelbar ersichtlich. Stattdessen findet sich die Formulierung "Gegenstand der Funktionsverlagerung". Allerdings ist in der Neuformulierung des Satzes 9 von „übertragenen oder überlassenen Wirtschaftsgüter(n) und sonstigen Vorteile(n)" die Rede, so dass die Lizenzierungsmöglichkeit weiterhin besteht. ${ }^{14}$

\section{Die neue „Escape-Klausel“ ${ }^{\text {des }} \S 1$ Abs. 3 Satz 10, 2. HS AStG}

\section{Die drei „Escape-Klauseln“ des § 1 Abs. 3 Satz 10 EStG}

Während die zuvor diskutierten Änderungen von $\S 1$ Abs. 3 Sätze 9 und 10 AStG eher sprachlicher Natur sind, enthält $\S 1$ Abs. 3 Satz 10, 2. HS AStG eine wesentliche inhaltliche Neuregelung. Dort heißt es:

14 Vgl. dazu Baumhoff/Greinert, Ubg 2009, 544. 
„macht der Steuerpflichtige glaubhaft, dass zumindest ein wesentliches immaterielles Wirtschaftsgut Gegenstand der Funktionsverlagerung ist, und bezeichnet er es genau, sind Einzelverrechnungspreise für die Bestandteile des Transferpakets anzuerkennen. "15 Mit dieser Regelung soll dem Steuerpflichtigen eine dritte Befreiungsmöglichkeit von der Gesamtbewertung eines Transferpakets eingeräumt werden (3. EscapeKlausel).

Nach $\S 1$ Abs. 3 Satz 10 AStG n. F. hat der Steuerpflichtige nunmehr insgesamt drei Möglichkeiten, die Bestandteile eines Transferpakets einzeln zu bewerten, nämlich indem er glaubhaft macht, dass

1. Alternative: keine wesentlichen immateriellen Wirtschaftsgüter und Vorteile Gegenstand der Funktionsverlagerung waren;

2. Alternative: die Summe der angesetzten Einzelverrechnungspreise, gemessen an der Bewertung des Transferpakets als Ganzes, dem Fremdvergleichsgrundsatz entspricht;

3. Alternative: zumindest ein wesentliches immaterielles Wirtschaftsgut Gegenstand der Funktionsverlagerung ist und er es genau bezeichnet.

Die erste und die zweite Alternative bringen in der Praxis keine wesentlichen Erleichterungen und stellen auch keine praktischen Gestaltungsalternativen dar. Im ersten Fall muss der Steuerpflichtige, um den "Wesentlichkeitsanteil" bestimmen zu können, zuvor den Wert des Transferpakets als Ganzes - zumindest überschlägig - ${ }^{16}$ als Bezugsbasis ermitteln. Im zweiten Fall ist dies noch komplexer, da der Steuerpflichtige hier sogar "präzise" den Einigungsbereich für das Transferpaket als Ganzes ermitteln muss, was durch die Escape-Klausel ja gerade vermieden werden soll. Es entsteht dadurch also doppelter Aufwand, da sowohl der Wert des Transferpakets als auch die Summe der Werte der Einzelwirtschaftsgüter ermittelt werden müssen.

Die dritte Alternative der Escape-Klausel ist im Kern Gegenstand der Änderung der Funktionsverlagerungsbesteuerung durch das EU-Umsetzungsgesetz (Änderung von $\S 1$ Abs. 3 Satz 10, 2. HS AStG n. F.), da die ersten beiden Alternativen sehr umstritten und - wie erwähnt - kaum praktikabel sind.

$15 \S 1$ Abs. 3 Satz 10, 2. HS AStG.

16 Rz. 71 der VWG-FVerl - BStBl. I 2010, 787 - führt aus, dass für diese erste Alternative keine "präzise Wertberechnung für das Transferpaket" erforderlich ist. Gemäß Rz. 72 ist jedoch eine präzise Wertberechnung für die 2. Alternative nötig. Wie die Unterscheidung in der Praxis zu treffen ist, ist unklar. M.E. müsste hier eine grobe Schätzung ausreichen. 
Nach der dritten Alternative ist der Ansatz von Einzelverrechnungspreisen für die Bestandteile des Transferpakets also dann statthaft, wenn der Steuerpflichtige glaubhaft macht, dass zumindest ein wesentliches immaterielles Wirtschaftsgut Gegenstand der Funktionsverlagerung ist und er es genau bezeichnet.

\section{Tatbestandsvoraussetzungen der neuen (dritten) „Escape-Klausel “}

Die neue Gesetzesformulierung wirft allerdings zahlreiche Fragen auf, die sich auf die folgenden Satzbestandteile beziehen:

- immaterielles Wirtschaftsgut,

- Wesentlichkeit,

- zumindest ein,

- glaubhaft machen,

- genau bezeichnen,

- Bestandteile des Transferpakets.

Der Begriff des immateriellen Wirtschaftsguts wurde bereits in der Vergangenheit für die erste Escape-Klausel (§ 1 Abs. 3 Satz 10, 1. HS 1. Alt. AStG) verwendet. Es gibt keine Anhaltspunkte dafür, dass hier eine spezifische Auslegung gelten sollte, die von dem generellen Verständnis eines immateriellen Wirtschaftsguts abweicht. Insofern kann auf die umfassende BFH-Rechtsprechung zur Definition immaterieller Wirtschaftsgüter Bezug genommen werden. ${ }^{17}$ In diesem Zusammenhang ist davon auszugehen, dass auch Geschäftschancen, soweit sie die Voraussetzungen eines (immateriellen) Wirtschaftsguts erfüllen, als immaterielles Wirtschaftsgut i. S. d. § 1 Abs. 3 Satz 10, 2. HS AStG anzusehen sind. ${ }^{18}$

Für die Inanspruchnahme der hier diskutierten Escape-Klausel ist es erforderlich, dass ein „wesentliches" immaterielles Wirtschaftsgut vorliegt. In der zur Konkretisierung der Funktionsverlagerungsbesteuerung ergangenen FVerlV ${ }^{19}$ findet sich in $\S 1$ Abs. 5 bereits eine Definition von „Wesentlichkeit". Demnach werden immaterielle Wirtschaftsgüter als wesentlich eingestuft, wenn „sie für die verlagerte Funktion erforderlich sind und ihr Fremdvergleichspreis insgesamt mehr als 25 Prozent der Summe der Einzelpreise aller Wirtschaftsgüter und Vorteile des Transferpakets beträgt ${ }^{\prime \prime}{ }^{20}$ Allerdings ist diese Definition gemäß dem eindeutigen Verordnungswortlaut nur für den Fall des $\S 1$ Abs. 3 Satz 10, 1. Alt. AStG

17 Vgl. nur Schmidt/Weber-Grellet, EStG 2010, § 5, Tz. 171 ff. m. w. N.

18 Vgl. dazu Ditz, DStR 2006, 1627; Ditz in Wassermeyer/Andresen/Ditz, Betriebsstätten-Handbuch, 2006, Rz. 4.55.

19 Vgl. FVerlV v. 12.8.2008, BGBl. I 2008, 1680.

$20 \S 1$ Abs. 5 FVerlV. 
relevant. Sollte die FVerlV nicht auch noch geändert werden, gilt diese Definition für $\S 1$ Abs. 3 Satz 10, 2. HS AStG jedenfalls nicht, ${ }^{21}$ zumal die Verordnung zeitlich vor der Neuregelung des $\S 1$ Abs. 3 Satz 10 2. Hs. AStG entstanden ist und insofern die hierdurch neu eingeführte 3. Escape-Klausel gar nicht berücksichtigen konnte. Dies ist auch konsequent, soll doch mit der hier diskutierten Escape-Klausel von der Gesamtbewertung eines Transferpakets abgesehen werden. Eine quantitative Gegenüberstellung des Werts eines immateriellen Wirtschaftsguts mit dem speziell für diesen Zweck zu ermittelnden - Wert eines Transferpakets wäre angesichts des Mehraufwands nicht nachvollziehbar. Die Frage der Wesentlichkeit eines immateriellen Wirtschaftsguts sollte für $\S 1$ Abs. 3 Satz 10, 2. HS AStG daher rein funktional bzw. qualitativ beantwortet werden. ${ }^{22}$

Nach dem neu gefassten Gesetzeswortlaut muss "zumindest ein“ wesentliches immaterielles Wirtschaftsgut Gegenstand der Funktionsverlagerung sein. Es genügt also, wenn nur genau ein solches Wirtschaftsgut übertragen wird. Aufgrund der Formulierung ,zumindest" wird allerdings deutlich, dass diese Escape-Klausel auch dann anwendbar ist, wenn mehrere wesentliche immaterielle Wirtschaftsgüter transferiert werden. ${ }^{23}$ Damit ergänzt die Regelung in $\S 1$ Abs. 3 Satz 10, 2. HS AStG (dritte Escape-Klausel) die Regelung im 1. HS (erste Escape-Klausel) komplementär:

Während die erste Escape-Klausel zur Anwendung kommt, wenn kein wesentliches immaterielles Wirtschaftgut übergegangen ist, greift die dritte Escape-Klausel, wenn ein oder mehrere immaterielle Wirtschaftsgüter Gegenstand der Funktionsverlagerung sind. In Bezug auf die übertragenen immateriellen Wirtschaftsgüter sind damit alle denkbaren Fälle abgedeckt. Durch die Ergänzung von $\S 1$ Abs. 3 Satz 10, 2. HS AStG besteht nunmehr die generelle Möglichkeit, unter Verwendung einer Escape-Klausel die Einzelbewertung der übertragenen Wirtschaftsgüter vorzunehmen. Damit wird die ursprüngliche Ausnahme (Einzelbewertung statt Gesamtbewertung als Transferpaket) nunmehr zur Regel. ${ }^{24}$

Weitere Tatbestandsvoraussetzung für die Inanspruchnahme der dritten Escape-Klausel ist, dass der Steuerpflichtige "glaubhaft" macht, dass

21 Gl. A. Kroppen/Rasch, IWB 2010, 322; Freudenberg/Ludwig, BB 2010, 1270.

22 Die VWG-FVerl - BStBl. I 2010, 788 - vertreten in Rz. 75 hierzu eine andere Auffassung. Es wird hier auch eine quantitative Gegenüberstellung für erforderlich gehalten; gleichwohl soll für diese Berechnung eine Erleichterung dahingehend möglich sein, dass die Glaubhaftmachung zumindest „keine präzise Wertberechnung für das Transferpaket" erfordert.

23 Vgl. Lenz/Rautenstrauch, DB 2010, 698.

24 So auch Antrag der Länder Rheinland-Pfalz, Berlin, Brandenburg, Bremen zur Einberufung des Vermittlungsausschusses, BR-Drs. 107/4/10. 
zumindest ein wesentliches immaterielles Wirtschaftsgut Gegenstand der Funktionsverlagerung ist. Die Anforderung an den Steuerpflichtigen, etwas glaubhaft zu machen, ist nicht neu im Rahmen der Funktionsverlagerungsbesteuerung. Bereits bei den beiden bekannten Escape-Klauseln (§ 1 Abs. 3 Satz 10, 1. HS AStG) gilt die gleiche Anforderung an den Steuerpflichtigen. Bedeutsam ist dabei, dass bei einer Glaubhaftmachung nur ein herabgesetztes Beweismaß zum Tragen kommt. ${ }^{25}$ Insofern sind keine zu umfangreichen Anforderungen an die Ausführungen des Steuerpflichtigen zu stellen. Der Steuerpflichtige muss lediglich zeigen können, dass nicht nur die Funktion selbst (z. B. Produktion), sondern auch ein funktional mit der verlagerten Funktion zusammenhängendes immaterielles Wirtschaftsgut (z. B. Patent) übertragen wurde. Insgesamt ist das Kriterium der Glaubhaftmachung jedoch nicht bedeutsam. Sollte es dem Steuerpflichtigen nicht gelingen, die Übertragung zumindest eines immateriellen Wirtschaftsguts glaubhaft $\mathrm{zu}$ machen, so bedeutet dies im Umkehrschluss, dass kein immaterielles Wirtschaftsgut Gegenstand der Funktionsverlagerung war. In diesem Fall kann jedoch die erste EscapeKlausel genutzt werden. ${ }^{26}$

Gemäß der neu eingefügten Vorschrift ist es schließlich erforderlich, das wesentliche immaterielle Wirtschaftsgut genau zu bezeichnen. Dass eine Bezeichnung des immateriellen Wirtschaftsguts bei Inanspruchnahme der Escape-Klausel erforderlich ist, sollte offensichtlich sein. Fraglich ist jedoch, was mit der ergänzenden Formulierung „genau" gemeint ist, gerade auch vor dem Hintergrund, dass gemäß den bereits bestehenden Dokumentationspflichten ${ }^{27}$ eine Zusammenstellung wesentlicher immaterieller Wirtschaftsgüter erforderlich ist. ${ }^{28}$ Hierfür mag es hilfreich sein, an in der Literatur ausgearbeitete Systematisierungen von immate-

25 Vgl. Wassermeyer/Baumhoff/Greinert in Flick/Wassermeyer/Baumhoff, Tz. V $90 \mathrm{zu} \S 1$ AStG; Kroppen/Rasch/Eigelshoven, IWB 2007, 301, 316f. In dem Entwurf des BMF-Schreibens Verwaltungsgrundsätze-Funktionsverlagerung v. 17.7.2009 wird gefordert darzulegen, „dass für die behauptete Tatsache eine überwiegende Wahrscheinlichkeit gegeben ist" (Tz. 2.1.6.2.2).

26 Die Finanzverwaltung fordert in Rz. 80 der VWG-FVerl - BStBl. I 2010, 788 -, dass für den Fall, dass mehrere immaterielle Wirtschaftsgüter übertragen werden, „jedes für sich die Voraussetzungen der Wesentlichkeit" erfüllen muss. Eine Zusammenfassung soll - gem. Rz. 81 - nur dann statthaft sein, wenn "deren gemeinsame Bewertung in Anwendung anerkannter betriebswirtschaftlicher Methoden sachgerecht ist". Diese Auffassung entbehrt einer Rechtsgrundlage. Zudem steht sie im Widerspruch zu Rz. 71, wo für die "Wesentlichkeitsgrenze" von $25 \%$ mehrere immaterielle Wirtschaftsgüter und Vorteile zusammengefasst werden dürfen.

27 Vgl. etwa $\S 4$ Nr. 2 b) und $\S 5$ Nr. 6 GAufzV.

28 Vgl. Geberth, DB 2010, Heft 7, M 28. 
riellen Wirtschaftsgütern anzuknüpfen. So können z.B. unterschieden werden:

- marketingbezogene (z. B. Marken, Geschmacksmuster, Internet-Domains),

- technologiebezogene (z.B. Patente, Gebrauchsmuster, Erfindungen, Rezepturen, Software),

- kundenbezogene (z. B. Kundenstamm, Auftragsbestand),

- vertragsbezogene (z.B. Lizenzen, Belieferungsrechte, Konzessionen) oder

- kunstbezogene (z. B. Zeitschriften, Bilder, Schauspiele)

immaterielle Wirtschaftsgüter. ${ }^{29}$ Orientiert sich der Steuerpflichtige an diesen Begriffen, genügt er jedenfalls der Anforderung des genauen Bezeichnens.

\section{Rechtsfolgen}

a) Einzelbewertung der Bestandteile eines Transferpakets statt Gesamtbewertung

Bei Erfüllung der vorstehenden Tatbestandsvoraussetzungen „sind Einzelverrechnungspreise für die Bestandteile des Transferpakets anzuerkennen." Bei dieser Rechtsfolge fällt zunächst auf, dass hier der Plural („Einzelverrechnungspreise") verwendet wird, während bei den Voraussetzungen der Singular („ein wesentliches immaterielles Wirtschaftsgut") zur Anwendung kommt. Mit dieser Unterscheidung wird jedenfalls klar, dass nicht nur das genau bezeichnete wesentliche immaterielle Wirtschaftsgut, sondern alle im Rahmen der Funktionsverlagerung übertragenen Wirtschaftsgüter einzeln zu bewerten sind. Bei der Ermittlung der Einzelverrechnungspreise finden dabei die allgemeinen Grundsätze der Verrechnungspreisermittlung Anwendung, oder anders formuliert: Die Einzelverrechnungspreise müssen nicht zwingend auf Basis eines hypothetischen Fremdvergleichs bestimmt werden. Vielmehr ist auch eine Anwendung der Standardmethoden (Preisvergleichs-, Wiederverkaufspreis- und Kostenaufschlagsmethode) denkbar.

29 Vgl. IFRS 3, Illustrative Examples. Eine weitere Systematisierung hat der Arbeitskreis „Immaterielle Werte im Rechnungswesen" der SchmalenbachGesellschaft erstellt. Vgl. hierzu und zu der Erläuterung der einzelnen Kategorien $A K$ „Immaterielle Werte im Rechnungswesen “ der Schmalenbach-Gesellschaft für Betriebswirtschaft e. V., DB 2001, $990 \mathrm{f}$. 
b) Berücksichtigung eines funktionsbezogenen Geschäfts- oder Firmenwertes?

Fraglich ist jedoch, ob bei Anwendung dieser Escape-Klausel neben den materiellen und immateriellen Einzelwirtschaftsgütern auch der funktionsbezogene Geschäfts- oder Firmenwert anzusetzen ist. Dieser Wert lässt sich nicht einzeln, sondern nur indirekt als Differenz aus dem Wert des Transferpakets und dem Wert der einzelnen übertragenen Wirtschaftsgüter ermitteln. ${ }^{30}$ Dass der Gesetzgeber von der Existenz eines solchen funktionsbezogenen Geschäfts- oder Firmenwerts ausgeht, wird nicht zuletzt aus der Begründung des Regierungsentwurfs zur Unternehmensteuerreform 2008 deutlich. Dort wurde die Gesamtbewertung durch Ansatz eines Transferpakets mit der Begründung gefordert, „weil der Preis der einzelnen übertragenen Wirtschaftsgüter den Wert der Funktion regelmäßig nicht adäquat widerspiegelt. ${ }^{\text {31 }}$ Der Transferpaket-Ansatz wurde also nur deshalb gewählt, um einen funktionsbezogenen Geschäfts- oder Firmenwert erfassen zu können.

Wenn nun die neue Escape-Klausel zur Anwendung kommt, ist der funktionsbezogene Geschäfts- oder Firmenwert nicht zu berücksichtigen. Dies ergibt sich zwar nicht ausdrücklich aus dem Wortlaut, ${ }^{32}$ lässt sich jedoch aus der Entstehung der Vorschrift ableiten. Gemäß dem Bericht des Finanzausschusses wird durch den angefügten 2. Halbsatz an den bisherigen $\S 1$ Abs. 3 Satz 10 AStG die Vereinbarung der Regierungsparteien im Koalitionsvertrag umgesetzt. ${ }^{33}$ Dort vereinbarten die Parteien, "bei den grenzüberschreitenden Leistungsbeziehungen unverzüglich die negativen Auswirkungen der Neuregelung zur Funktionsverlagerung auf den Forschungs- und Entwicklungsstandort Deutschland [zu] beseitigen" ${ }^{34}$ Die unverzügliche Umsetzung im Rahmen des Wachstumsbeschleunigungsgesetzes gelang ${ }^{35}$ zwar aus Zeitgründen nicht; mit dem EU-Umsetzungsgesetz wurden jedoch entsprechende Anpassungen vorgenommen.

30 Vgl. etwa BFH, Urt. v. 26.11.2009 - III R 40/07, DStR 2010, 371.

31 Begründung des Regierungsentwurfs zu $\S 1$ Abs. 3 Satz 9 AStG, BR-Drucksache 220/07, 144.

32 Geberth, DB 2010, Heft 7, M 28, merkt zu Recht an, dass der Gesetzestext „äuBerst kryptisch formuliert ist". Ebenso Kaminski, Stbg 2010, 196.

33 Vgl. Bericht des Finanzausschusses zu dem Gesetzentwurf der Bundesregierung, BT-Drs. 17/939, 16.

34 Vgl. Koalitionsvertrag v. 26.10.2009.

35 Vgl. Gesetz zur Beschleunigung des Wirtschaftswachstums v. 22.12.2009, BGBl. I, 3950. 
Die zu Recht festgestellte Beeinträchtigung des Forschungs- und Entwicklungsstandorts Deutschland beruht, wie in der Literatur ${ }^{36}$ nahezu einhellig deutlich gemacht wurde, auf dem Ansatz des - international unbekannten - Transferpakets in Kombination mit der sog. „Einigungsbereichsbetrachtung". Dieses Transferpaket enthält - allein schon aus methodischen Gründen - stets einen funktionsbezogenen Geschäftsoder Firmenwert. Es wird dabei aber nicht danach differenziert, ob dieser auch auf die empfangende Gesellschaft übergeht.

Die Frage des Übergangs eines Geschäfts- oder Firmenwerts ist freilich nicht neu. Nach der BFH-Rechtsprechung kann ein Geschäfts- oder Firmenwert bei der Übertragung eines Betriebs oder Teilbetriebs, bei einer Realteilung, bei einer Betriebsaufspaltung oder bei der Aufspaltung und Veräußerung eines für sich lebensfähigen Betriebsteils transferiert werden. ${ }^{37}$ Dabei kommt es für die Einordnung als Geschäfts- oder Firmenwert insbesondere darauf an, ob durch die Übertragung die sog. „geschäftswertbildenden Faktoren" übergehen. Denn der Geschäfts- oder Firmenwert "folgt ... denjenigen geschäftswertbildenden Faktoren, die durch ihn verkörpert werden. ${ }^{\prime 38}$

Diese bekannten und nachvollziehbaren Überlegungen zum Geschäftsoder Firmenwert müssen auch analog für das Transferpaket gelten. ${ }^{39}$ Der Ansatz eines funktionsbezogenen Geschäfts- oder Firmenwerts ist nur dann gerechtfertigt, wenn der Erwerber einen für sich lebensfähigen Betriebsteil übernimmt, der auch künftig Gewinne erwirtschaften kann. Dabei müssen die geschäftswertbildenden Faktoren übergehen. Nur unter diesen Voraussetzungen wäre ein fremder Erwerber bereit, den Wert für eine Einheit durch Diskontierung der erwarteten künftigen Erträge zu bestimmen. ${ }^{40}$ Diese Überlegungen spiegeln sich auch im neuen OECD-Bericht über „Transfer Pricing Aspects of Business Restructurings" ongoing concern" ${ }^{42}$ also einer Übertragung eines für sich lebensfähigen Betriebsteils, der eigenständig Überschüsse erwirtschaften kann, wird der Ansatz eines funktionsbezogenen Geschäfts- oder Firmenwerts zugestan-

36 Vgl. Welling, IStR 2010, Heft 3, III; Wehnert/Sano, IStR 2010, 53 ff.; Baumhoff/ Ditz/Greinert, DStR 2007, 1651.

37 Vgl. BFH, Urt. v. 27.3.2001 - I R 42/00, BStBl. II 2001, 771 m. w. N.; BFH, Urt. v. 16.6.2004 - X R 34/03, BStB1. II 2005, 378; BFH, Urt. v. 26.11.2009 - III R 40/07, DStR 2010,371.

38 BFH, Urt. v. 27.3.2001 - I R 42/00, BStBl. II 2001, 771.

39 Vgl. Oestreicher/Hundeshagen, IStR 2009, 145.

40 Vgl. Haas in FS Schaumburg, S. 717; Lenz/Rautenstrauch, DB 2010, 698.

41 Vgl. Tz. 9.93-9.98 der OECD-RL 2010, zum Richtlinienentwurf Baumhoff/ Puls, IStR 2009, $73 \mathrm{ff}$.

42 Tz. 9.93-9.95 OECD-RL 2010. 
den. ${ }^{43}$ Dies trifft bei einer Funktionsverlagerung typischerweise jedoch nicht $\mathrm{zu}$, weil der vorhandene organisatorische Bereich des abgebenden Unternehmens nicht unverändert beim aufnehmenden Unternehmen ankommt. Eine Funktionsverlagerung ist mit einer Betriebsverlagerung gerade nicht vergleichbar. ${ }^{44}$

Durch das BFH-Urteil vom 2.9.2008 ${ }^{45}$ wurde ferner deutlich herausgearbeitet, dass es nur dann zum Übergang des Geschäfts- oder Firmenwerts zwischen zwei Gesellschaften kommen kann, wenn die geschäftswertbildenden Faktoren „endgültig und nicht ... nur vorübergehend überlassen werden." Es ist erforderlich, dass die Nutzungsmöglichkeit der geschäftswertbildenden Faktoren durch die übernehmende Gesellschaft auf Dauer angelegt ist und ihr auch nicht mehr entzogen werden kann. Klarstellend führt der BFH weiter aus: „Der Übergang des Geschäftswerts setzt mithin voraus, dass das aufnehmende Unternehmen die geschäftswertbildenden Faktoren auf der Grundlage einer verfestigten Rechtsposition dauerhaft nutzen kann. Nicht ausreichend ist eine verfestigte tatsächliche Nutzungsmöglichkeit oder der tatsächliche Verbrauch der geschäftswertbildenden Faktoren." Erfolgt etwa die Funktionsverlagerung nicht durch Übertragung, sondern im Wege der Lizenzierung durch Nutzungsüberlassung, kommt es zu keinem endgültigen Übergang der geschäftswertbildenden Faktoren. ${ }^{46}$ Die Verrechnung eines funktionsbezogenen Geschäfts- oder Firmenwerts scheidet in diesem Fall somit aus. Ferner ist $\mathrm{zu}$ berücksichtigen, dass bei Funktionsverlagerungen ins Ausland der in der Regel standortbezogene Geschäfts- oder Firmenwert gerade nicht mit übertragen wird.

Nur unter den vorstehend beschriebenen einschränkenden Bedingungen lässt sich der Ansatz eines funktionsbezogenen Geschäfts- oder Firmenwerts überhaupt rechtfertigen. In allen anderen Fällen kommt dessen Verrechnung dagegen nicht in Betracht. ${ }^{47}$ Diese differenzierte Vorgehensweise ist auch international üblich. Bei Beachtung dieser Überlegungen wird zugleich das Ziel der Ergänzung von § 1 Abs. 3 Satz 10 AStG erfüllt, das sich aus dem Bericht des Finanzausschusses entnehmen lässt: „Der Ansatz fremdvergleichskonformer Einzelverrechnungspreise für die Bestandteile des Transferpakets führt zu einem Ergebnis, das auch für die Funktionsverlagerung insgesamt dem international anerkannten Fremdvergleichsgrundsatz entspricht. Dadurch wird die sachgerechte

43 Vgl. Welling, IStR 2010, Heft 3, IV.

44 Vgl. Kroppen/Rasch, IWB 2010, 322.

45 Vgl. BFH, Urt. v. 2.9.2008 - X R 32/05, BStBl. II 2009, 634; hierzu Levedag, NWB 2010, 106 ff.; Wendt, FR 2009, 958.

46 Vgl. Greinert, Ubg 2010, 109 f.; Baumhoff/Greinert, Ubg 2009, $544 \mathrm{ff}$.

47 So auch Kroppen/Rasch, IWB 2010, 320. 
Aufteilung internationaler Besteuerungsrechte zwischen den betroffenen Staaten gewährleistet." 48

\section{Praktische Relevanz der Neuregelung und zeitliche Anwendung}

Im Zusammenhang mit der Änderung von $\S 1$ Abs. 3 AStG wurden auch die Anwendungsvorschriften überarbeitet. Gemäß §21 Abs. 16 AStG sind die neuen Regelungen „erstmals für den Veranlagungszeitraum 2008 anzuwenden." Dabei wird im Bericht des Finanzausschusses klargestellt, dass diese rückwirkende Änderung „zu Gunsten der Steuerpflichtigen" erfolgt. ${ }^{49}$ Dies ist für diejenigen Fälle bedeutsam, in denen bereits in der Vergangenheit Funktionen verlagert wurden und eine Bewertung mit dem Transferpaket erfolgte. Durch die rückwirkende Anwendbarkeit der dritten Escape-Klausel ist es nunmehr vielfach möglich, den ursprünglichen Ansatz mit dem Transferpaket zu Gunsten des Steuerpflichtigen durch den Ansatz von Verrechnungspreisen für die einzelnen übertragenen Wirtschaftsgüter zu ersetzen. In den Fällen, in denen bereits ein Steuerbescheid ergangen ist und dieser unter dem Vorbehalt der Nachprüfung ${ }^{50}$ steht, kann der Steuerpflichtige einen entsprechenden Antrag auf Änderung gemäß $§ 164$ Abs. 2 Satz 2 AO stellen. ${ }^{51}$

Insgesamt ist durch die Ergänzung von $\S 1$ Abs. 3 Satz 10 AStG um einen zweiten Halbsatz eine Verbesserung für die in Deutschland tätigen Unternehmen eingetreten. Der ursprüngliche Regelfall der Gesamtbewertung eines Transferpakets ist jetzt eher zum Ausnahmefall geworden. Nunmehr ist es auch für Unternehmen mit wesentlichen immateriellen Wirtschaftsgütern, zu denen insbesondere forschungs- und entwicklungsintensive Unternehmen gehören, möglich, die bei einer Funktionsverlagerung übertragenen Wirtschaftsgüter einzeln $\mathrm{zu}$ bewerten. Dadurch kommt es nicht mehr zur - quasi automatischen - Aufdeckung eines funktionsbezogenen Geschäfts- oder Firmenwerts. Vielmehr kann in den Fällen, in denen kein Teilbetrieb übergeht, eine Einzelbewertung der materiellen und immateriellen Wirtschaftsgüter vorgenommen werden. Dies entspricht auch internationalen Grundsätzen. ${ }^{52}$

48 Vgl. Bericht des Finanzausschusses zu dem Gesetzentwurf der Bundesregierung, BT-Drs. 17/939, 16.

49 Vgl. Bericht des Finanzausschusses zu dem Gesetzentwurf der Bundesregierung, BT-Drs. 17/939, 16.

$50 \mathrm{Vgl}$. $164 \mathrm{AO}$.

51 Ein solcher Antrag führt auch insoweit zur Ablaufhemmung der Festsetzungsfrist, vgl. § 171 Abs. 3 AO.

52 Vgl. etwa Wehnert/Sano, IStR 2010, $53 \mathrm{ff}$. 
Auch wenn durch die gesetzliche Neuregelung das ursprüngliche RegelAusnahme-Prinzip (Regel: Gesamtbewertung eines Transferpakets; Ausnahme: Einzelbewertung von Wirtschaftsgütern) nunmehr faktisch umgekehrt wurde, bleiben dennoch zahlreiche Punkte, aufgrund derer die derzeitigen Regelungen zur Funktionsverlagerungsbesteuerung nicht vertretbar sind. Insbesondere stehen sie nicht im Einklang mit dem Fremdvergleichsgrundsatz gemäß Art. 9 OECD-MA und rufen damit das Risiko einer internationalen Doppelbesteuerung hervor. Dadurch kommt es zwangsläufig auch zur Beeinträchtigung des Forschungs- und Entwicklungsstandorts Deutschland. 


\title{
Entstrickung - quo vadis? - Rechtsprechung, Gesetzgebung und Verwaltung
}

\author{
Dr. Rolf Möhlenbrock, Berlin
}

Inhaltsübersicht
A. Einleitung
B. Befund
1. Rechtslage vor dem SEStEG (finale Entnahmelehre)
2. Entstrickungsregelungen des SEStEG
a) Entstrickungstatbestände
b) Bewertung der Entstrickung
c) Ausgleichsposten

3. Aufgabe der finalen Entnahmelehre durch den $\mathrm{BFH}$
a) Urteil vom 17.7.2008 (I R 77/06)
b) Urteil vom 28.10.2009 (I R 99/08)
c) Urteil vom 28.10 .2009 (I R 28/08)
C. Bewertung
1. Sichtweise des Gesetzgebers
2. Haltung des BFH
3. Exkurs: Besonderheiten der Ent- scheidung vom 17.7.2008
D. Zukunft der Entstrickung

\section{A. Einleitung}

Seit der Entscheidung des I. Senats des BFH vom 17.7.2008 zur Aufgabe der sog. finalen Entnahmetheorie wird in der Wissenschaft und der Finanzverwaltung eine intensive Diskussion zur Entstrickung geführt. Unter Entstrickung ist gemeinhin die Hebung stiller Reserven und Lasten in Einzelwirtschaftsgütern und Sachgesamtheiten anlässlich der Änderungen des steuerlichen Status dieser Wirtschaftsgüter oder Sachgesamtheiten zu verstehen. Hauptfall der Entstrickung ist die Überführung von Wirtschaftsgütern in eine andere (in der Regel ausländische) Betriebsstätte mit der Folge, dass deren künftige Wertentwicklung der deutschen Besteuerung ganz oder teilweise entzogen ist. Die Entwicklungen auf diesem Gebiet interessieren mittlerweile nicht mehr nur Wissenschaft und Finanzverwaltung, sondern auch den Gesetzgeber. So sah sich der Bundesrat im Rahmen seiner Stellungnahme zum Jahressteuergesetz 2010 (JStG 2010) berufen, Vorschläge zur Neuregelung der ertragsteuerlichen Entstrickungstatbestände zu unterbreiten. ${ }^{1}$ Der Bundestag ist diesem Vorschlag gefolgt und hat einige der mit dem Gesetz über steuerliche Begleitmaßnahmen zur Einführung der Europäischen Gesellschaft und zur Änderung weiterer steuerrechtlicher Vorschriften (SE-

1 BR-Drs. 318/10, 6. 
StEG) ${ }^{2}$ eingeführten Entstrickungstatbestände modifiziert. Im Folgenden sollen die Entwicklungen bis zu dieser Gesetzesänderung kurz nachgezeichnet werden.

\section{B. Befund}

\section{Rechtslage vor dem SEStEG (finale Entnahmelehre)}

Bis zum Inkrafttreten des SEStEG am 13.12.2006 war die Entstrickung entweder in Einzelsteuergesetzen (z. B. § 6 AStG, § 12 KStG, § 21 Abs. 2 Satz 1 Nr. 2 UmwStG) oder basierend auf der bis dahin noch anwendbaren Rechtsprechung des BFH in Verwaltungsanweisungen geregelt. Die zunächst im Regierungsentwurf für ein Drittes Steuerreformgesetz aus dem Jahre 1977 vorgesehene Einführung einer allgemeinen Entstrickungsregelung scheiterte. ${ }^{3}$ Stattdessen kam es zu vereinzelten gesetzgeberischen Maßnahmen wie dem durch das StEntlG 1999/2000/20024 eingefügten $\S 6$ Abs. 5 Satz 1 EStG. Dank der Rechtsprechung des BFH ${ }^{5}$ waren bei der Überführung eines Wirtschaftsguts oder einer Sachgesamtheit eines inländischen Stammhauses in eine ausländische DBA-Betriebsstätte dennoch die stillen Reserven aufzudecken, soweit das deutsche Besteuerungsrecht an den Wirtschaftsgütern verloren ging (sog. finale Entnahmelehre). Die Finanzverwaltung griff diese Rechtsprechung im sog. Betriebsstättenerlass ${ }^{6}$ auf. Im Einzelnen galt folgendes:

Die Überführung von Wirtschaftsgütern des Anlage- oder Umlaufvermögens in eine Betriebsstätte, die entweder in einem Nicht-DBA-Staat unterhalten wurde oder für die nach einem DBA die Anrechnungsmethode galt, löste keine Besteuerung aus, wenn die Erfassung der stillen Reserven gewährleistet war. Die Überführung in eine ausländische Betriebsstätte, deren Einkünfte durch ein DBA freigestellt waren, erfolgte hingegen unter Aufdeckung der stillen Reserven mit dem Fremdvergleichspreis im Zeitpunkt der Überführung. Aus Billigkeitserwägungen durfte ein Entstrickungsgewinn jedoch zunächst von der Besteuerung ausgenommen und in einen passiven Merkposten eingestellt werden. Dieser war beim Ausscheiden des Wirtschaftsguts aus der ausländischen Betriebsstätte erfolgswirksam aufzulösen. Bei abnutzbaren Anlagegütern war er fortlaufend gemäß der restlichen Nutzungsdauer in der auslän-

2 Gesetz v. 7.12.2006; BGBl. I 2006, 2782.

3 Benecke in Dötsch/Jost/Pung/Witt, § 12 KStG Rz. 1.

4 V. 24.3.1999; BGBl. I 1999, 402.

5 Etwa BFH v. 28.4.1971, BStBl. II 1971, 630; BFH v. 30.5.1972, BStBl. II 1972, 760; BFH v. 24.11.1982, BStBl. II 1983, 113; BFH v. 14.6.1988, BStBl. II 1989, 187; BFH v. 13.11.1990, BStBl. II 1991, 94; BFH v. 19.2.1998, BStBl. II 1998, 509.

6 BMF, Schr. v. 24.12.1999, BStBl. I 1076, Tz. 2.6. 
dischen Betriebsstätte aufzulösen. Ein Merkposten, der zehn Jahre nach Überführung des Wirtschaftsguts noch vorhanden war, musste ohne Rücksicht auf die Art des Wirtschaftsguts aufgelöst werden. Unabhängig hiervon hatten die Steuerpflichtigen im Zeitpunkt der Überführung immer die Möglichkeit, die Sofortbesteuerung zu wählen. Dieses Wahlrecht konnte für jedes Wirtschaftsjahr und jede Betriebsstätte getrennt ausgeübt werden. Dabei konnte die Wahl für die Wirtschaftsgüter des Anlage- und des Umlaufvermögens jeweils unterschiedlich, jedoch nur einheitlich für jede dieser Vermögensarten getroffen werden. Für selbst geschaffene immaterielle Wirtschaftsgüter galt Entsprechendes.

Die Entstrickungsgrundsätze waren auch anzuwenden, wenn Wirtschaftsgüter von einer Betriebsstätte, deren Ergebnisse der inländischen Besteuerung unterlagen, in eine Betriebsstätte überführt wurden, deren Ergebnisse nach einem DBA von der inländischen Besteuerung freizustellen waren. Bei der Überführung eines Wirtschaftsguts aus einem inländischen Betriebsvermögen in eine ausländische Personengesellschaft (einschließlich des Sonderbetriebsvermögens) war dagegen der Fremdvergleichspreis anzusetzen, ohne dass eine aufgeschobene Besteuerung in Betracht kam.

\section{Entstrickungsregelungen des SEStEG}

\section{a) Entstrickungstatbestände}

Mit dem SEStEG wollte der Gesetzgeber die unterschiedlichen und lediglich punktuellen Rechtsquellen zur Entstrickung in einem allgemeinen Entstrickungstatbestand zusammenführen. Es bestand der Anspruch, eine umfassende Neukonzeption der Entstrickung vorzunehmen. Erfasst werden sollte die Entstrickung sowohl im betrieblichen als auch im außerbetrieblichen Bereich. Als betriebliche Entstrickungsnormen wurden im Einkommensteuergesetz (§ 4 EStG) und Körperschaftsteuergesetz (§ $12 \mathrm{KStG}$ ) tatbestandlich aufeinander abgestimmte Einzelregelungen eingeführt, die heute die Grundlage des allgemeinen Entstrickungstatbestands bilden. ${ }^{7}$ Ausweislich der Begründung des Regierungsentwurfs ${ }^{8}$ sollte damit die Aufdeckung der stillen Reserven in allen Fällen gewährleistet werden, in denen

- ein Rechtsträgerwechsel im Wege der Einzel- oder Gesamtrechtsnachfolge stattfindet, ${ }^{9}$

- Betriebsvermögen die betriebliche Sphäre verlässt,

7 Zentrale Norm der privaten Entstrickung ist $\S 6$ AStG.

8 Siehe BT-Drs. 16/2710, 26.

9 Kritisch hierzu Wissenschaftlicher Beirat von Ernst \& Young, DB 2010, 1782 m. w. N. 
- die Steuerpflicht endet oder

- Wirtschaftsgüter dem deutschen Besteuerungszugriff entzogen werden.

Zusätzlich finden sich seit dem SEStEG in den Vorschriften zur Ermittlung des Umwandlungsergebnisses $(\S \S 3,11,15,20,21,24$ UmwStG) Aussagen zur Entstrickung. Diese Regelungen definieren die Voraussetzungen, unter denen umwandlungssteuerlich ein Vermögensübergang zu Buchwerten erfolgen kann. Das Umwandlungssteuergesetz enthält regelungstechnisch also Ausnahmen vom allgemeinen Entstrickungstatbestand. Nur im Falle des umwandlungsbedingten Wegfalls oder der Beschränkung des deutschen Besteuerungsrechts ist der Buchwertansatz insoweit ausgeschlossen. Weitere Ausnahmen vom Entstrickungsgrundsatz enthalten $\S 6$ Abs. 3 und 5 EStG für die unentgeltliche Übertragung von Betriebsvermögen sowie für die Überführung von Einzelwirtschaftsgütern zwischen mehreren Betriebsvermögen eines Steuerpflichtigen.

Technisch arbeiten die Entstrickungstatbestände mit einer Entnahmebzw. einer Veräußerungsfiktion. Es ist jeweils die Rede davon, dass der Ausschluss oder die Beschränkung des Besteuerungsrechts der Bundesrepublik Deutschland hinsichtlich des Gewinns aus der Veräußerung oder der Nutzung eines Wirtschaftsguts der Entnahme bzw. Veräußerung gleichstehe. Über diesen „Programmsatz" hinausgehende Aussagen enthält das Gesetz freilich nicht. Dabei sind die Entstrickungsregelungen so weit gefasst, dass selbst die bloße Änderung der Rechtslage (z. B. der Abschluss eines DBA oder die Änderung der Rechtsprechung) sanktioniert werden könnte. ${ }^{10}$ Eine Differenzierung nach der Entstrickung einzelner Wirtschaftsgüter, von Sachgesamtheiten, von positiven oder negativen $^{11}$ Wirtschaftsgütern, bzw. von materiellen oder immateriellen Wirtschaftsgütern ist nicht zu finden. Das Verhältnis der „betrieblichen“ zu den sonstigen Entstrickungsregelungen (z.B. Privatentnahme) bleibt

10 Die Gewährung einer Steuerbefreiung nach $\S 5$ KStG soll nach der Gesetzesbegründung allerdings keine Versteuerung der stillen Reserven gemäß $\S 12 \mathrm{KStG}$ auslösen; das Besteuerungsrecht der Bundesrepublik Deutschland gehe in diesen Fällen nicht verloren, vielmehr erfolge die Gewährung einer Steuerbefreiung "gerade in Ausübung des Besteuerungsrechts" (BT-Drs. 16/2710, 31). „In Ausübung des Besteuerungsrechts“ erfolgt allerdings auch die Anrechnung ausländischer Steuern oder die Gewährung einer Freistellung nach einem DBA.

11 Dabei ist allerdings die Besonderheit zu beachten, dass die Entstrickungsregelungen des UmwStG - anders als die (Grund-)Entstrickungstatbestände im Ertragsteuerrecht - zur Bewertung von Pensionsrückstellungen einen Verweis auf $\S 6$ a EStG enthalten. Aus diesem Vorgehen des Gesetzgebers ist zu folgern, dass für den Bereich des EStG und des KStG - ungeachtet der neuen Entstrickungstatbestände - weiterhin die allgemeinen Ansatzvorschriften gelten sollen. 
ungeklärt. ${ }^{12}$ Der Gesetzgeber ging offenbar davon aus, dass sich diese Fragen unter Hinzuziehung der allgemeinen (ertragsteuerlichen) Grundsätze beantworten lassen würden und unterlag damit offenbar einem Trugschluss, wie im Einzelnen noch zu zeigen sein wird.

\section{b) Bewertung der Entstrickung}

Das Gesetz sieht als einheitlichen Bewertungsmaßstab für die Entstrickung grundsätzlich den gemeinen Wert vor. ${ }^{13}$ Bei der Festlegung des Wertansatzes ging es dem Gesetzgeber darum, vor allem in den Fällen mit Auslandsberührung einen Gewinnaufschlag realisieren zu können. Der Ansatz mit dem gemeinen Wert ist allerdings nur für Fälle fiktiver Entnahmen und Einlagen infolge des Verlusts oder der Beschränkung des deutschen Besteuerungsrechts vorgesehen. In den Fällen der - tatsächlichen Entnahme oder Einlage bleibt es bei der Bewertung mit dem Teilwert.

Die Verwendung des gemeinen Werts im Rahmen der Entstrickungstatbestände wurde bereits im Vorfeld des Regierungsentwurfs kritisiert. Der gemeine Wert gemäß §9 Abs. 2 BewG entspricht dem Einzelveräußerungspreis und unterscheidet sich vom international eher gebräuchlichen Fremdvergleichspreis darin, dass außergewöhnliche Umstände bei der Ermittlung unberücksichtigt bleiben. Auch die Technik zur Ermittlung des gemeinen Werts ist eine andere, vom Bewertungsverfahren einmal ganz abgesehen. Der Gesetzgeber sah diese Probleme offenbar ebenfalls und reagierte darauf mit einer - allerdings eher lapidaren - Ergänzung des $\S 11$ Abs. 2 Satz 3 BewG, um die Anwendung des sog. Stuttgarter Verfahrens auszuschließen. $\S 11$ Abs. 2 BewG wurde durch das ErbStRG ${ }^{14}$ zwischenzeitlich bereits wieder geändert, und der durch das SEStEG eingeführte Satz 3 fiel zum 1. Januar 2009 weg.

\section{c) Ausgleichsposten}

Ihre eigentliche praktische Bedeutung entfalten die neuen Entstrickungstatbestände im Bereich der Betriebsstättenbesteuerung. Zwar ging es dem Gesetzgeber mit der Entstrickungsbesteuerung um die Nutzung des Betriebsstättenvorbehalts der Fusionsrichtlinie. ${ }^{15}$ Das zeigt ein Blick auf

12 Nach der Gesetzesbegründung soll die Spezialregelung zur verdeckten Gewinnausschüttung gemäß $\S 8$ Abs. 3 Satz 2 KStG Vorrang vor der allgemeinen Entstrickungsregelung haben; vgl. BT-Drs. 16/2710,30 f.

13 Eine Ausnahme gilt allerdings für die Verstrickung von Anteilen an einer Kapitalgesellschaft i. S. des $\S 17$ EStG.

14 Gesetz zur Reform des Erbschaftsteuer- und Bewertungsrechts (Erbschaftsteuerreformgesetz - ErbStRG) v. 24.12.2008. Anzuwenden ab 1.1.2009.

15 Richtlinie 90/434/EWG des Rates v. 23.6.1990 über das gemeinsame Steuersystem für Fusionen, Spaltungen, die Einbringung von Unternehmensteilen und 
die einschlägigen Tatbestände des UmwStG, die eine durch die Umwandlung unveränderte Zuordnung der Wirtschaftsgüter des übertragenden Rechtsträgers zu denjenigen Betriebsstätten fordern, zu deren Vermögen sie vor der Umwandlung gehörten. Dennoch wirken die Entstrickungsregelungen im gesamten Ertragsteuerrecht. Wenn also von einer Entstrickung in diesem Sinne die Rede ist, geht es immer um die veränderte Zuordnung eines bisher im Rahmen einer deutschen Betriebsstätte steuerverstrickten Wirtschaftsguts zu einer anderen (ausländischen) Betriebsstätte. ${ }^{16}$ Das führt unmittelbar zu der Frage, welche Besteuerungsfolgen diese grenzüberschreitenden Vorgänge unter Beachtung des Gemeinschaftsrechts auslösen. Der Regierungsentwurf zum SEStEG sah noch eine sofortige Entstrickung und Besteuerung der betroffenen Wirtschaftsgüter zum gemeinen Wert vor. Die Bundesregierung ging offenbar von dem uneingeschränkten Recht des deutschen Fiskus aus, die unter deutscher Steuerhoheit entstandenen betrieblichen stillen Reserven bei einer Änderung der Besteuerungszuordnung ohne Realisation sofort besteuern $z u$ dürfen. Der Lösungsansatz der Sofortversteuerung war bereits in der Entwurfsphase des SEStEG nicht unumstritten, und die Debatte setzte sich über den Regierungsentwurf hinaus fort. In der Diskussion befanden sich mehrere Alternativen: von der Aufdeckung der stillen Reserven bei Überführung mit sofortiger Festsetzung und zinsloser Stundung der Steuerschuld (entsprechend dem neu gefassten $\S 6$ AStG) bis hin zu diversen Varianten einer Ausgleichspostenlösung und natürlich der im Regierungsentwurf vorgesehen uneingeschränkten Sofortversteuerung. Letzten Endes einigten sich die Regierungsfraktionen auf eine Ausgleichspostenlösung auf der Basis der Stellungnahme des Bundesrats. Sie sieht im Entstrickungsfall vor, dass der Steuerpflichtige auf Antrag in Höhe der Differenz zwischen gemeinem Wert und Buchwert des entstrickten Wirtschaftsguts einen sog. Ausgleichsposten bilden kann, der über fünf Jahre verteilt in gleichen Jahresraten aufzulösen ist. Diese Möglichkeit einer aufgeschobenen Besteuerung steht ausschließlich unbeschränkt Steuerpflichtigen für Wirtschaftsgüter des Anlagevermögens zu. Weitere Voraussetzung ist, dass das entstrickte Wirtschaftsgut bis zur vollständigen Auflösung des Ausgleichsposten innerhalb der EU steuerlich verstrickt bleibt.

den Austausch von Anteilen, die Gesellschaften verschiedener Mitgliedstaaten betreffend.

16 Daneben sind auch Fälle denkbar, in denen die Betriebsstättenzuordnung nicht tangiert wird. Der Wechsel von der unbeschränkten in die beschränkte Steuerpflicht führt z. B. zur Entstrickung von Wirtschaftsgütern in einer Betriebsstätte, deren Doppelbesteuerung Deutschland bis dahin mittels der Anrechnungsmethode vermied. 


\section{Aufgabe der finalen Entnahmelehre durch den BFH}

a) Urteil vom 17.7.2008 (I R 77/06)

Mit seiner Entscheidung vom 17.7.200817 leitete der I. Senat des BFH den Wandel der höchstrichterlichen Rechtsprechung zur Entstrickung ein und gab seine Jahrzehnte alte Rechtsprechung zur finalen Entnahmelehre auf. Das Urteil betraf neben anderen Fragen ${ }^{18}$ die Übertragung eines Wirtschaftsguts im Wege der Sacheinlage von einer inländischen auf eine ausländische Personengesellschaft. Der Senat wandte, trotzdem die aufnehmende Personengesellschaft ihren Sitz in Österreich hatte, die Mitunternehmergrundsätze an. ${ }^{19}$ Möglicherweise abweichende ausländische Buchführungspflichten ständen dem wegen der in Art. 43 AEUV verankerten Niederlassungsfreiheit nicht entgegen. Ein Zwang zur Sofortbesteuerung der stillen Reserven lasse sich auch nicht damit rechtfertigen, dass der betreffende Vorgang nicht in den Anwendungsbereich der Fusionsrichtlinie falle. Die Fusionsrichtlinie als EU-Sekundärrecht schränke die Grundfreiheiten des AEUV weder ein noch gebe sie den Anwendungsbereich der Niederlassungsfreiheit vor. Das EU-Sekundärrecht müsse sich vielmehr seinerseits an den Grundfreiheiten des AEUV messen lassen. ${ }^{20}$

Zur Aufgabe der finalen Entnahmelehre führt letztlich die Erkenntnis des I. Senats, die im Inland entstandenen stillen Reserven seien im Falle einer späteren Veräußerung der Beteiligung trotz der Einbringung in die österreichische Tochterpersonengesellschaft nicht der deutschen Besteuerung entzogen. Das im Streitjahr geltende DBA mit Österreich entziehe der Bundesrepublik Deutschland selbst dann nicht den Besteuerungszugriff auf die im Inland entstandenen stillen Reserven der Beteiligung, wenn die Beteiligung funktional der österreichischen Personengesellschaft als Betriebsstätte zuzuordnen sei. Zu seiner bisherigen Rechtsprechung führt der I. Senat aus, sie finde im Gesetz keine hinreichende Grundlage und

17 BStBl. II 2009, 464.

18 Auch die weiteren Entscheidungssätze sind sehr bedeutsam. Danach ist die Einbringung eines Wirtschaftsguts als Sacheinlage in eine KG ertragsteuerlich auch insoweit als Veräußerungsgeschäft anzusehen, als ein Teil des Einbringungswerts in eine Kapitalrücklage eingestellt wird (entgegen BMF, Schr. v. 26.11.2004, BStB1. I 2004, 1190). Die das gesamte Nennkapital umfassende Beteiligung an einer Kapitalgesellschaft ist kein Teilbetrieb i. S. von $\S 24$ Abs. 1 UmwStG 1995. Die Fiktion des $\S 16$ Abs. 1 Satz 1 Nr. 1 EStG ist nicht entsprechend anwendbar (entgegen BMF, Schr. v. 25.3.1998, BStBl. I 1998, 268, Tz. 24.03).

19 Da Streitjahr 1995 war, gelangten die von der Rechtsprechung entwickelten Grundsätze des Mitunternehmererlasses (BMF, Schr. v. 20.12.1977, BStBl. I 1978, 8, Tz. 57) und nicht $§ 6$ Abs. 5 EStG zur Anwendung.

20 Kritisch hierzu Mitschke, FR 2008, $1144 \mathrm{f}$. 
beruhe auf einer unzutreffenden Beurteilung der Abgrenzung zwischen den in- und den ausländischen Einkünften und den Wirkungen der abkommensrechtlichen Freistellung. Der Einlage in die österreichische Personengesellschaft spricht der Senat die Eignung ab, als Überführung eines Wirtschaftsguts in eine ausländische Betriebsstätte des gleichen Unternehmers den bisherigen betrieblichen Funktionszusammenhang lösen zu können. Es handele sich hierbei um die Überführung aus einem Betrieb der steuerpflichtigen Mitunternehmer in einen anderen Betrieb derselben Steuerpflichtigen und nicht um eine die sofortige Besteuerung gebietende Außentransaktion. Der inländische Besteuerungszugriff auf Gewinne aus der Veräußerung beweglichen Betriebsvermögen einer Betriebsstätte in einem anderen Vertragsstaat gehe bei Vereinbarung der Freistellungsmethode nur in dem Umfang verloren, in dem das Vermögen der Betriebsstätte auch tatsächlich zuzuordnen sei und in dem die realisierten Gewinne durch jene Betriebsstätte erwirtschaftet worden seien. Abkommensrechtlich komme es zu einer Aufteilung des künftigen Veräußerungsgewinns zwischen Stammhaus und Betriebsstätte nach Verursachungsbeiträgen, die das Besteuerungsrecht des Stammhausstaats auf die dem Stammhaus zuzurechnenden Gewinnanteile unberührt lasse. Der Anwendung des im Rahmen der OECD für Zwecke der Gewinnabgrenzung bei Betriebsstätten entwickelten sog. Functionally Separate Entity Approach erteilt der BFH eine klare Absage. Nach der Rechtslage vor Inkrafttreten des $\S 4$ Abs. 1 Satz 3 EStG i.d. Fassung des SEStEG fehle sowohl eine Rechtsgrundlage als auch ein Bedürfnis dafür, die Überführung von Wirtschaftsgütern eines inländischen Unternehmens in dessen ausländische Betriebsstätte als Gewinnrealisierungstatbestand anzusehen. Im Weiteren gibt der Senat einen Überblick über die in der Literatur diskutierten Modelle zur Aufteilung eines etwaigen Veräußerungsgewinns, ohne sich aber für eine Methode zu entscheiden.

\section{b) Urteil vom 28.10.2009 (I R 99/08)}

Der I. Senat des BFH bestätigt mit dieser Entscheidung seine (geänderte) Rechtsprechung und erweitert diese sogar. ${ }^{21}$ Im Urteilsfall ging es um den Wegzug und die Verlegung des Unternehmens eines Erfinders nach Belgien (Streitjahr 1995). Bisher kam es nach der Rechtsprechung des BFH $z u$ einem der Betriebsaufgabe vergleichbaren Sachverhalt, wenn ein Betrieb als wirtschaftlicher Organismus zwar bestehen blieb, aber durch eine Handlung bzw. einen Rechtsvorgang in seiner ertragsteuerlichen Einordnung so verändert wurde, dass die Erfassung der stillen Reserven nicht gewährleistet war. Auch an dieser Rechtsprechung, die letztlich Ausfluss der finalen Entnahmelehre war, hält der I. Senat des BFH nicht

21 Ubg 2010, 143. 
mehr fest. Der Fall einer Verlegung führt nach seiner Auffassung nicht mehr zur Annahme einer (fiktiven) Betriebsaufgabe. Die Begründung entspricht im Kern den oben dargestellten Erwägungen des Senats zur Aufgabe der finalen Entnahmelehre: Von einer Entstrickung sei selbst dann nicht auszugehen, wenn die künftigen Gewinne der ausländischen festen Einrichtung (Betriebsstätte) im Inland nicht steuerbar oder aufgrund eines DBA von der Besteuerung im Inland freigestellt seien. Auf den Entscheidungsfall bezogen befindet der Senat, ein Veräußerungsgewinn sei im Hinblick auf die im Inland entstandenen stillen Reserven nicht der nach der Betriebsaufgabe im Ausland belegenen festen Einrichtung des Steuerpflichtigen zuzuordnen, sondern durch die ehemalige inländische Betriebsstätte veranlasst. An der späteren Besteuerung der im Inland entstandenen stillen Reserven sei die Bundesrepublik Deutschland nicht aufgrund abkommensrechtlicher Bestimmungen gehindert. Die nachträglichen Einkünfte, die auf der im Inland ausgeübten selbstständigen Arbeit beruhten, unterlägen der beschränkten Steuerpflicht. ${ }^{22}$ Allein die faktischen Schwierigkeiten beim Vollzug des späteren Besteuerungszugriffs seien nicht geeignet, eine Rechtsgrundlage dafür zu schaffen, die stillen Reserven des Betriebsvermögens ohne Realisationsvorgang der sofortigen Besteuerung zu unterwerfen.

\section{c) Urteil vom 28.10.2009 (I R 28/08)}

In einem Parallelverfahren ${ }^{23} \mathrm{zu}$ dem unter B.3.b) dargestellten Sachverhalt ging es um die Verlegung des Betriebs eines selbständigen Handelsvertreters ins Ausland (Streitjahre 1992 und 1993). Der I. Senat nahm hier ebenfalls keine (fiktive) Betriebsaufgabe an, trotzdem die künftigen Gewinne der ausländischen Betriebsstätte im Inland nicht steuerbar und aufgrund des anzuwendenden Doppelbesteuerungsabkommens von der Besteuerung im Inland freigestellt waren. Um eine fiktive Betriebsaufgabe soll es sich nach Auffassung des erkennenden Senats selbst dann nicht handeln, wenn die Verlegung mit einer vorübergehenden Betriebseinstellung verbunden ist. Der Betriebsinhaber bleibe mit einem späteren Veräußerungsgewinn, soweit dieser auf der Realisierung der im Inland gebildeten stillen Reserven beruhe, gemäß $§ 1$ Abs. 4 i. V.m. § 49 Abs. 1 Nr. 2 Buchstabe a EStG beschränkt steuerpflichtig. Es handele sich um Einkünfte aus Gewerbebetrieb, die durch die vormalige inländische Betriebsstätte erwirtschaftet worden seien. Aus der Formulierung in $\S 49$ Abs. 1 Satz 1 Nr. 2 Buchstabe a EStG 1990, dass für den Gewebebetrieb im Inland eine Betriebsstätte "unterhalten wird" , folge nicht, dass die inländische Betriebsstätte $\mathrm{zu}$ dem Zeitpunkt, in dem die Realisierung

$22 \mathrm{Zu}$ diesem Thema ausführlicher unter c).

23 IStR 2010, 103. 
eintrete und die Einkünfte erzielt würden, noch existieren müsse. In diesem Zusammenhang findet auch $\S 24$ Nr. 2 EStG Erwähnung. Abkommensrechtlich stehe der Zuordnung der Einkünfte nicht die Tatsache entgegen, dass die Betriebsstätte, in der die stillen Reserven erwirtschaftet worden seien, zum Zeitpunkt der Realisierung nicht mehr bestehe. ${ }^{24}$ Den auch in diesem Fall evidenten praktischen Problemen der (nachträglichen) Besteuerung begegnet der Senat mit der Empfehlung, der Gesetzgeber könne dem durch die Statuierung besonderer Mitwirkungspflichten entgegenwirken.

\section{Bewertung}

Die Aufgabe der finalen Entnahmelehre hat in der Literatur nicht nur Zustimmung erfahren. Vor allem Vertreter der Finanzverwaltung teilen die Auffassung des BFH nicht. Von der herrschenden Auffassung in der Literatur werden die Entstrickungsregelungen darüber hinaus als mehr oder weniger unveränderte Rezeption der (überholten) Rechtsprechungsgrundsätze zur finalen Entnahmelehre verstanden, sodass sie wie diese letztlich ins Leere laufen würden.

\section{Sichtweise des Gesetzgebers}

Das Verständnis der Bundesregierung bei Abfassung des Regierungsentwurfs zum SEStEG war - gemessen an den nunmehrigen Erkenntnissen des I. Senats - in der Tat ein anderes. Wie die einschlägigen Änderungen des JStG 2010 zeigen, will der Gesetzgeber hieran auch festhalten. Auslöser (= Tatbestandsvoraussetzung) der Entstrickungsbesteuerung ist hiernach der Umstand, dass infolge eines Verhaltens des Steuerpflichtigen künftige Wertveränderungen eines bislang im Inland steuerverstrickten Wirtschaftsguts nicht mehr (vollständig) der Besteuerung in Deutschland unterliegen. ${ }^{25}$ Als Rechtsfolge sehen $\S 4$ Abs. 1 Satz 3 EStG und die übrigen an diese Vorschrift anlehnenden, durch das SEStEG neu geschaffenen Entstrickungsnormen - wie zuvor schon der Betriebsstättenerlass den Ansatz des betreffenden Wirtschaftsguts mit dem gemeinen Wert vor. Tatbestandsvoraussetzung ist also prospektiv eine aus der Sicht des deutschen Fiskus steuerliche Statusveränderung (im Zweifel: Statusver-

24 Vgl. aber Wassermeyer, IStR 2010, 461 ff.; Mitschke, IStR 2010, 211.

25 Dass dies dem vom SEStEG-Gesetzgeber Gewollten entspricht, erkennt offenbar auch der Wissenschaftliche Beirat von Ernst \& Young (DB 2010, 1776f). Der insoweit klare Wille des Gesetzgebers hindert den Wissenschaftlichen Beirat aber nicht an der Feststellung, dass die objektiven Gesetzeswortlaute nicht das wiedergäben, was sich der Gesetzgeber vorgestellt habe. 
schlechterung) bezogen auf das Wirtschaftsgut. Die daraus resultierende Rechtsfolge ist - retrospektiv - die Aufdeckung der bis dahin generierten stillen Reserven bzw. Lasten dieses Wirtschaftsguts.

Mitnichten wird man dieser Sichtweise entgegen halten können, sie würde im Rahmen der Entstrickung auch die künftigen stillen Reserven der deutschen Besteuerung unterwerfen. ${ }^{26}$ Künftige stille Reserven sind selbst im Falle einer Veräußerung des Wirtschaftsguts - also einer echten Außentransaktion - der Besteuerung in Deutschland entzogen bzw. nur eingeschränkt unterworfen. Wie also sollte der Gesetzgeber dazu kommen, im Falle einer fiktiven Veräußerung (oder Entnahme) auch künftige stille Reserven bei Übertragenden besteuern zu wollen? Aufgabe der finalen Entnahmelehre ist (bzw. war) allein, die Besteuerung steuerlich verstrickter stiller Reserven im Inland sicherzustellen. Es handelte sich um eine Ultima-ratio-Besteuerung bezogen auf einen Vorgang, der zwar keinen gesetzlichen Besteuerungstatbestand auslöste, bei dem allerdings ein weiteres Zuwarten die Besteuerung der im Zeitpunkt der Tatbestandsverwirklichung vorhandenen stillen Reserven hätte gefährden oder gar unmöglich machen können. Um diesen zuletzt genannten Aspekt der Gefährdung oder Unmöglichkeit einer Besteuerung von im Inland entstandenen stillen Reserven ging es auch bei der Schaffung der neuen Entstrickungstatbestände durch das SEStEG. Selbst wenn DBA-rechtlich eine Besteuerung der „inländischen“ stillen Reserven durch die Überführung des Wirtschaftsguts in eine ausländische Betriebsstätte nicht ausgeschlossen sein sollte, war (und ist) doch die erhebliche tatsächliche Gefährdung der Besteuerung nicht von der Hand zu weisen. ${ }^{27}$ Eine Gefährdung der Besteuerung setzt in aller Regel bereits dann ein, wenn zwar ein Besteuerungsanspruch besteht, dieser aber nicht erkannt wird bzw. nicht vollzogen werden kann. Der Zeitpunkt des Eintritts der Gefährdungslage ist in aller Regel identisch mit dem Zeitpunkt, in dem prospektiv - für die Besteuerung künftig entstehender stiller Reserven nicht mehr (nur) der deutsche, sondern (auch) ein anderer Fiskus zuständig wird. Letzterer hat dann in der Regel ausschließlich den Zugriff auf das betreffende Wirtschaftsgut.

DBA-rechtlich ging der SEStEG-Gesetzgeber im Übrigen von einem anderen Verständnis aus als nunmehr der I. Senat - nämlich von einer funktionalen Selbständigkeitsfiktion bei der Betrachtung von Betriebsstätten. Sie lehnt an den sog. Functionally Separate Entity Approach der OECD

26 So aber offenbar das Verständnis des BFH, vgl. BFH v. 17.7.2008 unter III.3. b) cc) der Entscheidungsgründe.

27 Der Vorsitzende Richter des I. Senats des BFH selbst weist ausdrücklich und nachdrücklich auf sie hin, vgl. Gosch, HaufeIndex: 2282871; ebenso Prinz, DB 2009, 809; Mitschke, IStR 2010, 97. 
an. ${ }^{28}$ Überzeugend waren dabei insbesondere die unbestreitbare Klarheit und - verglichen mit anderen Modellen - Einfachheit dieses Ansatzes: ${ }^{29}$ Bei der Überführung von Wirtschaftsgütern zwischen verschiedenen Betriebsstätten wird die ausländische Betriebsstätte wie ein eigenständiger Rechtsträger behandelt. Nach Art. 7 Abs. 2 OECD-MA sind jeder Betriebsstätte die Gewinne zuzurechnen, die sie hätte erzielen können, wenn sie eine gleiche oder ähnliche Geschäftstätigkeit unter gleichen oder ähnlichen Bedingungen als selbstständiges Unternehmen ausgeübt hätte und im Verkehr mit dem Unternehmen, dessen Betriebsstätte sie ist, völlig unabhängig gewesen wäre. Die Überführung von Wirtschaftsgütern ist also wie eine Außentransaktion abzuwickeln. Der Veräußerungspreis und der Entstrickungsgewinn bzw. -verlust sind auf der Basis von Verkehrswerten zu ermitteln und im Zeitpunkt der Überführung zu versteuern. ${ }^{30}$

Die Vereinbarkeit der Sofortbesteuerung mit den unionsrechtlichen Grundfreiheiten wurde seinerzeit bejaht. Der Gesetzgeber ging davon aus, mit dem Ausgleichsposten nach § 4g EStG alles Erforderliche zur Vermeidung bzw. Rechtfertigung einer grundfreiheitenwidrigen Diskriminierung unternommen zu haben. Seine Abwägung lässt sich in etwa wie folgt zusammenfassen: Die durch die Überführung der Wirtschaftsgüter ausgelöste sofortige Entstrickung ist nur die eine Seite der Medaille. Im Staat der aufnehmenden Betriebsstätte geht sie in der Regel mit einer Verstrickung einher. Der dabei anzusetzende Wert ist nach dem Konzept der deutschen Entstrickungsregelungen der gemeine Wert oder ein damit vergleichbarer ausländischer Wert. ${ }^{31}$ Es kommt zu entsprechenden (höheren) Abschreibungen. ${ }^{32}$ Es galt unionsrechtlich also in erster Linie die Frage $\mathrm{zu}$ beantworten, inwieweit beim grenzüberschreitenden Wirtschaftsguttransfer im Unterschied zum reinen Inlandsfall auftretende Liquiditätseffekte eine unionsrechtlich nicht gerechtfertigte Diskriminierung auslösen würden. ${ }^{33}$ Liquiditätseffekte dieser Art sind indessen nahezu unvermeidbar, wenn mehrere Rechtsordnungen von einem wirtschaftlichen Sachverhalt betroffen sind. Im Steuerrecht sind sie Folge der

28 Kritisch hierzu Schneider/Oepen, FR 2009, 25.

29 Vgl. die Darstellung bei Kroppen, IStR 2010, 74 ff., der für die damalige Rechtslage vom Fehlen eines Art. 7 Abs. 2 OECD-MA ausfüllenden nationalen Besteuerungstatbestands ausging. Eben dieser sollte durch die neuen Entstrickungsnormen des SEStEG geschaffen werden.

30 Zweifelnd Prinz, DB 2009, 807.

31 Nach DBA-Maßstäben: der Fremdvergleichspreis.

32 Zu dieser Wechselwirkung vgl. auch Kroppen, IStR 2010, 75, der resümiert, dieses Dilemma sei kaum diskriminierungsfrei zu lösen.

33 Das verkennt Körner (IStR 2010, 210), indem er die zur Verrechen- bzw. Abziehbarkeit ausländischer Betriebsstättenverluste ergangene Rechtsprechung des EuGH für nicht einschlägig hält. 
Notwendigkeit, die auf einen Sachverhalt bezogenen Besteuerungsrechte mehrerer betroffener Staaten aufzuteilen bzw. abzugrenzen. ${ }^{34}$ Eine unionsrechtliche Relevanz erlangen sie erst dann, wenn sie in eine dauerhafte Last des Betroffenen umschlagen. Das aber sollte der auf Antrag zu gewährende Ausgleichsposten nach § 4g EStG vermeiden. ${ }^{35}$

\section{Haltung des BFH}

Bei einer Gewinnaufteilung nach Verursachungsbeiträgen - wie sie der $\mathrm{BFH}$ nunmehr in den hier besprochenen Entscheidungen verfolgt - sollen die Besteuerungsfolgen erst im Zeitpunkt einer tatsächlichen Außentransaktion gezogen werden. Der Schwenk der höchstrichterlichen Rechtsprechung erweist sich vor allem hinsichtlich des konkreten Aufteilungsmaßstabs als problematisch. Hierzu hat sich der BFH noch nicht geäußert. Über kurz oder lang wird er sich dieser Frage aber annehmen müssen. Er hat mehrere Alternativen zur Auswahl:

- Nach der Theorie der aufgeschobenen Gewinnrealisierung ist für die Gewinnabgrenzung auf den Wert abzustellen, der im Zeitpunkt der Überführung in die Betriebsstätte durch einen Außenumsatz hätte erzielt werden können. ${ }^{36}$ Dieser Wert soll in einem außerbilanziellen Erinnerungsposten festgehalten und bei einer späteren Außentransaktion besteuert werden. ${ }^{37}$ Im Ergebnis entspricht dies der Technik des Betriebsstättenerlasses. ${ }^{38}$ Allerdings bedarf es zur Gewinnrealisierung stets eines tatsächlichen Außenumsatzes. Dieser wird nicht in allen Fällen eintreten. Das Wirtschaftsgut kann in der ausländischen Betriebsstätte verbraucht werden oder zufällig untergehen. Der Wert

34 Hierzu und zu dem vom EuGH entwickelten Rechtfertigungsgrund der Aufteilung von Besteuerungsbefugnissen Mitschke, IStR 2010, 96.

35 A. A. Körner, IStR 2009, 742 f, der aus europarechtlichen Gründen von der Verpflichtung zur Entstrickung zum Buchwert mit Besteuerungsmöglichkeit der zum Transferzeitpunkt vorhandenen stillen Reserven im Falle eines späteren Realisationsakts und Verstrickung zum gemeinen Wert ausgeht. Körner will so die bereits beschriebenen Liquiditätseffekte vermeiden. Allerdings stellt seine Lösung nicht die von ihm behauptete Gleichbehandlung her, sondern übervorteilt den Überführungsfall gegenüber reinen Inlandssachverhalten. Denn der Steuerpflichtige kann das Wirtschaftsgut unter Einbeziehung der im Transferzeitpunkt vorhandenen stillen Reserven abschreiben, ohne diese zuvor besteuert zu haben.

36 Vgl. Buciek in Flick/Wassermeyer/Kempermann, DBA Deutschland-Schweiz, Art. 7 Rz. 461; Kramer, StuW 1991, 151, $160 \mathrm{ff}$.

37 Freilich hat der BFH die Frage nach dem tatsächlichen Wert der in die österreichische KG überführten Beteiligung in dem Verfahren I R 77/06 (siehe unter B.3.a) letztlich offen gelassen und die Sache nicht an das FG zurück verwiesen. Ebenfalls kritisch hierzu Schneider/Oepen, FR 2009, 26.

38 BMF, Schr. v. 24.12.1999, BStBl. I 1999, 1076. 
des Wirtschaftsguts kann sich aus anderen Gründen ändern, im Falle einer Beteiligung etwa durch die Ausschüttung von Gewinnen aus der Zeit vor der Betriebsstättenüberführung. Schließlich kann das Wirtschaftsgut in anderer Weise dem Unternehmenserfolg dienen. Denn der Wert von Wirtschaftsgütern des Anlagevermögens geht häufig in den hergestellten Endprodukten auf. In all diesen Fällen hätte der deutsche Fiskus mangels Außenumsatzes das Nachsehen. ${ }^{39}$

- Nach anderer Auffassung soll für die Abgrenzung der Gewinnanteile auf den Zeitpunkt der tatsächlichen Realisierung durch den Außenumsatz abgestellt werden und der sich hieraus ergebende Erlös und Aufwand nach den jeweils erbrachten Wertschöpfungsbeiträgen auf die verschiedenen Unternehmensteile (Betriebsstätten) aufgeteilt werden. ${ }^{40}$ Die Zuweisung des Verlusts aus dem zufälligen Untergang des Wirtschaftsguts soll dabei nach Wassermeyer ${ }^{41}$ anhand der Risikoverteilung erfolgen, nach der sich auch der Anteil an der Vermarktung bestimmt hätte. Das führt zu erheblichen Problemen: Wirtschaftsgüter des Anlage- und des Umlaufvermögens können ohne Außenumsatz oder zufälligen Untergang verbraucht, verbaut, genutzt etc. werden. Hier könnten zwar ebenfalls Wertschöpfungsbeiträge ermittelt werden. Oftmals setzen sich diese aber nicht am entstrickten Wirtschaftsgut selbst, sondern an anderen "Nachfolgewirtschaftsgütern" bis hin zum gesamten Unternehmensgegenstand fort. ${ }^{42}$ Hier eine sinnvolle Aufteilung des Unternehmensergebnisses nach Wertschöpfungsbeiträgen zu erreichen, ist für den Steuerpflichtigen eine Herausforderung. Für die Finanzverwaltung dürfte eine solche, vom Steuerpflichtigen vorzunehmende Aufteilung nur schwer nachvollziehbar, geschweige denn nachprüfbar sein. Die Aufteilung würde vermutlich primär nach betriebswirtschaftlichen Maßstäben erfolgen. Augenfällig wird das Problem bei der Entstrickung immaterieller Wirtschaftsgüter, etwa Patenten. In der Findungsphase bis hin zu ihrer Anmeldung bei den Patentbehörden verursachen sie in erster Linie (teils erhebliche) Kosten. In der Verwertungsphase des Patents fallen überwiegend Erträge an. Nach welchen Maßstäben sind die Kosten und die späteren Erträge aufzuteilen, wenn die Verwertung des Patents in einer anderen Betriebsstätte im Wege der Eigenproduktion erfolgt?

Es zeigt sich, dass der Entstrickungsansatz des BFH Zündstoff birgt. Zahlreiche Fragen sind noch offen. Verwaltungspraktisch ist die Theorie der Besteuerung nach Wertschöpfungsbeiträgen vermutlich die schlechtere

39 Kroppen, IStR 2010, 75.

40 Wassermeyer, IStR 2004, $733 \mathrm{ff}$.

41 Wassermeyer, IStR 2004, 735.

42 Beispiel: Das überführte Wirtschaftsgut dient der Fertigung. Die insoweit gefertigten Produkte tragen zum Unternehmensgewinn bei. 
Lösung. Denn die Finanzverwaltung müsste die vom BFH geforderte (und in ihren Eckpunkten teils noch unklare) Gewinnabgrenzung tagtäglich praktizieren. D.h., sie müsste insbesondere die besteuerungsrelevanten Handlungen des Steuerpflichtigen im Ausland in Erfahrung bringen. $\mathrm{Zu}$ guter Letzt müsste auch der Besteuerungszugriff gelingen. Dies alles in dem nicht seltenen Fall ${ }^{43}$ zu bewerkstelligen, in dem der Steuerpflichtige sich vollständig aus Deutschland zurückzieht, dürfte schwerlich gelingen. Der Vorsitzende Richter des I. Senats des BFH selbst ${ }^{44}$ spricht in diesem Zusammenhang von einer "permanenten Steuerkontrolle" der Finanzverwaltung, ohne allerdings selbst ernsthaft anzunehmen, dass der spätere Zugriff tatsächlich gelingt. Stattdessen weist Gosch darauf hin, dass ein strukturelles Vollzugsdefizit mit der Folge der Verfassungswidrigkeit des Steuerzugriffs drohen könnte. Von seinen jüngsten Entscheidung abzuhalten vermochte diese Erkenntnis den I. Senat (leider) nicht.

\section{Exkurs: Besonderheiten der Entscheidung vom 17.7.2008}

Die Entscheidung des I. Senats des BFH vom 17.7.2008 ${ }^{45}$ weist gegenüber dem herkömmlichen Fall der Überführung von Wirtschaftsgütern in eine ausländische Betriebsstätte desselben Steuerpflichtigen eine Besonderheit auf. Eine inländische Personengesellschaft hatte ihre Beteiligung an einer US-amerikanischen Gesellschaft in eine österreichische (Tochter-|Personengesellschaft eingelegt. Es kam zu einem Rechtsträgerwechsel. Der erkennende Senat ging deshalb zu Recht von einem veräußerungsgleichen Vorgang aus: Bei der Überführung von Wirtschaftsgütern in das Betriebsvermögen einer Personengesellschaft gegen Gewährung von Gesellschafterrechten - d.h. als Sacheinlage - handele es sich aus ertragsteuerlicher Sicht um ein tauschähnliches Geschäft, mithin um eine Veräußerung. ${ }^{46}$ Die Anteilsübertragung sei auch insoweit eine Veräußerung und keine verdeckte Einlage, als ihr Einbringungswert nicht auf die Kommanditeinlage angerechnet, sondern einem $\mathrm{zu}$ bildenden Rücklagenkonto bei der Ö-KG zugewiesen werde. ${ }^{47}$

Eine Veräußerung bzw. ein Rechtsträgerwechsel ist typischerweise der erforderliche Realisationsakt, um eine Entstrickung annehmen zu können. Die vom I. Senat angeführte Rechtfertigung für seine abweichende Sichtweise ist das Fehlen einer Abkommensberechtigung der beteiligten Personengesellschaften. Die Frage der Abkommensberechtigung stellt

43 Der Sachverhalt, der dem Urteil v. 28.10.2009 (I R 99/08) zugrunde lag, war solch ein Fall.

44 Vgl. Gosch, HaufeIndex: 2282871.

45 BFH v. 17.7.2008, BStB1. II 2009, 464.

46 Unter I.1. der Entscheidungsgründe.

47 Unter I.3. der Entscheidungsgründe. 
sich vorliegend jedoch nur, weil zwischen den beteiligten Personengesellschaften zeitgleich zum Veräußerungsvorgang ein Gesellschaftsverhältnis bestand. Dieses reichte freilich auch in den Augen des Senats nicht so weit, die Qualität der Einlage als Veräußerungsvorgang in Frage zu stellen. Handelt es sich aber trotz gesellschaftsrechtlicher Beziehungen zwischen den Personengesellschaft und ihrem Gesellschafter um eine Veräußerung und damit um einen Realisationsakt, muss dies auch ansonsten gelten. Jeder vergleichbare Übertragungsvorgang zwischen gesellschaftsrechtlich nicht miteinander verbundenen Personengesellschaften würde ja auch als ein Realisationsakt zu werten sein: so etwa die Weiterveräußerung der Beteiligung an der österreichischen Personengesellschaft an eine dritte, bislang unbeteiligte Personengesellschaft. Die Lösung des I. Senats wirft außerdem die Frage auf, wie ein Gewinn aus einer späteren Veräußerung der Beteiligung hinsichtlich der auf die (Mutter-) Personengesellschaft entfallenden Gewinnbestandteile bei dieser zu einer zutreffenden Gewinnerhöhung (und Besteuerung) führen soll. ${ }^{48}$

Vergleichbare Fragen können sich bei grenzüberschreitenden Vorgängen im Sinne des UmwStG stellen. ${ }^{49}$ Hier spielen die Entstrickungsregelungen ebenfalls eine große Rolle. Bei der Verschmelzung einer Kapitalgesellschaft auf eine Personengesellschaft etwa kann das Vermögen der Überträgerin nur auf Antrag mit dem Buchwert angesetzt werden. Voraussetzung ist u. a., dass das Recht der Bundesrepublik Deutschland hinsichtlich der Besteuerung des Gewinns aus der Veräußerung der übertragenen Wirtschaftsgüter bei den Gesellschaftern der übernehmenden Personengesellschaft oder bei der übernehmenden natürlichen Person nicht ausgeschlossen oder beschränkt wird (vgl. exemplarisch §3 Abs. 2 UmwStG). Mit Ausnahme der Fälle des Formwechsels handelt es sich bei den erfassten Umwandlungsarten um übertragende Umwandlungen. D.h., es findet ein Rechtsträgerwechsel und damit ein Realisationsakt statt, der an sich eine Besteuerung der stillen Reserven des übergehenden Vermögens rechtfertigen würde. Nur ausnahmsweise werden diese (normalen) steuerlichen Konsequenzen des Realisationsakts nicht gezogen. Der Tatbestandsaufbau der genannten Vorschriften führt dieses Regel-Ausnahme-Verhältnis plastisch vor Augen: Grundsätzlich mündet der Vermögensübergang in eine Besteuerung der stillen Reserven des übergehenden Vermögens. Auf die Besteuerung wird nur verzichtet, soweit sie beim übernehmenden Rechtsträger vollumfänglich nachgeholt werden kann. Das aber dürfte im Falle einer grenzüberschreitenden

48 Siehe auch Wassermeyer, IStR 2010, 463, der zutreffend darauf hinweist, dass der Gewinn bei der Tochterpersonengesellschaft ermittelt und jeweils anteilig von den beteiligten Mitunternehmern zu versteuern ist. Schneider/Oepen (FR 2009, 26 f) schlagen insoweit die Bildung einer Ergänzungsbilanz vor.

49 Vgl. nur die Interpretation von Körner, IStR 2009, 748 ff. 
Umwandlung nicht möglich sein, soweit infolge der Umwandlung inländisches $\mathrm{zu}$ ausländischem Betriebsvermögen wird. Der übertragende Rechtsträger wird nach der Umwandlung häufig gar nicht mehr existieren und der Übernehmer im Inland womöglich nie eine Betriebsstätte besessen haben. ${ }^{50}$

\section{Zukunft der Entstrickung}

Die Finanzverwaltung belegte die erste der o.g. drei Entscheidungen des I. Senats des BFH mit einem Nichtanwendungserlass ${ }^{51}$ und dokumentierte damit ihre gegenüber dem BFH grundsätzlich andere Haltung in der Entstrickungsfrage. $\mathrm{Zu}$ den neuerlichen Judikaten erfolgte keine solche Maßnahme mehr, zumal der Rechtsprechungswandel als gefestigt angesehen werden konnte. Zudem sprach eine große Wahrscheinlichkeit dafür, dass der BFH seine geläuterte Haltung auch unter dem neuen Recht beibehalten würde. Der Gesetzgeber musste deshalb handeln. Die wohl einfachste Möglichkeit für den Gesetzgeber, die aus seiner Sicht zutreffende Rechtslage herzustellen, bestand in einer klarstellenden Ergänzung der einschlägigen Entstrickungsregelungen. In diese Richtung zielte ein Vorschlag des Bundesrats zum JStG 2010,52 auf dessen Grundlage dann auch tatsächlich die Entstrickungsregelungen der Ertragsteuergesetze ${ }^{53}$ geändert wurden. In die einschlägigen Entstrickungsvorschriften wurde ein Regelbeispiel aufgenommen, wonach ein Ausschluss oder eine Beschränkung des Besteuerungsrechts hinsichtlich des Gewinns aus der Veräußerung eines Wirtschaftsguts insbesondere dann vorliegt, wenn das Wirtschaftsgut einer ausländischen Betriebsstätte zugeordnet wird. Mit der Anknüpfung der Entstrickung an den Verlust oder die Beschränkung des abkommensrechtlichen Besteuerungsrechts wird insbesondere der Fall der Überführung eines Wirtschaftsguts von einem inländischen Betrieb in eine ausländische (DBA-)Betriebsstätte erfasst. Das Regelbeispiel soll zu verstehen geben, dass in genau diesen Fällen von einer Beschränkung oder einem Ausschluss des Besteuerungsrechts auszugehen ist. ${ }^{54}$ Das entspricht nach dem Verständnis des Gesetzgebers nicht

50 Man denke etwa an den Fall der Verschmelzung einer inländischen Holdinggesellschaft auf eine ausländische Gesellschaft. A. A. Körner, IStR 2009, 748.

51 BStB1. II 2009, 464; kritisch dazu Körner, IStR 2009, 745 ff. Den Nichtanwendungserlass verteidigt Mitschke, IStR 2010, $95 \mathrm{ff}$

52 BR-Drs. 318/10 v. 9.7.2010.

53 V. 8.12.2010 (BGBl. I 2010, 1768).

54 A. A. der Wissenschaftliche Beirat von Ernst \& Young, DB 2010, 1778: Sollte bezüglich eines (Verf.: der inländischen Betriebsstätte zuzuordnenden) hypothetischen Produktionsgewinns weder eine Beschränkung noch ein Ausschluss des deutschen Besteuerungsrechts eintreten, so würden auch die Rechtsfolgen 
nur den OECD-Grundsätzen (Kommentar zu Art. 7 OECD-MA 2005, Tz. 15), sondern auch der internationalen Verwaltungspraxis. Geändert wurden neben $\S 4$ Abs. 1 EStG vor allem $\S 6$ Abs. 5 und $\S 16$ Abs. 3 EStG. Im Körperschaftsteuerrecht wurde $\S 12$ Abs. 1 KStG angepasst.

Mit der Einfügung von $\S 4$ Abs. 1 Satz 4 EStG steht ferner die Neuregelung des $\S 16$ Abs. 3a EStG im Zusammenhang. Mit seinen beiden Urteilen vom 28.10.200955 hatte der BFH seine bisherige Rechtsprechung zur sog. Theorie der finalen Betriebsaufgabe aus den gleichen Gründen aufgegeben, die ihn zur Aufgabe der sog. Theorie der finalen Entnahme bei der Überführung von Einzelwirtschaftsgütern in eine ausländische Betriebsstätte bewogen hatten. Die Regelung des § 16 Abs. 3a EStG setzt die Grundsätze der Theorie der finalen Betriebsaufgabe nun gesetzlich um. Sie stellt die Besteuerung der im Inland entstandenen stillen Reserven sicher und trägt dem Umstand Rechnung, dass es für die deutschen Finanzbehörden oftmals schwierig bis unmöglich ist, das weitere Schicksal des in das Ausland verlegten Betriebsvermögens zu überwachen und den tatsächlichen Realisationsakt im Ausland zu erkennen und zu erfassen. Ergänzt wird dieser neue Entstrickungstatbestand durch $\S 36$ Abs. 5 EStG. Bei Verlegung des Betriebs in einen anderen EU- oder EWR-Staat kann die Steuer auf den Aufgabegewinn und auf den durch den Wechsel der Gewinnermittlungsart erzielten Gewinn auf Antrag zinslos in fünf gleichen Jahresraten entrichtet werden.

Die Ergänzungen der Entstrickungsnormen sind grundsätzlich rückwirkend anzuwenden. Sie wirken sogar in die Zeit vor der Anwendbarkeit des SEStEG zurück. Denn für Fälle, in denen ein bisher einer inländischen Betriebsstätte zuzuordnendes Wirtschaftsgut einer nach dem DBA freizustellenden ausländischen Betriebsstätte eines unbeschränkt Steuerpflichtigen zuzuordnen ist oder wenn das Wirtschaftsgut bei einem beschränkt Steuerpflichtigen nicht mehr einer inländischen Betriebsstätte zuzuordnen ist, gilt $\S 4$ Abs. 1 Satz 3 EStG laut $\S 52$ Abs. 8b EStG auch für Wirtschaftsjahre, die vor dem 1.1.2006 endeten. Die von der Verwaltung im Betriebsstättenerlass vorgesehene Möglichkeit der aufgeschobenen Besteuerung wird hier aber möglicherweise bestehen bleiben.

des $\S 4$ Abs. 1 Satz 3 EStG und des $\S 12$ Abs. 1 KStG nicht eingreifen. Dies gelte auch nach Einfügung des vom Bundesrat vorgeschlagenen Satzes 4.

55 I R 28/08 und I R 99/08. 
5. Leitthema:

Bilanzen und Steuern 



\title{
Steuerbilanzpolitik unter dem BilMoG einschließlich Ausschüttungssperren
}

\author{
Dr. Ingo Ernsting \\ Düsseldorf
}

Inhaltsübersicht

1. Einführung

2. Eigenständigkeit der Steuerbilanzpolitik unter dem BilMoG

a) Neujustierung der Maßgeblichkeit

b) Grundwertungen des BMFSchreibens vom 12.3.2010 zum Maßgeblichkeitsgrundsatz

c) Steuerliche Wahlrechte als Parameter der Steuerbilanzpolitik

3. Praxisfragen bei der Ausübung steuerbilanzieller Wahlrechte

a) Teilwertabschreibungen

b) Zum Umfang der Herstellungskosten in der Steuerbilanz c) Eigene Aktien

d) Rücklage nach $\S 6$ b EStG

e) Pensionsrückstellungen gem. $\S 6$ a EStG

4. Zur Relevanz von Ausschüttungssperren

a) Handelsrechtliche Grundlagen

b) Zur Bilanzierung latenter Steuern im Zusammenhang mit Ausschüttungssperren

c) Wirkung der Abführungssperre im Rahmen der steuerlichen Organschaft

5. Thesenförmige Zusammenfassung

\section{Einführung}

Das Bilanzrechtsmodernisierungsgesetz vom 25.5.2009 (BilMoG) hat nicht nur die Rechnungslegung grundlegend verändert, sondern auch das Zusammenspiel von Handelsbilanz und Steuerbilanz neu geordnet. Ziel des Gesetzgebers war es, die umgekehrte Maßgeblichkeit abzuschaffen, um die Handelsbilanz von GoB-widrigen steuerrechtlichen Einflüssen zu befreien. ${ }^{2}$ Das BMF hat dazu mit Schreiben vom 12.3.2010 ausführlich Stellung genommen. ${ }^{3}$

Im ersten Teil dieses Beitrags ${ }^{4}$ wird dargestellt, welche neuen Koordinaten nunmehr bei der Steuerbilanzpolitik zu beachten sind. Anhand von

1 BMF, Schr. v. 12.3.2010 - IV C 6 - S 2133/09/10001, BStBl. I 2010, 650; vgl. auch BMF, Schr. v. 22.6.2010 - IV C6 - S 2133/08/10001, FR 2010, 676.

2 BT-Drs. 16/10067, 41, 99, 124; vgl. Anzinger/Schleiter, DStR 2010, 395.

3 BStBl. I 2010, 239.

4 Vgl. auch Ernsting, FR 2010, 1061. 
Beispielsfällen soll deren praktische Bedeutung aufgezeigt werden. Um Wiederholungen zu vermeiden, sei an dieser Stelle auch auf den Vortrag von Herrn Prof. Hennrichs verwiesen, den er anlässlich des letztjährigen Fachkongresses gehalten hat; dies gilt insb. hinsichtlich der Ausführungen zu Übergangsbestimmungen ${ }^{5}$ und zur zunehmenden Bedeutung von latenten Steuern. ${ }^{6}$

Der zweite Teil behandelt die neuen handelsrechtlichen Ausschüttungssperren. Dabei wird insb. auf die Anwendungsfragen in diesem Zusammenhang mit steuerlichen Organschaften eingegangen.

\section{Eigenständigkeit der Steuerbilanzpolitik unter dem BilMoG}

a) Neujustierung der Maßgeblichkeit

Nach dem neuen Wortlaut von $\S 5$ Abs. 1 Satz 1 EStG ist

„für den Schluss des Wirtschaftsjahres das Betriebsvermögen anzusetzen (§ 4 Absatz 1 Satz 1), das nach den handelsrechtlichen Grundsätzen ordnungsmäßiger Buchführung auszuweisen ist, es sei denn, im Rahmen der Ausübung eines steuerlichen Wahlrechts wird oder wurde ein anderer Ansatz gewählt."

Im Rahmen des BilMoG wurde damit die zentrale Vorschrift für die materielle und die formelle Maßgeblichkeit geändert. Es ist dadurch zu einer „Neujustierung der Maßgeblichkeit" gekommen, die durch folgende Aspekte gekennzeichnet ist: ${ }^{7}$

- Abschaffung der umgekehrten Maßgeblichkeit: Die Ausübung bestimmter steuerlicher Wahlrechte ist nicht mehr an die identische Abbildung in der Handelsbilanz gekoppelt. ${ }^{8}$ Dies ist Ausfluss der Abschaffung der formellen Maßgeblichkeit. ${ }^{9}$

- Neufassung der materiellen Maßgeblichkeit: Der handelsrechtliche Jahresabschluss bleibt Grundlage der steuerrechtlichen Gewinnermittlung; d.h. steuerbilanziell ist grds. das Betriebsvermögen anzusetzen, das nach den handelsrechtlichen Grundsätzen ordnungsmäßiger Buchführung auszuweisen ist. Der Gesetzgeber hält damit an der materiellen Maßgeblichkeit grds. fest; er verknüpft den GoB-Verweis aber mit

5 Vgl. Hennrichs, Bilanzrechtsmodernisierung und Besteuerung, StBJb 2009/2010, Köln 2010, 260 (262).

6 Vgl. zum Tax Accounting für latente Steuern auch Herzig, DStR 2010, 1900 (1905).

7 So Herzig, DStR 2010, 1900 (1901).

8 Zum alten Recht vgl. die Kommentierung von Ernsting/Haeger/Küting zu $\S 254 \mathrm{HGB}$ a. F. in Handbuch der Rechnungslegung, Einzelabschluss, hrsg. v. Küting/Weber, Stuttgart, 5. Aufl., Stand: März 2003.

9 Durch die Streichung von $\S 5$ Abs. 1 Satz 2 EStG a. F. wird die umgekehrte Maßgeblichkeit aufgehoben. Vgl. Meurer, FR 2009, 117 (118); Grützner, StuB 2009, 481; Künkele/Zwirner, DStR 2009, 1278; vgl. auch Mitschke, FR 2010, 214. 
einem steuerlichen Wahlrechtsvorbehalt. Die materielle Maßgeblichkeit tritt hinter die Ausübung von steuerlichen Wahlrechten zurück. Im Ergebnis besteht nur noch eine subsidiäre Maßgeblichkeit der handelsrechtlichen GoB. ${ }^{10}$ Zum Teil wird die Frage aufgeworfen, ob der Gesetzgeber auch die materielle Maßgeblichkeit so weitgehend preisgeben wollte; indes ist der Wortlaut eindeutig. ${ }^{11}$

Die bisherigen allgemeinen Grundsätze zur Aktivierung, Passivierung und Bewertung der einzelnen Bilanzposten hat das BilMoG zwar nicht geändert, aber ihre Bedeutung ist geschwunden. ${ }^{12}$

Diese sind:

- Handelsrechtliche Aktivierungsgebote und Aktivierungswahlrechte führen zu Aktivierungsgeboten in der Steuerbilanz, es sei denn, die Aktivierung ist aufgrund spezieller steuerrechtlicher Regelungen ausgeschlossen. Handelsrechtliche Aktivierungsverbote führen auch steuerlich zu Aktivierungsverboten.

- Handelsrechtliche Passivierungsgebote führen auch steuerlich zu Passivierungspflichten, handelsrechtliche Passivierungsverbote und Passivierungswahlrechte führen $\mathrm{zu}$ Passivierungsverboten in der Steuerbilanz.

Vielmehr sind insb. die folgenden Durchbrechungen des Maßgeblichkeitsgrundsatzes zu beachten: ${ }^{13}$

- Steuerliche Ansatzgebote/-vorbehalte/-verbote

z. B. selbsterstellte immaterielle Wirtschaftsgüter gem. § 5 Abs. 2 EStG,

- Steuerliche Bewertungsvorbehalte

z. B. Rückstellungsbewertung nach $\S 6$ Abs. 1 Nr. 3a lit. f EStG,

- Steuerliche Wahlrechtsvorbehalte

z. B. Richtlinienwahlrechte.

Neu geregelt ist insbesondere das Zusammenspiel von steuerlichen und handelsrechtlichen Bewertungswahlrechten. Auf die Grundwertungen des BMF-Schreiben vom 12.3.2010 zu dieser Frage wird nachfolgend eingegangen.

10 Vgl. Dörfler/Adrian, Ubg 2010, 385 (387).

11 Vgl. Hey, in Steuerrecht, hrsg. v. Tipke/Lang, München 2010, § 17 Rz. 43.

12 Die vom Großen Senat des BFH mit Beschluss v. 3.2.1969 - GrS 2/68 (BStBl. 1969 II, 291) aufgestellten Grundsätze zu den steuerrechtlichen Ansatzregelungen gelten weiter (so auch das BMF-Schreiben vom 12.3.2010, Tz. 3 f.). So ist zu beachten, dass die Grundsätze des GrS des BFH v. 3.2.1969 an Relevanz verlieren. Dazu trägt auch bei, dass die Zahl der Wahlrechte nach BilMoG abgenommen hat, vgl. Richter, GmbHR 2010, 505 (506).

13 Vgl. auch Herzig, DStR 2010, 1900 (1904). 
b) Grundwertungen des BMF-Schreibens vom 12.3.2010 zum Maßgeblichkeitsgrundsatz

Nach dem BMF-Schreiben vom 12.3.2010 ${ }^{14}$ ist von folgenden Grundwertungen auszugehen:

- Rein steuerliche Wahlrechte können unabhängig vom handelsrechtlichen Wertansatz ausgeübt werden. So weist das BMF in Tz. 13 ausdrücklich darauf hin, dass die Ausübung des steuerlichen Wahlrechts insoweit nicht nach $\S 5$ Abs. 1 Satz 1, 1. Halbsatz EStG durch die Maßgeblichkeit der handelsrechtlichen Grundsätze ordnungsmäßiger Buchführung (GoB) beschränkt wird. Dabei handelt es sich um eine Kernaussage des BMF-Schreibens.

- Bestehen gleichzeitig handelsrechtliche und steuerliche Wahlrechte, können diese Wahlrechte in Handelsbilanz und Steuerbilanz unterschiedlich ausgeübt werden.

- Bestehen nur handelsrechtliche Bewertungswahlrechte, ohne dass eigenständige steuerliche Regelungen existieren, wirken die handelsrechtlichen Bewertungswahlrechte über die fortbestehende Maßgeblichkeit auch auf die Steuerbilanz. ${ }^{15}$

Das BMF hat sich ausdrücklich für eine weitgehende Abkopplung der steuerlichen Wertansätze von den handelsrechtlichen Ansätzen entschieden. ${ }^{16}$ Steuerliche Wahlrechte können auch dann ausgeübt werden, wenn diese nicht den GoB entsprechen. ${ }^{17}$ Es kommt zu einer Entflechtung von Handels- und Steuerbilanz. Der Spielraum der steuerlichen Bilanzpolitik wird entsprechend erweitert. ${ }^{18}$

Voraussetzung für die Ausübung der steuerlichen Wahlrechte ist nach $\S 5$ Abs. 1 Satz 2 EStG die Aufnahme derjenigen Wirtschaftsgüter, die nicht mit dem handelsrechtlich maßgeblichen Wert in der Steuerbilanz ausgewiesen werden, in ein besonderes und laufend zu führendes Verzeichnis. In diesem Verzeichnis muss der Tag der Anschaffung oder Herstel-

14 BStBl. I 2010, 239.

15 Nach Auffassung des BMF in Tz. 5 soll dabei der konkrete Handelsbilanzansatz insoweit maßgebend sein. Das Gesetz hingegen verlangt von seinem Wortlaut her indes nur, dass das Wirtschaftsgut mit einem den handelsrechtlichen Grundsätzen ordnungsmäßiger Buchführung entsprechenden Wert auszuwiesen ist.

16 Vgl. auch Weber-Grellet, DB 2009, 2402; Herzig/Briesemeister, WPg 2010, $63 \mathrm{ff} . ;$ Herzig, DStR 2010, $1900 \mathrm{f} . ;$ Hey in Steuerrecht, hrsg. v. Tipke/Lang, 20. Aufl. 2010, § 17 Tz. 42; differenzierend Anzinger/Schleiter, DStR 2010, 396f.; Fischer/Kalina-Kerschbaum, DStR 2010, 399 f.

17 So auch Günkel in Fischer/Günkel/Heubeck/Pannen, Die Bilanzrechtsreform 2010/11, 4. Aufl., Bonn, 120.

18 Vgl. Petersen/Zwirner/Künkele, StuB 2009, 669 und 794; Grützner, StuB 2009, 481; Ott, StuB 2009, 469. 
lung, die Anschaffungs- oder Herstellungskosten, die Vorschrift des ausgeübten steuerlichen Wahlrechts und die vorgenommene Abschreibung enthalten sein. Eine besondere Form dieses Verzeichnisses ist dabei nicht vorgeschrieben. Soweit die Angaben bereits in dem Anlagenverzeichnis enthalten sind oder das Anlagenverzeichnis um die genannten Angaben ergänzt wird, ist dies ausreichend. ${ }^{19}$ Wird das Verzeichnis nicht oder nicht vollständig geführt, ist der Gewinn hinsichtlich des betreffenden Wirtschaftsguts so zu ermitteln, als wäre das Wahlrecht nicht ausgeübt worden. ${ }^{20}$ Nicht abschließend erklärt sind die praktischen Fragen der zeitlichen Vorgaben zur Erstellung des Verzeichnisses (ggfs. auch nachträgliche Erstellung). Darüber hinaus wird diskutiert, inwieweit einem eventuellen „Verzeichnisabbruch" ein gestalterisches Potenzial zukommt. ${ }^{21}$

\section{c) Steuerliche Wahlrechte als Parameter der Steuerbilanzpolitik}

Im Zentrum der Steuerbilanzpolitik steht die durch die Ausnutzung gesetzlicher Spielräume bewirkte Beeinflussung des zu ermittelnden Gewinns, um die Steuerbelastung des Unternehmens zu verringern. Die Steuerbilanzpolitik zielt dabei primär auf den Gewinn ab, der für die Ertragsbesteuerung zugrunde gelegt wird. Die wichtigsten Instrumente der Steuerbilanzpolitik sind Wahlrechte, Ermessensspielräume sowie sachverhaltsgestaltende Maßnahmen. ${ }^{22}$ Die steuerlichen Wahlrechte sind Gegenstand der folgenden Ausführungen.

Das Zurückdrängen der materiellen Maßgeblichkeit eröffnet Spielräume für eine eigenständige Steuerbilanzpolitik. In diesem Zusammenhang lassen sich die steuerlichen Wahlrechte wie folgt kategorisieren, wobei sich die Verweise auf das BMF-Schreiben vom 12.3.2010 beziehen:

- Subventionelle Wahlrechte

- § 6b EStG (Tz. 14) und R 6.6 EStR (siehe unten Richtlinienwahlrechte)

- Sonderabschreibung gem. §7g EStG (im BMF-Schreiben nicht angesprochen $)^{23}$

- Erhöhte Absetzungen (im BMF-Schreiben nicht angesprochen)

19 Vgl. BMF-Schr. v. 12.3.2010, Tz. 20; vgl. Ortmann-Babel/Bolik, BB 2010, 2099 f. mit einer Checkliste zur Abgrenzung der verzeichnungspflichtigen Bilanzpositionen.

20 Vgl. BMF, Schr. v. 12.3.2010, Tz. 21.

21 Vgl. Herzig/Briesemeister, Bedeutung des BilMoG für die steuerliche Ergebnispolitik, in Bilanzpolitik und Bilanzanalyse nach neuem Handelsrecht, hrsg. v. Fink/Schultze/Winkeljohann, Stuttgart 2010, 285 (289).

22 Vgl. Dörfler/Adrian, Ubg 2010, 385 f. m. w. N.

23 Vgl. Hennrichs, StBJb 2009/2010, Köln 2010, 261 f.; Brise/Suermann, DB 2010, 121. 
- Abschreibungswahlrechte

- Methodenwahlrechte bei planmäßiger Abschreibung (Tz. 18)

- Sofortabzug GWG/Pool-Abschreibung (nicht angesprochen) ${ }^{24}$

- Teilwertabschreibung (Tz. 15)

- Vereinfachungswahlrechte

- Lifo-Methode (Tz. 17)

- Richtlinienwahlrechte

- Investitionszuschüsse als Betriebseinnahme oder Minderung der AK/HK (R 6.5 Abs. 2 EStR); eigenständiges steuerliches Wahlrecht Tz. 12, 23.

- Wahlrecht zur Bildung und Übertragung einer Rücklage für Ersatzbeschaffung (R 6.6 EStR), Tz. 12.

- Fremdkapitalzinsen (R 6.3 Abs.4 EStR): Wahlrecht nach § 255 Abs. 3 HGB, Tz. 6. Steuerlich wird der handelsbilanziellen Wahlrechtsausübung gefolgt.

- Wahlrecht zur Gruppenbewertung/Festbewertung: Wahlrecht nach $\S 240$ Abs. 3 und 4 HGB; Tz. 7. Steuerlich wird der handelsbilanziellen Wahlrechtsausübung gefolgt.

Bevor auf Praxisfragen eingegangen wird, lässt sich zusammenfassend festhalten, dass mit dem umfassenden steuerlichen Wahlrechtsvorbehalt dem Steuerpflichtigen ein eigenständiges, von handelsrechtlichen Zielsetzungen abgekoppeltes und damit ein in der Qualität neues Instrument der Steuerbilanzpolitik eingeräumt wurde.

\section{Praxisfragen bei der Ausübung steuerbilanzieller Wahlrechte}

Nachfolgend sollen die neuen Möglichkeiten sowie die zu beachtenden Restriktionen der Steuerbilanzpolitik auf Basis von Fallstudien verdeutlicht werden. Dabei wird zunächst mit der zukünftigen Behandlung von Teilwertabschreibungen sowie der Neudefinition der Herstellungskosten durch das BMF auf zwei gegenwärtig ausgesprochen kontrovers diskutierte Aspekte eingegangen.

\section{a) Teilwertabschreibungen}

Bei der Teilwertabschreibung nach $\S 6$ Abs. 1 Nr. 1 Satz 2 EStG und $\S 6$ Abs. 1 Nr. 2 Satz 2 EStG besteht nunmehr ein rein steuerrechtliches Wahlrecht, das autonom von den handelsrechtlichen Bestimmungen in

24 Vgl. BMF, Schr. v. 30.9.2010 - IV C 6 - S 2180/09/10001, BStB1. I 2010, 755; siehe auch Kußmaul/Weiler, GmbHR 2011, 169. 
$\S 253$ Abs. 3 Satz 3 HGB und § 253 Abs. 4 HGB ausgeübt werden kann. Praktische Relevanz für dieses neu eingeführte faktische Wahlrecht kann sich insbesondere vor dem Hintergrund der Mindestbesteuerung, bei einem drohenden Anteilseignerwechsel in Verlustfällen (§8c KStG) sowie bei späteren Wertaufholungen ergeben.

Dem ersten Beispielfall liegt ein Sachverhalt zugrunde, der seinen Ursprung noch vor dem Inkrafttreten des BilMoG haben soll.

Beispiel 1: Teilwertabschreibung auf Anteile an Kapitalgesellschaften

Die A-GmbH nimmt in 2004 in der Handelsbilanz eine außerplanmäßige Abschreibung (voraussichtlich dauernde Wertminderung i.S.d. §253 Abs. 2 Satz 3 HGB) auf den Beteiligungsbuchwert an der B-GmbH von 6 Mio. Euro auf 4 Mio. Euro vor. In der Steuerbilanz wird keine Teilwert-AfA vorgenommen. Bis zum 31.12.2010 hat sich aufgrund zwischenzeitlich eingetretener Gewinne das Eigenkapital von 4 Mio. Euro auf 5 Mio. Euro erhöht. Handelsrechtlich soll eine Wertaufholung i. H. v. 1 Mio. Euro auf den HB-Buchwert vorgenommen werden.

Abwandlung: Die ursprüngliche Abschreibung in der HB erfolgt auf den 31.12.2009.

Lösungshinweise:

Wollte der Bilanzierende in Wirtschaftsjahren vor dem Inkrafttreten des BilMoG eine handelsrechtliche außerplanmäßige Abschreibung in der Steuerbilanz nicht vornehmen, hatte er nachzuweisen, dass in der Steuerbilanz keine voraussichtlich dauernde Wertminderung vorlag. ${ }^{25}$ Der BFH hat in seiner Infineon-Entscheidung ausgeführt, dass es sich bei $\S 6$ Abs. 1 Nr. 2 Satz 2 EStG um eine steuerrechtliche Regelung handelt, ${ }^{26}$ die losgelöst vom Handelsrecht auszulegen sei. ${ }^{27}$

Gegen eine Übernahme der Abschreibung auf Beteiligungen ${ }^{28}$ könnte sprechen, dass steuerrechtlich höhere Anforderungen an die Dauerhaftigkeit gestellt werden als in der Handelsbilanz. D. h. der steuerliche Teilwert kann höher sein als der handelsrechtliche Vergleichswert, „weil im Steuerrecht der Objektivierungsgedanke stärker betont wird" ${ }^{29}$

Auch wenn der Stpfl. für den höheren Steuerbilanzansatz bei der A-GmbH im Jahre 2004 gute Argumente anführen kann, ist davon auszugehen, dass ein von der Handelsbilanz abweichender Steuerbilanz-

25 Vgl. hierzu BMF, Schr., BStBl. I 2000, 372.

26 Vgl. BFH, Urt. v. 26.9.2007 - I R 58/06, BStBl. II 2009, 294. Die Auslegung müsse insb. berücksichtigen, den Zuwachs oder Verlust wirtschaftlicher Leistungsfähigkeit periodengerecht $\mathrm{zu}$ erfassen.

27 Allerdings werden die für die bisher vom BFH entschiedenen Fallgruppen entwickelten Grundsätze im Schrifttum als „widersprüchlich“ angesehen; ein inneres System der Rechtsprechung sei nicht erkennbar (so Kulosa in Schmidt, 29. Aufl., München 2010, § 6 EStG Rz. 364).

28 Zur dauerhaften Wertminderung bei Beteiligungen ausführlich Küting, DB 2005, 1121.

29 Scheffler, StuB 2010, 295 (300). 
ansatz für eine Beteiligung in der Praxis Gegenstand von Diskussionen mit den Finanzbehörden sein wird.

Nach Inkrafttreten des BilMoG besteht hinsichtlich der steuerrechtlichen Teilwertabschreibung nunmehr ein faktisches Wahlrecht. ${ }^{30}$ Dem Stpfl. wird es damit ermöglicht, den Buchwert „oben zu halten“. D. h. in dem Abwandlungsfall, in dem die Abschreibung zum 31.12.2009 in der Handelsbilanz erfasst wird, kann der Bilanzierende bei voraussichtlich dauernder Wertminderung in der Steuerbilanz Abschreibungen unterlassen, obwohl in der Handelsbilanz zwingend abzuschreiben ist. ${ }^{31}$

Steuerlich kann der Verzicht auf eine solche Teilwertabschreibung und eine entsprechende Erhöhung des steuerlichen Ergebnisses sinnvoll sein, ${ }^{32}$ um die Auswirkungen der Mindestbesteuerung auf die Steuerbelastung zu entschärfen. Die unabhängige Vornahme der außerplanmäßigen Abschreibung in Steuerbilanz und Handelsbilanz ist auch dann von Bedeutung, wenn es sich um Kapitalgesellschaftsanteile handelt, die von einer GmbH oder AG gehalten werden. Während die Abschreibung steuerlich grds. nicht abzugsfähig ist, unterliegt die Zuschreibung i. H. v. 5 \% der Besteuerung gem. § 8 b Abs. 5 KStG.

Das nachfolgende Beispiel geht auf die steuerbilanziellen Wahlrechte bei Wertschwankungen ein:

Beispiel 2: Wertschwankungen

Folgende Buchwerte sollen für ein Wirtschaftsgut gegeben sein:

31.12.2009: $\mathrm{HB}=\mathrm{StB}=100$

31.12.2010: $\mathrm{HB}=50 ; \mathrm{StB}=100$

31.12.2011: $\mathrm{HB}=\mathrm{StB}=50$

31.12.2012: $\mathrm{HB}=50 ; \mathrm{StB}=100$

Lösungshinweise:

Steuerliche Wertansätze auf den 31.12.2010

Es steht dem Stpfl. nach der Gesetzessystematik frei, im Jahre 2010 das steuerliche Wahlrecht dahingegen auszuüben, die Teilwertabschreibung trotz dauernder Wertminderung zunächst zu unterlassen.

Steuerliche Wertansätze auf den 31.12.2011

Im Folgejahr bleibt es dem Stpfl. "de lege lata" unbenommen, die Teilwertabschreibung nachzuholen. Dies setzt voraus, dass die Teilwertminderung voraussichtlich dauernd anhält und dies auf den 31.12.2011 nachgewiesen wird. Dies dürfte m. E. auch gelten, wenn die Abschreibung in

30 Vgl. ausführlich hierzu Bruckmeier/Zwirner/Busch, DStR 2010, $237 \mathrm{f}$.

31 Vgl. BMF, Schr. v. 12.3.2010 - IV C 6 - S 2133/09/10001, Tz. 15.

32 Hinweis auf die Fälle des Halb- oder Teileinkünfteverfahrens. 
der Steuerbilanz erst in 2012 oder 2013 nachgeholt wird. Dem BMFSchreiben sind jedenfalls keine entsprechenden Restriktionen zu entnehmen.

Es ist davon auszugehen, dass die Finanzverwaltung die Wahlrechtsausübung bei Teilwertabschreibungen kritisch hinterfragt. ${ }^{33}$

Steuerliche Wertansätze auf den 31.12.2012

Fraglich könnte sein, ob im Rahmen der Bilanzpolitik in 2012 eine Zuschreibung allein in der Steuerbilanz in Betracht kommt. Die Entscheidung, einen - real unverändert gesunkenen - Teilwert nicht nachzuweisen, wirkt m. E. als faktisches Zuschreibungswahlrecht. Wird auf den entsprechenden Nachweis verzichtet, obgleich der niedrigere Wert fortbesteht, kommt es zur Wertaufholung in der Steuerbilanz. ${ }^{34}$

Es stellt sich die Frage, ob dieser Lösung die Tz. 15 des BMF-Schreibens vom 12.3.2010 entgegen steht. Dort heißt es:

„Hat der Steuerpflichtige in einem Wirtschaftsjahr eine Teilwertabschreibung vorgenommen und verzichtet er in einem darauf folgenden Jahr auf den Nachweis der dauernden Wertminderung (z. B. im Zusammenhang mit Verlustabzügen) ist zu prüfen, ob eine willkürliche Gestaltung vorliegt."

Die Finanzverwaltung offenbart damit Bedenken gegen ein Alternieren von Teilwertabschreibung und Wertaufholung. Im Klartext heißt dies: Die Betriebsprüfung soll in solchen Fallkonstellationen prüfen, ob eine willkürliche Gestaltung vorliegt oder eine Art "Gesamtplan". Dabei bleibt es aus Sicht der Praxis unklar, wie der Begriff ",willkürlich" zu verstehen ist. Von einer willkürlichen Gestaltung kann nach Ansicht von Verwaltungsvertretern dann auszugehen sein, wenn „eine bewusste Verschiebung eines steuerrechtlich relevanten Gewinns vorgenommen wurde, um die Mindestbesteuerung zu umgehen oder den Teilwert nur punktuell zum Ausgleich eines hohen Gewinns zu nutzen" ${ }^{35}$

Damit könnte das faktische Wahlrecht leer laufen; zumindest aber droht eine Beweislastumkehr zu Lasten des Stpfl. Die restriktive Auffassung der Finanzverwaltung ist denn auch im Schrifttum nicht ohne Kritik geblieben. ${ }^{36}$ So weisen Geberth/Blasius darauf hin, dass steuerliche Wahlrechte von Jahr zu Jahr unterschiedlich ausgeübt werden können. Dafür spricht auch, dass dem Stetigkeitsgebot in der Steuerbilanz ein anderer Stellenwert zukommt als im Handelsrecht. Als Fazit bleibt festzuhalten, dass das Wahlrecht der Teilwertabschreibung nicht mehr den

33 Vgl. Meurer, BB 2010, 822.

34 Vgl. Herzig, DStR 2010, 1900 (1903).

35 So Klein, NWB, 2045 (2046).

36 Vgl. Kaminski, DStR 2010, 771; vgl. auch Herzig/Briesemeister, DB 2010, 917 (919). 
handelsrechtlichen Grundsätzen ordnungsmäßiger Bilanzierung, sondern "nur noch der Kontrolle anhand $\S 42 \mathrm{AO}$ als ultima ratio" unterliegt. ${ }^{37}$

Um ein aus gesetzgeberischer Sicht möglicherweise unerwünschtes und rein faktisches Wahlrecht auf Teilwertabschreibungen auszuschließen, wurden Gesetzesanpassungen im Rahmen des JStG 2010 diskutiert. ${ }^{38}$ Die vom Bundesrat vorgeschlagene Gesetzesänderung soll Fälle erfassen, in denen der Stpfl. in einem früheren Wirtschaftsjahr eine Teilwertabschreibung vorgenommen hat und im laufenden Wirtschaftsjahr den Nachweis der dauernden Wertminderung nicht erbringt und deshalb gesetzlich zur Zuschreibung nach $\S 6$ Abs. 1 Nr. 1 Satz 4 EStG gezwungen ist. Nach den Empfehlungen des Bundesrates zum JStG 2010 sollte der Stpfl. künftig an ein einmal ausgeübtes Wahlrecht auch in folgenden Wirtschaftsjahren gebunden sein, wenn die Gründe für die Wertminderung nicht entfallen sind. Die Bundesregierung hat in ihrer Gegenäußerung zur Stellungnahme des Bundesrates vom 9.7.2010 diesen Vorschlag als nicht erforderlich angesehen. Als Begründung wird angeführt, dass derartige Missbrauchsfälle bereits ausreichend durch die hierzu bestehende Regelung im BMF-Schreiben vom 12.3.2010 verhindert würden.

\section{b) Zum Umfang der Herstellungskosten in der Steuerbilanz}

Durch das BilMoG wurde die handelsrechtliche Herstellungskostenuntergrenze durch die Neufassung von $\S 255$ Abs. 2 Satz 2 HGB neu geregelt. ${ }^{39}$ Material- und Fertigungsgemeinkosten und die durch die Fertigung veranlassten Abschreibungen auf das Anlagevermögen sind nun genauso wie bisher bereits in der Handelsbilanz auch in der Steuerbilanz verpflichtende Bestandteile der Herstellungskosten. Insoweit kommt es zu einem Gleichlauf von Handels- und Steuerbilanz. ${ }^{40}$

Für angemessene Kosten der allgemeinen Verwaltung, Aufwendungen für soziale Einrichtungen und die freiwilligen sozialen Leistungen sowie für die betriebliche Altersversorgung besteht gem. § 255 Abs. 2 Satz 3 HGB ein handelsrechtliches Aktivierungswahlrecht. ${ }^{41}$ Entsprechendes regelt R 6.3 Abs. 4 EStR 2008 auch für die steuerliche Gewinnermittlung.

37 Geberth/Blasius, FR 2010, 408 (413). Dafür spricht auch, dass Vorschriften wie der $\S 10 \mathrm{~d}$ EStG oder der $\S 8 \mathrm{c} \mathrm{KStG}$ keine Missbrauchsverhinderungsvorschriften darstellen.

38 Vgl. BR-Drs. 318/1/10, 13 ff.

39 Vgl. Künkele/Koss in BilMoG, hrsg. v. Petersen/Zwirner, München 2009, 436; Förster/Schmidtmann, BB 2009, 1346.

40 Vgl. auch Ortmann-Babel/Bolik, BB 2010, 2099 (2102).

41 Dazu gehören angemessene Kosten der allgemeinen Verwaltung sowie angemessene Aufwendungen für soziale Einrichtungen des Betriebs, für freiwillige soziale Leistungen und für die betriebliche Altersversorgung, soweit diese Kosten auf den Zeitraum der Herstellung entfallen. 
Von dieser Behandlung wird mit dem Beispiel 3 in Tz. 8 des BMF-Schreibens vom 12.3.2010 abgewichen; vielmehr soll nunmehr ein steuerliches Einbeziehungsgebot für Verwaltungs- und Sozialgemeinkosten in die Herstellungskosten gelten. Dieser Standpunkt "verwundert und irritiert zugleich" ${ }^{42}$ Würde sich die Finanzverwaltung mit ihrem Vorgehen durchsetzen, käme dies einer gewichtigen Verschärfung gleich. Als Begründung wird im BMF-Schreiben das BFH-Urteil vom 21.10.199343 herangezogen. Dieses Urteil bezieht sich allerdings auf die Aktivierung von Material-und Fertigungsgemeinkosten, für die schon immer eine steuerliche Einbeziehungspflicht bestanden hat und wird als nicht einschlägig angesehen. ${ }^{44}$

Das BMF-Schreiben ist aus Sicht der Wirtschaft verständlicherweise auf nachhaltige Kritik gestoßen, ${ }^{45}$ da der Tz. 8 eine steuerverschärfende Wirkung quasi "durch die Hintertür" ${ }^{\prime 46}$ zukommt. Das BMF hat sich zwischenzeitlich mit Schreiben vom 22.6.2010 zum Anwendungszeitpunkt geäußert.

Für Gemeinkostenpositionen i. S.d. § 255 Abs. 2 Satz 3 HGB wird im Schrifttum abweichend von der Finanzverwaltungsauffassung weiterhin von einem steuerlichen Wahlrecht ausgegangen. ${ }^{47}$ Dieses kann steuerlich eigenständig ausgeübt werden. ${ }^{48}$ Der Wertung des BMF-Schreibens, die Ausübung eines Bewertungswahlrechts in der Handelsbilanz wirke wegen des maßgeblichen Handelsbilanzansatzes auch auf die Steuerbilanz ${ }^{49}$ ist $\mathrm{m}$. E. nicht $z u$ folgen.

Als Fazit ist festzuhalten, dass die Tz. 8 des BMF-Schreibens vom 12.3.2010 im Widerspruch zu R 6.3 Abs. 4 EStR steht. ${ }^{50}$ Zur Aufhebung dieses Widerspruchs hat das BMF am 22.6.2010 eine Änderung seines Schreibens zur Maßgeblichkeit veröffentlicht, wonach die bisherige Bilanzierungspraxis (d.h. eine optionale Einbeziehung der Verwaltungsund Sozialgemeinkosten) bis zur Modifikation der Einkommensteuer-

42 Richter, GmbHR 2010, 505 (507).

43 Vgl. BFH, Urt. v. 21.10.1993 - IV R 87/92, BStBl. II, 176.

44 Vgl. Freidank/Velte, StuW 2010, 189; Philipps, BBK 2010, 472; Scheffler, StuB 2010, $296 \mathrm{f}$.

45 Vgl. Herzig/Briesemeister, DB 2010, 917 (921); Velte/Sepetauz, StuB 2010, 523 (527).

46 So Günkel/Teschke, Ubg 2010, 401 (402).

47 Vgl. Günkel/Teschke, Ubg 2010, 401 (405).

48 Vgl. Herzig/Briesemeister, DB 2009, 976; Richter, GmbHR 2010, 507; Buchholz, DB 2010, 1430; Dörfler/Adrian, Ubg 2009, 393; Scheffler, StuB 2009, 841; Pfirmann/Schäfer, in: Küting/Pfitzer/Weber, Das neue deutsche Bilanzrecht, 2. Aufl., Stuttgart 2009, 127; Willeke, StuB, 2010, 90; a. A. Rammert/Thies, WPg 2009, $43 \mathrm{f}$.

49 Vgl. auch Weber-Grellet, DB 2009, 2403.

50 Vgl. Glanegger in Schmidt (Hrsg.), EStG, 28. Aufl., München 2009, § 6 EStG Rz. 171. 
richtlinien weiterhin Bestand hat. Für Wirtschaftsjahre, die vor der Veröffentlichung einer geänderten Richtlinienfassung enden, kann R 6.3 EStR 2008 in Abweichung zu Tz. 8 des BMF-Schreibens vom 12.3.2010 weiterhin Anwendung finden. Der ursprüngliche Erlass ist somit nachrangig zu den Richtlinien. Den betroffenen Unternehmen bleiben somit (zunächst) Anpassungen ihrer Kostenrechnung und die kostenintensive Anpassung von Prozessen, die ausschließlich für steuerliche Zwecke erforderlich gewesen wären, erspart. ${ }^{51}$ Die nachträgliche Änderung des BMF-Schreibens mag denn auch als „Fehlereingeständnis" gewertet werden, ${ }^{52}$ es ist aber festzuhalten, dass die strittige Tz. 8 nicht aufgehoben wurde. Sollte eine Verschärfung auch in den EStR erfolgen, ist mit einer Befassung der Finanzgerichte zu rechnen. ${ }^{53}$

Die nachfolgende Übersicht stellt die neuen Unter- und Obergrenzen der Herstellungskosten in der Handels- und Steuerbilanz dar:

\begin{tabular}{|c|c|c|c|}
\hline \multicolumn{4}{|c|}{$\begin{array}{l}\text { Unter- und Obergrenzen der Herstellungskosten in der Handels- } \\
\text { und Steuerbilanz }\end{array}$} \\
\hline \multicolumn{2}{|c|}{ Kostenkategorie } & Handelsbilanz & Steuerbilanz \\
\hline & Materialeinzelkosten & \multirow[t]{6}{*}{ Gebot } & \multirow[t]{6}{*}{ Gebot } \\
\hline+ & Fertigungseinzelkosten & & \\
\hline+ & Sondereinzelkosten der Fertigung & & \\
\hline+ & Materialgemeinkosten & & \\
\hline+ & Fertigungsgemeinkosten & & \\
\hline+ & Werteverzehr des Anlagevermögens & & \\
\hline \multicolumn{4}{|c|}{ = Untergrenze der Herstellungskosten } \\
\hline+ & allgemeine Verwaltungs(gemein)kosten & \multirow[t]{4}{*}{ Wahlrecht } & \multirow[t]{4}{*}{ Wahlrecht } \\
\hline+ & Aufwendungen für soziale Einrichtungen & & \\
\hline+ & $\begin{array}{l}\text { Aufwendungen für freiwillige soziale } \\
\text { Leistungen }\end{array}$ & & \\
\hline+ & $\begin{array}{l}\text { Aufwendungen für die betriebliche Alters- } \\
\text { versorgung }\end{array}$ & & \\
\hline+ & $\begin{array}{l}\text { Fremdkapitalzinsen (nur unter } \\
\text { bestimmten Voraussetzungen) }\end{array}$ & Wahlrecht & Wahlrecht \\
\hline \multicolumn{4}{|c|}{$=$ Obergrenze der Herstellungskosten } \\
\hline & Sondereinzelkosten des Vertriebs & \multirow[t]{3}{*}{ Verbot } & \multirow[t]{3}{*}{ Verbot } \\
\hline & Vertriebsgemeinkosten & & \\
\hline & Forschungskosten & & \\
\hline
\end{tabular}

51 Vgl. Buchholz, DB 2010, 1430.

52 So Velte/Sepetauz, StuB 2010, 523; ähnlich Kaminski, DStR 2010, 1395 (1395).

53 So auch Kaminski, DStR 2010, 1395 (1397). 
Das folgende Beispiel ${ }^{54}$ soll die Problematik verdeutlichen:

Beispiel 3: Steuerliche Herstellungskostenermittlung

Die A-GmbH baut Maschinen für die Zulieferindustrie. Es ist ihr gelungen, ein neuartiges Modell zu entwickeln. Für die Herstellung dieses neuartigen Produkts fallen die folgenden Kosten bis zum Bilanzstichtag 31.12.2009 an:

Material- und Fertigungseinzelkosten 3.800 Euro

Material- und Fertigungsgemeinkosten 1.000 Euro

Durch Fertigung veranlasster Werteverzehr des AV 200 Euro

Verwaltungs- und Sozialgemeinkosten 500 Euro

Sondereinzelkosten des Vertriebs 500 Euro

6.000 Euro

Der Geschäftsführer fragt seinen Steuerberater nach den handels- und steuerlichen Möglichkeiten der Vorratsbewertung auf den 31.12.2009.

Lösungshinweise:

Durch die Neuregelungen des BilMoG erhöht sich die handelsrechtliche Wertuntergrenze der Herstellungskosten im Vergleich zur bisherigen Rechtslage. Damit entsprechen sich (bei Anwendung der EStR) die Wertansätze in Handels- und Steuerrecht hinsichtlich der möglichen Wertunter- und der Wertobergrenze. Vertriebskosten dürfen nach wie vor weder in der Handels- noch in der Steuerbilanz als Herstellungskostenbestandteil aktiviert werden.

Insgesamt fallen für die Produktion der Maschine Herstellungskosten i. H. v. 6.000 Euro an. Aus den vorstehenden Daten ergeben sich bei der Bemessung der Herstellungskosten die folgenden Wertunter- sowie Wertobergrenzen für die handelsrechtlichen und steuerrechtlichen Wertansätze bei der A-GmbH:

\begin{tabular}{|l|c|c|c|c|}
\hline 31.12.2009 & $\begin{array}{c}\text { HGB vor } \\
\text { BilMoG }\end{array}$ & $\begin{array}{c}\text { HGB i. d. F. } \\
\text { BilMoG }\end{array}$ & $\begin{array}{c}\text { R 6.3 } \\
\text { Abs. 4 EStR } \\
2008\end{array}$ & $\begin{array}{c}\text { BMF-Schreiben } \\
\text { v. 12.3.2010 }\end{array}$ \\
\hline Wertuntergrenze & 3.800 Euro & 5.000 Euro & 5.000 Euro & 5.500 Euro \\
\hline Wertobergrenze & 5.500 Euro & 5.500 Euro & 5.500 Euro & 5.500 Euro \\
\hline
\end{tabular}

Die A-GmbH kann in ihrem handelsrechtlichen Jahresabschluss einen Wertansatz für die Vorratsgegenstände zwischen 5.000 Euro und 5.500 Euro ansetzen. Vollkommen unabhängig hiervon kann sie - nach der hier vertretenen Rechtsauffassung - steuerlich einen Wertansatz zwischen ebenfalls 5.000 Euro und 5.500 Euro wählen. Falls sich die A-GmbH entscheidet, unterschiedliche Wertansätze in Handels- und

54 In Anlehnung an Künkele/Zwirner, StuB 2010, 335 (339). 
Steuerbilanz anzusetzen, muss die Abgrenzung latenter Steuern beachtet werden. So minimiert die A-GmbH ihr steuerliches Ergebnis, wenn die Vorräte in der Steuerbilanz zur Wertuntergrenze von 5.000 Euro angesetzt werden. Unabhängig davon führt der Ansatz der Vorräte in der Handelsbilanz entsprechend zur Wertobergrenze i. H. v. 5.500 Euro zu einer Maximierung des handelsrechtlichen Jahresergebnisses und damit der Ausschüttungsbemessungsgrundlage.

Wie bereits ausgeführt hat die Finanzverwaltung in Ergänzung zum BMFSchreiben vom 12.3.2010 mit Schreiben vom 22.6.2010 bestimmt, dass es nicht zu beanstanden sei, wenn R 6.3 Abs. 4 EStR 2008 für Wirtschaftsjahre, die vor der Veröffentlichung einer geänderten Richtlinienfassung enden, noch Anwendung findet. Insoweit stellt in der obigen Tabelle die rechte Spalte ein steuerliches Wahlrecht für die Bilanzierung des Anlagevermögens dar. In der Praxis dürfte die Inanspruchnahme - nicht zuletzt aufgrund der Mehrarbeit bei der Ermittlung der Zahlenbasis - wohl nur in Einzelfällen anzutreffen sein.

\section{c) Eigene Aktien}

Unter dem BilMoG entfällt die Aktivierung eigener Anteile und es muss verpflichtend ein Ausweis auf der Passivseite erfolgen. Durch das BilMoG wurde mit $\S 272$ Abs. 1a HGB eine Vorschrift zur handelsbilanziellen Erfassung eigener Anteile geschaffen. ${ }^{55}$ Eigene Anteile sind nunmehr mit dem Eigenkapital zu verrechnen. Anschaffungsnebenkosten sind als Aufwand des Geschäftsjahres auszuweisen. Künftig entfällt damit die Aktivierung eigener Anteile und es muss verpflichtend ein Ausweis auf der Passivseite erfolgen. $§ 272$ Abs. 1b HGB regelt die Veräußerung eigener Anteile, dabei wird der wirtschaftliche Gehalt eines solchen Geschäfts berücksichtigt. Ein die ursprünglichen Anschaffungskosten übersteigender Veräußerungserlös ist mit dem Eigenkapital zu verrechnen. Bei der Veräußerung anfallende Nebenkosten sind schließlich gem. §272 Abs. 1a Satz 3 HGB Aufwand des Geschäftsjahrs.

Beispiel 4: Eigene Aktien

Die B-AG erwirbt eigene Anteile in 2010 zum Preis von 1 Mio. Euro mit der Absicht der Wiederveräußerung. In 2011 werden die Anteile zum Preis von 1,5 Mio. Euro veräußert. Es fallen dabei Nebenkosten i. H. v. 50 TEuro an.

Der Geschäftsführer fragt seinen Steuerberater nach der steuerlichen Behandlung des Veräußerungsgewinns in 2011.

55 Vgl. Hoffmann/Lüdenbach, NWB Kommentar Bilanzierung, Herne 2009, $\S 272$ HGB Rz. 26. 
Lösungshinweise:

In der Handelsbilanz liegt im Zusammenhang mit der Veräußerung eigener Anteile im Jahre 2011 nach der Neuregelegung durch das BilMoG kein erfolgswirksamer Veräußerungsvorgang vor. Es stellt sich die Frage, ob dies auch steuerlich gilt; dies hätte zur Folge, dass bei der Veräußerung in 2011, entgegen der bisherigen Behandlung, die 5\%-ige Besteuerung nach $\S 8$ b Abs. 2 i. V. m. Abs. 3 KStG entfällt. Für dieses Ergebnis spricht, dass die Handelsbilanz gemäß $§ 5$ Abs. 1 Satz 1 EStG auch nach dem BilMoG für die Steuerbilanz maßgeblich ist. Eine von der handelsrechtlichen Beurteilung abweichende steuerliche Spezialvorschrift $(z$. B. eine außerbilanzielle Hinzurechnung) liegt jedenfalls nicht vor. Die steuerbilanzielle Darstellung folgt damit der handelsrechtlichen Vorgehensweise mit der Folge, dass die $5 \%$-ige "Strafsteuer" nicht mehr zur Anwendung kommt. ${ }^{56}$ Die Veräußerungsnebenkosten von 50 TEuro sind nach dieser Wertung vollumfänglich steuerlich wirksam. ${ }^{57}$ Eine steuerliche Behandlung des handelsrechtlich neutralen Vorgangs als Erwerbsund Veräußerungsgeschäft würde zu einem unlösbaren Widerspruch zwischen Handels- und Steuerbilanz führen. ${ }^{58}$

Nachrichtlich sei erwähnt, dass das BMF mit Schreiben vom 10.8.201059 das bisherige BMF-Schreiben vom 2.12.1998 zur Bilanzierung eigener Anteile ${ }^{60}$ aufgehoben hat. Die bisherigen Grundsätze seien auf das damalige Vollanrechnungsverfahren zugeschnitten und aufgrund zwischenzeitlich erfolgter umfangreicher Gesetzesänderungen im Steuer- und Gesellschaftsrecht überholt. Dem Vernehmen nach arbeit die Verwaltung an einem neuen BMF-Schreiben. Es gilt an dieser Stelle, die weitere Rechtsentwicklung abzuwarten. Dies gilt auch für die Behandlung auf Anteilseignerebene. ${ }^{61}$

56 Vgl. Ortmann-Babel/Bolik/Gageur, DStR 2010, 934 (937); Herzig, DB 2008, 1339 (1342); Lechner/Haisch, Ubg 2010, 691 (693); a. A. Dötsch/Pung, in Dötsch/Jost/Pung/Witt, § 8 b KStG Rz. 72; Najdecki, NWB 2010, 349 (355).

57 Vgl. Herzig/Briesemeister, Bedeutung des BilMoG für die steuerliche Ergebnispolitik, in Bilanzpolitik und Bilanzanalyse nach neuem Handelsrecht, hrsg. v. Fink/Schultze/Winkeljohann, Stuttgart 2010, 285 (298); vgl. auch Breuninger/Müller, GmbHR 2011, S. 10 (15).

58 Vgl. Lechner/Haisch, Ubg 2010, 691 (693 f.); Köhler, DB 2011, 15 (21).

59 Vgl. BMF, Schr. v. 10.8.2010, BStBl. I 2010, 659.

60 Az.: IV C 6 - S 2741-12/98-, BStBl. I 1998, 1509.

61 Vgl. Lechner/Haisch, Ubg 2010, 691 (696). 
d) Rücklage nach § 6b EStG

Wie bereits ausgeführt, entfällt durch das BilMoG die umgekehrte Maßgeblichkeit; bei steuerlichen Wahlrechten muss zukünftig nicht mehr auf die entsprechende handelsrechtliche Abbildung geachtet werden. Der nachfolgende Fall soll dies verdeutlichen.

Beispiel 4: Übertragung von stillen Reserven nach § 6b EStG

Die A-GmbH veräußert in 2010 ein Grundstück zum Preis von 3 Mio. Euro, das in der Handels- und Steuerbilanz mit Anschaffungskosten von 1 Mio. Euro ausgewiesen wird. Die A-GmbH erwirbt in 2011 ein neues Grundstück zum Preis von 4 Mio. Euro.

Der Geschäftsführer fragt seinen Steuerberater nach den bilanzpolitischen Gestaltungsmöglichkeiten.

Lösungshinweise:

Die A-GmbH erzielt im Jahre 2010 einen Veräußerungsgewinn von 2 Mio. Euro. In der Handelsbilanz erhöht dieser Gewinn das Ausschüttungspotenzial. Eine ergebnisneutrale Vereinnahmung ist handelsbilanziell nach dem BilMoG nicht mehr möglich.

In der Steuerbilanz kann die A-GmbH im Veräußerungsjahr eine den steuerlichen Gewinn mindernde Rücklage nach $\S 6 \mathrm{~b}$ Abs. 3 EStG bilden, wenn die weiteren Voraussetzungen - wie die Beachtung von Mindestbesitzzeiten - erfüllt sind. Im Rahmen der Steuerbilanzpolitik kann der Vorgang damit weiterhin erfolgsneutral abgebildet werden. Dadurch wird erreicht, dass die Steuerzahlung in die Zukunft verschoben wird. ${ }^{62}$

Allerdings ist nach $\S 5$ Abs. 1 Satz 2 EStG zu beachten, dass Wirtschaftsgüter, die nicht mit dem handelsrechtlichen Wert in der steuerlichen Gewinnermittlung ausgewiesen werden, in besondere, laufend zu führende Verzeichnisse aufgenommen werden müssen. Ausweislich des BMF-Schreibens vom 12.3.2010 ist für die Bildung von steuerlichen Rücklagen eine Aufnahme in das besondere, laufend zu führende Verzeichnis nicht erforderlich, wenn die Rücklage in der Steuerbilanz abgebildet wird. Soweit die A-GmbH angabegemäß in 2011 die Rücklage auf die Anschaffungs- oder Herstellungskosten eines neuen Wirtschaftsguts überträgt, handelt es sich dabei nach Ansicht der Verwaltung um die Ausübung eines steuerlichen Wahlrechts i.S.d. §5 Abs. 1 Satz 1 Halbs. 2 EStG. Das neue Grundstück ist in das besondere, laufend zu führende Verzeichnis aufzunehmen. Soweit sich die Angaben aus der Buchführung i. S. d. § 6b Abs. 4 EStG ergeben, ist diese Dokumentation ausreichend. ${ }^{63}$

62 Vgl. auch Dörfler/Adrian, Ubg 2009, 385 (388).

63 Hinweis auf Tz. 21 des BMF-Schreibens. 
e) Pensionsrückstellungen gem. § 6a EStG

Unmittelbare Pensionsverpflichtungen aus Neuzusagen sind nach $\S 249$ Abs. 1 Satz 1 HGB i. V. m. Art. 28 Abs. 1 Satz 1 EGHGB verpflichtend als Rückstellungen für ungewisse Verbindlichkeiten in der Handelsbilanz zu passivieren. Damit bestand vor BilMoG in der Steuerbilanz die Verpflichtung, die in der Handelsbilanz passivierte Pensionsrückstellung in die Steuerbilanz zu übernehmen. ${ }^{64}$ Dies gilt allerdings nur, wenn die Voraussetzungen des § 6a EStG erfüllt werden.

Fraglich ist, ob $\S 5$ Abs. 1 Satz 1 Halbs. 2 EStG nunmehr ein eigenständiges steuerliches Wahlrecht für die Passivierung von Pensionsrückstellungen für Neuzusagen ermöglicht. ${ }^{65}$ Die Finanzverwaltung verneint dies im BMF-Schreiben vom 12.3.2010. Danach gelten handelsrechtliche Passivierungsgebote auch für die Steuerbilanz, wenn diesen keine steuerlichen Vorschriften entgegenstehen. ${ }^{66}$ Auch gewichtige Stimmen im Schrifttum ${ }^{67}$ vertreten die Auffassung, dass die Maßgeblichkeit der handelsrechtlichen GoB weiter zu beachten sei. Die Vertreter eines Wahlrechts ${ }^{68}$ dürften gegenwärtig nicht die h. M. repräsentieren. ${ }^{69}$ Gleichwohl gilt es, die weitere Diskussion zu dieser Frage abzuwarten. So sieht auch der Bundesrat offensichtlich eine Rechtsunsicherheit in dieser Frage und empfiehlt vor diesem Hintergrund im Rahmen des JStG 2010, die entsprechenden Passagen in den $\S \S 5$ und 6a EStG so zu ändern, dass für Pensionsrückstellungen sowie für Rückstellungen für Patent- und Urheberrechtsverletzungen und für Rückstellungen für Dienstjubiläen ein ausdrückliches Passivierungsgebot in der Steuerbilanz normiert wird (neue Formulierung: „sind zu bilden "). ${ }^{70}$ Die Bundesregierung hält in ihrer Stellungnahme die mit dem Vorschlag angestrebte Klarstellung eines solchen Passivierungsgebots für nicht erforderlich, da sich die Rechtsfolgen bereits aus der derzeitigen Gesetzessystematik ergeben.

64 Diese Auffassung, wonach das steuerliche Passivierungswahlrecht für Pensionsrückstellungen bislang von der Maßgeblichkeit der handelsrechtlichen GoB verdrängt wird, bestätigt auch der BFH (vgl. BFH, Urt. v. 13.2.2008 - I R 44/07, BStBl. II 2008, 673; v. 14.1.2009 - I R 5/08, BStBl. II 2009, 457 = FR 2009, 905 m. Anm. Buciek).

$65 \mathrm{Vgl}$. Herzig/Briesemeister, WPg 2010, $72 \mathrm{f}$.

66 Vgl. BMF, Schr. v. 12.3.2010 - IV C 6 - S 2133/09/10001, BStBl. I 2010, 239, Tz.9f.

67 Vgl. Hennrichs, Ubg 2009, 533 und $541 \mathrm{f} . ;$ Hey in Tipke/Lang, Steuerrecht, 20. Aufl., Köln 2010, § 17 Rz. 117; Anzinger/Schleiter, DStR 2010, 395 (398); ein Wahlrecht befürworten Herzig/Briesemeister, DB 2009, 976 (977).

68 Vgl. Herzig/Briesemeister, DB 2009, 978 (979).

69 Vgl. Geberth/Blasius, FR 2010, 408 (409); Döring/Heger, DStR 2009, 2064 (2068); Höfer/Rhiel/Veit, DB 2009, 1605 (1608).

70 Vgl. BR-Drucks. 318/10, 12. 


\section{Zur Relevanz von Ausschüttungssperren}

a) Handelsrechtliche Grundlagen

Mit dem Jahresabschluss 2010 wird für viele Unternehmen die Thematik von Ausschüttungssperren eine neue Bedeutung erlangen. ${ }^{71}$ Bislang war eine Ausschüttungssperre im Wesentlichen für aktivierte Aufwendungen für die Ingangsetzung und Erweiterung des Geschäftsbetriebs (§ 269 HGB a.F.) sowie einen ausgewiesenen Saldo aktiver latenter Steuern (§ 274 Abs. 2 HGB a. F.) vorgesehen. Da beide Positionen von der Bilanzierungspraxis eher vernachlässigt wurden, waren diese Fragestellungen im deutschen Handelsbilanzrecht bislang von untergeordneter Bedeutung. ${ }^{72}$

Die im Rahmen des BilMoG eingeführte Vorschrift des § 268 Abs. 8 HGB hat folgenden Wortlaut:

„Werden selbst geschaffene immaterielle Vermögensgegenstände des Anlagevermögens in der Bilanz ausgewiesen, so dürfen Gewinne nur ausgeschüttet werden, wenn die nach der Ausschüttung verbleibenden frei verfügbaren Rücklagen zuzüglich eines Gewinnvortrags und abzüglich eines Verlustvortrags mindestens den insgesamt angesetzten Beträgen abzüglich der hierfür gebildeten passiven latenten Steuern entsprechen. Werden aktive latente Steuern in der Bilanz ausgewiesen, ist Satz 1 auf den Betrag anzuwenden, um den die aktiven latenten Steuern die passiven latenten Steuern übersteigen. Bei Vermögensgegenständen im Sinn des § 246 Abs. 2 Satz 2 ist Satz 1 auf den Betrag abzüglich der hierfür gebildeten passiven latenten Steuern anzuwenden, der die Anschaffungskosten übersteigt."

So ist eine Ausschüttungssperre gem. § 268 Abs. 8 HGB vorgesehen im Zusammenhang mit:

- dem Wahlrecht zur Bilanzierung selbst erstellter immaterieller Vermögensgegenstände des Anlagevermögens (§§ 248 Abs. 2 und 255 Abs. 2a HGB);

- dem Wahlrecht zur Bilanzierung aktiver latenter Steuern (§ 274 Abs. 1 Satz 2 HGB) ${ }^{73}$

- der Pflicht zur Zeitwertbewertung von altersversorgungsbezogenem Vermögen (§ 253 Abs. 1 Satz 4 HGB).

Tritt in einem Unternehmen kein derartiger Sachverhalt auf bzw. werden die Wahlrechte nicht ausgeübt, kann auf eine Bilanzierung der hier diskutierten Ausschüttungssperren verzichtet werden. Ein entsprechendes (Sachverhalts-)Monitoring ist gleichwohl auch bei dieser Bilanzierungspolitik erforderlich.

71 Vgl. dazu im Einzelnen Zülch/Hoffmann, DB 2010, 909; zu Anwendungsbeispielen vgl. Lüdenbach, StuB 2010, 588; Küting/Lorson/Eichenlaub/Toebe, GmbHR 2011, 1.

72 Vgl. Lanfermann/Röhricht, DStR 2009, 1217.

73 Vgl. Kessler/Leinen/Paulus, KoR 2009, 716 (725f.). 
In Anbetracht der Bedeutung selbst erstellter immaterieller Vermögensgegenstände des Anlagevermögens in einigen Branchen sowie der durch das BilMoG tendenziell größer gewordenen Unterschiede zwischen Handels- und Steuerbilanz und der damit einhergehenden wachsenden Bedeutung latenter Steuern erscheint eine Auseinandersetzung mit der Thematik der Ermittlung der Ausschüttungssperre künftig indes für mehr Unternehmen als bislang geboten.

Gewinne dürfen nur insoweit ausgeschüttet werden, als nach der Ausschüttung frei verfügbare Rücklagen - zzgl. eines Gewinn- und abzgl. eines Verlustvortrags - in einer Höhe übrig bleiben, der mindestens dem jeweils insgesamt aktivierten Betrag abzgl. der hierfür gebildeten passiven latenten Steuern entspricht. Im Falle der Aktivierung von aktiven latenten Steuern ist die maximale Ausschüttungssperre auf den Betrag begrenzt, um den der Ausweis der aktiven latenten Steuern den Ausweis der passiven latenten Steuern übersteigt. ${ }^{74}$

Die Ausschüttungssperre dient in erster Linie dem Gläubigerschutz, da o.g. Aktiva eine gewisse Unsicherheit anhaftet, die eine Ausschüttung nicht rechtfertigt. ${ }^{75}$ Die Ausschüttungssperre soll bewirken, dass keine höheren Gewinnausschüttungen als diejenigen zulässig sind, die auch ohne die Aktivierung dieser Posten möglich gewesen wäre.

Die Beträge nach $\S 268$ Abs. 8 HGB sind gem. § 301 AktG auch im Rahmen von Ergebnisabführungsverträgen gesperrt. Man spricht treffender Weise von Abführungssperren.

\section{b) Zur Bilanzierung latenter Steuern im Zusammenhang mit Ausschüttungssperren}

Nach $\S 268$ Abs. 8 Satz 2 HGB unterliegt der Betrag, um den die aktiven latenten Steuern die passiven latenten Steuern übersteigen, einer Ausschüttungssperre, soweit keine frei verfügbaren Rücklagen und keine ausreichenden Ergebnisvorträge vorliegen. Die Ausschüttungssperre richtet sich grundsätzlich nach dem in der Bilanz ausgewiesenen Betrag.

Neben der Ausschüttungssperre für latente Steuern wurde - wie oben aufgeführt - eine Ausschüttungssperre für selbst geschaffene immaterielle Vermögensgegenstände sowie für die Fair-Value-Aufwertung des Deckungsvermögens von Altersversorgungsverpflichtungen eingeführt. Diese Ausschüttungssperren stehen mit derjenigen für aktive latente Steuern in Beziehung. Um eine doppelte Berücksichtigung zu vermeiden, ist die Ausschüttungssperre für selbst geschaffene immaterielle Ver-

74 Vgl. Ellrott/F. Huber in BeckBilKomm, 7. Aufl., München 2010, § 268 HGB Rz. 140.

75 Vgl. RegE BilMoG, 64. 
mögensgegenstände und die Aufwertung des Deckungsvermögens von Altersversorgungsverpflichtungen und ähnlichen langfristigen Verpflichtungen um die für diese Positionen gebildeten passiven latenten Steuern zu verringern, da in diesen Fällen die passiven latenten Steuern selbst das Eigenkapital und damit das Ausschüttungspotenzial reduzieren.

Zudem ist bei der Betrachtung der ausschüttungsgesperrten aktiven latenten Steuern zu berücksichtigen, dass aufgrund des vorgenannten Vorgehens schon ein Teil der passiven latenten Steuern "verbraucht" wurde, um ausschüttungsgesperrte Beträge zu reduzieren. ${ }^{76}$

Beispiel 6: Ermittlung der Ausschüttungssperre

Im Jahre 2010 wird von der A-GmbH ein selbst geschaffener immaterieller Vermögensgegenstand i. H. v. 200 TEuro aktiviert. Darauf erfolgt bei einem angenommenen pauschalen Steuersatz von $30 \%$, eine passive latente Steuerabgrenzung von 60 TEuro. In Summe wurden in 2010 jeweils 200 TEuro aktive und 120 TEuro passive latente Steuern ermittelt.

Der Geschäftsführer fragt seinen Steuerberater, in welcher Höhe eine Ausschüttungssperre zu beachten ist.

Lösungshinweise:

Gemäß § 268 Abs. 8 Satz 1 HGB besteht eine Ausschüttungssperre in Höhe der Differenz zwischen dem aktivierten Betrag der immateriellen Vermögensgegenstände i.H.v. 200 TEuro und den darauf entfallenden passiven latenten Steuern i.H.v. 60 TEuro, also i.H.v. insgesamt 140 TEuro.

Zudem ist nach $\S 268$ Abs. 8 Satz 2 HGB der Betrag ausschüttungsgesperrt, um den die aktiven latenten Steuern die passiven latenten Steuern übersteigen. Im vorliegenden Fall betrifft dies den Betrag i. H. v. 80 TEuro (200 TEuro aktive latente Steuern - 120 TEuro passive latente Steuern).

Folglich ergäbe sich in Summe ein ausschüttungsgesperrter Betrag i. H. v. 220 TEuro (80 TEuro + 140 TEuro). Folgt man dieser Vorgehensweise, dann würden die auf die selbst geschaffenen immateriellen Vermögensgegenstände gebildeten passiven latenten Steuern von 60 TEuro doppelt berücksichtigt, da sie bei der Ermittlung des Aktivüberhangs als Bestandteil der insgesamt bestehenden 120 TEuro passiven latenten Steuern nochmals einbezogen wurden. Diese Vorgehensweise widerspricht jedoch dem beabsichtigten Gläubigerschutz. Dementsprechend dürften die auf selbst geschaffenen immateriellen Vermögensgegenständen gebildeten passiven latenten Steuern bei der Ermittlung des Aktivsaldos von latenten Steuern nicht nochmals berücksichtigt werden.

76 Vgl. Kühne/Melcher/Wesemann, WPg 2009, 1005 (1011). 
Grundposten

Anpassung passive Latenz

Summe

Selbst erstellte immaterielle VGG

200 TEuro - 60 TEuro

$=140$ TEuro

Aktive latente Steuer

200 TEuro -120 TEuro +60 TEuro $=140$ TEuro

280 TEuro

Im Ergebnis ergibt sich ein ausschüttungsgesperrter Betrag von 280 TEuro. ${ }^{77}$

c) Wirkung der Abführungssperre im Rahmen der steuerlichen

Organschaft

Durch das BilMoG wurde auch §301 AktG neu gefasst. Der Gewinnabführungsvertrag unterliegt nach $\S 301 \mathrm{AktG}$ - wie bisher - höchstens der ohne die Gewinnabführung entstehende Jahresüberschuss, vermindert um den Verlustvortrag aus dem Vorjahr und um den Betrag, der nach $\S 300$ AktG in die gesetzliche Rücklage einzustellen ist, und - neu - vermindert um den nach $\S 268$ Abs. 8 HGB ausschüttungsgesperrten Betrag. $\S 268$ Abs. 8 HGB sperrt die Ausschüttung der Erträge aus der durch das BilMoG ermöglichten Aktivierung von selbst geschaffenen immateriellen Vermögensgegenständen des Anlagevermögens, aus der Aufdeckung stiller Reserven bei der Zeitwertbewertung des Planvermögens und der Aktivierung von aktiven latenten Steuern. Gewinne dürfen daher nur ausgeschüttet werden, wenn die nach Ausschüttung verbleibenden Rücklagen zuzüglich eines Gewinnvortrags und abzüglich eines Verlustvortrags mindestens den aktivierten Beträgen abzüglich der hierfür gebildeten passiven latenten Steuern entsprechen. ${ }^{78}$

Das BMF hat mit Schreiben vom 14.1.2010 zu der Frage Stellung genommen, inwieweit sich die Änderung einzelner Bilanzierungsvorschriften durch das BilMoG auf die steuerliche Anerkennung ertragsteuerlicher Organschaftsverhältnisse auswirkt. ${ }^{79}$ Dort wird zur Änderung des Höchstbetrags der Gewinnabführung nach $\S 301$ AktG und zur Anpassung von bestehenden EAV Folgendes ausgeführt:

„Die steuerliche Anerkennung der Organschaft bleibt durch die Änderung des $\S 301$ AktG i. V. m. § 268 Absatz 8 HGB grundsätzlich unberührt. Bei der Durchführung der Gewinnabführung sind jedoch die Neuregelungen zum Höchstbetrag der Gewinnabführung nach $\S 301$ AktG ungeachtet ggf. abweichender vertraglicher Vereinbarungen zwingend zu beachten. Für Organgesellschaften in der Rechtsform der GmbH fordert $§ 17$ Satz 2 Nummer 1 KStG nicht, dass die Begren-

77 Vgl. Lüdenbach, StuB 2010, 588 f. zum Vorgehen bei Verzicht auf die Aktivierung latenter Steuern.

78 Vgl. Kröner/Bolik/Gageur, Ubg 2010, 237 (240).

79 BStBl. I 2010, 65. 
zung der Gewinnabführung gem. §301 AktG in den Gewinnabführungsvertrag ausdrücklich aufgenommen wird."

Da für die steuerliche Anerkennung der Organschaft gefordert wird, dass der handelsrechtlich korrekt ermittelte Gewinn abgeführt wird, ist aus steuerlicher Sicht zu untersuchen, welche Auswirkungen die Abgrenzung latenter Steuern auf die Ermittlung des abzuführenden Gewinns haben kann bzw. wie der Gewinn zu ermitteln ist. Aus Sicht des steuerlichen Beraters ist sicher zu stellen, dass im Einzelabschluss eine korrekte Abbildung erfolgt, damit die Anerkennung der steuerlichen Organschaft nicht tangiert wird. ${ }^{80}$

Die körperschaftsteuerliche und gewerbesteuerliche Organschaft führen dazu, dass das Einkommen bzw. der Gewerbeertrag der Gesellschaften des Organkreises dem Organträger zugerechnet werden, soweit die Organgesellschaften kein eigenes steuerpflichtiges Einkommen aus Ausgleichzahlungen i. S. d. $§ 16$ KStG haben. ${ }^{81}$

Bisher enthielt $\S 301$ AktG keinen Verweis auf eine Abführungssperre und somit keine Verbindung zwischen latenten Steuern und der Ermittlung der Gewinnabführung. Nach dem Wortlaut der Neuregelungen der $\S 268$ Abs. 8 HGB i. V.m. § 301 AktG sind nunmehr latente Steuern bei der Ermittlung der Gewinnabführung zu berücksichtigen. Allerdings wurde durch das BilMoG nicht ausdrücklich geregelt, ob die Abgrenzung latenter Steuern für Vermögensunterschiede bei der Organgesellschaft auf Ebene des Organträgers oder auf Ebene der Organgesellschaft selbst zu erfolgen hat.

Das IDW hatte in dem nunmehr aufgehobenen Entwurf von ERS 27 mit dem Thema beschäftigt ${ }^{82}$ und sich für eine ausschließliche Behandlung im Einzelabschluss des Organträgers ausgesprochen. Das IDW folgte dabei der formalen Betrachtungsweise, die den Ausweis der latenten Steuern dort ansiedelt, wo formal die Steuerschuldnerschaft liegt. Der Deutsche Standardisierungsrat vertritt in dem am 3.9.2010 im Bundesanzeiger veröffentlichten DRS 18 ebenfalls die Auffassung, dass latente Steuern grds. beim Organträger zu bilden sind (vgl. 18.32); er hält allerdings ein Wahlrecht zur Bildung bei der Organgesellschaft in DRS 18.35 in dem Fall als zulässig, wenn eine Steuerumlagevereinbarung für die laufenden Steuern besteht. ${ }^{83}$

80 Vgl. BMF, Schr. v. 14.1.2010, BStBl. I 2010, 65.

81 Vgl. Wendholt/Wesemann, Beilage, DB 2009, 69 (70).

82 Vgl. Tz. 21, IDW ERS HFA 27. Am 9.9.2010 hat der HFA des IDW den ERS 27 zurück zu nehmen.

83 Vgl. Herzig, DStR 2010, 1900 (1907); Loitz, DB 2010, 2177 (2181). 
Beispiel 7: Ermittlung der Abführungssperre bei Organschaft

Der Jahresüberschuss der Organgesellschaft B-GmbH vor Steuern betrage 600 TEuro. Bei der Organgesellschaft wird ein selbst geschaffener immaterieller Vermögensgegenstand i. H. v. 200 TEuro aktiviert; darauf entstehen 60 TEuro passive latente Steuern (Annahme: Steuersatz 30 \%).

Wie hoch ist der von B-GmbH an den Organträger abzuführende Gewinn?

Lösungshinweise:

In der Literatur wird diskutiert, in welcher Form bei der Ermittlung der Abführungssperre einer Organgesellschaft latente Steuern zu berücksichtigen sind. Folgende Alternativen kommen in Betracht: ${ }^{84}$

a) "Bruttomethode"

Diese Methode basiert auf der Prämisse, dass künftige Steuerbe- und -entlastungen, die aus temporären Differenzen auf Ebene der Organgesellschaften resultieren, im Einzelabschluss des Organträgers zu berücksichtigen sind. Vor diesem Hintergrund wird der Bruttobetrag der Bilanzdifferenzen (also der Betrag vor Abzug von latenten Steuern) als abführungsgesperrt behandelt. Diese Systematik hat zur Folge, dass durch Bilanzierung von latenten Steuern auf Ebene des Organträgers der ausschüttungsfähige Gewinn des Organträgers reduziert wird, da die auf Ebene des Organträgers bilanzierte latente Steuer nicht bei der Ermittlung der Abführungssperre berücksichtigt wird.

Im Ergebnis wird im Beispielfall der Betrag der selbst geschaffenen immateriellen Vermögensgegenstände i. H. v. 200 TEuro als abführungsgesperrt behandelt, so dass der abzuführende Gewinn bei der Bruttomethode 400 TEuro beträgt. ${ }^{85}$ Die handelsrechtliche Gewinnabführung der Organgesellschaft entspricht dem steuerlichen Zurechnungseinkommen.

b) "Nettomethode"

Bei diesem Ansatz werden die gebildeten passiven latenten Steuern bereits bei Ermittlung des von der Organgesellschaft abzuführenden Gewinns abgezogen. Dadurch erhöht sich der Ertrag des Organträgers aus der Gewinnabführung korrespondierend zum Aufwand aus der Abgrenzung passiver latenter Steuern für den abführungsgesperrten Betrag. ${ }^{86}$ Zur Begründung der Nettomethode wird angeführt, dass im Rahmen einer weiteren und eher wirtschaftlichen Auslegung des §301 Satz 1 AktG i. V.m. $§ 268$ Abs. 8 HGB auch beim Organträger gebildete passive latente Steuern im Rahmen der Gewinnabführung der Organgesellschaft zu berücksichtigen seien, weil sie z. B. aus der Aktivierung von

84 Vgl. Ellerbusch/Schlüter/Hofherr, DStR 2009, 2443 (2446).

85 Die Gewinnabführung entspricht der steuerlichen Einkommenszurechnung, so dass kein organschaftlicher Ausgleichsposten entsteht.

86 Vgl. Ellerbusch/Schlüter/Hofherr, DStR 2009, 2443 (2446). 
selbst geschaffenen immateriellen Vermögensgegenständen entstehen und deshalb auch „hierfür" gebildet wurden. Die Nettomethode wird in der Literatur kritisiert, da sie die Gefahr einer doppelten Berücksichtigung passiver latenter Steuern bei der Ermittlung der Abführungssperre auf Ebene der Organgesellschaft und bei der Ermittlung der Ausschüttungssperre des Organträgers aus aktiven latenten Steuern berge. ${ }^{87}$ Bei der Nettomethode wäre es auch konsequent, die passiven latenten Steuern auf Ebene der Organgesellschaft zu buchen.

Im Beispiel würde bei der Nettomethode ein Betrag von 140 TEuro (200 TEuro - 60 TEuro) als abführungsgesperrt behandelt, so dass der abzuführende Gewinn bei dieser Methode 460 TEuro beträgt.

Die unterschiedlichen Ergebnisse der Gewinnabführung von Brutto- und Nettomethode werden nachfolgend gegenüber gestellt:

Bruttomethode: $600-200=400$ TEuro

Nettomethode: $600-(200-60$ TEuro $)=460$ TEuro

Es ist zu beachten, dass sich auf Ebene des Organträgers Unterschiede hinsichtlich des dort ausschüttungsfähigen Gewinns ergeben; dieser ist bei der Nettomethode um 60 TEuro höher. Auf weitere Besonderheiten, z. B. aufgrund der Ermittlung der Ausschüttungssperre des Organträgers im Zusammenhang mit aktiven latenten Steuern soll an dieser Stelle nicht eingegangen werden.

Für die steuerliche Anerkennung wird es darauf ankommen, dass nach der angewandten Methode der handelsrechtlich korrekt ermittelte Gewinn abgeführt wird. Hier könnte eine Analogie zur Rechtslage bei Umlageverträgen greifen. Dort wird die Auffassung vertreten, dass die Durchführung des Ergebnisabführungsvertrages nicht von der Abführung oder Nichtabführung der Bilanzierungshilfe für latente Steuern auf Ebene der Organgesellschaft abhängig sein darf. Dementsprechend sollten sich auch weder Abzug noch Nicht-Abzug der latenten Steuer bei Ermittlung der Gewinnabführung gemäß § 301 AKtG i. V. m. § 268 Abs. 8 HGB in der Fassung des BilMoG auf die Durchführung des Ergebnisabführungsvertrages auswirken. ${ }^{88} \mathrm{Im}$ Ergebnis sind $\mathrm{m}$. E. beide Methoden zu akzeptieren. Eine entsprechende Klarstellung der Finanzverwaltung bzw. des Berufsstands der Wirtschaftsprüfer ist wünschenswert. ${ }^{89}$ Ein solches Schreiben

87 Tatsächlich darf eine passive latente Steuer nicht zweimal bei der Ermittlung des abführungs- und des ausschüttungsgesperrten Betrags abgezogen werden. Dieses würde entsprechende Nebenrechnung erfordern. Vgl. Dahlke, BB 2009, $876(878)$.

88 Vgl. Ellerbusch/Schlüter/Hofherr, DStR 2009, 2443 (2446).

89 So Kröner/Bolik/Gageur, Ubg 2010, 237 (242). 
sollte auch klarstellen, dass die erstmaligen Anwendung des BilMoG bestehende EAV nicht tangiert.

\section{Thesenförmige Zusammenfassung}

- Die Reform der handelsrechtlichen Bilanzierung durch das BilMoG hat vielschichtige Auswirkungen auf die steuerrechtliche Bilanzierung. Mit der Änderung von $\S 5$ Abs. 1 EStG hat der Gesetzgeber einen Paradigmenwechsel im Verhältnis von Handels- und Steuerbilanz eingeschlagen. Er hat nicht nur das Prinzip der umgekehrten Maßgeblichkeit abgeschafft, sondern er hat mit $\S 5$ Abs. 1 Satz 12 . Halbsatz EStG dem Bilanzierenden die Möglichkeit einer eigenständigen Steuerbilanzpolitik eröffnet. Beides führt zu einer weitreichenden Entkoppelung der handelsrechtlichen und steuerrechtlichen Bilanzierung. Die eigenständige Steuerbilanzpolitik wird auch von der Finanzverwaltung mit dem BMF-Schreiben vom 12.3.2010 zur Maßgeblichkeit bestätigt. Nach Auffassung der Finanzverwaltung können Wahlrechte, die steuerrechtlich bestehen, unabhängig vom handelsrechtlichen Wertansatz ausgeübt werden. Die Maßgeblichkeit der Handelsbilanz für die Steuerbilanz führt nicht zur Einschränkung der Ausübung des steuerlichen Wahlrechts.

- Es bleibt vor dem Hintergrund des BMF-Schreibens vom 12.3.2010 festzuhalten, dass die Erosion der Maßgeblichkeit voranschreitet. Die Notwendigkeit der Abgrenzung latenter Steuern in der Handelsbilanz wird verstärkt. Auch die Rechtsprechung hat in der jüngsten Vergangenheit verstärkt die Eigenständigkeit der steuerlichen Gewinnermittlung unter Betonung des steuerlichen Bewertungsvorbehalts $\mid \S 5$ Abs. 6 EStG) und der eigenständigen Zwecksetzung hervorgehoben. Es ist daher eher fraglich, ob die in letzter Zeit zu vernehmenden Plädoyers für den Erhalt der Einheitsbilanz und zur Stärkung der Maßgeblichkeit den aktuellen Trend umkehren können. Vielmehr geht es aus Sicht der Praxis darum, dass die Steuerneutralität der Bilanzrechtsreform gewahrt bleibt. Es gilt der Tendenz entgegen zu wirken, dass ein Szenario eines „entfesselten Fiskus" Realität wird. ${ }^{90}$ Dies gilt insb. auch vor dem Hintergrund der aktuellen Bestrebungen, den steuerlichen Herstellungskostenbegriff neu zu regeln.

- Die Neujustierung der Maßgeblichkeit schafft dem Bilanzierenden Freiräume; dies ist zu begrüßen. So kann der Bilanzierende bewusst auf handelsrechtlich gebotene Abschreibungen verzichten, um z. B. einen Verlustvortrag nicht weiter zu erhöhen. Als Kehrseite lässt sich konstatieren, dass die Steuerbilanz Wertansätze enthalten kann, die eindeutig

90 So Hennrichs, Ubg 2009, 542. 
nicht den GoB entsprechen. Ferner sind die neuen Verzeichnispflichten zu beachten.

- Durch die gestalterische Nutzung der bilanzpolitischen Spielräume, die aus der Aufgabe der Umkehrmaßgeblichkeit resultieren, kann - wie im Falle der Bildung steuerfreier Rücklagen nach § 6b EStG - Ausschüttungspotenzial ohne unmittelbare Cash-Steuerbelastung generiert werden. Zudem können einige Wahlrechte zur Vermeidung unsystematischer Belastungen - z.B. im Rahmen der $5 \%$-igen Zuschreibung auf Gewinne aus der Wertaufholung von Anteilen an Kapitalgesellschaften - genutzt werden. Steuerliche Wahlrechte zur Verlagerung von Betriebsausgaben in spätere Veranlagungszeiträume können steuerbilanzpolitisch insbesondere in Situationen genutzt werden, in denen ein Wegfall von Verlusten (wg. Anteilsübertragungen) oder eine nur zeitlich gestreckte Verlustnutzung (wg. Mindestbesteuerung) droht. Dies erweist sich insb. im Sinne einer klassischen Barwertminimierung als vorteilhaft und kann auch positive Auswirkungen mit Blick auf die "effective tax rate" haben.

- Im Bereich der Ausschüttungssperren ergeben sich eine Vielzahl an Folgefragen. Die umfangreichen Änderungen des BilMoG können zu steuerlichen Risiken im Zusammenhang mit der Anerkennung einer steuerlichen Organschaft führen. Dies gilt insbesondere im Zusammenhang mit Abführungssperren. Klarstellungen hinsichtlich von Anwendungsfragen durch den Berufsstand und das BMF sind wünschenswert. 


\title{
§ 5b EStG: Elektronische Bilanz - Sachstandsbericht
}

\author{
Dipl.-Finw. Markus Hülshoff \\ Münster
}

Inhaltsübersicht
A. Ausgangslage
B. Gesetzliche Grundlagen
b) Mussfeld, Kontennachweis erwünscht
I. § 5b Abs. 1 EStG - Übermitt- lungspflicht
II. § 5b Abs. 2 EStG - Härtefall
III. § 51 Abs. 4 Nr. 1b EStG - Min- destumfang
IV. $§ 52$ Abs. 15a EStG - Anwen- dungsvorschrift
C. Ziele des Projekts „E-Bilanz
D. XBRL
I. XBRL-Taxonomie
1. HGB-Taxonomie
2. Taxonomie nach $\S 5 \mathrm{~b} \mathrm{EStG} \mathrm{(,Ta-}$ xonomie Steuer")
II. AG Taxonomie Steuer
1. Struktur der Taxonomie Steuer
2. Rechnerische Verknüpfungen
3. Mussfelder
c) Summenmussfeld/Rechne- risch notwendig, soweit vorhanden
d) Auffangpositionen
4. Anzahl von Mussfeldern
III. Branchenspezifische Unter- arbeitsgruppen
E. Sonderfälle
I. Anlagespiegel
II. Außerbilanzielle $\mathrm{Zu}$ - und Abrechnungen
III. Kapitalkontenentwicklung
IV. Sonder- und Ergänzungsbilanzen
F. Stellungnahme der im Projekt beteiligten Wirtschaftsvertreter
G. Zeitschiene
H. Zusammenfassung

\section{A. Ausgangslage}

Der automationsunterstützte Austausch von Finanz- und Unternehmensdaten ist in vielen Bereichen zur Routine geworden. Spätestens seit der Verabschiedung des EHUG, ${ }^{1}$ das ab 2007 für alle offenlegungspflichtigen Unternehmen gilt, wird außerhalb der Finanzverwaltungen an verschiedenen Lösungen zur elektronischen Übermittlung von Jahresabschlussdaten gearbeitet.

Im Verhältnis zwischen Unternehmen und Finanzverwaltung stellt sich dagegen das Bild wie folgt dar. Die für die Finanzverwaltung zur Besteuerung erforderlichen Daten der Jahresabschlüsse werden in der Regel durch

1 Gesetz über elektronische Handelsregister und Genossenschaftsregister sowie das Unternehmensregister (EHUG). 
elektronische Systeme verwaltet und liegen in auswertbarer Form vor. Der Jahresabschluss wird mit Hilfe entsprechender Anwendungen erstellt und anschließend in gedruckter Form dem Finanzamt vorgelegt.

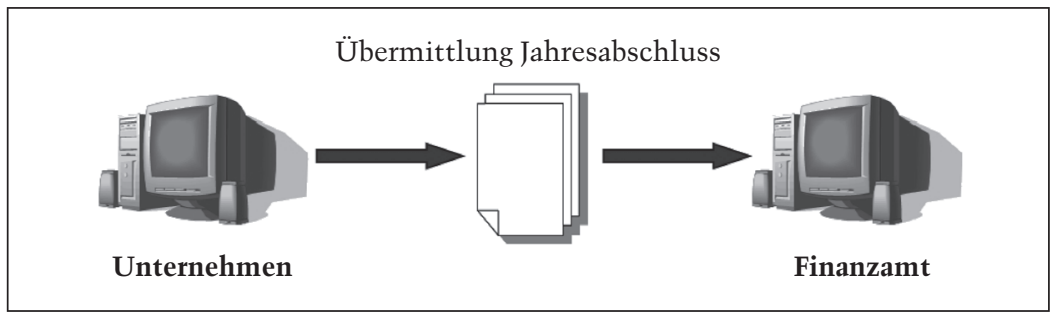

Mit dem Projekt E-Bilanz soll die erfolgreiche Strategie papierbasierte Verfahrensabläufe durch elektronische Kommunikation zu ersetzen, fortgesetzt und vertieft werden.

\section{B. Gesetzliche Grundlagen}

\section{I. § 5b Abs. 1 EStG - Übermittlungspflicht}

Mit Verabschiedung des Steuerbürokratieabbaugesetzes wurde mit $\S 5 \mathrm{~b} \mathrm{EStG}^{2}$ die elektronische Übermittlungsmöglichkeit des Inhalts der Bilanz, der Gewinn- und Verlustrechnung sowie einer ggf. notwendigen Überleitungsrechnung vorgesehen. Die in $\S 5$ bStG beschriebenen Daten können unabhängig von der zu übermittelnden Steuererklärung ${ }^{3}$ übertragen werden (z. B. Eröffnungsbilanz, geänderte Bilanz). Die bisher nach $\S 60$ Absatz 1 EStDV vorgeschriebene Übermittlung in Papierform entfällt.

\section{II. § 5b Abs. 2 EStG - Härtefall}

Nach $\S 5$ b Absatz 2 EStG kann auf Antrag die Finanzbehörde zur Vermeidung unbilliger Härten auf eine elektronische Übermittlung verzichten. Diese entscheidet im eigenen Ermessen, ob die Gründe für die Anerken-

$2 \S 5$ bStG eingefügt durch Artikel 1 des Steuerbürokratieabbaugesetzes vom 20.12.2008 (BGBl. I, 2850).

$3 \S 25$ Absatz 4 EStG, $\S 31$ Absatz 1 a KStG, $\S 181$ Absatz 2 a AO oder $\S 3$ Absatz 2 der Verordnung zu $\S 180$ Absatz 2 AO. 
nung eines Härtefalls (persönliche oder wirtschaftliche Unzumutbarkeit der elektronischen Übermittlung ${ }^{4}$ ) vorliegen.

\section{III. §51 Abs. 4 Nr. 1b EStG - Mindestumfang}

Nach dieser Vorschrift wird das Bundesministerium der Finanzen ermächtigt, im Einvernehmen mit den obersten Finanzbehörden der Länder den Mindestumfang der nach § $5 \mathrm{~b}$ EStG elektronisch zu übermittelnden Bilanz und Gewinn- und Verlustrechnung zu bestimmen. Der Entwurf des entsprechenden BMF-Schreibens ${ }^{5}$ liegt nunmehr vor.

\section{IV. $§ 52$ Abs. 15a EStG - Anwendungsvorschrift}

Nach dieser Vorschrift ist die Übermittlungspflicht erstmals für Wirtschaftsjahre anzuwenden, die nach dem 31.12.2010 beginnen. Nach $\S 51$ Abs. 4 Nr. 1c EStG kann das BMF durch Rechtsverordnung mit Zustimmung des Bundesrates die Vorschriften über einen von diesem vorgesehenen erstmaligen Anwendungszeitpunkt abweichenden späteren Anwendungszeitpunkt erlassen, wenn bis zum 31.12.2010 erkennbar ist, dass die technischen oder organisatorischen Voraussetzungen für eine Umsetzung der in $\S 5$ b Abs. 1 EStG vorgesehenen Verpflichtung nicht ausreichen.

Nach dem Wortlaut des vorgenannten BMF-Schreibens ${ }^{6}$ wird die Finanzverwaltung es nicht beanstanden, wenn für Übermittlungen im Jahre 2011 noch nicht die elektronische Übermittlung genutzt wird, sondern Bilanzen auf Papier eingereicht werden. Dies betrifft vor allem Eröffnungsbilanzen und Jahresabschlüsse von Rumpfwirtschaftsjahren.

\section{Ziele des Projekts „E-Bilanz“}

Im Rahmen des Vorhabens KONSENS ${ }^{7}$ haben die in Auftrag nehmenden Bundesländer Bayern und Nordrhein-Westfalen das Projekt E-Bilanz gegründet. Projektleiter ist Herr Hubertus Rust vom Bayerischen Landesamt für Steuern. In den diversen Gremien des Projektes arbeiten Vertreter

$4 \S 150$ Absatz 8 AO.

5 BMF, Schr. - Stand vor Verbandsanhörung - IV C 6 - S 2133-b/10/10001.

6 BMF, Schr. - Stand vor Verbandsanhörung - IV C 6 -S 2133-b/10/10001 - Tz. 25.

7 Verwaltungsabkommen KONSENS = Koordinierte neue Software-Entwicklung der Steuerverwaltung, vgl. Monatsbericht des BMF - Oktober 2006, 55 ff. 
der Fachrichtungen Einkommensteuer, Körperschaftsteuer, Bilanzsteuerrecht, Betriebsprüfung, Veranlagung, Organisation und Automation. Ziel des Projektes ist die fachliche und technische Umsetzung des $\S 5 \mathrm{~b}$ EStG auf Seiten der Finanzverwaltung einschließlich der notwendigen Schnittstellen zu den Systemen der Übermittler zu schaffen.

Vertreter der Wirtschaftsverbände, die Kammern der steuerberatenden Berufe und Softwarehersteller wurden frühzeitig in die Konzeption eingebunden. Insbesondere in der AG Taxonomie-Steuer arbeiten diese Vertreter aktiv an den diversen Aufgaben des Projekts mit. So soll sichergestellt werden, dass alle Interessen ausreichend Berücksichtigung finden und eine möglichst hohe Akzeptanz erreicht wird.

\section{XBRL}

Mit BMF-Schreiben vom 19.1.2010 ${ }^{8}$ wurden die grundlegenden Anforderungen an den Inhalt und die Form der Datenübermittlung der steuerlichen Gewinnermittlungen bestimmt. Insbesondere hat sich die Verwaltung darin auf das Format XBRL (eXXtensible Business Reporting Language) als ausschließlichen Übermittlungsstandard festgelegt. XBRL ist ein international weit verbreiteter Standard für den elektronischen Datenaustausch von Unternehmensinformationen. In Deutschland wird XBRL durch den Verein XBRL-Deutschland ${ }^{9}$ e. V. verwaltet. Mit dieser Festlegung wendete sich die Verwaltung nicht zuletzt gegen eine grundsätzlich auch denkbare Vordrucklösung, die nach den Auffassungen aller Beteiligten einen erhöhten Bürokratieaufwand hervorgerufen hätte.

XBRL ist eine frei verfügbare elektronische Sprache für das „Financial Reporting", also für die elektronische Übermittlung von Daten aus dem Rechnungswesen und eine besondere Ausprägung von XML. ${ }^{10}$

Das Votum für XBRL als Übermittlungsweg ermöglicht es den Unternehmen, einen bereits eingeführten Standard zur elektronischen Übermittlung sowohl im Rechtsverkehr mit der Finanzverwaltung als auch mit anderen Adressaten von Jahresabschlussdaten zu nutzen - etwa den Bundesanzeiger, der ebenfalls die Nutzung dieses Standards akzeptiert.

Hier eine nicht abschließende Auflistung von Anwendungsbereichen von XBRL in Deutschland:

8 BMF, Schr. v. 19.1.2010 - IV C 6-S 2133-b/0.

9 www.xbrl.de.

10 Flickinger, XBRL in der betrieblichen Praxis, Erich Schmidt Verlag 2007. 
- z.B. Bundesanzeiger: seit 2007 „Elektronischer Bundesanzeiger" mit XBRL-Annahme

- z. B. Bundesbank: Jahresabschlusspool mit XBRL-Annahme

- z.B. DATEV: seit einigen Jahren Erstellung von XBRL-Reports „auf Mausklick" für über 2 Millionen Mandanten

- z. B. Deutsche Bank: geplante Nutzung von XBRL bei der automatisierten Verarbeitung der Kreditwürdigkeitsprüfung

Bereits im Jahre 2001 wurde der Verein XBRL Deutschland e. V. gegründet. Träger des Vereins sind Organisationen und Unternehmen aus den Bereichen Wirtschaftsprüfung, Finanzdienstleistung, Rechnungslegung, Consulting, Wissenschaft und Software-Erstellung. Ziel von XBRL Deutschland e. V. ist es, den XBRL-Standard auch im Blick auf deutsche Belange $z u$ fördern, und weiter zu entwickeln. ${ }^{11} \mathrm{Zu}$ den Mitgliedern ${ }^{12}$ zählen heute neben Vertretern der vorgenannten Sektoren auch die bayerische und nordrhein-westfälische Finanzverwaltung. ${ }^{13}$

\section{XBRL-Taxonomie}

Die Taxonomie im XBRL-Kontext ist ein gegliedertes hierarchisches Datenschema, ähnlich einem Kontenrahmen, bestehend aus Bilanz- und Gewinn- und Verlustpositionen, die zur Übertragung das Übermittlungsformat XBRL nutzt. Sie enthält gleichsam einen Fundus für alle vorhersehbaren bzw. zu verwendenden Positionen eines Jahresabschlusses. Durch die flexibel zu nutzenden zusätzlichen Module bietet XBRL aber erheblich mehr als nur eine solchen Fundus. Sämtliche Bestandteile eines Jahresabschlusses können entweder in strukturierter Form oder als Freitext elektronisch an den Adressaten übermittelt werden.

Für unterschiedliche Verwendungen bzw. Bilanzierungsstandards (z.B. HGB, US-GAAP, IFRS) werden entsprechend unterschiedliche Taxonomien bereit gehalten.

11 Meyer-Pries/Gröner, „Web-Publizität und Datenaustausch mit XBRL“, Finanzbetrieb $1 / 2002$.

12 Die Liste der Mitglieder ist auf der Internetseite des Vereins www.xbrl.de veröffentlicht: http://www.xbrl.de/index.php?option=com_content\&view=article\&id=2\&Itemid= 17 .

13 Bayerisches Landesamt für Steuern, Finanzverwaltung des Landes NordrheinWestfalen (vertreten durch das Rechenzentrum), Düsseldorf. 


\section{HGB-Taxonomie}

Die aktuelle HGB-Taxonomie in der Version 4.0 vom 31. Januar 2010 berücksichtigt die Regelungen des BilMoG. ${ }^{14}$ Diese Taxonomie bildete die Arbeitsgrundlage für den vorliegenden Entwurf der Taxonomie Steuer. Die HGB-Taxonomie ${ }^{15}$ findet ihren Einsatz vor allem für die Übermittlung von Jahresabschlussdaten an den Bundesanzeiger.

\section{Taxonomie nach § 5b EStG („Taxonomie Steuer“)}

Der Begriff "Taxonomie Steuer" ist als Arbeitstitel der Taxonomie nach $\S 5$ b EStG zu verstehen. Sie ist die Basis für die elektronische Übermittlung von Bilanz und Gewinn- und Verlustrechnung nach $\S 5$ bStG. Prämisse bei der Entwicklung dieser Taxonomie war, den Übermittlern möglichst geringe Änderungen in der bisherigen Übermittlungspraxis abzuverlangen. Darüber hinaus bietet die Taxonomie-Steuer die Möglichkeit zur Übermittlung der Inhalte von Handelsbilanzen mit einer strukturierten Überleitungsrechnung oder alternativ der Steuerbilanz. Inhalt und Struktur der Taxonomie sollen keinen Eingriff in die Buchungspraxis erfordern. Schließlich ist es Ziel, eine Taxonomie für alle Unternehmensgrößen und Rechtsformen zu erarbeiten. Letzteres bedeutet, dass rechtsformspezifische Bilanzpositionen - etwa beim Kapital - nebeneinander Bestandteil der Taxonomie sind. Durch Referenzierungen ${ }^{16}$ sind diese rechtsformspezifischen Positionen identifizierbar. Die dem Entwurf des BMF-Schreibens beigefügten visualisierten Formen der Taxonomie Steuer stellen daher jeweils Auszüge einer Gesamt-Taxonomie dar.

\section{AG Taxonomie Steuer}

Die Taxonomie Steuer wurde nach den vorgenannten Prinzipien durch eine im Projekt E-Bilanz angegliederte AG Taxonomie Steuer erarbeitet. Diese Arbeitsgruppe nahm die Arbeit einer vor einigen Jahren bereits bestehenden gemeinschaftlichen Arbeitsgruppe aus Vertretern von XBRL Deutschland e. V. und der Finanzverwaltung wieder auf.

14 Gesetz zur Modernisierung des Bilanzrechts (Bilanzrechtsmodernisierungsgesetz, BilMoG.

15 Die HGB-Taxonomie ist abrufbar unter www.xbrl.de - HGB-Taxonomie - aktuelle Version - sowie unter www.abra-search.com.

16 Einzelunternehmen: legalFormEU: true; Kapitalgesellschaften: legalFormKSt: true; Personengesellschaften: legalFormPG: true. 


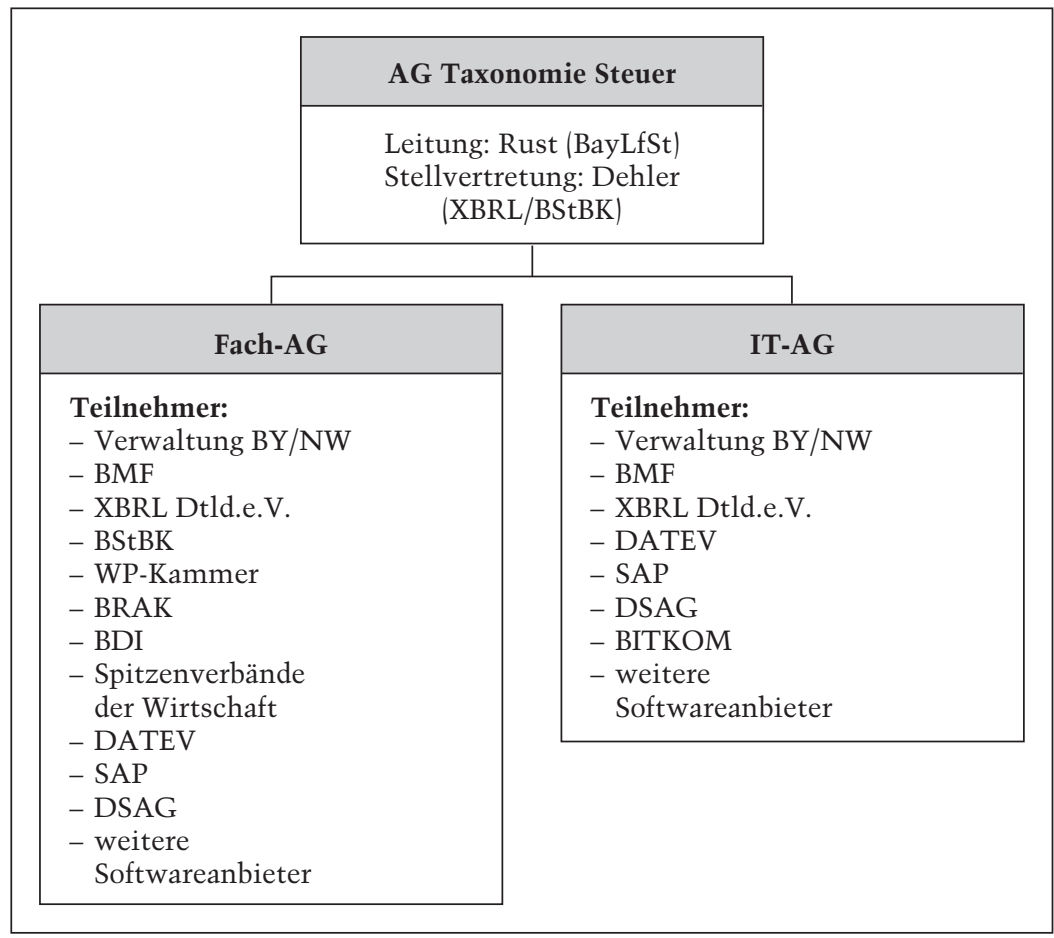

Die jetzt wieder neu gestartete AG Taxonomie-Steuer ist besetzt mit Vertretern der Finanzverwaltung sowie Vertretern der Wirtschaft. Leiter ist der Projektleiter der Finanzverwaltung, Herr Hubertus Rust. Sein Vertreter ist Herr Manfred Dehler, Präsident der Steuerberaterkammer Nürnberg und Vizepräsident der Bundessteuerberaterkammer. Die AG Taxonomie Steuer unterteilt sich in eine Fach-AG, ${ }^{17}$ in der die fachlichen Fragen beraten werden und in eine IT-AG, in der die technischen Fragen beraten wurden.

17 Mitglieder der Fach-AG sind Vertreter der Finanzverwaltungen Bayern und Nordrhein-Westfalen, Bundesfinanzministerium, XBRL Deutschland e. V., Bundessteuerberaterkammer, Wirtschaftsprüferkammer, Bundesrechtsanwaltskammer, BDI, Spitzenverbände der Wirtschaft, DATEV, SAP, DSAG, weitere Softwareanbieter.

Teilnehmer der IT-AG sind Vertreter der Finanzverwaltungen Bayern und Nordrhein-Westfalen, Bundesfinanzministerium, XBRL Deutschland e. V., DATEV, SAP, DSAG, BITKOM, weitere Softwareanbieter. 
In zahlreichen Sitzungen wurde schließlich der vorliegende Entwurf auf der Grundlage der HGB-Taxonomie erarbeitet. Auch künftige Überarbeitungen der Taxonomie - erforderlich etwa aufgrund von Gesetzesänderungen - werden ebenfalls in dieser fortbestehenden AG Taxonomie beraten. Die Zusammenarbeit in den beiden Fach-AGs war und ist außerordentlich fruchtbar. So konnten einerseits die Erfordernisse des Besteuerungsverfahrens und andererseits die Erfordernisse für die Prozesse auf Seiten der Übermittler (Unternehmen, Steuerabteilungen, Steuerberatende Berufe) in die Taxonomie Steuer einfließen.

Die Taxonomie-Steuer entspricht in ihrer Struktur der HGB-Taxonomie. Sie wird deshalb auch für die Übermittlung an außersteuerliche Adressaten (mit u. U. anderer Differenzierungstiefe) genutzt werden können. Zusätzlich von der Finanzverwaltung für erforderlich gehaltene Differenzierungen gegenüber der HGB-Taxonomie wurden grundsätzlich in zusätzlich eingeführte Hierarchieebenen verarbeitet.

\section{Beispiel Beteiligungserträge:}

- Finanz- und Beteiligungsergebnis ${ }^{18}$

HGB-Taxonomie 4.0

- Erträge aus Beteiligungen

- Finanz- und Beteiligungsergebnis ${ }^{18}$

- Erträge aus Beteiligungen

Erträge aus Beteiligungen an Kapitalgesellschaften $\{\mathrm{M}\}$

Erträge aus Beteiligungen an Personengesellschaften $\{\mathrm{M}\}$

Taxonomie Steuer

Für steuerliche Zwecke ist die Differenzierung ${ }^{19}$ der Beteiligungserträge in solche aus Beteiligungen an Kapitalgesellschaften und solche aus Beteiligungen an Personengesellschaften erforderlich.

\section{Beispiel Umsatzerlöse:}

Für die Zwecke der Finanzverwaltung ist die Differenzierung der Umsatzerlöse nach umsatzsteuerlichen Tatbeständen von erheblicher Bedeutung. Aus diesem Grunde wurde die Position „In Umsatzerlöse (GKV) enthaltener Bruttowert" entsprechend untergliedert.

$\mathrm{Da}$ in den Unternehmen nicht unbedingt diese Differenzierung sich in der Finanzbuchhaltung auf Kontenebene abbildet, führt diese Anforderung u. U. zu Schwierigkeiten bei der Zuordnung.

18 Auszug aus der Taxonomie Steuer, ergänzt um Rechenoperatoren; entnommen aus www.abra-search.com von ABZ Reporting GmbH, Darmstadt.

19 Vgl. $\S \S 8,9$ GewStG, 3 Nr. 40 EStG, 8b Abs. 6 KStG. 
Soweit diese Zuordnung in den Unternehmen maschinell nicht möglich ist, kann die so genannte Auffangposition (vgl. D. II. 3. d. unten) „Umsatzerlöse ohne Zuordnung nach Umsatzsteuertatbeständen" genutzt werden.

- Umsatzerlöse $\{$ M Summe $\}$

- in Umsatzerlöse (GKV) enthaltener Bruttowert \{M Summe\}

Sonstige Umsatzerlöse, nicht steuerbar $\{\mathrm{M}\}$

steuerfreie Umsätze nach § 4 Nr. 1a UStG (Ausfuhr Drittland) $\{M\}$

steuerfreue EG-Lieferungen $\S 4$ Nr. $1 \mathrm{~b}$ UStG

(Innergemeinschaftliche Lieferungen) $\{\mathrm{M}\}$

steuerfreie Umsätze nach $\S 4 \mathrm{Nr} .8 \mathrm{ff}$ UStG $\{\mathrm{M}\}$

steuerfreie Umsätze nach $\S 4$ Nr. 2-7 UStG $\{M\}$

sonstige umsatzsteuerfreie Umsätze $\{M\}$

Umsatzerlöse ermäßigter Steuersatz $\{\mathbf{M}\}$

Umsatzerlöse Regelsteuersatz $\{\mathrm{M}\}$

Umsatzerlöse nach $\S 25$ und $\S 25$ a UStG $\{M\}$

Umsatzerlöse sonstige Umsatzsteuersätze $\{M\}$

Umsatzerlöse ohne Zuordnung nach Umsatzsteuertatbeständen

$\{\text { M rechnerisch }\}^{20}$

\section{Struktur der Taxonomie Steuer}

Die Taxonomie Steuer umfasst ein Stammdaten-Modul („GCD-Modul“) und ein Jahresabschluss-Modul („GAAP-Modul“). Die Taxonomie bildet den amtlich vorgeschriebenen Datensatz nach $\S 5$ b Abs. 1 Satz 1 EStG.

Das „GCD" -Modul enthält ein Datenschema zur Übermittlung von

- Dokumentinformationen,

- Informationen zum Bericht und

- Informationen zum Unternehmen.

Das "GAAP“-Modul enthält ein Datenschema zur Übermittlung der gebräuchlichen Berichtsbestandteile für Unternehmen aller Rechtsformen und Größenordnungen. Folgende Berichtsbestandteile können zur Übermittlung genutzt werden:

- Bilanz (Ausgangsbasis HGB),

- Haftungsverhältnisse,

- Gewinn- und Verlustrechnung (Ausgangsbasis HGB) in den Varianten Gesamtkosten- und Umsatzkostenverfahren,

- Ergebnisverwendungsrechnung -Kapitalkontenentwicklung für Personenhandelsgesellschaften/Mitunternehmerschaften,

20 Auszug aus der Taxonomie Steuer, ergänzt um Rechenoperatoren; entnommen aus www.abra-search.com von ABZ Reporting GmbH, Darmstadt. 
- Eigenkapitalspiegel,

- Kapitalflussrechnung,

- Anhang,

- Anlagespiegel,

- diverse Felder zur Aufnahme von textlichen Informationen,

- steuerliche Modifikationen (Überleitungsrechnung der Wertansätze aus der Handelsbilanz zur Steuerbilanz und Zusatzangaben),

- Lagebericht,

- Bericht des Aufsichtsrats, Beschlüsse und zugehörige Erklärungen.

Die neben der Bilanz bzw. G+V existierenden Berichtsbestandteile, die nach $\S 60$ Absatz 3 EStDV weiterhin auf Papier vorzulegen sind, können darüber hinaus freiwillig elektronisch übermittelt werden $(z$. B. der von der Finanzverwaltung in der Regel benötigte Anlagespiegel im Anhang).

Die Taxonomie ermöglicht für den Steuerpflichtigen gem. §5b Absatz 1 EStG, eine Handelsbilanz mit Überleitungsrechnung oder alternativ eine "Steuerbilanz" zu übermitteln. Die Steuerbilanz stellt in diesem Fall eine auf den handelsrechtlichen Grundsätzen ordnungsmäßiger Bilanzierung beruhenden Bilanz und Gewinn- und Verlustrechung dar, die jeweils die steuerlich anzusetzenden Werte enthält.

Soweit eine Handelsbilanz mit Überleitungsrechnung übermittelt wird, erfolgt diese Überleitungsrechnung ebenfalls innerhalb der Taxonomie durch den Teil „Steuerliche Modifikationen“.

\section{Rechnerische Verknüpfungen}

Positionen mit numerischen Inhalten (z. B. von Bilanz bzw. Gewinn- und Verlustrechnung) lassen sich mit Hilfe der XBRL-Technik ${ }^{21}$ durch Addition oder Subtraktion miteinander verknüpfen. Diese Verknüpfung dient u. a. der Validierung von übermittelten Daten.

Der Datensatz kann also anhand der in der Taxonomie enthaltenen Rechenregeln auf seine (formal) rechnerische Richtigkeit hin überprüft werden. Diese Rechenregeln sind der Datensatzbeschreibung direkt zu entnehmen. Soweit in der Taxonomie Positionen rechnerisch verknüpft sind, müssen die übermittelten Werte diesen Rechenregeln genügen. Datensätze, die den Rechenregeln nicht entsprechen, werden zurückgewiesen. Die Bilanz und die Gewinn- und Verlustrechnung gelten in diesen Fällen als nicht übermittelt.

21 XBRL-Bezeichnung: Calculation Linkbase. 
- Sachanlagen $\{$ M Summe $\}$

- Grundstücke, grundstücksgleiche Rechte und Bauten einschließlich der Bauten auf fremden Grundstücken \{M Summe\}

$+\quad$ unbebaute Grundstücke \{M Kto.\}

+ grundstücksgleiche Rechte ohne Bauten \{M Kto.\}

+ - Bauten auf eigenen Grundstücken und grundstücksgleichen Rechnten \{M Kto. $\}$ davon Grund und Boden-Anteil $\{\mathrm{M}\}$

$+\quad$ Bauten auf fremden Grundstücken \{M Kto.\}

$+\quad$ Übrige Grundstücke $\{M$ rechnerisch $\}$

- technische Anlagen und Maschinen $\{M\}$ technische Anlagen Maschinen und maschinengebundene Werkzeuge Betriebsvorrichtungen Reserve- und Ersatzteile 22

\section{Mussfelder}

Der Mindestumfang der nach $\S 5$ b EStG elektronisch zu übermittelnden Bilanz und Gewinn- und Verlustrechnung ist nach $\S 51$ Abs. 4 Nr. $1 \mathrm{~b}$ EStG durch BMF Schreiben zu bestimmen. Dieser Mindestumfang wird in der Taxonomie technisch durch eine besondere Referenzierung gekennzeichnet.

Diese Referenzierung ${ }^{23}$ erfolgt in unterschiedlicher Weise und kennzeichnet die folgenden Arten von Mussfeldern:

- Mussfeld $\{M\}$,

- Mussfeld, Kontennachweis erwünscht \{M Kto.\},

- Summenmussfeld \{Summe\},

- Rechnerisch notwendig, soweit vorhanden.

\section{a) Mussfeld}

Die Übermittlung aller als „Mussfeld“ gekennzeichneten Positionen ist (unabhängig von Rechtsform, Sparten o. ä.) als Mindestumfang des amtlich vorgeschriebenen Datensatzes im Sinne des $\S 5 \mathrm{~b}$ EStG zwingend. Es wird elektronisch geprüft, ob formal alle Mussfelder im Datensatz enthalten sind.

Sofern sich ein Mussfeld nicht mit Werten füllen lässt, z. B. weil aufgrund der Rechtsform des Unternehmens kein dem Mussfeld entsprechendes

22 Auszug aus der Taxonomie Steuer, ergänzt um Rechenoperatoren; entnommen aus www.abra-search.com von ABZ Reporting GmbH, Darmstadt.

23 XBRL: fiscalRequirement: Mussfeld. 
Buchungskonto geführt wird, ist zur erfolgreichen Übermittlung des Datensatzes die entsprechende Position „leer" ${ }^{\prime 24}$ zu übermitteln.

\section{b) Mussfeld, Kontennachweis erwünscht}

Hierbei handelt es sich zunächst um Mussfelder, wie unter a) beschrieben. Darüber hinaus gilt der Hinweis, dass zur Vermeidung von Rückfragen seitens der Finanzverwaltung es sinnvoll erscheint, zu dieser Position einen Auszug aus der Summen- und Saldenliste in der folgenden Struktur mit zu übermitteln. Die in der Taxonomie hierfür vorgegebene Struktur umfasst die Felder „Kontonummer", 25 „Konto-Bezeichnung“, „Betrag". Der Kontennachweis unterliegt nicht der Übermittlungspflicht. Alle als „Mussfeld" oder als "Mussfeld, Kontennachweis erwünscht" gekennzeichneten Positionen bilden den Mindestumfang nach $\S 51$ Abs. 4 Nr. 1b EStG.

\section{c) Summenmussfeld/Rechnerisch notwendig, soweit vorhanden}

Die so gekennzeichneten Positionen könnte man als strukturelle Mussfelder bezeichnen. Werden im Datenschema rechnerisch in eine Oberposition verknüpfte Positionen übermittelt, so sind auch die zugehörigen Oberpositionen mit zu übermitteln. Oberpositionen, die über rechnerisch verknüpften Mussfeldern stehen, sind als Summenmussfelder gekennzeichnet.

Da der übermittelte Datensatz auch im Übrigen den im Datenschema hinterlegten Rechenregeln genügen muss, werden Positionen, die auf der gleichen Ebene wie rechnerisch verknüpfte Mussfelder stehen, als „Rechnerisch notwendig, soweit vorhanden" gekennzeichnet. Diese Positionen sind dann zwingend mit Werten zu übermitteln, wenn ohne diese Übermittlung die Summe der Positionen auf der gleichen Ebene nicht dem Wert der Oberposition entspricht, mit denen diese Positionen rechnerisch verknüpft sind.

\section{d) Auffangpositionen}

Um Eingriffe in das Buchungsverhalten zu vermeiden, aber dennoch einen möglichst hohen Grad an Standardisierung zu erreichen, sind im Datenschema der Taxonomie Auffangpositionen eingefügt (erkennbar durch die Formulierungen im beschreibenden Text "nicht zuordenbar" in der Positionsbezeichnung). Ein Steuerpflichtiger, der eine durch die Taxonomie vorgegebene Differenzierung für einen bestimmten Sachverhalt

24 Technisch: NIL-Wert.

25 Kontonummer aus der Finanzbuchhaltung. 
nicht aus der Buchhaltung ableiten kann, kann zur Sicherstellung der rechnerischen Richtigkeit für die Übermittlung diese Auffangpositionen nutzen.

\section{Anzahl von Mussfeldern}

Hervorzuheben ist an dieser Stelle, dass der eigentliche Mindestumfang nach $\S 51$ Abs. 4 Nr. 1b EStG sich inhaltlich allein aus den als „Mussfeld" bzw. „Mussfeld, Kontennachweis erwünscht" gekennzeichneten Positionen ergibt.

Die anderen beiden Kennzeichnungen „Summenmussfeld“ bzw. „Rechnerisch notwendig, soweit vorhanden" sind solche, die in erster Linie für die Validität des gesamten Rechenwerks von Bilanz und G+V von Bedeutung sind.

\section{Beispiel:}

- Sachanlagen $\{$ M Summe $\}$

- Grundstücke, grundstücksgleiche Rechte und Bauten einschließlich der Bauten auf fremden Grundstücken \{M Summe\} unbebaute Grundstücke \{M Kto.\} grundstücksgleiche Rechte ohne Bauten \{M Kto.\}

- Bauten auf eigenen Grundstücken und grundstücksgleichen Rechnten \{M Kto. $\}$ davon Grund und Boden-Anteil $\{\mathrm{M}\}$

Bauten auf fremden Grundstücken \{M Kto.\}

Übrige Grundstücke \{M rechnerisch\}

- technische Anlagen und Maschinen $\{\mathrm{M}\}$ technische Anlagen

Maschinen und maschinengebundene Werkzeuge

Betriebsvorrichtungen

Reserve- und Ersatzteile ${ }^{26}$

Die Position „Unbebaute Grundstücke" ist als „Mussfeld, Kontennachweis erwünscht" gekennzeichnet. Diese Position ist mit der Oberposition "Grundstücke, grundstücksgleiche Rechte und Bauten einschließlich der Bauten auf fremden Grundstücken $\{\mathrm{M}$ Summe\}" rechnerisch verknüpft - demzufolge ist diese Oberposition als "Summenmussfeld" gekennzeichnet. Es wird hier aber inhaltlich keine eigene Information, sondern lediglich das Rechenergebnis "Summe aus Unterpositionen" erwartet.

Diese Positionen enthalten keinen eigenen Informationsgehalt und können daher durch die Software des Unternehmens gefüllt werden. Dies gilt im Übrigen auch für die „echten“ Mussfelder, die rechtsformspezifisch

26 Auszug aus der Taxonomie Steuer; entnommen aus www.abra-search.com von ABZ Reporting GmbH, Darmstadt. 
im jeweils vorliegenden Fall nicht einschlägig sind; sie werden mit „NIL“ gefüllt.

Beispiel:

Bei der Übermittlung der Inhalte von Bilanz und G+V eines Einzelunternehmens sind die Mussfelder, die nur für andere Rechtsformen gelten (z. B. „Kapitalanteile der persönlich haftenden Gesellschafter \{M Summe\}" einschließlich der dazu gehörenden Unterpositionen „softwaregesteuert" leer zu übermitteln.

Diese Betrachtung relativiert die in der jüngsten Literatur ${ }^{27}$ aufgekommene Sorge an der hohen Anzahl festgelegter Mussfelder.

\section{Branchenspezifische Unterarbeitsgruppen}

Die vorliegende Taxonomie nach $\S 5 \mathrm{~b}$ EStG gilt für alle Übermittler, die nach steuerlichen oder nach den allgemeinen handelsrechtlichen Rechnungslegungsvorschriften bilanzieren. Für bestimmte Branchen bestehen besondere Formvorschriften (z. B. RechKredV ${ }^{28}$ oder RechVersV ${ }^{29}$ ). Insgesamt sind besondere Rechnungslegungsvorschriften oder andere Besonderheiten für die folgenden Branchen zu berücksichtigen:

- Banken,

- Versicherungen,

- Land- und Forstwirtschaft,

- Wohnungsunternehmen,

- Pflegebereich/Krankenhäuser,

- Verkehrsbetriebe,

- kommunale Betriebe.

Für diese Branchen sind eigene Taxonomien oder Taxonomie-Ergänzungen zurzeit in Arbeit. Sie werden in Unterarbeitsgruppen der AG Taxonomie Steuer beraten und zu einem späteren Zeitpunkt veröffentlicht.

27 Vgl. z. B. Herzig/Briesemeister, „Problemfelder E-Bilanz", Der Betrieb 2010, 57.

28 Verordnung über die Rechnungslegung der Kreditinstitute und Finanzdienstleistungsinstitute (Kreditinstituts-Rechnungslegungsverordnung-RechKredV).

29 Verordnung über die Rechnungslegung von Versicherungsunternehmen (Versicherungsunternehmens-Rechnungslegungsverordnung-RechVersV). 


\section{E. Sonderfälle}

\section{Anlagespiegel}

Soweit der Anlagespiegel nicht Bestandteil der Bilanz, sondern Bestandteil des Anhangs ist, unterliegt sein Inhalt nicht der Übermittlungspflicht nach $\S 5 \mathrm{~b}$ EStG. In jedem Fall kann der für die Finanzverwaltung wichtige Anlagespiegel mittels XBRL übermittelt werden.

\section{Außerbilanzielle Zu- und Abrechnungen}

Für außerbilanzielle Zu- und Abrechnungen sehen die Verfahren in der Finanzverwaltung und die Steuererklärungsvordrucke je nach Rechtsform des Unternehmens unterschiedliche Vorgehensweisen vor. Für die der Körperschaftsteuer unterliegenden Kapitalgesellschaften sieht die Körperschaftsteuererklärung entsprechende Felder vor.

Für den Bereich der Einzelunternehmen und der Personengesellschaften/ Mitunternehmerschaften ist dies anders. Bisher wird die Ermittlung des steuerlichen Gewinns formlos als Anlage zur Steuererklärung durch den Steuerpflichtigen bzw. seines steuerlichen Beraters vorgenommen. Die Taxonomie Steuer sieht für Einzelunternehmen und Personengesellschaften/Mitunternehmerschaften ein eigenes Modul ${ }^{30}$ vor, in dem der steuerliche Gewinn - ausgehend vom Jahresüberschuss - entwickelt wird.

\section{Kapitalkontenentwicklung}

Bei Personengesellschaften/Mitunternehmerschaften ist die Kapitalkontenentwicklung von besonderer Bedeutung. Sie wird in der Taxonomie in einem eigenen Teil abgewickelt. Da für diesen Komplex ein erhöhter Umstellungsaufwand zu erwarten ist, wurde in der AG TaxonomieSteuer der Kompromiss gefunden, der den Unternehmen und den steuerberatenden Berufen entsprechend längere Vorbereitungszeit lässt.

Die hier vorgesehenen Mussfelder werden erst zu einem späteren Zeitpunkt wirksam. Sie haben eine eigene zeitliche Gültigkeitsangabe in der Taxonomie ${ }^{31}$ und sind für eine verpflichtende Übermittlung erst für Wirtschaftsjahre vorgesehen, die nach dem 31.12.2013 beginnen.

30 "Steuerliche Gewinnermittlung".

31 fiscalValidSince: 2013-12-31. 
Bis zu diesem Zeitpunkt können Kapitalkontenentwicklungen in Textform, ${ }^{32}$ aber innerhalb der Taxonomie übermittelt werden.

\section{Sonder- und Ergänzungsbilanzen}

Inhalte von Sonder- und Ergänzungsbilanzen unterliegen ebenfalls der elektronischen Übermittlungspflicht. Da diesen häufig keine Finanzbuchhaltung zugrunde liegt, bedarf die Umsetzung der Übermittlungspflicht auch hier einer längeren Vorbereitungsphase. Ggf. liegen für Sonder- und Ergänzungsbilanzen einschließlich der dazu gehörigen $\mathrm{G}+\mathrm{V}$ Härtefallgründe nach $§ 5 \mathrm{~b}$ Absatz $2 \mathrm{EStG}$ vor.

In diesen Fällen ist es möglich, auch Sonder- und Ergänzungsbilanzen in einem Textfeld der Gesamthandsbilanz als Freitext zu übermitteln. Andererseits können Sonder- und Ergänzungsbilanzen technisch auch unabhängig von der Gesamthandsbilanz in einem eigenen Datensatz übermittelt werden.

\section{F. Stellungnahme der im Projekt beteiligten Wirtschaftsvertreter}

Bereits im Verlauf des Projektes konnten die Vertreter der Wirtschaft die Erfordernisse aus den Prozessen der Unternehmen in die Erarbeitung der Taxonomie einbringen. Nicht zuletzt durch die Schilderung der eigenen Prozesse bei der Erstellung der Jahresabschlüsse (handelsrechtlicht mit Überleitungsrechnung oder auch steuerlich) konnten praxistaugliche Anpassungen vorgenommen werden. Als Beispiel sei hier der Hinweis auf die so genannten Auffangpositionen in der Taxonomie erlaubt.

Nach Erarbeitung eines Entwurfs der Taxonomie Steuer nahmen die Vertreter der Wirtschaft in einem gemeinsamen Papier Stellung zu noch offenen Fragen bzw. zu ggf. abweichenden Auffassungen. Hinweise auf konkrete Positionen der Taxonomie konnten noch in den aktuellen Entwurf eingearbeitet werden.

Grundsätzlich wenden sich die Vertreter der Wirtschaft gegen die Differenzierungstiefe der erarbeiteten Taxonomie für die Bereiche Bilanz und Gewinn und Verlustrechnungen gegenüber den Anforderungen des Handelsrechts ( $\S 266$ und 275 HGB) und bezweifeln die Rechtsgrundlage in diesem Zusammenhang.

32 XBRL gestattet die Übermittlung von Text im HTML-Format. 
Im Einzelnen schlagen die Vertreter der Wirtschaft eine Verschiebung des Anwendungszeitpunktes für die E-Bilanz mit einer vorgelagerten Testphase (durch freiwillige Übermittlung von Jahresabschlüssen) vor.

Weitere Vorschläge betreffen vor allem technische Fragen. Besonders für die zukünftige Entwicklung der elektronischen Übermittlung von Jahresabschlüssen einerseits und Steuererklärungen andererseits wurde der Verzicht auf Redundanzen in beiden Bereichen eingefordert.

\section{G. Zeitschiene}

Das BMF-Schreiben zur Festlegung der Mindestanforderungen nach $\S 51$ Abs. 4 EStG ist im Entwurf am 31.8.2010 33 den Wirtschaftsverbänden zur Stellungnahme übersandt worden. Neben der Möglichkeit von schriftlichen Stellungnahmen hat das BMF zu einer mündlichen Verbandsanhörung am 11.10.2010 eingeladen.

$\mathrm{Ab}$ dem 1.1.2011 ${ }^{34}$ beginn die Übermittlungspflicht $z$. B. für Eröffnungsbilanzen. Im Jahre 2011 wird die Übermittlung von Papierbilanzen durch die Finanzverwaltung allerdings nicht beanstandet (vgl. B. IV. oben). Ab 2012 erste elektronische Übermittlungen von ordentlichen Jahresabschlüssen (Sonderregelung für Kapitalkontenentwicklung).

Zukünftig ist vorgesehen, Änderungen durch das Finanzamt - etwa im Rahmen einer Betriebsprüfung - ebenfalls elektronisch ggf. einschließlich einer Differenzanalyse auf der Basis steuerlicher Wertansätze an das Unternehmen zu übermitteln.

\section{H. Zusammenfassung}

Die Übermittlung der Inhalte von Bilanz und Gewinn- und Verlustrechnung vermeidet aktuell noch bestehende Medienbrüche und eröffnet neue Möglichkeiten der elektronischen Kommunikation zwischen Unternehmen und Finanzverwaltung.

33 Mit Schreiben v. 16.12.2010 (IV C 6 - S 2133-b/10/10001-2010/1012271) wurde die Taxonomie verbindlich veröffentlicht. Gleichzeitig ist für 2011 eine Pilotierung geplant. Die Erkenntnisse aus der Pilotierung werden in einer überarbeiteten Taxonomie berücksichtigt.

34 Durch Anwendungszeitpunktverschiebungsverordnung v. 17.12.2010 (§51 Absatz 4 Nummer 1 c EStG) wurde der Beginn der Übermittlungspflicht um ein Jahr verschoben. Die Übermittlungspflicht gilt nunmehr für Abschlüsse von Wirtschaftsjahren, die nach dem 31.12.2011 beginnen. 
Die sehr frühe Einbeziehung von Vertretern der Wirtschaft in die Erarbeitung der Taxonomie nach $\S 5$ bStG war sehr fruchtbar und ermöglichte es allen Beteiligten bereits im Beratungsprozess ihr know how und ihre Sichtweisen einzubringen.

Der Entwurf des BMF-Schreibens nach $\S 51$ Abs. 4 EStG einschließlich des in der AG Taxonomie Steuer erarbeiteten Entwurfs der Taxonomie Steuer liegen vor und werden im Rahmen der öffentlichen Verbandsanhörung am 11.10.2010 beraten.

Die Zusammenarbeit in der AG Taxonomie Steuer ist auch für alle künftigen Anpassungen der Taxonomie Steuer geplant.

In späteren Ausbaustufen der E-Bilanz wird die Finanzverwaltung geänderte Bilanzdaten (z.B. Prüferbilanzen) mit Differenzanalyse an das Unternehmen zurück übermitteln. 


\title{
Aktuelle Probleme aus dem Bilanzsteuerrecht
}

\author{
Dipl.-Kfm. Manfred Günkel, \\ Steuerberater, Wirtschaftsprüfer, Düsseldorf
}

Inhaltsübersicht

I. Teilwertzuschreibung auf Fremdwährungsverbindlichkeiten

1. Sachverhalt

2. Lösungshinweise

a) Rechtsprechung

b) Zusammenhang mit BFH vom 26.9.2007 (I R 58/06)

c) Stellungnahme

3. Fazit

II. Bilanzierung von angeschafften Drohverlustrückstellungen

1. Sachverhalt

2. Lösungshinweise

a) Rechtsprechung

b) Stellungnahme

c) Übertragbarkeit des BFHUrteils vom 16.12.2009 auf den Ansatz anderer Rückstellungen

3. Fazit

III. „Lifo-Methode“ bei Teilwertzuschreibungen von Beteiligungen (last down, first up)

1. Sachverhalt

2. Lösungshinweise

a) Finanzverwaltung

b) Rechtsprechung

3. Fazit

IV. Subjektiver Fehlerbegriff zu

(Un)Gunsten

der Finanzverwaltung

1. Sachverhalt

2. Lösungshinweise

a) (Un)richtiger Bilanzansatz

b) Ausübung von bilanzsteuerrechtlichen Bandbreiten c) Aufgabe des subjektiven Fehlerbegriffs aus Gründen der "Rechtshygiene"

3. Fazit

V. Laufzeitfiktion von unverzinslichen (Gesellschafter-)Darlehen

1. Sachverhalt

2. Lösungshinweise

a) Bilanzansatz des Gesellschafterdarlehens in der Steuerbilanz für das abgelaufene Geschäftsjahr

b) Bilanzansatz des Gesellschafterdarlehens in den Steuerbilanzen für die nächsten Geschäftsjahre

VI. Steuerliche Herstellungskosten nach BilMoG

1. Sachverhalt

2. Lösungshinweise

a) Umfang der zwingend zu aktivierenden Herstellungskosten im Handels- und Steuerrecht

b) Angedachte Neudefinition des Umfangs der zwingend zu aktivierenden Herstellungskosten

c) Historische Entwicklung der Definition des Umfangs der zwingend zu aktivierenden Herstellungskosten

d) Einbeziehungswahlrecht für Verwaltungs- und Sozialgemeinkosten als Gewohnheitsrecht

e) Unzutreffende Begründung der angedachten Neudefinition des Umfangs der zwingend zu aktivierenden 
Herstellungskosten durch das BMF

f) Vorläufige Aufgabe der angedachten Neudefinition des Umfangs der zwingend zu aktivierenden Herstellungskosten durch die Finanzverwaltung
3. Fazit

VII. Konsequenzen nicht vorgenommener Teilwertabschreibungen bei Umwandlungsvorgängen

1. Sachverhalt

2. Lösungshinweise

3. Fazit

\section{Teilwertzuschreibung auf Fremdwährungsverbindlichkeiten}

\section{Sachverhalt}

Eine GbR hat zum Gesellschaftszweck, einen Tanker zu erwerben und zu betreiben. Zur Finanzierung des Schiffes nimmt die GbR in 2005 ein langfristiges Darlehen (Laufzeit 14 Jahre) in japanischen Yen auf. Die Laufzeit endet im Jahr 2019. Im Jahr 2009 ergibt sich aufgrund des im Vergleich zum 31.12.2005 gestiegenen Yen-Kurses eine Höherbewertung der Verbindlichkeit. Das Finanzamt vertritt die Auffassung, dass eine Teilwertzuschreibung in der Steuerbilanz nicht zulässig sei, da die Werterhöhung des Darlehens nicht von Dauer sei.

\section{Lösungshinweise}

a) Rechtsprechung

Der IV. Senat des BFH hat mit Urteil vom 23.4.2009 1 in Übereinstimmung mit der Meinung der Finanzverwaltung ${ }^{2}$ und der Vorinstanz (FG Bremen $^{3}$ ) in einem gleichartig gelagerten Fall entschieden, dass die GbR das Darlehen aufgrund der Wechselkursänderung im Jahr 2009 nicht höher bewerten dürfe. Der höhere Teilwert könne - in sinngemäßer Anwendung des $\S 6$ Abs. 1 Nr. 2 S. 2 EStG - (nur) angesetzt werden, wenn er aufgrund einer voraussichtlich dauernden Wertveränderung höher sei als der ursprüngliche Rückzahlungsbetrag. ${ }^{4}$ Bei Verbindlichkeiten wird grundsätzlich wegen des Vorsichts- und Imparitätsprinzips ein höherer Teilwert als die Anschaffungskosten der Verbindlichkeit angesetzt,

1 Vgl. BFH, Urt. v. 23.4.2009 - IV R 62/06, BStBl. II 2009, 778.

2 Vgl. BMF, Schr. v. 12.8.2002, IV A 6-S 2175-7/02, BStBl. I 2002, 793. Hiernach berechtigen Wechselkursschwankungen bei Kursschwankungen unterliegenden Fremdwährungsverbindlichkeiten nicht zum höheren Ansatz der Verbindlichkeit.

3 Vgl. FG Bremen, Urt. v. 12.10.2006 - 1 K 181/05 (6), EFG 2007, 575; hierzu auch Günkel, StbJb 2008/2009, S. 298.

4 Vgl. BFH, Urt. v. 22.11.1988 - VIII R 62/85, BStBl. II 1989, 359. 
allerdings - entsprechend der Behandlung auf der Aktivseite - nur bei einer dauerhaften Wertveränderung, § 6 Abs. 1 Nr. 3 EStG. Eine voraussichtlich dauernde Wertminderung liege bei aktiven Wirtschaftsgütern vor, wenn der Teilwert nachhaltig unter dem maßgeblichen Buchwert gesunken sei. Das Kriterium der „Nachhaltigkeit" sei erfüllt, wenn aus der Sicht des Bilanzstichtags aufgrund objektiver Anzeichen ernstlich mit einem langfristigen Anhalten der Wertminderung gerechnet werden müsse. Hierfür bedürfe es einer an der Eigenart des Wirtschaftsguts ausgerichteten Prognose. Ob bei Fremdwährungsverbindlichkeiten eine Veränderung des Währungskurses zum Bilanzstichtag eine voraussichtlich dauerhafte Teilwerterhöhung darstelle, hängt nach Ansicht des IV. Senats des BFH maßgeblich von der Laufzeit der Verbindlichkeit ab. Die Grundsätze für nicht abnutzbare Wirtschaftsgüter des Anlagevermögens ließen sich daher auf Verbindlichkeiten nicht übertragen. Bei Fremdwährungsverbindlichkeiten, die - wie im vorliegenden Fall - eine Restlaufzeit von ca. zehn Jahren hätten, sei typisierend davon auszugehen, dass sich Währungsschwankungen grundsätzlich ausgleichen. Demnach sei bei diesen Verbindlichkeiten nicht jede Kursänderung als dauerhafte Wertänderung anzusehen. Eine Teilwertzuschreibung muss daher im vorliegenden Fall unterbleiben. Das Vorsichtsprinzip erfordert auch keine andere Bewertung, da nach den Gesetzesmaterialien mit der Neuregelung des $\S 6$ Abs. 1 EStG trotz Übernahme des Begriffs dauernde Wertminderung aus $\S 253$ Abs. 2 S. 3 HGB a.F. das handelsrechtliche Vorsichtsprinzip zugunsten des Prinzips der Besteuerung nach der wirtschaftlichen Leistungsfähigkeit zurückgedrängt werden sollte.

\section{b) Zusammenhang mit BFH vom 26.9.2007 (I R 58/06) $)^{5}$}

Die Entscheidung des IV. Senats des BFH erzeugt ein gewisses Spannungsfeld zur Entscheidung des I. Senats des BFH vom 26.9.20076 (Infineon-Urteil). Der I. Senat des BFH hatte dort den Börsenkurs für die Beurteilung der voraussichtlich dauernden Wertminderung von im Anlagevermögen gehaltenen Aktien als ausschlaggebenden Parameter zur Entscheidung über eine TW-Abschreibung angesehen, da der Börsenkurs zum Bilanzstichtag die Einschätzung der Marktteilnehmer über die künftige Ent-

5 Vgl. BFH, Urt. v. 26.9.2007 - I R 58/06, BStBl. II 2009, 294; hierzu auch Günkel, StbJb 2008/2009, S. $296 \mathrm{ff}$.

6 Vgl. BFH, Urt. v. 26.9.2007 (a. a. O. Fn. 5). Das BMF hat hierzu mit Schreiben v. 26.3.2009 - IV C 6-S 2171-b/0, BStBl. I 2009, 514, Stellung genommen. Das BFH-Urteil wird über den entschiedenen Einzelfall hinaus "prinzipiell“ angewendet. Dabei werden jedoch spezielle (neue) zeitliche und rechnerische Bandbreiten genannt, die als Voraussetzung für eine TW-Abschreibung dienen (Wertänderung um mehr $40 \%$ bezogen auf die Anschaffungskosten bzw. mehr als $25 \%$ mit Blick auf den letzten Bilanzstichtag). 
wicklung des Kurses widerspiegelt und daher eine Aussage zu der voraussichtlichen Dauerhaftigkeit einer Wertminderung ermöglicht. ${ }^{7}$

Der IV. Senat des BFH überträgt diesen - für nichtabnutzbare Wirtschaftsgüter des Anlagevermögens entwickelten Ansatz - nicht auf Fremdwährungsverbindlichkeiten. Vielmehr erachtet er im Rahmen einer an der Eigenart des Wirtschaftsgutes ausgerichteten Beurteilung die Restlaufzeit der Verbindlichkeit als das maßgebende Kriterium, anhand dessen eine Prognose über die voraussichtliche Dauerhaftigkeit der Wertminderung vorzunehmen ist. Bei langen Restlaufzeiten (im Urteilsfall: ca. zehn Jahre) soll typisierend davon auszugehen sein, dass sich Währungsschwankungen wieder ausgleichen. Die durch die Kurserhöhung der Fremdwährungsverbindlichkeit bewirkte Erhöhung des Teilwerts der Verbindlichkeit wird damit - da nicht dauerhaft - nicht steuerrelevant. Abweichend vom Infineon-Urteil des I. Senats ist damit nicht jede Kursänderung als dauerhafte Werterhöhung anzusehen. ${ }^{8}$ Diese Auffassung des IV. Senats deckt sich in gewisser Weise mit der Ansicht der Finanzverwaltung, die bei Wechselkursänderungen auf Devisenmärkten zwischen üblichen Wechselkursschwankungen und nachhaltigen Kurseinbrüchen unterscheidet, ${ }^{9}$ ohne dass ersichtlich ist, wie die Unterscheidung getroffen werden kann.

\section{c) Stellungnahme}

Das Urteil des IV. Senats des BFH steht dann in Übereinstimmung mit dem Urteil des I. Senats, wenn man in beiden Urteilen auf den jeweiligen Kerngedanken abstellt, dass die Prognose der voraussichtlich dauernden Wertminderung an der Eigenart des betreffenden Wirtschaftsguts auszurichten ist. ${ }^{10}$ Die Dauerhaftigkeit der Wertminderung einer langfristigen Fremdwährungsverbindlichkeit ist daher am Maßstab einer zeitkongruenten (sprich: langfristigen) Währungsschwankung zu messen. Vor diesem Hintergrund war der stichtagsbezogene Kursanstieg des Yen nur vorübergehend. Eine TW-Zuschreibung konnte daher nicht mit steuerlicher Wirkung geltend gemacht werden. ${ }^{11}$

7 Kritisch zu diesem Urteil (BFH, IR 58/06, a.a.O. Fn. 5) etwa Hahne, DStR 2008, 540 und Hoffmann, DB 2008, 260.

8 Zustimmend etwa Kiesel/Görner in H/H/R, §6 EStG, Rz. 115, Stichwort „Fremdwährungsverbindlichkeiten"; Ortmann-Babel in Lademann, EStG, $\S 6 \mathrm{Rz} .851$.

9 Vgl. BMF, Schr. v. 12.8.2002, IV A 6-S 2175-7/02, BStBl. I 2002, 793.

10 Vgl. Prinz, StuB 2009, 567. Kritisch zu dieser Übereinstimmung Hoffmann, DB 2009, 1439.

11 In diesem Sinne das BFH-Urteil v. 23.4.2009 (IV R 62/06, a. a. O. Fn. 1) befürwortend Weber-Grellet, BB 2009, 46. 
Beleuchtet man den Aspekt des Prognosezeitraums näher, können Zweifel an der Begründung des IV. Senats aufkommen. Mit der Vorgabe eines Prognosezeitraums nimmt der IV. Senat Bezug auf ein Urteil des I. Senats vom 14.3.2006, ${ }^{12}$ in dem für abnutzbare Wirtschaftsgüter des Anlagevermögens festgestellt wird, dass von einer voraussichtlich dauerhaften Wertminderung auszugehen sei, wenn der Wert des jeweiligen Wirtschaftsguts zum Bilanzstichtag mindestens für die halbe Restnutzungsdauer unter dem planmäßigen Buchwert liegt. ${ }^{13}$ Vor diesem Hintergrund stellt sich deshalb in gesetzessystematischer Hinsicht die Frage, ob die für abnutzbare Wirtschaftsgüter entwickelten Bewertungsgrundsätze auch für die Bewertung von Verbindlichkeiten (§6 Abs. 1 Nr. 3 EStG) gelten können. Denn der eindeutige Gesetzeswortlaut des $\S 6$ Abs. 1 Nr. 3 EStG zur Bewertung von Verbindlichkeiten verweist vielmehr auf die Bewertungsregeln für nicht abnutzbare Wirtschaftsgüter (§ 6 Abs. 1 Nr. 2 EStG). Eine Anwendung der Grundsätze des Infineon-Urteils zu nicht abnutzbaren Wirtschaftsgütern (Beteiligungen) vom 26.9.200714 auf den vorliegenden Fall der Teilwert-Zuschreibung von Verbindlichkeiten ist somit gesetzessystematisch vorgesehen. ${ }^{15}$ Die Bezugnahme des $\mathrm{BFH}$ auf die Bewertungsgrundsätze für abnutzbare Wirtschaftsgüter muss aus dieser Perspektive abgelehnt werden.

Fraglich erscheint zudem, ob nicht auch aus wirtschaftlichen Erwägungen heraus ein Abstellen auf den Marktpreis als Indikator für eine dauerhafte Wertminderung im Bereich der Bewertung von Verbindlichkeiten zulässig bzw. aus Sicht des Prinzips der Besteuerung nach der wirtschaftlichen Leistungsfähigkeit notwendig ist. Geht man davon aus, dass der Marktpreis Ertragserwartungen objektiviert abbildet, so besteht grundsätzlich keine Notwendigkeit, auf den „Hilfsmaßstab Wertminderungszeitraum" abzustellen. ${ }^{16}$ Ein Abstellen auf den Börsenkurs ist für den BFH im Infineon-Urteil vom 26.9.200717 möglich gewesen, da der Börsenkurs die Einschätzung der Marktteilnehmer über eine Rendite wider-

12 Vgl. BFH, Urt. v. 14.3.2006 - I R 22/05, BStBl. II 2006, 680.

13 Vgl. zur Besprechung des BFH-Urteils v. 14.3.2006 (a.a. O. Fn. 12) Günkel in StbJb 2007/2008, S. 238; kritisch zur Beurteilung der dauernden Wertminderung nach Maßgabe künftiger Zeiträume mit Hinweis auf einen Verstoß gegen das Stichtagsprinzip Paus, FR 2009, 945 und Weber-Grellet, BB 2009, 46.

14 Vgl. BFH, Urt. v. 26.9.2007 - I R 58/06, BStBl. II 2009, 294.

15 Vgl. in diesem Sinne Günkel, StbJb 2008/2009, S. 298; Hahne, BB 2009, 1467. Da der BFH im Urteil v. 23.4.2009 (a.a. O. Fn. 1) von den Grundsätzen des Urteils v. 26.9.2007 (a. a. O. Fn. 14) abweicht, erfolgt keine Klärung der Frage, ob Kursänderungen im Zeitraum zwischen Bilanzstichtag und Bilanzaufstellung auf den Bilanzansatz zurückwirken oder ob der Stichtagskurs anzusetzen ist (vgl. zu dieser Fragestellung Günkel, StbJb 2008/2009, S. 298).

16 Vgl. hierzu ausführlich Schlotter, FR 2009, 1059.

17 A. a. O. Fn. 14. 
spiegelt und damit zugleich eine Aussage zur Dauerhaftigkeit einer Wertminderung trifft. ${ }^{18}$ Die Bestimmung eines Prognosezeitraums ist daher entbehrlich. Dieser Grundsatz kann auch auf den vorliegenden Fall einer Fremdwährungsverbindlichkeit angewendet werden. ${ }^{19}$ Der Wechselkurs einer Währung ist ein Tauschwert, der sich ebenso wie ein Börsenkurs auf dem (Devisen-) Markt bildet. Wechselkursänderungen entstehen wie beim Börsenkurs durch das Angebots- und Nachfrageverhalten der Marktakteure. Eine Änderung des Wechselkurses beinhaltet damit ebenso wie ein Börsenkurs die Einschätzung der Marktteilnehmer über die Dauerhaftigkeit der Wertänderung.

Des Weiteren führt die Abhängigkeit der Feststellung einer voraussichtlichen Dauerhaftigkeit der Wertänderung von der verbleibenden Restlaufzeit der Verbindlichkeit zu der Unterstellung, dass sich langfristig Wertänderungen wieder ausgleichen. Ein derartiger Erfahrungssatz besteht jedoch gerade nicht. ${ }^{20}$ Für die Praxis entsteht zudem das Problem einer Abgrenzung der Laufzeiten von Verbindlichkeiten. So beschränkt der BFH seine Aussagen in der Entscheidung vom 23.4.2009 auf langfristige Verbindlichkeiten. Unklar bleibt damit, welche Kriterien für kurzfristige Verbindlichkeiten gelten und ab welcher Laufzeit eine Verbindlichkeit als "langfristig" einzustufen ist. ${ }^{21}$ Eine Abgrenzung der Laufzeiten könnte sich an handelsbilanziellen Kriterien ausrichten $(§ 285$ Nr. 1 HGB mit 5-Jahresgrenze für langfristige Verbindlichkeiten, § 268 Abs. 1 HGB mit 1-Jahresgrenze für kurzfristige Verbindlichkeiten). ${ }^{22}$ Denkbar wäre jedoch auch eine Kategorisierung der Verbindlichkeiten in "Verbindlichkeiten des laufenden Geschäftsverkehrs" und „sonstige Verbindlichkeiten", wie sie das BMF im Schreiben vom 12.8.2002 vorsieht, ${ }^{23}$ oder ein Abstellen auf einen bestimmten prozentualen Umfang der Wertänderung, ab dem eine steuerwirksame Zuschreibung zulässig ist. ${ }^{24}$

18 Vgl. BFH, Urt. v. 26.9.2007 - I R 58/06, BStBl. II 2009, 294.

19 Vgl. in diesem Sinne Günkel, StbJb 2008/2009, S. 298.

20 Vgl. Hahne, DStR 2009, 1573; Hoffmann, DB 2009, 1441; Schlotter, FR 2009, 1059; Prinz, StuB 2009, 567 merkt darüber hinaus relativierend an, dass - wenn Zweifel im Hinblick auf die prognostische Richtigkeit von Wertveränderungen geäußert werden - diese vor dem Hintergrund der Finanz- und Wirtschaftskrise indes auch für Börsenkurse gelten müss(t)en.

21 Vgl. zu dieser Kritik ausführlich Hahne, DStR 2009, 1573.

22 Vgl. Prinz, StuB 2009, 567.

23 Vgl. BMF, Schr. v 12.8.2002, IV A 6-S 2175-7/02, BStBl. I 2002, 793. Vgl. zu dieser Kategorisierung auch Hahne, DStR 2009, 1573.

24 Schlotter, FR 2009, 1059 schlägt vor, dass eine Wertänderung von mehr als $10 \%$ für eine steuerwirksame Zuschreibung ausreicht; vgl. zur $10 \%$-Grenze auch Heger, Ubg 2008, 68. Es ist zu erwarten, dass die Finanzverwaltung diesen Ansatz unter Verweis auf die stark kritisierten Wertänderungsgrenzen als Voraussetzung für TW-Abschreibungen nicht abnutzbarer Wirtschaftsgüter des 
Problematisch erscheint darüber hinaus, dass der BFH eine Unterscheidung in kurzfristige Marktbewegungen und fundamentale Wechselkursänderungen vornimmt und nur letztere zu einer TW-Zuschreibung mit steuerlicher Wirkung berechtigt. Ob eine Wechselkursänderung jedoch als "vorübergehend" oder "fundamental" einzustufen ist, wird sich schwerlich am Bilanzstichtag, sondern erst im Rückblick auf mehrere Jahre nachweisen lassen. Eine bei Aufstellung der Bilanz rechtssichere Beurteilung durch den Steuerpflichtigen ist somit fast nicht möglich. ${ }^{25}$ Zudem erscheint es vor diesem Hintergrund notwendig, die Währungsprognose, die mit der Laufzeit der Darlehensverbindlichkeit einhergeht, gutachterlich zu fundieren. ${ }^{26}$

\section{Fazit}

Vor dem Hintergrund der angestellten Überlegungen erscheint das Ergebnis des BFH im Urteil vom 23.4.2009 nicht zwingend. ${ }^{27}$ Zudem wirft die Entscheidung praktische (Prognose-) Probleme auf. Auf Basis dieses Urteils wird dem Steuerpflichtigen nichts anderes übrig bleiben als Währungsverluste durch Neuabschluss eines Darlehensvertrags und Ablösung des alten Darlehensvertrags den Verlust „formal“ zu realisieren. Es bleibt zu hoffen, dass eine derartig formale Interpretation des Prinzips der Besteuerung nach der wirtschaftlichen Leistungsfähigkeit von dem IV. Senat des BFH nicht gewollt war. Die Diskussion um die Frage der Abgrenzung einer "voraussichtlich dauernden Wertminderung" kann keinesfalls als beendet angesehen werden. Dabei muss man auch infrage stellen, ob es aufgrund des strengen Wertaufholungsgebotes einer solchen einschränkenden Rechtsprechung bedarf. Denn Wertkorrekturen in die andere Richtung wären aufgrund des auch für Verbindlichkeiten geltenden strengen Wertaufholungsgrundsatzes zu jedem Bilanzstichtag vorzunehmen.

Anlagevermögens (siehe BMF-Schreiben v. 26.3.2009 (a.a. O. Fn. 4) ablehnen wird.

25 Vgl. zu Prognosen im Bilanzrecht Hennrichs, AG 2006, 698; kritisch in Bezug auf die vorliegende Problematik auch Hahne, DStR 2009, 1573.

26 Vgl. Prinz, StuB 2009, 567.

27 Vgl. mit anderer Wertung schon Günkel, StbJb 2008/2009, S. 298. 


\section{Bilanzierung von angeschafften Drohverlustrückstellungen}

\section{Sachverhalt}

Die Z-GmbH hat durch Kauf- und Übertragungsvertrag sämtliche Vermögensgegenstände und Schulden der K-GmbH im Rahmen eines Asset Deals zu einem Kaufpreis von EUR 5 Mio. erworben. Im Rahmen des Asset Deals wurden durch die Z-GmbH drei Mietverträge von der K-GmbH übernommen. Der Kaufvertrag sieht ausdrücklich eine Freistellung der $\mathrm{K}-\mathrm{GmbH}$ von der Verpflichtung aus den Mietverträgen vor. Da die Mietverträge bereits für die K-GmbH keinen wirtschaftlichen Nutzen mehr versprachen, hatte diese handelsrechtlich eine entsprechende Rückstellung für drohende Verluste i. S. v. § 249 Abs. 1 Satz 1 HGB i. H. v. EUR 950.000 gebildet, die aufgrund des Passivierungsverbots in $\S 5$ Abs. 4a Satz 1 EStG in der Steuerbilanz nicht angesetzt wurde. Die Rückstellung für drohende Verluste wurde bei der Ermittlung des Kaufpreises kaufpreismindernd mit ihrem handelsrechtlichen Wertansatz berücksichtigt.

Fraglich ist, welche Auswirkungen sich in der Steuerbilanz der erwerbenden Z-GmbH hinsichtlich der Rückstellung für drohende Verluste für die Mietverträge ergeben.

\section{Lösungshinweise ${ }^{28}$}

a) Rechtsprechung

In dieser Frage hatte das FG Düsseldorf mit Urteil vom 9.9.2008 ${ }^{29}$ entgegen der Auffassung der Finanzverwaltung ${ }^{30}$ entschieden, dass der beim Erwerber handelsrechtlich zurückgestellte Betrag nicht gewinnerhöhend in der Steuerbilanz aufzulösen sei. ${ }^{31}$ Durch das Passivierungsverbot des $§ 5$ Abs. 4a Satz 1 EStG wolle der Gesetzgeber vermeiden, dass Verluste, die zwar wahrscheinlich sind, sich aber erst in den folgenden Veranlagungszeiträumen realisieren, bereits in früheren Veranlagungszeiträumen steuermindernd gebildet werden dürfen. Diese Voraussetzung sei im vorliegenden Fall nicht gegeben. Das FG Düsseldorf ließ in seiner Entscheidung

28 Dieser Fall wurde auf dem Fachkongress in ähnlicher Form schon behandelt, siehe hierzu Günkel, StbJb 2002/2003; S. 291 ff.; ders. in StbJb 2005/2006, S. 262 ff.; ders. in StbJb 2008/2009, S. 299; ders. in StbJb 2009/2010, S. 350 ff.

29 Vgl. FG Düsseldorf, Urt. v. 9.9.2008 - 6 K 1161/04 K, F, EFG 2009, 167.

30 Das Finanzamt vertrat im Streitfall die Auffassung, dass der Erwerber zwar verpflichtet gewesen sei, die entsprechende Rückstellung für drohende Verluste im Zeitpunkt des Erwerbs zu bilden, der Ansatz einer Rückstellung für drohende Verluste in der Schlussbilanz nach $§ 5$ Abs. 4a Satz 1 EStG indes nicht zulässig sei.

31 Vgl. zur Besprechung des Urteils des FG Düsseldorf (a. a. O. Fn. 3) und der sich hieraus ergebenden Implikationen Günkel, StbJb 2009/2010, S. 350 ff. 
indes die Frage offen, ob das Ansatzverbot des $\S 5$ Abs. 4a Satz 1 EStG bereits bei Erwerb zu beachten gewesen wäre und ob aufgrund des Anschaffungsgeschäfts nicht eine ungewisse Verbindlichkeit vorlag, auf die $\S 5$ Abs. 4a EStG keine Anwendung findet. Aufgrund der grundsätzlichen Bedeutung der Rechtssache war die Revision vor dem BFH zugelassen.

Der BFH hat zum FG Düsseldorf Fall mit Urteil vom 16.12.200932 entschieden, dass das Ansatzverbot des $\S 5$ Abs. 4a Satz 1 EStG auf den Erwerb einer Rückstellung für drohende Verluste im Rahmen eines Anschaffungsvorgangs nicht anwendbar ist. Wie auch die Vorinstanz sieht der BFH keine Rechtsgrundlage für eine Gewinnrealisierung durch einen Anschaffungsvorgang. In der Begründung unterscheidet sich das Urteil des BFH indes erheblich von der Vorinstanz. Das FG Düsseldorf hatte entschieden, dass eine etwaige Drohverlustrückstellung jedenfalls nicht erfolgswirksam aufzulösen sei. ${ }^{33}$ Demgegenüber argumentiert der $\mathrm{BFH}$, dass der Erwerber sich im vorliegenden Sachverhalt gegenüber dem Veräußerer verpflichtete, die drohenden Verluste aus den Mietverträgen zu übernehmen und deshalb für diese Verpflichtung eine ungewisse Verbindlichkeit zu passivieren habe. Denn wird der verlustbedrohte Vertrag entgeltlich gegen Schuldübernahme erworben, so ist der Erwerber im Verhältnis zum Veräußerer verpflichtet, ihn von der gegenüber dem Gläubiger der Schuld weiter bestehenden Zahlungspflicht - im Streitfall die Verpflichtung zur Mietzahlung - freizustellen. Die Übernahme steuerrechtlich aufgrund von $\S 5$ Abs. 4a EStG zu Recht nicht bilanzierter Rückstellungen für drohende Verluste aus schwebenden Geschäften ist Teil des vom Erwerber zu entrichteten Entgelts und erhöht mithin seine Anschaffungskosten. Bei dieser Freistellungsverpflichtung handelt es sich nicht um den Teil eines schwebenden Geschäfts; denn das Geschäft wurde infolge des Erwerbsvorgangs bereits erfüllt. Die Freistellungsverpflichtung ist mithin vom Erwerber sowohl in der Handels- als auch in der Steuerbilanz nach den für ungewisse Verbindlichkeiten geltenden Grundsätzen und nicht als Drohverlustrückstellung zu passivieren. ${ }^{34}$

\section{b) Stellungnahme}

Für die Freistellungsverpflichtungen sind beim Erwerber ungewisse Verbindlichkeiten und keine Rückstellungen für drohende Verluste aus schwebenden Geschäften zu passivieren. Als Begründung führt der BFH an, dass es sich bei der Freistellungsverpflichtung nicht um den Teil eines

32 Vgl. BFH, Urt. v. 16.12.2009 - I R 102/08, DStR 2010, 265.

33 Vgl. FG Düsseldorf, Urt. v. 9.9.2008 - 6 K 1161/04 K, F, EFG 2009, 167.

34 Vgl. in diesem Sinne auch Günkel, StbJb 2009/2010, S. 350 ff.; Hoffmann, GmbH-StB 2009, 145; Bogenschütz, Ubg 2008, 139; Koch, BB 2008, 2736; Ley, DStR 2007, $591 \mathrm{ff}$. 
schwebenden Geschäfts handelt, da das Geschäft infolge des Erwerbsvorgangs bereits erfüllt wurde. Diese Argumentation weist gewisse Parallelen zur Rechtsprechung des I. Senats zu Optionsgeschäften auf. ${ }^{35}$ Wie bei Optionsgeschäften mit Zahlung der Optionsprämie war für die Freistellungsvereinbarungen im vorliegenden Sachverhalt der Schwebezustand der gegenseitigen Geschäfte mit Zahlung des Veräußerers (in Form des geminderten Kaufpreises) beendet.

Nicht behandelt hat der BFH im besprochenen Urteil die Folgen der Schuldübernahme für den Veräußerer. Kann ein Veräußerer bestimmte Verpflichtungen aufgrund von Rückstellungsverboten in seiner Steuerbilanz nicht aufwandswirksam berücksichtigen, entsteht der steuerwirksame Aufwand bei Übertragung des Passivpostens („Wegschaffungskosten") an den Erwerber. ${ }^{36}$ Das Urteil lässt zudem ausdrücklich offen, ob die Rechtslage anders zu beurteilen wäre, wenn der Erwerber selbst in die verlustträchtigen Verträge eingetreten wäre. ${ }^{37}$ Hier wird vertreten, dass es dann möglicherweise zu einer Erfolgsauswirkung kommen könne. ${ }^{38}$ Stellt man jedoch konsequent auf das Prinzip der "Neutralität von Anschaffungsvorgängen " ab, so kann auch in diesem Fall eine Erfolgsneutralität zu bejahen sein. ${ }^{39}$ Denn auch hier wird die Verpflichtung kausal durch das Anschaffungsgeschäft und den geminderten Kaufpreis hervorgerufen. Des Weiteren ist zu beachten, dass das Urteil nur zum „Asset Deal", nicht aber zum Sachverhalt des "Share Deal" ergangen ist. Im Rahmen des "Share Deal“ kommt es auf Ebene des Veräußerers nicht zu einem Wegfall des Passivpostens - und (damit) beim Anschaffenden nicht zu einem Erwerb - da der Erwerbsvorgang ausschließlich auf Anteilseignerebene erfolgt (Share Deal). Die Drohverlustrückstellung wird dann auf Ebene der veräußerten Gesellschaft unter Berücksichtigung des steuerlichen Ansatzverbots fortgeführt. ${ }^{40}$

35 Vgl. BFH Urt. v. 18.12.2002 - IR 17/02, BStBl. II 2004, 126; BFH, Urt. v. 11.10.2007 - IV R 52/04, BStBl. II 2009, 705. Abwägend hierzu Buciek, FR 2009, 425; Wendt, FR 2009, 427 in ihren Anmerkungen zum hier besprochenen BFH-Urteil v. 16.12.2009 (a. a. O. Fn. 6).

36 Vgl. hierzu BFH, Urt. v. 17.10.2007 - I R 61/06, BStBl. II 2008, 555. Diese Entscheidung des BFH steht in Einklang mit den bereits auf den vorhergehenden Fachkongressen vorgestellten Lösungsvorschlägen, vgl. Günkel, StbJb 2002/2003; S. 291 ff.; ders. in StbJb 2005/2006, S. 262 ff.

37 Der BFH musste sich mit dieser Frage nicht näher befassen, da Anhaltspunkte für einen solchen Sachverhalt im Urteilsfall nicht festgestellt worden waren.

38 Vgl. Gosch, BFH/PR 2010, 123; Wendt, FR 2009, 427 ff. Gosch führt jedoch einschränkend aus, dass eine solche Konstellation nur dann eintreten könne, wenn der Vertragspartner des Drohverlustgeschäfts mit dem Austausch seines Vertragskontrahenten einverstanden ist.

39 Vgl. in diesem Sinne Buciek, FR 2010, 425; Ley, DStR 2007, 591.

40 Vgl. Schultz, DB 2010, 364. 
c) Übertragbarkeit des BFH-Urteils vom 16.12.200941 auf den Ansatz anderer Rückstellungen

Wenn auch die Entscheidung des BFH im Urteil vom 16.12.2009 ausschließlich auf die Behandlung von Rückstellungen aus drohenden Verlusten eingeht, so dürfte der Tenor des Urteils auf andere Formen des steuerlichen Ansatzverbots für Rückstellungen übertragbar sein ${ }^{42}$ und auch dann gelten, wenn die Rückstellungspassivierung in der Steuerbilanz zwar nicht verboten, jedoch der Höhe nach begrenzt ist. ${ }^{43}$ Grundsätzlich ist jeder Anschaffungsvorgang aus Sicht des Erwerbers erfolgsneutral zu behandeln. ${ }^{44}$ Im Folgenden soll geprüft werden, wie dieser Grundsatz auf den Fall der Übertragung von Pensionsrückstellungen im Rahmen eines Asset Deals angewendet werden kann.

Bei einem Asset Deal gehen die Arbeitsverhältnisse in der Regel gem. $\S 613$ a BGB auf den Erwerber über. Übernimmt der Erwerber in diesem Zusammenhang bestehende Versorgungsanwartschaften, so wird der Veräußerer entsprechend freigestellt. ${ }^{45}$ Die Gegenleistung des Veräußerers für diese Freistellung wird in Gestalt der überlassenen Aktiva grundsätzlich höher sein als der Anwartschaftsteilwert i. S.v. § 6a EStG. Für den Erwerber muss indes der reale Wert der Pensionsverpflichtung ausschlaggebend sein, der Teil seiner Anschaffungskosten darstellt, denn er wird den Kaufpreis um den wahren Wert der Pensionsverpflichtung reduzieren. Handelsrechtich wird der Erwerber daher seine Anschaffungskosten auf der Basis des realistischen Rückstellungsbetrages nach einem unter BilMoG anzuwendenden Verfahren berechnen (müssen). Der handelsrechtliche Anschaffungskostenbegriff stimmt grundsätzlich mit dem steuerlichen Begriff der Anschaffungskosten überein. ${ }^{46}$

Es ist deshalb wohl nicht möglich, für die Steuerbilanz von anderen Anschaffungskosten auszugehen, weil man einen Teil der Kaufpreisverbindlichkeit anders, nämlich nach $\S 6$ a EStG, bewertet.

Würde hier von einer weiteren Anwendbarkeit des §6a EStG nach dem Anschaffungsvorgang ausgegangen werden, so könnte es aufgrund der in Pensionsrückstellungen häufig enthaltenen stillen Lasten am nächsten Bilanzstichtag zu einem "Anschaffungsertrag" kommen, der dem Realisationsprinzip widerspricht. ${ }^{47}$ Vor diesem Hintergrund sollte es bei Über-

41 A. a. O. Fn. 6.

42 Vgl. Schultz, DB 2010, 364.

43 Vgl. Hahne, BB 2010, 496; Gosch, BFH/PR 2010, $123 \mathrm{ff}$.

44 Vgl. Gosch, BFH/PR 2010, 124; Emig/Walter, NWB 2010, 2127.

45 Vgl. Gosch, BFH/PR 2010, 124.

46 Fischer in Kirchhof, EStG, 9 Aufl. 2010, § 6 Rz. 22, 32.

47 Vgl. Emig/Walter, NWB 2010, 2128. Zur Bewertung von Pensionsrückstellungen vgl. auch Höfer, BetrAVG, Band II Steuerrecht. 
tragung von Pensionsrückstellungen im Rahmen eines Asset Deals zu einer Suspendierung der Passivierungsrestriktionen des § 6a EStG kommen. ${ }^{48}$ Das hat allerdings zunächst einmal nur eine entsprechend höhere Aktivierung der erworbenen Wirtschaftsgüter und damit eine höhere Abschreibung in Zukunft zur Folge. Fraglich ist, ob Zuführungen zur Pensionsrückstellung in der Folgezeit erst dann wieder getätigt werden dürfen, wenn der Teilwert der Pensionsrückstellung dem realen Wert der Pensionsverpflichtung zum Zeitpunkt des Asset Deals entspricht. Zutreffend wird im Schrifttum festgestellt, dass dies zwar der Verwaltungspraxis entspricht, jedoch zu einer Schieflage zulasten des objektiven Nettoprinzips führen würde. Die Zuführung zur Pensionsrückstellung wäre folglich uneingeschränkt zuzulassen. ${ }^{49}$ Noch deutlicher wird dies, wenn im Rahmen der Betriebsübernahme der Verkäufer nach § 613 a BGB übergehen, da sie keine ArbN mehr sind, vom Erwerber von seiner Verpflichtung freigestellt wird. Es handelt sich dann beim Erwerber noch nicht einmal um eine Pensionsverpflichtung, die nach §6aEStG zu bewerten wäre, sondern um eine Rückstellung für eine sonstige Verbindlichkeit gegenüber dem Veräußerer.

Gleiche Überlegungen sind grundsätzlich in allen Fällen anzustellen, in denen der Rückstellungsansatz steuerlich nur eingeschränkt möglich ist (bspw. Jubiläumsrückstellungen, Rückstellungen für Verletzung fremder Patent-, Urheber- oder ähnlicher Schutzrechte oder Rückstellungen für öffentlich-rechtliche Verpflichtungen $\left.\right|^{50}$ oder Bewertungsvorbehalte bestehen (bspw. steuerliche Nichtberücksichtigung von Preis- und Kostensteigerungen gem. $\S 6$ Abs. 1 Nr. 3a lit. f EStG). ${ }^{51}$

\section{Fazit}

Die Entscheidung des BFH im Urteil vom 16.12.2009 ist zu begrüßen. Dies auch deshalb, weil der I. Senat sich mit der Betonung des Grundsatzes der Erfolgsneutralität von Anschaffungsvorgängen auf einen Eckpfeiler der Dogmatik des deutschen Steuerrechts bezieht. Zudem wird die grundsätzliche Möglichkeit einer vorzeitigen Berücksichtigung stiller Lasten auf Ebene des Veräußerers eröffnet, ohne die Besteuerung auf Ebene des Erwerbers negativ zu beeinflussen.

48 Gl. A. Gosch, BFH/PR 2010, 124; Bogenschütz, Ubg 2008, 139 ff.

$49 \mathrm{Vgl}$. Gosch, BFH/PR 2010, 124.

50 Vgl. mit weiteren Beispielsfällen Emig/Walter, NWB 2010, 2128 ff.; vgl. auch FG Düsseldorf v. 29.6.2010, BB 2010, 2232 zu Pensionsrückstellungen.

51 Vgl. zu Bewertungsvorbehalten Fischer/Günkel/Neubeck/Pannen, Die Bilanzrechtsreform 2009/10, S. 63, 66. 


\section{III. „Lifo-Methode“ bei Teilwertzuschreibungen von Beteiligungen (last down, first up)}

\section{Sachverhalt}

Die X-GmbH ist kein Finanzunternehmen i. S. v. § 8 b Abs. 7 Satz 2 KStG. Das Wirtschaftsjahr der X-GmbH entspricht dem Kalenderjahr. Die $\mathrm{X}-\mathrm{GmbH}$ hat ihre $100 \%$-Beteiligung an einer Tochterkapitalgesellschaft (TG) mit Sitz und Ort der Geschäftsleitung im Inland im Anlagevermögen unter den Finanzanlagen ausgewiesen (§ 271 Abs. 1 i. V. m. § 266 Abs. 2 III. HGB). Die Anschaffungskosten der Beteiligung i. S. v. § 255 Abs. 1 HGB an TG betrugen EUR 1.000. In der Handels- und Steuerbilanz zum 31. Dezember 2001 der X-GmbH wurde die Beteiligung an TG mit ihrem niedrigeren beizulegenden Wert i. S. v. § 253 Abs. 2 Satz 3 HGB bzw. ihrem niedrigeren Teilwert i. S. v. § 6 Abs. 1 Nr. 2 EStG in Höhe von EUR 750 angesetzt. Im folgenden Wirtschaftsjahr 2002 ergab sich wiederum ein Abwertungsbedarf der Beteiligung an der TG. In der Handelsund Steuerbilanz zum 31. Dezember 2002 der X-GmbH wurde die Beteiligung an TG mit ihrem niedrigeren beizulegenden Wert i.S. v. § 253 Abs. 2 Satz 3 HGB bzw. ihrem niedrigeren Teilwert i.S.v. §6 Abs. 1 Nr. 2 EStG in Höhe von EUR 450 angesetzt. Durch die Einführung des Halbeinkünfteverfahrens sind jedoch Gewinnminderungen, die im Zusammenhang mit einem Anteil i. S. v. § 8 b Abs. 2 KStG an einer Tochterkapitalgesellschaft mit Sitz und Geschäftsleitung im Inland (hier: TG) entstehen bei der Ermittlung des Einkommens im Veranlagungszeitraum 2002 nicht $\mathrm{zu}$ berücksichtigen $(\S 8 \mathrm{~b}$ Abs. 3 S. 3 KStG i.V.m. $\S 34$ Abs. 7 Satz 1 Nr. 2 KStG). Nach erfolgreicher Sanierung der TG ergibt sich ein Wertaufholungspotential in Höhe von EUR 400 zum Ende des Wirtschaftsjahrs 2008. Die X-GmbH bittet ihren Steuerberater um Erläuterung der entsprechenden steuerrechtlichen Konsequenzen der Wertaufholung im Veranlagungszeitraum 2008.

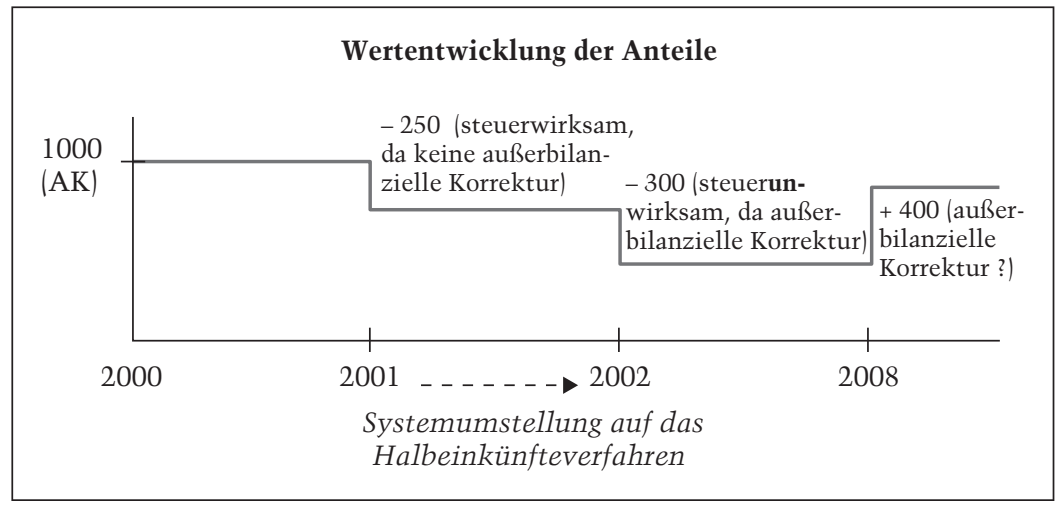




\section{Lösungshinweise}

Wird bei einer Beteiligung eine Abschreibung nach $\S 253$ Abs. 2 Satz 3 HGB vorgenommen und stellt sich in einem späteren Geschäftsjahr heraus, dass die Gründe dafür nicht mehr bestehen, so ist der Betrag dieser Abschreibung im Umfang der Werterhöhung in der Handelsbilanz zuzuschreiben (§ 280 Abs. 1 HGB a. F./§ 253 Abs. 5 Satz 1 HGB n. F.). Von der Zuschreibung nach $\S 280$ Abs. 1 HGB a. F. konnte nach der Regelung vor BilMoG abgesehen werden, wenn der niedrigere Wertansatz bei der steuerrechtlichen Gewinnermittlung beibehalten werden kann und wenn Voraussetzung für die Beibehaltung ist, dass der niedrigere Wertansatz auch in der Handelsbilanz beibehalten wird (§ 280 Abs. 2 HGB a. F.). Nach dem Maßgeblichkeitsgrundsatz i. S. v. §5 Abs. 1 Satz 1 EStG war $§ 280 \mathrm{HGB}$ a. F. grundsätzlich auch für die Steuerbilanz einschlägig.

Nach $\S 5$ Abs. 6 EStG sind die Vorschriften des Einkommensteuergesetzes über die Bewertung von Wirtschaftsgütern beim steuerlichen Wertansatz zu befolgen. Steuerrechtliche Wahlrechte bei der Gewinnermittlung waren nach der Regelung vor BilMoG gem. $§ 5$ Abs. 1 Satz 2 EStG a. F. in Übereinstimmung mit der handelsrechtlichen Jahresbilanz auszuüben. Bei der Bewertung von Beteiligungen ist $\S 6$ Abs. 1 Nr. 1 Satz 4 EStG entsprechend anzuwenden (§ 6 Abs. 1 Nr. 2 Satz 3 EStG). Beteiligungen, die bereits am Schluss des vorangegangenen Wirtschaftsjahres zum Anlagevermögen des Steuerpflichtigen (hier: TG) gehört haben, sind in den folgenden Wirtschaftsjahren mit den Anschaffungskosten anzusetzen, es sei denn, der Steuerpflichtige weist nach, dass ein niedrigerer Teilwert nach $\S 6$ Abs. 1 Satz 2 EStG angesetzt werden kann (§ 6 Abs. 1 Nr. 1 Satz 4 EStG). Steuerrechtlich ist aufgrund des Wertanstiegs der Beteiligung im vorliegenden Fall somit zwingend eine Wertaufholung geboten. $\S 280$ Abs. 2 HGB a.F. lief aufgrund der speziellen steuerrechtlichen Bewertungsvorschriften ins Leere, so dass auch in der Handelsbilanz eine Wertaufholung zwingend zu erfolgen hatte. ${ }^{52}$

Gewinne aus Anteilen i. S. v. $\S 8$ b Abs. 2 KStG sind seit der Einführung des sog. Halbeinkünfteverfahrens grundsätzlich steuerfrei, soweit die Beteiligung in früheren Jahren nicht steuerwirksam auf den niedrigeren Teilwert abgeschrieben und die Gewinnminderung nicht durch den Ansatz eines höheren Wertes ausgeglichen wurde $(\S 8$ b Abs. 2 Sätze 1 und $2 \mathrm{KStG}$ a. F./§ 8 b Abs. 2 Sätze 1 und $4 \mathrm{KStG}$ n. F.). Dies ist hier für die erste Wertminderung der Fall. Grund für diese Ausnahme ist $\S 8$ b Abs. 3 KStG, wonach Gewinnminderungen, die im Zusammenhang mit einem Anteil i. S. v. $\S 8$ b Abs. $2 \mathrm{KStG}$ an einer Tochterkapitalgesellschaft mit Sitz und Geschäftsleitung im Inland (hier: TG) entstehen, bei der Ermittlung des

52 Vgl. Winkeljohann/Taetzner in Beck`scher Bilanzkommentar, 6. Auflage 2006. $\S 280$ HGB, Rz. 23. 
Einkommens im Veranlagungszeitraum nicht zu berücksichtigen waren (§ 8 b Abs. 3 S. 3 KStG i. V.m. § 34 Abs. 7 Satz 1 Nr. 2 KStG). Dieser Abzugsausschluss gem. $\S 8$ b Abs. 3 KStG wurde indes erst mit der Systemumstellung vom körperschaftsteuerlichen Anrechnungsverfahren zum sog. Halbeinkünfteverfahren geschaffen. Zuvor blieben die Gewinnminderungen / Gewinnerhöhungen prinzipiell steuerwirksam.

Von dem jeweiligen steuerfreien Gewinn i. S. v. § 8 b Abs. 2 KStG gelten 5 Prozent als Ausgaben, die nicht als Betriebsausgaben im Rahmen der Einkommensermittlung abgezogen werden dürfen (§ 8 Abs. 3 Satz $1 \mathrm{KStG}$ ).

Im vorliegenden Sachverhalt ergibt sich nun die Frage, ob der Ertrag aus der Zuschreibung im Jahr 2008 vorrangig mit der steuerunwirksamen Teilwertabschreibung von 2002 („Last down, first up“-Methode) oder der steuerwirksamen Teilwertabschreibung von 2001 („First down, first up"-Methode) zu verrechnen ist, denn die Reihenfolge der Verrechnung ist entscheidend für die Höhe des steuerpflichtigen Betrags aus der Zuschreibung, wie der nachfolgenden Tabelle zu entnehmen ist:

\begin{tabular}{|c|c|c|c|c|c|c|}
\hline \multirow[t]{2}{*}{ Jahr } & \multirow[t]{2}{*}{ Vorgang } & \multirow{2}{*}{$\begin{array}{l}\text { Buchwert } \\
\text { Steuer- } \\
\text { bilanz }\end{array}$} & \multirow[t]{2}{*}{ Methode } & \multicolumn{2}{|c|}{$\begin{array}{l}\text { Außerbilanzielle } \\
\text { Korrektur }\end{array}$} & \multirow{2}{*}{$\begin{array}{l}\text { Einkom- } \\
\text { mens } \\
\text { auswir- } \\
\text { kung }\end{array}$} \\
\hline & & & & $\begin{array}{l}\text { nach } \S 8 \text { b } \\
\text { Abs. 2,3 } \\
\text { Satz 3 } \\
\text { KStG }\end{array}$ & $\begin{array}{l}\text { nach } \S 8 \text { b } \\
\text { Abs. } 3 \\
\text { Satz } 1 \\
\text { KStG }\end{array}$ & \\
\hline & $\begin{array}{l}\text { Anschaf- } \\
\text { fung }\end{array}$ & 1000 & & & & \\
\hline 31.12.20XX) & & 1000 & & & & \\
\hline 2001 & $\begin{array}{l}\text { Teilwert- } \\
\text { abschrei- } \\
\text { bung }\end{array}$ & -250 & & 0 & - & -250 \\
\hline 31.12 .2001 & & 750 & & & & \\
\hline 2002 & $\begin{array}{l}\text { Teilwert- } \\
\text { abschrei- } \\
\text { bung }\end{array}$ & -300 & & +300 & - & 0 \\
\hline 31.12 .2002 & & 450 & & & & \\
\hline \multirow[t]{2}{*}{2008} & \multirow[t]{2}{*}{$\begin{array}{l}\text { Wertauf- } \\
\text { holung }\end{array}$} & \multirow[t]{2}{*}{+400} & $\begin{array}{l}\text { "Last } \\
\text { down, } \\
\text { first up }\end{array}$ & -300 & +15 & 115 \\
\hline & & & $\begin{array}{l}\text { "First } \\
\text { down, } \\
\text { first up }\end{array}$ & -150 & $+7,5$ & 257,5 \\
\hline 31.12 .2008 & & 850 & & & & \\
\hline
\end{tabular}


Erläuterung: Wird die Wertaufholung der Kapitalgesellschaftsanteile (EUR 400) vorrangig mit der (spätesten) steuerunwirksamen Teilwertabschreibung verrechnet („Last down, first up"-Methode) ergibt sich eine Einkommenserhöhung von EUR 115 aufgrund der nachrangigen Umkehr der (früheren) steuerwirksamen Abschreibung von EUR 100 (= EUR 400 - EUR 300) zuzüglich einer Erhöhung um $5 \%$ des steuerfreien Teils der Zuschreibung von EUR 15 (= EUR $300 \times$ EUR 0,05). Die „First down, first up"-Methode dagegen sieht eine Verrechnung mit der (frühesten) steuerwirksamen Abschreibung vor, wodurch der steuerfreie Betrag auf EUR 150 (=EUR 400 - EUR 250) und die $5 \%$ ige Hinzurechnung auf EUR 7,5 (= EUR $150 \times$ EUR 0,05) reduziert wird.

\section{a) Finanzverwaltung}

Nach Auffassung der Finanzverwaltung führt eine Teilwertaufholung im zeitlichen Geltungsbereich des sog. Halbeinkünfteverfahrens in vollem Umfang zu einer Gewinnerhöhung, soweit sich eine während der Geltung des sog. Anrechnungsverfahrens vorgenommene Teilwertabschreibung gewinnmindernd ausgewirkt hat. Sie ist also in voller Höhe steuerwirksam und nicht vorrangig mit einer während der Geltung des sog. Halbeinkünfteverfahrens vorgenommenen, nicht steuerwirksamen Teilwertabschreibung ( $\$ 8$ b Abs. 2 Satz 3 KStG a.F.) zu verrechnen. ${ }^{53}$ Die Finanzverwaltung vertritt somit die „First down, first up" - Methode.

\section{b) Rechtsprechung}

Mit seinem Urteil vom 19.8.200954 hat der BFH das Urteil des Finanzgerichts Düsseldorf ${ }^{55}$ und die überwiegende Ansicht im Schrifttum ${ }^{56}$ bestätigt, wonach die „Last down, first up"-Methode als zutreffende Ver-

53 Vgl. OFD Hannover, Verfg. v. 30.5.2006, DStR 2006, 1891; OFD Koblenz, Verfg. v. 18.9.2006, DStR 2006, 2033; OFD Münster, Verfg. v. 23.2.2005, aktualisiert am 20.7.2009, BeckVerw 163557; ebenso Dötsch/Pung in Dötsch/Jost/Pung/ Witt, KStG, § 8 b, Rz. 91.

54 Vgl. BFH, Urt. v. 19.8.2009 - I R 2/09, DStR 2009, 2483.

55 Vgl. FG Düsseldorf, Urt. v. 1.12.2008 - 6 K 2726/06 K, BB 2009, 1291. In der dem BFH-Urteil zugrunde liegenden Revisionsklage wurde zudem die Verfassungsmäßigkeit der pauschalen Nichtberücksichtigung von $5 \%$ als nicht abziehbare Betriebsausgabe ( $\S 8$ b Abs. 3 Satz 1 KStG bzw. $\S 8$ b Abs. 5 KStG) in Frage gestellt. Der BFH geht darauf nicht weiter ein, da bereits das FG Düsseldorf nicht von der Verfassungswidrigkeit überzeugt war. Demgegenüber vertrat das FG Hamburg in einem anderem Fall die Ansicht, dass diese Regelung gegen den Gleichheitsgrundsatz (Art. 3 Abs. 1 GG) verstößt; vgl. dazu FG Hamburg Vorlagebeschluss an das BVerfG, DStRE 2008, 427, Az. des anhängigen Verfahrens: 1 BvL 12/07.

56 Vgl. Gosch in Gosch, KStG, § 8 b, Rz. 241; Gröbl/Adrian in Erle/Sauter, KStG, 3. Aufl., §8 b, Rz. 139; Rödder/Schumacher, DStR 2003, 909; Zieren/Adrian, DB 2006, 299; ergänzend BFH Urteil v. 19.8.2009 - I R 2/09, DStR 2009, 2484 m. w. N. 
rechnungsreihenfolge zu erachten ist. Wertaufholungen sind demnach so lange steuerfrei zu belassen bzw. nur in Höhe von $5 \%$ steuerpflichtig, bis die steuerlich unwirksamen Teilwertabschreibungen vollständig ausgeglichen sind. Allein diese Reihenfolge ist sachgerecht und korrespondiert mit dem dargestellten Regelungszweck des Gesetzes. Denn danach sollen die Erträge aus den Wertaufholungen vorrangig von der Anwendung des sog. Halbeinkünfteverfahrens profitieren und steuerfrei bleiben. Indem das Gesetz die betreffende (steuerwirksame) Gewinnminderung und die nachfolgende Wertaufholung durch das "soweit" verknüpft, geht es von einer betraglichen (Wert-)Korrespondenz und damit gewissermaßen von einem "Gesamt-Wertspeicher" aus, der nur anteilig - eben "soweit" - der Steuerpflicht unterworfen ist, als er in der Vergangenheit bereits einmal steuerwirksam geworden ist. ${ }^{57}$ Die Auffassung der Finanzverwaltung lässt sich nur halten, sofern in den Gesetzeswortlaut eine Bedingungsabhängigkeit („,sobald “) und eine Zeitkomponente („,solange") hineingelesen wird. An beidem fehlt es jedoch. „Soweit" jener schädliche Wertverbrauch nicht erreicht oder überschritten ist, bleibt es deswegen bei der beschriebenen regelungsimmanenten Reihenfolge.

Der BFH hat in seiner Entscheidung offen gelassen, ob für entsprechende, jedoch anderslautende Regelungen (z. B. § 4 Abs. 1 Satz 2 UmwStG a. F., $\S 8$ b Abs. 3 Satz $8 \mathrm{KStG})$ in anderen Normzusammenhängen Gleiches anzunehmen ist.

\section{Fazit}

Im Beispielfall ist die „Last down, first up"-Methode anzuwenden. Es kommt zu einer Einkommenserhöhung von 115 im Veranlagungszeitraum 2008 .

\section{Subjektiver Fehlerbegriff zu (Un)Gunsten der Finanzverwaltung}

\section{Sachverhalt}

Die T-GmbH hat ein dem Kalenderjahr entsprechendes Wirtschaftsjahr. Geschäftszweck ist die Erbringung von Telekommunikationsdienstleistungen. Im Rahmen dieser Tätigkeit werden den Kunden bei Abschluss oder Verlängerung eines Laufzeitvertrages entsprechende Endgeräte zur Nutzung der Dienstleistung zu einem verbilligten Entgelt zur Verfügung gestellt. Eine gesetzliche Regelung in Bezug auf die steuerliche Behandlung dieser Vorgänge existiert nicht. Finanzgerichtliche Rechtsprechung liegt ebenfalls nicht vor. Nach eingehender Analyse des Schrifttums kommt die

57 A. A. Heuermann, StBp 2010, 28. 
T-GmbH im März 2002 zu dem Ergebnis, dass kein aktiver Rechnungsabgrenzungsposten für die verbilligte Abgabe der Telefone bei der Aufstellung des Jahresabschlusses 2001 zu bilden ist. Das Finanzamt berücksichtigt den auf dieser Basis ermittelten Gewinn in den Steuerbescheiden, die gem. § 164 Abs. 1 AO unter dem Vorbehalt der Nachprüfung ergehen.

Im Rahmen der steuerlichen Außenprüfung des Veranlagungszeitraums 2001 im Jahr 2004 vertritt die Finanzverwaltung, gestützt auf die in der Zwischenzeit ergangene höchstrichterliche Rechtsprechung, dass für die verbilligte Überlassung der Endgeräte in der Bilanz ein aktiver Rechnungsabgrenzungsposten hätte gebildet werden müssen, der über die Vertragslaufzeit aufzulösen ist. Ferner hat sich im Jahr 2003 herausgestellt, dass eine Forderung, die in der Bilanz des Jahres 2001 ausgewiesen war, tatsächlich zum Abschlussstichtag 31.12.2001 nicht mehr werthaltig war. Die Forderung ist nach Ansicht der Finanzverwaltung auch weiterhin in der Steuerbilanz zum 31.12.2001 zu bilanzieren und erst in dem Jahr ertragswirksam abzuschreiben, in dem die T-GmbH von der fehlenden Werthaltigkeit wissen konnte.

Die Steuerbilanz und der Steuerbescheid für das Jahr 2001 werden entsprechend korrigiert.

Die T-GmbH möchte von ihrem Steuerberater wissen, ob die Finanzverwaltung zwar die Erkenntnisse aus der neueren Rechtsprechung berücksichtigen kann, um einen aktiven Rechnungsabgrenzungsposten in der Prüferbilanz zu bilden, die neuen Erkenntnisse bezogen auf die Forderung aber nicht gelten lassen muss.

\section{Lösungshinweise}

\section{a) (Un)richtiger Bilanzansatz}

Im Rahmen einer Bilanzberichtigung nach $\S 4$ Abs. 2 Satz 1 EStG kann ein unrichtiger Bilanzansatz nach Einreichung der Bilanz beim Finanzamt durch einen richtigen Bilanzansatz ersetzt werden. In Abgrenzung hierzu ist die Bilanzänderung gemäß $\S 4$ Abs. 2 Satz 2 EStG zu sehen, wonach ein richtiger Bilanzansatz durch einen ebenfalls richtigen Bilanzansatz ersetzt werden kann. Eine solche Änderung der Bilanz kann nur in einem sachlichen und zeitlichen Zusammenhang mit einer Bilanzänderung i. S. d. § 4 Abs. 2 Satz 1 EStG vorgenommen werden und wirkt nur soweit die Gewinnänderung auf Grund der Bilanzberichtigung reicht.

Es ist daher zunächst zu bestimmen, wann ein Bilanzansatz "falsch" bzw. "richtig“ ist. Nach der BFH-Rechtsprechung ${ }^{58}$ zum sog. subjektiven

58 Vgl. BFH, Urt. v. 5.4.2006 - I R 46/04, BStBl. II 2006, 688; bestätigt durch BFH, Urt. v. 5.6.2007 - I R 47/06, BStBl. II 2007, 818; BFH, Urt. v. 23.1.2008 - I R 
Fehlerbegriff ist ein Bilanzansatz im Sinne des $\S 4$ Abs. 2 Satz 1 EStG "richtig", wenn er denjenigen Kenntnisstand widerspiegelt, den der Kaufmann im Zeitpunkt der Bilanzaufstellung bei pflichtgemäßer und gewissenhafter Prüfung haben konnte. Bei Tatsachenfragen (z. B. die Werthaltigkeit einer Forderung) ist der Kenntnisstand im Zeitpunkt der Bilanzerstellung zugrundezulegen. Sofern zum Zeitpunkt der Bilanzerstellung noch keine Rechtsprechung zu der in Rede stehenden Bilanzierungsfrage (z. B. der Bildung eines aktiven Rechnungsabgrenzungspostens für die verbilligte Abgabe von Telefonen) ergangen ist, muss nach o.g. BFH-Rechtsprechung jede der kaufmännischen Sorgfalt entsprechende (Nicht-)Bilanzierung als "richtig" angesehen werden. Dieser im Zeitpunkt der Bilanzerstellung subjektiv "richtige" Bilanzansatz sowohl in Bezug auf eine Tatsachenfrage als auch in Bezug auf eine Rechtsfrage ist auch weiterhin der Besteuerung zu Grunde zu legen, wenn er sich bei Berücksichtigung später gewonnener Erkenntnisse als objektiv unrichtig herausstellt. ${ }^{59}$

Eine objektiv fehlerhafte Bilanz i.S.d. $§ 4$ Abs. 2 Satz 1 EStG liegt nur dann vor, wenn eine bestimmte Rechtsfrage durch höchstrichterliche Rechtsprechung bereits abschließend zum Zeitpunkt der Bilanzerstellung geklärt ist und die Bilanzierung des Steuerpflichtigen davon abweicht oder ein Verstoß gegen eine eindeutige bilanzsteuerrechtliche Vorgabe vorliegt. In diesen Fällen kann eine Berichtigung der fehlerhaften Bilanz gem. $§ 4$ Abs. 2 Satz 1 EStG vorgenommen werden. ${ }^{60}$

\section{b) Ausübung von bilanzsteuerrechtlichen Bandbreiten}

Gemessen am Maßstab einer vernünftigen kaufmännischen Beurteilung besteht eine Bandbreite richtiger Entscheidungsmöglichkeiten. Der Steuerpflichtige hat das Vorrecht zur Einschätzung und Ausübung von Entscheidungsspielräumen im tatsächlichen Bereich. ${ }^{61}$ Bei dieser Beurteilung ist der Steuerpflichtige nicht zwingend (i) an eine gefestigte Übung in der Bilanzierungspraxis, (ii) an eine in der Literatur herrschende Meinung oder (iii) an gleichlautende erstinstanzlich finanzgerichtliche Urteile gebunden. ${ }^{62}$ Vor diesem Hintergrund wurde im Schrifttum bei fehlender höchstrichterlicher Rechtsprechung bezüglich einer Rechts-

40/07, BStB1. II 2008, 669; BFH, Urt. v. 17.7.2008 - I R 85/07, BStBl. II 2008, 924.

59 Vgl. BFH, Urt. v. 5.6.2007 - I R 47/06, BStBl. II 2007, 818.

60 Vgl. BFH, Urt. v. 5.4.2006 - I R 46/04, BStBl. II 2006, 688; bestätigt durch BFH, Urt. v. 5.6.2007 - I R 47/06, BStBl. II 2007, 818; BFH, Urt. v. 23.1.2008 - I R 40/07, BStBl. II 2008, 669; BFH, Urt. v. 17.7.2008 - I R 85/07, BStBl. II 2008, 924.

61 Vgl. Werra/Rieß, DB 2007, 2505; Rödder/Hageböke, Ubg 2008, 404.

62 Vgl. BFH, Urt. v. 23.1.2008 - I R 40/07, BStBl. II 2008, 669 (noch deutlicher die Vorinstanz: FG Köln, Urt. v. 21.3.2007 - 13 K 4358/06, EFG 2007, 1472); zustim- 
frage dem Steuerpflichtigen zutreffend empfohlen, diejenige für ihn günstige Auffassung zu Grunde zu legen, die ein sorgfältiger und gewissenhafter Kaufmann gerade noch vertreten kann. Hierbei kommt insbesondere dem Vorsichtsprinzip eine wesentliche Bedeutung zu. ${ }^{63}$ Die Grenze des Vertretbaren ist nach Ansicht des BFH dort gesetzt, wo die gängige Bilanzierungspraxis auch ohne explizite gesetzliche Regelung oder finanzgerichtlicher Rechtsprechung nicht streitig ist. Eine abweichende Bilanzierung entspricht dann nicht mehr einer vernünftigen kaufmännischen Sorgfalt und führt in diesem Punkt bereits bei Aufstellung des Jahresabschlusses zu einer objektiven Fehlerhaftigkeit der Bilanz. ${ }^{64}$

Die bisherige BFH-Rechtsprechung zum subjektiven Fehlerbegriff betraf Fälle, in denen der Steuerpflichtige "rückwirkend" durch eine Bilanzberichtigung versuchte, eine inzwischen ergangene für ihn günstigere BFH-Rechtsprechung anzuwenden. Grundsätzlich muss dies auch für den umgekehrten Fall zu Lasten der Finanzverwaltung gelten. Dies würde dazu führen, dass die Finanzverwaltung bei Anwendung dieser Grundsätze im Rahmen der Veranlagung nach einer steuerlichen Außenprüfung aber auch an einen durch den Steuerpflichtigen rechtlich vertretbaren Bilanzansatz gebunden wäre. Nach der Rechtsprechung des BFH ist die Finanzverwaltung bis zur höchstrichterlichen Klärung einer Rechtsfrage an jede vertretbare Rechtsansicht des Steuerpflichtigen im Steuerverfahren gebunden. Der Finanzverwaltung ist es auch nicht nach $\S 85$ Satz 1 AO möglich im Rahmen der Veranlagung von der Bilanzierung des Steuerpflichtigen abzuweichen. ${ }^{65}$ Daher kann ein "subjektiv" richtiger Bilanzansatz auch dann nicht durch die Finanzverwaltung korrigiert werden, wenn später z. B. durch eine höchstrichterliche Entscheidung, seine Unrichtigkeit erkannt wird. Die Finanzverwaltung muss auch nicht durch eine entsprechende Veranlagung zustimmen, um an die Bilanzansätze des Steuerpflichtigen gebunden zu sein, da es im Rahmen des subjektiven Rechtsbegriffs keinen Vorrang für die Rechtsauffassung der Finanzverwaltung gibt. ${ }^{66}$

mend Rödder/Hageböke, Ubg 2008, 404; a. A. Herzig/Nitzschke, DB 2007, 306; Prinz/Schulz, DStR 2007, 779; Werra/Rieß, DB 2007, 2505.

63 Vgl. Rödder/Hageböke, Ubg 2008, 405; Prinz in S:R 2009, 373.

64 Vgl. BFH, Urt. v. 19.5.2010 - I R 65/09, veröffentlich auf der homepage des BFH am 11.8.2010 (www.bundesfinanzhof.de).

65 Vgl. BFH, Urt. v. 5.6.2007 - I R 47/06, BStBl. II 2007, 818; Rödder/Hageböke, Ubg 2008, 406; Werra/Rieß, DB 2007, 2505 f.; a. A. Herzig/Nitzschke, DB 2007, 308; Richter, StuB 2010, 532. Anmerkung: § 176 AO eröffnet ebenfalls keine Änderungsmöglichkeit, da hierzu ein nichtiges Gesetz, eine verfassungswidrige Regelung oder die Änderung einer Rechtsprechung erforderlich ist, die bei der Veranlagung unstrittig zu Grunde gelegt wurde.

66 Vgl. Rödder/Hageböke, Ubg 2008, 406; Werra/Rieß, DB 2007, 2506. 
Wir haben im letzten Jahr an dieser Stelle ausführlich behandelt, dass die BFH-Entscheidung vom 5.6.2007 so zu verstehen ist, dass die Berichtigungssperre bei subjektiv richtiger, nachträglich aber festgestellter objektiv unrichtiger Bilanzierung auch zugunsten des Steuerpflichtigen besteht. Dies hat nun der Vorlagebeschluss bestätigt.

Im vorliegenden Fall der T-GmbH bedeutet dies, dass weder für die mit der Finanzverwaltung im Rahmen der steuerlichen Außenprüfung diskutierte Tatsachenfrage (Werthaltigkeit der Forderung) noch die offene Rechtsfrage (Bildung des aktiven Rechnungsabgrenzungspostens für die verbilligte Überlassung der Telefone) Raum für eine Anpassung der Steuerbilanz 2001 besteht.

Folge dieser Auslegung des „subjektiven Fehlerbegriffs" ist, dass „richtige" Bilanzansätze nur begrenzt durch die Finanzverwaltung geändert werden könnten. Die Steuerbilanz wäre damit deutlich änderungsresistenter als außerbilanzielle (Einkommens-)Korrekturen.

\section{c) Aufgabe des subjektiven Fehlerbegriffs aus Gründen der "Rechtshygiene"}

Beim I. Senat des BFH ist aktuell ein Verfahren anhängig, ${ }^{67}$ in dem die Anerkennung der subjektiven Einschätzungsprärogative des Steuerpflichtigen hinsichtlich der Beantwortung einer zum Zeitpunkt der Bilanzerstellung ungeklärten Bilanzierungsfrage strittig ist. Die bisherige $\mathrm{BFH}$ Rechtsprechung ist in Bezug auf diese Frage nicht zweifelhaft und gibt auch ausreichend Kriterien an die Hand, nach denen der Senat ein Urteil fällen könnte.

Der I. Senat möchte seine bisherige Rechtsprechung hinsichtlich der Begrenzung der Änderungsbefugnis von Steuerbilanzen seitens der Finanzverwaltung im Rahmen von Betriebsprüfungen nicht fördern. Er hat deshalb aus Gründen der "Rechtshygiene" ${ }^{\prime 68}$ entschieden, die Frage der Existenz, Beibehaltung und Reichweite des subjektiven Fehlerbegriffs dem großen Senat des BFH zur Entscheidung vorzulegen. ${ }^{69}$

Der I. Senat vertritt in seinem Vorlagebeschluss die Auffassung, dass der von der Rechtsprechung entwickelte "subjektive Fehlerbegriff" nicht auf die Beurteilung bilanzrechtlicher Rechtsfragen übertragen werden sollte. Letztlich, um die Berücksichtigung der späteren Rechtsprechung - und damit die gängige Praxis - grundsätzlich beizubehalten. Die Finanzverwaltung hätte andernfalls keine Handhabe mehr eine bisher allseits akzeptierte Bilanzierungspraxis in Frage zu stellen oder neu aufzuwerfen

67 Az. I R 77/08.

68 Vgl. Gosch in BFH/PR 2010, 283.

69 Vgl. BFH, Beschl. v. 7.4.2010 - I R 77/08, DStRE 2010, 699. 
und gerichtlich - letztlich durch den BFH - klären zu lassen. Als weiteres Argument wird angeführt, dass mit der Aufgabe der Übertragung des subjektiven Fehlerbegriffs auf Bilanzierungsfragen ein Gleichlauf zwischen der Änderbarkeit der Steuerfestsetzung einerseits und der Bilanzansätze anderseits hergestellt wird, wodurch insgesamt konsistentere und überzeugungskräftigere Ergebnisse erzielt würden.

\section{Fazit}

Folge dieses geänderten Verständnisses des subjektiven Fehlerbegriffs ist die Berücksichtigung der späteren Rechtsprechung und damit die grundsätzliche Änderbarkeit von Bilanzansätzen im Rahmen einer steuerlichen Außenprüfung. Zu unterscheiden ist hierbei zwischen (i) erstmaliger Rechtsprechung in Bezug auf eine Rechtsfrage und (ii) einer Rechtsprechungsänderung. Die Berücksichtigung einer erstmaligen BFHRechtsprechung, wie in Bezug auf die Bildung eines aktiven Rechnungsabgrenzungspostens für die verbilligte Abgabe der Telefone, ist sowohl zu Gunsten wie zu Ungunsten des Steuerpflichtigen möglich. Der BFH macht in seinem Vorlagebeschluss m. E. deutlich, dass die Aufgabe des subjektiven Fehlerbegriff für bilanzrechtliche Rechtsfragen zur rückwirkenden Berichtigung in noch offenen Veranlagungszeiträumen zu Gunsten wie zu Ungunsten des Steuerpflichtigenmöglich sein sollte. Eine geänderte BFH-Rechtsprechung kann hingegen nur zu Gunsten des Steuerpflichtigen berücksichtigt werden, da $\S 176$ Abs. 1 Satz 1 Nr. 3 AO eine Änderung zu Ungunsten ausschließt.

\section{Laufzeitfiktion von unverzinslichen (Gesellschafter-)Darlehen}

\section{Sachverhalt}

Die X-GmbH hat von ihrem alleinigen Gesellschafter im abgelaufenen Geschäftsjahr ein unverzinsliches Darlehen über EUR 10 Mio. erhalten. Der Darlehensvertrag sieht keine Laufzeit vor. Die Gesellschaft wird auf absehbare Zeit nicht in der Lage sein, das Darlehen zu tilgen. Im Anhang des Jahresabschlusses für das abgelaufene Geschäftsjahr weist die Gesellschaft die Darlehensverpflichtung gem. §285 Nr. 1 Buchstabe a HGB unter den Verbindlichkeiten mit einer Laufzeit von mehr als fünf Jahren aus.

Der Geschäftsführer der X-GmbH möchte wissen, wie das Gesellschafterdarlehen in der Steuerbilanz für das abgelaufene und in den folgenden Geschäftsjahren bis zur Tilgung zu behandeln ist. 


\section{Lösungshinweise}

a) Bilanzansatz des Gesellschafterdarlehens in der Steuerbilanz für das abgelaufene Geschäftsjahr

Unverzinsliche Verbindlichkeiten, deren Laufzeit am Bilanzstichtag mindestens zwölf Monate beträgt, sind in der Steuerbilanz unter sinngemäßer Anwendung von $\S 6$ Abs. 1 Nr. 2 EStG mit einem Zinssatz von 5,5\% abzuzinsen ( $§ 6$ Abs. 1 Nr. 3 EStG).

Die Regelung gilt nach Auffassung des I. Senats des BFH auch für Darlehen, die eine Kapitalgesellschaft von ihrem Gesellschafter erhält. Der I. Senat teilt insoweit in seinen Entscheidungen vom 6.10.200970 und vom 27.1.2010 ${ }^{71}$ nicht die Zweifel des IV. Senats. ${ }^{72}$ Eine Einschränkung des Anwendungsbereichs von $\S 6$ Abs. 1 Nr. 3 EStG ergebe sich weder aus dem Gesetz noch aus dem Gesetzeszweck. Der Gesetzgeber habe mit der Abzinsung unverzinslicher Verbindlichkeiten dem Umstand Rechnung tragen wollen, dass eine erst in Zukunft zu erfüllende Verpflichtung für den Schuldner wirtschaftlich weniger belastend sei als eine sofortige Leistungspflicht. Das treffe auf Gesellschafterdarlehen und andere Darlehensverhältnisse gleichermaßen zu. Die Gewinnerhöhung durch die Abzinsung des Gesellschafterdarlehens in der Steuerbilanz könne auch nicht dadurch neutralisiert werden, dass eine verdeckte Einlage angesetzt werde, da Nutzungsvorteile nicht einlagefähig seien. ${ }^{73}$

Vorliegend enthält der Darlehensvertrag keine Bestimmung über die Laufzeit. Zivilrechtlich sind derartige Darlehensverhältnisse mit einer Frist von drei Monaten kündbar (§ 488 Abs. 3 Satz 2 BGB). Der Schuldner muss somit stets damit rechnen, dass das Darlehen gekündigt wird und er kurzfristig zur Rückzahlung verpflichtet ist. Es fragt sich deshalb, ob hier die Ausnahme des $\S 6$ Abs. 1 Nr. 3 Satz 2 EStG eingreift, wonach Verbindlichkeiten mit einer Laufzeit von weniger als zwölf Monaten nicht abzuzinsen sind.

Das BMF ist in seinem Schreiben vom 26.5.2005 ${ }^{74}$ der Auffassung, dass die Restlaufzeit jederzeit oder mit gesetzlicher Kündigungsfrist kündbarer Darlehensverhältnisse analog zu den Fällen mit nicht feststehenden Rückzahlungszeitpunkten zu schätzen ist. Sofern für eine objektive Schätzung keine Anhaltspunkte vorliegen, könne hilfsweise $\S 13$ Abs. 2 BewG

70 Vgl. BFH, Urt. v. 6.10.2009 - I R 4/08, BStBl. II 2010, 177.

71 Vgl. BFH, Urt. v. 27.1.2010 - I R 35/09, BStBl. II 2010, 478.

72 Vgl. BFH, Urt. v. 10.11.2005 - IV R 13/04, BStBl. II 2006, 618; wie der I. Senat bereits BMF, Schr. v. 26.5.2005 - IV B 2-S-2175-7/05, BStBl. I 2005, 699, Tz. 21; ferner FG Berlin-Brandenburg, Urt. v. 8.9.2008 - 12 V 12115/07, EFG 2008, 1947.

73 Vgl. BFH, Urt. v. 26.10.1987 - GrS 2/86, BStBl. II 1987, 348.

74 Vgl. BMF, Schr. v. 26.5.2005 - IV B 2-S-217-7/05, Tz. 6. ff. 
analog angewendet werden. Danach sind Nutzungen und Leistungen von unbestimmter Dauer, die nicht vom Leben bestimmter Personen abhängen, mit dem 9,3-fachen des Jahreswerts zu bewerten. Der Vervielfältiger entspricht einer Laufzeit von 12 Jahren, 10 Monaten und 12 Tagen. Es ergibt sich ein Abzinsungsfaktor von 0,503. In seinen Entscheidungen vom 6.10.2009 ${ }^{75}$ und vom 27.1.2010 76 hat der BFH diese Ansicht des BMF bestätigt. Ob ein Darlehen eine Laufzeit von weniger als zwölf Monaten habe, richte sich nicht allein nach zivilrechtlichen Gesichtspunkten, sondern danach, auf welche Dauer der Schuldner nach den tatsächlichen Verhältnissen mit der Überlassung des Kapitals rechnen könne. Maßgebend sei die wahrscheinliche tatsächliche Entwicklung.

Für den vorliegenden Fall bedeutet dies: Da die Gesellschaft auf absehbare Zeit nicht in der Lage sein wird, das Darlehen zu tilgen und das Darlehen im Anhang des Jahresabschlusses unter den Verbindlichkeiten mit einer Laufzeit von mehr als fünf Jahren (§ $285 \mathrm{Nr} .1$ Buchstabe a HGB) ausgewiesen wird, ist davon auszugehen, dass am Ende des abgelaufenen Geschäftsjahrs mit einer kurzfristigen Kündigung des Darlehens nicht zu rechnen war. Das Darlehen ist deshalb in der Steuerbilanz für das abgelaufene Geschäftsjahr als Verbindlichkeit mit unbestimmter Laufzeit unter Verwendung des Abzinsungsfaktors von 0,503 abzuzinsen.

\section{b) Bilanzansatz des Gesellschafterdarlehens in den Steuerbilanzen für die nächsten Geschäftsjahre}

Weder die Rechtsprechung noch die Finanzverwaltung haben sich bisher mit der Frage beschäftigt, ob Verbindlichkeiten mit unbestimmter Laufzeit bei unveränderten tatsächlichen Verhältnissen in den folgenden Geschäftsjahren über die bei erstmaliger Abzinsung angenommene Laufzeit von 12 Jahren, 10 Monaten und 12 Tagen aufzuzinsen sind.

Das Gesetz sieht eine Aufzinsung von abgezinsten Verbindlichkeiten in der Steuerbilanz nicht ausdrücklich vor. Sie ergibt sich nur mittelbar daraus, dass $\S 6$ Abs. 1 Nr. 3 EStG zu jedem Bilanzstichtag ${ }^{77}$ anzuwenden ist und der Barwert der Verbindlichkeit durch Verkürzung der Restlaufzeit von Jahr zu Jahr zunimmt.

Eine solche Verkürzung der Restlaufzeit scheint das BMF in seinem Schreiben vom 26.5.2005 indes bei Darlehen mit unbestimmter Laufzeit nicht anzunehmen, solange die Laufzeit sich nicht konkretisiert. Dies ist zumindest aus dem Einleitungssatz zur vorgesehenen Bewertung analog $\S 13$ Abs. 2 BewG zu schließen, in dem es heißt: „Steht am Bilanzstich-

75 Vgl. BFH, Beschl. v. 6.10.2009 - I R 4/08, BStBl. II 2010, 177.

76 Vgl. BFH, Urt. v. 27.1.2010 - I R 35/09, BStBl. II 2010, 478.

77 Vgl. § 6 Abs. 1 Nr. 3 Satz 2 EStG: „deren Laufzeit am Bilanzstichtag“. 
tag der Rückzahlungszeitpunkt ... nicht fest ..." ${ }^{178}$ Fehlt es auch an den folgenden Bilanzstichtagen an einem feststehenden Rückzahlungszeitpunkt, so bliebe es folglich mangels anderweitiger Anhaltspunkte bei der Abzinsung des Darlehens mit dem Abzinsungsfaktor von 0,503. Eine ratierliche Aufzinsung des Darlehens fände nicht statt.

Die Folgerung, dass unverzinsliche Darlehen mit unbestimmter Laufzeit grundsätzlich nicht ratierlich aufzuzinsen sind, könnte auch einem obiter dictum des FG Köln in dem Urteil vom 1.9.2009 entnommen werden. Das Gericht hatte darin die erstmalige Abzinsung eines unverzinslichen Gesellschafterdarlehens mit unbestimmter Laufzeit zu beurteilen. Nach der Darlegung, dass der Ansatz der Verbindlichkeit mit dem abgezinsten Betrag unter Anwendung eines typisierten Zinssatzes von 5,5\% dem wahren Belastungswert näher komme als der Nominalwert, führt das Gericht aus: „Durch die im Falle bestimmbarer Laufzeit ratierliche Aufzinsung der Schulden zu den nachfolgenden Bilanzstichtagen wird der Wertansatz - ebenfalls typisierend - bis zum Rückzahlungszeitpunkt wieder an den Nominalwert angepasst. " 79 Eine Auseinandersetzung mit der Rechtsfrage enthält das Urteil aber nicht.

Aus dem BFH-Beschluss vom 6.10.200980 könnte demgegenüber der Schluss gezogen werden, dass der BFH eher zu einer im weiteren Verlauf vorzunehmenden Aufzinsung und Verteilung des Zinsaufwands neigt. So weist er in der Entscheidung darauf hin, es sei „Vom Gestaltungsspielraum des Gesetzgebers gedeckt, wenn dieser eine Regelung schafft, die im Fall der Gewährung eines Gesellschafterdarlehens zunächst zu einer - im weiteren Verlauf durch Aufzinsungen kompensierten - Erhöhung des Gewinns der Kapitalgesellschaft führt. Die Abzinsung von Darlehen für Zwecke der Besteuerung ist als solche weder sachwidrig noch unverhältnismäßig; sie dient vielmehr der Verteilung des Zinsaufwands nach Maßgabe einer wirtschaftlichen Zuordnung (Groh, DB 2007, 2275, 2277). "81 Die wirtschaftliche Zuordnung des Zinsaufwands kann nur eine solche sein, die ihn über die erwartete Laufzeit des Darlehens verteilt. Dies aber erfordert eine ratierliche Aufzinsung.

Für eine solche Aufzinsung ließe sich ferner anführen, dass Darlehen mit unbestimmter Laufzeit - anders als etwa immerwährende Leistungen eine begrenzte, wenn auch am Bilanzstichtag nicht bekannte Laufzeit haben und dass sich diese Laufzeit durch Zeitablauf verkürzt. Das Gesetz

78 Vgl. BMF, Schr. v. 26.5.2005 - IV B 2-S-2175-7/05, BStB1. I 2005, 699, Tz. 6.

79 Vgl. FG Köln, Urt. v. 1.9.2009 - 13 K 93/07, 94/07, 93-94/07, EFG 2010, 318, Revision eingelegt (BFH I R 102/09), unter 1.1 der Gründe; ebenso wohl Ortmann-Babel, BB 2010, 953.

80 Vgl. BFH, Beschl. v. 6.10.2009 - I R 4/08, BStBl. II 2010, 177.

81 Unter II. 5. der Gründe. 
typisiert diese Laufzeit in $\S 13$ Abs. 2 BewG mit 12 Jahren, 10 Monaten und 12 Tagen. Die ratierliche Aufzinsung würde der Verkürzung dieses Zeitraums Rechnung tragen. Es könnte sich dann allerdings die Frage ergeben, wie nach Ablauf des Zeitraums vorzugehen wäre, ob die Verbindlichkeit danach mit dem Nennwert zu bilanzieren oder - wegen dann vorliegender neuer Erkenntnisse - erneut abzuzinsen und in den folgenden Jahren aufzuzinsen wäre. Ist das Darlehen nach Ablauf der fiktiven Laufzeit noch nicht getilgt, so würde es der zugrunde liegenden Logik entsprechen, keine neue Laufzeitfiktion in Gang zu setzen, da die Typisierung sowohl zu Ungunsten als auch zu Gunsten des Steuerpflichtigen gelten muss. Bei einer tatsächlich kürzen Laufzeit des Darlehens würde sich die Laufzeitfiktion zu Ungunsten des Steuerpflichtigen auswirken. Folgerichtig müsste sie ihm im umgekehrten Fall zugute kommen. Eine erneute Abzinsung des Gesellschafterdarlehens müsste somit unterbleiben.

Um die vorstehend dargestellten Probleme der Aufzinsung unverzinslicher Darlehen mit unbestimmter Laufzeit zu vermeiden, erscheint es ratsam, von Vornherein eine wenn auch geringe Verzinsung zu vereinbaren oder aber einen langfristigen Tilgungszeitpunkt. Eine verzinsliche Verbindlichkeit liegt nach dem BMF-Schreiben vom 26.5.2005 ${ }^{82}$ schon dann vor, wenn ein Zinssatz von mehr als $0 \%$ vereinbart wurde. Lediglich ein Zinssatz nahe $0 \%$ kann kritisch sein. ${ }^{83}$ Eine verzinsliche Verbindlichkeit ist nach dem BMF-Schreiben zudem auch bei einer Stundung der Zinszahlungen anzunehmen. ${ }^{84}$

\section{Steuerliche Herstellungskosten nach BilMoG}

\section{Sachverhalt}

Der Geschäftsführer der A-GmbH bittet den Steuerberater um steuerbilanzielle Würdigung der Kalkulation der Herstellungskosten für ein Produkt nach der Bilanzrechtsmodernisierung durch das BilMoG. ${ }^{85}$ Insbesondere bittet er um Auskunft und Stellungnahme, inwieweit er von dem in $\S 255$ Abs. 2 Satz 3 HGB enthaltenen Wahlrecht zur Einbeziehung von Kosten der allgemeinen Verwaltung und für soziale Aufwendungen im Betrieb in der Steuerbilanz Gebrauch machen kann.

82 Vgl. BMF, Schr. v. 26.5.2005 - IV B 2-S-2175-7/05, BStBl. I 2005, 699, Tz. 13.

83 Vgl. BMF, Schr. v. 23.8.1999 - IV C 2-S 2175-25/99, BStBl. I 1999, 818.

84 Vgl. BMF, Schr. v. 26.5.2005 - IV B 2-S-2175-7/05, Tz. 13.

85 BilMoG v. 25.5.2009, BGBl. I 2009, 1102. 


\section{Lösungshinweise}

a) Umfang der zwingend zu aktivierenden Herstellungskosten im Handels- und Steuerrecht

Herstellungskosten i. S. v. § 255 Abs. 2 HGB sind die Aufwendungen, die durch den Verbrauch von Gütern und der Inanspruchnahme von Dienstleistungen für die Herstellung eines Vermögensgegenstandes, seine Erweiterung oder für eine über seinen ursprünglichen Zustand hinausgehende wesentliche Verbesserung entstehen. Gemäß § 255 Abs. 2 Satz 2 HGB gehören hierzu die Materialkosten, die Fertigungskosten und die Sonderkosten der Fertigung sowie angemessene Teile der Materialund Fertigungsgemeinkosten und des Werteverzehrs des Anlagevermögens, soweit dieser durch die Fertigung veranlasst ist. Angemessene Teile der Kosten für allgemeine Verwaltung sowie angemessene Aufwendungen für soziale Leistungen und für die betriebliche Altersvorsorge dürfen wahlweise nach $\S 255$ Abs. 2 Satz 3 HGB einbezogen werden, soweit diese auf den Zeitraum der Herstellung entfallen. Forschungs- und Vertriebskosten gehören nach $\S 255$ Abs. 2 Satz 4 HGB nicht zu den Herstellungskosten. Im Steuerrecht wird der Begriff der Herstellungskosten in $\S 6$ Abs. 1 Nr. 1 Satz 1 EStG genannt, aber im Gesetz nicht definiert. Über den Grundsatz der Maßgeblichkeit der Handelsbilanz für die Steuerbilanz in § 5 Abs. 1 EStG gilt daher der handelsrechtliche Herstellungskostenbegriff und -umfang auch im Steuerrecht. Durch die Änderung des Umfangs der handelsrechtlich zwingend zu aktivierenden Herstellungskosten um die angemessenen Teile der Material- und Fertigungsgemeinkosten sowie des Werteverzehrs des Anlagevermögens durch das BilMoG stimmen der Umfang der zwingend zu aktivierenden Herstellungskosten in Handels- und Steuerrecht erstmalig überein. Die Finanzverwaltung definiert den Umfang der zwingend zu aktivierenden Herstellungskosten in R 6.3. EStR 2008 entsprechend der gesetzlichen handelsrechtlichen Regelung in $\S 255$ Abs. 2 HGB.

\section{b) Angedachte Neudefinition des Umfangs der zwingend zu aktivierenden Herstellungskosten}

Das BMF hat mit Schreiben vom 12.03.2010 86 zu den steuerlichen Auswirkungen des BilMoG Stellung genommen. Wie erwartet wurde in diesem Schreiben u. a. die Möglichkeit der eigenständigen Ausübung von steuerlichen Wahlrechten in der Steuerbilanz bestätigt. Überraschend enthält das Schreiben jedoch an versteckter Stelle innerhalb eines Beispiels eine erhebliche Änderung der in R 6.3 EStR 2008 enthaltenen Verwaltungsauffassung zum Umfang der zwingend zu aktivierenden Herstel-

86 Vgl. BMF, Schr. v. 12.3.2010 - IV C 6-S 2133/09/10001, BStBl. I 2010, 239 ff. 
lungskosten in der Steuerbilanz. Demnach soll das handelsrechtliche Wahlrecht des $\S 255$ Abs. 2 Satz 3 HGB für die Einbeziehung von angemessenen Teilen der Kosten der allgemeinen Verwaltung und angemessenen Aufwendungen für soziale Einrichtungen des Betriebs, freiwillige soziale Leistungen und die betriebliche Altersversorgung im Steuerrecht zu einer Ansatzpflicht werden. Aufgrund des Wegfalls der umgekehrten Maßgeblichkeit in $\S 5$ Abs. 1 Satz 2 EStG ab dem Veranlagungszeitraum 2009 soll diese Regelung entsprechend für alle Veranlagungszeiträume ab 2009 zur Anwendung kommen. Im Schrifttum ist die Neuregelung aus den nachstehenden Gründen einhellig auf Ablehnung gestoßen. ${ }^{87}$

\section{c) Historische Entwicklung der Definition des Umfangs der zwingend zu aktivierenden Herstellungskosten}

Das steuerliche Wahlrecht zur Einbeziehung von Verwaltungs- und Sozialgemeinkosten ist seit Jahrzehnten in Rechtsprechung und Verwaltungspraxis verankert. Erstmals nahm der Große Senat des RFH im Jahre 1934 in einem Gutachten zum Begriff der Herstellungskosten Stellung, lange vor der erstmaligen detaillierten Definition der Herstellungskosten im Handelsrecht durch das Bilanzrichtlinien-Gesetz 1985. Danach zählten zu den Herstellungskosten ",alle auf die Herstellung verwandten Kosten“, nämlich die Einzelkosten zur Herstellung und die "Herstellungsgemeinkosten", also die Fertigungsgemeinkosten und die Materialgemeinkosten. Diese Definition wurde in die Einkommensteuerrichtlinien 1955 übernommen und in diesen für die Verwaltungsgemeinkosten ein Wahlrecht eingeräumt. ${ }^{88}$ Der BFH billigte diese Verwaltungsauffassung mit Urteil vom 26.1.1960. ${ }^{89}$ Seitdem sah die Finanzverwaltung keinen Anlass zur Änderung dieser Regelung, sodass diese in den noch gültigen Einkommensteuerrichtlinien 2008 enthalten ist. Auch in der Gesetzesbegründung zum Bilanzrichtlinien-Gesetz 1985 wurde darauf hingewiesen, dass der damalige R 33 EStR den GoB entsprach und „\$ 255 Abs. 2 und 3 HGB die wesentlichen Eckdaten dieses Abschnitts so festigt, dass dieser Abschnitt unverändert fortgeführt werden kann und wegen der Maßgeblichkeit der Handelsbilanz auch fortgeführt werden muss". 90 Die von einem Einbeziehungswahlrecht ausgehende Besteuerungspraxis sollte daher abgesichert werden. Mit der Wertung des Wahlrechts als GoB durch den Gesetzgeber findet es auch bereits im Wege der materiellen Maßgeblichkeit Eingang in die Steuerbilanz.

87 Vgl. Kaminski, DStR 2010, 771; Scheffler, StuB 2010, 295; Herzig/Briesemeister, DB 2010, 917; Geberth/Blasius, FR 2010, 408; Richter, GmbHR 2010, 505; Günkel/Teschke, Ubg 2010, 401.

88 Vgl. EStR 1955, R 33, BStBl. I 1956, 97.

89 Vgl. BFH, Urt. v. 26.1.1960 - I D 1/58, BStBl. III 1960, 191 ff.

90 Vgl. BT-Drucks. 10/4268, 101. 
Mit dem BilMoG sollte eine Angleichung der handels- und steuerrechtlichen Herstellungskosten erreicht werden. ${ }^{91}$ Im Rahmen des BilMoG wurden die Material- und Fertigungsgemeinkosten und der mit der Herstellung verbundene Werteverzehr des Anlagevermögens als Pflichtbestandteile in die Herstellungskosten einbezogen. Bei den Verwaltungs- und sozialen Gemeinkosten blieb es beim Ansatzwahlrecht. Das BilMoG glich damit die handelsrechtliche Bewertungsuntergrenze der seit jeher in den Einkommensteuerrichtlinen enthaltenen Wertuntergrenze an, weswegen das Schrifttum einhellig von einem künftigen Gleichklang der Herstellungskosten in Handels- und Steuerrecht ausging. ${ }^{92}$ Die erklärte Zielsetzung des Gesetzgebers war, dass die Änderungen durch das BilMoG nicht zu einer Mehrbelastung führen sollen. Dies würde nun jedoch verhindert, denn neben den höheren steuerlichen Wertansätzen werden die Steuerpflichtigen künftig mit einem nachhaltig gestiegenen Ermittlungsaufwand belastet. Insbesondere mittelständischen Unternehmen würde es schwer fallen, die angemessenen Teile des Verwaltungsaufwandes zu ermitteln..$^{93}$ Entstehungsgeschichte und Regelungsziel des $\S 255$ Abs. 2 HGB stützen daher das steuerliche Wahlrecht zur Einbeziehung von Verwaltungs- und Sozialgemeinkosten. Es verwundert deshalb nicht, dass sich auch die herrschende Meinung im Schrifttum in Übereinstimmung mit der bisherigen jahrzehntelangen Verwaltungspraxis für ein Einbeziehungswahlrecht, auch nach Verabschiedung des BilMoG, ausspricht. ${ }^{94}$

\section{d) Einbeziehungswahlrecht für Verwaltungs- und Sozialgemeinkosten als Gewohnheitsrecht}

Im Hinblick auf die Entstehungsgeschichte und die jahrzehntelange Verwaltungspraxis ist $\mathrm{zu}$ fragen, ob das Einbeziehungswahlrecht für Verwaltungs- und Sozialgemeinkosten nicht bereits zum Gewohnheitsrecht erstarkt ist, dem die neue Verwaltungsauffassung unzulässigerweise

91 Vgl. BT-Drs. 16/10067, S. 36.

92 Vgl. Künkele/Koss in Petersen/Zwirner (Hrsg.), BilMoG, 2009, S. 436; Petersen/ Zwirner/Künkele, Bilanzanalyse und Bilanzpolitik nach BilMoG, 2. Auflage 2010, S. 44; Köhler, StBp 2010, 75, Strahl, KÖSDI 2009, 16653; Förster/ Schmidtmann, BB 2009, 1346.

93 Vgl. den RegE-BilMoG v. 21.5.2008, 89, BT-Drs. 16/10067, 130; Müller/Reinke, StBg 2008, 336; Kaminski, StBg 2009, 197; ders. DStR 2010, 771.

94 Vgl. zum Überblick über den Meinungsstand Glanegger in Schmidt, EStG, 29. Auflage 2010, § 6, Rz. 172 ff.; Für die h. M.: Bordewin, DStZ 1986, 89; Moxter, BB 1988, 942; Weber-Grellet, Steuerbilanzrecht 1996, §7, Rz. 8; Wiedmann, Bilanzrecht, 2. Auflage 2003, § 255, Rz. 62; Ellrott/Brendt in Beck`scher Bilanzkommentar, 7. Auflage 2010, § 255, Rz. 115 ff.; Scheffler, StuB 2009, 841; Dörfler/Adrian, Ubg 2009, 73; Strahl, KÖSDI 2009, 16653; Herzig/Briesemeister, DB 2009, 977; dies. WPg 2010, 73; Zwirner, DStR 2010, 592; Weber-Grellet, DB 2009, 2403. 
zuwiderläuft. Nach den von Rechtsprechung und Schrifttum herausgearbeiteten Kriterien beinhaltet Gewohnheitsrecht alle ungeschriebenen Rechtsnormen, die sich durch langanhaltende Übung gebildet haben und von einem allgemeinen Rechtsbewusstsein bestätigt worden sind. Dies liegt insbesondere vor, wenn die Verwaltungspraxis mit der Rechtsüberzeugung der beteiligten Kreise übereinstimmt. ${ }^{95}$ Gewohnheitsrechtliche Steuerfolgen können nur durch Ausfüllung von Gesetzeslücken entstehen. Dies ist bei dem streitigen Wahlrecht der Fall, da $\S 6$ Abs. 1 Nr. 2 EStG nur regelt, dass Wirtschaftsgüter mit den Herstellungskosten anzusetzen sind, aber keine Aussage hinsichtlich des Umfangs der zwingend $\mathrm{zu}$ aktivierenden Gemeinkosten trifft. ${ }^{96}$

Im Weiteren sind die Voraussetzungen für das Vorliegen von Gewohnheitsrecht bei dem Wahlrecht der allgemeinen Verwaltungs- und Sozialgemeinkosten erfüllt. So liegt unzweifelhaft eine jahrzehntelange, langanhaltende Übung vor, welche in das bis heute nicht geschwundene oder sich veränderte Rechtsbewusstsein eingegangen ist. Das Wahlrecht erfüllt die Voraussetzung einer hinreichenden Bestimmtheit, ${ }^{97}$ da es (i) hinsichtlich der Rechtsanwendung klar ist, (ii) in den Einkommensteuerrichtlinien enthalten ist und (iii) höherrangigem Recht nicht zuwider läuft. Es ist zudem unstreitig, dass inzwischen einige GoB zu Gewohnheitsrecht erstarkt sind. ${ }^{98}$ Da der Gesetzgeber das Wahlrecht bereits in der Begründung zum BiRiLG 1985 als GoB gewertet hat, sollte auch dieses als Gewohnheitsrecht anzuerkennen sein. So ist anerkannt, dass z. B. die ebenfalls vom Reichsfinanzhof geschaffene Rücklage für Ersatzbeschaffung in R 6.6 EStR 2008 zum Gewohnheitsrecht erstarkt ist und seit Jahrzehnten praktiziert und für zutreffend empfunden wird. ${ }^{99}$

e) Unzutreffende Begründung der angedachten Neudefinition des Umfangs der zwingend zu aktivierenden Herstellungskosten durch das BMF

Das BMF begründet seine Auffassung in Tz. 8 des BMF-Schreibens unter Bezugnahme an die Entscheidung des BFH vom 21.10.1993. ${ }^{100}$ Daraus ergebe sich, dass nach $\S 6$ Abs. 1 Nr. 2 Satz 1 EStG die Herstellungskosten

95 Vgl. Lang in Tipke/Lang, Steuerrecht, 20. Auflage 2010, S. 142; Drünen in Tipke/Kruse, AO/FGO, § 4, Rz. 100.

96 Vgl. Herzig/Briesemeister, a. a. O. Fn. 2, m. w. N.

97 Vgl. Wernsmann in Hübschmann/Hepp/Spitaler, AO/FGO, § 4, Rz. 145.

98 Vgl. Drünen in Tipke/Kruse, AO/FGO, § 4, Rz. 102.

99 Vgl. BFH, Urt. v. 24.5.1973 - IV R 23-24/68, BStBl. II 1973, 582; BFH, Urt. v. 29.4.1982 - IV R 10/79, BStBl. II 1982, 568; BFH, Urt. v. 28.10.1998 - X R 96/96, BStBl. II 1999, 217; Kulosa in Schmidt, EStG, 29. Auflage 2010, § 6, Rz. 102.

100 Vgl. BFH, Urt. v. 21.10.1993 - IV R 87/92, BStBl. II 1994, 176. 
anzusetzen sind, also alle Aufwendungen, die ihrer Art nach Herstellungskosten sind, somit auch Verwaltungs- und Sozialgemeinkosten. Der BFH hat diese Frage jedoch in diesem Urteil gar nicht behandelt, sondern vielmehr ausdrücklich offen gelassen. Der BFH vertritt lediglich mit Bezug auf die bisherige Rechtsprechung zum Herstellungskostenbegriff, dass auch Material- und Fertigungsgemeinkosten sowie Sonderkosten der Fertigung unbeschadet des handelsrechtlichen Wahlrechts steuerlich aktiviert werden müssen. Nach der Rechtslage nach BilMoG besteht hier ohnehin handelsrechtlich eine Aktivierungspflicht. Der BFH nimmt außerdem Bezug auf sein Urteil vom 26.1.1960,101 welches der damaligen und bis heute gültigen Richtlinienregelung zustimmte. Das zitierte Urteil gibt nichts her, um die angedachte Auffassung der Finanzverwaltung zu stützen.

Ferner führt die Finanzverwaltung an, das gem. § 5 Abs. 6 EStG die steuerlichen Spezialvorschriften zur Bewertung den handelsrechtlichen GoB vorgehen, so dass es auch im Bereich der Bewertung zu einer Einschränkung des Maßgeblichkeitsgrundsatzes kommt. Diese Argumentation ist unzutreffend, da es weder eine steuerliche Spezialvorschrift zur Bewertung in Gestalt einer steuerlichen Definition des Herstellungskostenbegriffs noch eine erweiterte Auslegung des Begriffs durch die Rechtsprechung gibt. Allgemeine Grundsätze des Steuerrechts wie z.B. der Grundsatz der Besteuerung nach der Leistungsfähigkeit, reichen hierbei nicht aus. ${ }^{102}$ So könnte die Finanzverwaltung nicht argumentieren, dass eine Ansatzpflicht für allgemeine Verwaltungs- und Sozialgemeinkosten in diesem Sinne erforderlich sei, um die Besteuerung des vollen Gewinns sicherzustellen. Dem wäre zu entgegnen, dass es weder eine objektiv richtige Bemessung des Gewinns bzw. der Leistungsfähigkeit noch einen vollen Gewinn gibt. ${ }^{103}$ Nach den rechtsstaatlichen Prinzipien des Vorbehalts des Gesetzes und des Vorrangs des Gesetzes ${ }^{104}$ kann es nur den gesetzlich normierten Gewinn geben. Zudem ist zu berücksichtigen, dass jede Gewinnermittlung mit subjektiven Wertungen verbunden ist und ein Ansatzwahlrecht in diesem Sinne aus verschiedenen wirtschaftlichen Gründen gerechtfertigt werden kann. So besteht zum einen zwischen Verwaltungskosten und dem Herstellungsprozess nur ein mittelbarer Veranlassungszusammenhang ${ }^{105}$ und zum anderen rechtfertigt der

101 Vgl. BFH, Urt. v. 26.1.1960, a. a. O. Fn. 4.

102 Vgl. Stobbe in Herrmann/Heuer/Raupach, EStG und KStG, § 5, Rz. 105.

103 Heinrichs, Maßgeblichkeitsgrundsatz oder eigenständige Prinzipien für die Steuerbilanz?, DStJG 2001, S. 309; Günkel/Techke, a. a. O. Fn. 2 m. w. N.

$104 \mathrm{Vgl}$. Lang in Tipke/Lang, Steuerrecht, 20. Auflage 2010, $107 \mathrm{ff}$.; Birk, StuW 1989, 212.

105 Vgl. Goberth/Blasius, FR 2010, 409; Ellrodt/Brendt in Beck`scher Bilanzkommentar, 7. Auflage 2010, §255, Rz. $115 \mathrm{ff}$. 
erhebliche Aufwand für die zutreffende Ermittlung des angemessenen Teils des Verwaltungsaufwandes durchaus eine Vereinfachungsregelung. ${ }^{106}$ Im Übrigen ist bis heute streitig, ob es sich bei dem handelsrechtlichen Einbeziehungswahlrecht für allgemeine Verwaltungs- und Sozialgemeinkosten nicht nur um eine Bewertungshilfe und nicht "echte" Herstellungskosten handelt. ${ }^{107}$

Das BMF-Schreiben vom 12.3.2010 erweckt durch den Aufgriff des Themas im Rahmen der Äußerungen zur Änderung des $\S 5$ Abs. 1 EStG den Eindruck, dass die Änderung der Verwaltungsauffassung als eine Folge des BilMoG gesehen werden kann. Dies ist jedoch unzutreffend. Im Rahmen des BilMoG wurde die umgekehrte Maßgeblichkeit in §5 Abs. 1 EStG a. F. abgeschafft, sodass künftig steuerliche Wahlrechte, also auch zur Einbeziehung von Verwaltungs- und Sozialgemeinkosten, abweichend von der Handelsbilanz ausgeübt werden können. Hieraus lässt sich jedoch nicht ableiten, dass handelsrechtliche Aktivierungswahlrechte zu einem steuerlichen Aktivierungsgebot werden. Im Ergebnis ist daher für Gemeinkostenpositionen in $\S 255$ Abs. 2 Satz 3 HGB abweichend von der Finanzverwaltungsauffassung weiterhin von einem steuerlichen Einbeziehungswahlrecht auszugehen.

\section{f) Vorläufige Aufgabe der angedachten Neudefinition}

des Umfangs der zwingend zu aktivierenden Herstellungskosten durch die Finanzverwaltung

Das BMF hat mit Schreiben vom 22.6.2010 auf die vielfältige Kritik in der Literatur reagiert. Die geänderte Verwaltungsauffassung wurde jedoch (noch) nicht revidiert, sondern die Aussagen zur zeitlichen Anwendung der neuen Regelung im BMF-Schreiben vom 12.03.2010 im Einvernehmen mit den obersten Finanzbehörden der Länder um eine Randnummer 25 ergänzt. Danach wird nicht beanstandet, wenn im Hinblick auf die in Tz. 8 des Schreibens von R 6.3 Abs. 4 EStR 2008 geäußerte abweichende Auffassung für Wirtschaftsjahre, die vor der Veröffentlichung einer geänderten Richtlinienfassung enden, noch nach der bisherigen Richtlinienregelung verfahren wird. Mit dieser Ergänzung beseitigte das BMF zumindest die Unsicherheiten für die Steuerpflichtigen, wie künftig in den Steuererklärungen zu verfahren ist. Da in der Beraterschaft fast einhellig empfohlen wurde, bis zur Klärung der Rechtsfrage an einem Einbeziehungswahlrecht für Kosten der allgemeinen Verwaltung und sozialen Vorsorge festzuhalten und dies in den Steuererklärungen offen zu legen,

106 Im Steuerrecht sind sowohl Billigkeits- als auch Vereinfachungswahlrechte anerkannt, welche aber nicht kodifiziert sind, vgl. hierzu Herzig/Briesemeister, a. a. O. Fn. 2 m. w. N.

107 Vgl. Fischer in Kirchhoff, EStG, 9. Auflage 2010, § 6, Rz. 74 m. w. N. 
hätte die Verwaltung sich wohl ohne die Übergangsregelung mit einer Vielzahl von Rechtsbehelfsverfahren konfrontiert gesehen. Obsiegte der Steuerpflichtige später mit seiner abweichenden Auffassung, wäre eine Bilanzberichtigung nach R 4.4 Abs. 1 EStR grundsätzlich möglich. Ob beabsichtigt oder unbeabsichtigt begegnet das BMF mit dieser Regelung auch den in der Literatur geäußerten Bedenken hinsichtlich des Vorrangs einer Richtlinienregelung vor einem BMF-Schreiben. Denn die Einkommensteuerrichtlinien bedürfen immerhin nach Art. 108 Abs. 7 GG der Zustimmung des Bundesrates. ${ }^{108}$

\section{Fazit}

Die geänderte Fassung des R 6.3 Abs. 4 EStR darf mit Spannung erwartet werden. Vor dem Hintergrund des Gewichts der vorbeschriebenen Argumente, vor allem aus den Aspekten der Entstehungsgeschichte des $\S 255$ HGB und des steuerlichen Herstellungskostenbegriffs, der Systematik des Gesetzes und der fast einhelligen Ablehnung der überraschenden neuen Verwaltungsauffassung würde ein Festhalten an dieser umso mehr überraschen.

\section{Konsequenzen nicht vorgenommener Teilwertabschreibungen bei Umwandlungsvorgängen}

\section{Sachverhalt}

Die M-GmbH mit Sitz und Geschäftsleitung im Inland ist als einzige Kommanditistin zu $100 \%$ am Vermögen der T-GmbH \& Co. KG beteiligt. Die T-GmbH \& Co. KG hält wiederum sämtliche Anteile an der E-GmbH, die ebenfalls Sitz und Geschäftsleitung im Inland hat. Neben ihrer Beteiligung an der E-GmbH verfügt die T-GmbH \& Co. KG über vernachlässigbares Vermögen, das sie zum Betrieb ihres eigenen Gewerbebetriebs einsetzt. Das Wirtschaftsjahr der $\mathrm{M}-\mathrm{GmbH}$, der T-GmbH \& Co. KG und der E-GmbH entspricht jeweils dem Kalenderjahr.

Die Anschaffungskosten i. S. v. § 255 Abs. 1 HGB der T-GmbH \& Co. KG für die Anteile an der E-GmbH betrugen TEUR 1.000. Die E-GmbH hatte im Rahmen der Finanzmarktkrise erhebliche wirtschaftliche Probleme, so dass die T-GmbH \& Co. KG von einer dauerhaften Wertminderung der Anteile an der E-GmbH ausging. Sie schrieb die Anteile an der E-GmbH deshalb gem. §253 Abs. 3 Satz 3 HGB in ihrer Handelsbilanz zum 31.12.2009 auf den niedrigeren beizulegenden Wert in Höhe von TEUR $500 \mathrm{ab}$.

108 Vgl. Günkel/Teschke, a. a. O. Fn. 2. 
Im Hinblick auf den Wegfall der umgekehrten Maßgeblichkeit (§ 5 Abs. 1 Satz 2 EStG a. F.) ab dem Veranlagungszeitraum 2009 durch das Gesetz zur Modernisierung des Bilanzrechts (Bilanzrechtsmodernisierungsgesetz, BilMoG) ${ }^{109}$ entschloss sich die T-GmbH \& Co. KG im Einklang mit der Auffassung der Finanzverwaltung, ${ }^{110}$ die Abschreibung in der Steuerbilanz nicht vorzunehmen, sondern den bisherigen steuerlichen Buchwert der Anteile an der E-GmbH in Höhe von TEUR 1.000 beizubehalten. Dem lag die Überlegung zugrunde, dass eine Teilwertabschreibung der Anteile i. S. v. § 6 Abs. 1 Nr. 2 Satz 2 EStG keine Auswirkungen auf das zu versteuernde Einkommen (§8b Abs. 3 Satz 3, Abs. 6 KStG) und damit den Gewerbeertrag (§ 7 Satz 1, Satz 4 Halbsatz 2 GewStG) hätte, der Ertrag aus einer Wertaufholung der Anteile aber in Höhe von $5 \%$ steuerpflichtig wäre $(\S 6$ Abs. 1 Nr. 2 Satz 3 EStG i. V.m. $\S 8$ b Abs. 2 Satz 3, Abs. 3 Satz 3, Abs. 6 KStG, § 7 Satz 1, Satz 4 Halbsatz 2 GewStG).

Die M-GmbH möchte ihren Kommanditanteil an der T-GmbH \& Co. KG zum 31.12.2010 auf eine neu zu gründende Kapitalgesellschaft (NewCo) mit Sitz und Geschäftsleitung im Inland gem. § 123 Abs. 3 UmwG gegen Gewährung neuer Gesellschaftsanteile steuerneutral ausgliedern. Die Ausgangs- und Zielstruktur ist der nachstehenden Abbildung zu entnehmen. Es soll angenommen werden, dass der niedrigere beizulegende Wert i.S.v. §253 Abs. 3 Satz 3 HGB und der gemeine Wert i.S.v. §9 Abs. 2 BewG der Anteile an der E-GmbH identisch sind.

Die T-GmbH \& Co. KG bittet ihren Steuerberater um steuerbilanzielle Würdigung des Ausgliederungsvorgangs.

109 BGBl. I 2009, $1102 \mathrm{ff}$.

110 Vgl. BMF, Schr. v. 12.3.2010 - IV C 6-S 2133/09/100001, BStBl. I 2010, 239, Tz. 8. 


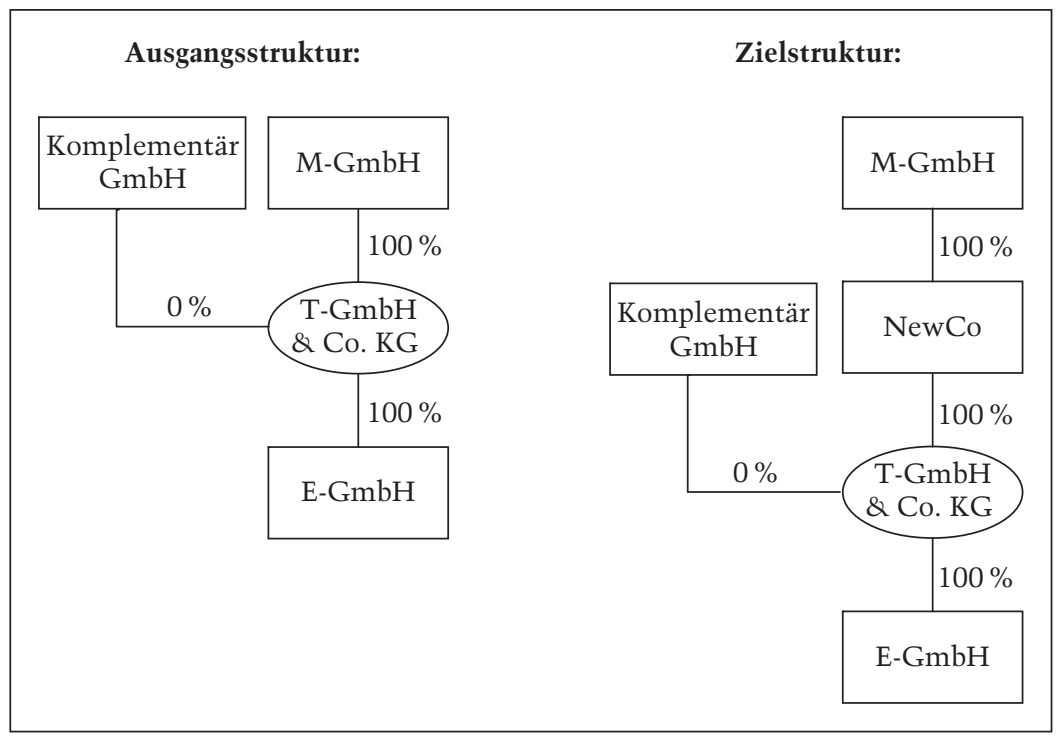

\section{Lösungshinweise}

Die geplante Ausgliederung i.S. v. $§ 123$ Abs. 3 UmwG fällt in den persönlichen und sachlichen Anwendungsbereich des Umwandlungssteuergesetzes ( $§ 1$ Abs. 3 und 4 UmwStG). Sofern ein Mitunternehmeranteil (hier: T-GmbH \& Co. KG) in eine Kapitalgesellschaft (hier: NewCo) eingebracht wird und der Einbringende (hier: $\mathrm{M}-\mathrm{GmbH}$ ) dafür neue Anteile an der Gesellschaft (hier: NewCo) erhält, ist $§ 20$ UmwStG für die Bewertung des eingebrachten Betriebsvermögens und der neuen Gesellschaftsanteile an der NewCo anzuwenden (§ 20 Abs. 1 UmwStG).

Nach $\S 20$ Abs. 2 Satz 1 UmwStG hat die übernehmende Gesellschaft das eingebrachte Betriebsvermögen grundsätzlich mit dem gemeinen Wert anzusetzen. Auf Antrag kann das übernommene Betriebsvermögen gem. $\S 20$ Abs. 2 Satz 2 UmwStG einheitlich mit dem Buchwert oder einem höheren Wert, höchstens jedoch mit dem gemeinen Wert angesetzt werden, soweit

- sichergestellt ist, dass das eingebrachte Betriebsvermögen später bei der übernehmenden Körperschaft der Besteuerung mit Körperschaftsteuer unterliegt,

- die Passivposten des eingebrachten Betriebsvermögens die Aktivposten nicht übersteigen; dabei ist das Eigenkapital nicht zu berücksichtigen, 
- das Recht der Bundesrepublik Deutschland hinsichtlich der Besteuerung des Gewinns aus der Veräußerung des eingebrachten Betriebsvermögens bei der übernehmenden Gesellschaft nicht ausgeschlossen oder beschränkt wird.

Wird ein Mitunternehmeranteil eingebracht, so ist das Bewertungswahlrecht i. S. v. § 20 Abs. 2 Satz 2 UmwStG nicht auf Ebene der übernehmenden Gesellschaft, sondern in der Steuerbilanz der Personengesellschaft auszuüben, deren Anteile eingebracht werden (hier: T-GmbH \& Co. KG). Da ein Mitunternehmeranteil steuerrechtlich kein Wirtschaftsgut ist, obliegt die Bewertung mithin der Personengesellschaft. ${ }^{111} \mathrm{Im}$ vorliegenden Fall entscheidet somit die T-GmbH \& Co. KG über die Bewertung des eingebrachten Betriebsvermögens. An die Handelsbilanzansätze ist sie dabei nicht gebunden.

Der Wert, mit dem die übernehmende Gesellschaft das eingebrachte Betriebsvermögen ansetzt, gilt für den Einbringenden (hier: $\mathrm{M}-\mathrm{GmbH}$ ) als Veräußerungspreis und als Anschaffungskosten der Gesellschaftsanteile an der NewCo (§ 20 Abs. 3 UmwStG).

Die Voraussetzungen für eine Einbringung zum steuerlichen Buchwert sind beim vorliegenden innerstaatlichen Umwandlungsvorgang unter Beteiligung inländischer Rechtsträger und ihrer inländischen Anteilseigner erfüllt, so dass die T-GmbH \& Co. KG abweichend vom Grundsatz der Bewertung des eingebrachten Betriebsvermögens zum gemeinen Wert das antragsgebundene Bewertungswahlrecht zum Buchwert grundsätzlich ausüben darf.

Der steuerliche Buchwert der Anteile an der E-GmbH auf Ebene der T-GmbH \& Co. KG übersteigt hier indes den gemeinen Wert der Anteile an der E-GmbH. Nach dem Wortlaut des $§ 20$ Abs. 2 Satz 2 UmwStG darf das eingebrachte Betriebsvermögen "mit dem Buchwert oder einem höheren Wert, höchstens jedoch mit dem Wert im Sinne des Satzes 1", d. h. höchstens mit dem gemeinen Wert, angesetzt werden. Daraus ist zu schließen, dass eine Buchwertfortführung nicht möglich ist, wenn der Buchwert über dem gemeinen Wert des eingebrachten Betriebsvermögens liegt. ${ }^{112}$ Das ist vorliegend der Fall. Die Anteile an der E-GmbH sind daher auf Ebene der T-GmbH \& Co. KG zwingend mit dem gemeinen Wert, also mit TEUR 500, anzusetzen. Dem dürfte nicht entgegenstehen, dass die Finanzverwaltung $\mathrm{zu}$ der ähnlichen Regelung des $§ 20$

111 Vgl. BFH, Urt. v. 30.4.2003 - I R 102/01, BStB1. II 2004, 804.

112 Vgl. Schmitt in Schmitt/Hörtnagl/Stratz, UmwG/UmwStG, 5. Auflage 2009, $\S 20$ UmwStG, Rz. 287; Menner in Haritz/Menner, UmwStG, 3. Auflage 2010, $\S 20, \mathrm{Rz} .334$ mit dem Hinweis, dass es sich um die Berücksichtigung der für den Einbringenden geltenden Verpflichtung zur Teilwertabschreibung handele. 
Abs. 2 UmwStG a. F. die Auffassung vertrat, der Ansatz des eingebrachten Betriebsvermögens mit einem niedrigeren Wert als dem bisherigen Buchwert sei nicht zulässig. ${ }^{113}$ Denn nach überwiegender Meinung im Schrifttum sollte dies nicht ausnahmslos, sondern nur dann gelten, wenn nicht zwingend ein niedrigerer Teilwert anzusetzen war. ${ }^{114}$

Der Ansatz des gemeinen Wertes der Anteile an der E-GmbH bedeutet für die T-GmbH \& Co. KG, dass bei ihr ein Einbringungsverlust entsteht, der steuerlich nicht abzugsfähig ist (§ 8 b Abs. 2 Satz 1 und 2, Abs. 6 KStG, $\S 7$ Satz 1, Satz 4 Halbsatz 2 GewStG).

Der Gesetzgeber hat diese Auswirkung des Wegfalls der umgekehrten Maßgeblichkeit i.S. v. § 5 Abs. 1 Satz 2 EStG a. F. auf das Umwandlungssteuergesetz offensichtlich nicht erkannt. So regelt (i) §23 Abs. 1 UmwStG den Fall, dass die übernehmende Gesellschaft das eingebrachte Betriebsvermögen mit einem Wert unter dem gemeinen Wert ansetzt und (ii) § 23 Abs. 3 UmwStG den Fall, dass die übernehmende Gesellschaft das eingebrachte Betriebsvermögen mit einem über dem Buchwert, aber unter dem gemeinen Wert liegenden Wert ansetzt. Der Fall, dass der gemeine Wert unter dem steuerlichen Buchwert liegt, ist vom Gesetz nicht vorgesehen, da dies auch vor Wegfall der umgekehrten Maßgeblichkeit i. S. v. § 5 Abs. 1 Satz 2 EStG a. F. nicht erforderlich war.

\section{Fazit}

Das vorstehende Dilemma lässt sich nur im Wege einer Anpassung des Umwandlungssteuergesetzes durch den Gesetzgeber lösen. Im vorliegenden Fall, dass der gemeine Wert eines Wirtschaftsgutes unter dem steuerlichen Buchwert liegt, wäre für sämtliche Vorgänge, die in den Anwendungsbereich des Umwandlungssteuergesetzes fallen, zu regeln, dass für Zwecke des Umwandlungssteuergesetzes der steuerliche Buchwert fortgeführt werden darf. Bis zu einer entsprechenden Gesetzesänderung sollte die Finanzverwaltung dies kurzfristig im Erlasswege klarstellen. ${ }^{115}$

113 Vgl. BMF, Schr. v. 25.3.1998 - IV B 7-S-1978-21/98/IV B 2-S 1909-33/98, BStB1. I 1998, 268, Tz. 20.23.

$114 \mathrm{Vgl}$. Widmann in Widmann/Mayer, Umwandlungsrecht, § 20 UmwStG (SEStEG), Rz. R 412 sowie $§ 20$ UmwStG a. F., Rz. 667; Patt in Dötsch/Jost/Pung/ Witt, Die Körperschaftsteuer, §20 UmwStG, Rz. 155.

115 Würde eine Buchwertfortführung bei Wirtschaftsgütern, deren gemeiner Wert unter dem steuerlichen Buchwert liegt, nicht zugelassen, ergäbe sich die weitere Frage, ob damit der Buchwertansatz auch für das übrige eingebrachte Betriebsvermögen ausscheidet, da $§ 20$ Abs. 2 Satz 2 UmwStG verlangt, dass die gewählte Bewertungsmethode (Buchwert, gemeiner Wert, Zwischenwert) für das eingebrachte Betriebsvermögen einheitlich anzuwenden ist. 



\section{Leitthema: \\ Kapitalgesellschaften}





\title{
Anwendungsfragen des neuen $\S 8 \mathrm{c} \mathrm{KStG}$
}

\author{
Dr. Gottfried E. Breuninger \\ Rechtsanwalt, München
}

Inhaltsübersicht
I. Beschränkung der Verlustnut- zung ohne Ende?
1. Die unendliche Geschichte der Rechtsprechung und Gesetz- gebung zum Mantelkauf und $\S 8$ Abs. 4 KStG
2. Die Neuregelung des $\S 8 \mathrm{c} \mathrm{KStG}$
3. Trendwende durch Einführung einer Sanierungsklausel?
4. Die Neuregelungen durch das "Gesetz zur Beschleunigung des Wirtschaftswachstums"

\author{
II. Kernproblemfelder der Neurege- \\ lung \\ 1. Konzernklausel \\ 2. Stille-Reserven-Klausel \\ 3. Übergangsregelung $\S 34$ Abs. 6 \\ Satz 3 KStG \\ III. Der neue $\$ 8$ c und Debt-Equity- \\ Swap-Strukturen: Notleidende \\ Gesellschafterdarlehensstruktu- \\ ren und die Defizite des deut- \\ schen Sanierungssteuerrechts \\ IV. Resümee
}

Der Titel „Anwendungsfragen des neuen $\S 8 \mathrm{c} \mathrm{KStG}$ " klingt zunächst eher nach einer Ansammlung von Detailproblemen, aber es verbirgt sich in Wahrheit ein Kernbereich des Unternehmenssteuerrechts dahinter, der gerade in Krisenzeiten essentiell ist. Es geht um die Beschränkung der Verlustnutzung insbesondere bei Kapitalgesellschaften. Dabei ist ganz wichtig, dass $\S 8 \mathrm{c}$ KStG nur eine - aber eine ganz besonders bedeutsame Vorschrift unter vielen anderen Bestimmungen im deutschen Steuerrecht ist, die zum Wegfall der Verlustnutzungsmöglichkeit führen. Zu nennen sind etwa die Mindestbesteuerung (§10d Abs. 2 EStG), ${ }^{1} \S 8 \mathrm{~b}$ Abs. 3 S. 4-7 KStG, §§ 15 Abs. 4 S. 6-8, 15a EStG, die grenzüberschreitende Nutzung von Betriebsstättenverlusten ${ }^{2}$ usw. Das Thema des Beitrages ist die geänderte Fassung der Vorschrift des $\S 8 \mathrm{c} \mathrm{KStG}$, die ohne einen näheren Sinn und Zweck als bloße Verlustvernichtungsvorschrift als Maßnahme zur Gegenfinanzierung der Steuersatzsenkung im Rahmen der Unternehmensteuerreform geboren wurde. Im Hinblick auf die geänderte Fassung

$1 \mathrm{Zu}$ Zweifeln an der Verfassungsmäßigkeit der Mindestbesteuerung bei endgültigem Ausschluss der Verlustverrechnung vgl. jüngst BFH, Beschl. v. 26.8.2010 I B 49/10, DStR 2010, 2179. Das BVerfG hat die Vorlage des BFH, Beschl. v. 6.9.2006 - XI R 26/04, BStBl. II 2007, 167, zu § 2 Abs. 3 und $\S 10$ d EStG i. d. F. des Steuerentlastungsgesetzes 1999/2000/2002 dagegen als unzulässig zurückgewiesen, vgl. BVerfG, Beschl. v. 12.10.2010, 2 BvL 59/06, DStR 2010, 2290.

2 Vgl. dazu die beiden jüngeren BFH-Entscheidungen v. 9.6.2010 - I R 100/09 und I R $107 / 09$. 
der Vorschrift stellt sich die Frage: Kann man eine von vornherein „totgeborene" Vorschrift durch punktuelle „Nachbesserungen" zum Leben erwecken? Ich meine nein.

\section{Beschränkung der Verlustnutzung ohne Ende?}

Die nun erfolgten Änderungen des § $8 \mathrm{c}$ KStG (Konzernklausel/StilleReserven-Klausel/Sanierungsklausel) fügen sich nahtlos ein in die unendliche Geschichte der Vorgängervorschrift des § 8 Abs. 4 KStG, so dass man generell von einer unendlichen Geschichte der Beschränkung der Verlustnutzung sprechen kann (die sich im übrigen auch bei anderen Vorschriften manifestiert).

\section{Die unendliche Geschichte der Rechtsprechung und Gesetzgebung zum Mantelkauf und § 8 Abs. 4 KStG}

Ausgangspunkt ist die BFH-Rechtsprechung zum sogenannten Mantelkauf, die zunächst angenommen hatte, dass trotz unbestrittener rechtlicher Identität bei grundlegender Änderung des personalen und sachlichen Substrats die Verlustverwertung steuerlich zu verneinen ist. Diese Rechtsprechung hatte der BFH im Jahre 1986 aufgegeben und die Anforderungen auf das Merkmal der zivilrechtlichen Personenidentität eingeschränkt. ${ }^{3}$ Dies führte zur Einführung des $\S 8$ Abs. $4 \mathrm{KStG}$ durch das Steuerreformgesetz 1990 vom 25.7.1988, ${ }^{4}$ wodurch sichergestellt werden sollte, dass nicht ausgeglichene Verluste nur dann steuerlich genutzt werden, wenn die Körperschaft, die den Verlust nutzt, mit derjenigen, die ihn erlitten hat, sowohl rechtlich als auch wirtschaftlich identisch ist. Aber - wie bekannt - hat es sich in der Folgezeit herausgestellt, dass die Voraussetzung von $\S 8 \mathrm{Abs} .4 \mathrm{KStG}$, wonach der Verlust verursachende Geschäftsbereich eingestellt worden sein musste, in vielen Fällen durch Vermeidung der Einstellung dieses Geschäftsbereichs die Verlustnutzung sichergestellt werden konnte.

Dies führte zu einer Verschärfung von $\S 8$ Abs. 4 KStG in der Fassung des Gesetzes zur Fortsetzung der Unternehmensteuerreform vom 29.10.1997. ${ }^{5}$ Hier war lange Jahre unklar, ob diese Gesetzesänderung in verfassungsrechtlich zutreffender Form (im Hinblick auf die im Vermittlungsausschuss beschlossene Änderung) zustande gekommen ist. Das

3 Vgl. BFH v. 29.10.1986 - I R 202/82 und I R 318-319/83, BStB1. II 1987, 308 und 310 .

4 BGBl. I 1988, 1093.

5 BGBl. I 1997, 2590. 
Bundesverfassungsgericht hat hier dem Gesetzgeber durch seine Entscheidung vom 15.1.2008 ${ }^{6}$ sozusagen eine "Lernkurve" zugebilligt, in dem es zwar festhielt, die Vorschrift sei mit dem Grundgesetz in unvereinbarer Weise zustande gekommen, dass aber die Änderung letztlich gültig bleibt, weil es an der nötigen Evidenz des Verfahrensverstoßes fehlte. Der BFH war dann in der Folgezeit mit der Ausjudizierung der offenen Fragen zu $\S 8$ Abs. 4 KStG beschäftigt und hat hier nach und nach zur weiteren Klärung der Auslegungsfragen beigetragen. ${ }^{7}$ Dies betrifft insbesondere die Fragen zur schädlichen Anteilsübertragung (insbesondere Beschränkung auf unmittelbare Übertragungen). ${ }^{8}$ Bei der Frage der schädlichen Betriebsvermögenszuführung führt die Auffassung des BFH bzgl. einer wirtschaftlichen Betrachtungsweise (Stichwort: gegenständliche Betrachtungsweise) zu einer extrem weiten Auslegung bzgl. möglicher Zuführungen. ${ }^{9}$ Vergleicht man das mit der „Urform “ des § 8 Abs. 4 KStG, hätte man durchaus noch weiter an der Vorschrift festhalten können vielleicht in modifizierter Form.

\section{Die Neuregelung des $§ 8 \mathrm{c} \mathrm{KStG}$}

Daher stellt sich berechtigterweise die Frage, ob die grundsätzliche Abschaffung der Vorschrift zu Gunsten der Neuregelung des $§ 8 \mathrm{c} \mathrm{KStG}$ gerechtfertigt war. Jedenfalls wurde als Gegenfinanzierungsmaßnahme zur Steuerreform $2008 \S 8 \mathrm{c} \mathrm{KStG}$ neu in das Gesetz aufgenommen. ${ }^{10}$ Dabei haben sich klar die sogenannten „Verlustvernichter" gegen die mehr missbrauchsorientierten "Verlustbegrenzer" durchgesetzt. So wurde insbesondere auch die noch streitige, aber vom BFH im Sinne einer unmittelbaren Anteilsübertragung entschiedene Problematik geregelt, ${ }^{11}$ dass auch mittelbare Anteilsübertragungen schädlich sind. $\S 8 \mathrm{c} \mathrm{KStG}$ in der ursprünglich verabschiedeten Fassung lautete:

„Werden innerhalb von fünf Jahren mittelbar oder unmittelbar mehr als 25 Prozent des gezeichneten Kapitals der Mitgliedschaftsrechte, Beteiligungsrechte oder der Stimmrechte an einer Körperschaft an einen Erwerber oder diesem nahe stehende Personen übertragen oder liegt ein vergleichbarer Sachverhalt vor (schädlicher Beteiligungserwerb), sind insoweit die bis zum schädlichen Beteiligungserwerb nicht ausgeglichenen oder abgezogenen negativen Einkünfte (nicht genutzte Ver-

6 BVerfG v. 15.1.2008 - 2 BvL 12/01, DStR 2008, 556.

7 Siehe hierzu die Übersicht zur Rechtsprechungsentwicklung bei Roser, in Gosch, KStG, 2. Aufl., § 8 Rz. 1430 f. und Lang, in Ernst \& Young, KStG, § 8 Rz. $1273 \mathrm{f}$.

8 BFH v. 20.8.2003 - I R 61/01, BStBl. II 2004, 616.

9 Vgl. Roser, aaO (Fn. 7); Breuninger/Frey/Schade, GmbHR 2007, 1161.

10 Durch das UntStRefG 2008 v. 14.8.2007, BStBl. II 2007, 630.

11 Siehe oben Fn. 8. 
luste) nicht mehr abziehbar. Unabhängig von Satz 1 sind bis zum schädlichen Beteiligungserwerb nicht genutzte Verluste vollständig nicht mehr abziehbar, wenn innerhalb von fünf Jahren mittelbar oder unmittelbar mehr als 50 Prozent des gezeichneten Kapitals der Mitgliedschaftsrechte, Beteiligungsrechte oder der Stimmrechte an einer Körperschaft an einen Erwerber oder diesem nahe stehende Personen übertragen werden oder ein vergleichbarer Sachverhalt vorliegt." [...]

Hierdurch ist eine entscheidende Wendung im Vergleich zur bisherigen Vorschrift des $\S 8$ Abs. 4 KStG eingetreten (darüber hinaus ist die bisherige Vorschrift des $\S 8$ Abs. 4 KStG durch die Übergangsvorschrift des $\S 34$ Abs. 6 S. 3 KStG in besonderen Fällen weiterhin anwendbar). Es kommt danach nur auf die schädliche Anteilsübertragung, egal ob mittelbar oder unmittelbar, an. Von einer wirtschaftlichen Identität kann keine Rede mehr sein. Das wird besonders deutlich, wenn man sich einen Fall vor Augen führt, bei dem zehn Stufen über der Verlustgesellschaft auf der Ebene eines ausländischen mittelbaren Anteilsinhabers eine konzerninterne Umstrukturierung z. B. durch eine Verschmelzung stattfindet. Es findet sozusagen ein Durchgriff ",bis zu den Sternen " statt. ${ }^{12}$ Auf schädliche Betriebsvermögenszuführungen kam es nicht mehr an. Ein irgendwie gearteter Zweck ist hierin nicht erkennbar. Kann bei einer schädlichen Anteilsübertragung im Konzern 10 Stufen über dem Anteilsinhaber von einem Verlust des personellen Substrats gesprochen werden? Die Gesetzesbegründung geht davon aus, dass sich die „wirtschaftliche Identität" einer Gesellschaft durch das wirtschaftliche Engagement eines anderen Anteilseigners ändert. ${ }^{13}$ In diesem Fall ist das wohl nicht so. Vielmehr stellt die Vorschrift einen eklatanten Systembruch dar, da gegen das objektive Nettoprinzip und auch das Trennungsprinzip verstoßen wurde (es entsteht eine partielle Transparenz). ${ }^{14}$ Es ist ein Armutszeugnis für einen Rechtsstaat, dass Neuregelungen nur noch als reine Gegenfinanzierungsmaßnahme dienen und damit die Steuersystematik keine relevante Rolle mehr spielt.

Der Befund war klar: $\S 8 \mathrm{c}$ KStG war weit über das Ziel hinaus geschossen. M.E. war es von vornherein eine Totgeburt. Im Zuge der sich verstärkenden Rezession nach den Boomjahren zeigte die Steuerreform für "Siegertypen ${ }^{\prime 15}$ ihre Wirkung, notwendige Umstrukturierungen von Verlustgesellschaften zur Sanierung wurden in das Gegenteil verkehrt:

12 Dötsch/Pung, DB 2008, 1703, 1706.

13 BT-Drucks. 16/4841, 34 und 76.

14 Der Verstoß des $\S 8 \mathrm{c}$ KStG gegen grundlegende Prinzipien ist im Schrifttum vielfach scharf kritisiert worden, vgl. nur Blumenberg/Benz, Die Unternehmenssteuerreform 2008, 201; Hey, BB 2007, 1303, 1306; Lenz/Ribbrock, BB 2007, 587, 590; Schwedhelm, GmbHR 2008, 404; Suchanek/Herbst, FR 2007, 863, 869; Zerwas/Fröhlich, DStR 2007, 1933, 1935.

15 Schön, FAZ v. 15.3.2007, 12. 
Die Verluste entfielen durch eine mittelbare oder unmittelbare Anteilsübertragung. Der Erhalt von Verlustvorträgen war reiner Zufall und verkam damit zum Roulette: Ein Tax Asset konnte jederzeit wegfallen, denn die Werthaltigkeit hing davon ab, ob nicht gerade eine schädliche Anteilsübertragung 10 Stufen über dem Anteilsinhaber durchgeführt worden ist.

Im Rahmen des Finanzmarktstabilisierungsfondsgesetzes ${ }^{16}$ wurde für einen Spezialbereich $\S 8 \mathrm{c}$ KStG suspendiert, nachdem der Gesetzgeber realisiert hatte, dass eine Bankenrettung erst einmal zur Zerstörung von Verlusten führen kann. Man glaubte zu hoffen, dass spätestens hier der Gesetzgeber realisiert hätte, dass $\S 8 \mathrm{c} \mathrm{KStG}$ ein Irrweg war. Aber warum galt die Neuregelung nur für diesen Spezialbereich? Hinzukommt, dass man in der Folgezeit zu Beginn des Jahres 2009 § 8 c KStG sogar noch weiter verschärft hat, ${ }^{17}$

- einmal durch die Einführung des $\S 2$ Abs. 4 UmwStG (Einschränkung der Verrechnung von steuerlichen Verlusten bei Umwandlung mit steuerlicher Rückwirkung ${ }^{18}$ und

- zum anderen durch die Erstreckung der Vorschrift auf gewerbesteuerliche Verlustvorträge von Personengesellschaften gem. dem jetzigen $\S 10$ a Satz 10 GewStG. ${ }^{19}$

Hinzukommt die Veröffentlichung eines äußerst restriktiven Anwendungserlasses zu $\S 8 \mathrm{c} \mathrm{KStG} .{ }^{20}$

Auch die Anwendung von $\S 8 \mathrm{c} \mathrm{KStG}$ auf Mitunternehmerschaften, an denen Kapitalgesellschaften beteiligt sind, ist durch die Regelung des $\S 10$ a Satz 10 GewStG äußerst problematisch. Dies verdeutlicht folgendes Beispiel einer doppelstöckigen Personengesellschaft:

$16 \S 14$ Abs. 3 FMStFG v. 17.10.2008, BGBl. I 2008, 1982. Zu den steuerlichen Auswirkungen siehe Berg, IStR 2009, 156; Eilers/Bühring, DStR 2009, 137; Goksch/ Gröger/Schuck, DB 2008, 2668; Korn, DStR 2008, 2248; Rodewald, BB 2009, 356; Spindler, DStR 2008, 2268.

17 Durch das Jahressteuergesetz 2009 v. 19.12.2008, BGBl. I 2008, 2794.

18 Vgl. dazu Rödder/Schönfeld, DStR 2009, 560; Sistermann/Brinkmann, DStR 2008, 2455; Suchanek, Ubg 2009, 178.

19 Siehe dazu z. B. Dörfler/Rautenstrauch/Adrian, BB 2009, 580, $581 \mathrm{f}$.

20 BMF, Schr. v. 4.7.2008 - IV C 7 - S 2745-a/08/10001, BStBl. I 2008, 736. Siehe dazu bspw. Breuninger/Schade, Ubg 2008, 261; Dörr, NWB 2008, 3099; Dötsch/ Pung, DB 2008, 1073; Lang, DStZ 2008, 549; Suchanek, FR 2008, 904; van Lishaut, FR 2008, 789. 


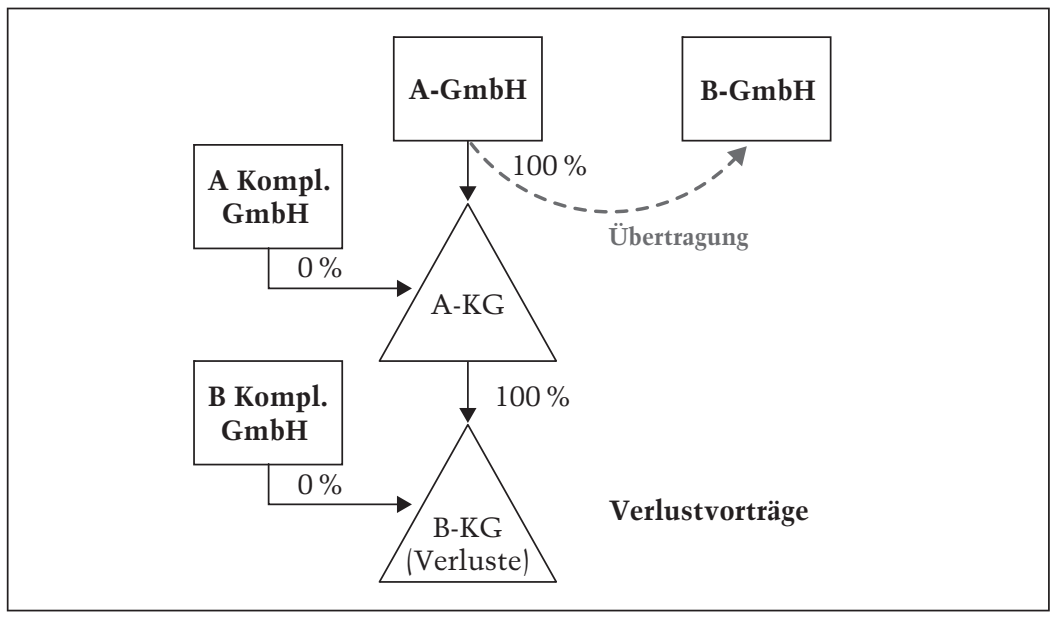

Der Erhalt des gewerbesteuerlichen Verlustabzugs verlangt Unternehmens- und Unternehmeridentität, d.h. bei einem vollständigen oder teilweisen Unternehmerwechsel geht der Verlustvortrag der Untergesellschaft ganz oder teilweise unter. Bei einer doppelstöckigen Personengesellschaft ist für steuerliche Zwecke anerkannt, dass nicht die Gesellschafter der Obergesellschaft, sondern die Obergesellschaft als solche Gesellschafterin und Mitunternehmerin der Untergesellschaft ist. ${ }^{21}$ Findet wie im Beispielsfall ein Gesellschafterwechsel bei der Obergesellschaft (oder einer Ebene darüber) statt, entfaltet die Obergesellschaft im Hinblick auf die bei der Untergesellschaft bestehenden Verlustvorträge Abschirmwirkung. Da die Obergesellschaft als solche Mitunternehmerin der Untergesellschaft ist und die Unternehmeridentität gewahrt bleibt, bleibt der gewerbesteuerliche Verlustvortrag erhalten.

Wandelt man den Fall dergestalt ab, dass oberhalb einer vollständig durch eine Kapitalgesellschaft (B-GmbH) gehaltene doppelstöckigen Personengesellschaft ein Anteilseignerwechsel in Bezug auf erstere stattfindet, so beurteilt sich dieser Fall nach Maßgabe von § 10a S. 10 GewStG.

21 Siehe grundlegend BFH v. 3.5.1993 - GrS 3/92, BStBl. II 1993, 616. 
Abwandlung:

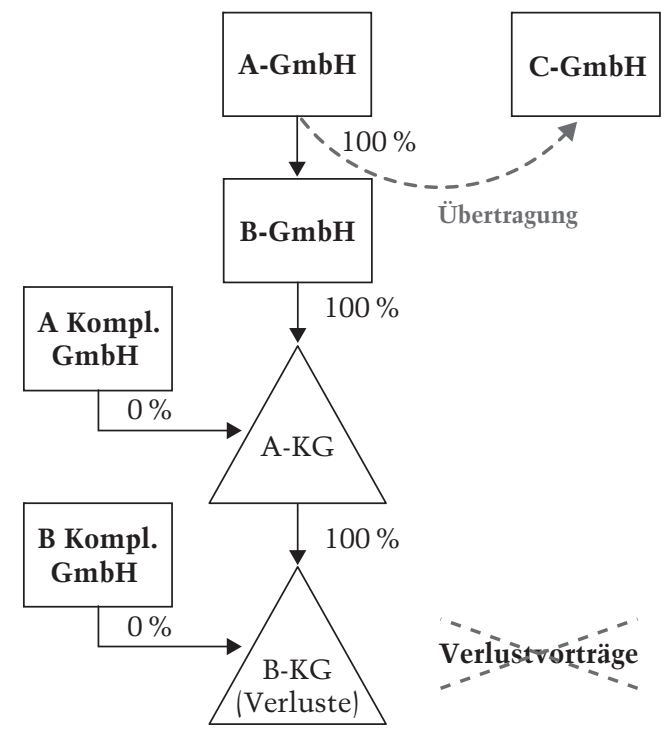

$\S 10$ a S. 10 GewStG bestimmt die entsprechende Anwendbarkeit des $\S 8 \mathrm{c}$ KStG auf Fehlbeträge, soweit diese (i) einer Körperschaft unmittelbar oder (ii) einer Mitunternehmerschaft, soweit an dieser eine Körperschaft unmittelbar oder mittelbar über eine oder mehrere Personengesellschaften beteiligt ist, zuzurechnen sind. Die Regelung führt daher hier zum vollständigen Entfallen des gewerbesteuerlichen Verlustvortrags. Dieses Ergebnis ist im Vergleich zum Ausgangsfall ebenso frappierend wie unsystematisch:22 Das Vorhandensein einer Kapitalgesellschaft innerhalb der Beteiligungskette, oberhalb derer ein Gesellschafterwechsel stattfindet, führt zur Durchbrechung der im Ausgangsfall gegebenen Abschirmwirkung der Oberpersonengesellschaft, indem ein Durchgriff durch die Kapitalgesellschaft stattfindet. Der Fall ist ein weiterer Beleg für die Tendenz der neueren Gesetzgebung zur umfassenden „Verlustvernichtung".

Darüber hinaus verbleiben Unklarheiten bei der Auslegung der in $\S 8 \mathrm{c} \mathrm{KStG}$ genannten unbestimmten Rechtsbegriffe, z. B. „vergleichbarer Sachverhalt" oder „Erwerbergruppe mit gleichgerichteten Interessen".

22 So zu Recht auch Brandenberg, FR 2010, 732. 
Letztendlich stellt sich die Frage, ob nicht aufgrund einer eklatanten Durchbrechung oder Verletzung des objektiven Nettoprinzips, des Trennungsprinzips und des Gebots der Folgerichtigkeit die Vorschrift verfassungswidrig ist. M. E. ist das zu bejahen. Der Gegenfinanzierungscharakter der Vorschrift rechtfertigt diesen Verstoß auf jeden Fall nicht.

\section{Trendwende durch Einführung einer Sanierungsklausel?}

Schließlich ergab sich doch eine gewisse Besserung: Man hat eingesehen, dass man - anders als beim alten $\S 8$ Abs. 4 KStG - eine Sanierungsregelung vergessen hatte. Die Berufung auf den Sanierungserlass war spätestens seit der Entscheidung des FG München ${ }^{23}$ mit erheblichen Unsicherheiten belegt. Der Gesetzgeber hat daher immerhin im Sommer 2009 eine Sanierungsklausel in $\S 8 \mathrm{c}$ KStG in einem neuen Absatz 1a geschaffen. ${ }^{24}$ Allerdings war die Anwendung dieser Vorschrift zunächst zeitlich befristet. Die zeitliche Befristung ist mittlerweile aufgehoben worden. ${ }^{25}$ Während die OFD Rheinland noch durch Verfügung vom 30.3.201026 ausführlich zu den Anwendungsvoraussetzungen der Vorschrift Stellung nahm, hatte die europäische Kommission schon mit Schreiben vom 24.2.2010 mitgeteilt, ein Verfahren nach Art. 108 Abs. 2 AEUV dahingehend einzuleiten, ob die Sanierungsklausel gegen das europarechtliche Beihilfeverbot verstößt, da sie notleidende Unternehmen gegenüber "gesunden" Unternehmen privilegieren könnte. Das BMF hat am 30.4.2010 diesen Beschluss der Kommission zusammen mit einem weiteren Schreiben vom selben Tag veröffentlicht. Inzwischen liegt eine Negativentscheidung der Kommission vom 26.1.2011 vor, wonach die Sanierungsklausel als mit Gemeinschaftsrecht nicht $z$ u vereinbarende Beihilfe einzustufen ist. ${ }^{27}$ Das BMF hat in seinem Schreiben vom 24.2.2010 darauf hingewiesen, dass „,im Falle einer Negativentscheidung durch die Kommission alle rechtswidrigen Beihilfen von den Empfängern zurückgefordert werden müssen". Dies gilt - so das BMF - auch für bereits ergangene

23 FG München v. 12.12.2007 - 1 K 4487/06, EFG 2008, 615.

24 Durch das Bürgerentlastungsgesetz Krankenversicherung v. 16.7.2009, BGBl. I 2009, 1959. Zur Sanierungsklausel siehe Altrichter-Herzberg, GmbHR 2009, 466; Dörr, NWB 2009, 2050; Fey/Neyer, DB 2009, 1368; Mückl/Remplik, FR 2009, 689; Neumann/Stimpel, Der Konzern 2009, 409; Ortmann-Babel/Bolik/Gageur, DStR 2009, 2173; Roser, FR 2009, 937; ders., EStB 2010, 265; Sistemann/Brinkmann, DStR 2009, 1453; Suchanek/Herbst, Ubg 2009, 525; de Weerth, DB 2010, 1205; Ziegenhagen/Thewes, BB 2009, 2116.

25 Aufgrund des Wachstumsbeschleuningungsgesetzes v. 22.12.2009, BGBl. I $2009,3950$.

26 OFD Rheinland, Verf. v. 30.3.2010 - S-2745-1007-St 131, DStR 2010, 929.

27 EU-Kommission, IP/11/65. Vgl. dazu die Anmerkung von Drüen, DStR 2011, 289. 
Bescheide und sogar in den Fällen, in denen bereits eine verbindliche Auskunft erteilt worden ist.

Maßgeblich für die Prüfung des Vorliegens der Voraussetzungen für eine Beihilfe sind grundsätzlich folgende Erwägungen:

- Zunächst geht es darum zu bestimmen, wie der Normalfall geregelt wird (Feststellung des Referenzsystems).

- In einem zweiten Schritt ist zu prüfen, ob die Maßnahme selektiven Charakter hat.

- Schließlich wäre bei Vorliegen eines selektiven Charakters die Frage der Rechtfertigung zu prüfen.

M. E. stellt die Sanierungsklausel keine unzulässige Beihilfe dar. ${ }^{28}$ Denn als Grundsatz gilt das Nettoprinzip und nicht die Verlustvernichtung. Dies gilt spätestens nach den Neuerungen durch das "Gesetz zur Beschleunigung des Wirtschaftswachstums", denn der Verlusterhalt ist danach nicht Ausnahme vom, sondern Ausdruck des Leistungsfähigkeitsprinzips. ${ }^{29}$ Die Sanierungsklausel ist Korrelat zur Stille-ReservenKlausel. Die Ausführungen der Kommission berücksichtigen dies alles nicht, da sie weitestgehend die Überlegungen zum gescheiterten MoRaKG übernommen hatten.

Letztlich ist die Einführung der Sanierungsklausel aufgrund der Entscheidung der EU-Kommission ins Leere gegangen, obwohl in der Praxis ein dringender Bedarf besteht. Die unbefriedigende Rechtslage im Hinblick auf sanierungsbedürftige Unternehmen bleibt damit bestehen. Es besteht dringender Handlungsbedarf.

\section{Die Neuregelungen durch das „Gesetz zur Beschleunigung des Wirtschaftswachstums"}

Immerhin hat das „Gesetz zur Beschleunigung des Wirtschaftswachstums" gewisse Erleichterungen im Hinblick auf $\S 8 \mathrm{c}$ KStG gebracht, indem die sogenannte Konzernklausel in $\S 8 \mathrm{c}$ Abs. 1 S. $5 \mathrm{KStG}$ und die sogenannte Stille-Reserven-Klausel im Rahmen einer Verlustverrechnungsregelung des $\S 8 \mathrm{c}$ Abs. 1 S. 6-8 KStG eingeführt worden sind. Beide Neuregelungen sind ausdrücklich zu begrüßen, führen aber in der Praxis schon wieder zu erheblichen Anwendungsproblemen, die derzeit einer Lösung harren. Zum Beispiel hat die vorgenannte entsprechende Anwen-

28 Siehe Breuninger/Ernst, GmbHR 2010, 561, 564; a. A. de Weerth, DB 2010, 1205.

29 So auch Drüen, Ubg. 2010, 543, 547. 
dung des $\S 8 \mathrm{c}$ KStG auf gewerbesteuerliche Verlustvorträge bei Mitunternehmerschaften durch die Stille-Reserven-Klausel und Konzernklausel eine weitere Verkomplizierung gefunden.

\section{Kernproblemfelder der Neuregelung}

\section{Konzernklausel}

Nach der neu eingeführten Konzernklausel in $\S 8$ c Abs. 1 Satz 5 UStG liegt ein schädlicher Beteiligungserwerb nicht vor, wenn an dem übertragenden und an dem übernehmenden Rechtsträger dieselbe Person zu jeweils $100 \%$ mittelbar oder unmittelbar beteiligt ist. ${ }^{30}$ Nach der Gesetzesbegründung sollen durch die Konzernklausel lediglich Umstrukturierungen innerhalb eines Konzerns von den Verlustverrechnungsbeschränkungen ausgeschlossen werden, wenn die Übertragung der Verluste auf Dritte ausgeschlossen ist. ${ }^{31}$

Die Konzernklausel ist ein absolut notwendiges Korrelat für den Umstand, dass sowohl unmittelbare als auch mittelbare Anteilsübertragungen schädlich sind. Ausgangspunkt sollte die Prämisse sein, dass in einem Konzern auch ohne eine Anteilsübertragung die Nutzung der Verluste in einer Verlustgesellschaft durch entsprechende Maßnahmen möglich ist. Daher ist der Gesetzgeber wohl davon ausgegangen, dass die konzerninterne Umstrukturierung ohne Untergang der Verlustvorträge möglich ist, da sich hierdurch grundsätzlich nicht die Gefahr ergibt, dass sich der Wert des Verlustes durch Übertragung innerhalb des Konzerns erhöht. ${ }^{32}$ Allerdings ist der Wortlaut der Bestimmung in $\S 8 \mathrm{c}$ Abs. 1 Satz 5 KStG äußerst eingeschränkt geraten. Der Wortlaut wäre unstreitig erfüllt, wenn die Übertragung der Verlustgesellschaft nur zwischen zwei $100 \%$-igen Tochtergesellschaften oder zwischen zwei Schwestergesellschaften erfolgen würde. Dies soll folgendes Beispiel verdeutlichen:

30 Zur Konzernklausel vgl. z.B. Altrichter-Herzberg, GmbHR 2010, 799; Bien/ Wagner, BB 2009, 2627; dies., BB 2010, 923; Cortez/Brucker, BB 2010, 991; Franz, BB 2010, 734; Frey/Mückl, GmbHR 2010, 71; Herzig/Bohn, DStR 2009, 2341; Schneider/Roderburg, FR 2010, 58; Sistermann/Brinkmann, DStR 2009, 2341.

31 BT-Drucks. 17/15, 31 .

32 So Eisgruber/Schaden, Ubg 2010, 73. 


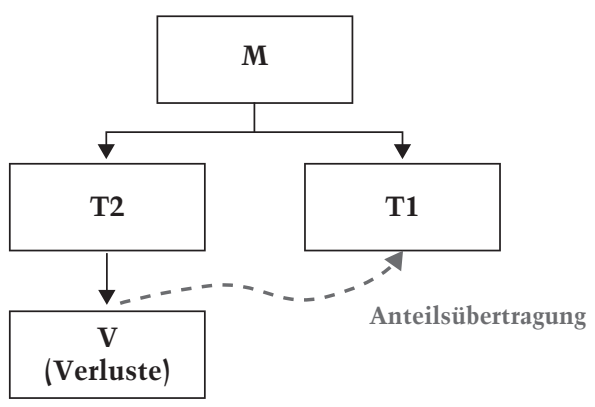

Anders ist dies bei folgendem Beispiel:

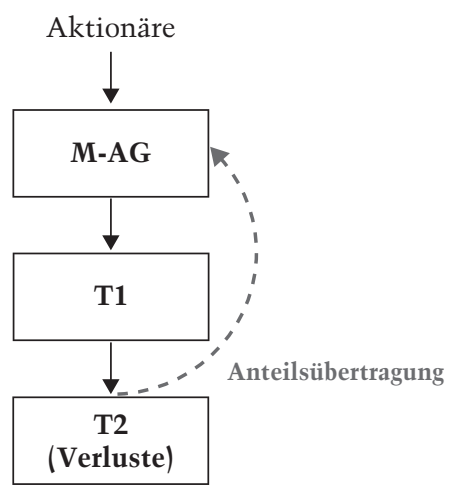

Wenn hier die Verlustgesellschaft von der Tochter- auf die Muttergesellschaft übertragen wird, stellt dies eine rein konzerninterne Übertragung dar, allerdings ist der Wortlaut der Vorschrift nicht erfüllt, da an dem übernehmenden Rechtsträger, hier der Muttergesellschaft, nicht dieselbe Person zu jeweils $100 \%$ beteiligt ist, sondern durch die Börsennotierung der Gesellschaft mehrere Personen. ${ }^{33}$

Eine ähnliche Problematik besteht dann, wenn z. B. Konzernspitze eine natürliche Person ist und die Konzernspitze mehrere 100\%-ige Betei-

33 Vgl. Lang in Ernst \& Young, KStG; § 8 c Rz. 120; Frey/Mück1, GmbHR 2010, 71, 72 . 
ligungen hält und nun die Beteiligung an der Verlustgesellschaft zwischen zwei Tochtergesellschaften übertragen wird. Dann sind die Voraussetzungen der Vorschrift unproblematisch erfüllt. Wird nun die Verlustgesellschaft von einer Tochtergesellschaft an die Konzernspitze, also die natürliche Person, übertragen, stellt sich die Frage, ob die natürliche Person ein tauglicher Rechtsträger nach $\S 8 \mathrm{c}$ Abs. 1 Satz $5 \mathrm{KStG}$ ist, da an der natürlichen Person keine anderen Personen beteiligt sein können. ${ }^{34}$ In beiden vorgenannten Fällen zeigt sich deutlich, dass eine Übertragung eigentlich auch keinen schädlichen Beteiligungserwerb darstellen sollte, da entsprechend der Gesetzesbegründung in beiden Fällen eine Übertragung der Verluste auf Dritte ausgeschlossen ist, sondern vielmehr die Verlustgesellschaft innerhalb des betreffenden Konzerns verbleibt.

Daher besteht ein erhebliches Problem in Bezug auf den Wortlaut des $\S 8$ c Abs. 1 Satz 5 KStG in der Gestaltungsberatung, da nach dem Wortlaut grundsätzlich nur Umhängungen auf der zweiten oder einer nachfolgenden Stufe des Konzerns möglich wären, wenn man davon ausgeht, dass an der Konzernspitze mehrere Personen beteiligt sind und damit keine Person zu $100 \%$ allein beteiligt ist.

Eine ähnliche Problematik besteht bei einer Übertragung auf eine $\mathrm{GmbH}$ \& Co. KG, bei welcher sämtliche Anteile an der ohne Kapitaleinlage an der KG beteiligten Komplementär-GmbH von konzernfremden Dritten gehalten werden. Hier stellt sich die Frage, ob bei einer Übertragung einer $100 \%$-igen Tochterverlustgesellschaft durch den Kommanditisten auf eine solche $\mathrm{GmbH} \&$ Co. KG, bei der der $100 \%$-ige Kommanditist auch der mittelbare Alleingesellschafter des übertragenden Rechtsträgers ist, die Voraussetzungen der Vorschrift erfüllt sind. ${ }^{35}$

Diese offenen Fragen der Neuregelung der Konzernklausel zeigen deutlich, dass hier noch erhebliche Defizite bestehen und im Hinblick auf den

34 Vgl. zu dieser Problematik Lang in Ernst \& Young, KStG, § 8 c Rz. 115, 120; Bien/Wagner, BB 2009, 2627, 2628; Sistermann/Brinkmann, DStR 2009, 2633.

35 Bei diesem Problemkreis ist zu beachten, dass Personengesellschaften entsprechend Tz. 24 des BMF-Schreibens vom 4.7.2008 (BStBl. I 2008, 736) grundsätzlich als Rechtsträger zu qualifizieren sind, da hier klargestellt wird, dass die Mitunternehmerschaft für Zwecke des $\S 8 \mathrm{c}$ KStG nicht als transparent zu betrachten, sondern einer zivilrechtlichen Betrachtungsweise der Vorzug zu geben ist. Es ergibt sich hierbei jedoch das Problem, dass Personengesellschaften zivilrechtlich mindestens zwei Gesellschafter haben müssen und daher eine einzelne Person nicht zu 100 \% beteiligt sein kann. Zur Lösung dieses Problems wird in der Literatur vorgeschlagen, dass nicht auf das Zivilrecht, sondern auf die Vermögensbeteiligung abzustellen sei, vgl. Bien/Wagner, BB 2009, 2627, 2628; Sistermann/Brinkmann, DStR 2009, 2633, 2634; Scheunemann/ Dennisen/Behrens, BB 2010, 23, 26. 
unterstellten Sinn und Zweck der Vorschrift (Fehlendes Risiko einer Verlustübertragung außerhalb des Konzerns als Normzweck?) die Regelung dem Wortlaut nach viel zu kurz greift. Es bleibt zu hoffen, dass die Finanzverwaltung in dem zu erwartenden Anwendungsschreiben diese Unklarheiten beseitigt und für die Gestaltungspraxis eine klare Linie aufzeigt.

\section{Stille-Reserven-Klausel}

Die sogenannte Verschonungsregelung oder Stille Reserven-Klausel in $\S 8$ c Abs. 1 Satz 6-8 KStG stellt eine weitere, sehr zu begrüßende Einschränkung des bisherigen Anwendungsbereichs der Verlustvernichtungsvorschrift des $\S 8 \mathrm{c} \mathrm{KStG}$ dar. ${ }^{36}$ Die Vorschrift lautet:

„Ein nicht abziehbarer und nicht genutzter Verlust kann abweichend von Satz 1 und Satz 2 abgezogen werden, soweit er bei einem schädlichen Beteiligungserwerb i. S. des Satzes 1 der Beteiligung, bei einem schädlichen Beteiligungserwerb i. S. des Satzes 2, die gesamten, zum Zeitpunkt des schädlichen Beteiligungserwerbs vorhandenen stillen Reserven des inländischen Betriebsvermögens der Körperschaft nicht übersteigt. Stille Reserven i. S. des Satzes 6 sind der Unterschiedsbetrag zwischen dem anteiligen oder bei einem schädlichen Beteiligungserwerb i. S. des Satzes 2 dem gesamten in der steuerlichen Gewinnermittlung ausgewiesenen Eigenkapital und dem auf dieses Eigenkapital jeweils entfallenden gemeinen Wert der Anteile an der Körperschaft, soweit diese im Inland steuerpflichtig sind. Bei der Ermittlung der stillen Reserven ist nur das Betriebsvermögen zu berücksichtigen, das der Körperschaft ohne steuerrechtliche Rückwirkung, insbesondere ohne Anwendung des $§ 2$ Abs. 1 des UmwStG, zuzurechnen ist."

Der Neuregelung liegt der Gedanke zugrunde, dass nicht genutzte Verluste mindestens in Höhe der vorhandenen stillen Reserven genutzt werden könnte. Nach einem früheren Gesetzgebungsvorschlag aus Nordrhein-Westfalen zu Zeiten des alten $\S 8$ Abs. 4 KStG sollte schon einmal wahlweise die Möglichkeit eingeräumt werden, dass vor einem Untergang der Verlustvorträge ein sogenannter Step-Up zur Verrechnung der stillen Reserven mit den Verlustvorträgen, ggf. ohne Anwendung der Mindestbesteuerung, möglich ist. ${ }^{37}$ Die Idee ist, dass durch die vorhandenen stillen Reserven ein vorhandenes Gewinnpotential zur Verrechnung mit den Verlustvorträgen vorhanden ist und daher ein Untergang der Ver-

36 Zur Stille-Reserven-Klausel vgl. z. B. Lang in Ernst \& Young, KStG, §8c Rz. 127 f.; Frotscher, KStG, § 8 c Rz. 128 f.; Roser, EStB 2010, 265; Frey/Mück1, GmbHR 2010, 71, 73 f.; Rödder/von Freeden, Ubg 2010, 551.

37 Das Eckpunktepapier der Kommission Koch/Steinbrück v. 3.11.2006, Anl., S. 2, Stand 13.10.2006 sah vor, dass nur der Teil des Verlustabzugs untergehen sollte, der die im Unternehmen vorhandenen stillen Reserven überstieg. Siehe dazu auch Thiel, FR 2000, 499. 
lustvorträge durch eine schädliche Anteilsübertragung nicht sachgerecht erscheint.

Die Regelung entspricht der nicht in Kraft getretenen Regelung des $\S 8 \mathrm{c}$ Abs. 2 KStG für Erwerbe von und durch Wagniskapitalbeteiligungsgesellschaften $^{38}$ (durch das Gesetz zur Modernisierung der Rahmenbedingungen für Kapitalbeteiligungen (MoRaKG)). Diese Vorschrift wurde jüngst von der EU-Kommission als eine mit dem gemeinsamen Markt unvereinbare Beihilfe qualifiziert.

Auch wenn die Vorschrift sehr zu begrüßen ist, ergibt sich doch eine Vielzahl von offenen Anwendungsfragen, die nachfolgend kurz angesprochen werden sollen. Ausgangspunkt der Regelung ist, dass grundsätzlich ein Beteiligungserwerb i.S. des $\S 8 \mathrm{c}$ Abs. 1 Satz $1 \mathrm{KStG}$ (schädliche Anteilsübertragung zwischen $25 \%$ und $50 \%$ ) oder $\S 8$ c Abs. 1 Satz 2 KStG (mehr als $50 \%$ ) vorliegt, der grundsätzlich zu einem anteiligen oder vollständigen Untergang nicht genutzter Verluste führt. Dieser Untergang der Verluste wird nur in Höhe der vorhandenen stillen Reserven des inländischen Betriebsvermögens verhindert.

Auf der ersten Stufe sind somit die gesamten stillen Reserven zu ermitteln. Stille Reserven sind gemäß §8 c Abs. 1 Satz 7 KStG der Unterschiedsbetrag zwischen dem anteiligen (in den Fällen des $\S 8 \mathrm{c}$ Abs. 1 S. $1 \mathrm{KStG}$ ) oder dem gesamten in der steuerlichen Gewinnermittlung ausgewiesenen Eigenkapital und dem auf dieses Eigenkapital jeweils entfallenden gemeinen Wert der Anteile an der Körperschaft.

Danach sind in einem zweiten Schritt die nicht im Inland steuerpflichtigen stillen Reserven abzuziehen. Dabei ist insbesondere für eine HoldingGesellschaft derzeit ungeklärt, ob die stillen Reserven in einer Beteiligung nur zu $95 \%$ in Abzug zu bringen sind oder zu $100 \%$.

In einem dritten Schritt ist die entsprechende Quote der stillen Reserven zu ermitteln.

Der Entwurf eines Jahressteuergesetzes $2010^{39}$ sieht hier eine Änderung dergestalt vor, dass zur Ermittlung der stillen Reserven auch das im

38 Die im Zuge des Gesetzes zur Modernisierung der Rahmenbedingungen für Kapitalbeteiligungen (MoRaKG) v. 12.08.2008, BGBl, I 2008, 1672 vorgesehene Stille-Reserven-Klausel bei Beteiligungen an Wagniskapitalgesellschaften ist nach einer Negativentscheidung der EU-Kommission v. 30.9.2009 (IP/09/1449) nie in Kraft getreten. Vgl. dazu Dörr, NWB 2009, 3499 sowie Breuninger/Ernst, FR 2008, 659, 663.

39 BR-Drucks. 679/10 v. 5.11.2010, 19. Der Bundesrat hat am 26.11.2010 dem vom Bundestag am 28.10.2010 verabschiedeten Jahressteuergesetz 2010 (BRDrs. 679/10) zugestimmt, vgl. BR-Drs. 679/10(B). 
Inland steuerpflichtige ausländische Betriebsvermögen herangezogen werden kann. ${ }^{40}$ Ferner soll durch einen neu eingefügten S. 8 bei Vorliegen eines negativen Eigenkapitals die Ermittlung der zu berücksichtigenden stillen Reserven durch eine Gegenüberstellung des Eigenkapitals der Körperschaft und des gemeinen Werts des Betriebsvermögens erfolgen. ${ }^{41}$

In der praktischen Anwendung bedeutet dies, dass zum Beispiel bei einer schädlichen Anteilsübertragung von $46 \%$ natürlich auch nur die stillen Reserven in Höhe von $46 \%$ zu berücksichtigen sind. Zu beachten ist die Regelung § $8 \mathrm{c}$ Abs. 1 Satz $8 \mathrm{KStG}$, wonach nur das Betriebsvermögen zu berücksichtigen ist, das der Körperschaft ohne steuerrechtliche Rückwirkungen, insbesondere ohne Anwendung des §2 Abs. 1 des UmwStG, zuzurechnen ist. Das bedeutet, dass insbesondere die Verschmelzung einer Gesellschaft mit Wirtschaftgütern mit stillen Reserven zu Buchwerten in die Verlustgesellschaft nicht möglich ist. Allerdings ist m.E. eine Begründung einer steuerlichen Organschaft in dem jeweiligen Wirtschaftsjahr keine nach $\S 8 \mathrm{c}$ Abs. $1 \mathrm{~S} .8 \mathrm{KStG}$ schädliche steuerrechtliche Rückwirkung, sondern eine anzuerkennende Gestaltung. ${ }^{42}$ Dies folgt m. E. aus der zwingenden gesetzlichen Anordnung zum zeitlichen Beginn der Organschaft in $\S 14$ Abs. 1 S. 2 KStG ${ }^{43}$ wonach das Einkommen der Organgesellschaft dem Organträger „erstmals für das Kalenderjahr zuzurechnen ist, in dem das Wirtschaftsjahr der Organgesellschaft endet, in dem der Gewinnabführungsvertrag wirksam wird". Denn es handelt sich dabei nicht um eine Rückwirkung, sondern eine gesetzliche Anordnung zum zeitlichen Beginn der Organschaft. Beispiel Organschaft:

40 Damit wird insbesondere Betriebsvermögen aus Nicht-DBA-Staaten und im Verhältnis zu Staaten, bei denen die Anrechnungsmethode vereinbart wurde, erfasst.

41 Vgl. BT-Drucks. 17/3449 v. 27.10.2010, 51: „Ist das Eigenkapital der Körperschaft negativ, sind stille Reserven i. S. des Satzes 6 der Unterschiedsbetrag zwischen dem anteiligen oder bei einem schädlichen Beteiligungserwerb i. S. des Satzes 2 dem gesamten in der steuerlichen Gewinnermittlung ausgewiesenen Eigenkapital und dem diesem Anteil entsprechenden gemeinen Wert des Betriebsvermögens der Körperschaft."

42 Dabei muss aber beachtet werden, dass in der "organschaftsfreien Zeit" jeweils eigene Verluste bei der Organgesellschaft entstanden sind (vororganschaftliche Verluste), vgl. hierzu Dötsch, Der Konzern 2010, 99.

43 Unterstellt, dass die jeweilige Organgesellschaft ein kalendergleiches Wirtschaftsjahr hat. 


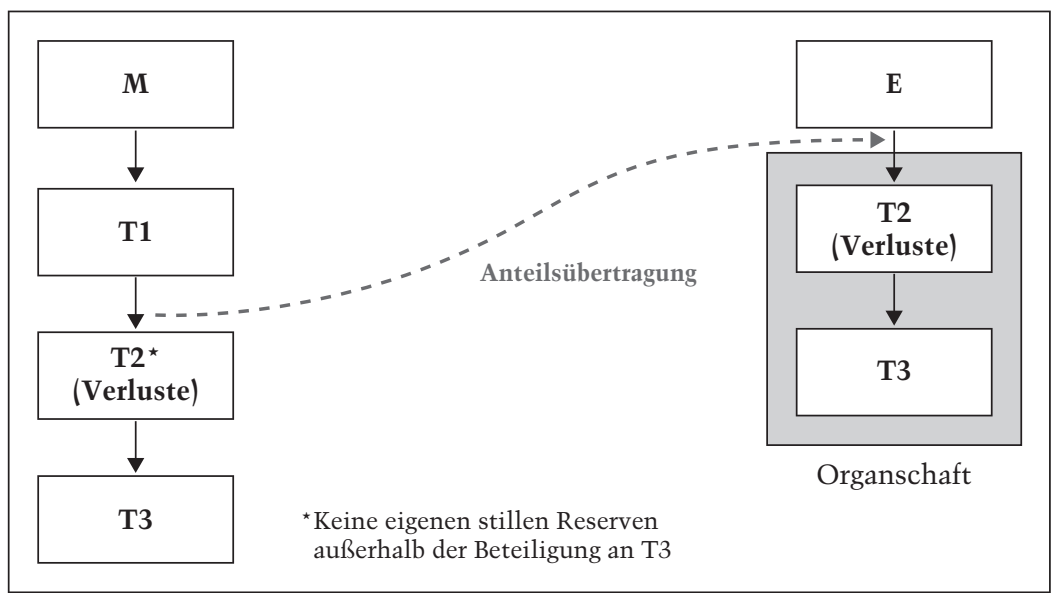

Offene Fragen und Anwendungsprobleme ergeben sich in der Praxis insbesondere in mehrstöckigen Strukturen. ${ }^{44}$ Hier stellt sich die Problematik, dass eine schädliche Anteilsübertragung auf der Ebene der Muttergesellschaft gleichzeitig zur mittelbaren, schädlichen Anteilsübertragung auf den nachgeordneten Ebenen führt. Hier stellen sich besondere Fragen in Bezug auf die Ermittlung der stillen Reserven. Des Weiteren stellt sich die Frage, wie Organschaften zu behandeln sind. Gleiches gilt für nachgeordnete Personengesellschaften.

Im Hinblick auf den Umstand, dass eine Holdinggesellschaft grundsätzlich so gut wie keine relevanten stillen Reserven für Zwecke der Anwendung des $\S 8 \mathrm{c}$ Abs. 1 Satz 6-8 KStG haben wird, stellt sich die Frage, ob sich durch eine bestehende Organschaft oder ggf. durch die Begründung einer Organschaft daran etwas ändert. Bei bestehender Organschaft sollte m. E. für Zwecke der Stille-Reserven-Klausel auf die in den nachgeordneten Gesellschaften enthaltenen stillen Gesellschaften abgestellt werden. ${ }^{45}$

Entsprechend der alten Regelung zu $\S 8$ Abs. $4 \mathrm{KStG}^{46}$ ist m. E. bei einer Organschaft davon auszugehen, dass eine konsolidierte Ermittlung der

44 S. dazu Rödder/von Freeden, Ubg 2010, 551.

45 So auch bspw. Dörr, NWB 2010, 184, 196 f.; Eisgruber/Schaden, Ubg 2010, 73, 83 f.; Frey/Mückl, GmbHR 2010, 71, 76; Lang, Der Konzern 2010, 35, 43; Orth, Ubg 2010, 169, 177.

46 Vgl. dazu das BMF-Schreiben zu § 8 Abs. 4 KStG, v. 16.4.1999, IV C 6 S 2745-12/99, BStBl. I 1999, 455, Tz. 9, wonach im Hinblick auf die Frage der schädlichen Betriebsvermögenszuführung auf der Ebene des Organträgers der 
stillen Reserven möglich ist. Allerdings kann es auch Konstellationen geben, in denen sich in einer Organgesellschaft sogenannte eingefrorene Verluste befinden ${ }^{47}$ Dabei dürfte auch hier wiederum eine Stand-AloneBetrachtung der Organgesellschaft relevant sein. Es stellt sich die Frage, inwieweit hierbei eine betragsmäßige Begrenzung zu beachten ist. Nach der Gesetzesbegründung darf die Summe der in den untergeordneten Unternehmen ermittelten stillen Reserven, die im Kaufpreis bzw. im Unternehmenswert der erworbenen Gesellschaft enthaltenen stillen Reserven nicht übersteigen. ${ }^{48}$ Hierin eine Beschränkung der stillen Reserven zu sehen, ist meines Erachtens unzutreffend. ${ }^{49}$

Dies soll das folgende Beispiel verdeutlichen:

Der Verkäufer verkauft seine Beteiligungen zum Preis von 200 (gemeiner Wert) an den Käufer. Hinsichtlich eines Gewinns aus der Veräußerung der Anteile an einer Untergesellschaft greift § 8 b Abs. 2 S. 1 KStG. T2 verfügt über im Inland steuerpflichtige stille Reserven in Höhe von 100.

Folgen unter der Stille-Reserven-Klausel?

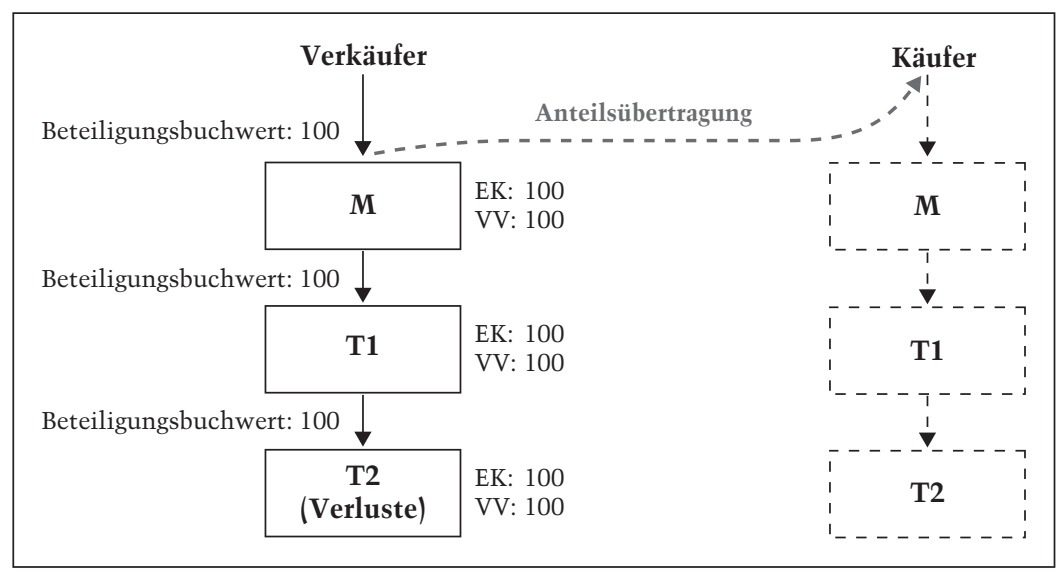

Beteiligungsbuchwert durch die entsprechende Aktivseite der nachgeordneten Organgesellschaft ersetzt wird.

47 Vgl. dazu Gröger, BB 2010, 2926, 2928; Frey/Mück1, GmbHR 2010, 71, 76.

48 Vgl. BT-Drs. 17/15, 31.

49 So auch das Verständnis der überwiegenden Literatur, vgl. Dörr, NWB 2010, 184, 197; Dötsch in Dötsch/Pung/Jost/Witt, KStG, §8c Rz. 761; Scheipers/ Linn, Ubg 2010, 8, 14; Sistermann/Brinkmann, DStR 2009, 2633, 2636; Neyer, BB 2010, 1055, 1058; Rödder/von Freeden, Ubg 2010, 551, 553; Wittkowski/ Hielscher, DB 2010, 11, 17. 
In Bezug auf sämtliche Verluste und Verlustvorträge innerhalb der Beteiligungskette liegen nach $\S 8 \mathrm{c}$ Abs. $1 \mathrm{~S} .1 \mathrm{KStG}$ drei schädliche unmittelbare bzw. mittelbare Anteilsübertragungen vor. Unter der Stille-Reserven-Klausel gelten folgende Erwägungen zur Falllösung:

$\mathrm{Da}$ - hier unterstellt - nur T2 über im Inland steuerpflichtige Reserven verfügt, ${ }^{50}$ können unter der Stille-Reserven-Klausel grundsätzlich nur diese verschont werden. Es stellt sich dabei die Frage, ob als Obergrenze für die Verschonungsregelung auf die stillen Reserven bei der M abzustellen ist und dabei nur steuerpflichtige stille Reserven oder auch steuerfreie stille Reserven der M zugrunde zu legen sind. Im ersteren Fall würde die Obergrenze zunächst 0 betragen bzw. wären unter Berücksichtigung von $\S 8$ b Abs. 3 S. $1 \mathrm{KStG}$ höchstens $5 \%$ steuerpflichtige stille Reserven heranzuziehen und die Stille-Reserven-Klausel würde damit in Bezug auf die T2 (teilweise) leerlaufen. Bei Abstellen auf die steuerfreien stillen Reserven auf Ebene der $\mathrm{M}-\mathrm{GmbH}$ ergäbe sich als Obergrenze ein Wert von $100 .{ }^{51}$ M. E. ist letztere Lösung im Ergebnis zutreffend. Es sollte bei einem mehrstufigen Beteiligungserwerb nicht auf eine Obergrenze ankommen, sondern die Prüfung der Stille-Reserven-Klausel jeweils auf Ebene der einzelnen Gesellschaften durchgeführt werden. Dies ist auch deswegen zutreffend, da $\S 8 \mathrm{c}$ KStG bei einem mehrstufigen Erwerb auch auf jeder Ebene zur Anwendung kommt und daher nach dem Sinn und Zweck dieser Bestimmung eine Obergrenze für die Berücksichtigung von stillen Reserven gerade im Fall des mehrstufigen Erwerbs keinen Sinn macht. ${ }^{52}$

\section{3. Übergangsregelung $§ 34$ Abs. 6 Satz 3 KStG}

Ein weiteres Problemfeld der Neuregelung liegt in der Weitergeltung von $\S 8$ Abs. 4 KStG durch die Übergangsregelung $\S 34$ Abs. 6 KStG. Nach dieser Vorschrift ist $\S 8$ Abs. $4 \mathrm{KStG}$ in der bisherigen Fassung neben $\S 8 \mathrm{c}$ KStG letztmals anzuwenden, wenn

„mehr als die Hälfte der Anteile an der Kapitalgesellschaft innerhalb eines Zeitraums von fünf Jahren übertragen werden, der vor dem 1. Januar 2008 beginnt und der Verlust der wirtschaftlichen Identität vor dem 1. Januar 2013 eintritt."

Hierdurch wird deutlich, dass die ursprünglich durch die Neuregelung des $\S 8 \mathrm{c}$ KStG beabsichtigte Vereinfachung im Hinblick auf die parallele Anwendung der alten und neuen Vorschriften völlig konterkariert wor-

50 In Bezug auf M und T1 greift die Regelung des $\S 8$ b Abs. 2 S. 1 KStG.

51 Berechnet aus dem Veräußerungserlös (gemeiner Wert) von 200 abzüglich des steuerlichen Eigenkapitals von 100.

52 So auch Rödder/von Freeden, aaO., 555. 
den ist. Auch finden natürlich die neue Konzernklausel und die Stille-Reserven-Klausel nicht auf die Übergangsregelung Anwendung. Dies kann zu besonderen Problemen führen.

Dies soll an folgendem Beispiel erläutert werden:

Die X-GmbH hat erhebliche Verlustvorträge. Im Jahre 2007 scheidet ein Gesellschafter, der einen Anteil von $1 \%$ hatte nach Rückkauf des Anteils durch die X-GmbH aus. Der bisherige $99 \%$ Gesellschafter, die X-AG, hält somit zukünftig alle außenstehenden Anteile. Im Jahre 2010 möchte die X-AG ihre Beteiligung auf eine Konzerngesellschaft übertragen. Diese Konzerngesellschaft möchte nachfolgend einen Teilbetrieb in die $\mathrm{X}-\mathrm{GmbH}$ einbringen.

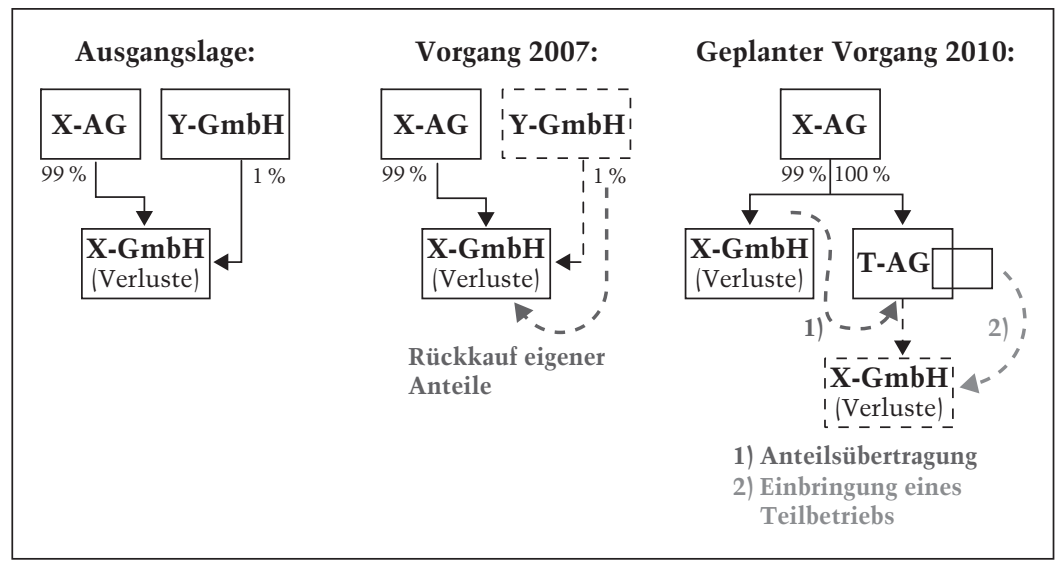

Die Problematik dieses Falles besteht darin, dass die Übergangsregelung des $\S 34$ Abs. 6 S. 3 KStG zu einem Nebeneinander der Vorschriften des $\S 8 \mathrm{c} \mathrm{KStG}$ und des „alten ${ }^{\prime} \S 8 \mathrm{Abs} .4 \mathrm{KStG}$ führt. ${ }^{53}$ Nach dem Wortlaut genügt zur Erfüllung des Tatbestands der Übergangsregelung ein „Teilakt" (hier der Rückkauf eigener Anteile im Jahr 2007) zur Auslösung des fünfjährigen Beobachtungszeitraums, da bei der Prüfung, ob mehr als $50 \%$ der Anteile übertragen wurden, alle in den Fünfjahreszeitraum fallenden Anteilsübertragungen zusammengerechnet werden. ${ }^{54}$ Auf dieser Grundlage käme es im Beispielsfall mit Blick auf die geplante Umstrukturierung im Jahr 2010 zur Anwendung von $\S 8$ Abs. 4 KStG, da innerhalb eines Fünfjahreszeitraums, beginnend vor dem 1.1.2008, mehr als $50 \%$

53 Vgl. hierzu auch Neumann/Stimpel, GmbHR 2007, 1194.

54 Damit übernimmt der Gesetzgeber die bislang im BMF v. 14.5.1999 - IV C 6 S 2745-12/99, BStBl. I 1999, 455, in Tz. 6 enthaltene Regelung. 
der Anteile an der X-GmbH übertragen wurden (auf einen sachlichen Zusammenhang kommt es nach dem Wortlaut der Anwendungsregelung insoweit nicht an) und mit der Teilbetriebseinbringung eine schädliche Betriebsvermögenszuführung nach dem 31.12.2007 und vor dem 1.1.2013 erfolgen würde. ${ }^{55}$

Die Neuregelungen (Sanierungsklausel, Stille-Reserven-Klausel) zu $\S 8 \mathrm{c}$ KStG greifen in Bezug auf die fortgeltende "Altregelung" des $\S 8$ Abs. $4 \mathrm{KStG}$ dann nicht. Folglich kann auch ein an sich unter die Neuregelungen fallender Vorgang aufgrund der Anwendung der Übergangsregelung schädlich sein, wenn und weil ein unter § 8 Abs. 4 KStG fallender Verlust der wirtschaftlichen Identität vor dem 1.1.2013 vorliegt. Hier zeigt sich, dass die Neuregelungen und die Übergangsregelung nicht sinnvoll aufeinander abgestimmt sind, da zeitlich vor dem 1.1.2008 liegende Anteilsübertragungen schädliche Wirkungen nach § 8 Abs. 4 KStG zeitigen können, obwohl sie zugleich in den zeitlichen Anwendungsbereich der Neuregelungen des $\S 8 \mathrm{c} \mathrm{KStG}$ fallen, die dann allerdings nicht greifen.

\section{Der neue $\S 8$ c und Debt-Equity-Swap-Strukturen: Notleidende Gesellschafterdarlehensstrukturen und die Defizite des deutschen Sanierungssteuerrechts}

Die typische Situation einer Gesellschaft in der Krise soll anhand des folgenden Beispiels beschrieben werden:

Bei der T-GmbH ist durch erhebliche Verluste, welche durch Darlehen finanziert worden sind, ein negatives Eigenkapital entstanden und es bestehen auch große Darlehensverbindlichkeiten. Eine vorliegende Überschuldung kann nur durch Rangrücktritt oder andere vergleichbare Maßnahmen verhindert werden.

Die Gesellschaft macht zum 31.12.2010 von dem nach § 274 Abs. 1 Satz 2 i. V.m. Satz 4 HGB i.d. F. des BilMoG bestehenden Wahlrecht Gebrauch zur Aktivierung der aktiven latenten Steuern auf den Verlustvortrag.

55 Hinsichtlich der Frist innerhalb derer der Körperschaft kein überwiegend neues Betriebsvermögen zugeführt werden darf, nimmt die Finanzverwaltung in Reaktion auf das Urteil des BFH v. 14.3.2006 - I R 8/05, BStBl. II 2007, 602 eine Frist von zwei Jahren für die Möglichkeit einer schädlichen Betriebsvermögenszuführung nach der 50 \%-igen Anteilsübertragung an, vgl. BMF v. 2.8.2007 IV B 7 - S 2745/0, BStB1. I 2007, 624. 
Das Bilanzbild stellt sich wie folgt dar:

Aktiva

Passiva

Anlagevermögen

\begin{tabular}{l|l} 
8.5 Mio Euro & Stammkapital \\
1.5 Mio Euro & Verlustvortrag \\
& Eigenkapital
\end{tabular}

2.5 Mio Euro

Aktive latente Steuern

Bilanzsumme

10 Mio Euro

Rückstellungen

./. 3.5 Mio Euro

./. 1.0 Mio Euro

Verbindlichkeiten

4.5 Mio Euro

6.5 Mio Euro

10 Mio Euro

Es muss dringend gehandelt werden. In den meisten Fällen wird versucht werden, einen neuen Investor zu finden, der entweder eine Barkapitalerhöhung zeichnet oder einen Teilbetrieb im Wege einer Sachkapitalerhöhung einbringt. Hier muss natürlich auf die Anwendung von $\S 8 \mathrm{c} \mathrm{KStG}$ geachtet werden. Gleichzeitig muss eine Entschuldung der Gesellschaft durchgeführt werden. ${ }^{56}$ Die Entschuldung kann regelmäßig durch einen Forderungsverzicht erreicht werden. Hier droht aber Ungemach, da der Forderungsverzicht grundsätzlich nur durch eine Gewinnrealisierung erreicht werden kann, da nach der Rechtsprechung des Großen Senats des $\mathrm{BFH}$ ein Forderungsverzicht nur insoweit als steuerneutrale Einlage zu werten ist, als die Forderung gemessen am Bewertungsmaßstab ihres Teilwertes (§ 6 Abs. 1 Nr. 5 S. 1 EStG) werthaltig ist. ${ }^{57}$ Dies wird regelmäßig nicht der Fall sein. Es würde daher bei Durchführung eines Forderungsverzichts im ungünstigsten Fall ein steuerpflichtiger Ertrag in Höhe des Nennbetrages der Forderung entstehen und gleichzeitig würde die Mindestbesteuerung zu einer Steuerzahlung führen. Darüber hinaus würden noch nicht untergegangene Verlustvorträge verbraucht werden. Durch die Entscheidung des BFH zum Sanierungserlass sollte dieser zwar grundsätzlich wieder zur Verfügung stehen. ${ }^{58}$ Es ergeben sich insoweit aber erhebliche Probleme und Rechtsunsicherheiten: ${ }^{59}$

56 Vgl. Hierstetter, DStR 2010, 882, 885

57 BFH, Urt. v. 9.6.1997 - GrS 1/94, BStBl. II 1998, 307.

58 BFH, Urt. v. 14.7.2010 - X R 34/08, BB 2010, 2606. Der BFH hat in dieser Entscheidung die Auffassung vertreten, dass der Sanierungserlass (BMF v. 27.3.2003 - IV A 6-S 2140-8/03, BStBl. I 2003, 240) zum Erlass eines unternehmensbezogenen Sanierungsgewinns aus sachlichen Gründen nicht den Grundsatz der Gesetzmäßigkeit der Verwaltung tangiert, dem Streitfall lag aber eine unternehmerbezogene Sanierung zugrunde, so dass der BFH offen lassen konnte, ob der Sanierungserlass gemessen an der Intention des Gesetzgebers (Streichung von $\S 3$ Nr.66 EStG a.F.) zu weitreichende Billigkeitsmaßnahmen ermöglicht. Vgl. hierzu Mückl/Frey, GmbHR 2010, 1193, 1196.

59 Siehe auch Hierstetter, DStR 2010, 882, 885 f. 
- Es können sich Unsicherheiten bei den Anwendungsvoraussetzungen für den Steuererlass ergeben. Dies bezieht sich insbesondere auf die Frage der erforderlichen Sanierungsfähigkeit.

- Es sind im Regelfall mehrere Behörden einzuschalten, da zunächst das zuständige Finanzamt für die Körperschaftsteuer einzuschalten ist, aber gleichzeitig für den Erlass der Gewerbesteuer die jeweilige Gemeinde zuständig ist und eine Bindung der Gemeinde an Billigkeitsmaßnahmen des Finanzamtes nicht besteht.

- Auch wird bis zu einem Abschluss einer Betriebsprüfung jahrelang Unsicherheit bestehen, ob die jeweiligen Voraussetzungen i.S. des Sanierungserlasses erfüllt worden sind. In der Zwischenzeit wird möglicherweise nur eine Stundung und kein Erlass erfolgt sein.

Damit hängen möglicherweise auch die Sanierungsmaßnahmen in der Luft. Das bedeutet, dass der Sanierungserlass im Regelfall kein optimales Instrument ist, um die negativen steuerlichen Folgen eines Debt-EquitySwaps ${ }^{60}$ oder eines Forderungsverzichtes zu vermeiden.

Als weitere Möglichkeit könnte der Gläubiger seine Forderung gegenüber der Gesellschaft im Wege der Sachkapitalerhöhung einbringen, so dass die bisherige Verbindlichkeit bilanziell in Eigenkapital umgewandelt werden. Es ergäben sich die gerade schon dargestellten Probleme des Forderungsverzichts. ${ }^{61}$ Gleichzeitig droht ein Entfallen der Verlustvorträge, da durch den Debt-Equity-Swap ein Gesellschafterwechsel eintreten kann, der zu einer Übertragung von mehr als $25 \%$ oder ggf. mehr als $50 \%$ des Kapitals erfolgen kann. Dies würde wiederum zu einem höheren Verlust in der Bilanz führen, da der Posten für die aktiven latenten Steuern entfallen würde. ${ }^{62}$ Auch steht derzeit die Sanierungsklausel des $\S 8 \mathrm{c}$ Abs. 1a KStG nicht mehr zur Verfügung, da wegen der offenen Beihilfeproblematik die Anwendung suspendiert ist. Die Stille-Reserven-Klausel wird im Regelfall nichts nützen, da keine stillen Reserven vorhanden sind; bei Eintritt eines neuen Gesellschafters kann auch die Konzernklausel nichts nützen.

60 Vgl. dazu auch Born, BB 2009, 1730; Ekkenga, Ubg 2009, 761, 763 f.; Mück1, FR 2009, 497 f.; Schmidt/Schlitt, Der Konzern 2009, 279, 287 f.; Schwenker/Fischer, DStR 2010, 1117, 1120.

61 Auch gesellschaftsrechtlich ist die Bewertung einer nicht werthaltigen Forderung umstritten: Nach herkömmlicher Auffassung ist eine Nennkapitalerhöhung mit wertlosen Forderungen gegen die Gesellschaft mit dem Grundsatz der realen Kapitalaufbringung unvereinbar und daher unzulässig (vgl. z.B. Priester, DB 2010, 1445 mwN), während die Gegenauffassung eine Einbringung zum Nennwert auch dann für möglich hält, wenn dieser wesentlich über dem tatsächlichen Wert der Forderung liegt (vgl. hierzu zusammenfassend Cahn/Simon/Theiselmann, CF 2010, 238 f.).

$62 \mathrm{Zu}$ diesen Auswirkungen Hierstetter, DStR 2010, 882, 885. 
Auch eine Barkapitalerhöhung durch einen neuen Gesellschafter mit anschließender Schuldentilgung löst das Problem nicht, da durch die anzunehmende Anwendung des $\S 8 \mathrm{c}$ KStG mindestens ein Teil der Verlustvorträge verloren gehen würde. Möglicherweise würde auch die Bareinlage mit anschließender Schuldentilgung zu einer Gewinnrealisierung führen, wenn die Finanzverwaltung dies als einen Missbrauch von Gestaltungsmöglichkeiten den Rechtsfolgen des Forderungsverzichts gleichsetzt. Hinzu kommt, dass sich zusätzlich zu den gerade dargestellten Problemen innerhalb der Gesellschaft auch sehr negative Auswirkungen auf der Ebene des Gesellschafters und Forderungsinhabers ergeben können (§ 8 b Abs. 3 Satz 4 ff. KStG).

Ggf. könnte auch die Schuldübernahme mit Regressverzicht erfolgversprechend sein. ${ }^{63}$ In diesem Fall würde die Schuld der Gesellschaft durch die Muttergesellschaft oder eine dieser nahestehende Person unbedingt und unter Verzicht auf Regressansprüche übernommen, sodass die entsprechende Verbindlichkeit bei der T-GmbH wegfällt und zukünftig als Eigenkapital ausgewiesen wird. Allerdings bestehen trotz eines Beschlusses des BFH vom 20.12.200164 gewisse Unsicherheiten, ob auch die erfolgsneutrale steuerliche Behandlung sichergestellt werden kann. Das bedeutet im Ergebnis, dass es im sog. Sanierungssteuerrecht doch noch erhebliche Defizite gibt und hier dringend ein gesetzgeberischer Änderungsbedarf angezeigt ist.

Als Alternative zu den diskutierten Gestaltungsformen eines Debt-Equity-Swaps könnte daran gedacht werden, dass sich der neue Gesellschafter durch eine atypisch stille Beteiligung oder eine andere hybride Form an der Verlust-GmbH beteiligen könnte, ${ }^{65}$ ggf. diese Beteiligung zu einem späteren Zeitpunkt nach Nutzung der Verlustvorträge in eine Beteiligung auch am Kapital der Gesellschaft umgewandelt würde. Ggf. könnte auch das bestehende Darlehen in ein Mezzanine-Darlehen "umgewandelt" werden. ${ }^{66}$ Dieses Mezzanine-Darlehen wäre steuerlich Fremdkapital und handelsrechtlich ggf. Eigenkapital, so dass insoweit eine Entschuldung eingetreten wäre.

63 Vgl. dazu Bogenschütz, Ubg 2010, 407.

64 BFH, Urt. v. 20.12.2001 - I B 74/01, BFH/NV 2002, 678.

$65 \mathrm{Zu}$ dieser Gestaltungsmöglichkeit Breuninger/Ernst, GmbHR 2010, 561, 566.

66 Vgl. dazu Frey/Mückl, GmbHR 2010, 1193, 1999. 


\section{Resümee}

Die unendliche Geschichte der Begrenzung der Verlustnutzung fand mit dem $\S 8 \mathrm{c} \mathrm{KStG}$ in der ursprünglichen Fassung ihren vorläufigen Höhepunkt - danach stellte sich der Verlust der Verlustvorträge als Roulette dar.

Die später eingefügte Sanierungsklausel geht infolge der Einstufung als rechtswidrige durch die EU-Kommission Beihilfe ins Leere. Spätestens mit dem Scheitern der Sanierungsklausel ist auch $\S 8 \mathrm{c} \mathrm{KStG}$ gescheitert. Die erfolgten Erleichterungen in Form der Konzernklausel und der StilleReserven-Klausel sind zwar ausdrücklich zu begrüßen, werfen aber zahlreiche offene Anwendungsfragen auf. Im Übrigen dürfte sich auch aus dem Vorlagebeschluss des $\mathrm{BFH}^{67}$ bzgl. der Verfassungsmäßigkeit der Mindestbesteuerung bei endgültigem Ausschluss der Verlustverrechnung Handlungsbedarf ergeben. Gefragt ist nun eine grundlegende Neuregelung des $\S 8 \mathrm{c}$ KStG (entsprechend der Zielvorgabe im Koalitionsvertrag), die in erster Linie die Elemente der Konzernklausel, der Stille-ReservenKlausel und der Sanierungsklausel (unter Beseitigung der oben diskutierten Regelungsdefizite) in einer Neuregelung vereint und gleichzeitig als Missbrauchsvermeidungsvorschrift und weniger als Verlustvernichtungsregelung konzipiert ist.

Das Beispiel einer Gesellschaft in der Krise hat gezeigt, dass dringend ein Sanierungssteuerrecht erforderlich ist, welches eine steuerneutrale Entschuldung ermöglicht und Verluste bei zur Rettung eintretenden Anteilseignern nicht entfallen lässt.

67 BFH, Beschl. v. 26.8.2010 - I B 49/10, DStR 2010, 2179. 


\title{
Organschaft: Zivilrecht - Steuerrecht - Haftung
}

\author{
Dr. Norbert Schneider ${ }^{1}$ \\ Rechtsanwalt, Steuerberater, Köln
}

Inhaltsübersicht

I. Einleitung: Bedeutung des Zivilrechts für das Recht

der Organschaft

II. Auslegung von Gewinnabführungsverträgen

1. Überblick

2. Auslegung schuldrechtlicher Willenserklärungen/Verträge

3. Auslegung von Satzungen sowie GAVs

4. Fallgruppe 1: (Mindest-)Laufzeit von GAVs

4.1 Vertragslaufzeit im Zivilrecht

4.2 Steuerrechtliche Mindestlaufzeit

5. Fallgruppe 2: Vereinbarung einer Verlustübernahme i. S. d.

$\S 302$ AktG

5.1 Anforderungen an die

Einbeziehung des

$\S 302$ AktG

5.1.1 Regelung im GAV nach BFH notwendig

5.2 Auslegungsstreit: angeblich „eingeschränkte" Verweisung auf $\S 302$ AktG
6. Beseitigung und Vermeidung von Mängeln - Notarieller Nachtragsvermerk gemäß § 44a BeurkG

7. Fazit und Ausblick

III. Tatsächliche Durchführung des GAV

IV. Heilung eines steuerlich unwirksamen GAV

V. Ausgleichszahlungen an außenstehende Aktionäre

1. Überblick

2. Höhe der Ausgleichszahlungen

2.1 Aktienrechtliche Vorgaben

2.2 Steuerrechtliche Vorgaben

2.3 Bisheriger Meinungsstand

2.4 BFH-Urteil vom 4.3.2009I R $1 / 08$

2.5 Reaktion auf das Urteil in der Literatur

2.6 Nichtanwendungserlass der Finanzverwaltung

3. Praktische Auswirkungen und Ausblick

VI. Haftung bei Organschaft

1. Grundsätzlicher Umfang der Haftung

2. Begrenzung der Haftung auf Verursachungsbeitrag der Organgesellschaft?

1 RA/StB/Dipl.-Finw. (FH) Dr. Norbert Schneider ist Partner bei Freshfields Bruckhaus Deringer LLP und Lehrbeauftragter für Steuerrecht an den Universitäten Düsseldorf und Köln. Wertvolle Mitarbeit bei der Vorbereitung des Beitrags hat Herr RA Dr. Christian Tobias Roth, wiss. Mitarbeiter bei Freshfields Bruckhaus Deringer LLP in Düsseldorf, geleistet. 


\section{Einleitung: Bedeutung des Zivilrechts für das Recht der Organschaft}

Durch die Begründung einer ertragsteuerlichen Organschaft i.S.d. $\S \S 14 \mathrm{ff}$. KStG kann innerhalb von deutschen ${ }^{2}$ Unternehmensgruppen eine zusammengefasste Besteuerung hergestellt werden, die insbesondere zu einer Verrechnung der Einkommen der Organmitglieder führt. Die Organschaft ist deshalb einer der (wenn nicht der) zentralen Bausteine des Konzernsteuerrechts und einer entsprechenden Planung. Allerdings sind beim Einsatz von Organschaften nicht nur steuerliche Regelungen zu beachten; vielmehr kommt zivilrechtlichen Regelungen und Anforderungen eine erhebliche Bedeutung zu. Der Grund dafür liegt darin, dass die ertragsteuerliche Organschaft ${ }^{3}$ heute immer noch als zentrale Voraussetzung einen Gewinnabführungsvertrag (GAV) i. S. d. $\S \S 291 \mathrm{ff}$. AktG fordert. Dieser Vertrag muss für die Anerkennung einer solchen Organschaft nicht einfach geschlossen sein, sondern er muss u. a. zivilrechtlich wirksam sein ${ }^{4}$ und auch (nach zivilrechtlichen Maßstäben) tatsächlich durchgeführt werden. Zudem sind im GAV (ohne dass dies zivilrechtlich erforderlich wäre) zusätzlich auch genuin steuerliche Regelungen aufzunehmen, für deren steuerliche Anerkennung wieder die zivilrechtlich wirksame Vereinbarung erforderlich ist; das betrifft insbesondere die Vereinbarung einer mindestens 5-jährigen Mindestlaufzeit in allen GAVs sowie die Vereinbarung einer Verlustübernahmeverpflichtung entsprechend den Vorschriften des $\S 302$ AktG in GAVs mit einer $\mathrm{GmbH}$ als Organgesellschaft. ${ }^{5}$

Durch das quasi-akzessorische "Anhängen" des Steuerrechts an das Bestehen eines zivilrechtlichen GAV, besondere Anforderungen an dessen Inhalt sowie die Notwendigkeit der tatsächlichen Durchführung des GAV werden zivilrechtliche Voraussetzungen, aber auch Fragen und

$2 \mathrm{Ob}$ bzw. unter welchen Voraussetzungen auch ausländische Tochtergesellschaften in eine Organschaft einbezogen werden können, ist heftig umstritten. Vgl. dazu u. a. FG Rheinland Pfalz v. 17.3.2010, DStRE 2010, 802 (Rev. I R 34/10); FG Niedersachsen v. 11.2.2010, IStR 2010, 260 (Rev. I R 16/10) sowie v. Brocke, DStR 2010, 964.

3 Für die körperschaftsteuerliche Organschaft gilt das bereits seit langem; die gewerbesteuerliche Organschaft setzt dagegen einen GAV erst seit der Änderung des $\S 2$ GewStG durch das Gesetz v. 20.12.2001 mit Wirkung ab Erhebungszeitraum 2002 voraus. Die umsatzsteuerliche Organschaft, bei der ein GAV nicht notwendig ist, wird hierin nicht behandelt.

4 Ist der GAV fehlerhaft oder nichtig, so ist die Organschaft auch dann nicht anzuerkennen, wenn der Vertrag zivilrechtlich nach den Regeln über die fehlerhafte Gesellschaft als wirksam behandelt wird; vgl. BFH v. 30.7.1997 - I R 7/97, BStB1. II 1998, 33; Frotscher in Frotscher/Maas, KStG, § 14 Rz. 175.

$5 \mathrm{Zu}$ beiden Anforderungen vgl. unten S. $6 \mathrm{ff}$. 
Unklarheiten aus dem Konzernrecht als Fehlerquellen in das Steuerrecht importiert. Das Steuerrecht macht sich damit - entgegen der Grundregel des $\S 41 \mathrm{AO}$ - in einem zentralen Bereich in erheblichem Maße abhängig vom Zivilrecht. Die daraus resultierenden Probleme können vielfältig sein. ${ }^{6}$ Einige sollen hierin näher beleuchtet werden.

\section{Auslegung von Gewinnabführungsverträgen}

\section{1. Überblick}

Da das Steuerrecht bestimmte Inhaltsanforderungen an einen GAV stellt, kommt der Auslegung von GAVs in der (insbesondere steuerlichen) Praxis eine bedeutende Rolle zu. Auslegungsfragen ergeben sich vor allem bei den Punkten hinsichtlich derer nur das Steuerrecht (nicht aber das Zivilrecht) bestimmte Anforderungen an den Inhalt des Vertrags stellt, vor allem also bei Mindestlaufzeit und der Verlustübernahmeverpflichtung entsprechend $\S 302$ AktG. Kommt der Vertragstext seinem Wortlaut nach diesen Anforderungen nicht völlig eindeutig nach, ist er auszulegen. Den Möglichkeiten der Vertragsauslegung sind jedoch bei GAVs engere Grenzen gesetzt als bei anderen Verträgen. Denn die für die Auslegung von schuldrechtlichen Willenserklärungen anerkannten Kriterien kommen nur in beschränktem Maße zur Anwendung. Die Frage, ob eine umfassende Auslegung nach $\S \S 133,157$ BGB oder aber nur eine eingeschränkte, den Grundsätzen der "objektivierten Auslegung" folgende Auslegung zulässig ist, kann vor diesem Hintergrund auch über die steuerrechtliche Wirksamkeit eines GAV entscheiden. ${ }^{7}$

\section{Auslegung schuldrechtlicher Willenserklärungen/Verträge}

Für die Auslegung schuldrechtlicher Verträge sowie der ihnen zugrunde liegenden Willenserklärungen normieren die $\S \S 133,157$ BGB allgemeine Grundsätze, die jedoch kein vollständiges System von Auslegungsregeln darstellen. ${ }^{8}$ Willenserklärungen sind danach so auszulegen, wie sie der Empfänger nach Treu und Glauben unter Berücksichtigung der Verkehrssitte verstehen musste. ${ }^{9}$ Der Empfänger hat sich in den Grenzen zumutbarer Sorgfalt unter Berücksichtigung aller ihm erkennbarer Umstände zu bemühen, die Erklärung so zu verstehen, wie sie der Erklärende

6 Vgl. ausführlich z. B. Schneider/Hinz, Ubg 2009, 738 ff. (u. a. auch zu formellen Wirksamkeitserfordernissen des GAV).

7 Passarge, BB 2006, 2769, 2769.

8 Coing, ZGR 1978, 659, 659.

9 BGH v. 5.7.1990 - IX ZR 10/90, NJW 1990, 3206; BGH v. 12.3.1992 - IX ZR 141/91, NJW 1992, 1446 f.; BGH v. 5.10.2006 - III ZR 166/05, NJW 2006, 3777. 
gemeint hat. ${ }^{10}$ Für die Auslegung einer empfangsbedürftigen Willenserklärung ist darauf abzustellen, wie ein objektiver Dritter bei vernünftiger Beurteilung der ihm bekannten oder erkennbaren Umstände die vom Erklärenden gewählten Ausdrucksformen hätte verstehen können und müssen. ${ }^{11}$ Dabei ist aber nicht allein der Wortlaut maßgeblich. Es ist vielmehr der übereinstimmende Wille der Vertragsparteien auch dann zu berücksichtigen, wenn er vom Wortlaut der Erklärung abweicht oder in ihr nur unvollkommen Ausdruck findet. Hat z. B. der Empfänger die Erklärung so verstanden, wie sie vom Erklärenden gemeint war, kommt es auf einen ggfls. abweichenden objektiven Erklärungswert nicht maßgeblich an („falsa demonstratio non nocet “). ${ }^{12}$ Der tatsächliche Wille der Parteien geht in einem solchen Fall nicht nur dem Wortlaut, sondern jeder anderweitigen Interpretation vor. ${ }^{13}$

Diese Methoden gelten - jedenfalls grundsätzlich - auch bei der Auslegung formbedürftiger Erklärungen. Auch hier geht ein vom Wortlaut der Erklärung abweichender übereinstimmender Wille der Parteien dem beurkundeten Wortlaut vor. Voraussetzung ist aber, dass der so ermittelte Wille wenigstens andeutungsweise in der formgerechten Vertragsurkunde Niederschlag gefunden hat. ${ }^{14}$ Bei einer Falschbezeichnung reicht es insoweit aus, wenn das - von den Parteien in anderem Sinne verstandene - objektiv Erklärte dem Formerfordernis genügt. Beurkundet ist dann das wirklich Gewollte, nur falsch Bezeichnete. ${ }^{15}$

\section{Auslegung von Satzungen sowie GAVs}

Etwas anderes gilt jedoch u. a. bei der Auslegung von Satzungen: Die allgemeinen Auslegungsregeln sind nur eingeschränkt anwendbar auf korporationsrechtliche Bestimmungen, d.h. solche Satzungsregelungen, die die innere Organisationsstruktur der Gesellschaft und ihrer Organe sowie die Rechte und Pflichten der Aktionäre bestimmen. Hintergrund dieser Einschränkung ist der Umstand, dass korporationsrechtliche Satzungsbestimmungen nicht nur für die derzeitigen, bei Inkrafttreten der Bestimmung vorhandenen Gesellschafter von Bedeutung sind, sondern für einen unbestimmten Personenkreis, zu dem sowohl gegenwärtige als auch

10 BGH v. 12.2.1981 - IVa ZR 103/80, NJW 1981, 2295, 2296; BAG v. 15.12.2005 2 AZR 148/05, NJW 2006, 2284, 2286.

11 BGH v. 20.10.2005 - 3 ZR 37/05, NJW 2006, 286, 287.

12 BGH v. 15.3.1978 - VIII ZR 180/76, BGHZ 71, 75, 77 f.; BGH v. 11.11 .1993 VII ZR 47/93, BGHZ 124, 64, 68.

13 BGH v. 26.10.1983 - IVa ZR 80/82, NJW 1984, 721.

14 BGH v. 7.2.1996 - IV ZR 16/95, NJW 1996, 1678, 1679; BGH v. 18.1.2008 - V ZR 174/06, NJW 2008, 1658, 1659; Hohage/Willkommen, BB 2010, 1119, 1121.

15 BGH v. 25.3.1983 - V ZR 268/81, BGHZ 87, 150. 
künftige Gesellschafter und/oder Gläubiger gehören. ${ }^{16}$ Sie entfalten Rechtsfolgen für einen offenen Personenkreis, dem die bei Entstehung der jeweiligen Regelung zugrunde gelegten Beweggründe der ursprünglich beteiligten Parteien nicht ohne weiteres bekannt sind. ${ }^{17}$

Satzungen sind deshalb allein nach objektiven Gesichtspunkten einheitlich aus sich heraus auszulegen. ${ }^{18}$ Wortlaut sowie dem erkennbaren Sinn und Zweck der Regelung kommt dabei ebenso maßgebende Bedeutung zu wie dem systematischen Bezug der Klausel zu anderen Satzungsvorschriften. Umstände, die für sich keine ausreichenden Anhaltspunkte in der Satzung oder öffentlich zugänglichen Unterlagen finden, können zur Auslegung grundsätzlich nicht herangezogen werden. ${ }^{19}$ Entscheidend kommt es im Unterschied zu Individualverträgen darauf an, ob die Umstände außerhalb der Vertragsurkunde liegen und nicht allgemein erkennbar sind. ${ }^{20}$ Für die Auslegung maßgeblich ist deshalb, wie die jeweilige Bestimmung von der Allgemeinheit und nicht nur von den eigentlichen Vertragsparteien vernünftigerweise verstanden werden muss. ${ }^{21}$

Diese verschärften Anforderungen finden aber nicht nur auf Satzungen Anwendung, sondern auch auf sog. Organisationsverträge. ${ }^{22} \mathrm{Zu}$ diesen gehören auch die aktienrechtlichen Unternehmensverträge wie der $\mathrm{GAV}_{i}{ }^{23}$ denn sie werden zwar als Vertrag zwischen zwei Parteien abgeschlossen, ändern aber gleichzeitig satzungsgleich den rechtlichen Status einer Gesellschaft. ${ }^{24}$ Indem sie den Gesellschaftszweck am Konzerninteresse ausrichten und in das Gewinnbezugsrecht der Gesellschafter eingreifen, entfalten sie korporative Wirkung. ${ }^{25}$

16 BGH v. 9.6.1954 - II ZR 70/53, BGHZ 14, 25, 36 f.; BGH v. 13.7.1967 II ZR 238/64, BGHZ 48, 141, 144; BGH v. 11.10.1993 - II ZR 155/92, BGHZ 123, 347, $350 \mathrm{f}$.

17 Passarge, BB 2006, 2769, 2770.

18 BGH v. 6.3.1967 - II ZR 261/64, BGHZ 47, 172, 179 f.; BGH v. 21.1.1991 - II ZR 144/90, NJW 1991, 1727, 1727.

19 BGH v. 11.11.1985 - II ZB 5/85, BGHZ 96, 245, 250; BGH v. 16.12.1991 - II ZR 58/91, BGHZ 116, 359; BGH v. 11.10.1993 - II ZR 155/92, BGHZ 123, 347, $350 \mathrm{f}$.

20 BGH v. 20.1.1983 - II ZR 243/81, NJW 1983, 1910, 1910 f.

21 Passarge, BB 2006, 2769, 2770.

22 Koppensteiner in Kölner Kommentar zum AktG, Vor. § 291 Rz. 158; Altmeppen in MüKo-AktG, § 291 Rn. 33, 34.

23 BGH v. 14.12.1987 - II ZR 170/87, BGHZ 103, 1, 4 f.; BGH v. 24.10.1988 - II ZB 7/88, BGHZ 105, 324, 331; Hüffer, AktG, 9. Aufl., § $291 \mathrm{Rz} .17$.

24 BGH v. 24.10.1988 - II ZB 7/88, BGHZ 105, 324, 331.

25 BGH v. 14.12.1987 - II ZR 170/87, BGHZ 103, 1; Emmerich in Emmerich/Habersack, Aktien- und GmbH-Konzernrecht, 5. Aufl., §291 Rz. 26; Zöllner in Baumbach/Hueck, GmbHG, 18. Aufl., SchlAnhKonzernR Rz. 52. 
Konsequenterweise wendet die Rechtsprechung auf GAVs die für korporationsrechtliche Bestimmungen entwickelten Auslegungsgrundsätze teilweise an. Auch GAVs sind demnach grundsätzlich objektiv und nur unter Einbeziehung allgemein zugänglicher Unterlagen auszulegen; ${ }^{26}$ dazu gehört nicht nur der GAV allein, sondern z. B. auch die Satzung sowie die mit dem GAV zum Handelsregister eingereichten Unterlagen. ${ }^{27}$ Für Dritte nicht erkennbare Absichten und Erwägungen der Vertragsparteien sind daher bei der Auslegung grundsätzlich nicht verwertbar; die Auslegung ist in erster Linie auf den Wortlaut und den Sinnzusammenhang im Vertrag zu stützen. ${ }^{28}$ Aber auch der erkennbare Vertragszweck ist bei der Auslegung zu berücksichtigen. Deshalb kann es durchaus relevant sein, wenn die Parteien im Vertrag darlegen (z. B. in der Präambel), dass der Zweck des Vertrags in der Begründung einer Organschaft i. S. d. $\S \S 14 \mathrm{KStG}, 2 \mathrm{GewStG}$ liegt. Allerdings reicht die Erkennbarkeit dieser Absicht - jedenfalls nach dem BFH - allein nicht aus, um einzelne Vertragsklauseln gegen deren klaren Wortlaut so auslegen zu können, dass sie jeweils mit den für eine Organschaft geforderten. Mindestvoraussetzungen übereinstimmen. ${ }^{29}$ Anders ist dies u. E. aber dann, wenn die in Frage stehende Vertragsklausel unklar und/oder mehrdeutig ist - hier kann u. E. diesem Zweck u. U. entscheidende Bedeutung für die Auslegung in die entsprechende "organschaftserhaltende" Richtung beikommen.

Zu den nicht allgemein erkennbaren und damit nicht $\mathrm{zu}$ berücksichtigenden Umständen zählen die außerhalb des Handelsregisters eingereichten Unterlagen, die Entstehungsgeschichte eines GAV, die vom beurkundenden Notar gefertigten Vorentwürfe und die Vorstellungen und Äußerungen der am Vertragsschluss beteiligten Personen. ${ }^{30}$ Für eine Einbeziehung derartiger Sachzusammenhänge ist allenfalls Raum, wenn dadurch keine Interessen außenstehender Dritter beeinträchtigt werden. ${ }^{31}$

26 Vgl. BGH v. 5.11.2007 - II ZR 230/06, NJW-RR 2008, 419, 420; BGH v. 19.3.2007 - II ZR 73/06, NJW-RR 2007, 832, 833; BGH v. 25.9.1989 - II ZR 304/88, NJW-RR 1990, 99, 99 jeweils zu Gesellschaftsverträgen; ferner: BGH v. 11.10.1993 - II ZR 155/92, NJW 1994, 51, 52; Altmeppen in MüKo-AktG, $\S 291 \mathrm{Rz} .33$; Hüffer, AktG, 9. Aufl., § 23 Rz. 39, 40; Roth in Roth/Altmeppen, GmbHG 4. Aufl., § 2 Rz. 15.

$27 \mathrm{Zu}$ diesen gehören grundsätzlich neben dem GAV die Zustimmungsbeschlüsse der Gesellschafterversammlung sowie die Anlagen dazu (§294 Abs. 1 S. 2 AktG). Konsequenterweise sind deshalb auch diese u. E. zur Auslegung des GAV heranzuziehen.

28 Grunewald, ZGR 1995, 68, 72.

29 BFH v. 28.11.2007 - I R 94/06, BFH/NV 2008, 1270. Vgl. dazu unten S. 9.

30 BGH v. 25.9.1989 - II ZR 304/88, NJW-RR 1990, 99 m. w. N.; Leitzen, GmbHStB 2009, 278, 279.

31 BFH v. 28.11.2007 - I R 94/06, BFH/NV 2008, 1270. 
Lässt sich der Vertragsinhalt bei der gebotenen objektiven Vertragsauslegung nicht eindeutig feststellen, gehen verbleibende Zweifel zu Lasten der Parteien. ${ }^{32}$ Unrichtigkeiten und missverständliche Formulierungen bedeuten insofern unter steuerrechtlichen Gesichtspunkten ein erhebliches Risiko.

Ein Rückgriff auf die allgemeinen Auslegungsregeln der (§§ 133, 157 BGB) ist dagegen erlaubt und geboten, wenn einer Regelung im Einzelfall kein korporativer Charakter zukommt. Dabei handelt es sich um Regelungen in Gesellschaftsverträgen, die lediglich eine individuelle Vereinbarung der Gesellschafter untereinander oder zwischen Gesellschaft und Gesellschafter betreffen. ${ }^{33}$ Deshalb ist bei der Auslegung von GAVs zwischen korporativen und schuldrechtlichen Bestimmungen zu unterscheiden. ${ }^{34}$

\section{Fallgruppe 1: (Mindest-)Laufzeit von GAVs}

Eine Fallgruppe, bei der es aus steuerlichen Grünen zu Auslegungsfragen kommen kann, ist die Laufzeit des Vertrags. Der Grund liegt darin, dass das Steuerrecht eine Mindestlaufzeit vorsieht: der GAV muss auf 5 Jahre abgeschlossen sein (§ 14 Abs. 1 S. 1 Nr. 3 S. 1 KStG). Die Mindestlaufzeit muss im GAV selbst geregelt sein. ${ }^{35}$ Bei dieser Frage muss man Zivilrecht und Steuerrecht auseinanderhalten und sich u.a. Beginn und Beendigungsmöglichkeiten näher ansehen.

\subsection{Vertragslaufzeit im Zivilrecht}

Zivilrechtlich ist eine Mindestlaufzeit nicht erforderlich. Der GAV kann grundsätzlich auf jede denkbare Laufzeit abgeschlossen werden. Wirksam wird der GAV erst mit seiner Eintragung im Handelsregister (§ 294 Abs. 2 AktG); ${ }^{36}$ eine Rückbeziehung der Wirksamkeit auf den Zeitpunkt der Antragstellung erfolgt grundsätzlich nicht. ${ }^{37}$ Allerdings können die Parteien einen GAV vertraglich auch für zurückliegende Zeiträume vereinbaren. Ohne weiteres ist dies möglich auf den Beginn des Jahres, in dem der Vertrag abgeschlossen wird. Selbst für frühere Geschäftsjahre ist eine Vereinbarung möglich, aber nur, falls für diese Geschäftsjahre noch kein Jahresabschluss festgestellt ist. ${ }^{38}$

32 Busche in MüKo-BGB, 5. Aufl., § 133 Rz. 37.

33 Grunewald, ZGR 1995, 68, 71.

34 Passarge, BB 2006, 2769, 2771.

35 BFH v. 28.11.2007 - I R 94/06, BFH/NV 2008, 1270.

36 Die Eintragung im Handelsregister hat konstitutiven Charakter, vgl. BFH v. 26.8.1987 - I R 28/84, BStBl. II 1988, 77; Schneider/Hinz, Ubg 2009, 738, 741.

37 Tappen/Riegel, SteuK 2010, 309, 309.

38 Neumann in Gosch, KStG, 2. Aufl., § 14 Rz. 242 ff. m. w. N.; Hüffer, AktG, 9. Aufl., § $291 \mathrm{Rz} .20$. 
Ist der Vertrag einmal wirksam begründet worden, so sind für seine Beendigung allerdings bestimmte Regeln $\mathrm{zu}$ beachten. Ist eine vertragliche Laufzeit von den Parteien vereinbart, endet der GAV mit dessen Ablauf. Gleichfalls können beide Parteien im Zusammenwirken den GAV beenden durch einen Aufhebungsvertrag; einzige Begrenzung ist, dass dieser nicht unterjährig, sondern nur auf das Ende eines Geschäftsjahres abgeschlossen werden kann (§296 Abs. 1 AktG). Ist keine Vertragslaufzeit bestimmt, werden die Parteien im GAV Regelungen für die (einseitige) ordentliche Kündigung vorgesehen haben. In allen Fällen ist der GAV auch aus wichtigem Grund einseitig kündbar; dies ergibt sich bereits aus $\S 297$ AktG. Anerkannt ist von der Rechtsprechung des BGH im Grundsatz auch, dass die Parteien im Vertrag den unbestimmten Rechtsbegriff des "wichtigen Grundes" in gewissen Umfang konkretisieren können; ${ }^{39}$ sehr häufig wird es deshalb Regelungen geben im GAV, die eine Kündigung bei Veräußerung aller oder wesentlicher Anteile an der Gesellschaft ermöglichen. Dieser Fall ist insbesondere auch aus steuerlichen Gründen von erheblicher Bedeutung, weil mit einem Verlust der Stimmrechtsmehrheit die finanzielle Eingliederung (§ 14 Abs. 1 S. 1 Nr. 1 S. 1 KStG) endet und damit eine Voraussetzung für eine Organschaft wegfällt - da ein GAV in aller Regel nur abgeschlossen wird, um eine steuerliche Organschaft zu begründen, würde das alleinige zivilrechtliche Weiterführen des GAV typischerweise keinen Sinn mehr machen.

\subsection{Steuerrechtliche Mindestlaufzeit}

Steuerlich ist die Vertragslaufzeit aus mehreren Gründen besonders relevant. Zum einen ist die Frage zu klären, ab wann eine Organschaft überhaupt erstmalig anerkannt werden kann, sofern die übrigen Voraussetzungen vorliegen. Steuerlich ist der GAV seit der Einführung des $\S 14$ Abs. 1 S. 2 KStG zum 1.1.2002 erst ab dem Beginn des Wirtschaftsjahres zu beachten, in dem er zivilrechtlich wirksam wird, m.a.W.: im Handelsregister eingetragen wird. ${ }^{40}$ In Übereinstimmung mit dem Handelsrecht können die Parteien des GAV vertraglich den Beginn der Organschaft auf den Anfang des laufenden Wirtschaftsjahres der Organgesellschaft legen, wenn die Erfüllung der vertraglichen Verpflichtung bereits ab Beginn des Wirtschaftsjahres und nicht erst zu einem späteren Zeitpunkt vorgesehen ist. Das Steuerrecht zwingt also nicht zur Bildung eines Rumpfwirtschaftsjahres, wenn der GAV im Laufe des Wirtschaftsjahres der Organgesellschaft in das Handelsregister eingetragen wird. ${ }^{41}$

39 BGH v. 5.4.1993 - V ZR 87/92, BGHZ 122, 211.

40 Schneider/Hinz, Ubg 2009, 738, 741.

41 Neumann in Gosch, KStG, 2. Aufl., § 14 Rz. 249. 
Eine steuerliche Rückwirkung in frühere Wirtschaftsjahre ist dagegen nicht (mehr) möglich. Trägt z.B. das Registergericht den Vertrag aus irgendeinem Grund erst im Wirtschaftsjahr nach dem Vertragsschluss und beabsichtigten Beginn der Organschaft ein, so entfaltet der GAV trotz frühzeitiger Anmeldung zum Handelsregister steuerlich erst im Folgejahr seine Wirkungen. Dies gilt auch, wenn der Steuerpflichtige die Verzögerung nicht zu vertreten hat. Der Wortlaut des $\S 14$ Abs. 1 S. 2 KStG ist nach Auffassung des BFH insoweit eindeutig und keiner einschränkenden Auslegung zugänglich. ${ }^{42}$

$\S 14$ Abs. 1 S. 1 Nr. 3 KStG schreibt außerdem eine Mindestlaufzeit des GAV von fünf Jahren sowie dessen tatsächliche Durchführung während der gesamten Geltungsdauer vor. Die Mindestlaufzeit soll ein häufiges Wechseln zwischen Bestehen und Nichtbestehen einer Organschaft verhindern und damit eine willkürliche Gewinnbeeinflussung. ${ }^{43}$ Nach überwiegender Auffassung handelt es sich bei dieser Frist nicht um fünf Wirtschaftsjahre, sondern um fünf Zeitjahre (60 Monate). ${ }^{44}$

Welche konkreten Vertragsformulierungen genügen, um den GAV auf mindestens 5 Jahre fest abzuschließen, bestimmt weder das Gesetz noch die KStR. Die gesetzliche Formulierung verlangt, dass der Vertrag während der Mindestlaufzeit grundsätzlich besteht und nicht ohne wichtigen Grund beendet werden kann; deswegen ist erforderlich, dass eine ordentliche Kündigung während der Mindestlaufzeit ausgeschlossen ist. ${ }^{45}$ Nicht ausreichend wäre deswegen z. B. auch ein Abschluss des GAV auf unbestimmte Zeit ohne jede weitere Regelung. ${ }^{46}$

Die Mindestlaufzeit muss im GAV selbst geregelt sein. ${ }^{47}$ Das Gleiche gilt für ihre Verlängerung; rein schuldrechtliche Abreden außerhalb des GAV reichen nicht aus. Da die Verlängerung i. d. R. eine Änderung des bestehenden GAV ist, müssen die gleichen formalen Anforderungen erfüllt werden wie beim Abschluss des GAV (§295 Abs. 1 i. V. m. $§ \S 293,294$ AktG); folglich ist für die Wirksamkeit und steuerliche Berücksichtigung

42 BFH v. 12.6.2008 - I B 20/08 (NV); FG Hannover v. 13.12.2007 - 6 K 411/07, EFG 2008, 885.

43 Neumann in Gosch, KStG, 2. Aufl., § 14 Rz. 212.

44 R 60 Abs. 2 S. 1 KStR; FG Köln v. 9.12.2009 - 13 K 4379/07, EFG 2010, 668; Nodoushani, DStR 2009, 620; Sterner in Herrmann/Heuer/Raupach, EStG/ KStG, § 14 KStG Anm. 200 m. w. N.; Dötsch in Dötsch/Jost/Pung/Witt, KStG, $\S 14$ Rz. 216; a. A. Frotscher in Frotscher/Maas, KStG, § 14 Rn. 232 b.

45 Walter in Ernst \& Young, KStG, § 14 Rz. 636; entsprechend FG Berlin-Brandenburg v. 21.8.2007 - 6 K 39/06, EFG 2007, 1897; BFH v. 22.10.2008 - I R 66/07, BStBl. II 2009, 972.

46 Walter in Ernst \& Young, KStG, § 14 Rz. 636; Dötsch/Witt in Dötsch/Jost/ Pung/Witt, KStG, § 14 Rz. 216.

47 BFH v. 28.11.2007 - I R 94/06, BFH/NV 2008, 1270. 
erforderlich, dass die Änderung durch Eintragung im Handelsregister zivilrechtlich wirksam wird. ${ }^{48}$

Der BFH qualifiziert die Festlegung der Vertragslaufzeit als eine echte korporative Bestimmung. ${ }^{49} \mathrm{Da}$ die Laufzeit des GAV sowohl für potenzielle Anteilserwerber als auch für die Finanzverwaltung als jeweils außenstehende Dritte von erheblicher Bedeutung sei, müsse sie klar und eindeutig aus dem Vertragswerk hervorgehen. Vor allem die Finanzverwaltung habe ein berechtigtes Interesse, sich anhand der objektiv erkennbaren Gegebenheiten ein Bild darüber machen zu können, ob ein GAV die in $\S \S 14 \mathrm{ff}$. KStG statuierte Mindestlaufzeit erfülle. Das Gesetz knüpfe die mit weitreichenden Folgen verbundene steuerliche Anerkennung solcher Verträge bewusst an eigene, streng formale Voraussetzungen. Deren Einhaltung müsse dementsprechend von der Finanzverwaltung auf sicherer Grundlage geprüft und beurteilt werden können. Hiermit wäre es nicht vereinbar, wenn neben der Auswertung der Vertragsurkunde auch noch ein etwa vom Wortlaut abweichender Wille der Vertragschließenden erforscht werden müsste. ${ }^{50}$ Die Mindestlaufzeit muss deshalb ausdrücklich in den Vertrag aufgenommen werden oder sich anderweitig eindeutig aus dem Vertrag erforderlichenfalls im Wege der objektiven Auslegung - ergeben. ${ }^{51}$

Vor dem Hintergrund dieser strengen Anforderungen an die Vereinbarung im GAV und ihre objektive Auslegung erklärt sich, wieso der BFH den Fall I R 94/0652 kaum anders entscheiden konnte. Wegen eines Versehens war bei einem GAV, der ab 1.1.2002 galt, der 31.3.2006 als frühester Zeitpunkt einer ordentlichen Kündigung festgelegt, also nur ein Zeitraum von 4 Jahren und 3 Monaten. ${ }^{53}$ Klarstellungsversuche erfolgten nur durch schuldrechtliche Abreden, die aber nicht im Handelsregister eingetragen wurden, und zudem zeitlich erst später erfolgten. Bei objektiver Auslegung ergab sich aus dem GAV oder sonstigen öffentlich zugänglichen Urkunden letztlich nichts, was eine Auslegung ermöglichte, dass die Parteien im Vertrag in Wahrheit eine erstmalige Kündigung erst zum 31.12.2006 nach 5 Jahren zulassen wollten. Der Wortlaut dieser Klausel ließ nur das Verständnis „31.3.2006" $\mathrm{zu}$; auch aus dem systematischen Zusammenhang mit anderen Regelungen ergab sich nichts, aus dem man eine 5-jährige Mindestlaufzeit bzw. den 31.12.2006 hätte herleiten kön-

48 BFH v. 22.10.2008 - I R 66/07, BStB1. II 2009, 972 m. w. N.

49 BFH v. 28.11.2007 - IR 94/06, BFH/NV 2008, 1270; a. A. Passarge, BB 2006, $2769,2772$.

50 BFH v. 28.11.2007 - I R 94/06, BFH/NV 2008, 1270; Walter, in Ernst \& Young, KStG, § 14 Rz. 636.

51 Neumann in Gosch, KStG, 2. Aufl., § $14 \mathrm{Rz} .212$.

52 BFH v. 28.11.2007 - I R 94/06, BFH/NV 2008, 1270.

53 Es lagen auch keine 5 Wirtschaftsjahre vor, so dass sich die Frage nicht stellte, ob dies allein hätte ausreichen können. 
nen. Aus Verweisen auf die KStR konnte man zwar ableiten, dass die Parteien wohl eine wirksame Organschaft begründen wollten; der Verweis ging aber nur auf R 55 Abs. 7 KStR 1995 (den heutigen R 60 Abs. 6 KStR) und damit auf eine Reglung, die sich mit einer vorzeitigen Beendigung aus wichtigem Grund befasste, nicht aber der Länge der Mindestlaufzeit als solcher. In dieser Situation konnte dem BFH die allgemeine Absicht, eine Organschaft zu begründen, alleine nicht ausreichen, weil der Wortlaut zu eindeutig war und keine anderen bei objektiver Auslegung verwertbaren Erkenntnisse vorhanden waren, die für die Auslegung "volle 5 Jahre Mindestlaufzeit vereinbart" sprachen. Vereinfacht: „31. März" kann man nicht umdeuten in „31. Dezember".

Ein anderes Auslegungsergebnis wäre u.E. dagegen möglich gewesen, wenn der Verweis auf die KStR im GAV auf den R 55 Abs. 2 KStR 1995 gegangen wäre, der die Notwendigkeit der 5-jährigen Mindestlaufzeit wiedergibt. Je nach Zusammenhang hätte man aus einem solchen Verweis objektiv! - ableiten können, dass die Vertragsparteien die 5-jährige Mindestlaufzeit vereinbaren wollten. Wegen des gleichwohl vorhandenen „falschen" Datums für die erstmalige ordentliche Kündigung wäre der GAV objektiv widersprüchlich gewesen. Bei der Auflösung des Widerspruchs wäre u. E. durchaus eine Auslegung möglich, dass die "richtige " 5-jährige Mindestlaufzeit vereinbart wurde (insbesondere bei klar zum Ausdruck kommenden Zwecks, eine steuerliche Organschaft zu begründen, z. B. im Rahmen einer eindeutigen Präambel). Gleiches gilt z. B. dann, wenn sich aus anderen objektiv zugänglichen Unterlagen (bspw. den zum Handelsregister eingereichten Gesellschafterbeschlüssen) das "richtige" Datum 31.12.2006 oder die erstrebte 5-jährige Mindestlaufzeit ergeben hätte.

Wegen der ggfls. möglichen Richtigstellung eines GAV durch notariellen Nachtragsvermerk vgl. unten S. 16.

\section{Fallgruppe 2: Vereinbarung einer Verlustübernahme i. S. d. §302 AktG}

Ist die Organgesellschaft eine AG oder KGaA, gelten die aktienrechtlichen Vorschriften der $\S \S 291 \mathrm{ff}$. AktG unmittelbar. Nach $\S 302$ AktG ist das herrschende Unternehmen (steuerlich der Organträger) zur Verlustübernahme verpflichtet. § $302 \mathrm{AktG}$ hat heute vier Absätze. Dabei ist die eigentliche Verlustübernahmeverpflichtung des Organträgers gegenüber der Organgesellschaft in Abs. 1 geregelt. Abs. 2 enthält eine eigenständige, betragsmäßig begrenzte Verlustübernahmepflicht für Fälle eines Betriebsüberlassungsvertrags; bei gleichzeitigem Bestehen eines GAV wird sie verdrängt. ${ }^{54}$ Abs. 3 und 4 treffen bloße Annexregelungen zu die-

54 Altmeppen in MüKo-AktG, $\S 302$ Rz. 53 m.w. N. Ein Verweis auf diese Regelung wird deshalb durch $\S 17 \mathrm{KStG}$ auch nicht gefordert; vgl. Pache in Herrmann/Heuer/Raupach, EStG/KStG, § 17 KStG Anm. 29. 
sen Verlustübernahmepflichten: auf den Anspruch auf Verlustübernahme ist ein Verzicht oder Vergleich frühestens 3 Jahre nach Beendigung des jeweiligen Vertrags möglich (Abs.3); die Ansprüche auf Verlustübernahme verjähren in 10 Jahren ab Beendigung (Abs. 4).

Bei einer Organschaft mit einer $\mathrm{GmbH}$ gilt $\S 302$ AktG nicht unmittelbar. § 17 S. 2 Nr. 2 KStG verlangt demgegenüber, dass eine Verlustübernahme entsprechend den Vorschriften des $\S 302$ AktG vereinbart sein muss. Diese Vereinbarung muss nach Auffassung der Rechtsprechung und Finanzverwaltung im GAV selbst erfolgen. In Anbetracht der objektiven Auslegung von GAVs kommt es deshalb auch hier auf eine sorgfältige Formulierung im Vertragstext an. ${ }^{55}$ Fälle zur steuerlich richtigen Einbeziehung des $\S 302$ AktG in den GAV mit einer GmbH sind deshalb häufig Gegenstand von Streitigkeiten gewesen, insbesondere in der jüngeren Vergangenheit.

\subsection{Anforderungen an die Einbeziehung des § 302 AktG}

\subsubsection{Regelung im GAV nach BFH notwendig}

Der BFH und die Finanzverwaltung fordern zunächst, dass die Vereinbarung der Geltung des $\S 302$ AktG im GAV selbst erfolgt, 56 und zwar nicht nur der eigentlichen Verlustübernahmeverpflichtung des $\S 302$ Abs. 1 AktG, sondern auch der bloßen "Annexregeln" des Abs. 3 sowie seit seiner gesetzlichen Einführung - des Abs. 4. ${ }^{77}$ Es soll nicht reichen, dass die Regeln des $\$ 302 \mathrm{AktG}$ nach ständiger Rechtsprechung des $\mathrm{BGH}^{58}$ analog für GAVs mit GmbHs gelten und daher gar keiner expliziten Erwähnung im GAV bedürfen, damit sie zivilrechtlich auf den ent-

55 Lenz, Ubg 2010, 179, 179.

56 BFH v. 29.3.2000 - I R 43/99, BFH/NV 2000, 1250; BFH v. 22.2.2006 - I R 74/05, BFH/NV 2006, 1513; BFH v. 17.6.2008 - I R 67/05, BFH/NV 2008, 1705; BFH v. 3.3.2010 - I R 68/09, BFH/NV 2010, 1132; BFH v. 28.7.2010 - I B 27/10 Rz. 26, DStR 2010, 1777, 1779.

$57 \mathrm{Zu}$ Abs. 3 vgl. die Entscheidungen in Fn. 56. Zu Abs. 4 ausdrücklich BFH v. 28.7.2010 - I B 27/10, DStR 2010, 1777, 1779, sowie Beschluss v. 22.12.2010 I B 83/10, DStR 2011, 219. Die Finanzverwaltung verlangt die vertragliche Einbeziehung des Abs. 4 nur in GAVs, die ab dem 1.1.2006 geschlossen wurden; vgl. BMF v. 16.12.2005, BStBl. I 2006, 12. Nicht notwendig ist eine Einbeziehung des Abs.2, denn dieser ist bei Bestehen eines Beherrschungs- oder Gewinnabführungsvertrags nicht anwendbar; vgl. Koppensteiner in Kölner Kommentar zum AktG, §302 Rz. 60 m.w. N.; insofern jetzt bestätigt durch BFH v. 22.12.2010 - I B 83/10, a. a. O., Tz. 16.

58 Vgl. BGH v. 24.10.1988 - II ZB 7/88, BGHZ 105, 324; v. 11.11 .1991 - II ZR 287/90, BGHZ 116, 37; v. 11.10.1999 - II ZR 120/98, NJW 2000, 210; Hahn, DStR 2009, 1834 ff. m. w. N. Das gilt nach der ganz h. M. im Zivilrecht auch bei GAVs, wenn die Organgesellschaft-GmbH nur einen Gesellschafter hat; vgl. dazu Kutsch, GmbHR 2010, 953, 956 m. w. N. 
sprechenden GAV anwendbar sind. ${ }^{59}$ Diese strenge Auffassung rechtfertigt der BFH insbesondere mit dem eindeutigen Wortlaut des $\S 17 \mathrm{~S} .2$ Nr. 2 KStG. Die darin geforderte Verlustübernahme sei im Hinblick auf ihren Erklärungswert, ihre Überprüfbarkeit sowie ihre Warnfunktion mit einer im Wege der zivilrechtsdogmatisch analogen Anwendung des $\S 302$ AktG auf die GmbH gewonnenen gesetzlichen Verpflichtung nicht vergleichbar.

Im Ergebnis stellt sich das Erfordernis der expliziten vertraglichen Regelung des $\S 302$ AktG im GAV als ein rein steuerrechtlich erforderliches bloßes Formerfordernis dar. Die Auffassung des BFH wird daher in der Literatur und z.T. auch der Rechtsprechung der FG - u. E. zu Recht erheblich kritisiert. Dabei gibt es insbesondere zwei Kernpunkte der Kritik:

Gegen die Rechtsprechung des BFH spricht zunächst die Entstehungsgeschichte des $\S 17$ S. 2 Nr. 2 KStG. Im Zeitpunkt seiner Einführung war die Frage der Anwendbarkeit der $\S \S 302,303$ AktG für den GmbH-Vertragskonzern zivilrechtlich noch ungeklärt. Die Entstehungsgeschichte der Norm zeigt indes deutlich, dass der Steuergesetzgeber die Organschaftsregeln im GmbH-Vertragskonzern mit den aktienrechtlichen Regelungen synchronisieren wollte. Für die aktienrechtliche Organschaft gilt aber gerade keine besondere Formvorschrift zur Wiedergabe des Wortlauts von $\S 302$ Abs. 3 AktG. Die derzeitige Fassung des $\S 17$ S. 2 Nr. 2 KStG mit ihrer Bezugnahme auf $\S 302$ AktG resultiert somit allein aus dem Umstand, dass der Steuergesetzgeber die gegenwärtige zivilrechtliche Rechtslage noch nicht umgesetzt hat, die bei Schaffung der Norm noch ungeklärt war. ${ }^{60}$

Angesichts der vom Steuergesetzgeber beabsichtigten und heute auch zivilrechtlich praktisch umgesetzten Gleichbehandlung des GmbH-Vertragskonzerns mit dem Aktien-Vertragskonzern erscheint es des Weiteren wenig nachvollziehbar, wenn nun das Steuerrecht für den $\mathrm{GmbH}$ Konzern höhere formelle Anforderungen stellt als das Zivilrecht. Die von der Finanzverwaltung und dem BFH vertretene Interpretation läuft deshalb der gesetzgeberischen Intention zuwider, wenn sie für die $\mathrm{GmbH}$ über das Aktienrecht hinausgehende Formvorschriften statuiert. ${ }^{61}$ Auch der Sinn und Zweck des $\S 302$ Abs. 3 AktG widerspricht der Auffassung des BFH und der Finanzverwaltung. Die Norm trifft eine genuin konzern-

59 Crezelius (Ubg 2009, 733) spricht daher zu Recht von einer „überflüssigen Anordnung".

60 Crezelius, Ubg 2009, 733, 736, m. w. N.; Wulf, AG 2007, 320, 321; vgl. Hahn, DStR 2009, 1834, 1836.

61 Dötsch in Dötsch/Jost/Pung/Witt, KStG, § 17 Rz. 22 ff.; Hohage/Willkommen, BB 2010, 1119, 1120. 
rechtliche Aussage zum Schutz der Organgesellschaft und der außenstehenden Gesellschafter, so dass der Norm keine eigenständige steuerrechtliche Bedeutung zukommt. ${ }^{62}$ Eine Auseinandersetzung mit dem Inhalt des $\S 302 \mathrm{AktG}$ fehlt jedoch in der Rechtsprechung des BFH. ${ }^{63}$ Aus diesen Gründen löst - nicht anders als beim aktienrechtlichen GAV bereits der schlichte Vertragsabschluss mit der $\mathrm{GmbH}$ die Verpflichtung zur Verlustübernahme aus. ${ }^{64}$

Das FG Köln sah in der strengen Auffassung des BFH sogar eine verfassungsrechtlich unzulässige (weil sachlich nicht gerechtfertigte) Ungleichbehandlung und drohte dem BFH, einen solchen Fall dem BVerfG vorlegen zu wollen, wenn der BFH bei seiner strengen Rechtsprechung bliebe. ${ }^{65}$ All das hat den BFH nicht dazu bewegen können, seine strenge förmlich anmutende Linie zu verlassen. Vielmehr hat er erneut seine ständige Rechtsprechung zum Erfordernis einer expliziten Vereinbarung einer Verlustübernahme nach $\S 302 \mathrm{AktG}$ in einem GAV mit einer GmbH bestätigt. ${ }^{66}$ Zwar wurde gegen das BFH-Urteil vom 3.3.2010, mit der die Entscheidung das FG Köln verworfen wurde, dann auch Verfassungsbeschwerde eingelegt; das BVerfG hat diese jedoch mittlerweile nicht zur Entscheidung angenommen. ${ }^{67}$

Dieser Streit hätte zur Rechtshistorie werden können, wenn eine vom Bundesrat angeregte rückwirkende Änderung des $\S 17$ S. 2 Nr. 2 KStG umgesetzt worden wäre, nach der es nicht mehr auf die "Vereinbarung" einer Verlustübernahmeverpflichtung angekommen wäre, sondern nur noch auf ihr "Bestehen". ${ }^{68}$ Angesichts der BGH-Rechtsprechung zur analogen Anwendung des $\S 302$ AktG auf GAVs mit einer $\mathrm{GmbH}$ wäre einer Regelung im Vertrag obsolet gewesen. Diese Änderung ist jedoch nicht umgesetzt worden, so dass es bei der bisherigen Lage bleibt. ${ }^{69} \mathrm{Z}$.Zt. ist kaum damit zu rechnen, dass sich an der strengen Linie des BFH etwas ändert.

62 Frotscher in Frotscher/Maas, KStG, § 17 Rz. 12.

63 Crezelius, Ubg 2009, 733, 736.

64 Crezelius, Ubg 2009, 733, 736; Lenz, Ubg 2010, 179, 180; Hahn, DStR 2009, 1834, 1836f.; Wulf, AG 2010, 34; ders. AG 2007, 320 m. w. N.

65 FG Köln v. 13.5.2009 - 13 K 4779/04, EFG 2009, 1969.

66 BFH v. 3.3.2010 - I R 68/09, BFH/NV 2010 1132; BFH v. 28.7.2010 - I B 27/10 Rz. 26; DStR 2010, 1777, 1779; BFH v. 15.9.2010 - I B 27/10 Rz. 4, DStR 2010, $1984,1984 \mathrm{f}$.

67 Az. 2 BvR 998/10; der ablehnende Beschluss datiert vom 31.8.2010, Tenor abzurufen über Beck-Online.

68 Vgl. dazu u. a. Prinz, DStR 2010, 1512; Schneider, DK 2010, 486, 489.

69 Dazu Schneider, DK 2010, 604. 


\subsection{Auslegungsstreit: angeblich „eingeschränkte“ Verweisung auf § $302 \mathrm{AktG}$}

Weder der BFH noch die Finanzverwaltung hatten bislang die ausdrückliche Übernahme des Wortlauts von $\S 302$ AktG in den Vertragstext noch die Bezugnahme auf die einzelnen einschlägigen Absätze verlangt. Ausreichend war vielmehr eine "pauschale Bezugnahme", d. h. eine Bezugnahme auf $\S 302$ AktG im Ganzen (ggfls. in der jeweils geltenden Fassung) oder auch eine Gestaltung des Vertragstextes entsprechend dem Inhalt der Vorschriften der Absätze 1, 3 und 4 durch Übernahme des Wortlauts. $^{70}$

Die Finanzverwaltung beanstandete jüngst in „erweiternder Anwendung ${ }^{\prime \prime 11}$ der restriktiven BFH-Rechtsprechung zu den Formalanforderungen des $\S 17$ S. 2 Nr. 2 KStG eine Formulierung, die nach einem allgemeinen Verweis auf $\S 302$ AktG nur den Wortlaut des $\S 302$ Abs. 1 AktG wiedergibt. Die Formulierung lautete:

„Die X verpflichtet sich, entsprechend §302 AktG jeden während der Vertragsdauer sonst entstehenden Jahresfehlbetrag der Y-GmbH auszugleichen, soweit dieser nicht dadurch ausgeglichen wird, dass den freien Gewinnrücklagen Beträge entnommen werden, die während der Vertragsdauer in sie eingestellt wurden".

Bekannt wurde diese Auffassung durch eine angeblich bundeseinheitliche abgestimmte Verfügung der Oberfinanzdirektionen Rheinland und Münster. ${ }^{72}$ Die Formulierung sollte die Anforderungen des $\S 17 \mathrm{KStG}$ nicht erfüllen, weil der (unzweifelhaft vorhandene) numerische Verweis auf den ganzen $\S 302$ AktG nur im Gesamtzusammenhang verständlich sei und durch die - erst nachfolgende - wörtliche Wiedergabe nur der Verlustübernahmepflicht (Abs. 1) eingeschränkt werde. Letztere soll also den Inhalt bestimmen und begrenzen, und der vorhandene Verweis auf den ganzen $\S 302 \mathrm{AktG}$ daher - gegen den Wortlaut - entweder ignoriert oder jedenfalls gelesen werden als bloßer Verweis nur auf $\S 302$ Abs. 1 AktG.

Die Versagung der steuerrechtlichen Organschaft in dieser Konstellation stieß in der Literatur auf großen Widerstand. ${ }^{73}$ Mittlerweile hat der BFH überraschend schnell - in einem AdV-Verfahren eine ähnliche Klausel

70 R 66 Abs. 3 KStR 2004; Hohage/Willkommen, BB 2010, 1119, 1120.

71 So treffend Prinz, DStR 2010, 1512, 1512.

72 OFD Rheinland und OFD Münster v. 12.8.2009, BB 2010, 101.

73 U.a. Crezelius, Ubg 2009, 733, 737; Schneider/Hinz, Ubg 2009, 738, 741; Schulze Grotthoff, BB 2010, 101, 102; Kaeser, DStR Beihefter 30, 2010, 56, 59; Hohage/Willkommen, BB 2010, 1119, 1121 f.; Rödder, DStR 2010, 1218, 1219; Walter/Speidel, GmbHR 2010, R 17 f; Weber, Ubg 2010, 556 ff. Auch das IDW schloss sich der massiven Kritik indirekt an; es hielt die Argumente gegen die Auffassung der Finanzverwaltung für so stichhaltig, dass betroffene Steuerpflichtige keine Steuerrückstellung zu bilden brauchen (IDW, Ubg 2010, 72). 
akzeptiert, ${ }^{74}$ woraufhin das BMF die OFD-Verfügung faktisch aufgehoben hat. ${ }^{75}$ Gleichwohl sollen hier noch einmal die Argumente vertieft dargestellt werden, weil der Fall ein Paradebeispiel für die Auslegung von GAVs bietet.

Die (nunmehr gegenstandslose) Auslegung in der OFD-Verfügung, wonach die Klausel nur als Verweis auf den Absatz 1 zu verstehen sei, verstieß nämlich bereits gegen den klaren vertraglichen Wortlaut. ${ }^{76}$ Durch den Verweis auf den gesamten $\S 302$ AktG bringen die Parteien bei "objektiver" Auslegung deutlich zum Ausdruck, dass sie die in $\S 302$ Abs. 1 AktG geregelte Primärrechtsfolge um die anderen Inhalte des $\S 302$ AktG ergänzt wissen wollen. Würde man den (unzweifelhaft im Wortlaut vorhandenen) numerischen Verweis auf den ganzen $\S 302 \mathrm{AktG}$ wie die OFDen verstehen, würde man ihn entweder umdeuten in einen Verweis nur auf $\S 302$ Abs. 1 AktG oder ihn sogar insgesamt leugnen. Das würde eine Auslegung gegen den eindeutigen Wortlaut darstellen, die nach dem BFH unzulässig ist. Die Art der Kombination des numerischen Verweises auf den ganzen $\S 302 \mathrm{AktG}$ mit der nachfolgenden wörtlichen Wiedergabe der Verlustübernahmeverpflichtung bietet keinerlei Anhaltspunkt für eine solche Einschränkung. Der an §302 Abs. 1 AktG angelehnte Satzteil ist nur als erläuternde deklaratorische Hervorhebung der wesentlichen Regelung des $\S 302$ AktG - der Verlustübernahmeverpflichtung des Abs. 1 -, nicht aber als Einschränkung des Verweises auf die übrigen Regelungen des $\$ 302 \mathrm{AktG}$ zu verstehen, die materiell nur Annexregeln sind. Eine wörtliche Wiederholung der Nebenvorschriften des Abs. 3 und 4 des $\S 302$ AktG hätte die Regelung zudem schwer lesbar gemacht. ${ }^{77}$ Eine andere - mit dem klaren Vertragswortlaut unvereinbare Auslegung von GAVs ist in Hinblick auf die ständige Rechtsprechung des $\mathrm{BFH}$ zu den Grundsätzen über die Auslegung von GAVs unzulässig. ${ }^{78}$

Selbst wenn man - hilfsweise - unterstellte, dass der Wortlaut der Klausel neben der Einbeziehung des gesamten Verweises auf den $\S 302 \mathrm{AktG}$ auch die Deutung der Finanzverwaltung trägt, die Klausel also mehrdeutig wäre, müsste sie ergänzend auf Grundlage des sich bei verständiger objektiver Würdigung ergebenden Sinn und Zwecks der Vereinbarung ausgelegt werden. Eine solche Auslegung ist nicht nur zulässig, sondern

74 BFH v. 28.7.2010 - I B 27/10, DStR 2010, 1777, 1779; dazu u. a. Gosch, BFH/ PR 2010, 433; Schneider, DK 2010, 486.

75 BMF v. 19.10.2010; DStR 2010, 2193; dazu Schneider, Der Konzern 2010, 604.

76 Schneider/Hinz, Ubg 2009, 738, 741; Hohage/Willkommen, BB 2010, 1119, 1121 f.; Lenz, Ubg 2010, 179, 180; Schulze Grotthoff, BB 2010, 101, 102.

77 Rödder, DStR 2010, 1218, 1219; Hohage/Willkommen, BB 2010, 1119, 1122; Schulze Grotthoff, BB 2010, 101, 102.

78 BFH v. 28.11.2007 - I R 94/06, BFH/NV 2008, 1270. 
nach der Rechtsprechung des BFH sogar geboten; lediglich eine Auslegung gegen einen unzweideutigen Wortlaut ist u. U. nicht möglich. Dem Sinn und Zweck der Vertragsklausel entsprechend wollen die Steuerpflichtigen aus Sicht eines objektiven Betrachters mit dem Verweis auf den ganzen $\S 302 \mathrm{AktG}$ den steuerlichen Erfordernissen des $\S 17 \mathrm{~S} .2$ Nr. 2 KStG gerade Rechnung tragen und deshalb § 302 AktG vollumfänglich in die Klausel einbeziehen. Anderenfalls würde man den Vertragsparteien unterstellen, eine Regelung (§ 302 Abs. 3 und 4 AktG) ausschließen zu wollen, die sie zivilrechtlich gar nicht ausschließen können und die gleichzeitig steuerlich erforderlich ist. Damit würde man den Parteien eine doppelte Unvernunft unterstellen, was einer Auslegung nach Sinn und Zweck diametral entgegengesetzt wäre. ${ }^{79}$ Bezöge sich die Textpassage "entsprechend $\S 302 \mathrm{AktG}^{\prime}$ - wie von der OFD behauptet - nur auf den ersten Absatz der Vorschrift, würde der (eingeschränkt verstandene) Verweis die folgende wörtliche Wiedergabe der Verlustübernahmepflicht den Inhalt des Folgetextes nur vorwegnehmen. Es käme letztlich zu einer unsinnigen Verdoppelung, weshalb es evident erscheint, dass mit dem ersten Teil der Verlustübernahmeregelung ein Mehr vereinbart wurde und damit eine Zitierung der Vorschrift im Ganzen vorliegt. ${ }^{80}$

Gegen die Auffassung der Oberfinanzdirektionen spricht schließlich auch die Systematik der $\S 17 \mathrm{KStG}, \S 302$ AktG. Aus der Kombination von wörtlicher Erwähnung der eigentlichen Verlustübernahmepflicht und numerischer Erwähnung des ganzen §302 AktG in $\S 17 \mathrm{~S} .2$ Nr. 2 KStG folgert der $\mathrm{BFH}^{81}$ dass der Verweis auf $\S 302 \mathrm{AktG}$ mehr bedeuten müsse als einen Verweis nur auf Absatz 1. Ansonsten wäre der Verweis überflüssig. ${ }^{82}$ Nach gefestigter $\mathrm{BFH}$-Rechtsprechung umfasst daher der Generalverweis auf $\S 302 \mathrm{AktG}$ sämtliche Regelungen der Norm. Dies hat der BFH für $\S 302$ Abs. 3 AktG schon 1980 geklärt. ${ }^{83}$ Auch die Einbeziehung der weit nach Inkrafttreten des §17 S. 2 Nr. 2 KStG eingeführten Vorschrift des $\$ 302$ Abs. 4 AktG ist heute anerkannt. ${ }^{84}$ Wenn der BFH den Verweis in $\S 17 \mathrm{~S} .2$ Nr. $2 \mathrm{KStG}$ auf $\S 302 \mathrm{AktG}$ - trotz der wörtlichen Erwähnung lediglich der Verlustübernahmeverpflichtung - als Verweis auf den gesamten $\S 302$ AktG versteht,

79 Schneider/Hinz, Ubg 2009, 738, 741; zustimmend: Schulze Grotthoff, BB 2010, 101, 102.

80 Schneider/Hinz, Ubg 2009, 738, 741; Hohage/Willkommen, BB 2010, 1119, 1122; Schulze Grotthoff, BB 2010, 101, 102.

81 BFH v. 17.12.1980 - I R 220/78, BStBl. II 1981, 383.

82 Schneider/Hinz, Ubg 2009, 738, 741; vgl. Lenz, Ubg 2010, 179, 180.

83 BFH v. 17.12.1980 - I R 220/87, BStBl. II 1981, 383, 384.

84 BFH v. 28.7.2010 - I B 27/10 Rz. 24, DStR 2010, 1777, 1779; vgl. dazu BMF v. 16.12.2005 - IV B 7 - S 2770 - 30/05, BStBl. I 2006, 12. 
muss die gleiche Auslegung auch für eine vertragliche Verlustübernahmeklausel gelten, die genau die gleichen Komponenten wie das Gesetz enthält. ${ }^{85}$ Hinsichtlich der Vertragsklausel bedeutet dies, dass die Erwähnung des $\S 302 \mathrm{AktG}$ sinnlos wäre, wenn nur die Verlustübernahmepflicht des Absatz 1 gemeint wäre.

Mit einem AdV-Beschluss vom 28.7.2010 hat sich der BFH den zahlreichen Literaturstimmen angeschlossen und die Auffassung der Finanzverwaltung erfreulich schnell abgelehnt. ${ }^{86}$ Im Streitfall war die Formulierung zwar nicht absolut mit derjenigen aus der OFD-Verfügung identisch, entsprach ihr aber im Kern. ${ }^{87}$ Der BFH verstand die Vertragsformulierung ohne größere Diskussion als ausreichend, um sämtliche Regelungen des $\S 302$ AktG einzubeziehen. Durch den - unstreitig vorhandenen - numerischen Verweis auf den ganzen $\S 302$ AktG würden alle Absätze (inkl. Abs. 3 und 4) einbezogen. Die nachgestellte wörtliche Wiederholung der Verlustübernahmepflicht solle erkennbar nur die Hauptpflicht beschreiben, aber nicht die Abs. 3 und 4 ausschließen; auf - u. E. objektiv sinnwidrige und unvernünftige - Eventualauslegungen des Wortlauts auf Basis der Reihenfolge der Bestandteile lässt sich der BFH gar nicht ein. Er nimmt auch en passant zu der leicht anderen Formulierung in der OFDVerfügung Stellung und bezeichnet sie (zu Recht) als vergleichbar; damit wird auch diese Formulierung (inzident) als völlig ausreichend qualifiziert.

Das Bundesfinanzministerium hat diese Entscheidung rasch akzeptiert und damit die Auslegung der OFDen Rheinland und Münster kassiert. In seinem Schreiben vom 19.10.2010 ${ }^{88}$ heißt es (verkürzt): Ein numerischer Verweis auf den gesamten $\S 302 \mathrm{AktG}$ ist grundsätzlich ausreichend; im Anschluss daran erfolgende weitere Ausführungen (wie eine im BFH-Fall und auch der OFD-Verfügung anzutreffende Wiedergabe der Verlustübernahmepflicht i.S.d. §302 Abs. 1 AktG) sind unschädlich, es sei denn, dass sie erkennbar darauf gerichtet sind, die umfassende Bezugnahme auf $\S 302$ AktG zu relativieren und bestimmte Absätze auszuschließen, wovon nur dann auszugehen sei, wenn der Wortlaut die Einschränkung

85 Vgl. Schneider/Hinz, Ubg 2009, 738, 741) m. w. N.

86 BFH v. 28.7.2010 - I B 27/10 Rn. 30, DStR 2010, 1777.

87 Sie lautete letztlich: „Die (D-AG) ist entsprechend den Vorschriften des $\S 302$ des Aktiengesetzes verpflichtet, jeden während der Vertragsdauer sonst entstehenden Jahresfehlbetrag auszugleichen, soweit dieser nicht dadurch ausgeglichen wird, ..." Der Unterschied zur OFD-Verfügung besteht darin, dass hier die Formulierung nicht „entsprechend §302 AktG" lautet, sondern - etwas länger - „entsprechend den Vorschriften des $\S 302 \mathrm{AktG}^{\prime \prime}$.

88 BMF v. 19.10.2010, DStR 2010, 2193; zu Einzelfragen vgl. Schneider, Der Konzern 604. 
eindeutig vorsehe oder über den Wortlaut hinaus konkrete weitere Anhaltspunkte vorliegen.

Mit dem vom BMF angeordneten strengen Regel-Ausnahme-Verständnis (d. h. GAV bei numerischem Verweis auf ganzen $\S 302$ AktG immer anzuerkennen, es sei denn, es ergibt sich „eindeutig“ aus dem Wortlaut des Vertrages etwas anderes) tritt u. E. zu Recht ein generelles Auslegungsverständnis in den Vordergrund, was dem Sinn und Zweck des GAV ${ }^{89}$ eine stärkere Bedeutung zumisst als nur dem Wortlaut bzw. theoretisch u. U. noch denkbaren Wortlautverständnis: denn Steuerpflichtige wollen objektiv mit einem GAV steuerlich wirksame Organschaften begründen und dabei nicht Teile des $\S 302$ AktG ausschließen, die sie womöglich zivilrechtlich gar nicht ausschließen können. Insgesamt ergibt sich daraus und aus den Erkenntnissen aus dem BFH-Fall I R 94/06 ${ }^{90}$ u. E. ein allgemeiner Auslegungsgrundsatz für zukünftige Fälle der Auslegung von GAV: der (i. d. R. objektiv erkennbare) Sinn und Zweck der Begründung einer steuerlichen Organschaft sollte stets bei der Auslegung eines GAV besonders berücksichtigt werden, soweit es dafür und die konkret in Rede stehende Frage im Wortlaut einen Anhalt gibt und nicht (ausnahmsweise) Regelungen im Vertragswortlaut explizit und ausdrücklich einem „organschaftserhaltenden" Verständnis entgegenstehen.

\section{Beseitigung und Vermeidung von Mängeln - Notarieller Nachtragsvermerk gemäß § 44a BeurkG}

Genügt der GAV den steuerlichen Anforderungen nicht, ist er zu ändern, damit zumindest für die Zukunft eine Anerkennung der Organschaft erfolgen kann. Grundvoraussetzung für eine solche „Heilung" durch Vertragsänderung bzw. -ergänzung ist, dass die Anpassung zivilrechtlich wirksam erfolgt. Bei der Änderung des GAV sind alle formellen Voraussetzungen zu beachten, die auch beim Abschluss des GAV gelten $(\S 295$ Abs. 1 Satz 2 AktG). Die Wirksamkeit der Änderungs- bzw. Ergänzungsvereinbarung setzt daher insbesondere ihre Eintragung im Handelsregister voraus. Eine rein schuldrechtliche Vereinbarung ist nicht ausreichend. ${ }^{91}$ Steuerlich ist die Änderung bzw. Ergänzung erst zu beachten, sobald sie zivilrechtlich wirksam geworden ist. Eine rückwirkende Heilung für vergangene Wirtschaftsjahre ist daher ausgeschlossen. ${ }^{92}$ Geklärt

89 Sinn und Zweck sind bei der Auslegung eines GAV stets zu berücksichtigen, nicht nur der Wortlaut; vgl. BFH v. 28.11.2007 - I R 94/06, BFH/NV 2008, 1270.

90 BFH v. 28.11.2007 - I R 94/06, BFH/NV 2008, 1270; vgl. dazu oben S. 9.

91 Vgl. BFH v. 22.10.2008 - I R 66/07, DStR 2009, 100 zur Verlängerung der Mindestlaufzeit; vgl. BFH v. 22.2.2006 - I R 74/05, DStR 2006, 1224 zur Einfügung des $\S 302$ Abs. 3 AktG.

92 Vgl. BFH v. 22.2.2006 - I R 73/05, GmbHR 2006, 890. 
ist jetzt zumindest, dass eine wirksame Änderung bereits im Jahr ihres zivilrechtlichen Wirksamwerdens steuerlich zu berücksichtigen ist und nicht erst im folgenden Wirtschaftsjahr. ${ }^{93}$

Etwas anderes im Sinne einer „rückwirkenden Berichtigung“ kommt jedoch in Fällen des sog. notariellen Nachtragsvermerks in Betracht (§ 44a BeurkG). Nach dieser Norm ist eine Änderung einer notariellen Urkunde möglich, sofern eine offensichtliche Unrichtigkeit vorliegt (§ 44a Abs. 2 S. 1 BeurkG) und die Richtigstellung durch einen Nachtragsvermerk des Notars erfolgt. ${ }^{94}$ In diesem Fall liegt nämlich keine echte Änderung des Vertrags vor (die nach der BFH-Rechtsprechung nicht rückwirkend erfolgen kann), sondern nur eine "Zerstörung des falschen Scheins" ${ }^{\prime \prime}$ der vom unrichtigen Wortlaut der Niederschrift ausgeht; die offensichtliche Unrichtigkeit wird also nur im korrekten Sinne klargestellt. ${ }^{95}$ Dementsprechend darf ein Nachtragsvermerk aber nicht den Inhalt des GAV ändern, sondern lediglich den Verlautbarungsmangel beheben. ${ }^{96}$ Liegen die Voraussetzungen vor, besteht ein Beurkundungszwang, um die Existenz unrichtiger Urkunden zu vermeiden.

Voraussetzung ist, dass eine offensichtliche Unrichtigkeit vorliegt. Als solche kommen z.B. Schreib- und Rechenfehler oder andere ähnliche Fehlerquellen in Betracht. Das offensichtliche Versehen muss sich aus den Gesamtumständen der Beurkundung ergeben, wobei die Umstände auch außerhalb der Urkunde liegen können. Offensichtlich ist ein Fehler auch dann, wenn sich dies aus anderen Umständen für jeden ergibt, der diese Umstände kennt. Da Gegenstand der Beurkundung die Wahrnehmungen des Notars sind, genügt es bereits, wenn die Unrichtigkeit für ihn offensichtlich ist. ${ }^{97}$ Ein denkbarer Fall einer offensichtlichen Unrichtigkeit lag u. E. z. B. im Fall des BFH-Falls I R 74/06 ${ }^{98}$ vor, wo wegen der Verwendung eines Musters aus einem anderen GAV versehentlich ein Datum als früheste Kündigungsmöglichkeit beurkundet wurde, welches weder dem Willen der Parteien noch des Notars entsprach.

Die Möglichkeit des $\S 44 a$ Abs. 2 BeurkG ist jedoch nur dann eröffnet, wenn der GAV Teil der notariellen Urkunde geworden ist. Dabei genügt für den GAV eigentlich die Schriftform (§ 293 Abs. 3 AktG). Notariell

93 BFH v. 15.9.2010 - I B 27/10, DStR 2010, 1984 (= Berichtigungsbeschluss zum Beschluss v. 28.7.2010 I B 27/10, DK 2010, 524; zur Problematik Schneider/ Hinz, Ubg 2009, 738, 742 m. w. N.

94 Dötsch in Dötsch/Jost/Pung/Witt, KStG, § 14 Rz. 165a; Schöneborn, DB 2010, $245,246 \mathrm{f}$.

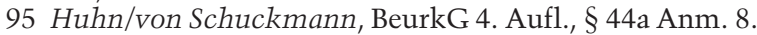

96 Velte in Bonner Bp-Nachrichten, 2/2007, 16, 16) m. w. N.

97 Winkler, BeurkG, §9 Rz. 19; Velte in Bonner Bp-Nachrichten, 2/2007, 16, 16) m. w. N.; vgl. Leitzen, GmbH-StB 2009, 278, 281.

98 BFH v. 28.11.2007 - I R 94/06, BFH/NV 2008, 1270; vgl. dazu oben S. 9. 
beurkundet werden muss grundsätzlich nur der Zustimmungsbeschluss der Gesellschafterversammlung der beherrschten Gesellschaft. ${ }^{99}$ Jedoch kann auch formell beurkundet werden, was nach materiellem Recht nicht beurkundet werden muss; so kann ersetzend verwiesen werden, ohne dass ein Beurkundungserfordernis vorliegt, sowie Überflüssiges mit beurkundet werden. ${ }^{100}$ In der Praxis wird der GAV in vielen Fällen der Niederschrift über den Zustimmungsbeschluss so beigefügt und gleichzeitig im Beschluss inhaltlich so auf ihn verwiesen, dass sein Inhalt (zumindest durch Verweis) Teil der notariellen Niederschrift des Notars wird. Jedenfalls in diesen Fällen kann dann auch eine offensichtliche Unrichtigkeit im GAV durch Nachtragsvermerk „geheilt" werden.

\section{Fazit und Ausblick}

Indem der BFH seine formale und streng an der zivilrechtlichen Beurteilung der Unternehmensverträge orientierte Rechtsprechung bestätigt und die nachträgliche Änderung zur Erhaltung der körperschaftsteuerlichen Organschaft strengen Voraussetzungen unterwirft, perpetuiert er den Charakter des GAV als besonders fehleranfälliges Element der Konzernsteuerplanung. Vor diesem Hintergrund ist es dringend empfehlenswert, mögliche Risiken für die Anerkennung der körperschaftsteuerlichen Organschaft im GAV auszuschließen und jegliche Notwendigkeit für eine ergänzende Auslegung von vornherein zu vermeiden. Beim Abschluss oder der Änderung von GAVs muss daher weiterhin höchste Sorgfalt walten.

Für den Bereich der Einbeziehung des § 302 AktG in den GAV hat sich die "Auslegungslage" zwar durch den Beschluss des BFH vom 28.7.2010101 sowie das zeitnah folgende BMF-Schreiben vom 19.10.2010 102 etwas entspannt, weil insbesondere die übergezogenen Anforderungen aus den früheren Verfügungen verworfen wurden. Allerdings hat diese Entspannung bei der Auslegung zugleich den Druck auf den Gesetzgeber entweichen lassen. Denn eigentlich bestand die große Chance, dass aufgrund einer Prüfbitte des Bundesrats ${ }^{103}$ der $\S 17$ KStG im JStG 2010 so geändert werden sollte, dass es bei einem GAV mit einer $\mathrm{GmbH}$ auf eine vertragliche

99 BGH v. 24.10.1988 - II ZB 7/88, BGHZ 105, 324. Für den Zustimmungsbeschluss der herrschenden Gesellschaft ist eine notarielle Beurkundung zwingend, wenn sie AG oder KGaA ist.

100 Vgl. dazu BGH v. 23.9.1977 - V ZR 90/75, BGHZ 69, 266; BGH v. 10.6.1977 V ZR 99/75, NJW 1977, 2072; BGH v. 23.2.1979 V ZR 99/77, NJW 1979, 1495, 1498; BGH v. 30.5.1984 - VIII ZR 20/83, NJW 1984, 1966; Winkler, BeurkG § 9 Rz. 28.

101 BFH v. 28.7.2010 - I B 27/10 Rn. 30, DStR 2010, 1777, 1779.

102 BMF v. 19.10.2010, DStR 2010, 2193.

103 BR-Drs. 318/10. 
Vereinbarung der Verlustübernahmeverpflichtung gar nicht mehr angekommen wäre; ${ }^{104}$ nach der Entscheidung des BFH und ihrer Übernahme durch das BMF schien der Gesetzgeber jedoch keine Notwendigkeit mehr für eine solche Änderung zu sehen. ${ }^{105}$ Das ist aber nur z. T. richtig; ${ }^{106}$ denn die Gesetzesänderung wäre noch weiter gegangen, da es gar keiner Vereinbarung im GAV mehr bedurft hätte, sofern (wie bei GAVs mit GmbHs) die Regelung des $\S 302$ AktG analog aufgrund der BGH-Rechtsprechung gilt. Damit wären auch alle jene GAVs mit GmbHs steuerlich zu akzeptieren gewesen (und zwar rückwirkend), bei denen der GAV heute (i) entweder gar keine Regelung zur Verlustübernahmepflicht i. S. d. $\S 302$ AktG enthält oder (ii) zwar eine Regelung enthält, die aber nicht alle notwendigen Absätze des $\S 302$ AktG (Abs. 1, 3, und 4) enthält. Jedenfalls Fälle der zweiten Fallgruppe trifft man in der Praxis immer wieder noch an. Soll die Organschaft zumindest für die Zukunft wirken, sind die Verträge zu ändern. Dabei sind die strengen Voraussetzungen zu berücksichtigen, die der BFH an eine steuerlich wirksame Änderung stellt.

\section{Tatsächliche Durchführung des GAV}

Eine weitere wesentliche und z. T. fehleranfällige Einwirkung des Zivilrechts auf die steuerliche Behandlung der Organschaft ergibt sich aus dem Erfordernis der tatsächlichen Durchführung des GAV während seiner Laufzeit (§ 14 Abs. 1 Satz 1 Nr. 3 KStG). Tatsächlich durchgeführt wird ein GAV, wenn er entsprechend den vertraglichen Vereinbarungen vollzogen wird, also die nach den Grundsätzen ordnungsmäßiger Buchführung ermittelten Gewinne tatsächlich vertragsgemäß an den Organträger abgeführt werden. ${ }^{107}$ Dementsprechend hat die Organgesellschaft ihren „ganzen Gewinn“ an den Organträger abzuführen und dieser im Gegenzug einen etwaigen Verlust der Organgesellschaft zu übernehmen. Der "ganze Gewinn" ist dabei nicht steuerrechtlich, sondern handelsrechtlich zu ermitteln. Auszuschöpfen ist der Höchstbetrag der Gewinn-

104 Vgl. zur geplanten Änderung z. B. Prinz, DStR 2010, 1512, 1512 f.

105 Vgl. BT-Drs. 17/3549, S. 8 rechte Spalte.

106 Vgl. ausführlicher zur Aufgabe der Gesetzesänderungspläne Schneider, Der Konzern 2010, 604.

107 BFH v. 5.4.1995 - I R 156/93, BFHE 177, 429 = DB 1995, 1593; v. 21.10 .2010 IV R 21/07, GmbHR 2011, 40, 42. Der tatsächlichen Durchführung steht dabei nicht entgegen, wenn Meinungsverschiedenheiten zwischen der Finanzverwaltung und dem Unternehmen über den Ansatz oder die Bewertung von Bilanzposten entstehen und es später zu Mehrergebnissen aufgrund einer Betriebsprüfung kommt (BFH v. 5.4.1995, a. a. O.). 
abführung i. S. d. § 301 AktG. ${ }^{108}$ Dieser Höchstbetrag ergibt sich aus dem ohne die Gewinnabführung entstehenden Jahresüberschuss, vermindert um einen Verlustvortrag aus dem Vorjahr sowie um den Betrag, der nach $\S 300 \mathrm{AktG}$ in die gesetzlichen Rücklagen einzustellen ist, und um den nach $\S 268$ Abs. 8 HGB ausschüttungsgesperrten Betrag (§301 AktG); er erhöht sich wiederum durch Entnahmen aus anderen Gewinnrücklagen, die während der Laufzeit des GAV gebildet worden sind (§ 301 S. 2 AktG). Diese aktienrechtlichen Regelungen gelten steuerlich für $\mathrm{GmbHs}$ entsprechend (§ 17 S. 2 Nr. 1 und 2 KStG). Wird gemessen an diesen aktienrechtlichen Vorgaben zu viel oder zu wenig abgeführt, so ist der GAV nicht ordnungsgemäß durchgeführt worden.

Im Hinblick auf die tatsächliche Durchführung gibt es eine Reihe offener Fragen und Problemkreise, die hier nur gestreift werden können. ${ }^{109}$ Nicht abschließend geklärt sind z. B. die Fragen

- bis zu welchem Zeitpunkt eine Gewinnabführung bzw. Verlustübernahme tatsächlich erfolgt sein muss, damit sie steuerlich noch anzuerkennen ist; ${ }^{110}$

- ob jedweder, ggfls. auch nur (betragsmäßig oder sonst) unwesentliche Verstoß zur steuerrechtlichen Nichtanerkennung der Organschaft führt oder ob (z. B. wegen des Grundsatzes der Verhältnismäßigkeit) Einschränkungen zu machen sind. ${ }^{111}$ Jedenfalls für bestimmte Fallkonstellationen ist dies auch von der Finanzverwaltung anerkannt; ${ }^{112}$

- ob bzw. unter welchen Voraussetzungen es steuerlich schädlich ist, wenn die tatsächliche Durchführung auf dem tatsächlich handelsbilanziell ausgewiesenen Ergebnis (vor Gewinnabführung bzw. Verlustausgleich) beruht, sich aber später herausstellt, dass dieses handelsbilanziell nicht richtig ermittelt wurde. Denn nach dem BGH kommt es für die Bestimmung des Höchstbetrages der Gewinnabführung nicht auf

108 Vgl. Dötsch, Der Konzern 2009, 171 m. w. N.

109 Vgl. weiterführend Schneider/Hinz, Ubg 2009, 738, 743 ff. m. w. N.

110 Die Meinungen reichen u.a. von „zeitnah" über „in angemessener Zeit" zur (so wohl die h. M. in der Literatur) Forderung eines Ausgleichs erst bei Beendigung des GAV; vgl. z.B. Sterner in Herrmann/Heuer/Raupach, EStG/KStG, $\S 14$ KStG Anm. 203 m. w. N.

111 Dafür z. B. Baldamus, Ubg 2009, 488; Walter in Ernst \& Young, KStG, § 14 Rz. 649 f.; Schneider/Hinz, Ubg 2009, 738, 744; differenzierend Dötsch, Der Konzern 2009, 172.

112 Vgl. BMF v. 15.10.2007, BStBl. I 2007, 765 (unterbliebene Verzinsung des Verlustausgleichsanspruchs als bloße Verletzung einer Nebenpflicht); zur (handelsbilanziell ggfls. unzutreffenden) Behandlung eines Körperschaftsteuerguthabens der Organgesellschaft OFD Hannover v. 5.11.2008, DStR 2009, 325. 
das tatsächlich festgestellte Ergebnis an, sondern auf das sich bei objektiv ordnungsgemäßer Bilanzierung ergebende Ergebnis. ${ }^{113}$

Ein in der Praxis häufig auftretender Fehler in diesem Bereich ist das Vergessen des Ausgleichs eines vorvertraglichen Verlustvortrags vor erstmaliger Gewinnabführung. Nach §301 AktG sind Gewinnabführungen an den Organträger erst zulässig, wenn ein vorvertraglicher Verlustvortrag der Organgesellschaft durch Gewinne in der Vertragszeit vollständig ausgeglichen wurde. Werden Gewinne der Organgesellschaft ohne einen vollständigen Ausgleich ihres vorvertraglichen Verlusts an den Organträger abgeführt, liegt eine schädliche „Zuvielgewinnabführung" vor. Nach der wohl h. M. ist dies auch bei einem bloß geringfügigen Betrag ein Verstoß gegen das Gebot der tatsächlichen Durchführung; ${ }^{114}$ der IV. Senat des BFH hat sich dem jüngst angeschlossen. ${ }^{115}$ Jedoch muss ein solches Versehen nicht automatisch zu einem Scheitern der Organschaft führen; vielmehr kann der Steuerpflichtige den Fehler ggfls. heilen. Dafür eignen sich nach h. M. zwei „Techniken“:

- Es erfolgt eine rückwirkende Änderung des Jahresabschlusses des ersten innervertraglichen Gewinn-Jahres, in dem die Verrechnung vergessen wurde. In diesem ist eine entsprechende Forderung der Organgesellschaft gegen den Organträger auf Rückzahlung des zuviel abgeführten Gewinns gewinnerhöhend einzubuchen. Dadurch wird im Ergebnis die bilanzielle Abrechnung dem tatsächlich bereits abgeführten Betrag angepasst. ${ }^{116}$ U.E. ist bei diesem Ansatz auch eine Anpassung der Bilanzen der Folgejahre bei der Organgesellschaft vorzunehmen, wohingegen eine Änderung der Handelsbilanzen des Organträgers nicht notwendig sein sollte, sondern eine Korrektur in offener Rechnung erfolgen kann. ${ }^{117}$

- Sind im letzten Jahresabschluss vor Wirksamwerden des GAV noch freie ausschüttungsfähige (Kapital- oder Gewinn-) Rücklagen in Höhe des Verlustvortrags vorhanden, kann alternativ auch der Ergebnisverwendungsbeschluss dieses Wirtschaftsjahres dahingehend geändert werden, dass Beträge aus der Kapital- oder Gewinnrücklage zum Aus-

113 BGH v. 14.2.2005 - II ZR 361/02, BB 2005, 1104.

114 Vgl. Witt in Dötsch/Jost/Pung/Witt, KStG, § 14 Rz. 181; Frotscher in Frotscher/Maas, KStG, § 14 Rn. 200, 200a; Neumann in Gosch, KStG, 2. Aufl., $\S 14$ Rz. 310; im Ergebnis auch Schneider/Hinz, Ubg 2009, 738, 745. A. A. Walter in Ernst \& Young, KStG, § 14 Rz. 680.2 m. w. N.

115 BFH v. 21.10.2010 - IV R 21/07, GmbHR 2011, 40.

116 Vgl. Berger, DB 2005, 905; Walter in Ernst \& Young, KStG, § 14 Rz. 680.2; Witt in Dötsch/Jost/Pung/Witt, KStG, §14 Rz.181; Schneider/Hinz, Ubg 2009, 738, 745 f.; ablehnend dagegen Frotscher, KStG, § 14 Rz. 200a.

117 Schneider/Hinz, Ubg 2009, 738, $745 \mathrm{f}$. 
gleich des Verlustvortrages aufgelöst werden. ${ }^{118}$ Der Verlustvortrag wird damit vororganschaftlich ausgeglichen, so dass dieser in der folgenden organschaftlichen Zeit nicht mehr auszugleichen ist. Der Fehler wird also an der Wurzel selbst beseitigt.

Der BFH hat sich mit der Möglichkeit einer solchen Änderung bisher noch nicht im Detail beschäftigt. In einem jüngst vom IV. Senat des BFH behandelten Fall (der IV. Senat war zuständig, weil der Organträger eine KG war) hätte sich die Gelegenheit bieten können. Vereinfacht war der Sachverhalt in diesem Punkt wie folgt: Für 1998 wurde erstmalig eine Organschaft begründet. Die Organgesellschaft hatte zu diesem Zeitpunkt einen vororganschaftlichen Verlustvortrag von ca. DM 5,5 Mio. Im ersten Organschaftsjahr 1998 ergab sich bei ihr ein weiterer (jetzt organschaftlicher) Verlust, aber im Folgejahr 1999 ein Gewinn von ca. DM 2,7 Mio. Dieser Betrag wurde an den Organträger (über Verbuchung auf einem Verrechnungskonto) abgeführt. In 2000 verkaufte der Organträger $50 \%$ der Anteile an der Organgesellschaft; der GAV wurde beendet, die (ehemalige) Organgesellschaft zudem in eine KG umgewandelt. Später wurde ein Gesellschafterbeschluss bei der ehemaligen Organgesellschaft (jetzt KG) gefasst, dass ein evtl. Rückforderungsanspruch der ehemaligen Organgesellschaft gegen den Organträger wegen zu Unrecht erfolgter Gewinnabführung durch den Formwechsel obsolet geworden sei. Nachdem eine Betriebsprüfung später eine Nichtdurchführung des GAV rügte, wurde eine berichtige Bilanz erstellt, in der eine Forderung gegen den Organträger und ein entsprechender Jahresüberschuss ausgewiesen wurde; eine tatsächliche Rückforderung der erfolgten Gewinnabführung wurde aber nicht geltend gemacht, sondern unter Verweis auf den alten Beschluss weiter ausgeschlossen.

Der BFH hat die Organschaft im Ergebnis nicht anerkannt. Eine Gewinnabführung trotz bestehenden vororganschaftlichen Verlustvortrags sei ein Verstoß gegen den GAV und $\S 301 \mathrm{AktG}$. Dies führe bereits dem Grunde nach zu einer Nichtdurchführung des GAV und damit (grundsätzlich) zu einem Scheitern der Organschaft; auf die Höhe des vergessenen Ausgleichs komme es nicht an. Ob eine Heilung dieses Verstoßes rückwirkend möglich sei, ließ er dagegen offen: der Einbuchung der Forderung gegen den Organträger wurde keine Bedeutung beigemessen, weil sie tatsächlich nicht geltend gemacht wurde und aufgrund der Gesellschafterbeschlüsse auch nicht geltend gemacht werden sollte; die Bilanzänderung war nur ein formeller Akt ohne materielle Konsequenzen.

118 Vgl. dazu u. a. Kreidl/Riehl, BB 2006, $1880 \mathrm{ff}$.; Rohrer/von Goldacker/Huber, DB 2009, $360 \mathrm{ff}$.; Schneider/Hinz, Ubg 2009, 738, 746; ablehnend wiederum Frotscher in Frotscher/Maas, KStG, § 14 Rz. 200a. 
Mit diesem Urteil dürfte nochmals klar geworden sein, dass beim Vorhandensein von vororganschaftlichen Verlustvorträgen höchste Sorgfalt erforderlich ist; sie sollten vor einer Gewinnabführung immer ausgeglichen werden, und zwar unabhängig von der Höhe. Einer Einschränkung bei kleineren Beträgen erteilt der BFH eine generelle Absage; ${ }^{119}$ eine solch grundlegende Aussage wäre im Streitfall angesichts der Höhe der Beträge eigentlich nicht notwendig gewesen. Er verwirft damit in diesem Bereich eine Eingrenzung der Anforderungen aus Verhältnismäßigkeitsgründen; das bedeutet $u$. E. allerdings nicht, dass derartige Eingrenzungen auch bei anderen Fragen der Organschaft ausgeschlossen sind; vielmehr ist u. E. eine Differenzierung angezeigt zwischen dem gesetzlich in $\S 301$ AktG konkret angeordneten Gebot des Ausgleichs vororganschaftlicher Verluste und anderen Anforderungen; nur beim ersteren erscheint wegen der besonderen Bedeutung des $\S 301$ AktG eine strenge, Verhältnismäßigkeitsüberlegungen ausschließende Betrachtung vertretbar. ${ }^{120} \mathrm{Ob}$ und unter welchen konkreten Voraussetzungen ein derartiger Verstoß durch die oben beschriebenen Bilanzierungsmaßnahmen rückwirkend geheilt werden kann, bleibt dagegen weiterhin offen: wer eine solche Heilung versucht, muss aber nicht nur die Bilanz ändern, sondern auch ggfls. gegen den Organträger eingebuchte Forderungen auf Rückzahlungen "tatsächlich durchführen", d. h. die Forderung erfüllen.

\section{Heilung eines steuerlich unwirksamen GAV}

Entspricht ein zivilrechtlich wirksamer GAV nicht den steuerlichen Anforderungen, so ist er anzupassen, um die Wirkungen der Organschaft wenigstens für die Zukunft herbeizuführen. Diese Notwendigkeit liegt z.B. vor, wenn der GAV selbst den steuerlichen Anforderungen nicht genügt und unzureichende Regelungen zur Mindestlaufzeit oder zur Einbeziehung des ganzen $\S 302$ AktG enthält. Unabhängig von diesen Fällen nicht genügender Vertragsformulierungen fordert die Finanzverwaltung eine neue 5-jährige Vertragslaufzeit, wenn ein (an sich genügender) GAV nach Ablauf der Mindestlaufzeit wegen nicht tatsächlicher Durchführung in einem Jahr nicht anzuerkennen ist (R 60 Abs. 8 Nr. 2 S. 2 KStR). Dies ist u. E. zwar unzutreffend, denn es gibt keine gesetzliche Grundlage für das Einfordern einer solchen zweiten Mindestlaufzeit; gleichwohl sollte man in entsprechenden Fällen eine Vertragsanpassung vornehmen, wenn man einen Streit mit der Finanzverwaltung von vornherein vermeiden will.

119 Kritisch deswegen Walter, GmbHR 2011, 43 f.

120 Vgl. bereits Schneider/Hinz, Ubg 2009, 738, 744. 
Für die Anpassung des GAV gibt es zwei Möglichkeiten: Zum einen die Änderung bzw. Ergänzung des zivilrechtlich weiterbestehenden GAV, zum anderen die Beendigung des bisherigen mit anschließendem Abschluss eines neuen, steuerlich ausreichenden GAV. Die zweite Möglichkeit ist i. d. R. komplizierter und u. E. auch ohne zivilrechtliche oder steuerliche Vorteile. In der Praxis werden Anpassungen daher in aller Regel durch eine Änderung des GAV vorgenommen. ${ }^{121}$ Hier sollen noch einmal die strengen Anforderungen an eine Vertragsänderung in Erinnerung gerufen werden: Eine Heilung durch Vertragsänderung bzw. -ergänzung setzt voraus, dass die Anpassung zivilrechtlich wirksam erfolgt. Bei der Änderung sind alle formellen Voraussetzungen zu beachten, die auch beim Abschluss des GAV gelten (§ 295 Abs. 1 Satz 2 AktG). Die Wirksamkeit der Änderungs- bzw. Ergänzungsvereinbarung setzt daher insbesondere ihre Eintragung im Handelsregister voraus. Eine rein schuldrechtliche Vereinbarung ist nicht ausreichend. ${ }^{122}$

Zeitlich ist die Änderung bzw. Ergänzung erst zu beachten, sobald sie zivilrechtlich wirksam geworden ist. Eine rückwirkende Heilung für vergangene Wirtschaftsjahre scheidet in jedem Fall aus. ${ }^{123}$ Nicht völlig geklärt war bislang, ob eine Vertragsänderung zu einer Heilung bereits für das (gesamte) laufende oder nur für zukünftige Wirtschaftsjahre führen kann. ${ }^{124}$ Diese Frage hat der BFH nunmehr letztlich dahin entschieden, dass die Vertragsänderung steuerlich bereits im Wirtschaftsjahr der zivilrechtlich wirksamen Änderung anzuerkennen ist. Zunächst hatte er das zwar anders entschieden (Anerkennung erst für das nächste Wirtschaftsjahr), ${ }^{125}$ sich dann aber selber in einem Änderungsbeschluss korrigiert. ${ }^{126}$ Nunmehr stimmt er zu, dass die Änderung des GAV steuerlich bereits im Jahr der Änderung selbst anzuerkennen ist und zu einer wirksamen Organschaft führt. Die Richtigstellung durch den BFH ist zu begrüßen. Eine andere Entscheidung wäre u. E. auch nicht vertretbar gewesen: Das KStG fordert kumulativ (i) einen zivilrechtlich wirksamen Gewinnabführungsvertrag, der (ii) den steuerlichen Mindestinhalt hat. Diese Voraus-

121 Vgl. Schneider/Hinz, Ubg 2009, 738, 742 f., auch zur Frage, ob bzw. wann eine Vertragsverlängerung durch Änderung des GAV zivilrechtlich (aber nicht zwingend steuerlich) wie ein Neuabschluss zu werten ist.

122 BFH v. 22.10.2008 - I R 66/07, DStR 2009, 100 (zur Verlängerung der Mindestlaufzeit); v. 22.2.2006 - I R 74/05, DStR 2006, 1224 (zur Einfügung des § 302 Abs. 3 AktG).

123 BFH v. 22.2.2006 - I R 73/05, GmbHR 2006, 890.

$124 \mathrm{Vgl}$. dazu die bisher unklaren Ausführungen des BFH im Urt. v. 22.2.2006 - I R 74/05, DStR 2006, $1224 \mathrm{f}$.

125 BFH v. 28.7.2010 - I B 27/10, DStR 2010, 1777, 1779, Rz. 27, 31.

126 BFH v. 15.9.2010 - B 27/10 Rz. 8, DStR 2010, 1984, 1984f. Dazu Schneider, Der Konzern 2010, 486. Der Senatsvorsitzende Gosch (in BFH/PR 2010, 433, 434) bezeichnet das selbst als "Lapsus". 
setzungen sind mit der zivilrechtlich wirksamen Änderung des GAV erfüllt. Das muss steuerlich auch ab Beginn des Änderungsjahres gelten, wenn vertraglich die Wirksamkeit auf diesen zurückbezogen wurde. Dies ist beim Erstabschluss eines GAV unzweifelhaft möglich, und es ist kein Grund ersichtlich, wieso eine Änderung des GAV schlechter behandelt werden sollte als sein Abschluss. Denn es handelt sich hierbei gerade nicht um den Fall einer Rückwirkung in abgeschlossene Veranlagungszeiträume. ${ }^{127}$

\section{Ausgleichszahlungen an außenstehende Aktionäre}

\section{1. Überblick}

Eine weitere interessante Schnittstelle zwischen Zivilrecht und Steuerrecht ergibt sich bei Ausgleichszahlungen i. S. d. § 304 AktG. Hier stellen sich einige Fragen, u. a. ${ }^{128}$

- Müssen Ausgleichszahlungen zwingend vereinbart werden? Was ist die Rechtsfolge bei einem Pflichtverstoß?

- Wie sind Ausgleichszahlungen zu bemessen?

Die Frage der Pflicht von Ausgleichszahlung wird für eine Organgesellschaft in der Rechtsform der AG, KGaA oder SE von $\S 304$ AktG beantwortet. Sind "außenstehende Aktionäre" im Zeitpunkt des Beschlusses der Hauptversammlung vorhanden, muss der GAV eine Ausgleichszahlung vorsehen (§304 Abs. 1 AktG). Wenn dies nicht erfolgt, ist der GAV zivilrechtlich nichtig (§304 Abs. 3 S. 1 AktG). Ein solches zivilrechtliches Defizit schlägt auf das Steuerrecht durch, d. h. ein derart nichtiger GAV ist steuerlich nicht geeignet, eine wirksame Organschaft zu begründen. Insofern ist die Rechtslage klar. Abgrenzungsschwierigkeiten können sich aber z. B. bei der Frage ergeben, ob ein Gesellschafter als „außenstehend" einzustufen ist oder ob dies deshalb zu verneinen ist, weil er dem herrschenden Unternehmen zugerechnet werden kann. ${ }^{129}$

Anders ist die Situation bei einer Organgesellschaft in der Rechtsform einer GmbH. § 304 AktG gilt nach der h. M. im Zivilrecht nicht analog. Der Schutz der Minderheitsgesellschafter ist einer $\mathrm{GmbH}$ nach der (wiederum h. M.) dadurch gewährleistet, dass ein GAV nur mit Zustimmung aller $\mathrm{GmbH}$-Gesellschafter der zukünftigen Organgesellschaft zustande

127 So auch Kolbe, StuB 2009, 229; Schneider/Hinz, Ubg 2009, 738, 742.

$128 \mathrm{Vgl}$. ausführlich Baldamus, ZGR 2007, $819 \mathrm{ff}$.

129 Vgl. dazu z. B. Hüffer, AktG, 10. Aufl., § 304 Rz. 2 f.; Paulsen in MüKo-AktG, 3. Aufl., § 304 Rz. 26 ff.; Baldamus, ZGR 2007, 819 ff., jeweils m.w. N. zum Meinungsstand. 
kommt. ${ }^{130}$ Es bedarf daher des Schutzes des $\S 304$ AktG nicht. Folglich ist ein GAV, dem alle Gesellschafter zugestimmt haben, auch nicht nichtig, wenn er keine Ausgleichszahlung enthält; dementsprechend kann ein solcher GAV auch die Grundlage für eine steuerlich wirksame Organschaft sein. ${ }^{131}$

\section{Höhe der Ausgleichszahlungen}

Bei der Bemessung der Ausgleichszahlungen gilt es wiederum zivilrechtliche und steuerliche Vorgaben auseinanderzuhalten. Hier hat es in letzter Zeit einige Bewegung gegeben, da der BFH mit einem neueren Urteil vom 4.3.2009132 eine Verschärfung ausgesprochen hat, die die Finanzverwaltung jedoch letztlich nicht übernommen hat. Zunächst sollen die zivil- und steuerrechtlichen Grundlagen noch einmal betrachtet werden:

\subsection{Aktienrechtliche Vorgaben}

$\S 304$ AktG sieht zunächst zwei Möglichkeiten für die Bemessung von Ausgleichszahlungen vor. Den vom Gesetz vorgesehenen Normalfall bildet die feste Ausgleichszahlung (§304 Abs. 2 S. 1 AktG); der fixe Betrag richtet sich dabei grundsätzlich nach den erwarteten zukünftigen Ertragsaussichten. Alternativ kann, wenn es sich beim Organträger um eine AG, KGaA oder SE handelt, auch eine variable Ausgleichszahlung gewählt werden, die sich nach dem Gewinn des Organträgers bemisst $\ 304$ Abs. 2 S. 2 AktG). Beide Arten können auch miteinander kombiniert werden. ${ }^{133}$ Nicht vorgesehen ist im Gesetz eine variable Vergütung, die an den Gewinn der Organgesellschaft anknüpft.

\subsection{Steuerrechtliche Vorgaben}

Das KStG enthält keine expliziten Regelungen für die Bemessung von Ausgleichszahlungen; das Gesetz regelt insofern nur, dass die Organgesellschaft in Höhe der Ausgleichszahlungen (bzw. des ihnen zugrunde gelegten hochgerechneten Bruttogewinns) selbst steuerpflichtig ist (§ $16 \mathrm{KStG}$ ). Allerdings fordert $\S 14$ Abs. $1 \mathrm{~S} .1 \mathrm{KStG}$, dass sich die Organgesellschaft verpflichtet, ihren ganzen Gewinn an den Organträger abzuführen. ${ }^{134} \mathrm{Ob}$ und inwieweit diese generelle Anforderung - über die zivil-

130 Hasselbach/Hirte in Großkomm. AktG, § 304 Rz. 142; Emmerich in Emmerich/Habersack, Konzernrecht, § 304 Rz. 11; Paulsen, in MüKo-AktG, 3. Aufl., $\S 304 \mathrm{Rz} .19$.

131 Baldamus, ZGR 2007, 819, 847 m. w. N.

132 BFH v. 4.3.2009 - I R 1/08, BStBl. II 2010, 407 = DStR 2009, 1749.

133 Paulsen in MüKo-AktG, 3. Aufl., § 304 Rz. 45.

134 Lohmann/Goldacker/Annecke, BB 2009, 2344, 2345; Tappen/Riegel, SteuK 2010, 309, 309. 
rechtlichen Anforderungen hinaus - Auswirkung auf die Ausgestaltung der Ausgleichszahlungen hat, lässt das Gesetz offen.

\subsection{Bisheriger Meinungsstand}

Trotz seines primär aktienrechtlichen Charakters handelt es sich bei dem GAV um einen Vertragstyp, der an einer Schnittstelle zwischen Zivilrecht und Steuerrecht liegt. Er muss deshalb grundsätzlich den Anforderungen beider Rechtsgebiete gerecht werden. ${ }^{135}$ Zivilrechtlich zulässige Ausgleichszahlungen an außenstehende Aktionäre der Organgesellschaft wirken sich zugleich auf die Höhe des verbleibenden und an den Organträger abzuführenden Gewinns aus. Es kommt somit u. U. zu einem gewissen Spannungsverhältnis zwischen der aktienrechtlich vorgeschriebenen Ausgleichszahlung und der steuerrechtlich generell vorausgesetzten vollständigen Gewinnabführungspflicht. An dieser Stelle ist letztlich zu prüfen, ob bei der Gestaltung und Bemessung von Ausgleichszahlungen und ihren Auswirkungen auf die Abführung des ganzen Gewinns im Sinne des $\S 14$ Abs. 1 S. 1 KStG steuerrechtlich ein anderer (strengerer) Maßstab anzulegen ist als im Handelsrecht. ${ }^{136}$

Zum Teil wurde bisher in der Literatur vertreten, dass sich die zulässige Ausgestaltung von Ausgleichszahlungen an außenstehende Aktionäre nicht primär nach gesellschaftsrechtlichen, sondern nach steuerrechtlichen Maßstäben richte. Es gehe bei dem Tatbestandsmerkmal der Abführung des gesamten Gewinns und des Vertragsvollzugs darum, mögliche Manipulationen der Gewinnzuordnung zwischen Mehrheitsgesellschafter und Minderheitsgesellschafter zu vermeiden. Aus diesem Grund soll eine Organschaft steuerlich voraussetzen, dass die Minderheitsgesellschafter grundsätzlich nicht mehr am laufenden Gewinn und Verlust der Organgesellschaft beteiligt sind. Eine zu große Kopplung der Ausgleichszahlungen an das Ergebnis der Organgesellschaft wurde daher kritisch gesehen und lediglich eine gewisse variable Aufstockung eines überwiegend fixen Betrags für zulässig erachtet. ${ }^{137}$

Nach a.A. ist das Kriterium der Abführung des ganzen Gewinns ausschließlich zivilrechtlich auszulegen, u. a. weil weder § 14 Abs. 1 S. 1, $\S 16$ noch $\S 17$ KStG sich den Regelungsgehalt des $\S 304$ AktG zu Eigen machten, so dass dieser auch nicht zur Voraussetzung für die Anerken-

135 Vgl. BFH v. 30.7.1997 - I R 7/97; Baldamus, ZGR 2007, 819, 848.

136 Vgl. Baldamus, Ubg 2010, 483, 483, 490; Kaeser, Beihefter zu DStR 2010 Heft 30, 5658.

137 Vgl. z. B. Dötsch, Der Konzern 2006, 64; Dötsch in Dötsch/Jost/Pung/Witt, KStG, § $16 \mathrm{Rz} .17$ a (variabler Anteil über mehrere Jahre hinweg maximal ein Drittel); Frotscher in Frotscher/Maas, KStG, § 16 Rz. 10 (variabler Teil max. $10 \%$ ); Neumann, in Gosch, KStG, 2. Aufl., § 16 Rz. 10. 
nung der steuerlichen Organschaft erklärt werden könne. Maßgebend sei daher das Zivilrecht; es komme nur darauf an, dass überhaupt eine Ausgleichszahlung vorgesehen sei, nicht aber, dass diese den Kriterien des $\S 304$ Abs. 2 AktG standhalte. ${ }^{138}$ Der Gesetzgeber habe mit $\S 16$ KStG bestätigt, dass die wirtschaftliche Einheit aus Organgesellschaft und Organträger durch Ausgleichszahlungen beeinträchtigt werde. ${ }^{139}$

Die Finanzverwaltung ${ }^{140}$ vertrat bis zum Urteil des BFH v. 4.3.2009 den Standpunkt, dass zwar die Bemessung der Ausgleichszahlung allein auf Grundlage einer prozentualen Beteiligung am Gewinn der Organgesellschaft in § 304 Abs. 2 AktG nicht vorgesehen und damit auch steuerlich nicht zulässig sei. Da der feste Ausgleich jedoch nur ein Mindestbetrag sei, sei eine Erhöhung (nicht dagegen eine Verminderung) der festen Ausgleichszahlung (als garantiertem Mindestausgleich) um einen Zuschlag, der sich nach dem tatsächlichen Gewinn der Organgesellschaft bemesse, möglich. Letztlich knüpft damit die steuerliche Betrachtung an die gesellschaftsrechtlichen Vorgaben an, geht aber nicht darüber hinaus. ${ }^{141}$

\subsection{BFH-Urteil vom 4.3.2009 - I R 1/08}

In seinem Urteil vom 4.3.2009 nimmt der BFH zur Frage der Höhe von Ausgleichszahlungen Stellung. Dem Rechtsstreit lag ein GAV zugrunde, bei dem neben einer festen Ausgleichszahlung je Stammaktie eine variable Vergütung mit einem außenstehenden Gesellschafter vereinbart war. Die variable Vergütung orientierte sich am Bilanzgewinn der Organgesellschaft, der sich ergeben hätte, wenn der GAV nicht bestanden hätte; soweit der Bilanzgewinn je Aktie die Festvergütung überstieg, war zusätzlich ein entsprechender variabler Ausgleich an den außenstehenden Aktionär zu zahlen. Im Ergebnis wurde der Außenstehende damit so gestellt, als würde der GAV nicht bestehen, allerdings nur, sofern der anteilige Bilanzgewinn größer war als der feste Ausgleich. Im Streitjahr machte die variable Komponente $58 \%$ der Gesamtausgleichszahlung aus. Der BFH erkannte die Organschaft im Ergebnis nicht an; jedenfalls in einem solchen Fall, in dem der Außenstehende bei der Gewinnbeteiligung so gestellt wird, wie er ohne GAV/Organschaft gestanden hätte, würde gegen das steuerliche Merkmal der Abführung des ganzen Gewinns an den Organträger verstoßen. Dass die Regelung dem Außen-

138 Mensching, BB 2004, 1421, 1422f.; Baldamus, Ubg 2010, 483, 489; Meiisel/Bokeloh, DB 2009, 2067, 2068; Marquardt/Krack, FR 2009, 1098, 1100; vgl. Baldamus, ZGR 2007, 819, 847 f.; Neumann in Gosch, KStG, 2. Aufl., § 14 Rz. 207.

139 Baldamus, Ubg 2010, 483, 491.

140 BMF v. 13.9.1991 - IV B 7 S 2770 34/91, DB 1991, 2110.

141 Zustimmend insoweit: Kaeser, DStR Beiheft 30 2010, 56, 59. 
stehenden wegen des garantierten Mindestbetrags eine bessere Position verschafft als im Fall ohne GAV (sofern die Beteiligung am Bilanzgewinn kleiner wäre als der Festbetrag) spielte für ihn keine wesentliche Rolle. ${ }^{142}$ Der BFH stellt somit im Ergebnis spezielle steuerliche Anforderungen auf, die über die zivilrechtlichen hinausgehen. Eine vertiefte Begründung, ob bzw. warum das Steuerrecht weitergehende Anforderungen stellt als das Zivilrecht, fehlt jedoch, ebenso eine konkretere Herleitung und Abgrenzung der Anforderungen die sich aus dem Grundsatz der „Abführung des ganzen Gewinns" ergeben sollen.

\subsection{Reaktion auf das Urteil in der Literatur}

Die ersten Reaktionen in der Literatur sahen das BFH-Urteil überwiegend nicht als grundsätzliches Votum gegen die Zulässigkeit einer Kombination von festen und variablen Ausgleichszahlungen. ${ }^{143}$ Das ist u.E. zutreffend, denn der BFH hat sich explizit (, jedenfalls...") nur zu der Situation geäußert, bei der die variable Ausgleichszahlung (sofern der Mindestbetrag überstiegen wird) eine echte prozentuale Beteiligung am Gewinn herstellt. Nach überwiegender Auffassung belässt das Urteil einen bestimmten Rahmen für die Ausgestaltung von Ausgleichszahlungen. Die Minimalgrenze ergebe sich dabei aus der ausdrücklichen Anordnung in $\S 304$ Abs. 2 S. 1 AktG, der als festen Ausgleich mindestens den Betrag zusichert, den der Minderheitsgesellschafter nach der bisherigen Ertragslage und den künftigen Ertragsaussichten der Gesellschaft voraussichtlich als durchschnittlichen Gewinnanteil erhalten hätte. Die Zahlung eines Ausgleichs, der sich ausschließlich prozentual am tatsächlichen Stand Alone-Gewinn der Organgesellschaft bemesse, sei daher aktienrechtlich unzulässig. Anderenfalls müssten die Minderheitsaktionäre befürchten, dass der Mehrheitsgesellschafter profitables Geschäft aus der Organschaft heraus und defizitäres Geschäft in die Organschaft hinein verlege, um die Mittelabflüsse an die Minderheitsgesellschafter zu verringern. ${ }^{144}$ Als Maximalgrenze für den gesamten Ausgleichsanspruch soll ein Betrag anzusetzen sein, welcher der Höhe nach den hypothetischen Gewinnanteil des außenstehenden Aktionärs nicht erreichen

142 Kritisch (weil durch die Garantie des festen Ausgleichs gerade eine Abkopplung des Risikos vom Ergebnis der Organgesellschaft bewirkt wird) z. B. Marquardt/Krack, FR 2009, 1098, 1100; Baldamus, Ubg 2010, 483, 486.

143 Meiisel/Bokeloh, DB 2009, 2067, 2069; Erle/Heurung in Erle/Sauter, KStG, 3. Aufl., § 16 Rz. 40; Hubertus/Lüdemann, DStR 2009, 2136, 2138. Nur wenige Autoren rieten gänzlich von variablen Ausgleichszahlungen ab; vgl. Nodoushani, SteuK 2009, 17; Heger, JurisPR-SteuerR 41/2009 Anm. 6.

144 Frotscher in Frotscher/Maas, KStG, § 16 Rz. 8; Baldamus, Ubg 2010, 483, 485; Marquardt/Krack, FR 2009, 1098, 1099; in diesem Sinne bereits BFH v. 31.3.1976 - I R 123/74, BStB1. II 1976, 510. 
darf. ${ }^{145}$ Innerhalb dieses Rechtsrahmens bestehe ein „Gestaltungsspielraum " ${ }^{146}$ der verschiedene zivilrechtlich wie steuerrechtlich zulässige Ausgleichsmodelle umfasst, der weiterhin auch feste und variable Komponenten kombiniert. Nach überwiegender Meinung dürfe aber eben für den variablen Teil keine unmittelbare, ungedeckelte prozentuale Koppelung an den Gewinn der Organgesellschaft erfolgen, um dem unmittelbaren Anwendungsbereich des BFH-Urteils zu entrinnen. Vorgeschlagen werden daher Steigerungen in Festbeträgen ${ }^{147}$ oder (absolute oder relative) höhenmäßige Begrenzung des variablen Teils. ${ }^{148}$

\subsection{Nichtanwendungserlass der Finanzverwaltung}

Die Finanzverwaltung hat sich einiges an Zeit gelassen, um ihre Position festzulegen. Zwischenzeitlich schien es so, dass sie das Urteil anwenden und variable Ausgleichszahlungen (weitgehend) nicht mehr anerkennen wollte. Da dies in erheblichem Maße Beschränkungen für bestehende und zukünftige Strukturen (insbesondere im kommunalen Bereich) bedeutet hätte, wurde auch die Möglichkeit einer Gesetzesänderung zur Absicherung variabler Ausgleichszahlungen kolportiert. Letztlich hat das BMF im April 2010 aber mit einem Nichtanwendungserlass zum BFH-Urteil reagiert. ${ }^{149} \mathrm{Im}$ Wesentlichen bestätigt die Finanzverwaltung ihre bisherige Auffassung: ${ }^{150}$ Wenn eine Ausgleichszahlung als fester Mindestbetrag vereinbart wird ( $\$ 304$ Abs. 2 S. 1 AktG), dann sei es zivilrechtlich zulässig, einen Zuschlag zu gewähren, der sich am Gewinn der Organgesellschaft orientiert. Und wenn die Ausgleichszahlung zivilrechtlich zulässig sei, dann stehe sie der Durchführung des GAV nicht entgegen.

145 Hubertus/Lüdemann, DStR 2009, 2136, 2138; Lohmann/von Goldacker/Annecke, BB 2009, 2344, 2348; Dötsch in Dötsch/Jost/Pung/Witt, KStG, § 16 Rz. 17 a.

146 Baldamus, Ubg 2010, 483, 483, 491.

147 Z. B. Dötsch in Dötsch/Jost/Pung/Witt, KStG, § 16 Rz. 17 a.

148 Meiisel/Bokeloh, DB 2009, 2067; ähnlich Hubertus/Lüdemann, DStR 2009, 2136; Dötsch in Dötsch/Jost/Pung/Witt, KStG, §16 Rz.17a; vgl. Scheunemann/Bauersfeld, BB 2010, 1582, 1583. Zur relativen Begrenzung z. B. Hubertus/Lüdemann, DStR 2009, 2136, 2138. Dötsch (in Dötsch/Jost/Pung/Witt, $\mathrm{KStG}, \S 16 \mathrm{Rz}$. 17a) hält weiterhin an der Auffassung fest, dass der variable Zuschlag im Durchschnitt nicht mehr als ein Drittel der Gesamt-Ausgleichszahlungen betragen dürfe.

149 BMF v. 20.4.2010, BStBl. I 2010, 372; kritisch hierzu: Dötsch in Dötsch/Jost/ Pung/Witt, KStG, § 16 Rn. 17a.

150 Vgl. BMF v. 13.9.1991, DB 1991, 2110. 


\section{Praktische Auswirkungen und Ausblick}

Die Auswirkungen des BFH-Urteils sowie des folgenden Nichtanwendungserlasses des BMF wird man differenzierend betrachten müssen. Zum einen ist es aus Sicht der Steuerpflichtigen grundsätzlich positiv, dass das einschränkende BFH-Urteil - welches sich mit dem Spannungsverhältnis zwischen Zivil- und Steuerrecht nicht wirklich auseinandergesetzt hat - aufgrund des Nichtanwendungserlasses von der Finanzverwaltung nicht angewandt wird. Eine Reihe von Detailfragen bleibt aber weiterhin offen, z. B. ob jedwede Angemessenheitskontrolle des Mindestbetrags überflüssig ist. Vor allem verbleibt das Risiko, das Fälle mit derartigen GAVs möglichst nicht in Klageverfahren geraten sollten, und zwar auch nicht aus anderen Gründen - insofern verbleibt die (nicht unerhebliche) Gefahr, dass die Finanzgerichte aufgrund des BFH-Urteils die Organschaft aberkennen könnten. Diese Situation könnte man als ein "faktisches Klageverbot" bezeichnen. Schutz bietet hier u. U. eine Absicherung der Ausgleichszahlungs-Klauseln durch eine verbindliche Auskunft.

In einer Rechtsfrage von einer solchen Bedeutung (insbesondere im kommunalen Bereich) ist diese Situation keineswegs ideal. Es bleibt zu hoffen, dass der Gesetzgeber dieses Problem spätestens bei einer (hoffentlich demnächst) anstehenden Reform der Gruppenbesteuerung rechtssicher löst, ohne die wirtschaftlich wünschenswerte Flexibilität zu sehr einzuschränken.

\section{Haftung bei Organschaft}

Abschließend soll noch ein Thema aus dem Recht der Organschaft gestreift werden, nämlich die Haftung der Organschaft nach § 73 AO. Das Thema hat in den letzten Jahren in der Praxis deutlich an Bedeutung zugenommen, z. T. weil krisenbedingt Organträger häufiger in Zahlungsschwierigkeiten geraten sind. Die Rechtsentwicklung ist bei diesem Komplex aber noch in keiner Weise abgeschlossen.

\section{Grundsätzlicher Umfang der Haftung}

$\S 73$ AO ordnet bei Vorliegen eines steuerlich wirksamen Organschaftsverhältnisses eine Haftung der Organgesellschaft für bestimmte Steuern des Organträgers an. Die Haftung ist in mehrfacher Hinsicht beschränkt:

- Die Haftung erstreckt sich auf alle Steuern des Organträgers, für welche "die Organschaft steuerlich von Bedeutung ist". Das sind diejenigen Steuerarten, auf die sich die konkrete Organschaft bezieht. Besteht nur eine umsatzsteuerliche Organschaft, haftet die Organgesellschaft 
also nicht für Ertragsteuern (und umgekehrt). Erst recht besteht keine Haftung für Steuern, bei denen eine Organschaft im technischen Sinne nach den Steuergesetzen nicht möglich ist (wie z. B. Verbrauchsteuern, Grundsteuern oder u. E. auch die Grunderwerbsteuer).

- Die Haftung besteht auch nur für Zeiträume, für die eine Organschaft besteht. Maßgebend ist, ob die Steuer für diesen Zeitraum entsteht. Auf die Fälligkeit kommt es dagegen nicht an; die Inanspruchnahme kann also auch noch erfolgen, nachdem die Organschaft beendet wurde. Umgekehrt besteht keine Haftung z. B. für Steuern vororganschaftlicher Zeiträume, wenn diese in der "Organschaftszeit" fällig werden.

Bsp.: M-GmbH und T-GmbH haben beide ein Wirtschaftsjahr 1.7.-30.6. Zum 1.7.2010 wird eine Organschaft i. S. d. § $14 \mathrm{KStG}$ begründet.

T-GmbH haftet erstmals für KSt/GewSt des Wirtschaftsjahres 2010/2011, die technisch erst im Veranlagungszeitraum 2011 entsteht. Keine Haftung besteht für Steuern der M-GmbH aus dem VZ 2010, auch wenn diese erst am 31.12.2010 entstehen.

- Die Haftung erfasst nur die eigentlichen Steuern, aber nicht Zinsen oder sonstige Nebenleistungen. ${ }^{151}$

- Die Haftung ist akzessorisch. Wenn beim Steuerschuldner (Organträger) gar keine Steuer anfällt, diese erloschen ist oder wegen Festsetzungsverjährung oder Zahlungsverjährung nicht mehr festgesetzt oder erhoben werden kann, schlägt dies wegen der Akzessorietät auf die Organgesellschaft durch; sie kann dann ebenfalls nicht mehr nach $\S 73 \mathrm{AO}$ in Anspruch genommen werden. Das gilt bei ertragsteuerlicher Organschaft z.B. dann, wenn eine Organgesellschaft zwar Gewinne erzielt hat, im Organkreis aber (wegen höherer Verluste z. B. des Organträgers oder von Schwester-Organgesellschaften) insgesamt kein steuerlicher Gewinn vorliegt.

- Die Haftung ist zudem subsidiär (§219 Abs. 1 AO): grundsätzlich muss erst der Organträger als Steuerschuldner in Anspruch genommen werden. Eine Ausnahme besteht dann, wenn von vornherein die Wahrscheinlichkeit besteht, dass eine Vollstreckung beim Organträger aussichtslos ist.

$\S 73 \mathrm{AO}$ findet seine Rechtfertigung darin, dass Steuerschuldner bei einer Organschaft nur der Organträger ist; die von ihm zu zahlende Steuer erfasst auch die Beträge, die ohne diese Organschaft von der Organgesellschaft geschuldet worden wären, also z. B. bei ertragsteuerlicher Organschaft Ertragsteuern auf Gewinne der Organgesellschaft. Die Organschaft bewirkt aus steuerlicher Sicht ein Auseinanderfallen formeller Steuerschuld (beim Organträger) und materieller Steuerverursachung und eine

151 BFH v. 5.10.2004 - VII R 76/03, BStB1. II 2006, 3. 
Verteilung auf zwei zivilrechtlich selbständige Subjekte. Die Finanzverwaltung kann mittels Steuerbescheid nur auf den Organträger als Steuerschuldner zugreifen. Erst durch den Haftungsbescheid ist $u$. U. eine Vollstreckung in das Vermögen der Organgesellschaft als möglicher Steuerverursacherin möglich.

\section{Begrenzung der Haftung auf Verursachungsbeitrag der Organgesellschaft?}

Nicht abschließend geklärt ist bisher insbesondere, ob die Haftung der Organgesellschaft auf den Teil der Steuern des Organträgers beschränkt ist, der durch sie bzw. ihren Betrieb verursacht wurden. Im Ergebnis dürfte weitgehend Einigkeit bestehen, dass eine Eingrenzung erfolgen muss bzw. kann. Zum Teil wird vertreten, dass bereits auf der Tatbestandsseite der $§ 73 \mathrm{AO}$ einschränkend auszulegen ist, dass die Organgesellschaft stets nur für Steuern aus ihrem Verursachungsbereich haftet. ${ }^{152}$ Die (bisher) h. M. lässt jedoch auf Tatbestandsseite noch keine Einschränkung zu, hält diese aber jedenfalls auf der Rechtsfolgenseite im Rahmen der Ermessensausübung grundsätzlich für möglich: ${ }^{153}$

Nach dem Wortlaut des § 191 Abs. 1 S. 1 AO „kann" die Haftung durch Haftungsbescheid geltend gemacht werden. Der Erlass des Haftungsbescheids steht mithin im Ermessen der Finanzverwaltung, welches sie gemäß $§ 5 \mathrm{AO}$ entsprechend dem Zweck der Ermächtigung auszuüben und dabei die gesetzlichen Ermessensgrenzen einzuhalten hat. Das Verhalten der Finanzverwaltung ist rechtswidrig, wenn Ermessensfehler vorliegen, weil die Finanzverwaltung das ihr eingeräumte Ermessen nicht ausschöpft (Ermessensunterschreitung) oder sachfremd ausübt (Ermessensfehlgebrauch), oder sie die Grenzen des eingeräumten Ermessens überschreitet (Ermessensüberschreitung). Ein solcher Fehler kann insbesondere vorliegen, wenn der Ermessensspielraum so weit reduziert ist, dass nur eine Entscheidung richtig ist und dem Grundsatz der Verhältnismäßigkeit entspricht (sog. Ermessensreduzierung auf Null) ${ }^{154}$ und die Finanzverwaltung diese Entscheidung nicht trifft.

Vor diesem Hintergrund ist von einer Inanspruchnahme der Organgesellschaft als Haftungsschuldnerin bei einer Ermessensreduzierung aufgrund des sog. Verursachungsprinzips (als u. E. spezielle Ausprägung des Ver-

152 In diesem Sinne (teleologische Reduktion auf Tatbestandsseite) z. B. Reiß, StuW 1979, 343, 345; Probst, BB 1978, 1992, 1994; jüngst auch Lüdicke, Festschrift Herzig, S. 259, 263 ff. Explizit offengelassen z. B. von FG Nürnberg v. 11.12.1990 - II 238/86, EFG 1991, 437.

153 BR-Drs. 23/71; Loose in Tipke/Kruse, AO, § 73 Rz. 6 ff. m. w. N.; Breter, AOStB 2003, 342, 344.

154 Ausführlich dazu Schwarz, FGO, § 102 Rz. 2 f. und 5 f. 
hältnismäßigkeitsprinzips) abzusehen, wenn bzw. soweit die Steuer wirtschaftlich nicht durch ihren Betrieb veranlasst worden ist. ${ }^{155}$ Dabei wird vielfach vertreten, dass der Nachweis der Nichtverursachung durch den Betrieb der Organgesellschaft von dieser zu führen sei, d. h. die Finanzverwaltung also ihrerseits nicht den „Verursachungsnachweis" führen müsse. ${ }^{156}$ Die Organgesellschaft muss also mit Hilfe geeigneter Berechnungen und Unterlagen nachweisen, dass die in Rede stehenden Steuern nicht durch ihren Betrieb, sondern denjenigen der Organträgerin oder einer anderen Organgesellschaft angefallen sind; bei entsprechender ordnungsgemäßer Buchführung sollte dies i. d. R. möglich sein. ${ }^{157}$

Allerdings werden jedoch für Sonderkonstellationen wiederum Ausnahmen aufgestellt, in denen gleichwohl eine Inanspruchnahme zulässig sein soll. Das wird für folgende Konstellationen vertreten:

\section{- Erhebliche Vermögensverschiebungen auf die Organgesellschaft}

Es haben Vermögensverschiebungen stattgefunden, durch die erhebliche Vermögenswerte vom Organträger auf die Organgesellschaft übertragen wurden, so dass eine Beschränkung der Haftung der Organgesellschaft auf ihren Steueranteil in einem Missverhältnis zu den übertragenen Vermögenswerten stünde. ${ }^{158}$ Letztlich liegt dieser Fallkonstellation der Gedanke zugrunde, dass durch derartige Vermögensverschiebungen das Vermögen des Steuerschuldners Organträger ausgehöhlt wird, was die Realisierung der Steuerschuld erschwert oder verhindert. Dieser Gedanke ist aber nur bedingt zutreffend, denn aus Sicht des Organträgers dürfte i. d. R. (jedenfalls, sofern er alle Anteile an der Organgesellschaft hält) nur ein „wirtschaftlicher Aktivtausch" vorliegen, da durch eine Vermögensübertragung ohne gleichwertige

155 In diesem Sinne insbesondere einige Gerichtsentscheidungen., vgl. BFH v. 8.9.1983 - VR 114/78, UR 1983, 222, 223 (der u. E. inzident diese Frage bejaht); FG Baden-Württemberg v. 30.4.1985 - I 174/81, EFG 1985, 533; FG Nürnberg v. 11.12.1990 - II 238/86, EFG 1991, 473 ff.; offengelassen von FG Saarland v. 19.3.2002 - 2 K 206/98, Der Konzern 2003, 74. In der Literatur finden sich ebenfalls zahlreiche Ansätze zu einer Haftungsbegrenzung auf Ermessensebene mit unterschiedlichen Begründungen: Loose in Tipke/Kruse, AO, §73 Rz. 6 und 9; Schwarz in Schwarz, AO, §73 Rn.9; Breuer, AOStB 2003, 342 ff. (Haftungsbegrenzung nach Sinn und Zweck); jüngst insbesondere Mayer, DStR 2011, 109, sowie Lüdicke, Festschrift Herzig, S. 259 ff.

156 So z. B. Schwarz in Schwarz, AO, §73 Rz. 9; Boeker in Hübschmann/Hepp/ Spitaler, AO, §73 Rz. 22 f.; Intemann in Pahlke/König, AO, 2. Aufl. §73 Rz. 18.

157 Ebenso Mayer, DStR 2011, 109.

158 In diesem Sinne u. a. die Entscheidungen der Instanzgerichte FG Baden-Württemberg v. 30.4.1985 - I 174/81, EFG 1985, 533; FG Nürnberg v. 11.12.1990 II 238/86, EFG 1991, 473 ff.; FG Saarland v. 19.3.2002 - 2 K 206/98, Der Konzern $2003,74,76$. 
Gegenleistung (nur solche können überhaupt als Vermögensverschiebung in diesem Sinne gemeint sein) zugleich der Wert der Beteiligung an der Organgesellschaft gestärkt wird. In die Beteiligung als Wirtschaftsgut im Eigentum des Organträgers kann die Finanzverwaltung aber ohnehin bereits vollstrecken. Zudem sind, worauf Lüdicke zu Recht hinweist, ${ }^{159}$ derartige Vermögensverschiebungen auch außerhalb von Organschaftsverhältnissen ohne Weiteres möglich - auch in diesen Fällen kann die Finanzverwaltung i.d. R. nur in den Anteil an der Tochtergesellschaft vollstrecken, nicht aber in deren Vermögen. Anknüpfend an die u.E. vorliegende Ratio dieser Ausnahme, missbräuchliche Konstellationen der "Entreicherung“ des Organträgers zu erfassen, wird diese Fallgruppe in der jüngeren Literatur abgelehnt, wenn Vermögen durch typische gesellschaftsrechtliche Umstrukturierungen (wie z. B. eine Ausgliederung) auf die Organschaft übertragen wird $^{160}$

\section{- Besondere wirtschaftliche oder steuerliche Vorteile für die Organge- sellschaft}

Eine weitere Ausnahme von der Haftungsbegrenzung der Organgesellschaft wird in Teilen der Literatur (bisher - soweit ersichtlich - aber nicht in der Rechtsprechung) für den Fall argumentiert, in dem die Organgesellschaft durch die Organschaft besondere steuerliche oder wirtschaftliche Vorteile gezogen hat. Besondere Bedeutung könnte diese Fallgruppe (sofern sie denn zu Recht die Begrenzung der Inanspruchnahme wieder einschränkt) haben hinsichtlich der Folgen, die sich bei einer ertragsteuerlichen Organschaft aufgrund des GAV ergeben. Erzielt die Organgesellschaft einen Gewinn, ${ }^{161}$ hat sie auf den ersten Blick durch die Organschaft einen steuerlichen Vorteil, denn sie muss keine Steuern zahlen; das obliegt dem Organträger. Gleichwohl sollte dies nicht zur Haftungsinanspruchnahme führen, denn per saldo hat die Organschaft insofern keinen Vorteil für die Organgesellschaft sie spart zwar die Steuer, muss aber den typischerweise viel höheren Gewinn an den Organträger abführen; der Vorteil liegt also bei vollzogener Gewinnabführung vielmehr beim Organträger. Bedeutender ist deshalb die Frage, was im Verlustfall gilt, sofern der Organträger die Verlustausgleichsverpflichtung tatsächlich aus eigenem Vermögen erfüllt hat. Steuerlich hat die Organgesellschaft in diesem Fall keinen Vorteil: sie hätte auch ohne Organschaft keine Steuern bezahlt; durch die Zurechnung ihrer Verluste an den Organträger sinkt sogar dessen

159 Lüdicke, Festschrift Herzig, S. 259, 273 f.

160 Mayer, DStR 2011, 109, unter 2.1.

161 Auf Unterschiede zwischen dem abzuführenden handelsrechtlichen Jahresüberschuss und dem steuerlich zuzurechnenden Einkommen wird hier nicht eingegangen. 
Steuerbelastung, während die Organgesellschaft das mögliche "tax asset" Verlustvortrag nicht aufbauen kann. Ein (nicht-steuerlicher) Vorteil kann daher nur in der tatsächlichen Leistung des Verlustausgleichs liegen. ${ }^{162}$ Dieser wird aber aus gesellschaftsrechtlichen Gründen von $\S 302$ AktG gefordert; das Begründen der Haftung mit diesem Anspruch wird daher $z$.T. als widersprüchlich angesehen; ${ }^{163}$ möglicherweise wird man eine Haftungsinanspruchnahme sogar als gesellschaftsrechtlich unzulässig ansehen können, weil damit faktisch der Organgesellschaft der geleistete Verlustausgleich wieder entzogen würde.

Letztlich sind viele Fragen in diesem Bereich noch ungeklärt, obwohl sie für die Praxis von erheblicher Bedeutung sind. Der weiteren Rechtsentwicklung ist daher mit Spannung entgegen zu sehen.

162 Darauf stützen z. B. Breuer, AO-StB 2003, 342, 345, und Loose in Tipke/Kruse, AO, § 73 Rz. 8. eine zulässige Haftungsinanspruchnahme der Organgesellschaft.

163 Mayer, DStR 2011, 109, unter 2.2. 

7. Leitthema:

Steuerstrafrecht und Kapitaleinkünfte 



\title{
Aktuelles Steuerstrafrecht einschließlich internationaler Finanzanlagen
}

\author{
Alexandra Mack \\ Rechtsanwältin, Fachanwältin für Steuerrecht, Köln
}

Inhaltsübersicht

A. Selbstanzeigeberatung in Zeiten des Datendiebstahls

I. Der Wind wird rauer; Verschärfende BGH-Rechtsprechung zur Teilselbstanzeige und zum Strafmaß; Ende der Selbstanzeige zum 31.12.2010?

1. Verschärfende BGH-Rechtsprechung zur Teilselbstanzeige: Der Beschluss des BGH vom 20.5.2010

2. Verschärfende Rechtsprechung zum Strafmaß bei der Steuerhinterziehung: Der Beschluss des BGH vom 2.12.2008

3. Ende der Selbstanzeige mit dem 31.12.2010? Abschaffung des $\S 371 \mathrm{AO}$ ?

II. Die richtige Selbstanzeige: Inhalt, Zeitrahmen, Form

1. Voraussetzungen und Folgen der Selbstanzeige
2. Adressat und Inhalt der Selbstanzeige

B. Selbstanzeige - und was dann? Beratererfahrungen und Handlungsalternativen für laufende Selbstanzeigeverfahren

I. Einleitung eines Steuerstrafverfahrens

II. Konkretisierungen nach Abgabe der Selbstanzeige

III. Nachzahlung der hinterzogenen Steuern

C. Anlageberatung als Beihilfe zur Steuerhinterziehung?

I. Die sichere Anlage

II. Entdeckungsgefahren

III. Haftungsgefahr, $\S 71$ AO

D. Wenn die Steuerfahndung kommt. Grundsätzliche Verhaltensmaximen für Mandant und Berater

\section{A. Selbstanzeigeberatung in Zeiten des Datendiebstahls}

\section{Der Wind wird rauer; Verschärfende BGH-Rechtsprechung zur Teilselbstanzeige und zum Strafmaß; Ende der Selbstanzeige zum 31.12.2010?}

1. Verschärfende BGH-Rechtsprechung zur Teilselbstanzeige: Der Beschluss des BGH vom 20.5.2010

a) Mit seinem Beschluss vom 20.5.2010 (1 StR 577/09; DStR 2010, $1133 \mathrm{ff}$.) hat der BGH seine bis dahin geltende Rechtsprechung zur sogenannten Teilselbstanzeige aufgegeben. Die Selbstanzeige soll nur dann zur Straffreiheit führen, wenn vollständig „reiner Tisch“ gemacht worden 
ist. Negativ: Keine Straffreiheit, wenn nur ein Teil der hinterzogenen Steuern nacherklärt wurde.

b) Gemäß § 371 Abs. 1 AO gilt: „Wer in den Fällen des § 370 AO unrichtige oder unvollständige Angaben bei der Finanzbehörde berichtigt oder ergänzt oder unterlassene Angaben nachholt, wird insoweit straffrei."

Nach überwiegender Ansicht in der Literatur tritt bei teilweiser Berichtigung entsprechende teilweise Straffreiheit ein; erklärt der Anzeigeerstatter zu wenig, lässt dies die Wirksamkeit der Selbstanzeige bezüglich der erklärten Beträge unberührt. Die Selbstanzeige ist als sogenannte Teilselbstanzeige wirksam (vgl. Jäger in Klein, AO, 10. Aufl., 2009, § 371 Rz. 2). Dies wird zutreffend insbesondere aus dem Wort „insoweit" im Wortlaut des $\S 370$ Abs. 1 AO geschlussfolgert.

c) In der Vergangenheit hatte der 5. Strafsenat des BGH auch ausdrücklich eine Teilselbstanzeige als strafbefreiende Nacherklärung anerkannt, "insoweit", wie sie die notwendigen Angaben enthielt (vgl. BGH v. 13.10.1998 - 5 StR 392/98, wistra 1999, 27 (28)). Der Strafsenat begründete dies ebenfalls mit dem im Wortlaut der Vorschrift verwendeten Begriff „insoweit" sowie mit Sinn und Zweck der Selbstanzeigevorschrift.

d) Von diesem Ansatzpunkt ist der 1. Strafsenat des BGH jetzt abgewichen.

Im Beschluss vom 20.5.2010 heißt es:

„Der Senat hält eine Teilselbstanzeige für nicht ausreichend, um die Strafbefreiung zu erlangen. ... Soweit in der Rechtsprechung des BGH bislang eine solche Teilselbstanzeige als wirksam angesehen worden ist, ... hält der Senat daran nicht fest."

Die vom BGH angeführte Begründung fußt insbesondere auf rechtspolitischen Gesichtspunkten. Allein fiskalisches Interesse an der Entrichtung hinterzogener Steuern sei nicht geeignet, die Privilegierung der Straffreiheit im Falle der Selbstanzeige zu rechtfertigen. Hinzukommen müsse die „vollständige Rückkehr zur Steuerehrlichkeit", so die Entscheidung ausdrücklich. Diese sei nur dann gegeben, wenn der Täter nunmehr vollständige und richtige Angaben, mithin „reinen Tisch" mache. Schließlich stelle, so der BGH, die Strafbefreiung nach §371 AO eine Ausnahmevorschrift dar, die - insbesondere angesichts des Verzichts auf den staatlichen Strafanspruch - restriktiv auszulegen sei.

Dieses Verständnis, gegensätzlich zum Beschluss des 5. Strafsenats vom 13.10.1998 (siehe oben), begründet der 1. Strafsenat mit zwei Ansätzen: Zum einen habe der fiskalische Zweck der Selbstanzeige, noch unbekannte Steuerquellen zu erschließen, angesichts der heute bestehenden Ermittlungsmöglichkeiten und der verbesserten internationalen Zusammenarbeit zunehmend an Bedeutung verloren. Damit habe der zweite 
Zweck der Selbstanzeige, die Belohnung zur Rückkehr der Steuerehrlichkeit, zusätzlich an Gewicht gewonnen. Außerdem solle der Wortlaut und damit die Verwendung des Worts „insoweit" im Text des §371 Abs. 1 AO lediglich ausdrücken, dass der Steuerhinterzieher durch seine Nacherklärung keine Strafbefreiung für Nicht-Steuerstraftaten erlangen könne, die mit der begangenen Steuerhinterziehung zusammenhängen.

Weitergehende Ausführungen und Konkretisierungen der neuen Rechtssätze enthält der Beschluss vom 20.5.2010 nicht.

e) Die Entscheidung des BGH vom 20.5.2010 ist $\mathrm{mE} z u$ Recht auf viel negative Kritik gestoßen (vgl. zB Salditt, PStR 2010, 168 (173); Weidemann, PStR 2010, 175; Wulf, wistra 2010, 286 ff.).

Der Wortlaut des $\S 371$ Abs. $1 \mathrm{AO}$ ist seit 1977 unverändert geblieben. Ebenso (natürlich) die Motive. Die vom BGH ins Feld geführten geänderten Ermittlungsmöglichkeiten oder eine verbesserte internationale Zusammenarbeit haben hierauf keinen Einfluss. Auch die Neuinterpretation des Worts „insoweit" ist alles andere als zwingend. Der unvoreingenommene Leser der Vorschrift wird das Wort „insoweit" auf den Umfang der korrigierten Angaben und nicht auf die Reichweite der außersteuerlichen Rechtsfolgen beziehen.

Schwer wiegt außerdem: Die Entscheidung hat zu großer Rechtsunsicherheit geführt. Die Ausführungen sind unscharf und lassen eine Vielzahl von Fragen sowohl materiell-rechtlicher als auch verfahrensrechtlicher Art offen.

Die Finanzverwaltung steht bezeichnenderweise keineswegs einmütig hinter der Kehrtwende des BGH. In der Presse (vgl. zB FAZ vom 11.8.2010) werden Stimmen aus der Steuerfahndung zitiert, die offen kritisieren, der Gerichtsbeschluss diene nur „vermeintlich" der Klarstellung. Tatsächlich ändere er ein gefestigtes Regelwerk, auf das sich alle Beteiligten - Steuerpflichtige, Berater und die Ermittlungsbehörden - in der Vergangenheit gut eingestellt haben. Auf die ohnehin überlasteten Behörden komme nur weitere Arbeit zu. Strafprozessual möge die Entscheidung wegweisend sein, fiskalische Aspekte der Selbstanzeige habe der Bundesgerichtshof jedoch geopfert.

f) Es bleibt abzuwarten, welche Konsequenzen die Praxis aus der neuen Entscheidung zieht (zu möglichen Problembereichen vgl. Kanz, DB 2010, $1488,1490 \mathrm{ff}$. .).

Bisher sind die Reaktionen unterschiedlich: Angesichts der bestehenden Unsicherheiten nehmen Straf- und Bußgeldsachenstellen aktuell die Entscheidung bereits zum Anlass, in Selbstanzeigeverfahren größere Strenge an den Tag zu legen und die neuen BGH-Maximen als Drohkulissen ins Feld zu führen. 
Es bleibt abzuwarten, auf welche einheitliche Linie die Finanzverwaltung sich festlegen wird.

\section{Verschärfende Rechtsprechung zum Strafmaß bei der Steuerhinterziehung: Der Beschluss des BGH vom 2.12.2008}

a) Gemäß $\S 370$ Abs. 1 AO wird die Steuerhinterziehung mit Freiheitsstrafe bis zu fünf Jahren oder mit Geldstrafe bestraft.

Die Strafe kann höher sein, wenn ein „besonders schwerer Fall“ vorliegt. Die Freiheitsstrafe kann dann bis zu zehn Jahre betragen. Die Mindestfreiheitsstrafe beträgt sechs Monate. Wann ein besonders schwerer Fall vorliegt, definiert $\S 370$ Abs. 3 AO. Gemäß $\S 370$ Abs. 3 Satz 2 Nr. 1 AO liegt ein besonders schwerer Fall immer dann vor, wenn Steuern „in großem Ausmaß" verkürzt werden.

Wann eine Steuerhinterziehung „in großem Ausmaß“ verkürzt ist, definiert das Gesetz nicht weiter. Nach bisheriger Rechtsprechung war hier eine "Gesamtbetrachtung" erforderlich, es war kein Grenzbetrag festgeschrieben.

b) Hier setzt die Entscheidung des 1. Senats des BGH vom 2.12.2008 (BGH v. 2.12.2008 - 1 StR 416/08, BGHSt 53, 71 ff.) an. Es werden erstmals "Stufen" festgelegt:

- Eine Steuerhinterziehung „in großem Ausmaß“ im Sinne des Regelbeispiels des $\S 370$ Abs. 3 Satz Nr. 1 AO ist danach anzunehmen, wenn der Steuerschaden im Einzelfall mehr als 50.000,- Euro beträgt.

- Jedenfalls bei einem Schaden ab 100.000,- Euro kommt die Verhängung einer Geldstrafe nur bei Vorliegen von gewichtigen Milderungsgründen in Betracht.

- Bei einem Steuerschaden ab 1 Mio. Euro kommt eine aussetzungsfähige Freiheitsstrafe nur bei Vorliegen von besonders gewichtigen Milderungsgründen noch in Betracht. Dies bedeutet gleichzeitig, dass diese Fälle für eine Erledigung im Strafbefehlsverfahren regelmäßig nicht geeignet sind.

Bis 50.000,- Euro ist danach unverändert eine Einstellung (§ 153a StPO) oder Geldstrafe denkbar.

Bei einem Schaden zwischen 50.000,- und 100.000,- Euro kommt es auf die Art der Tatbegehung an. Jedenfalls bei bloßem Unterlassen bleiben Einstellung ( $§ 153 \mathrm{a}$ StPO) und Geldstrafe denkbar. Anders bei betrugsähnlichem Geschehen.

Ab 100.000,- Euro muss regelmäßig eine Freiheitsstrafe (gegebenenfalls auf Bewährung) verhängt werden, soweit nicht besondere Strafmilderungsgründe greifen. 
$\mathrm{Ab} 1$ Mio. Euro kommt eine aussetzungsfähige Freiheitsstrafe nur bei Vorliegen von besonders gewichtigen Milderungsgründen noch in Betracht.

c) In der Presse ist die Entscheidung des BGH vom 2.12.2008 teilweise so kommentiert worden, dass der Eindruck entstand, es gäbe jetzt auch im Steuerstrafrecht so etwas wie einen „Bußgeldkatalog “, also starre Grenzen.

Tatsächlich ist dies eindeutig nicht der Fall. Auch wenn jetzt erstmals konkrete Grenzen vorgegeben werden, kommt es für die Strafzumessung bei der Steuerhinterziehung auf den Einzelfall an, es gelten die Grundsätze der Strafzumessung gem. § 46 StGB. Dh.: Die Höhe des Steuerschadens ist ein bestimmender, aber keineswegs der einzig ausschlaggebende Strafzumessungsumstand.

Wichtig ist außerdem: Die genannten Grenzbeträge von 50.000,- Euro, 100.000,-Euro und 1 Mio. Euro sind nicht die Steuermehrbeträge, die sich für den gesamten Strafzeitraum ergeben, sondern abzustellen ist auf die jeweilige Tat. Die Tat definiert sich durch Veranlagungszeitraum und Steuerart. Es gilt also, jeweils bezogen auf eine konkrete Tat (beispielsweise Einkommensteuer 2006) zu prüfen, ob die Grenzbeträge überschritten sind.

Schon dadurch relativieren sich die Grenzbeträge im Streitfall ganz erheblich, dh. ist auch bei relativ hohen Summen nicht zwingend die Grenze zur schweren Steuerhinterziehung überschritten.

\section{Ende der Selbstanzeige mit dem 31.12.2010? Abschaffung des $§ 371 \mathrm{AO}$ ?}

a) Nicht zuletzt aufgrund der Vielzahl von Selbstanzeigen, ausgelöst durch gestohlene Bankdaten und den Ankauf entsprechender Daten-CDs, sind die Selbstanzeige und ihre Berechtigung aktuell in die öffentliche Diskussion geraten.

Nachdem die SPD den Stein ins Rollen gebracht und vorgeschlagen hatte, die Selbstanzeige ganz abzuschaffen (vgl. BT-Drs. 17/1411), folgten Vorschläge, die bisherigen Selbstanzeigeregelungen zumindest einzuschränken (vgl. zB Antrag der Fraktion der CDU/CSU und FDP, BT-Drs. 17/1755 v. 19.5.2010).

b) Aktueller Stand am 29.9.2010 (Tag des Vortrags): In seinem Beschluss zum Entwurf eines Jahressteuergesetzes 2010 vom 9.7.2010 (BRDrucks. 318/1/10, 79 ff.) schlägt der Bundesrat nachhaltige Verschärfungen der $\S \S 371,378$ Abs. 3 AO vor. Danach besteht die Selbstanzeige zwar weiter, wird also nicht zum Jahresende 2010 abgeschafft, es soll aber wesentliche Beschränkungen geben. Insbesondere sollen die bisherigen Sperrgründe zu Lasten des Steuerhinterziehers ausgeweitet werden. 
Es geht im Wesentlichen um folgende Einzeländerungen:

- Ausschluss der Teilselbstanzeige. Hier knüpft der Entwurf an die BGHEntscheidung vom 20.5.2010 (siehe oben) an. Wirksam soll nur die vollständige Selbstanzeige sein.

- Keine weitere Berichtigungsmöglichkeit mehr nach bereits erfolgter Selbstanzeige. Diese Regelung rundet den Ausschluss der Teilselbstanzeige ab.

- Erweitert werden soll die Sperrwirkung bei Betriebsprüfungen: Nicht erst das Erscheinen des Prüfers soll die Selbstanzeige sperren, sondern bereits die "Absendung einer Prüfungsanordnung".

- Bereits bisher sperrte die Einleitung eines Straf- oder Bußgeldverfahrens die Selbstanzeige. Allerdings nur, wenn die Einleitung dem Täter oder seinem Vertreter bekanntgegeben worden war. Dieser subjektive Aspekt soll entfallen.

- Auch beim bisherigen Sperrgrund des $\S 371$ Abs. 2 Nr. 2 AO, Tatentdeckung, soll das subjektive Element entfallen. Für den Eintritt der Sperrwirkung soll es genügen, dass „die Tat ganz oder zum Teil bereits entdeckt war".

- Neu aufgenommen werden soll ins Recht der Selbstanzeige ein sogenannter "Selbstanzeige-Zuschlag". Er soll $5 \%$ des Hinterziehungsbetrags betragen. Dieser Zuschlag würde zusätzlich zu den Hinterziehungszinsen gem. § $235 \mathrm{AO}$ (6\% pa.) anfallen.

- Schließlich sieht der Vorschlag des Bundesrats vor, die sogenannte strafbefreiende Selbstanzeige gem. §371 Abs. 4 AO abzuschaffen.

$\mathrm{Ob}$ und inwieweit diese Vorschläge im Gesetzgebungsverfahren umgesetzt werden, bleibt abzuwarten (aktuellster Stand am 25.2.2011: Gesetzentwurf der Fraktionen der CDU/CSU und FDP „Entwurf eines Gesetzes zur Verbesserung der Bekämpfung von Geldwäsche und Steuerhinterziehung (Schwarzgeldbekämpfungsgesetz) - BT-Drs. 17/4182 v. 14.12.2010).

\section{Die richtige Selbstanzeige: Inhalt, Zeitrahmen, Form}

\section{Voraussetzungen und Folgen der Selbstanzeige}

Voraussetzungen und Folgen der Selbstanzeige sind in $\S 371$ AO geregelt. Die Selbstanzeige kann viel leisten. Sie ist allerdings kein Allheilmittel. Die Selbstanzeige führt ausschließlich dazu, dass eine Bestrafung wegen Steuerhinterziehung entfällt. Sind andere Straftaten begangen, bleiben diese unberührt. Das Gleiche gilt insbesondere für disziplinarische Maß- 
nahmen. Die hinterzogenen Steuern sind nachzubezahlen. Hinzu treten $6 \%$ Hinterziehungszinsen.

\section{Adressat und Inhalt der Selbstanzeige}

Die Selbstanzeige ist abzugeben beim Finanzamt. Steuerlich handelt es sich um eine reine Nacherklärung. Der Begriff "Selbstanzeige" muss nicht verwendet werden. Es müssen auch nicht subjektive Hintergründe für die begangene Hinterziehung erklärt werden.

Die Selbstanzeige muss sich auf den Zeitraum beziehen, der steuerstrafrechtlich noch nicht verjährt ist. Allerdings: Der Steuerpflichtige, der eine Selbstanzeige abgibt, muss wissen, dass sich die Zahlungspflicht für die Wirksamkeit der Selbstanzeige zwar nur auf den Zeitraum bezieht, der steuerstrafrechtlich noch nicht verjährt ist. De facto wird die Selbstanzeige jedoch teurer: Es wird regelmäßig über den strafrechtsrelevanten Bereich hinaus ermittelt werden bis zur steuerlichen Zehn-Jahres-Grenze.

Die Selbstanzeige ist so genau zu formulieren, dass das Finanzamt auf ihrer Basis Steuerbescheide erlassen kann. Ist dies - insbesondere weil noch keine Bankunterlagen vorliegen - zunächst nicht möglich, die Selbstanzeige aber dringend, empfiehlt es sich, die sogenannte "Selbstanzeige in Stufen" abzugeben: Dem Finanzamt werden konkrete, aber geschätzte Zahlen mitgeteilt. Es können sodann die konkreten Zahlen nachgereicht werden, wenn die Bankunterlagen vorliegen.

Es empfiehlt sich, bei diesen Schätzungen eher zu hoch als zu niedrig zu gehen. Die Zahlen können wieder "abgeschmolzen" werden. Sind dagegen die geschätzten Zahlen zu niedrig, kann dies später problematisch sein.

In der Praxis werden "Selbstanzeigen" hin und wieder so abgegeben, dass der Steuerpflichtige oder sein Berater zunächst lediglich eine Selbstanzeige ankündigen. Die Zahlen werde man nachliefern.

Von derartigen "Selbstanzeigen" ist dringend abzuraten: Die bloße Ankündigung der Selbstanzeige ist keine Selbstanzeige.

In der Praxis ist allerdings zu beobachten, dass Straf- und Bußgeldsachenstellen häufig „gnädig" mit derartigen Erklärungen umgehen. Werden tatsächlich die Zahlen nachgeliefert und werden die Steuern gezahlt, wird die Nacherklärung behandelt wie eine wirksame Selbstanzeige. Dies ist allerdings reine Pragmatik der Finanzverwaltung.

Vor dem Hintergrund des BGH-Beschlusses vom 20.5.2010 (siehe oben) ist es für die Beratung dringend notwendig, den selbstanzeigebereiten Mandanten darauf hinzuweisen, dass die Selbstanzeige vollständig sein muss. Es kann nicht darauf gebaut werden, dass die Finanzverwaltung spätere „Nachbesserungen“ zwingend noch akzeptiert. 


\section{B. Selbstanzeige - und was dann? \\ Beratererfahrungen und Handlungsalternativen für laufende Selbstanzeigeverfahren}

\section{Einleitung eines Steuerstrafverfahrens}

Wird eine Selbstanzeige - beim Finanzamt - abgegeben, wird den Steuerpflichtigen als Nächstes die Mitteilung der Straf- und Bußgeldsachenstelle erreichen, es sei ein Steuerstrafverfahren eingeleitet.

Dies ist erforderlich und korrekt: Die Einleitung des Ermittlungsverfahrens ist erforderlich, um die Wirksamkeit und Vollständigkeit der Selbstanzeige zu überprüfen.

"Nette" Einleitungsverfügungen weisen ausdrücklich auf den reinen Überprüfungscharakter des Strafverfahrens hin. Notwendig ist das nicht. Es empfiehlt sich daher in jedem Fall, den Mandanten, für den die Selbstanzeige abgegeben wird, darauf hinzuweisen, dass automatisch ein Steuerstrafverfahren gegen ihn eingeleitet werden wird.

In dem Einleitungsschreiben wird umschrieben, auf welche Jahre sich das Steuerstrafverfahren bezieht. Meist wird die Straf- und Bußgeldsachenstelle darüber hinaus darauf hinweisen, man werde steuerlich den gesamten Zehn-Jahres-Zeitraum ebenfalls nachprüfen.

\section{Konkretisierungen nach Abgabe der Selbstanzeige}

Darüber hinaus stellen die Straf- und Bußgeldsachenstellen nach Erhalt von Selbstanzeigen regelmäßig weitere Fragen bzw. schreiben zu Vorstellungen zum Fortgang des Verfahrens.

Die Forderungen und Vorstellungen über die weiteren Abläufe sind von Finanzamt zu Finanzamt bzw. je nach Straf- und Bußgeldsachenstelle unterschiedlich.

Geht es um bisher unerklärte Kapitalerträge aus dem Ausland, ist „Mindestanforderung", dass für die gesamten Zeiträume Erträgnisaufstellungen und Vermögensübersichten (jeweils zum 31.12.) vorgelegt werden.

Darüber hinaus gibt es Straf- und Bußgeldsachenstellen, die noch weiter gehen. Man fordert Auswertungen der Bankunterlagen an, die in Steuererklärungsform vorgelegt werden. Man benötige Vollständigkeitserklärungen der Banken, Aussagen zur Mittelherkunft und anderes mehr. Schließlich gibt es Straf- und Bußgeldsachenstellen, die vom selbstanzeigenden Steuerpflichtigen das "Bekenntnis" verlangen, man habe mit Sicherheit keine weiteren bisher nicht erklärten Konten und Erträge. Wie mit diesen Anforderungen umgegangen wird, ist Einzelfallentscheidung. 
Die Wirksamkeit der Selbstanzeige hängt von der Mitarbeit im Folgeverfahren nicht ab: Sind die Nacherklärungen vollständig und korrekt, ist die Selbstanzeige wirksam.

In den meisten Praxisfällen liegt dem Steuerpflichtigen allerdings nichts an Auseinandersetzungen um Forderungen der Finanzverwaltung, möchte er das Verfahren so schnell wie möglich beendet wissen.

Sind - insbesondere für die Altjahre vor dem Veranlagungsjahr 2000 Bankunterlagen von den Banken nicht mehr zu erhalten, kann dies den Straf- und Bußgeldsachenstellen mitgeteilt werden. Es wird dann regelmäßig geschätzt.

\section{Nachzahlung der hinterzogenen Steuern}

Zur Wirksamkeit der Selbstanzeige gehört, dass die hinterzogenen Steuern bezahlt werden.

Die Praxis ist hier sehr unterschiedlich: Eine ausdrückliche strafrechtliche Frist wird in den seltensten Fällen gesetzt.

Meist wertet zunächst die Straf- und Bußgeldsachenstelle die Daten und Zahlen aus. Es wird dann ein Bericht erstellt und die Finanzämter erlassen die entsprechenden Auswertungsbescheide. Das kann Monate dauern.

Es gibt daher Finanzämter, die bereits kurz nach der Selbstanzeige (auch wenn die Zahlen dort geschätzt sind) Steuerbescheide erlassen und darin die in den Selbstanzeigen genannten Zahlen ansetzen.

Für den Steuerpflichtigen hat das den Vorteil, dass die Hinterziehungszinsen, $\S 235 \mathrm{AO}$, aufhören zu laufen.

Die meisten Finanzämter warten jedoch ab, bis im Steuerstrafverfahren die Zahlen endgültig ermittelt sind. Will der Steuerpflichtige hier den Fortlauf der Zinsen stoppen, kann mit dem Finanzamt die Zahlung auf die zu erwartenden Steuern vereinbart werden.

\section{Anlageberatung als Beihilfe zur Steuerhinterziehung? I. Die sichere Anlage}

Die Frage der "sicheren" Finanzanlage im Ausland stellt sich im Hinblick auf steuerliche Beratung heute praktisch nicht mehr. Es gibt keine "sichere" Finanzanlage im Ausland im Sinne einer garantierten Unentdecktheit. 


\section{Entdeckungsgefahren}

Die aktuelle Situation hat gezeigt, dass die Palette der Entdeckungsmöglichkeiten unbegrenzt ist.

Darüber hinaus hat die aktuelle Entwicklung dazu geführt, dass auch vormals "sichere" Länder wie Liechtenstein, Luxemburg und die Schweiz heute Rechts- und Amtshilfe leisten bzw. auf dem Wege dorthin sind.

Schließlich: Hat die Finanzverwaltung Kenntnis - auch nur Teilkenntnis - von Anlagen im Ausland erlangt, stehen ihr zum einen wachsende Ermittlungsmöglichkeiten im Ausland zur Seite. Stattdessen kann aber auch geschätzt werden: Gibt es konkrete Hinweise für nicht erklärte Kapitalanlagen im Ausland und verweigert der Steuerpflichtige die freiwillige - Mithilfe, kann steuerlich geschätzt werden. Dies gilt relativ weit für die sogenannten normalverjährten Zeiträume. Will die Finanzverwaltung allerdings noch weiter zurück, also in steuerlich normalverjährte Zeiträume, muss sie selbst die angenommene Steuerhinterziehung nachweisen. Die Hinterziehung muss „mit an Sicherheit grenzender Wahrscheinlich" feststehen. Diese Hürde ist für die Finanzverwaltung nicht leicht und wird häufig von dort unterschätzt.

\section{Haftungsgefahr, § 71 AO}

Wer einem anderen Hilfe leistet, Steuern zu hinterziehen, ist selbst der Beihilfe schuldig, er macht sich strafbar und kann nach $\S 71$ AO für Steuerschäden haften.

Diese Haftung kann bekanntlich auch Steuerberater treffen. In den Fokus sind aktuell Bankmitarbeiter geraten. Mit einer groß angelegten Aktion versendet zB. die Staatsanwaltschaft Düsseldorf Fragebogen an Kunden der Credit Suisse. Hintergrund sind Ermittlungen gegen Mitarbeiter dieser Bank. Es sollen die Umstände aufgeklärt werden, unter denen Geldanlagen bei der Credit Suisse zustande kamen.

Die Staatsanwaltschaft verschickt diese Fragebogen insbesondere an Steuerpflichtige, die Selbstanzeige abgegeben haben. Diese besitzen im Regelfall ein umfassendes Auskunftsverweigerungsrecht. Die Aussage gegenüber der Staatsanwaltschaft beschränkt sich dann auf die Angaben zur Person und die Geltendmachung des Auskunftsverweigerungsrechts. 


\section{Wenn die Steuerfahndung kommt. Grundsätzliche Verhaltensmaximen für Mandant und Berater}

Hier gelten die allgemeinen Verhaltensmaximen auch in heutiger Zeit fort. Jeder Steuerpflichtige und jeder Berater sollte sich darüber bewusst sein, dass auch vor seiner Tür jederzeit die Steuerfahndung stehen kann. Die Erfolge der Steuerfahndung beruhen häufig auf dem Überraschungseffekt: Unterlagen werden gefunden, die längst nicht mehr hätten aufgehoben werden müssen, Aussagen werden gemacht, wo Schweigen geboten wäre etc.

Erfahrungsgemäß ist es das Hauptziel der Steuerfahndung am Tag der Durchsuchung vom Steuerpflichtigen eine Aussage zu erhalten.

Aussagen im Steuerfahndungsverfahren können durchaus sinnvoll sein. Allerdings: Am Tag der Durchsuchung ist Schweigen das oberste Gebot. Auch wenn der Steuerpflichtige meint, alle Vorwürfe entkräften zu können, ist dies selten der Fall. Außerdem: Am Tag der Durchsuchung gilt das Augenmerk der Steuerfahndung nicht Argumenten, die den Steuerpflichtigen entlasten, sondern man ist auf der Suche nach Belastungsdetails.

Oberstes Gebot für den Tag der Durchsuchung ist daher das Schweigen. 



\title{
Abgeltungsteuer auf Einkünfte aus Kapitalvermögen
}

\author{
Dr. Thomas Arntz \\ Rechtsanwalt, Frankfurt am Main
}

Inhaltsübersicht

\begin{abstract}
I. Grundzüge der Kapitalertragsteuerregelungen

1. Rechtslage bis zum 31.12.2008

2. Rechtslage nach dem 31.12.2008

II. Wirtschaftliche Auswirkungen beim Privatanleger

1. Einflussfaktoren

2. Bedeutung der Portfoliostruktur

III. Persönliche Kapitalertragsteuerpflicht

1. Kapitalertragsteuerpflicht für Steuerinländer

2. Kapitalertragsteuerpflicht für Steuerausländer

IV. Sachliche Kapitalertragsteuerpflicht/Abgeltungswirkung

1. Voraussetzungen zum Kapitalertragsteuerabzug

2. Überblick über Erträge aus Kapitalvermögen und sachliche Kapitalertragsteuerpflicht nach Anlegergruppen
\end{abstract}

3. Abgeltende Wirkung des Kapitalertragsteuerabzugs

V. Abzugspflichtige Kapitalerträge/ Bemessungsgrundlage

1. Abzugsverpflichtete

2. Bemessungsgrundlage für den Kapitalertragsteuerabzug

3. Verbrauchsfolgeverfahren

4. Währungsumrechnung

5. Kapitalerträge im Einzelnen

a) Laufende Zinserträge

b) Optionsanleihen

c) Gewinne aus der Veräußerung, Abtretung und Einlösung von Wertpapieren und sonstigen Kapitalforderungen
d) In- und ausländische Dividen- den
e) Gewinn aus der Veräußerung und Abtretung von Aktien und ähnlichen Beteiligungen
f) Zertifikate
g) Tilgung von Anleihen durch Wertpapierlieferungen
h) Termingeschäfte

6. Kapitalmaßnahmen
a) Übersicht
b) Kapitalmaßnahmen im Einzelnen

VI. Verlustverrechnung durch die Kreditinstitute

1. Notwendigkeit der Verlustverrechnung durch die Kreditinstitute

2. Grundsätze der Verlustverrechnung
a) Erfasster Personenkreis
b) Grenzen der Verlustverrechnung
c) Verlustverrechnungstöpfe und Quellensteuertopf

3. Verlustverrechnung innerhalb eines Kalenderjahres
a) Reihenfolge der Verlustver- rechnung unter Berücksichti- gung von Freistellungsauf- trägen und ausländischer Quellensteuer
b) Beispiele für Verlustverrech- nungen innerhalb eines Kalen- derjahres

4. Verlustvortrag auf Kreditinstitutsebene und Bescheinigung von Verlusten

5. Nicht genutzter Freistellungsauftrag/Quellensteuertopf 
VII. Abstandnahme vom Steuerabzug/Steuererstattung

1. Betragsmäßig begrenzte Freistellung aller Kapitalerträge

2. Betragsmäßig begrenzte/unbegrenzte Freistellung bestimmter Kapitalerträge

3. Betragsmäßig unbegrenzte Freistellung bestimmter Kapitalerträge für Körperschaften und betriebliche Anleger

4. Betragsmäßig unbegrenzte Freistellung bestimmter Kapital- erträge für bestimmte Anlegergruppen

VIII. Steuersatz und Steuerberechnung

1. Formel zur Kapitalertragsteuerermittlung

2. Anrechnung ausländischer Quellensteuer

3. Solidaritätszuschlag und Kirchensteuer

IX. Veranlagungsfälle

1. Überblick

2. Einzelne Veranlagungsfälle

\section{Grundzüge der Kapitalertragsteuerregelungen}

Die folgende Darstellung soll einen einführenden Überblick über die ab dem 1.1.2009 geltenden Regelungen über die Besteuerung der Einkünfte aus Kapitalvermögen geben. Die Steuer wird nunmehr i. d. R. mit abgeltender Wirkung an der Quelle erhoben (Abgeltungsteuer). ${ }^{1}$ Um den Rahmen einer solchen Darstellung nicht zu sprengen, wurde bewusst auf die Darstellung einzelner Teilaspekte verzichtet, so wird u.a. auf die Besteuerung von Erträgen aus Investmentfonds und die Übergangsregelungen nicht oder nur sehr punktuell eingegangen.

Der Begriff „Abgeltungsteuer" verengt den Blick auf einen Teilaspekt der neuen gesetzlichen Regelungen zur Besteuerung von Kapitalerträgen, nämlich auf den der abgeltenden Wirkung der an der Quelle erhobenen Kapitalertragsteuer. Mit den gesetzlichen Neuregelungen gingen aber auch weitere fundamentale Änderungen einher, etwa die der weitgehenden Abschaffung der Unterscheidung zwischen Einkunfts- und Vermögensebene und des Verbots des Werbungskostenabzugs.

\section{Rechtslage bis zum 31.12.2008}

Fundamental für die Besteuerung der Kapitalerträge bis zum 31.12.2008 war, dass i.d.R. zwischen der Einkunfts- und Vermögensebene unterschieden wurde. Der Einkommensteuer unterlagen grundsätzlich nur die Früchte aus der Überlassung von Kapital (§ 20 EStG a. F). ${ }^{2}$ Wertzuwächse

1 Neuregelungen eingeführt durch Unternehmensteuerreformgesetz 2008 v. 14.8.2007, BGBl. I 2007, 1921.

2 Bei Finanzinnovationen sahen die alten gesetzlichen Regelungen jedoch auch eine Besteuerung von Wertzuwächsen am Kapitalstamm in Veräußerungs- und Einlösungsfällen vor. 
am Kapitalstamm und Gewinne aus der Veräußerung von Finanzanlagen (einschließlich z.B. von Aktien, Vollrisikozertifikaten und Derivaten) unterlagen nur dann im Privatbereich der Besteuerung, wenn sie innerhalb der sog. Spekulationsfrist erzielt wurden (§ 23 EStG a. F.).

Folgerichtig wurde unter dem alten System auf Veräußerungs- und Einlösungsgewinne grundsätzlich keine Kapitalertragsteuer einbehalten. ${ }^{3}$

Desweiteren hatte die Kapitalertragsteuer keine abgeltende Wirkung, sondern war eine Vorauszahlung auf die Einkommen- bzw. Körperschaftsteuer. Sie wurde demnach im Rahmen der zwingend zu erfolgenden Veranlagung auf die Einkommen- bzw. Körperschaftsteuer angerechnet.

Der Kapitalertragsteuersatz war nicht einheitlich ausgestaltet. Auf Zinserträge und diesen gleichgestellten Erträge wurde Kapitalertragsteuer in der Form der Zinsabschlagsteuer erhoben, zu einem Satz von i. d. R. $30 \%$ zuzüglich 5,5 \% Solidaritätszuschlag hierauf.

Die Zinsabschlagsteuer war als Zahlstellensteuer ausgestaltet, d. h. zum Einbehalt war die die Kapitalerträge an den Anleger auszahlende Stelle verpflichtet, nicht der Emittent des Finanzproduktes.

Insbesondere auf Dividendenerträge wurde Kapitalertragsteuer in Höhe von $20 \%$ zuzüglich 5,5\% Solidaritätszuschlag hierauf erhoben und zwar als Emittentensteuer, d. h. zum Einbehalt war der Emittent des Finanzproduktes verpflichtet. Wegen der Vorbelastung bei der ausschüttenden Körperschaft unterlagen Dividendenerträge im Privatvermögen nur zur Hälfte der Besteuerung (Halbeinkünfteverfahren).

Werbungskosten (insbesondere Refinanzierungskosten, Kosten der Vermögensverwaltung) konnten geltend gemacht werden.

\section{Rechtslage nach dem 31.12.2008}

Mit der Einführung der neuen gesetzlichen Regelungen zur Besteuerung der Kapitalerträge wurde die Unterscheidung zwischen Einkunfts- und Vermögensebene weitgehend aufgehoben. Der Umfang der Kapitalerträge, die der Besteuerung ohne Einschränkung unterliegen, wurde stark erweitert (§20 EStG n. F., insbesondere durch §20 Abs. 2 EStG n. F.). Neben den laufenden Kapitalerträgen (insbesondere Zinsen und Dividenden) werden auch Gewinne aus der Veräußerung bzw. Einlösung von Wertpapieren und Termingeschäften erfasst, unabhängig innerhalb welcher Frist die Veräußerung bzw. Einlösung erfolgt. Die Bedeutung der privaten Veräußerungsgeschäfte (§ $23 \mathrm{EStG}$ n. F.) ist demnach, abgesehen von Immobilieninvestitionen, stark zurückgegangen. Praktisch relevant

3 Ausnahme war der Einbehalt von Kapitalertragsteuer auf Veräußerungsgewinne aus Finanzinnovationen. 
sind sie nur noch für physisch gehandelte Edel-, Industriemetalle, Agrarrohstoffe und Fremdwährungen.

Weiterer Eckpunkt der gesetzlichen Neuregelungen ist, dass die einbehaltene Kapitalertragsteuer für inländische Privatanleger abgeltende Wirkung hat. Nach der gesetzgeberischen Intention soll es bei inländischen Privatanlegern nur noch in Ausnahmefällen zu Veranlagungen kommen.

Eingeführt wurde nunmehr ein einheitlicher Kapitalertragsteuersatz von $25 \%$ zuzüglich 5,5\% Solidaritätszuschlag hierauf und ggf. einzubehaltender Kirchensteuer. Die Unterscheidung zwischen Zahlstellen- und Emittentensteuer besteht allerdings fort.

Das Halbeinkünfteverfahren wurde abgeschafft und Werbungskosten sind nicht mehr abzugsfähig. Eingeführt wurde ein einheitlicher SparerPauschbetrag.

\section{Wirtschaftliche Auswirkungen beim Privatanleger}

\section{Einflussfaktoren}

Die Neuregelung der Besteuerung von Erträgen aus Kapitalvermögen ist insbes. durch drei Elemente gekennzeichnet:

- Zum einen ist es zur Erweiterung des Umfanges der steuerpflichtigen Kapitalerträge gekommen. Mit einbezogen sind nun vor allem Veräußerungs- und Einlösungsgewinne aus Wertpapieren und Termingeschäften, unabhängig von der Haltedauer der Wirtschaftsgüter (weitgehende Aufgabe der Trennung zwischen Einkunfts- und Vermögensebene). Dies erscheint zunächst als ausschließlich nachteilig für den Steuerpflichtigen. Zu berücksichtigen ist dabei jedoch, dass nunmehr auch Veräußerungsverluste und Einlösungsverluste steuerlich geltend gemacht werden können. Insoweit stellt dies einen kompensatorischen Effekt zur Erweiterung des Umfangs der steuerpflichtigen Kapitalerträge dar.

- Ein weiteres Element der Neuregelungen ist, dass die Erträge aus Kapitalvermögen mit einem einheitlichen Steuersatz von 25 \% (zuzüglich 5,5\% Solidaritätszuschlag) versteuert werden. Es erfolgt demnach keine Versteuerung mehr mit dem individuellen Steuersatz. ${ }^{4}$ Dies bedeutet im Ergebnis, dass Einkünfte aus Kapitalvermögen im Vergleich zur alten Rechtslage immer dann einem niedrigeren Steuersatz unterliegen, wenn der individuelle Steuersatz über $25 \%$ liegt. Liegt der individuelle Steuersatz bei $25 \%$ oder darunter, findet wie nach der alten Rechtslage eine Besteuerung zum individuellen Steuersatz statt.

4 Ausnahme u.a. dann, wenn der individuelle Steuersatz unter $25 \%$ liegt. Dann erfolgt Versteuerung im Wege der Veranlagung zum niedrigeren individuellen Steuersatz. 
- Nach neuer Rechtslage können Werbungskosten, die im Zusammenhang mit Erträgen aus Kapitalvermögen stehen, nicht mehr in Abzug gebracht werden.

Im Ergebnis bleibt festzuhalten, dass den steuerverschärfenden Regelungen, wie der Erweiterung der Bemessungsgrundlage und dem Verbot des Werbungskostenabzugs, durch die Senkung des Steuersatzes ein gegenläufiger Effekt gegenübersteht.

\section{Bedeutung der Portfoliostruktur}

Die oben dargestellten Einflussfaktoren haben naturgemäß die größte Auswirkung auf Portfolios, die eine "extreme" Strukturierung aufweisen, also z.B. Portfolios die ausschließlich Zinserträge generieren oder ausschließlich nach alter Rechtslage steuerfreie Veräußerungsgewinne und der Anleger einen individuellen Steuersatz hat, der über $25 \%$ liegt.

Unterstellt man, dass ein Privatanleger ausschließlich Zinserträge erzielt und sein individueller Steuersatz dem Spitzensteuersatz entspricht, so ergibt sich nach alter und neuer Rechtslage folgendes Bild:

\begin{tabular}{|lr|l|}
\hline $\begin{array}{l}\text { Alte Rechtslage } \\
\text { (Spitzensteuersatz: 45 \% plus SolZ) }\end{array}$ & $\begin{array}{l}\text { Neue Rechtslage } \\
\text { (Abgeltungsteuer: 25 \% plus SolZ) }\end{array}$ \\
\hline Zinseinkünfte: & 1.000 & 1.000 \\
\hline Steuer: & 475 & 264 \\
\hline Netto: & 525 & 736 \\
\hline Vorteil: & & 211 \\
\hline
\end{tabular}

Unter den getroffenen Annahmen wird ersichtlich, dass sich im Vergleich zur alten Rechtslage ein substantieller Vorteil ergibt. Ggf. wird der Vorteil aber dadurch geschmälert, dass nach neuer Rechtslage ein Werbungskostenabzug nicht möglich ist.

Erzielt der Privatanleger ausschließlich Dividendeneinkünfte ergibt sich folgendes Bild:

\begin{tabular}{|lr|l|}
\hline $\begin{array}{l}\text { Alte Rechtslage } \\
\text { (Halbeinkünfteverfahren, } \\
\text { Spitzensteuersatz: 45 \% plus Solz) }\end{array}$ & $\begin{array}{l}\text { Neue Rechtslage } \\
\text { (Abgeltungssteuer: 25 \% plus Solz) }\end{array}$ \\
\hline Dividendeneinkünfte: & 1.000 & 1.000 \\
\hline Steuerpflichtig: & 500 & 1.000 \\
\hline Steuer: & 237 & 264 \\
\hline Netto: & 763 & 736 \\
\hline Nachteil: & & 27 \\
\hline
\end{tabular}


Hierbei ergibt sich, dass die Steuerbelastung nach neuer Rechtslage nachteilig im Vergleich zur alten Rechtslage ist, der Nachteil aber geringfügig ausfällt. Der Nachteil des Wegfalls des Halbeinkünfteverfahrens wird weitgehend kompensiert durch den niedrigeren Steuersatz. Auch hier wäre noch zu berücksichtigen, dass ein Abzug von Werbungskosten nicht mehr möglich ist.

Unterstellt man, dass ein Privatanleger ausschließlich Veräußerungsgewinne erzielt, die außerhalb der Spekulationsfrist nach altem Recht erzielt werden, ergibt sich folgende steuerliche Situation:

\begin{tabular}{|c|c|}
\hline $\begin{array}{l}\text { Alte Rechtslage } \\
\text { (Steuerfrei, nach Ablauf der Spekula- } \\
\text { tionsfrist) }\end{array}$ & $\begin{array}{l}\text { Neue Rechtslage } \\
\text { (Abgeltungssteuer: } 25 \% \text { plus SolZ) }\end{array}$ \\
\hline Veräußerungsgewinn: & 1.000 \\
\hline Steuerpflichtig: & 1.000 \\
\hline Steuer: & 264 \\
\hline Netto: & 736 \\
\hline Nachteil: & 264 \\
\hline
\end{tabular}

Da Veräußerungsgewinne nach alter Rechtslage außerhalb der Spekulationsfrist steuerfrei waren, nach neuer Rechtslage aber steuerpflichtig sind, wirkt sich die Neuregelung stark negativ aus. Es ist allerdings zu berücksichtigen, dass nach alter Rechtslage Veräußerungsverluste außerhalb der Spekulationsfrist nicht geltend gemacht werden konnten, dies ist nach neuer Rechtslage nun möglich. Dies dürfte in der Praxis wohl zu einer deutlichen Abmilderung der negativen Auswirkungen führen.

Die Auswirkungen der Portfoliostruktur sind im folgenden noch einmal dargestellt für Portfolios, die unterschiedliche Kapitalerträge mit unterschiedlichen Gewichtungen generieren:

\begin{tabular}{|l|r|r|r|r|}
\hline $\begin{array}{l}\text { Alte Rechtslage } \\
\text { (Steuersatz 45 \% plus 5,5 \% SolZ) }\end{array}$ & \multicolumn{2}{|l|}{$\begin{array}{l}\text { Neue Rechtslage } \\
\text { (Steuersatz 25 \% } \\
\text { plus 5,5 \% SolZ) }\end{array}$} \\
\hline Zinseinkünfte: & 500 & 1.100 & 500 & 1.100 \\
\hline Steuern: & 237 & 522 & 132 & 290 \\
\hline Netto: & 263 & 578 & 368 & 810 \\
\hline Dividenden: & 500 & 300 & 500 & 300 \\
\hline Steuerpflichtig: & 250 & 150 & 500 & 300 \\
\hline Steuern: & 119 & 71 & 132 & 79 \\
\hline Netto: & 381 & 229 & 368 & 221 \\
\hline Veräußerungsgewinn $\leq 1$ Jahr: & 500 & 300 & 500 & 300 \\
\hline
\end{tabular}




\begin{tabular}{|c|c|c|c|c|}
\hline \multicolumn{3}{|l|}{$\begin{array}{l}\text { Alte Rechtslage } \\
\text { (Steuersatz } 45 \% \text { plus } 5,5 \% \text { SolZ) }\end{array}$} & \multicolumn{2}{|c|}{$\begin{array}{l}\text { Neue Rechtslage } \\
\text { (Steuersatz } 25 \% \\
\text { plus 5,5\% SolZ) }\end{array}$} \\
\hline Steuerpflichtig: & 250 & 150 & 500 & 300 \\
\hline Steuern: & 119 & 71 & 132 & 79 \\
\hline Netto: & 381 & 229 & 368 & 221 \\
\hline Veräußerungsgewinn $\geq 1$ Jahr: & 500 & 300 & 500 & 300 \\
\hline Steuern: & - & - & 132 & 79 \\
\hline Netto: & 500 & 300 & 368 & 221 \\
\hline Gesamt-Brutto: & 2.000 & 2.000 & 2.000 & 2.000 \\
\hline ¿Steuern: & 475 & 664 & 528 & 528 \\
\hline$\Sigma$ Netto: & 1.525 & 1.336 & 1.472 & 1.472 \\
\hline Steuerquote (effektiv): & $23,75 \%$ & $33,20 \%$ & $26,4 \%$ & $26,4 \%$ \\
\hline
\end{tabular}

Aus den dargestellten Beispielsrechnungen wird ersichtlich, dass nur schwer eine eindeutige Antwort darauf zu finden ist, ob die gesetzliche Neuregelung den Privatanleger im Vergleich zur alten Rechtslage schlechter oder besser stellt. Nicht zu übersehen ist jedoch, dass sich bei Portfolios mit stark gemischten Kapitalerträgen die Steuerbelastungen zwischen alter und neuer Rechtslage tendenziell angleichen dürften.

Offensichtlich ist allerdings auch, dass Zinserträge bei Privatanlegern mit hohen Steuersätzen nach neuer Rechtslage stark begünstigt werden. Dies obwohl die Zinszahlungen i.d. R. beim Zahler abzugsfähige Betriebsausgaben darstellen.

\section{Persönliche Kapitalertragsteuerpflicht}

\section{Kapitalertragsteuerpflicht für Steuerinländer}

Grundsätzlich unterliegen nur Privatpersonen die Steuerinländer (unbeschränkt Steuerpflichtige) sind mit ihren im Inland unterhaltenen Geldund Kapitalanlagen der abgeltenden Abzugsbesteuerung. Im Ausland unterhaltene Geld- und Kapitalanlagen unterliegen nicht der deutschen Abzugsbesteuerung und sind demnach im Veranlagungswege abgeltend zu besteuern.

Inländische betriebliche Anleger können ggf. mit ihren Kapitalerträgen der deutschen Abzugsbesteuerung unterliegen, sie hat jedoch keine abgeltende Wirkung. 


\section{Kapitalertragsteuerpflicht für Steuerausländer}

Steuerausländer (nicht unbeschränkt steuerpflichtige Personen) unterliegen nur mit den inländischen Einkünften aus Kapitalvermögen der Kapitalertragsteuerpflicht, die in $\S 49$ Abs. 1 Nr. 5 EStG abschließend aufgeführt sind (z.B. Dividenden und Ausschüttungen auf eigenkapitalähnliche Genussrechte einer inländischen Gesellschaft, Erträgen aus Wandelanleihen, Gewinnobligationen und fremdkapitalähnlichen Genussrechten eines inländischen Emittenten).

Weitere Einschränkungen der Kapitalertragsteuerpflicht können sich aus Doppelbesteuerungsabkommen ergeben.

\section{Sachliche Kapitalertragsteuerpflicht/Abgeltungswirkung}

\section{Voraussetzungen zum Kapitalertragsteuerabzug}

Ein Abzug von Kapitalertragsteuer setzt zunächst voraus, dass es sich bei den Erträgen um solche aus Kapitalvermögen handelt, diese auch tatsächlich dem Abzug zu unterwerfen sind und keine Abstandnahme vom Abzug zu erfolgen hat.

Einkünfte aus Kapitalvermögen sind in $\S 20$ EStG und $\S \S 2$ und 8 InvStG definiert.

Innerhalb des $\S 20$ EStG erfolgt eine Unterscheidung in

- Laufende Kapitalerträge (§ 20 Abs. 1 EStG), insbesondere Zinsen, Dividenden, ausschüttungsgleiche Erträge inländischer Fonds, ausgeschüttete Erträge in- und ausländischer Fonds, Stillhalterprämien und

- Gewinne bzw. Verluste (§ 20 Abs. 2 EStG) aus der Veräußerung von Kapitalanlagen, insbes. Aktien, Anleihen, Zertifikaten, Fondsanteilen, Termingeschäften. Einer Veräußerung gleichgestellt sind die Einlösung, Rückzahlung und Abtretung.

Liegen Gewinne aus privaten Veräußerungsgeschäften i. S. d. § 23 EStG vor, ist kein Abzug vorzunehmen, da es sich nicht um Kapitalerträge handelt.

Nicht alle Erträge aus Kapitalvermögen i. S. d. § 20 EStG unterliegen vollumfänglich dem Kapitalertragsteuerabzug i. S. d. §43 EStG. Ein Kapitalertragsteuerabzug findet z.B. nicht statt wegen sachlicher Befreiungen und bei im Ausland erzielten Kapitalerträgen.

Handelt es sich um Erträge aus Kapitalvermögen i.S.d. § 20 EStG und unterliegen diese nach $\S 43$ EStG auch dem Kapitalertragsteuerabzug bestehen jedoch zahlreiche Ausnahmetatbestände, auf Grund derer vom 
Abzug Abstand genommen oder eine Erstattung der Kapitalertragsteuer erlangt werden kann (persönliche Befreiungen). ${ }^{5}$

\section{2. Überblick über Erträge aus Kapitalvermögen und sachliche Kapitalertragsteuerpflicht nach Anlegergruppen}

Die folgende Übersicht stellt dar, wann bei laufenden Kapitalerträgen i. S. d. § 20 Abs. 1 EStG bei den einzelnen Anlegergruppen (Privatanleger, Körperschaften und sonstige betriebliche Anleger, Steuerausländer) eine sachliche Kapitalertrag-steuerpflicht gegeben ist:

\begin{tabular}{|c|c|c|c|c|c|}
\hline \multicolumn{3}{|c|}{ Kapitalerträge } & \multirow{2}{*}{$\begin{array}{c}\text { Privat- } \\
\text { anleger }\end{array}$} & \multirow{2}{*}{$\begin{array}{l}\text { Körperschaf- } \\
\text { ten (z. B. AG, } \\
\text { GmbH) und } \\
\text { sonstige } \\
\text { betriebliche } \\
\text { Anleger } \\
\text { KESt-Pflicht }\end{array}$} & \multirow{2}{*}{$\begin{array}{c}\begin{array}{c}\text { Steuer- } \\
\text { aus- } \\
\text { länder }\end{array} \\
\text { KESt- } \\
\text { Pflicht }\end{array}$} \\
\hline \multirow{7}{*}{ 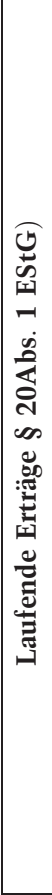 } & Nr. 1 & $\begin{array}{l}\text { Gewinnanteile (Dividenden), } \\
\text { Ausbeuten und sonstige } \\
\text { Bezüge aus Beteiligungen an } \\
\text { inländischen Kapitalgesell- } \\
\text { schaften (inkl. aktienähn- } \\
\text { lichen Genussrechten) }\end{array}$ & & & \\
\hline & Nr. 2 & $\begin{array}{l}\text { Bezüge, die bei Auflösung einer } \\
\text { unbeschränkt steuerpflichti- } \\
\text { gen Körperschaft anfallen und } \\
\text { nicht in der Rückzahlung von } \\
\text { Nennkapital bestehen }\end{array}$ & $\begin{array}{l}\text { KESt- } \\
\text { Pflicht }\end{array}$ & KESt-Pflicht & $\begin{array}{l}\text { KESt- } \\
\text { Pflicht }\end{array}$ \\
\hline & Nr. 4 & $\begin{array}{l}\text { Einnahmen aus stiller Gesell- } \\
\text { schaft oder aus partiarischen } \\
\text { Darlehen }\end{array}$ & $\begin{array}{l}\text { KESt- } \\
\text { Pflicht }\end{array}$ & KESt-Pflicht & $\begin{array}{l}\text { KESt- } \\
\text { Pflicht }\end{array}$ \\
\hline & Nr. 5 & $\begin{array}{l}\text { Zinsen aus Hypotheken und } \\
\text { Grundschulden sowie Renten } \\
\text { aus Rentenschulden (Schuld- } \\
\text { ner ist keine Bank) }\end{array}$ & - & - & - \\
\hline & Nr. 6 & $\begin{array}{l}\text { Erträge aus nicht begünstigten } \\
\text { Versicherungen }\end{array}$ & $\begin{array}{l}\text { KESt- } \\
\text { Pflicht }\end{array}$ & KESt-Pflicht & $\begin{array}{l}\text { KESt- } \\
\text { Pflicht }\end{array}$ \\
\hline & Nr. 7 & $\begin{array}{l}\text { Erträge aus sonstigen Kapital- } \\
\text { forderungen jeder Art, ins- } \\
\text { besondere Zinsen }\end{array}$ & $\begin{array}{l}\text { KESt- } \\
\text { Pflicht }\end{array}$ & KESt-Pflicht & $\begin{array}{l}\text { KESt- } \\
\text { Pflicht * }\end{array}$ \\
\hline & Nr. 8 & $\begin{array}{l}\text { Diskontbeträge von Wechseln } \\
\text { und Anweisungen (Schuldner } \\
\text { ist keine Bank) }\end{array}$ & - & - & - \\
\hline
\end{tabular}

5 Vgl. unter VII. 


\begin{tabular}{|l|l|c|c|c|}
\hline \multicolumn{2}{|l|}{ Kapitalerträge } & $\begin{array}{c}\text { Privat- } \\
\text { anleger }\end{array}$ & $\begin{array}{c}\text { Körperschaf- } \\
\text { ten (z. B. AG, } \\
\text { GmbH) und } \\
\text { sonstige } \\
\text { betriebliche } \\
\text { Anleger }\end{array}$ & $\begin{array}{c}\text { Steuer- } \\
\text { aus- } \\
\text { länder }\end{array}$ \\
\hline \multirow{2}{*}{ Nr.9 } & $\begin{array}{l}\text { Ausschüttungsgleiche Leis- } \\
\text { tungen von nicht körperschaft- } \\
\text { steuerbefreiten Körperschaf- } \\
\text { ten, soweit diese nicht unter } \\
\text { §20 Abs. 1 Nr. 1 EStG fallen }\end{array}$ & - & - & - \\
\hline Nr. 10 & $\begin{array}{l}\text { Ausschüttungsgleiche Leis- } \\
\text { tungen sowie nicht den Rück- } \\
\text { lagen zugeführte Gewinne von } \\
\text { Betrieben gewerblicher Art }\end{array}$ & - & - & - \\
\hline Nr. 11 & $\begin{array}{l}\text { Stillhalterprämie bei Options- } \\
\text { geschäften }\end{array}$ & $\begin{array}{c}\text { KESt- } \\
\text { Pflicht }\end{array}$ & $-{ }^{\star \star}$ & - \\
\hline $\begin{array}{l}\text { In 7 } \\
\text { InvStG }\end{array}$ & $\begin{array}{l}\text { Ausgeschüttete Erträge inlän- } \\
\text { discher und ausländischer } \\
\text { Fonds/Ausschüttungsgleiche } \\
\text { Erträge von inländischen } \\
\text { Fonds }\end{array}$ & $\begin{array}{c}\text { KESt- } \\
\text { Pflicht }\end{array}$ & KESt-Pflicht & $\begin{array}{c}\text { KESt- } \\
\text { Pflicht } \\
\star \star \star\end{array}$ \\
\hline
\end{tabular}

* Nur ausnahmsweise für Zinsen aus inländischen Wandelanleihen, Gewinnobligationen und Genussrechten sowie insbesondere generell im Schaltergeschäft (= Tafelgeschäft).

* * Nur wenn die formalen Voraussetzungen für die Abzugsbefreiung erfüllt sind (z. B. Freistellungserklärung soweit erforderlich).

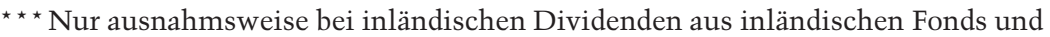
generell im Schaltergeschäft.

Die folgende Übersicht stellt dar, wann bei Veräußerungs- bzw. Einlösungsgewinnen i. S. d. § 20 Abs. 2 EStG bei den einzelnen Anlegergruppen (Privatanleger, Körperschaften und sonstige betriebliche Anleger, Steuerausländer) eine sachliche Kapitalertragsteuerpflicht gegeben ist: 


\begin{tabular}{|c|c|c|c|c|c|}
\hline \multicolumn{3}{|c|}{ Kapitalerträge } & \multirow{2}{*}{$\begin{array}{c}\text { Privat- } \\
\text { anleger }\end{array}$} & \multirow{2}{*}{$\begin{array}{c}\text { Körperschaf- } \\
\text { ten (z. B. AG, } \\
\text { GmbH) und } \\
\text { sonstige } \\
\text { betriebliche } \\
\text { Anleger } \\
-^{\star}\end{array}$} & \multirow{2}{*}{$\begin{array}{c}\begin{array}{c}\text { Steuer- } \\
\text { aus- } \\
\text { länder }\end{array} \\
\text { KESt- } \\
\text { Pflicht im } \\
\text { Schalter- } \\
\text { geschäft }\end{array}$} \\
\hline \multirow{10}{*}{ 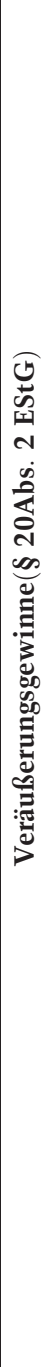 } & Nr. 1 & $\begin{array}{l}\text { Gewinn aus der Veräußerung } \\
\text { von Anteilen an Körperschaf- } \\
\text { ten (z. B. Aktien, aktienähn- } \\
\text { liche Genussrechte, GmbH- } \\
\text { Anteile) }\end{array}$ & & & \\
\hline & Nr. 2 a) & $\begin{array}{l}\text { Gewinn aus der Veräußerung } \\
\text { von Dividendenscheinen und } \\
\text { sonstigen Ansprüchen ohne } \\
\text { das Stammrecht }\end{array}$ & $\begin{array}{l}\text { KESt- } \\
\text { Pflicht }\end{array}$ & KESt-Pflicht & - \\
\hline & Nr. 2 b) & $\begin{array}{l}\text { Gewinn aus der Veräußerung } \\
\text { von Zinsscheinen und Zinsfor- } \\
\text { derungen ohne die Schuldver- } \\
\text { schreibungen }\end{array}$ & $\begin{array}{l}\text { KESt- } \\
\text { Pflicht }\end{array}$ & $-{ }^{\star}$ & $\begin{array}{l}\text { KESt- } \\
\text { Pflicht im } \\
\text { Schalter- } \\
\text { geschäft }\end{array}$ \\
\hline & Nr. 3 a) & $\begin{array}{l}\text { Gewinn bei Termingeschäften } \\
\text { mit Differenzausgleich }\end{array}$ & $\begin{array}{l}\text { KESt- } \\
\text { Pflicht }\end{array}$ & $-^{\star}$ & - \\
\hline & Nr. 3 b) & $\begin{array}{l}\text { Gewinn aus der Veräußerung } \\
\text { eines als Termingeschäft aus- } \\
\text { gestalteten Finanzinstruments } \\
\text { (z. B. Optionsscheine) }\end{array}$ & $\begin{array}{l}\text { KESt- } \\
\text { Pflicht }\end{array}$ & $-{ }^{\star}$ & - \\
\hline & Nr. 4 & $\begin{array}{l}\text { Gewinn aus der Veräußerung } \\
\text { einer stillen Gesellschaft oder } \\
\text { aus einem partiarischen Darle- } \\
\text { hen }\end{array}$ & - & - & - \\
\hline & Nr. 5 & $\begin{array}{l}\text { Gewinn aus der Übertragung } \\
\text { von Hypotheken, Grundschul- } \\
\text { den und Rentenschulden }\end{array}$ & - & - & - \\
\hline & Nr. 6 & $\begin{array}{l}\text { Gewinn aus der Veräußerung } \\
\text { von nicht begünstigten Ver- } \\
\text { sicherungen }\end{array}$ & - & - & - \\
\hline & Nr. 7 & $\begin{array}{l}\text { Gewinn aus der Veräußerung } \\
\text { von sonstigen Kapitalforderun- } \\
\text { gen jeder Art (z. B. Anleihen, } \\
\text { Zertifikate und bisherige } \\
\text { Finanzinnovationen) }\end{array}$ & $\begin{array}{l}\text { KESt- } \\
\text { Pflicht }\end{array}$ & $-^{\star}$ & $\begin{array}{l}\text { KESt- } \\
\text { Pflicht im } \\
\text { Schalter- } \\
\text { geschäft }\end{array}$ \\
\hline & Nr. 8 & $\begin{array}{l}\text { Gewinn aus der Übertragung } \\
\text { oder Aufgabe einer Rechtsposi- } \\
\text { tion an z. B. Versicherungs- } \\
\text { und Pensionsvereine, nicht- } \\
\text { rechtsfähige Vereine und Stif- } \\
\text { tungen }\end{array}$ & - & - & - \\
\hline
\end{tabular}




\begin{tabular}{|c|c|c|c|c|}
\hline \multicolumn{2}{|c|}{ Kapitalerträge } & \multirow{2}{*}{$\begin{array}{c}\begin{array}{c}\text { Privat- } \\
\text { anleger }\end{array} \\
\text { KESt- } \\
\text { Pflicht }\end{array}$} & \multirow{2}{*}{$\begin{array}{c}\text { Körperschaf- } \\
\text { ten (z. B. AG, } \\
\text { GmbH) und } \\
\text { sonstige } \\
\text { betriebliche } \\
\text { Anleger } \\
\text { KESt-Pflicht } \\
\text { bei verein- } \\
\text { nahmten } \\
\text { Zwischen- } \\
\text { gewinnen }\end{array}$} & \multirow{2}{*}{\begin{tabular}{|c|}
$\begin{array}{c}\text { Steuer- } \\
\text { aus- } \\
\text { länder }\end{array}$ \\
$\begin{array}{c}\text { KESt- } \\
\text { Pflicht im } \\
\text { Schalter- } \\
\text { geschäft }\end{array}$
\end{tabular}} \\
\hline $\begin{array}{l}\text { \$ } 7 \\
\text { InvStG }\end{array}$ & $\begin{array}{l}\text { Gewinn aus Veräußerung von } \\
\text { Anteilen an inländischen und } \\
\text { ausländischen Fonds }\end{array}$ & & & \\
\hline
\end{tabular}

* Nur wenn die formalen Voraussetzungen für die Abzugsbefreiung erfüllt sind (z. B. Freistellungserklärung soweit erforderlich)

\section{Abgeltende Wirkung des Kapitalertragsteuerabzugs}

Eine der gesetzgeberischen Intentionen bei der Neuregelung des Kapitalertragsteuerabzugs war es, dass eine abgeltende Wirkung eintreten und demnach für bestimmte Anlegergruppen eine Veranlagung der Erträge aus Kapitalvermögen vermieden werden soll. Grundsätzlich ist die abgeltende Wirkung des Steuerabzugs begrenzt auf inländische Privatanleger.

Aus der folgenden Übersicht ergibt sich, welche Wirkungen der Kapitalertragsteuerabzug bei den einzelnen Anlegergruppen hat:

\begin{tabular}{|l|l|}
\hline Anlegergruppe & Wirkung des KESt-Abzugs \\
\hline $\begin{array}{l}\text { Inländische Privatanleger } \\
\text { (natürliche Personen und vermögens- } \\
\text { verwaltende Personengesellschaften) }\end{array}$ & Grundsätzlich Abgeltungswirkung \\
\hline $\begin{array}{l}\text { Körperschaften } \\
\text { (Kapitalgesellschaften wie z. B. AG und } \\
\text { GmbH) }\end{array}$ & $\begin{array}{l}\text { Vorauszahlung auf Körperschaftssteu- } \\
\text { er, d. h. KESt ist auf die Körperschafts- } \\
\text { steuer anrechenbar }\end{array}$ \\
\hline $\begin{array}{l}\text { Inländische sonstige betriebliche } \\
\text { Anleger ohne Freistellungserklärung } \\
\text { für Betriebsvermögen } \\
\text { (gewerbliche Personenunternehmen } \\
\text { wie offene Handelsgesellschaften und } \\
\text { Kommanditgesellschaften) }\end{array}$ & $\begin{array}{l}\text { Vorauszahlung auf Einkommensteuer, } \\
\text { d.h. KESt ist auf die Einkommensteuer } \\
\text { anrechenbar }\end{array}$ \\
\hline $\begin{array}{l}\text { Inländische sonstige betriebliche } \\
\text { Anleger mit Freistellungserklärung } \\
\text { für Betriebsvermögen } \\
\text { (gewerbliche Personenunternehmen) }\end{array}$ & $\begin{array}{l}\text { Vorauszahlung auf Einkommensteuer, } \\
\text { d.h. KESt ist auf die Einkommensteuer } \\
\text { anrechenbar }\end{array}$ \\
\hline $\begin{array}{l}\text { Steuerausländer } \\
\text { (Privatanleger, sonstige betriebliche } \\
\text { Anleger und Körperschaften) }\end{array}$ & $\begin{array}{l}\text { Grundsätzlich Abgeltungswirkung, } \\
\text { soweit KESt überhaupt zu erheben ist }\end{array}$ \\
\hline
\end{tabular}




\section{Abzugspflichtige Kapitalerträge/Bemessungsgrundlage}

\section{Abzugsverpflichtete}

Auch nach der Neuregelung des Kapitalertragsteuerabzugs wird unterschieden nach Emittenten- und Zahlstellensteuer. Je nach Art der Kapitalerträge ist entweder

- der Schuldner der Kapitalerträge (Emittentensteuer) oder

- die die Kapitalerträge auszahlende Stelle (Zahlstellensteuer)

zum Einbehalt der Kapitalertragsteuer verpflichtet (§ 44 Abs. 1 S. 3 EStG).

Eine Abzugsverpflichtung besteht nur für inländische Emittenten und inländische Zahlstellen (i. d. R. Kreditinstitute).

Aus der nachfolgenden Übersicht ergibt sich, wer Abzugsverpflichteter bei den einzelnen Kapitalerträgen nach $\S 43$ Abs. 1 und 2 EStG ist bzw. bei welchen Kapitalerträgen kein Abzug vorzunehmen ist:

\begin{tabular}{|l|l|l|}
\hline \multirow{2}{*}{$\begin{array}{l}\text { Kapitalerträge } \\
\text { (\$ } 43 \text { Abs. 1 und 2 EStG) }\end{array}$} & \multicolumn{2}{|l|}{ KESt-Abzugsverpflichteter } \\
\cline { 2 - 3 } & laufende Erträge & $\begin{array}{l}\text { Veräußerungs- } \\
\text { gewinne }\end{array}$ \\
\hline InländischeAktien & Emittent & Kreditinstitut \\
\hline ausländische Aktien & Kreditinstitut & Kreditinstitut \\
\hline $\begin{array}{l}\text { Inländische Wandelanleihen, } \\
\text { Gewinnobligationen und Genussrechte }\end{array}$ & Emittent & Kreditinstitut \\
\hline $\begin{array}{l}\text { sonstige Anleihen und Schuldverschreibun- } \\
\text { gen }\end{array}$ & Kreditinstitut & Kreditinstitut \\
\hline $\begin{array}{l}\text { Bundesschatzbriefe Typ A und B, } \\
\text { Zerobonds }\end{array}$ & Kreditinstitut & Kreditinstitut \\
\hline Girokonto, Sparbuch, Tages- und Festgelder & Kreditinstitut & - \\
\hline Eigene Schuldscheindarlehen & Kreditinstitut & - \\
\hline Stillhalterprämien & Kreditinstitut & - \\
\hline Zertifikate & Kreditinstitut & Kreditinstitut \\
\hline Termingeschäfte & - & Kreditinstitut \\
\hline GmbH-Beteiligung & Emittent & kein KESt-Abzug \\
\hline Stille Gesellschaft, partiarisches Darlehen & Emittent & kein KESt-Abzug \\
\hline Privatdarlehen und Gesellschafterdarlehen & kein KESt-Abzug \\
\hline $\begin{array}{l}\text { Übertragung von Hypotheken und Grund- } \\
\text { schulden }\end{array}$ & kein KESt-Abzug \\
\hline $\begin{array}{l}\text { Bundesschatzbriefe Typ A \& B, Zerobonds } \\
\text { bei Verwahrung durch die Bundes- oder } \\
\text { Landesschuldenverwaltung }\end{array}$ & $\begin{array}{l}\text { Schulden- } \\
\text { verwaltung }\end{array}$ & $\begin{array}{l}\text { Schulden- } \\
\text { verwaltung }\end{array}$ \\
\hline
\end{tabular}




\section{Bemessungsgrundlage für den Kapitalertragsteuerabzug}

Wesentlich für den Kapitalertragsteuerabzug ist die zutreffende Ermittlung der Bemessungsgrundlage. Da die Kapitalertragsteuer bei Privatanlegern abgeltende Wirkung haben soll und eine Veranlagung vermieden werden soll, können die Bruttoerträge bzw. Einnahmen aus der Veräußerung nicht ohne weiteres als Bemessungsgrundlage zu Grunde gelegt werden. Vielmehr sind bei der Ermittlung der Bemessungsgrundlage schon vom Abzugsverpflichteten ggf. vorhandene Verluste aus Kapitalvermögen, Anschaffungskosten, Anschaffungsnebenkosten, Aufwendungen, die in unmittelbarem sachlichen Zusammenhang mit Veräußerungsgeschäften stehen und bestehende Freistellungsaufträge zu berücksichtigen, um eine Geltendmachung dieser Merkmale in der Veranlagung zu vermeiden.

Nachfolgend ist dargestellt, wie sich die Bemessungsgrundlage für den Kapitalertragsteuerabzug bei laufenden Kapitalerträgen (i.S.d. §20 Abs. 1 EStG) ermittelt:

Bruttoerträge aus Kapitalvermögen ohne jeden Abzug

./. ggf. vorhandene Verluste aus Kapitalvermögen

./. ggf. bestehender Freistellungsauftrag

= Bemessungsgrundlage nach Verlustverrechnung und Freistellungsauftrag

Bei Veräußerungsgewinnen (i. S.d. § 20 Abs. 2 i. V.m. Abs. 4 S. 1 EStG) ermittelt sich die Bemessungsgrundlage wie folgt:

Einnahmen aus der Veräußerung

./. Aufwendungen, die in unmittelbarem sachlichen Zusammenhang mit den Veräußerungsgeschäften stehen

./. Anschaffungskosten

.. Anschaffungsnebenkosten

$=$ Veräußerungsgewinn $/$-verlust als maßgeblicher Bruttoertrag

./. ggf. vorhandene Verluste aus Kapitalvermögen

./. ggf. bestehender Freistellungsauftrag

= Bemessungsgrundlage nach Verlustverrechnung und Freistellungs$\underline{\underline{\text { auftrag }}}$

Falls dem Kreditinstitut Anschaffungskosten nicht bekannt sind, erfolgt der Steuerabzug auf Basis der Ersatzbemessungsgrundlage (§ 43 Abs. 2 S. 7 EStG). Die Ersatzbemessungsgrundlage beläuft sich auf $30 \%$ zuzüglich 5,5\% Solidaritätszuschlag. 
Bei Termingeschäften (i. S. d. § 20 Abs. 4 S. 5 EStG) wird folgendes Ermittlungsschema zu Grunde gelegt:

Differenzausgleich, Geldbetrag oder Vorteil

.1. Aufwendungen im unmittelbaren sachlichen Zusammenhang mit dem Termingeschäft

$=$ maßgeblicher Bruttoertrag

./. ggf. vorhandene Verluste aus Kapitalvermögen

.1. ggf. bestehender Freistellungsauftrag

$=$ Bemessungsgrundlage nach Verlustverrechnung und Freistellungs$\underline{\underline{\text { auftrag }}}$

\section{Verbrauchsfolgeverfahren}

Bei Kapitalanlagen der selben Gattung, die zu unterschiedlichen Zeitpunkten und damit auch meist zu unterschiedlichen Anschaffungskosten angeschafft wurden, ergibt sich in den Fällen, in denen nicht der Gesamtbestand veräußert wird, die Frage, in welcher Reihenfolge die Veräußerung erfolgt (Verbrauchsfolgeverfahren). Bedeutung hat dies insbesondere im Rahmen von ggf. bestehenden Übergangsregelungen (Altbestände). Bei vertretbaren Wertpapieren gilt die First-in-first-out (Fifo) Verbrauchsreihenfolge (§ 20 Abs. 4 S. 7 EStG). Die Verbrauchsreihenfolge gilt für jedes Depot bzw. Unterdepot gesondert, auch wenn mehrere Depots bei einem Kreditinstitut unterhalten werden. ${ }^{6}$ Durch die Verteilung der Kapitalanlagen auf mehrere Depots/Unterdepots hat der Steuerpflichtige die Möglichkeit, die Reihenfolge der Veräußerungen zu steuern.

Sofern die Fifo-Methode nicht anwendbar ist (z. B. bei unverbrieften Forderungen und insbes. Derivaten), ist die Gewinnermittlung grundsätzlich unter Zugrundelegung der durchschnittlichen Anschaffungskosten der Finanzprodukte zu ermitteln. ${ }^{7}$

\section{Währungsumrechnung}

Laufende Erträge aus Kapitalvermögen werden zum Zeitpunkt des Zuflusses in Euro zum Devisenbriefkurs umgerechnet. ${ }^{8}$

6 BMF, Schr. v. 22.12.2009 - IV C 1 - S 2252/08/10004, BStBl. I 2010, 94, Rz. 97 f.

7 Zur Zulässigkeit der verbindlichen Vereinbarung von Verwendungsreihenfolgen zwischen Kreditinstitut und Kunde vgl. Dahm/Hamacher, DStR 2008, 1910 (1916ff.).

8 BMF, Schr. v. 22.12.2009, a. a. O., Rz. 246. 
Bei Veräußerungsgeschäften sind Anschaffungskosten in Fremdwährung im Zeitpunkt der Anschaffung in Euro umzurechnen und Einnahmen in Fremdwährung im Zeitpunkt der Veräußerung.

\section{Kapitalerträge im Einzelnen}

Im Folgenden werden ausgewählte Kapitalerträge bezüglich des Kapitalertrag-steuerabzugs detaillierter dargestellt.

\section{a) Laufende Zinserträge}

Bei laufenden Zinserträgen ( $\S 20$ Abs. 1 Nr. 7 i. V.m. 43 Abs. 1 S. 1 Nr. 7 Buchst. a und b EStG) unterscheidet man bezüglich des Kapitalertragsteuerabzuges zwischen den sogenannten

- A-Fällen: Zinserträge aus verbrieften Forderungen gem. § 43 Abs. 1 S. 1 Nr. 7 Buchst. $a$ EStG

und

- B-Fällen: Zinserträge aus „einfachen“ (unverbrieften) Forderungen gem. $§ 43$ Abs. 1 S. 1 Nr. 7 Buchst. $b$ EStG

Bei A-Fällen ist immer Kapitalertragsteuer von der auszahlenden Stelle einzubehalten, unabhängig davon, wer Schuldner ist (Unternehmen, Kreditinstitute, Bund, Länder) und wo dieser Schuldner ansässig (In- oder Ausland) ist.

Bei B-Fällen ist Kapitalertragsteuer nur einzubehalten, wenn der Schuldner ein inländisches Kreditinstitut oder Finanzdienstleistungsunternehmen ist.

\section{b) Optionsanleihen}

Eine Optionsanleihe setzt sich zusammen aus einer Anleihe, die das Recht auf Rückzahlung des Nominalbetrages verbrieft und einem Optionsschein, der das Recht auf Lieferung einer bestimmten Anzahl von anderen Wirtschaftsgütern verbrieft (z.B. Aktien), gegen Zahlung einer im Voraus bestimmten Gegenleistung.

Anleihe und Optionsscheine stellen unabhängig von der tatsächlichen Trennung zwei Wirtschaftsgüter dar. Zinserträge aus der Anleihe sind laufende Erträge nach $\S 20$ Abs. 1 Nr. 7, Gewinne aus der Veräußerung oder Einlösung der Anleihe sind Erträge nach $§ 20$ Abs. 2 S. 1 Nr. 7 EStG. Optionsscheine werden steuerlich als Termingeschäfte behandelt. ${ }^{9}$ Beim Ersterwerb sind Anschaffungskosten zwischen Anleihe und Options-

9 BMF, Schr. v. 22.12.2009, a. a. O., Rz. 6 f. 
schein nach den Angaben im Emissionsprospekt aufzuteilen. ${ }^{10}$ In allen anderen Fällen (z. B. Zweiterwerb) ist es hingegen zulässig, die Anschaffungskosten ausschließlich den Anleihen zuzuordnen. ${ }^{11}$

c) Gewinne aus der Veräußerung, Abtretung und Einlösung von Wertpapieren und sonstigen Kapitalforderungen

Gewinne aus der Veräußerung, Abtretung oder Einlösung von Wertpapieren und sonstigen Kapitalforderungen unterliegen grundsätzlich dem Kapitalertragsteuerabzug (§ 20 Abs. 2 S. 1 Nr. 7 EStG). Der Steuerabzug ist von der inländischen auszahlenden Stelle (Kreditinstitut) vorzunehmen. Verluste aus der Veräußerung, Abtretung und Einlösung sind steuerlich beachtlich und in den Verlustverrechnungstopf einzustellen. Ein Forderungsausfall ist keine Veräußerung i.S.d. § 20 Abs. 2 S. 2 EStG und demnach einkommensteuerlich unbeachtlich. ${ }^{12}$

Beim Veräusserer sind vereinnahmte Stückzinsen Bestandteil der Einnahmen aus der Veräußerung. ${ }^{13}$ Vom Erwerber gezahlte Stückzinsen sind vom Kreditinstitut in den Allgemeinen Verlustverrechnungstopf einzustellen und so steuermindernd beim Kapitalertragsteuerabzug zu berücksichtigen (negative Einnahmen i. S. d. § 20 Abs. 1 Nr. 7 EStG). ${ }^{14}$

\section{d) In- und ausländische Dividenden}

Körperschaften mit Sitz oder Geschäftsleitung im Inland haben auf Ausschüttungen Kapitalertragsteuer (zuzüglich Solidaritätszuschlag) einzubehalten und abzuführen (Emittentensteuer). Individuelle Steuermerkmale der Anleger (z. B. Verlustverrechnung, Freistellungsaufträge) werden dabei nicht berücksichtigt; dies erfolgt bei der die Dividenden auszahlenden inländischen Zahlstelle.

Auf Ausschüttungen von Körperschaften, die weder Sitz noch Geschäftsleitung im Inland haben, hat die die Dividende auszahlende inländische Zahlstelle auf die Bruttodividende die Kapitalertragsteuer einzubehalten. Ausländische Quellensteuern werden auf die deutsche Kapitalertragsteuer grundsätzlich angerechnet bzw. in den Quellensteuertopf eingestellt.

10 BMF, Schr. v. 22.12.2009, a. a. O., Rz. 86.

11 Vgl.Haisch/Krampe, FR 2010, 311 (313) zur Anwendung dieser Grundsätze auch auf andere sog. unechte strukturierte Finanzinstrumente.

12 BMF, Schr. v. 22.12.2009, a.a.O., Rz. 60; kritisch hierzu Haisch/Krampe, FR 2010, 311 (319).

13 BMF, Schr. v. 22.12.2209, a. a. O., 4 Rz. 50.

14 BMF, Schr. v. 22.12.2009, a. a. O., Rz. 51. 
e) Gewinn aus der Veräußerung und Abtretung von Aktien und ähnlichen Beteiligungen

Veräußerungsgewinne aus Aktien, aktienähnlichen Genussrechten und ähnlichen Beteiligungen und Anwartschaften unterliegen unabhängig davon, ob es sich um in- oder ausländische Emittenten handelt dem Kapitalertragsteuerabzug durch die auszahlende Zahlstelle.

\section{f) Zertifikate}

Bei Zertifikaten erfolgt eine Unterscheidung in solche

- ohne Kapitalgarantie und Vergütungszusage („Vollrisikozertifikate“) und

- solche mit teilweiser oder vollständiger Kapitalgarantie und/oder Vergütungszusage ("Garantiezertifikate").

Vor Einführung der Abgeltungsteuer waren Gewinne aus der Veräußerung von Vollrisikozertifikaten nach Ablauf von einem Jahr steuerfrei. Garantiezertifikate waren nach alter Gesetzeslage Finanzinnovationen, ein Veräußerungsgewinn bzw. -verlust war unabhängig von der Haltedauer steuerlich relevant.

Mit Einführung der Abgeltungsteuer sind laufende Erträge aus Zertifikaten und Gewinne aus der Veräußerung, Abtretung und Einlösung von Vollrisiko- und Garantiezertifikaten der Kapitalertragsteuer zu unterwerfen. ${ }^{15}$

Die Unterscheidung zwischen Vollrisiko- und Garantiezertifikaten hat im Rahmen der neuen gesetzlichen Bestimmungen nur noch Bedeutung für die Übergangsregelungen. ${ }^{16}$

Die Regelungen für Zertifikate gelten auch für Schuldverschreibungen, wenn deren Rückzahlungsbetrag an Gold oder andere Rohstoffe gekoppelt ist, auch wenn ein Anspruch auf physische Erfüllung (Lieferung) verbrieft wird. ${ }^{17}$

\section{g) Tilgung von Anleihen durch Wertpapierlieferungen}

Werden Wandelanleihen, Aktienanleihen oder Umtauschanleihen nicht in Geld sondern durch Lieferung von Wertpapieren (z. B. Aktien) getilgt, gelten die Erwerbskosten der Anleihe als deren Veräußerungspreis und

15 Vgl. zur Behandlung von Zertifikaten mit mehreren Tilgungszeitpunkten, BMF, Schr. v. 16.11.2010, IV C1-S2252/10/10010, dieses Schreiben ergänzt BMF, Schr. v. 22.12.2009, a. a. O. um Rz. 8a.

16 BMF, Schr. v. 22.12.2009, a. a. O., Rz. 320.

17 BMF, Schr. v. 22.12.2009, a.a.O., Rz. 57; a. A. Haisch/Krampe, FR 2010, 311 (318f.). 
als Anschaffungskosten der gelieferten Wertpapiere (§20 Abs. 4a S. 3 EStG). ${ }^{18}$

Bei der Tilgung der Anleihe durch Lieferung anderer Wertpapiere handelt es sich demnach immer um einen steuerneutralen Vorgang, so wird z. B. bei einer Aktienanleihe durch die Lieferung der Aktien kein Verlust realisiert. Zu einer Verlustrealisation kann es erst ggf. bei einer anschließenden Veräußerung der Aktien selbst kommen. ${ }^{19}$

\section{h) Termingeschäfte}

Termingeschäfte sind als Options- oder Festgeschäfte ausgestaltete Finanzinstrumente, deren Preis unmittelbar oder mittelbar von einem Basiswert (z. B. Preis von Wertpapieren, Indizes, Devisen, Zinssätzen, Metallen, anderen Rohstoffen) abhängt und bei denen Vertragsabschluss und Vertragserfüllung zeitlich auseinanderfallen. ${ }^{20}$ Es handelt sich hierbei z. B. um Optionsgeschäfte, Swaps, Forwards, Futures und Kombinationen hieraus. Das Termingeschäft ist in den Steuergesetzen selbst nicht definiert.

Steuerlich erfasst wird sowohl der Gewinn bzw. Verlust bei Endfälligkeit (soweit es nicht zur physischen Lieferung des Basiswertes kommt) als auch der Gewinn bzw. der Verlust aus der Veräußerung des Termingeschäftes selbst (§ 20 Abs. 2 S. 1 Nr. 3 Buchst. a und b EStG).

Nach alter Gesetzeslage bestand eine Steuerpflicht nur, wenn Endfälligkeit bzw. Veräußerung innerhalb der Jahresfrist erfolgten (§ 23 EStG a. F.).

Ist das Termingeschäft auf die (optionale) Lieferung des Basiswertes gerichtet und kommt es zu einer tatsächlichen Lieferung des Basiswertes, liegt zum Zeitpunkt der Lieferung ein steuerneutrales Anschaffungsgeschäft vor. ${ }^{21}$ Aufwendungen für den Erwerb des Terminkontrakts und ggf. zu leistende Zuzahlungen sind Anschaffungskosten des Basiswertes. Bei Optionsgeschäften gilt bezüglich der durch den Stillhalter vereinnahmten Stillhalterprämien allerdings, dass diese nicht als Anschaffungsnebenkosten bzw. Veräusserungskosten beim Stillhalter anzusehen sind. ${ }^{22}$

18 Vgl. BMF, Schr. v. 22.12.2009, a. a. O., Rz. 104; zu Fragen der Übergangsregelung bei Vollrisikozertifikaten mit Andienungsrecht vgl. Rz. 105.

19 Zur teilweisen Tilgung in bar vgl. BMF, Schr v. 22.12.2009, a. a. O., Rz. 106.

20 Vgl. BMF, Schr v. 22.12.2009, a. a. O., Rz. 9; Haisch/Krampe, FR 2010, 311 (315).

21 Einzelheiten zu Devisentermingeschäften vgl. Haisch/Krampe, FR 2010, 311 (316f).

22 BMF, Schr v. 22.12.2009, a.a. O., Rz. 26 Satz 2 und Rz. 33 Satz 2; zur Begründung vgl. Haisch/Krampe, FR 2010, 311 (314) m. w. N. 
Bei einer nachfolgenden Veräußerung des Basiswertes kommt es je nach Art des Basiswertes zu einer Besteuerung nach $\S 20$ Abs. 2 EStG oder ggf. nach $\S 23$ Abs. 1 S. 1 Nr. 2 EStG (z. B. bei Fremdwährungen, Rostoffen, Metallen).

Verfällt ein Termingeschäft, so soll dies, nach umstrittener Auffassung der Finanz-verwaltung, ein steuerlich unbeachtlicher privater Vermögensschaden sein. ${ }^{23}$

\section{Optionen}

Bei Optionsgeschäften erwirbt der Käufer (Optionsnehmer) vom Verkäufer (Optionsgeber, Stillhalter) gegen Zahlung einer Prämie (Stillhalterprämie) das Recht, am Ende oder während der Optionslaufzeit zu einem vereinbarten Preis einen Basiswert zu kaufen (Kaufoption-Call) oder an ihn zu verkaufen (Verkaufsoption-Put).

Bei Kauf- und Verkaufsoptionen ist jeweils zwischen den steuerlichen Auswirkungen beim Käufer bzw. Verkäufer der Option zu unterscheiden und dabei wiederum zwischen Vertragsabschluss, Veräußerung bzw. Glattstellung der Option, Ausübung der Option mit physischer Lieferung oder mit Barausgleich und Verfall der Option.

In der folgenden Übersicht sind die Besteuerungsgrundsätze bei einer Kaufoption dargestellt. ${ }^{24}$

\begin{tabular}{|c|c|c|}
\hline \multirow[t]{2}{*}{ Transaktion } & \multicolumn{2}{|l|}{ Kaufoption (Call) } \\
\hline & Käufer Long Position & Stillhalter Short Position \\
\hline $\begin{array}{l}\text { Vertrags- } \\
\text { schluss (Op- } \\
\text { tionsprämie/ } \\
\text { Stillhalter- } \\
\text { prämie) }\end{array}$ & $\begin{array}{l}\text { - Kein KESt-Abzug: Gezahlte } \\
\text { Optionsprämie und Trans- } \\
\text { aktionskosten führen zu } \\
\text { Anschaffungskosten der } \\
\text { Option. }\end{array}$ & $\begin{array}{l}\text { - KESt-Abzug auf erhaltene } \\
\text { Stillhalterprämie nach Abzug } \\
\text { der Transaktionskosten } \\
\text { - Bemessungsgrundlage: } \\
\text { Erhaltene Stillhalterprä- } \\
\text { mie } \\
\text {./. Transaktionskosten }\end{array}$ \\
\hline $\begin{array}{l}\text { Veräußerung/ } \\
\text { Glattstellung }\end{array}$ & $\begin{array}{l}\text { - KESt-Abzug auf Veräuße- } \\
\text { rungsgewinn, Verluste wer- } \\
\text { den in den Allgemeinen Ver- } \\
\text { lustverrechnungstopf einge- } \\
\text { stellt } \\
\text { - Bemessungsgrundlage: } \\
\quad \text { Einnahmen aus der Ver- } \\
\text { äußerung/Glattstellung } \\
\text { /. Anschaffungskosten }\end{array}$ & $\begin{array}{l}\text { - Kein KESt-Abzug: Stillhalter } \\
\text { kann die Option nicht ver- } \\
\text { äußern } \\
\text { - Bei Glattstellung: Aufwen- } \\
\text { dungen für Glattstellung } \\
\text { werden in den Allgemeinen } \\
\text { Verlustverrechnungstopf ein- } \\
\text { gestellt }\end{array}$ \\
\hline
\end{tabular}

23 BMF, Schr. v. 22.12.2009, a. a. O., Rz. 27.

24 Vgl. hierzu auch BMF, Schr. v. 22.12.2009, a. a. O., Rz. 21 ff. 


\begin{tabular}{|c|c|c|}
\hline \multirow[t]{2}{*}{ Transaktion } & \multicolumn{2}{|l|}{ Kaufoption (Call) } \\
\hline & Käufer Long Position & Stillhalter Short Position \\
\hline $\begin{array}{l}\text { Ausübung mit } \\
\text { physischer } \\
\text { Lieferung }\end{array}$ & $\begin{array}{l}\text { - Kein ESt-Abzug zum Zeit- } \\
\text { punkt der Lieferung/Erhalt } \\
\text { des Basiswertes } \\
\text { - KESt-Relevanz bei späterer } \\
\text { Veräußerung des erhaltenen } \\
\text { Basiswertes (z. B. Aktie) mit } \\
\text { Bemessungsgrundlage: } \\
\text { Einnahmen aus der Ver- } \\
\text { äußerung } \\
\text {./. Anschaffungskosten } \\
\text { - sonst privates Veräußerungs- } \\
\text { geschäft (§ 23 EStG bei z. B. } \\
\text { Rohstoffe, Gold) }\end{array}$ & $\begin{array}{l}\text { - Lieferung des Basiswertes ist } \\
\text { Veräußerung } \\
\text { - KESt-Abzug auf Veräußerung } \\
\text { des Basiswertes (z. B. Aktie) } \\
\text { mit Bemessungsgrundlage: } \\
\text { Einnahmen aus der Ver- } \\
\text { äußerung } \\
\text { /. Anschaffungskosten } \\
\text { (ohne erhaltene Stillhal- } \\
\text { terprämie) } \\
\text {./. Transaktionskosten } \\
\text { - sonst privates Veräußerungs- } \\
\text { geschäft (§ 23 EStG bei z. B. } \\
\text { Rohstoffen, Gold oder im } \\
\text { Falle der Veräußerung des } \\
\text { Basiswerts mit Bestand- } \\
\text { schutz) }\end{array}$ \\
\hline $\begin{array}{l}\text { Ausübung mit } \\
\text { Barausgleich }\end{array}$ & $\begin{array}{l}\text { - KESt-Abzug auf erhaltene } \\
\text { Differenz zwischen dem ver- } \\
\text { einbarten Basispreis und dem } \\
\text { Tageskurs des Basiswertes } \\
\text { - Bemessungsgrundlage: } \\
\text { erhaltener Barausgleich } \\
\text {./. Anschaffungskosten }\end{array}$ & $\begin{array}{l}\text { - Kein KESt-Abzug: Geleis- } \\
\text { teter Barausgleich ist privater } \\
\text { Vermögensschaden } \\
\text { - keine Berücksichtigung im } \\
\text { Allgemeinen Verlustverrech- } \\
\text { nungstopf }\end{array}$ \\
\hline Verfall & $\begin{array}{l}\text { - Kein KESt-Abzug: Anschaf- } \\
\text { fungskosten sind privater } \\
\text { Vermögensschaden } \\
\text { - keine Berücksichtigung im } \\
\text { Allgemeinen Verlustverrech- } \\
\text { nungstopf }\end{array}$ & $\begin{array}{l}\text { - Kein KESt-Abzug: Verfall ist } \\
\text { für Stillhalter unbeachtlich }\end{array}$ \\
\hline
\end{tabular}

Kritisiert wird die Auffassung der Finanzverwaltung, dass ein Verfall der Option beim Käufer der Option ein steuerlich irrelevanter Vermögensschaden sei. Eine Ausweichmöglichkeit wäre, die Option kurz vor Verfall unter Verlustrealisation zu verkaufen. ${ }^{25}$

Kritisiert wird weiterhin, dass Barausgleichszahlungen eines Stillhalters einkommensteuerlich unbeachtlich sind. ${ }^{26}$

25 Zur Frage des Missbrauchs i. S.d. §42 Abs. 1 S. 2 AO vgl. Haisch/Krampe, FR 2010, 311 (315f.).

26 BMF, Schr. v. 22.12.2009, a.a. O., Rz. 26 Satz 3; vgl. zum Meinungsstand Haisch/Krampe, FR 2010, 311 (314f.) m. w. N. 
In der nachfolgenden Übersicht sind die Besteuerungsgrundsätze bei einer Verkaufsoption dargestellt. ${ }^{27}$

\begin{tabular}{|c|c|c|}
\hline \multirow[t]{2}{*}{ Transaktion } & \multicolumn{2}{|l|}{ Verkaufoption (Put) } \\
\hline & Käufer Long Position & Stillhalter Short Position \\
\hline $\begin{array}{l}\text { Vertrags- } \\
\text { schluss (Op- } \\
\text { tionsprämie/ } \\
\text { Stillhalter- } \\
\text { prämie) }\end{array}$ & $\begin{array}{l}\text { - Kein KESt-Abzug: gezahlte } \\
\text { Optionsprämie und Trans- } \\
\text { aktionskosten führen zu } \\
\text { Anschaffungskosten der } \\
\text { Option }\end{array}$ & $\begin{array}{l}\text { - KESt-Abzug auf erhaltene } \\
\text { Stillhalterprämie nach Abzug } \\
\text { der Transaktionskosten } \\
\text { - Bemessungsgrundlage: } \\
\text { Erhaltene Stillhalterprä- } \\
\text { mie } \\
\text {./. Transaktionskosten }\end{array}$ \\
\hline $\begin{array}{l}\text { Veräußerung/ } \\
\text { Glattstellung }\end{array}$ & $\begin{array}{l}\text { - KESt-Abzug auf Veräuße- } \\
\text { rungsgewinn, Verluste wer- } \\
\text { den in den Allgemeinen Ver- } \\
\text { lustverrechnungstopf einge- } \\
\text { stellt } \\
\text { - Bemessungsgrundlage: } \\
\text { Einnahmen aus der Ver- } \\
\text { äußerung/Glattstellung } \\
\text { /. Anschaffungskosten }\end{array}$ & $\begin{array}{l}\text { - Kein KESt-Abzug: Stillhalter } \\
\text { kann die Option nicht ver- } \\
\text { äußern } \\
\text { - Bei Glattstellung: Aufwen- } \\
\text { dungen für Glattstellung } \\
\text { werden in den Allgemeinen } \\
\text { Verlustverrechnungstopf ein- } \\
\text { gestellt }\end{array}$ \\
\hline $\begin{array}{l}\text { Ausübung mit } \\
\text { physischer } \\
\text { Lieferung }\end{array}$ & $\begin{array}{l}\text { - Lieferung des Basiswertes ist } \\
\text { Veräußerung } \\
\text { - KESt-Abzug auf Veräußerung } \\
\text { des Basiswertes (z. B. Aktie) } \\
\text { mit Bemessungsgrundlage } \\
\text { Einnahmen aus der Ver- } \\
\text { äußerung } \\
\text {./. Anschaffungskosten } \\
\text { - sonst privates Veräußerungs- } \\
\text { geschäft (§ 23 EStG bei z. B. } \\
\text { Rohstoffen, Gold oder im } \\
\text { Falle der Veräußerung des } \\
\text { Basiswerts mit Bestand- } \\
\text { schutz) }\end{array}$ & $\begin{array}{l}\text { - Kein KESt-Abzug zum Zeit- } \\
\text { punkt der Lieferung/Erhalt } \\
\text { des Basiswertes } \\
\text { - KESt-Abzug bei späterer Ver- } \\
\text { äußerung des erhaltenen } \\
\text { Basiswertes (z. B. Aktie) mit } \\
\text { Bemessungsgrundlage: } \\
\text { Einnahmen aus der Ver- } \\
\text { äußerung } \\
\text { /. Anschaffungskosten } \\
\text { /. Transaktionskosten } \\
\text { - sonst privates Veräußerungs- } \\
\text { geschäft (§ 23 EStG bei z. B. } \\
\text { Rohstoffe, Gold) }\end{array}$ \\
\hline $\begin{array}{l}\text { Ausübung mit } \\
\text { Barausgleich }\end{array}$ & $\begin{array}{l}\text { - KESt-Abzug auf erhaltene } \\
\text { Differenz zwischen dem ver- } \\
\text { einbarten Basispreis und dem } \\
\text { Tageskurs des Basiswertes } \\
\text { - Bemessungsgrundlage: } \\
\text { erhaltener Barausgleich } \\
\text { /. Anschaffungskosten }\end{array}$ & $\begin{array}{l}\text { - Kein KESt-Abzug: Geleis- } \\
\text { teter Barausgleich ist privater } \\
\text { Vermögensschaden } \\
\text { - keine Berücksichtigung im } \\
\text { Allgemeinen Verlustverrech- } \\
\text { nungstopf }\end{array}$ \\
\hline
\end{tabular}

27 Vgl. auch BMF, Schr. v. 22.12.2009, a. a. O., Rz. 28 ff. 
Arntz, Abgeltungsteuer auf Einkünfte aus Kapitalvermögen

\begin{tabular}{|c|c|c|}
\hline \multirow[t]{2}{*}{ Transaktion } & \multicolumn{2}{|l|}{ Verkaufoption (Put) } \\
\hline & Käufer Long Position & Stillhalter Short Position \\
\hline Verfall & $\begin{array}{l}\text { - Kein KESt-Abzug: Anschaf- } \\
\text { fungskosten sind privater } \\
\text { Vermögensschaden } \\
\text { - keine Berücksichtigung im } \\
\text { Allgemeinen Verlustverrech- } \\
\text { nungstopf }\end{array}$ & $\begin{array}{l}\text { - Kein KESt-Abzug: Verfall ist } \\
\text { für Stillhalter unbeachtlich }\end{array}$ \\
\hline
\end{tabular}

Futures and Forwards

Futures und Forwards sind als Festgeschäft ausgestaltete Termingeschäfte, bei denen die Liefer- bzw. Abnahmeverpflichtung eines Wirtschaftsgutes zu einem fest vereinbarten Preis (z. B. Aktien, Währungen) oder die Verpflichtung zum Differenzausgleich zeitlich hinausgeschoben ist. ${ }^{28}$

Kommt es bei Futures und Forwards zu einem Differenzausgleich, führt dies zu einem Gewinn bzw. Verlust i.S.d. §20 Abs. 2 S. 1 Nr. 3 Buchst. a EStG. Wird ein Basiswert geliefert, liegt für den Erwerber zunächst ein steuerneutrales Anschaffungsgeschäft vor. ${ }^{29}$ Je nach Art des erworbenen Wirtschaftsgutes führt seine Weiterveräußerung zu Erträgen nach $\S 20$ Abs. 2 EStG oder ggf. zu privaten Veräußerungsgeschäften nach $\S 23$ Abs. 1 S. 1 Nr. 2 EStG (z. B. bei Währungen, Rohstoffen). ${ }^{30}$

Swaps

Swaps sind unbedingte Termingeschäfte mit Dauerschuldcharakter, bei denen die Vertragsparteien nach bestimmten Parametern ermittelte Geldbeträge tauschen, z. B. Zinsswaps, Aktienswaps, Cross Currency Swaps.

\section{Zinsswaps}

Bei Zinsswaps werden Zahlungsströme über eine bestimmte Laufzeit ausgetauscht, die sich nach den jeweils zu Grunde gelegten Zinssätzen bezogen auf einen Nominalbetrag ermitteln. Gezahlt werden z. B. fixe gegen variable Zinsen, berechnet auf einen Nominalbetrag über eine bestimmte Zeit. ${ }^{31}$

Für steuerliche Zwecke ist auf die jeweils tatsächlich erfolgten Zahlungen abzustellen. Erhaltene Zahlungen sind Kapitalerträge aus Termingeschäften und unterliegen dem Kapitalertragsteuerabzug (§§ 44 Abs. 1 S. 4 Nr. 1.i. V. m. 43 Abs. 1 S. 1 Nr. 11, 20 Abs. 2 S. 1 Nr. 3 Buchst. a EStG).

28 BMF, Schr. v. 22.12.2009, a. a. O., Rz. 36.

29 Vgl. hierzu auch die Übersicht bei Haisch/Krampe, FR 2010, 311 (317).

30 Vgl. BMF, Schr. v. 22.12.2009, a. a. O., Rz. 36 f.

31 Vgl. BMF, Schr. v. 22.12.2009, a. a. O., Rz. 47. 
Geleistete Zahlungen sind in den Allgemeinen Verlustrechnungstopf einzustellen (§ 43a Abs. 3 EStG).

\section{Aktienswap}

Bei einem Aktienswap übernimmt der Sicherungsgeber für eine bestimmte Zeit das Kurs- und Dividendenrisiko aus einer Aktie, ohne die Aktie selbst zu übernehmen. ${ }^{32}$

Bei einem Aktienswap tauschen Sicherungsgeber und Sicherungsnehmer die folgenden Zahlungsströme aus:

Sicherungsgeber: erhält: Dividendenausgleichszahlung

Kurssteigerungsäquivalent

zahlt: Refinanzierungskosten

Kursverlustäquivalent

Sicherungsnehmer: erhält: Dividende (§ 20 Abs. 1 Nr. 1 EStG)

Kursverlustausgleich

(Ertrag i. S. d. § 20 Abs. 4 S. 5 EStG)

Refinanzierungskostenersatz

(Ertrag i. S. d. § 20 Abs. 4 S. 5 EStG)

zahlt: Dividendenausgleich

(Aufwand i. S. d. § 20 Abs. 4 S. 5. EStG)

Kurssteigerungsäquivalent

(Aufwand i. S. d. §20 Abs. 4 S. 5 EStG)

Die jeweiligen Zahlungen sind Einnahmen bzw. Aufwendungen aus Termingeschäften. Verbleibende Zahlungsüberschüsse sind kapitalertragsteuer-pflichtige Gewinne und verbleibende Zahlungsüberhänge sind in den Allgemeinen Verlustverrechnungstopf einzustellen (§ 43a Abs. 3 EStG). Die Dividende selbst unterliegt der Kapitalertragsteuer bei der auszahlenden Aktiengesellschaft (Emittentensteuer).

\section{Zinsbegrenzungsvereinbarungen}

Zinsbegrenzungsvereinbarungen sind bedingte Termingeschäfte, bei denen sich der Verkäufer des Kontrakts verpflichtet an den Käufer Ausgleichszahlungen zu leisten, wenn der zu Grunde gelegte Zinssatz, die vereinbarte Höhe über- oder unterschreitet. ${ }^{33}$

Bei Zinsbegrenzungsvereinbarungen werden folgende Grundformen unterschieden:

- Caps (Zinsoberbegrenzung)

- Floors (Zinsunterbegrenzung)

- Collars (Kombination, Cap/Floor)

32 Vgl. BMF, Schr. v. 22.12.2009, a. a. O., Rz. 45 f.

33 Vgl. BMF, Schr. v. 22.12.2009, a. a. O., Rz. 40 ff. 
Geleistete Zahlungen für den Erwerb des Zinsbegrenzungsgeschäfts sind im Zeitpunkt der ersten Ausgleichszahlung beim Erwerber des Kontraktes nach $\S 20$ Abs. 4 S. 5 EStG zu berücksichtigen. Kommt es während der gesamten Vertragslaufzeit nicht zu Ausgleichszahlungen, ist von einem Verfall der Rechtsposition auszugehen. Die für den Erwerb der Rechtsposition gemachten Aufwendungen führen zu einem steuerlich unbeachtlichen Vermögensschaden. ${ }^{34}$

Die vom Veräußerer bei Vertragsbeginn vereinnahmte Prämie ist Ertrag i. S. d. $§ 20$ Abs. 1 Nr. 11 EStG, von dieser Prämie können geleistete Ausgleichszahlungen nicht in Abzug gebracht werden. ${ }^{35}$

Cross-Currency Swap

Bei Cross-Currency-Swaps werden in der Regel zu Beginn und/oder am Ende des Kontraktes zwei unterschiedliche Währungen und während der Vertragslaufzeit Zinszahlungsströme ( $z$. B. fix gegen floating) getauscht.

Bei dem Austausch von unterschiedlichen Währungen handelt es sich um Liefergeschäfte, die nicht der Kapitalertragsteuer unterliegen. Bei einer Anschlussveräußerung der Fremdwährung kommt es ggf. zu privaten Veräußerungsgeschäften i. S. d. § 23 Abs. 1 S. 1Nr. 2 EStG.

\section{Kapitalmaßnahmen}

a) Übersicht

Einige Kapitalmaßnahmen bei Körperschaften sind gesetzlich gesondert geregelt (§ 20 Abs. 4a EStG). Es handelt sich dabei insbesondere um folgende Maßnahmen:

- Tausch von Anleihen an Körperschaften gegen Anteile anderer Körperschaften, wenn die Körperschaft weder Sitz noch Geschäftsleitung im Inland hat

- Barzahlungen, die neben Anteilen als Gegenleistung gewährt werden

- Zuteilung von Bezugsrechten

- Zuteilung neuer Stücke (z. B. Freianteile, Bonusaktien) ohne Gegenleistung

Die vorgenannten Maßnahmen sind $z$. T. dadurch gekennzeichnet, dass es $z u$ - normalerweise gewinnrealisierenden - Tauschvorgängen oder zum Zufluss von Wirtschaftsgütern ohne Barmittelzufluss kommt. Der sofortige Einbehalt von Kapitalertragsteuer wäre kompliziert, da keine Barmittel zufließen, von denen ein Kapitalertragsteuerabzug vorgenommen werden könnte. Demnach stellen die gesetzlichen Regelungen

34 BMF, Schr. v.22.12.2009, a. a. O., Rz. 43.

35 BMF, Schr. v. 22.12.2009, a. a. O., Rz. 44. 
sicher, dass stille Reserven dauerhaft verstrickt bleiben, Kapitalertragsteuer aber erst dann einbehalten wird, wenn die neuen Wirtschaftsgüter mit Geldzufluss veräußert werden (Cash-Flow-Prinzip).

\section{b) Kapitalmaßnahmen im Einzelnen}

Anteilstauschvorgänge ( $\$ 20$ Abs. $4 a$ S. 1 f EStG).

Die Übertragung von Anteilen an Körperschaften, die weder Sitz noch Geschäftsleitung im Inland haben, im Rahmen von Verschmelzungen, Spaltungen und Tauschvorgängen, ist unter bestimmten Voraussetzungen insoweit begünstigt, als ein Einbehalt von Kapitalertragsteuer nicht bei der Durchführung der Kapitalmaßnahme erfolgt, sondern erst bei einer ggf. später stattfindenden Veräußerung der (neuen) Anteile.

Erhält der Anleger gegen Hingabe seiner Anteile neue Anteile an einer anderen Körperschaft, treten die erhaltenen Anteile an die Stelle der hingegebenen Anteile, d.h., die Anschaffungskosten und der Anschaffungszeitpunkt der eingetauschten Anteile werden auf die neuen Anteile übertragen (,Fußstapfentheorie $\left.{ }^{\prime \prime}\right) \cdot{ }^{36}$

Bei Spaltungen erfolgt die Anschaffungskostenaufteilung nach dem Spaltungs- oder Übernahmevertrag. Ist dieser nicht bekannt, ist auf das rechnerische Umtauschverhältnis abzustellen. ${ }^{37}$

Durch das Jahressteuergesetz 2010 soll der Anwendungsbereich der Regelungen auch auf inländische Körperschaften ausgedehnt werden.

Barzuzahlungen

Werden neben Anteilen Barzuzahlungen an den Anleger geleistet, sind diese als dividendenähnliche Erträge der Kapitalertragsteuer zu unterwerfen.

\section{Bezugsrechte}

Zugeteilte Bezugsrechte werden mit Anschaffungskosten von Null Euro eingebucht (§ 20 Abs. 4a S. 4 EStG). Die Ausübung des Bezugsrechts gilt nicht als Veräußerung des Bezugsrechts. ${ }^{38}$ Werden bei Ausübung des Bezugsrechts Zuzahlungen zum Erwerb der jungen Aktien geleistet, sind diese Anschaffungskosten der jungen Aktien.

Freianteile, Bonusaktien

Werden Aktien ohne Entgelt ausgegeben, sind die Einkünfte aus dem Bezug und die Anschaffungskosten mit Null Euro anzusetzen, wenn die

36 Vgl. BMF, Schr. v. 22.12.2009, a. a. O., Rz. 100.

37 Vgl. BMF, Schr. v. 22.12.2009, a. a. O., Rz. 101.

38 Vgl. BMF, Schr. v. 22.12.2009, a. a. O., Rz. 110. 
Ermittlung der Höhe des Kapitalertrages nicht möglich ist (§ 20 Abs. 4a S. 5 EStG).

Kapitalrückzahlungen und Ausschüttungen aus dem steuerlichen Einlagenkonto

Ausschüttungen aus dem steuerlichen Einlagenkonto (§27 KStG) und die Rückzahlung von Nennkapital sind grundsätzlich nicht kapitalertragsteuerpflichtig. Zahlungen mindern die Anschaffungskosten der Anteile. Falls die Rückzahlungen die Anschaffungskosten übersteigen, entstehen negative Anschaffungskosten. ${ }^{39}$

\section{Verlustverrechnung durch die Kreditinstitute}

\section{Notwendigkeit der Verlustverrechnung durch die Kreditinstitute}

Ziel der Abgeltungsteuer ist es, Veranlagungen bei Einkünften aus Kapitalvermögen weitgehend zu vermeiden, soweit es sich um inländische Privatanleger handelt.

Folge davon ist, dass im Idealfall schon auf Ebene des Kreditinstituts alle individuellen steuerlichen Merkmale des Anlegers zu berücksichtigen sind. Demnach erfolgt innerhalb eines Kalenderjahres auf Ebene des Kreditinstituts

- eine Verrechnung von Verlusten,

- eine Berücksichtigung von Freistellungsaufträgen (Sparer-Pauschbetrag),

- eine Berücksichtigung ausländischer Quellensteuern,

- eine ehegattenübergreifende Verlustverrechnung,

- ggf. ein Übertrag eines verbleibenden Verlustüberhanges ins Folgejahr.

\section{Grundsätze der Verlustverrechnung}

a) Erfasster Personenkreis

Die Verlustverrechnung ist beschränkt auf Anleger, deren Kapitalerträge zum Privatvermögen gehören, also insbesondere Privatanleger und inländische vermögensverwaltende Personengesellschaften. Nicht erfasst sind z. B. betriebliche Konten/Depots und Konten/Depots von Steuerausländern (vgl. § 43a Abs. 3 S. 7 EStG). ${ }^{40}$

39 Vgl. BMF, Schr. v. 22.12.2009, a. a. O., Rz. 92.

40 Vgl. BMF, Schr. v. 22.12.2009, a. a. O., Rz. 214 ff. 


\section{b) Grenzen der Verlustverrechnung}

Die Verlustverrechnung erfolgt nicht kreditinstitutsübergreifend, sondern nur innerhalb eines Kreditinstituts. Innerhalb eines Kreditinstituts kann eine stammnummernübergreifende Verlustverrechnung erfolgen. Hat ein Anleger Konten/Depots bei mehreren Kreditinstituten erfolgt keine kreditinstitutsübergreifende Verlustverrechnung. Es muss auf Kundenwunsch eine Bescheinigung des Verlustes durch das Kreditinstitut erfolgen, um im Wege der Veranlagung eine Verlustverrechnung vorzunehmen (§§ 20 Abs. 6 S. 6 EStG i. V. m. 43a Abs. 3 S. 4 EStG). Ansonsten überträgt das Kreditinstitut den Verlustüberhang ins Folgejahr.

Ab dem Jahr 2010 wird bei Ehegatten eine personenübergreifende Verlustverrechnung durch das Kreditinstitut durchgeführt, sog. ehegattenübergreifende Verlustverrechnung (§43a Abs. 3 S. 2 EStG). ${ }^{41}$ Erforderlich dafür ist die Abgabe eines gemeinsamen Freistellungsauftrages. ${ }^{42}$

\section{c) Verlustverrechnungstöpfe und Quellensteuertopf}

Um eine Verlustverrechnung und Anrechnung ausländischer Quellensteuer zu erreichen, führt das Kreditinstitut pro Kundenstammnummer einen

- Aktien Verlustverrechnungstopf,

- Allgemeinen Verlustverrechnungstopf,

- Quellensteuertopf.

Daneben werden erteilte Freistellungsaufträge berücksichtigt. ${ }^{43}$

Aktien Verlustverrechnungstopf

In den Aktien Verlustverrechnungstopf werden nur Verluste aus der Veräußerung von Aktien, bestimmten REIT-Anteilen (die als Aktien gelten), ADR (American Depositary Receipts) und GDR (Global Depositary Receipts) eingestellt. Nicht erfasst werden z. B. Verluste aus Aktienanleihen, Aktienzertifikaten, Aktienfonds und Optionsrechten auf Aktien. Veräußerungsverluste aus Aktien können nur mit Veräußerungsgewinnen aus Aktien verrechnet werden ( $\S \S 43$ a Abs. 3 S. 2 i. V.m. 20 Abs. 6 S. 5 EStG). Veräußerungsgewinne aus Aktien können jedoch mit Verlusten im Allgemeinen Verlustverrechnungstopf verrechnet werden. ${ }^{44}$

41 Vgl. BMF, Schr. v. 22.12.2009, a. a. O., Rz. $266 \mathrm{ff}$.

$42 \mathrm{Zu}$ den Einzelheiten der ehegattenübergreifenden Verlustverrechnung vgl. Elser/Bindl, FR 2010, 360 (364f.).

43 Zum Verlusttopf bei der auszahlenden Stelle vgl. Elser/Bindl, FR 2010, 360 (363f.).

44 Vgl. BMF, Schr. v. 22.12.2009, a. a. O., Rz. 228 f. 


\section{Allgemeiner Verlustverrechnungstopf}

In den Allgemeinen Verlustverrechnungstopf werden alle Veräußerungsverluste (außer Veräußerungsverluste aus Aktien), Einlösungsverluste, gezahlte Stückzinsen und Zwischengewinne sowie andere negative Ertragskomponenten (z. B. Vorschusszinsen, Swapzahlungen) eingestellt. In den Allgemeinen Verlustverrechnungstopf eingestellte negative Kapitalerträge können mit allen positiven Kapitalerträgen - auch mit Gewinnen aus der Veräußerung von Aktien - verrechnet werden.

\section{Quellensteuertopf}

Bei inländischen Privatanlegern werden ausländische Quellensteuern grundsätzlich auf die Kapitalertragsteuer angerechnet (§§ 43a Abs. 3 S. 1 i. V.m. 32d Abs. 5 EStG). Um dies zu ermöglichen, wird die einbehaltene Quellensteuer in den Quellensteuertopf eingestellt. Maximal anrechenbar sind $25 \%$ des Bruttoertrages. Es gilt der jeweils anwendbare DBASteuersatz, begrenzt jedoch auf maximal $25 \%$.

Die Anrechnung der ausländischen Quellensteuer auf die Kapitalertragsteuer erfolgt unabhängig davon, ob die Kapitalertragsteuer auf in- oder ausländische Kapitalerträge entfällt. ${ }^{45}$

\section{Verlustverrechnung innerhalb eines Kalenderjahres}

a) Reihenfolge der Verlustverrechnung unter Berücksichtigung von Freistellungsaufträgen und ausländischer Quellensteuer

Bei der Verlustverrechnung werden alle Kapitalerträge in der Reihenfolge berücksichtigt in der sie entstehen. Verluste werden auch rückwirkend mit früheren positiven Erträgen innerhalb desselben Kalenderjahres verrechnet (Liquiditätsoptimierung). ${ }^{46}$

Erst wenn nach Verlustverrechnung ein positiver Saldo verbleibt, wird ein noch nicht genutztes Freistellungsvolumen in Anspruch genommen, danach noch nicht angerechnete ausländische Quellensteuer. ${ }^{47}$

Hat das Kreditinstitut auf frühere positive Kapitalerträge unter Nutzung eines Freistellungsauftrages und ausländischer Quellensteuer Kapitalertragsteuer einbehalten, ist Folge der fortlaufenden Verlustverrechnung, dass der Quellensteuertopf, der Freistellungsauftrag und der Verlustverrechnungstopf wieder aufleben können.

$45 \mathrm{Zu}$ den Einzelheiten vgl. BMF, Schr. v. 22.12.2009, a. a. O., Rz. $201 \mathrm{ff}$.

46 Vgl. BMF, Schr. v. 22.12.2009, a. a. O., Rz. 212.

47 Vgl. BMF, Schr. v. 22.12.2009, a. a. O., Rz. 230. 
b) Beispiele für Verlustverrechnungen innerhalb eines Kalenderjahres Zuerst positive, dann negative Kapitalerträge

Ein inländischer, lediger Privatanleger erzielt im Laufe eines Kalenderjahres zuerst positive und dann negative Kapitalerträge. Im Wege der Liquiditätsoptimierung werden die Verluste mit den vorher erzielten Kapitalerträgen verrechnet und dem Anleger wird vorher einbehaltene Kapitalertragsteuer erstattet (vereinfachtes Beispiel ohne Berücksichtigung eines Freistellungsauftrages, ausländischer Quellensteuer, Solidaritätszuschlag und Kirchensteuer):

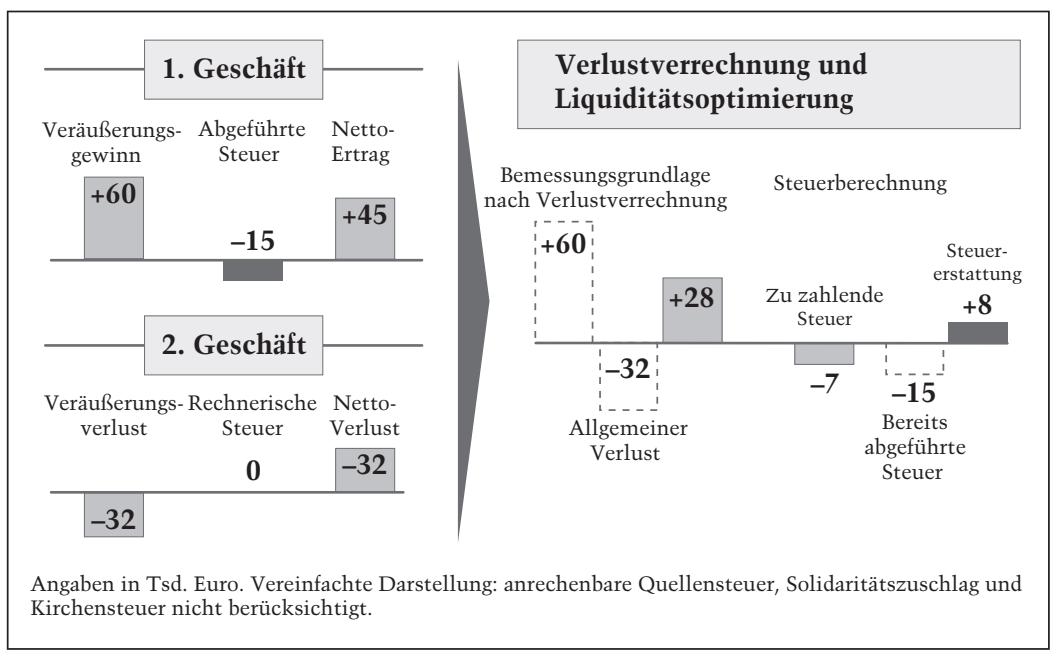

\section{"Tausch“ der Verlustverrechnungstöpfe}

Das Kreditinstitut hat Veräußerungsgewinne aus Aktien mit dem Allgemeinen Verlustverrechnungstopf verrechnet. Entstehen später Veräußerungsverluste aus Aktien, werden diese nachträglich mit dem Veräußerungsgewinn aus Aktien verrechnet. Der Allgemeine Verlustverrechnungstopf lebt ganz oder teilweise wieder auf (vereinfachtes Beispiel ohne Berücksichtigung eines Freistellungsauftrages, ausländischer Quellensteuer, Solidaritätszuschlag und Kirchensteuer): 


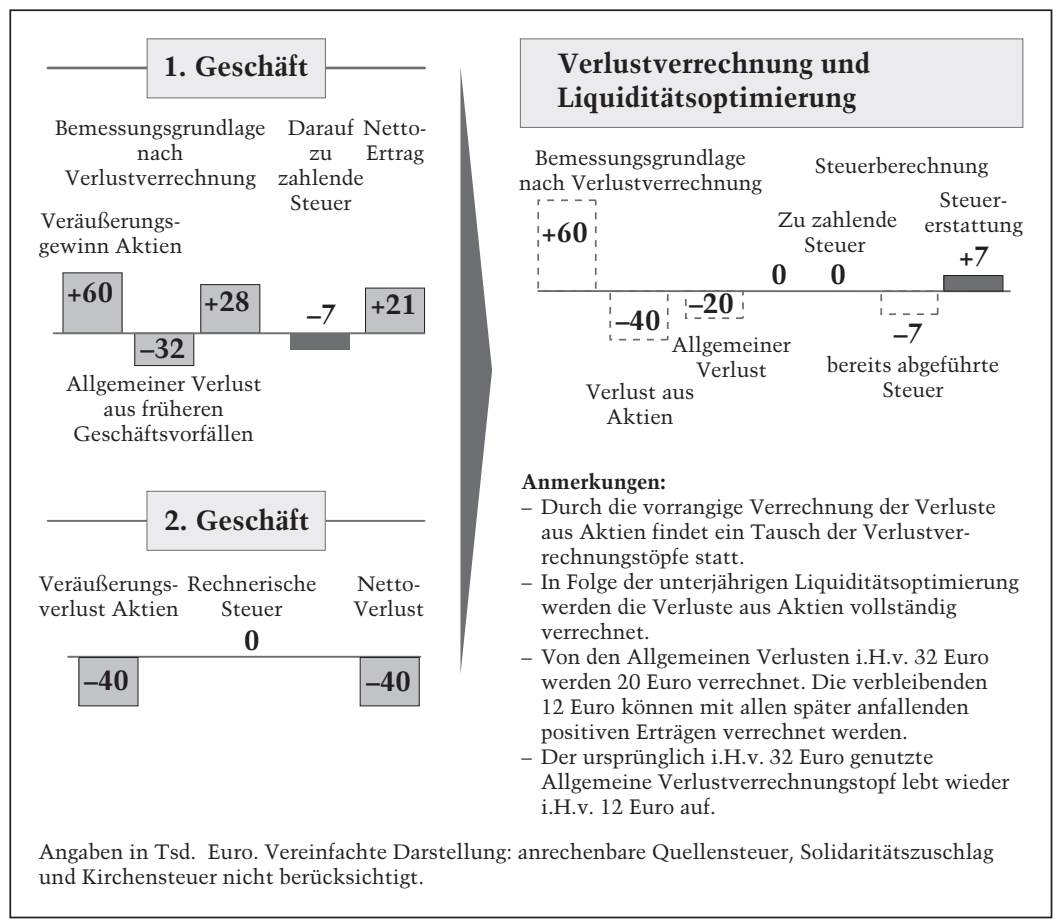

\section{Freistellungsauftrag und Verlustverrechnung}

Ein inländischer, lediger Privatanleger hat einen Freistellungsauftrag i. H. v. 801 Euro erteilt. Innerhalb des Kalenderjahres wird zunächst ein positiver Kapitalertrag erzielt, der gegen den Freistellungsauftrag läuft. Später werden negative Kapitalerträge erzielt, diese werden rückwirkend mit den positiven Kapitalerträgen verrechnet, der Freistellungsauftrag lebt wieder auf (vereinfachtes Beispiel ohne Berücksichtigung ausländischer Quellensteuer, Solidaritätszuschlag und Kirchensteuer): 


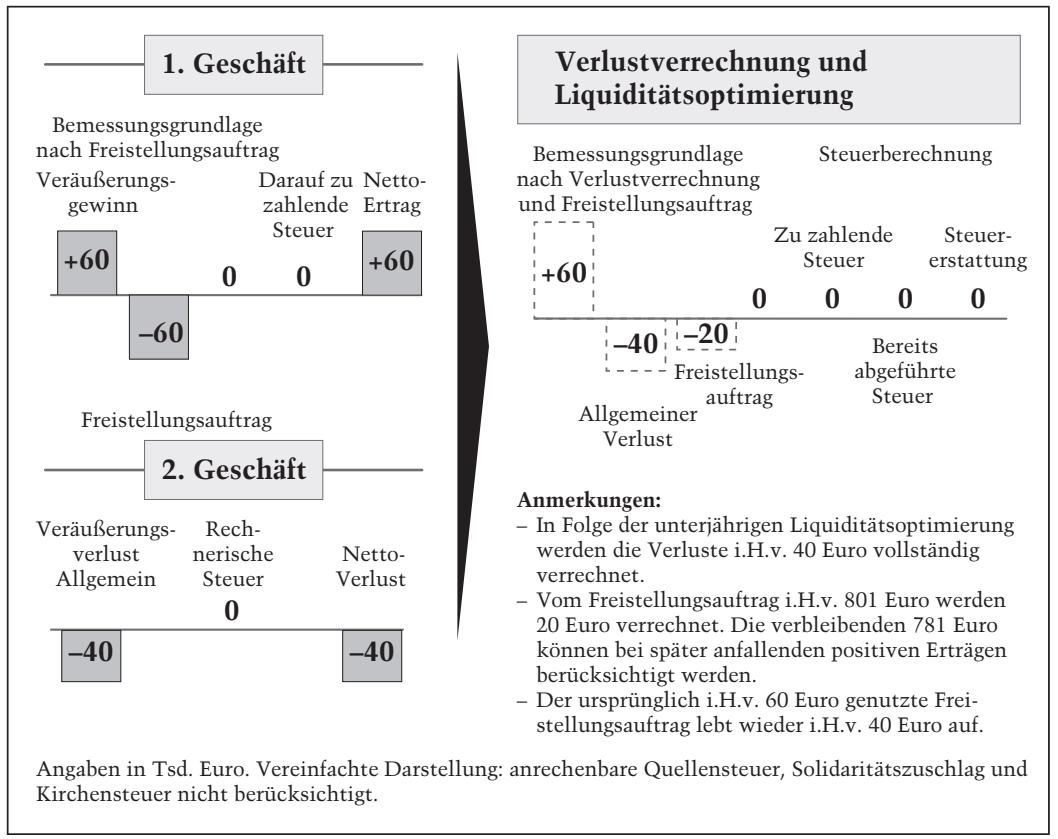

\section{Verlustvortrag auf Kreditinstitutsebene und Bescheinigung von Verlusten}

Nicht innerhalb des Kalenderjahres ausgeglichene Verluste werden getrennt nach Aktien Verlustverrechnungstopf und Allgemeiner Verlustverrechnungstopf - auf Kreditinstitutsebene für den Anleger auf das nächste Kalenderjahr übertragen (§43a Abs. 3 S. 3 EStG). Ein Verlustrücktrag auf Kreditinstitutsebene scheidet aus (§ 20 Abs. 6 S. 2 EStG).

Ein inländischer Privatanleger kann bis zum 15.12. jeden Jahres einen Antrag auf Bescheinigung der nicht verrechneten Verluste zum 31.12. des Jahres stellen. Die Bescheinigung kann getrennt nach Allgemeinem Verlustverrechnungstopf und Aktien Verlustverrechnungstopf gestellt werden. ${ }^{48}$ Im Falle der Bescheinigung werden die Verlustverrechnungstöpfe auf Kreditinstitutsebene auf Null gesetzt (§ 43a Abs. 3 S. 4 EStG).

48 Vgl. BMF, Schr. v. 22.12.2009, a. a. O., Rz. 233. 
Die bescheinigten Verluste können z. B. mit Gewinnen aus Konten/Depots bei anderen Kreditinstituten verrechnet werden ( $\S \S 20$ Abs. 6 S. 6 i. V.m. 43a Abs. 3 S. 4 EStG).

\section{Nicht genutzter Freistellungsauftrag/Quellensteuertopf}

Ein am Jahresende nicht bzw. nicht vollständig genutzter Freistellungsauftrag verfällt auf Kreditinstitutsebene, ein Vortrag ins nächste Jahr ist nicht möglich. Das Kreditinstitut stellt jedoch eine Bescheinigung über die Höhe des nicht genutzten Freistellungsauftrages aus. Dieser kann dann im Wege der Veranlagung geltend gemacht werden.

In den Quellensteuertopf eingestellte ausländische Quellensteuer, die bis zum Jahresende nicht angerechnet werden konnte, verfällt ebenfalls auf Kreditinstitutsebene und kann nicht in das nächste Kalenderjahr vorgetragen werden. Auch hier erfolgt eine Bescheinigung durch das Kreditinstitut, so dass der nicht genutzte Teil im Wege der Veranlagung geltend gemacht werden kann.

\section{Abstandnahme vom Steuerabzug/Steuererstattung}

Bei einer dem Grunde nach gegebenen Steuereinbehaltungspflicht kann aufgrund von persönlichen Freistellungsmerkmalen vom Kapitalertragsteuerabzug (einschl. Solidaritätszuschlag und ggf. Kirchensteuer) ganz oder teilweise Abstand genommen werden.

\section{Betragsmäßig begrenzte Freistellung aller Kapitalerträge}

Von großer praktischer Bedeutung ist der Freistellungsauftrag für inländische Privatanleger (natürliche Personen, §§ 44a Abs. 1 Nr. 1 Abs. 2 S. 1 Nr. 1 i. V.m. 20 Abs. 9 EStG).

Mit Wirkung vom 1.1.2009 wurde der Sparer-Freibetrag und der Werbungskostenpauschbetrag zum Sparer-Pauschbetrag (§ 20 Abs. 9 EStG) zusammengefasst. Er beträgt 801 Euro für Ledige sowie getrennt veranlagte Ehegatten und 1.602 Euro für zusammenveranlagte Ehegatten.

Die Erteilung eines Freistellungsauftrages an das Kreditinstitut ist Voraussetzung zur Berücksichtigung der Freibeträge. Antragsberechtigt sind Einzelpersonen sowie Ehegatten, soweit sie zusammenveranlagt werden.

Freigestellt sind Kapitalerträge i. S. d. § 43 Abs. 1 S. 1 Nr. 3, 4, 6, 7 und 8 bis 12 sowie S. 2 EStG (vgl. § 44a Abs. 1 EStG). 


\section{Betragsmäßig begrenzte/unbegrenzte Freistellung bestimmter Kapitalerträge}

Inländische Privatanleger können unter den gesetzlichen Voraussetzungen eine Nichtveranlagungsbescheinigung erlangen (§ 44a Abs. 1 Nr. 2, Abs. 2 S. 1 Nr. 2 EStG). Das Finanzamt stellt diese Bescheinigung aus, wenn zu erwarten ist, dass auch im Falle der Günstigerprüfung ( $\$ 32$ Abs. 6 EStG) keine Steuer entsteht. Im Gegensatz zum Freistellungsauftrag ist bei der Nichtveranlagungsbescheinigung die Höhe der freigestellten Kapitalbeträge nicht begrenzt.

Nichtveranlagungsbescheinigungen und Freistellungsbescheide können unter den gegebenen gesetzlichen Voraussetzungen auch von inländischen Körperschaften erlangt werden. Berechtigt sind z. B. gemeinnützige Stiftungen und Vereine, Städte, Gemeinden, Sterbe- und Pensionskassen, inländische Investmentfonds, Holdinggesellschaften, Versicherungsunternehmen.

\section{Betragsmäßig unbegrenzte Freistellung bestimmter Kapitalerträge für Körperschaften und betriebliche Anleger}

Bei den nachfolgend aufgeführten Anlegern unterliegen nur die laufenden Kapitalerträge (§ 20 Abs. 1 EStG, insbes. Zinsen, inländische Dividenden) dem Kapitalertragsteuerabzug. Freigestellt sind die neu eingeführten Abzugstatbestände $(\S 20$ Abs. 2 EStG, insbes. Veräußerungsgewinne, Gewinne aus Termingeschäften):

- Freistellung kraft Rechtsform. Freigestellt sind unbeschränkt steuerpflichtige Körperschaften, Personenvereinigungen und Vermögensmassen (§ 43 Abs. 2 S. 3 Nr. 1 EStG).

- Freigestellt sind sonstige juristische Personen des privaten Rechts (z. B. rechtsfähige Vereine) oder nicht rechtfähige Vereine oder Stiftungen.

- Freistellung ist gegeben für Betriebsvermögen, wenn Kapitalerträge beim Anleger Betriebseinnahmen eines inländischen Betriebs sind (§ 43 Abs. 2 S. 3 Nr. 2 EStG) und dem Kreditinstitut eine Freistellungserklärung vorliegt.

\section{Betragsmäßig unbegrenzte Freistellung bestimmter Kapitalerträge für bestimmte Anlegergruppen}

Ein Kapitalertragsteuerabzug ist nicht vorzunehmen, wenn eine Personenidentität zwischen Schuldner und Gläubiger vorliegt, etwa wenn ein Anleiheemittent eigene Emissionen hält (§ 43 Abs. 2 S. 1 EStG).

Nach dem sog. Interbankenprivileg ist Kapitalertragsteuer für bestimmte Kapitalerträge nicht einzubehalten, wenn der Gläubiger der Kapital- 
erträge ein inländisches Kreditinstitut, Finanzdienstleistungsinstitut oder eine Kapitalanlagegesellschaft ist (§ 43 Abs. 2 S. 2 EStG).

\section{Steuersatz und Steuerberechnung}

\section{Formel zur Kapitalertragsteuerermittlung}

Die Formel zur Kapitalertragsteuerermittlung (§ 32d Abs. 1 S. 4 EStG) lautet wie folgt: Kapitalertragsteuer: $\frac{\mathrm{e}-4 \mathrm{q}}{4+\mathrm{k}}$

Dabei ist $\quad \mathrm{e}=$ Summe aller Kapitalerträge nach Verlustverrechnung und Freistellungsauftrag

$\mathrm{q}=$ Anrechenbare ausländische Steuer

$\mathrm{k}=$ Kirchensteuersatz der erhebenden Religionsgemeinschaft

Durch die Formel wird die Abzugsfähigkeit der Kirchensteuer von den Kapitalerträgen e wie eine Sonderausgabe für inländische Privatanleger berücksichtigt.

\section{Anrechnung ausländischer Quellensteuer}

Unterlagen ausländische Kapitalerträge im Ausland einer der deutschen Einkommensteuer entsprechenden Steuer ("Quellensteuer “), hat das Kreditinstitut dies bei der Ermittlung des Kapitalertragsteuerabzuges zu berücksichtigen (§§ 43a Abs. 3 S. 1 i. V. m. 32d Abs. 5 EStG). Eine Anrechnung erfolgt nur, wenn es sich beim Gläubiger der Kapitalerträge um inländische Privatpersonen handelt. ${ }^{49}$

Fiktive ausländische Quellensteuer ist im Rahmen des Kapitalertragsteuerabzugs nur zu berücksichtigen, wenn die Anrechnung nach dem anwendbaren Doppelbesteuerungsabkommen nicht an besondere Voraussetzungen geknüpft ist. Sonst kann die Geltendmachung nur im Wege der Veranlagung erfolgen.

\section{Solidaritätszuschlag und Kirchensteuer}

Bemessungsgrundlage für den Solidaritätszuschlag ist die vom Kreditinstitut ermittelte Kapitalertragsteuer. Der Solidaritätszuschlag wird auch vom Kreditinstitut ermittelt und abgezogen.

49 Vgl. BMF, Schr. v. 22.12.2009, a. a. O., Rz. 202. 
Die Kirchensteuer wird nur auf Antrag des inländischen Privatanlegers vom Kreditinstitut einbehalten. Erfolgt kein Antrag, ist eine Erhebung nur im Wege der Veranlagung möglich.

Die Kirchensteuer kann nur für bestimmte Religionsgemeinschaften einbehalten werden (Kirchensteuersatz $8 \%$ oder 9\%), sonst nur Einbehalt im Wege der Veranlagung.

\section{Veranlagungsfälle}

\section{1. Überblick}

Wesentliches Ziel der gesetzlichen Neuregelungen zum Einbehalt von Kapitalertragsteuer ist, dass beim inländischen Privatanleger die Einkommensteuer (Kapitalertragsteuer) mit abgeltender Wirkung erhoben wird, um eine Veranlagung bei Einkünften aus Kapitalvermögen zu vermeiden.

Gleichwohl kann es in vielen Fällen zu einer Veranlagung kommen; die wesentlichen Fälle sind in der folgenden Übersicht zusammengefasst:

\begin{tabular}{|c|c|c|c|}
\hline \multicolumn{4}{|c|}{ Erhebung der Abgeltungsteuer auf private Kapitalerträge } \\
\hline $\begin{array}{c}\text { durch } \\
\text { Steuerabzug } \\
\text { (= endgültig } \\
\text { im Idealfall) }\end{array}$ & $\rightarrow$ & $\begin{array}{l}\text { durch Antragsveranlagung } \\
\text { § 32d Abs. } 4 \text { EStG zur korrekten } \\
\text { Besteuerung (punktuell) `) } \\
\text { - Berücksichtigung von Verlusten } \\
\text { - Anwendung Sparer-Pauschbetrag } \\
\text { - Vermeidung Ersatzbemessungs- } \\
\text { grundlage } \\
\text { - Anrechnung ausländischer } \\
\text { Quellensteuern } \\
\text { - zur Erhebung der Kirchen- } \\
\text { steuer u.a. } \\
\text { § 32d Abs. 6 EStG } \\
\text { - wegen einer individuell niedrigeren } \\
\text { Steuerbelastung als 25\% über eine } \\
\text { Günstigerprüfung durch das } \\
\text { Finanzamt }\end{array}$ & \begin{tabular}{|l} 
§ 32 d Abs. 3 \\
EStG \\
- für im Ausland \\
realisierte \\
Kapitalerträge \\
- für im Inland \\
realisierte \\
Kapitalerträge \\
die nicht dem \\
Steuerabzug \\
unterlegen \\
haben (z. B. \\
ausl. thesau- \\
rierende Fonds)
\end{tabular} \\
\hline & & noch nicht berüc & tigt \\
\hline
\end{tabular}




\section{Einzelne Veranlagungsfälle}

Unterhält ein inländischer Privatanleger Konten/Depots im Ausland, so unterliegen die dort realisierten Kapitalerträge nicht der deutschen Kapitalertragsteuer, da ausländische Kreditinstitute nicht der deutschen Einbehaltungspflicht unterliegen. Der in Deutschland unbeschränkt steuerpflichtige Privatanleger ist verpflichtet, diese Erträge im Veranlagungsweg der deutschen Besteuerung zu unterwerfen.

Falls dem inländischen Kreditinstitut bei einer Veräußerung von Finanzanlagen die Anschaffungskosten und/oder der Veräußerungspreis nicht bekannt sind, kommt es zu einer Pauschalbesteuerung im Abzugswege, d. h. der Steuerabzug bemisst sich nach $30 \%$ der Einnahmen aus der Veräußerung oder Einlösung der Wirtschaftsgüter (§ 43a Abs. 2 S. 7 EStG). Eine Korrektur der Pauschalbesteuerung kann im Wege der Veranlagung erfolgen, wenn der Anleger die tatsächlichen Anschaffungskosten und/ oder Veräußerungspreise nachweist.

Thesauriert ein ausländischer Fonds seine Erträge, so ist dieser ausschüttungsgleiche Ertrag im Prinzip der Kapitalertragsteuer zu unterwerfen, obwohl dem Anleger keine Liquidität zugeflossen ist. Ausländische Fonds sind jedoch nicht zum Einbehalt deutscher Kapitalertragsteuer verpflichtet. Demnach besteht für den inländischen Privatanleger die Verpflichtung, diese ausschüttungsgleichen Erträge im Veranlagungswege der Besteuerung zu unterwerfen.

Wie oben dargestellt, wird eine vollständige Verlustverrechnung auf Ebene des Kreditinstituts angestrebt. Unterhält ein Anleger jedoch Konten/Depots bei mehreren Kreditinstituten ist eine institutsübergreifende Verlustverrechnung nicht möglich. Somit muss der Anleger bei dem Kreditinstitut, bei dem am Jahresende ein Verlustüberhang verblieben ist, eine Bescheinigung anfordern, um dann im Wege der Veranlagung diesen Verlust mit positiven Kapitalerträgen bei anderen Kreditinstituten zu verrechnen. Entsprechendes gilt für noch nicht angerechnete ausländische Quellensteuer (Quellensteuertopf) und nicht oder nicht vollständig ausgenutzte Freistellungsaufträge. 
